Rafael Yuji Lemos

Revisão e análise cladística das espécies do gênero Sphecozone O. P.-Cambridge, 1870 (Araneae, Linyphiidae, Erigoninae).

Revision and cladistic analysis of species from genus Sphecozone O. P.-Cambridge, 1870 (Araneae, Linyphiidae, Erigoninae). 
Rafael Yuji Lemos

Revisão e análise cladística das espécies do gênero Sphecozone O. P.-Cambridge, 1870 (Araneae, Linyphiidae, Erigoninae).

Revision and cladistic analysis of species from genus Sphecozone O. P.-Cambridge, 1870 (Araneae, Linyphiidae, Erigoninae).

Tese (Versão Corrigida) apresentada ao Instituto de Biociências da Universidade de São Paulo, para a obtenção de Título de Doutor em Ciências, na Área de Zoologia.

Orientador(a): Antonio Domingos Brescovit

São Paulo 
Lemos, Rafael Yuji

Revisão e análise cladística das espécies

do gênero Sphecozone O. P.-Cambridge, 1870

(Araneae, Linyphiidae, Erigoninae). Versão

Corrigida.

$283 \mathrm{pp}$.

Tese (Doutorado) - Instituto de

Biociências da Universidade de São Paulo.

Departamento de Zoologia.

1. Aranha 2. Linyphiidae 3. Filogenia I.

Universidade de São Paulo. Instituto de

Biociências. Departamento de Zoologia.

\section{Comissão Julgadora:}

$\operatorname{Prof}(\mathrm{a}) . \operatorname{Dr}(\mathrm{a})$.

Prof(a). Dr(a).
$\operatorname{Prof}(\mathrm{a}) . \operatorname{Dr}(\mathrm{a})$.

Prof(a). Dr(a).

Prof. Dr. Antonio Domingos Brescovit

Orientador 


\section{Agradecimentos}

Gostaria de agradecer à Fapesp, pelo financiamento do projeto. Ao Instituto Butantan pela infraestrutura e material necessários para realização deste trabalho. Aos curadores de todos os museus pelo empréstimo do material. Ao Carlos Jared, Marta Maria Antoniazzi e Beatriz Maurício, do Laboratório de Biologia Celular, do Instituto Butantan, pelas fotos de microscopia eletrônica de varredura.

Ao meu orientador, Dr. Antonio D. Brescovit, pelas oportunidades, ensinamentos e, principalmente, pela paciência, concedidos ao longo de meus 15 anos no laboratório.

Aos colegas e amigos do Instituto Butantan e do Instituto de Biociências, pelos incentivos e amizade.

Aos meus pais, Joaquim Aparecido Lemos e Tomoko Suzuki Lemos, e à minha irmã Barbara Yumi Lemos, minhas fontes de inspiração, meus exemplos de garra e força de vontade.

À Mariana Schmidt, pelo carinho e paciência devidos às noites em claro, sempre apoiando com carinho e amor. 
Índice

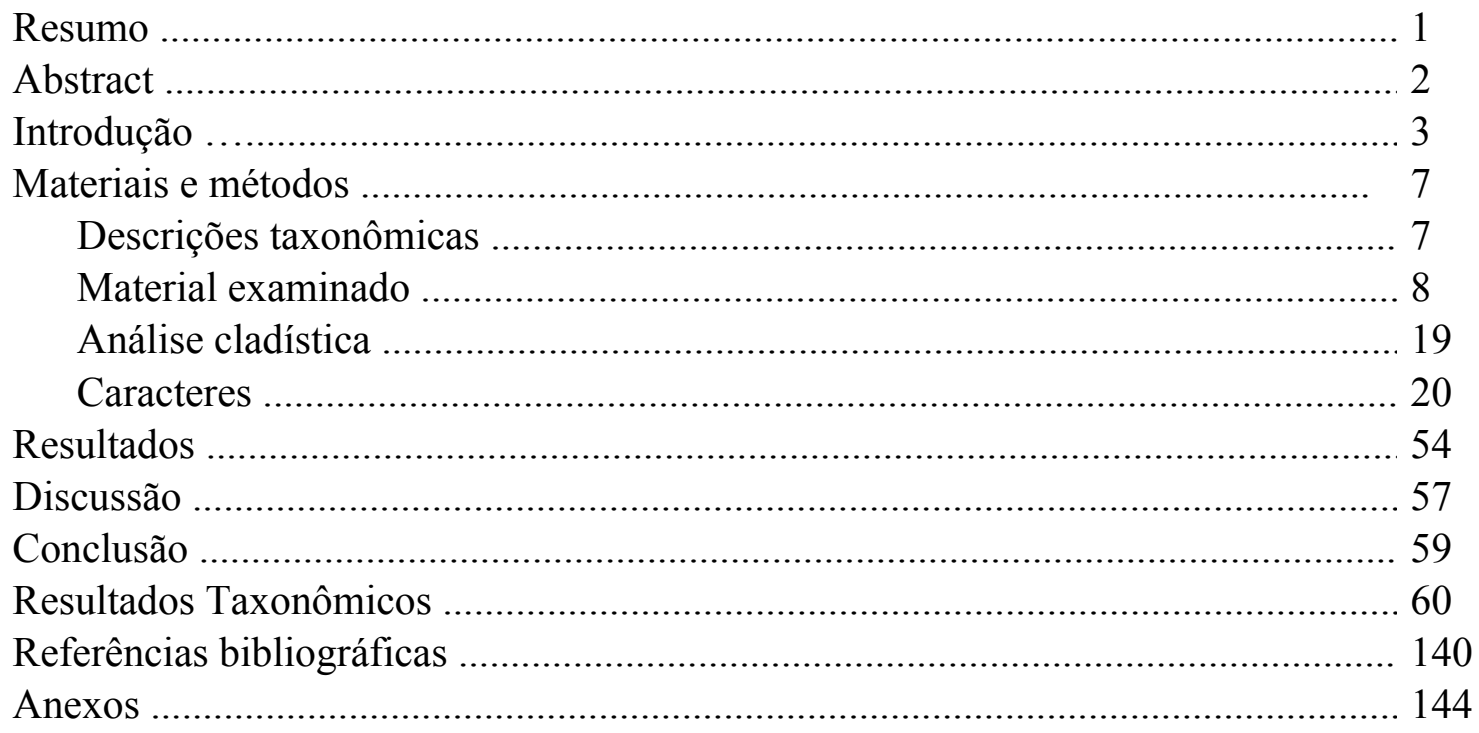


Índice de figuras

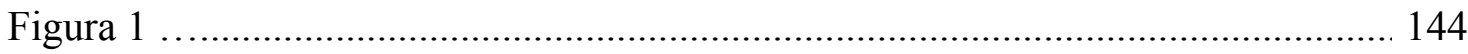

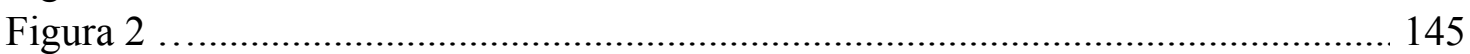

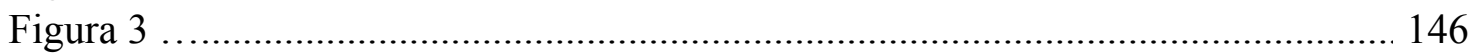

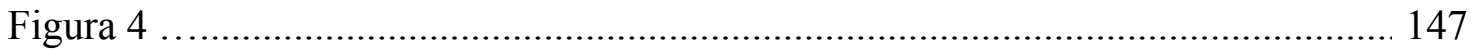

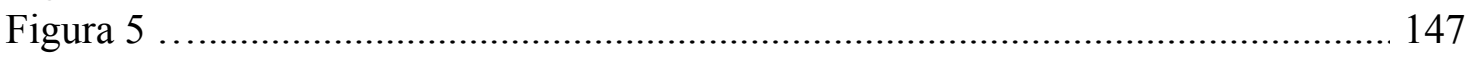

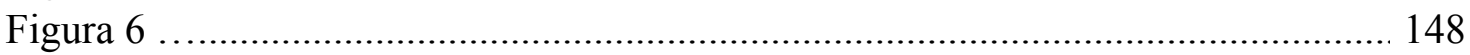

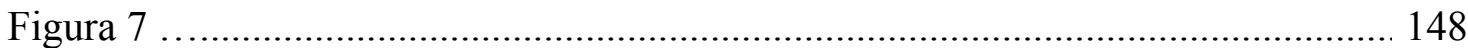

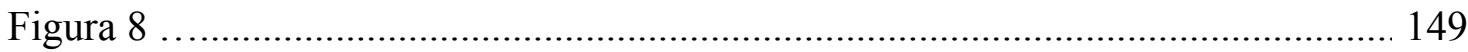

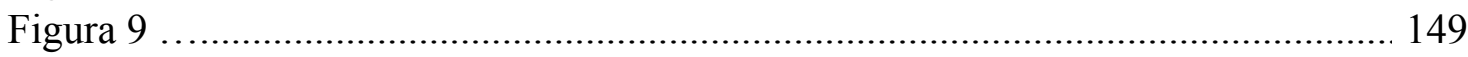

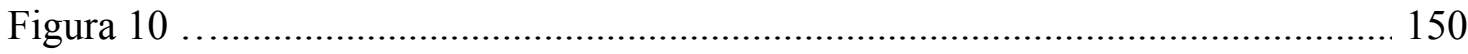

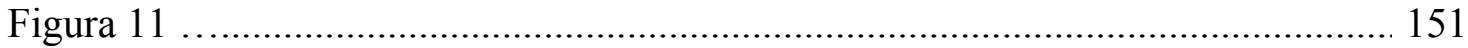

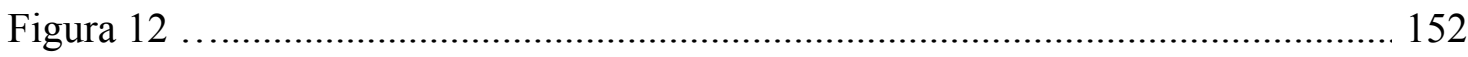

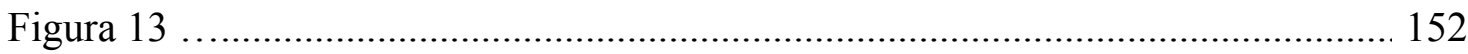

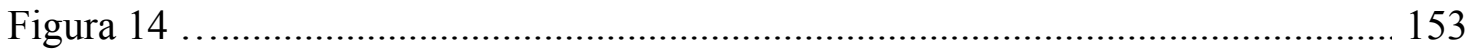

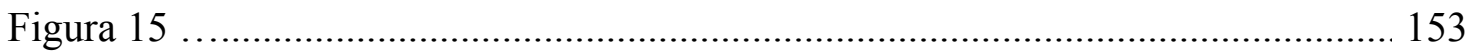

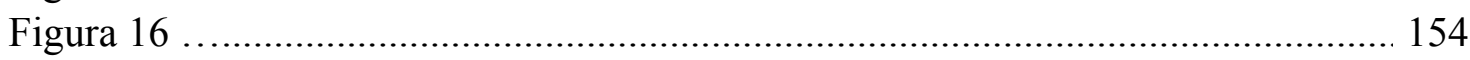

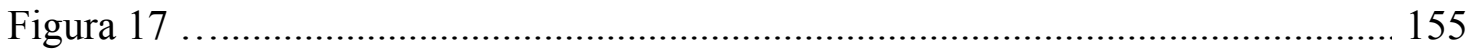

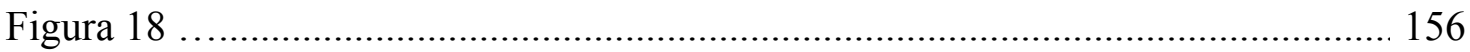

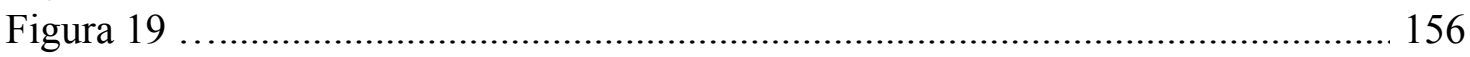

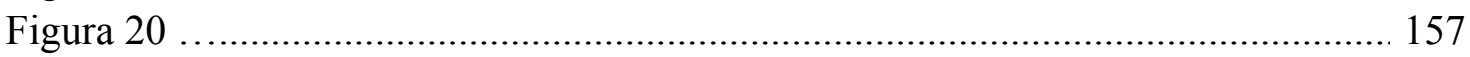

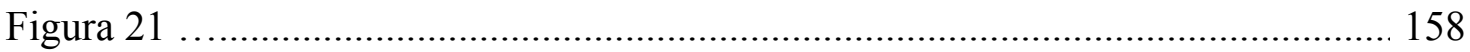

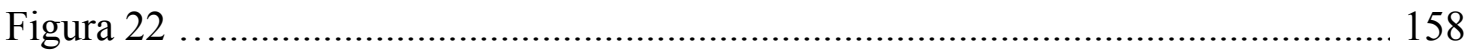

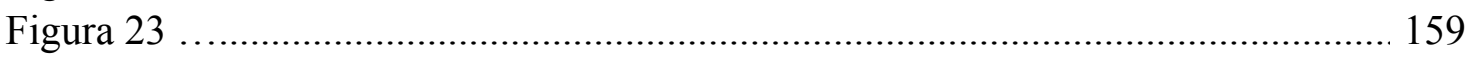

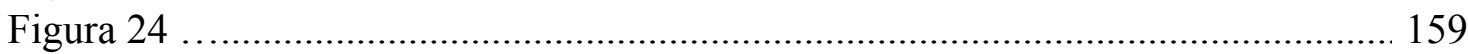

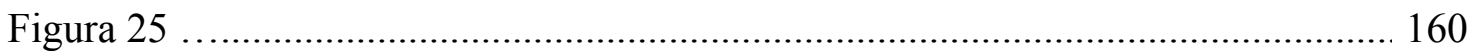

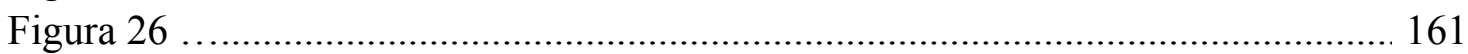

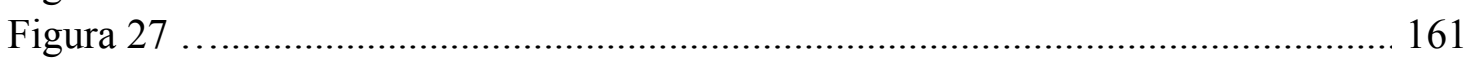

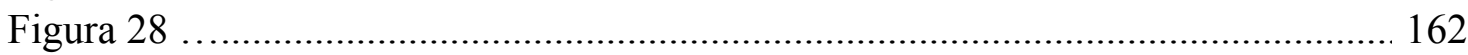

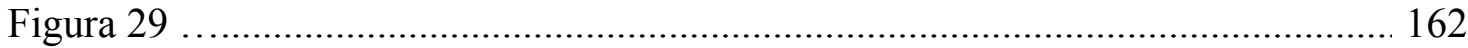

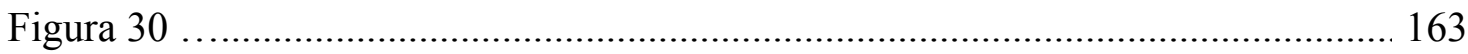

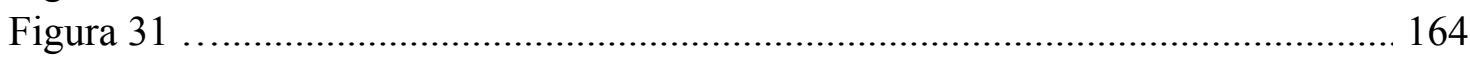

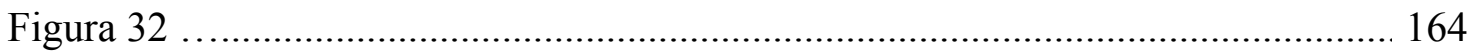

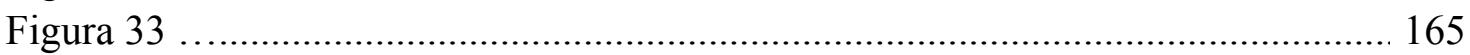

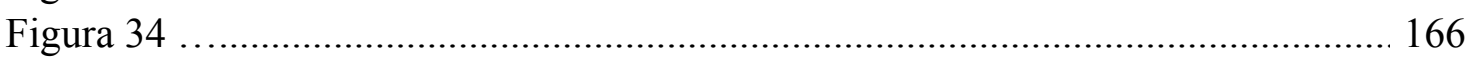

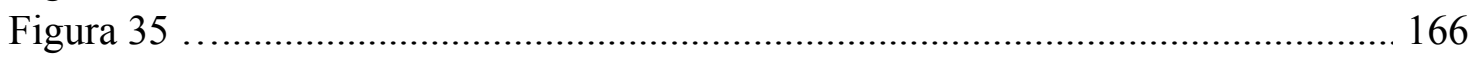

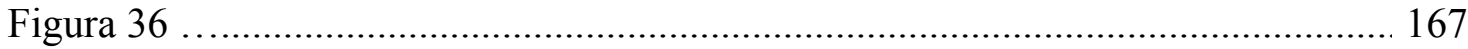

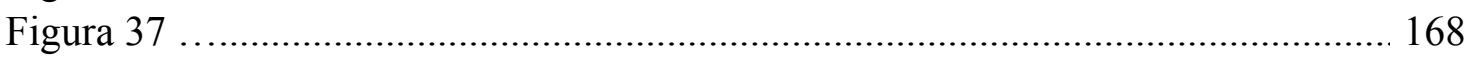

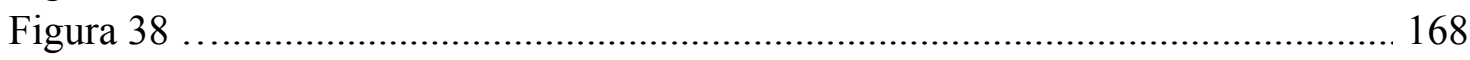

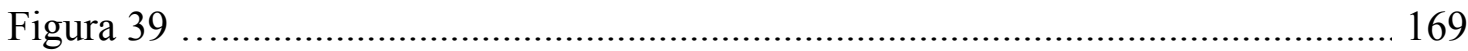

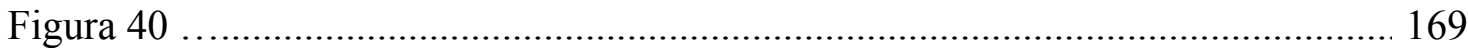

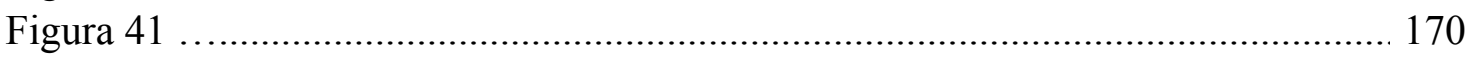

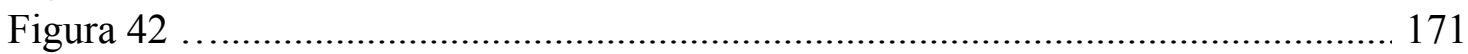

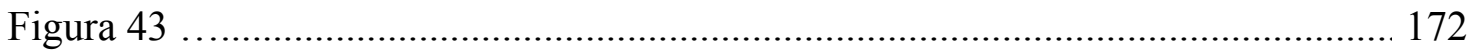

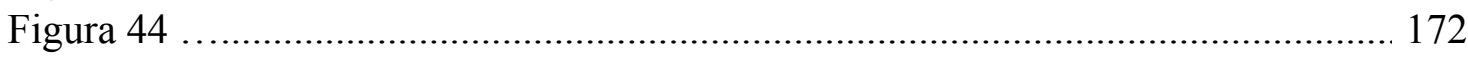

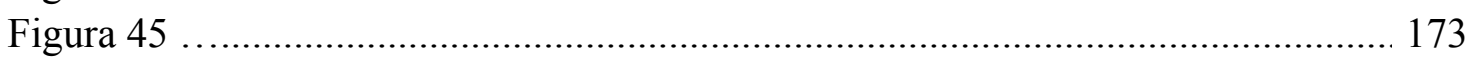




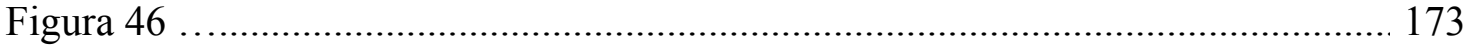

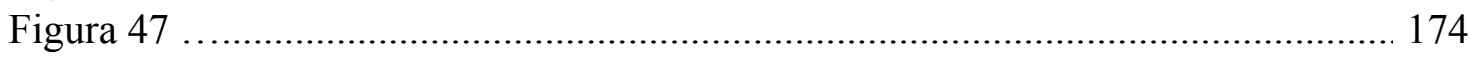

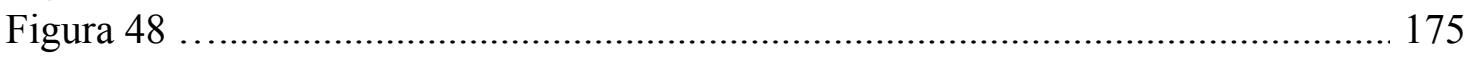

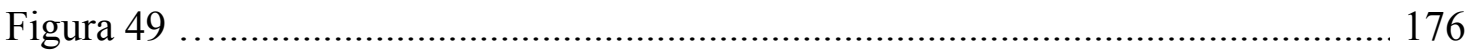

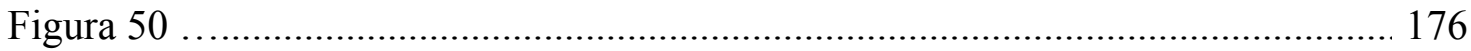

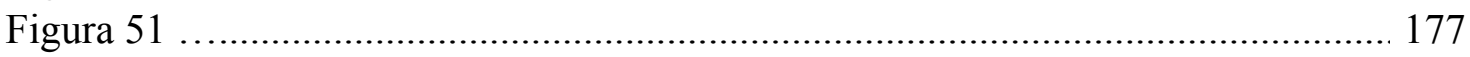

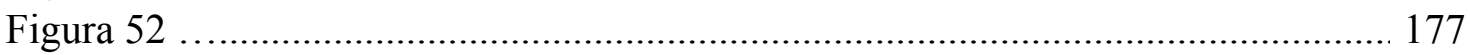

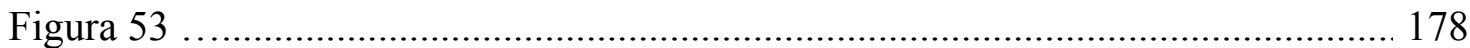

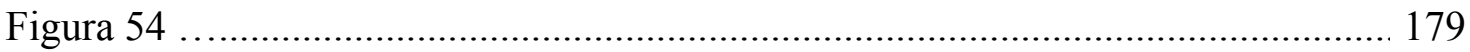

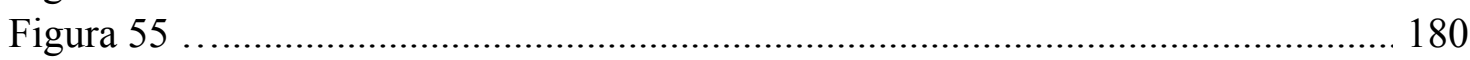

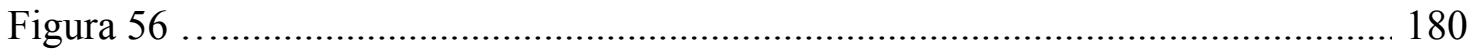

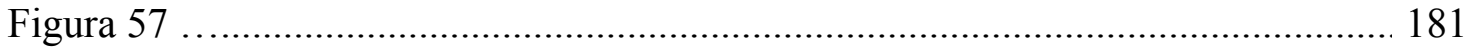

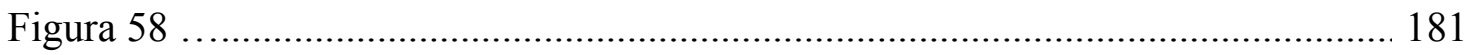

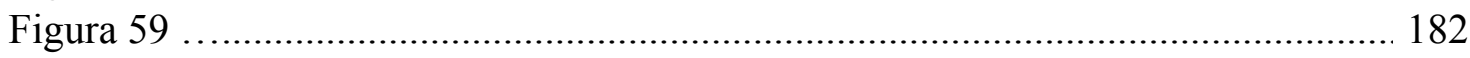

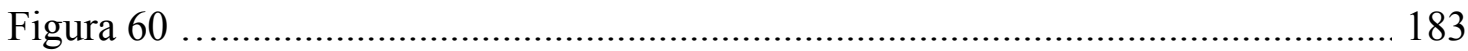

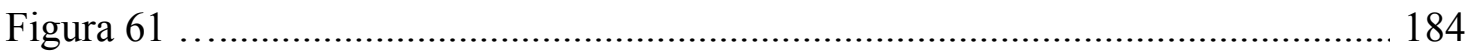

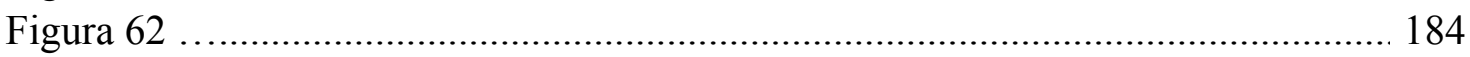

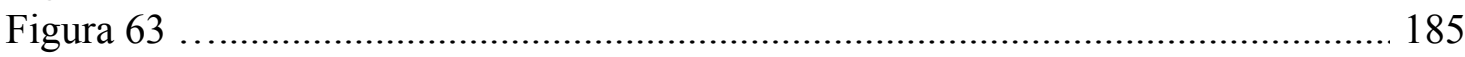

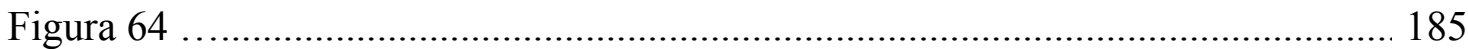

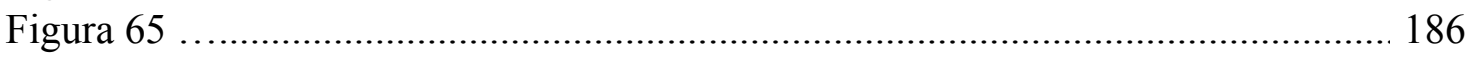

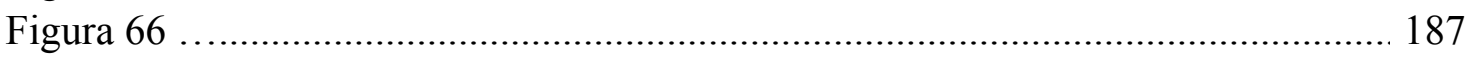

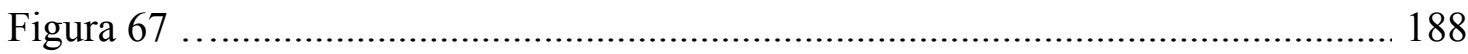

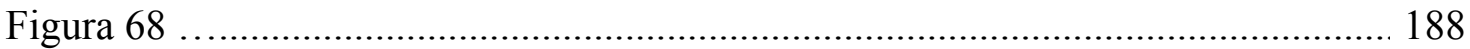

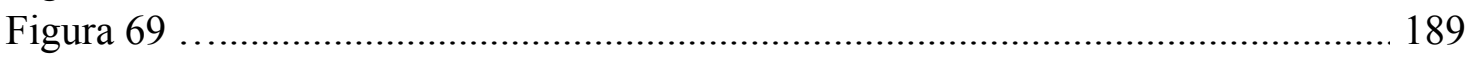

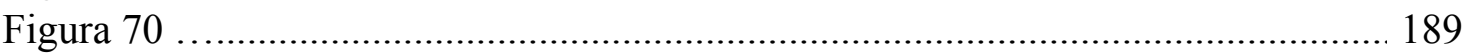

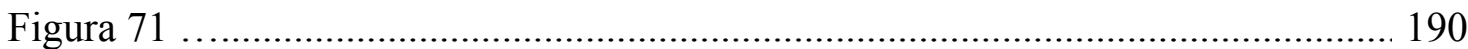

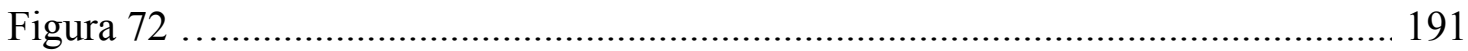

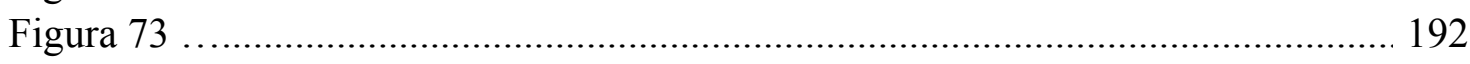

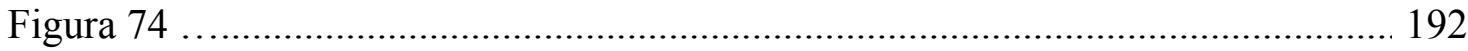

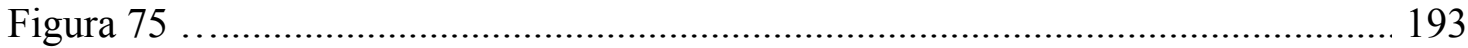

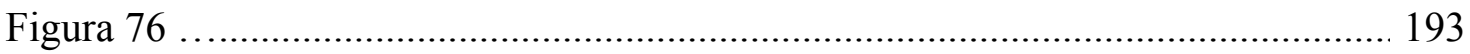

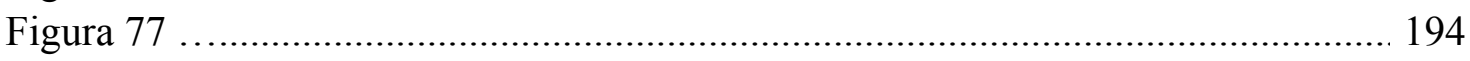

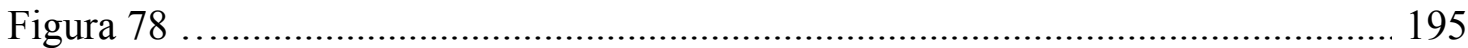

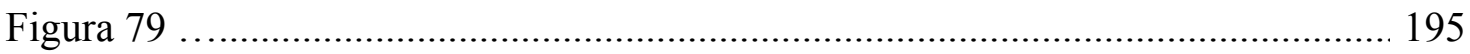

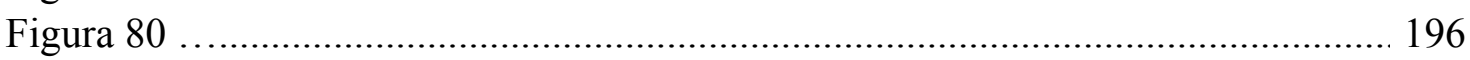

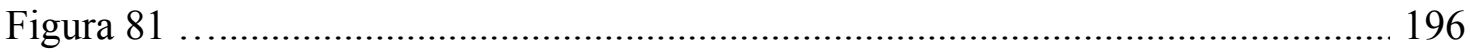

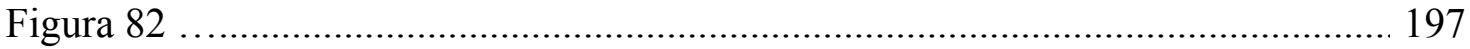

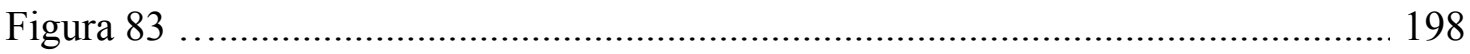

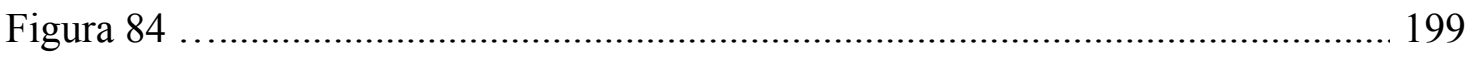

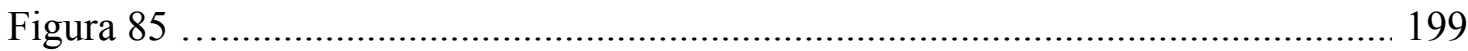

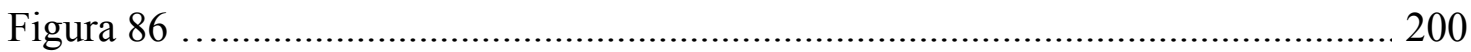

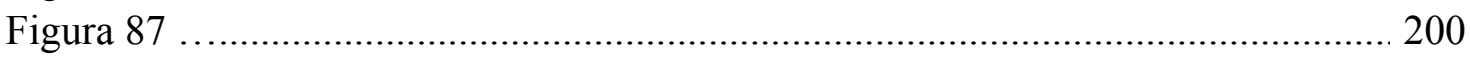

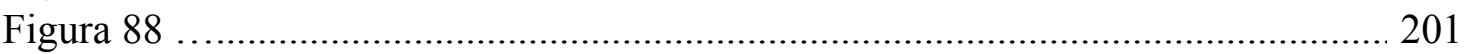

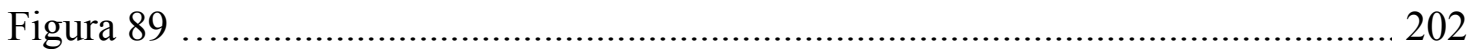

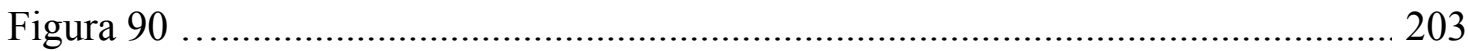

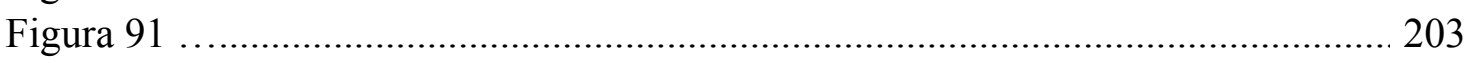




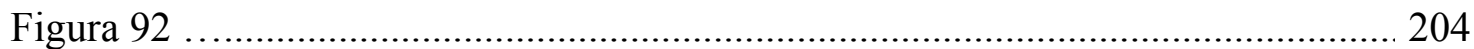

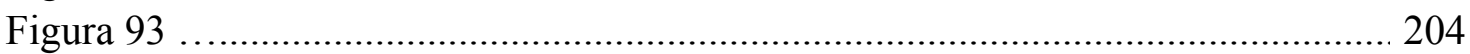

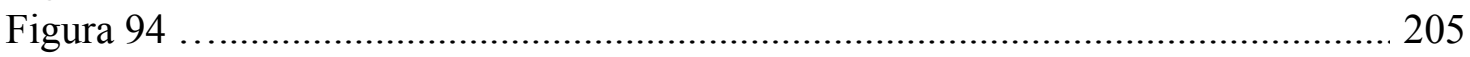

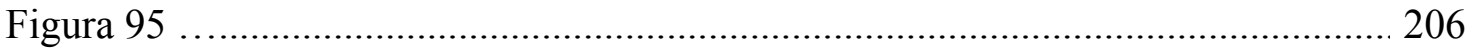

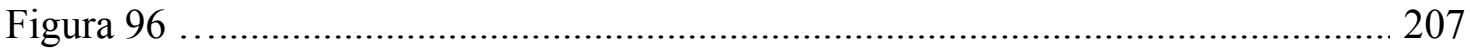

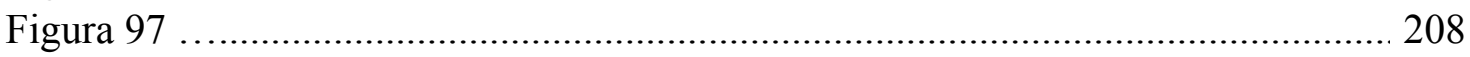

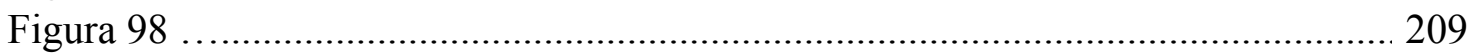

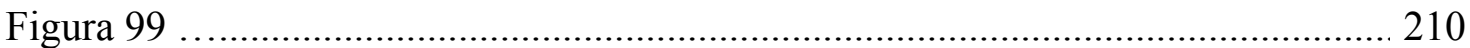

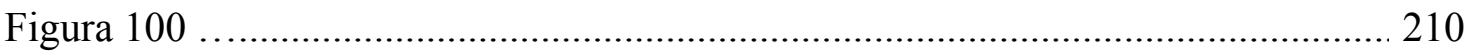

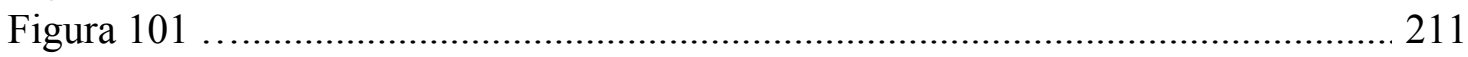

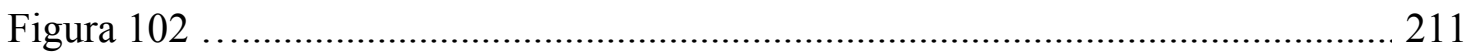

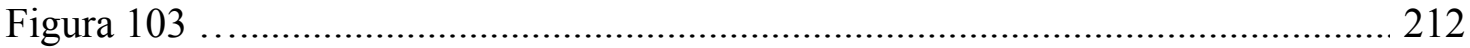

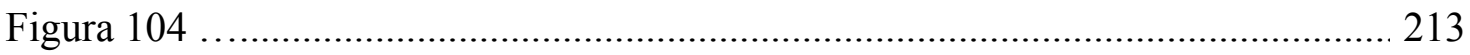

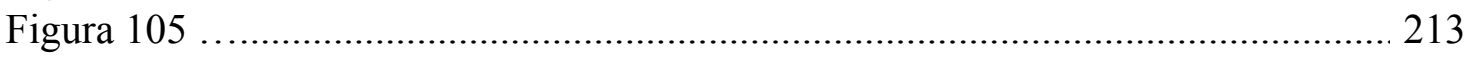

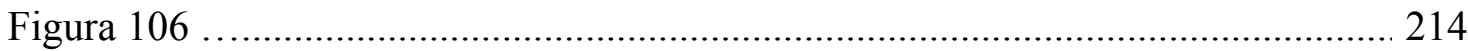

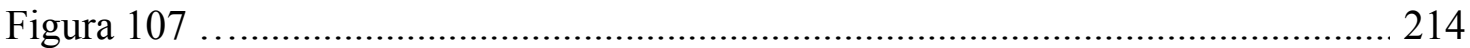

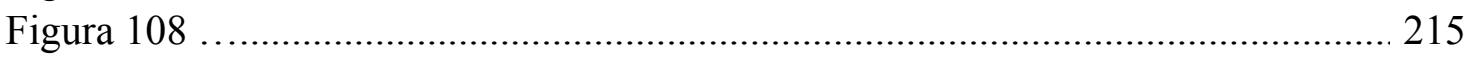

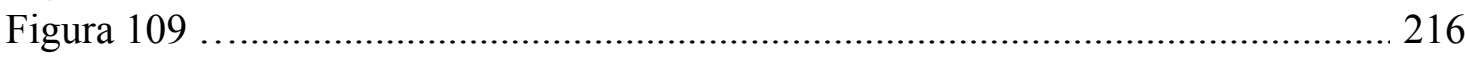

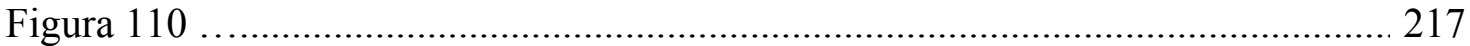

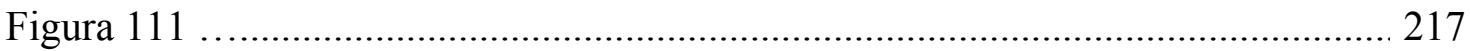

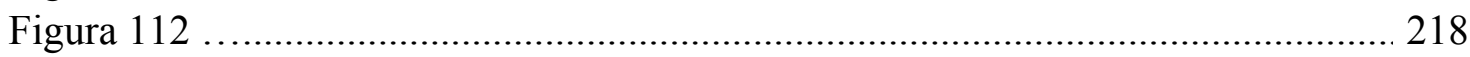

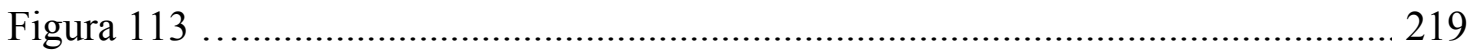

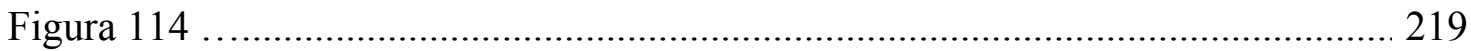

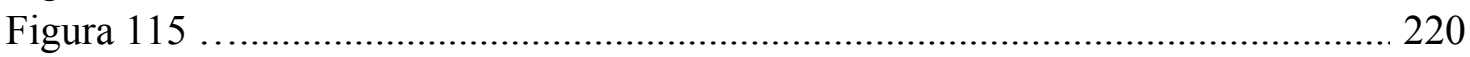

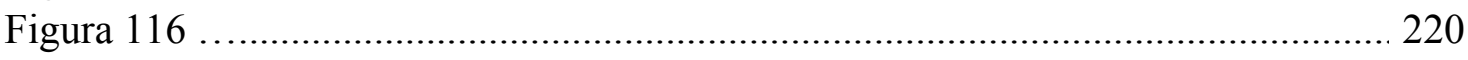

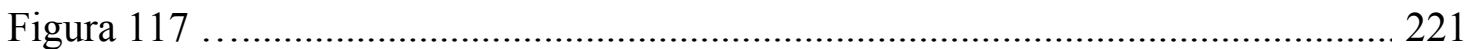

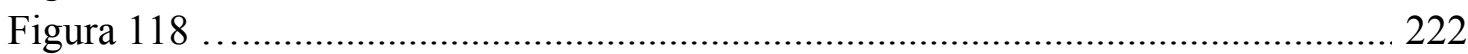

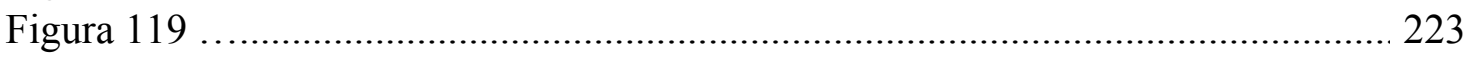

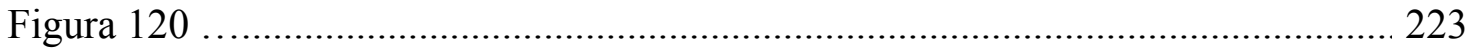

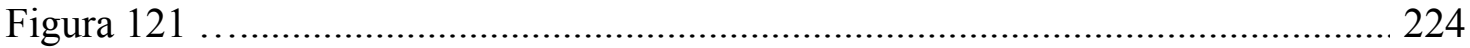

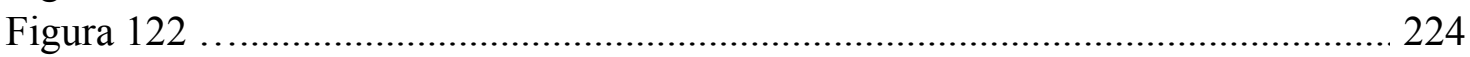

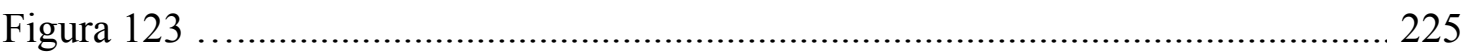

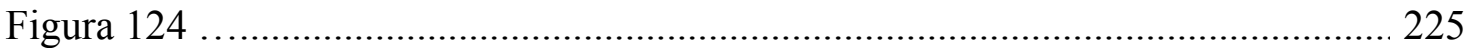

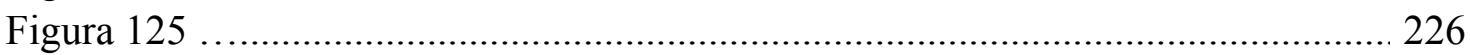

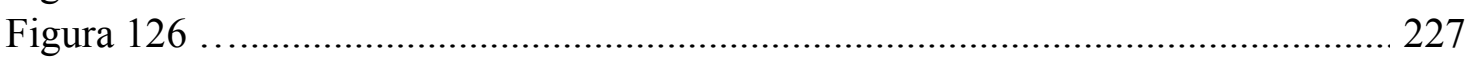

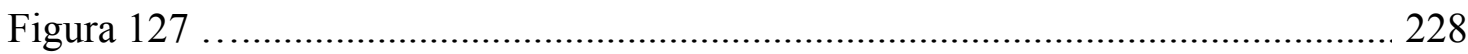

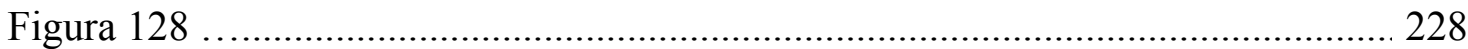

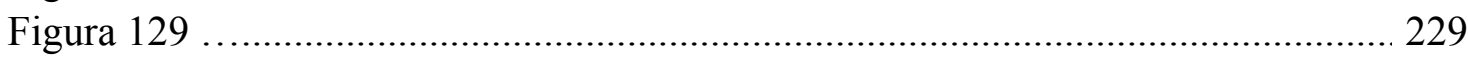

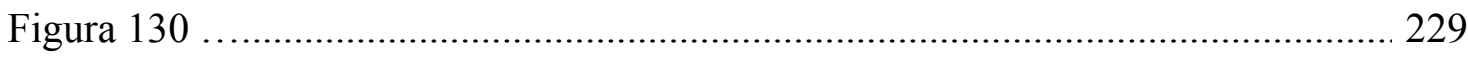

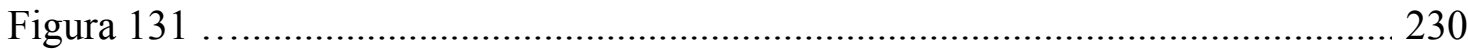

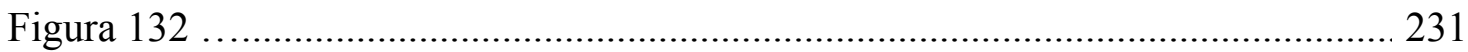

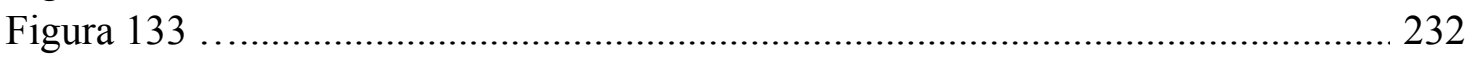

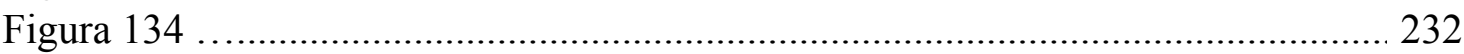

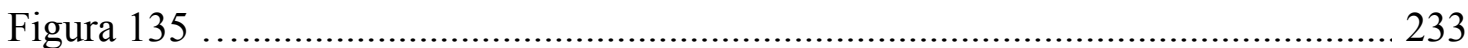

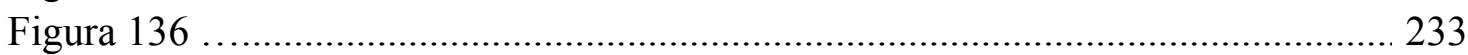

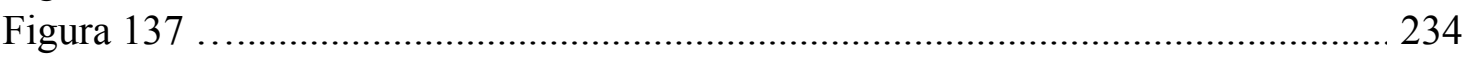




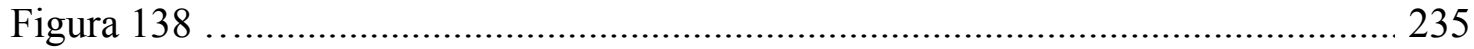

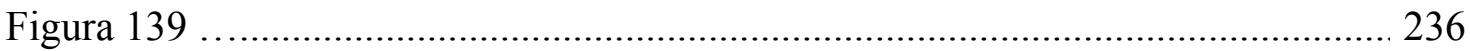

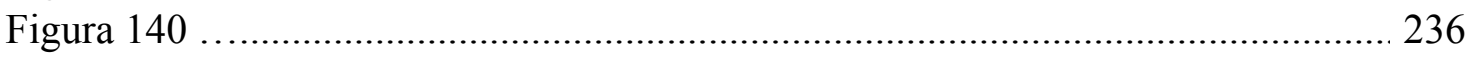

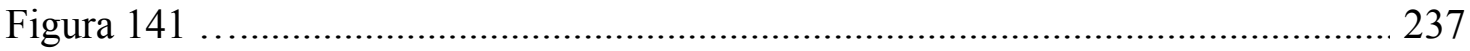

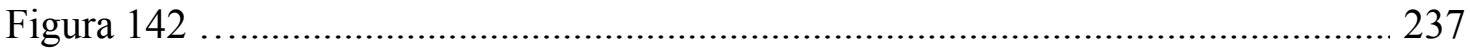

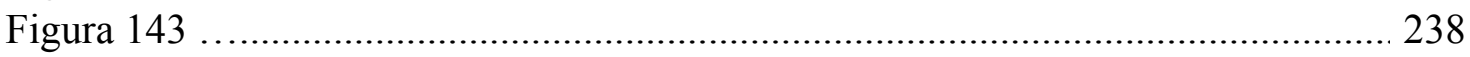

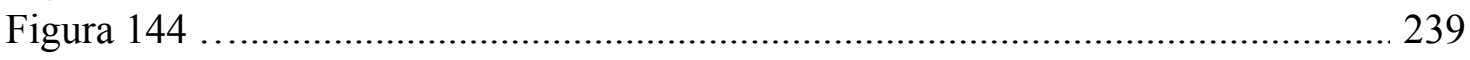

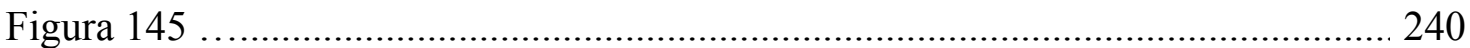

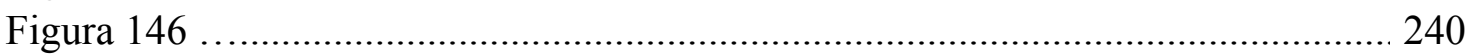

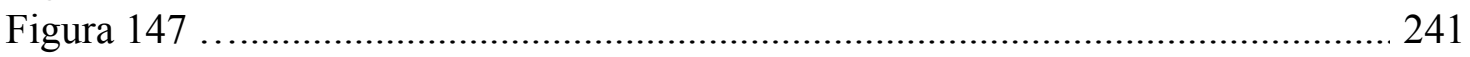

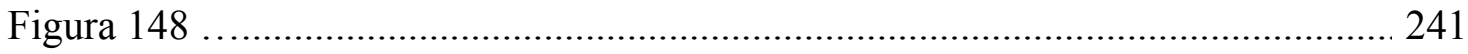

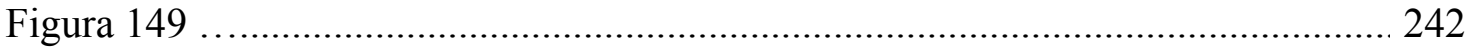

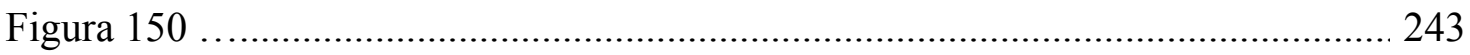

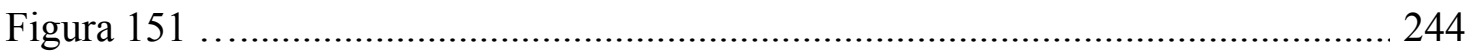

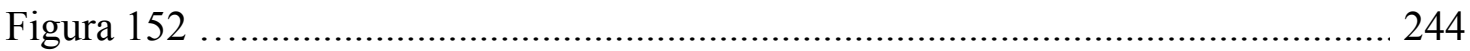

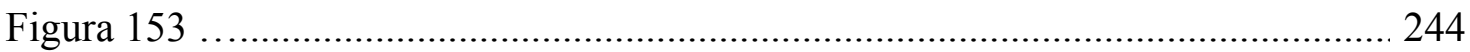

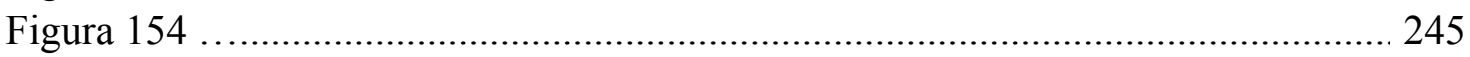

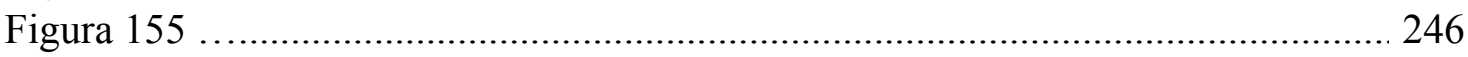

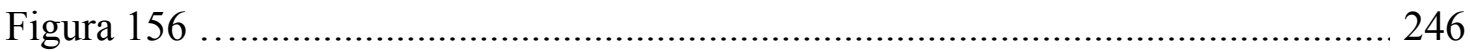

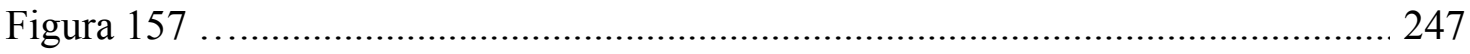

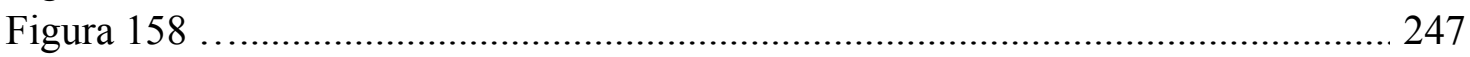

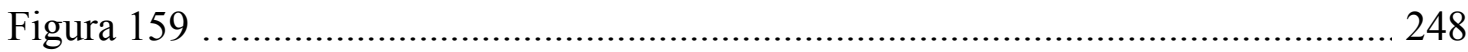

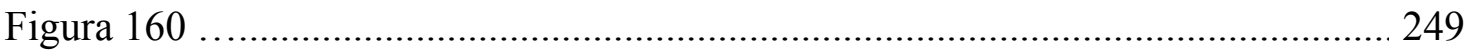

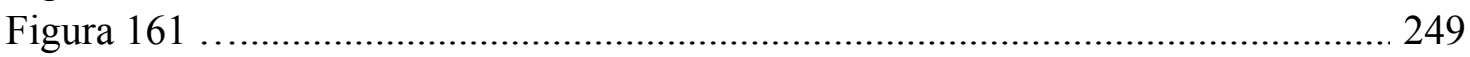

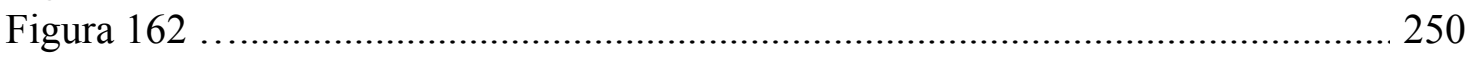

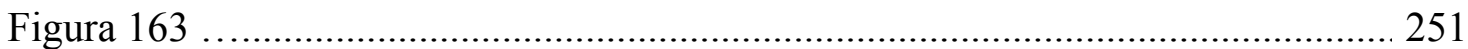

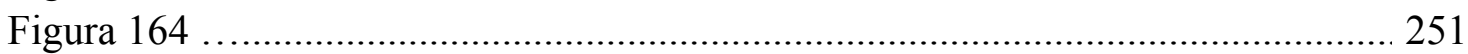

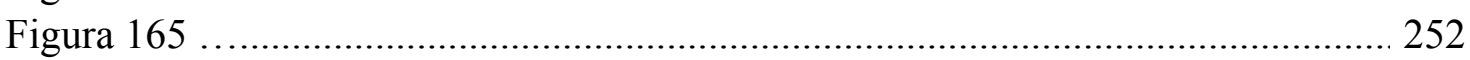

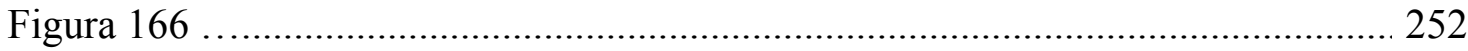

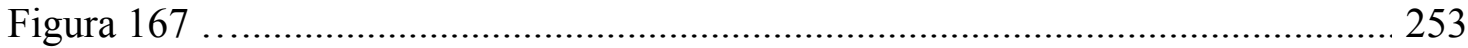

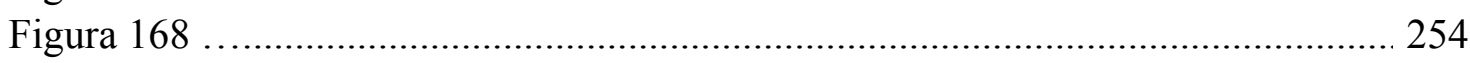

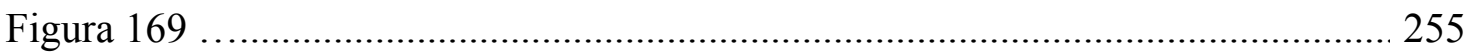

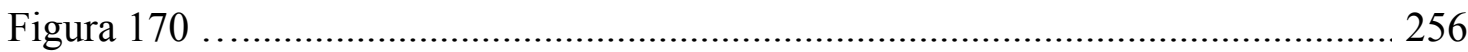

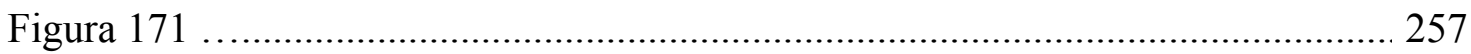

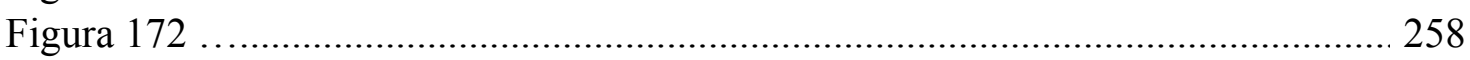

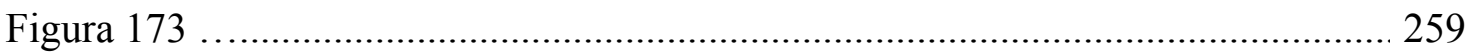

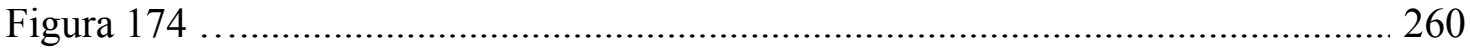

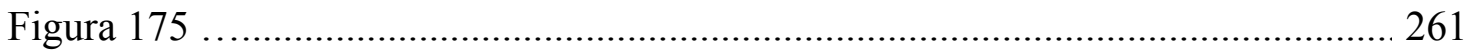

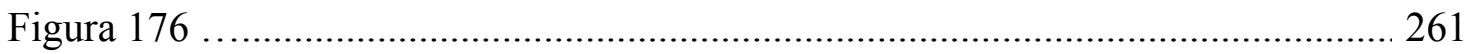

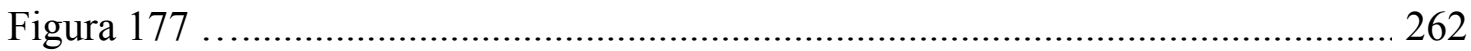

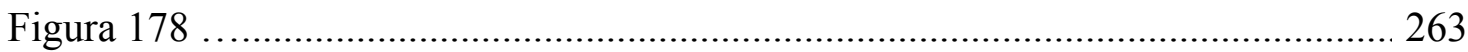

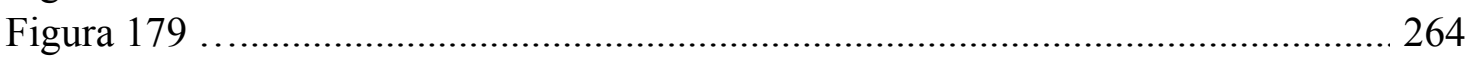

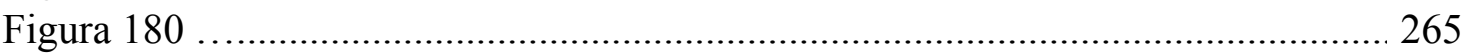

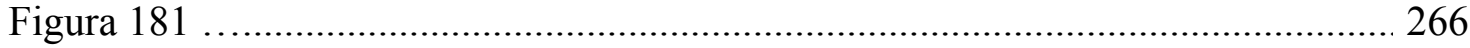

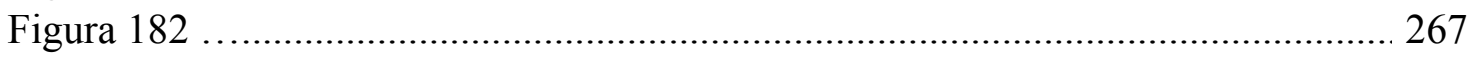

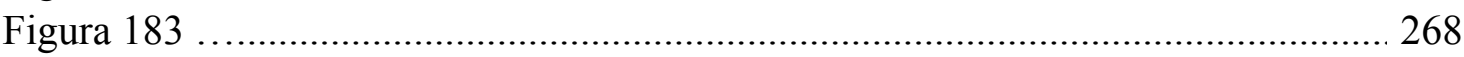




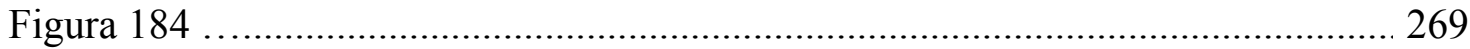

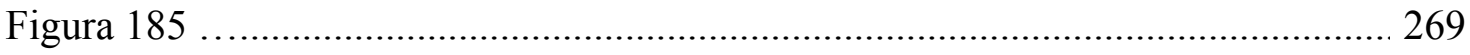

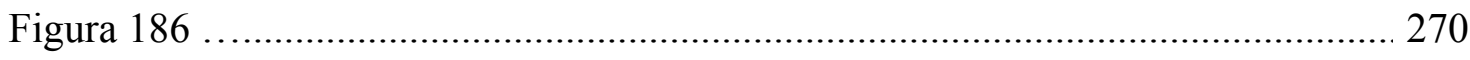

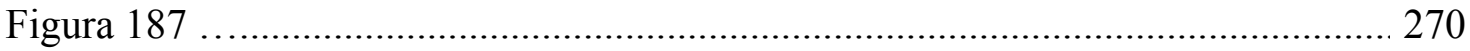

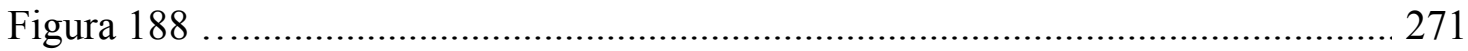

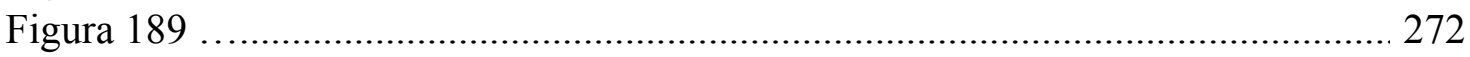

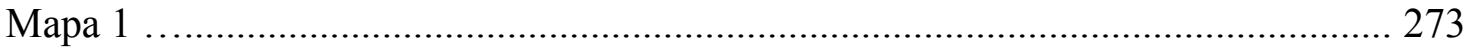

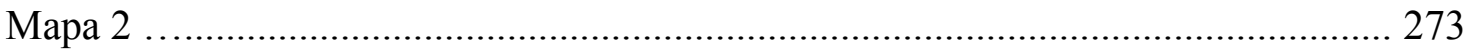

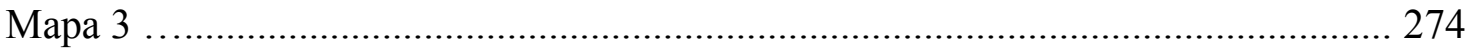

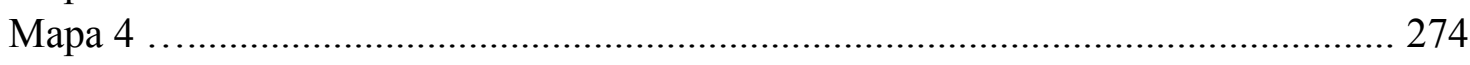

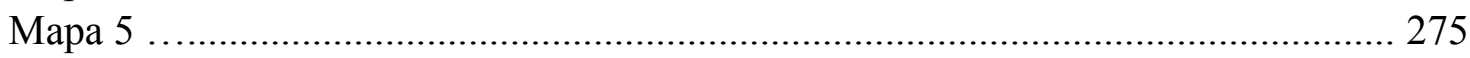

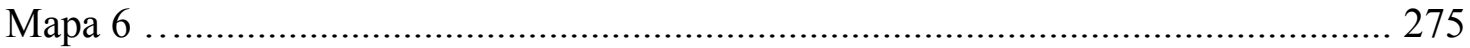

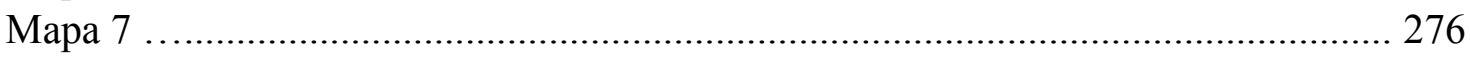

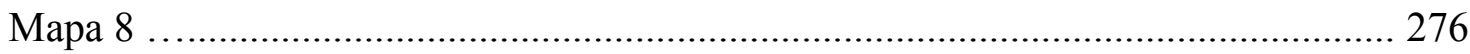

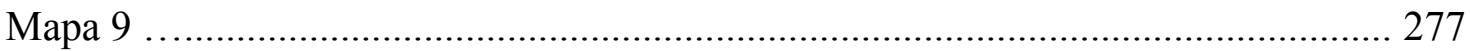

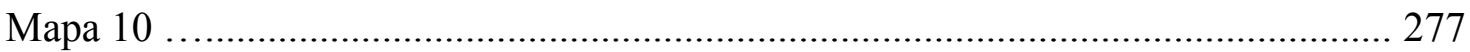

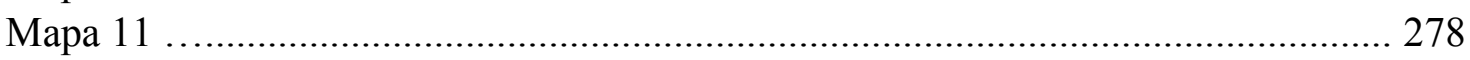

Índice de tabelas

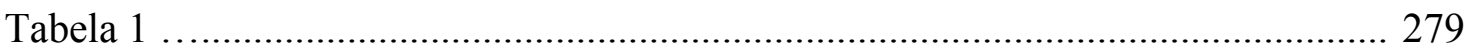

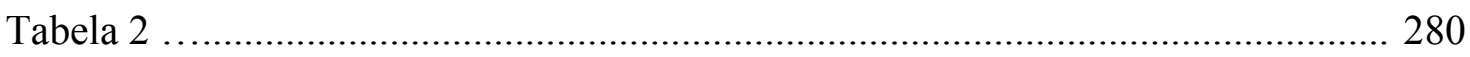

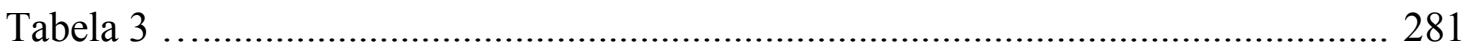


Índice de figuras por espécies

Espécies

Gen. Clitolyna

C. alticeps

C. alticeps

C. alticeps

C. alticeps

C. alticeps

C. castanea

C. castanea

C. castanea

C. castanea

C. castanea

C. castanea

C. chumota

C. chumota

C. chumota

C. chumota

C. chumota

C. chumota

C. crassa

C. crassa

C. crassa

C. fastibilis

C. fastibilis

C. fastibilis

C. fastibilis

C. fastibilis

C. fastibilis

C. formosa

C. formosa

C. gravis

C. gravis

C. gravis

C. gravis

C. gravis

C. gravis

C. novaeteutoniae

C. novaeteutoniae

C. novaeteutoniae

C. novaeteutoniae

C. novaeteutoniae

C. novaeteutoniae

C. personata

C. personata

C. personata

C. personata

C. personata

C. personata

C. prativaga
Figuras

(palpo do macho)

(corpo da fêmea)

(epígino da fêmea)

(ilustração)

(corpo do macho)

(corpo do macho)

(palpo do macho)

(corpo da fêmea)

(epígino da fêmea)

(ilustração)

(imagens MEV)

(corpo do macho)

.(palpo do macho)

(corpo da fêmea)

.(epígino da fêmea)

.(ilustração) .

(imagens MEV)

(corpo da fêmea)

(epígino da fêmea)

.(ilustração)

.(corpo do macho)

(palpo do macho)

.(corpo da fêmea)

.(epígino da fêmea)

.(ilustração)

(imagens MEV)

(corpo da fêmea)

(epígino da fêmea)

(corpo do macho)

(palpo do macho)

(corpo da fêmea)

(epígino da fêmea)

(ilustração)

(imagens MEV)

(corpo do macho)

(palpo do macho)

(corpo da fêmea)

(epígino da fêmea)

(ilustração)

(imagens MEV)

(corpo do macho)

(palpo do macho)

.(corpo da fêmea)

.(epígino da fêmea)

.(ilustração)

(imagens MEV)

(corpo do macho)

\section{Páginas}

.Figura 100 ...... 210

Figura 101 ....2 211

Figura 102 ....211

Figura 103 .....212

Figura 99 ....... 210

Figura 104 ..... 213

Figura 105 .....213

Figura 106 ....2 214

Figura 107 .... 214

Figura 108 .... 215

Figura 109 ..... 216

Figura 184 ....269

Figura 185 .....269

Figura 186 .... 270

Figura 187 .... 270

Figura 188 .... 271

Figura 189 .... 272

Figura 110 .... 217

Figura $111 \ldots .217$

Figura $112 \ldots .218$

Figura 113 .... 219

Figura 114 .... 219

Figura 115 .... 220

Figura 116 .....220

Figura 117 ....2221

Figura 118 .....222

Figura 119 .... 223

Figura 120 .... 223

Figura 121 ..... 224

Figura 122 ..... 224

Figura 123 .... 225

Figura 124 .... 225

Figura 125 .....226

Figura 126 ..... 227

Figura 127 .... 228

Figura 128 ..... 228

Figura 129 .... 229

Figura 130 .... 229

Figura 131 ....2230

Figura 132 .... 231

Figura 133 .... 232

Figura 134 .... 232

Figura 135 .... 233

Figura $136 \ldots 233$

Figura 137 .....234

Figura 138 .... 235

Figura 139 ....236 


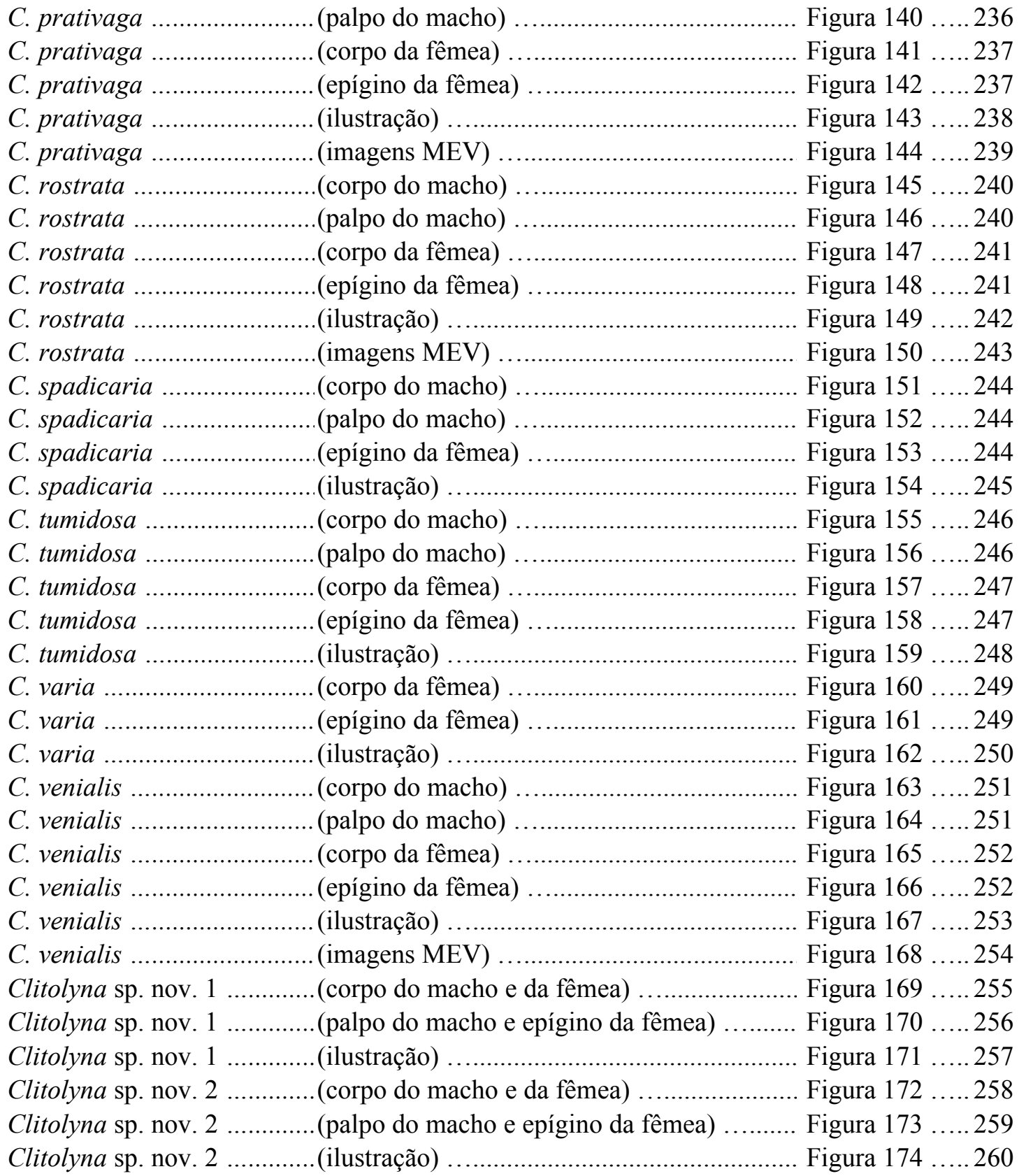

Gen. nov.

Gen. nov. magnipalpis ........(corpo do macho) ..................................... Figura 175 .....2261

Gen. nov. magnipalpis ........(palpo do macho) .................................... Figura 176 ..... 261

Gen. nov. magnipalpis ........(ilustração) ............................................... Figura 177 .....262

Gen. nov. sp. nov. 1 ...........(corpo do macho e da fêmea) ..................... Figura 178 _.... 263

Gen. nov. sp. nov. 1 ............(palpo do macho e epígino da fêmea) .......... Figura 179 .....2 264

Gen. nov. sp. nov. 1 ...........(ilustração) .......................................... Figura 180 _....265

Gen. nov. sp. nov. 2 …........(corpo do macho e da fêmea) ...................... Figura 181 .....266

Gen. nov. sp. nov. 2 ...........(palpo do macho e epígino da fêmea) .......... Figura 182 ..... 267

Gen. nov. sp. nov. 2 _..........(ilustração) ............................................. Figura 183 _.... 268

Gen. Hypselistoides

H. altehabitans ...................(corpo da fêmea) ……............................... Figura 18 ........ 156

H. altehabitans ....................(epígino da fêmea) .................................... Figura 19 ........ 156 


\begin{tabular}{|c|c|}
\hline 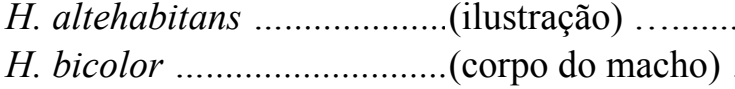 & Figura $21 \ldots$ \\
\hline ....(palpo do macho) & Figura $22 \ldots \ldots .158$ \\
\hline ...(corpo da fêmea) & Figura $23 \ldots \ldots . .159$ \\
\hline ....(epígino da fêmea) & Figura $24 \ldots . . .159$ \\
\hline H. bicolor ................. & Figura $25 \ldots \ldots .160$ \\
\hline .....(corpo do macho) & Figura $26 \ldots . . .161$ \\
\hline ....(palpo do macho) & Figura $27 \ldots . . .161$ \\
\hline H. capitatus ........................(corpo da fêmea) & Figura $28 \ldots \ldots .162$ \\
\hline ....(epígino da fêmea) & Figura 29 .. \\
\hline H. capitatus ........ & Figura $30 \ldots \ldots .163$ \\
\hline H. corniculans .....................(corpo do macho) & Figura $31 \ldots \ldots 164$ \\
\hline H. corniculans ......................(palpo do macho) & Figura $32 \ldots . . .164$ \\
\hline H. corniculans ....................(ilustração) ......... & Figura $33 \ldots . . . .165$ \\
\hline ......(corpo do macho) & Figura $34 \ldots . . . .166$ \\
\hline H. cornutus ........................... (palpo do macho) & Figura $35 \ldots . . .166$ \\
\hline H. cornutus .................. & Figura $36 \ldots . . .167$ \\
\hline H. crinitus ........................... (corpo do macho) & Figura $37 \ldots \ldots . .168$ \\
\hline H. crinitus ........................... (palpo do macho) & Figura $38 \ldots \ldots . .168$ \\
\hline H. crinitus ............................ (corpo da fêmea) & Figura $39 \ldots . . .169$ \\
\hline H. crinitus .......................... (epígino da fêmea) & Figura $40 \ldots . . . .169$ \\
\hline 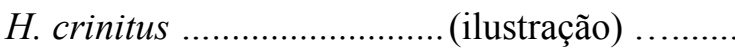 & Figura $41 \ldots . . .170$ \\
\hline H. crinitus .........................(imagens MEV) & Figura $42 \ldots \ldots . .171$ \\
\hline H. diversicolor .....................(corpo do macho) & Figura $43 \ldots \ldots 172$ \\
\hline ....(palpo do macho) & Figura $44 \ldots . . .172$ \\
\hline H. diversicolor ....................... (corpo da fêmea) & Figura $45 \ldots . . .173$ \\
\hline H. diversicolor ...................... (epígino da fêmea) & Figura $46 \ldots . . .173$ \\
\hline H. diversicolor ...................(ilustração) ........... & Figura $47 \ldots \ldots .174$ \\
\hline H. diversicolor .....................(imagens MEV) & Figura $48 \ldots \ldots .175$ \\
\hline H. ignigenus ........................(corpo do macho) & Figura $49 \ldots \ldots .176$ \\
\hline H. ignigenus ................. & Figura $50 \ldots . . .176$ \\
\hline H. ignigenus .......................... (corpo da fêmea) & Figura $51 \ldots . . .177$ \\
\hline H. ignigenus .........................(epígino da fêmea) & Figura $52 \ldots \ldots . .177$ \\
\hline H. ignigenus ........................(ilustração) & Figura $53 \ldots \ldots . .178$ \\
\hline .....(imagens $\mathrm{MEV})$ & Figura $54 \ldots . . . .179$ \\
\hline H. labiatus ...........................(corpo do macho) & Figura $55 \ldots . . .180$ \\
\hline H. labiatus ............................(palpo do macho) & Figura $56 \ldots . . . .180$ \\
\hline H. labiatus ............................. (corpo da fêmea) & Figura $57 \ldots . . . .181$ \\
\hline H. labiatus .............................. (epígino da fêmea) & Figura $58 \ldots \ldots . .181$ \\
\hline H. labiatus ...........................(ilustração) & Figura $59 \ldots . . . .182$ \\
\hline H. labiatus ..........................(imagens MEV) & Figura $60 \ldots \ldots . .183$ \\
\hline H. lobatus ...........................(corpo do macho) & Figura $61 \ldots \ldots . .184$ \\
\hline H. lobatus .............................. (palpo do macho) & Figura $62 \ldots \ldots .184$ \\
\hline H. lobatus .............................. (corpo da fêmea) & Figura $63 \ldots \ldots . .185$ \\
\hline H. lobatus .............................epígino da fêmea) & Figura $64 \ldots \ldots .185$ \\
\hline 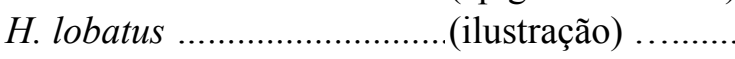 & Figura $65 \ldots . . .186$ \\
\hline H. lobatus ..........................(imagens MEV) .. & Figura $66 \ldots . . . .187$ \\
\hline H. modestus ........................(corpo do macho) & Figura $67 \ldots \ldots .188$ \\
\hline H. modestus ..........................(palpo do macho) & Figura $68 \ldots . . . .188$ \\
\hline H. modestus ...........................(corpo da fêmea) & Figura 69 \\
\hline
\end{tabular}




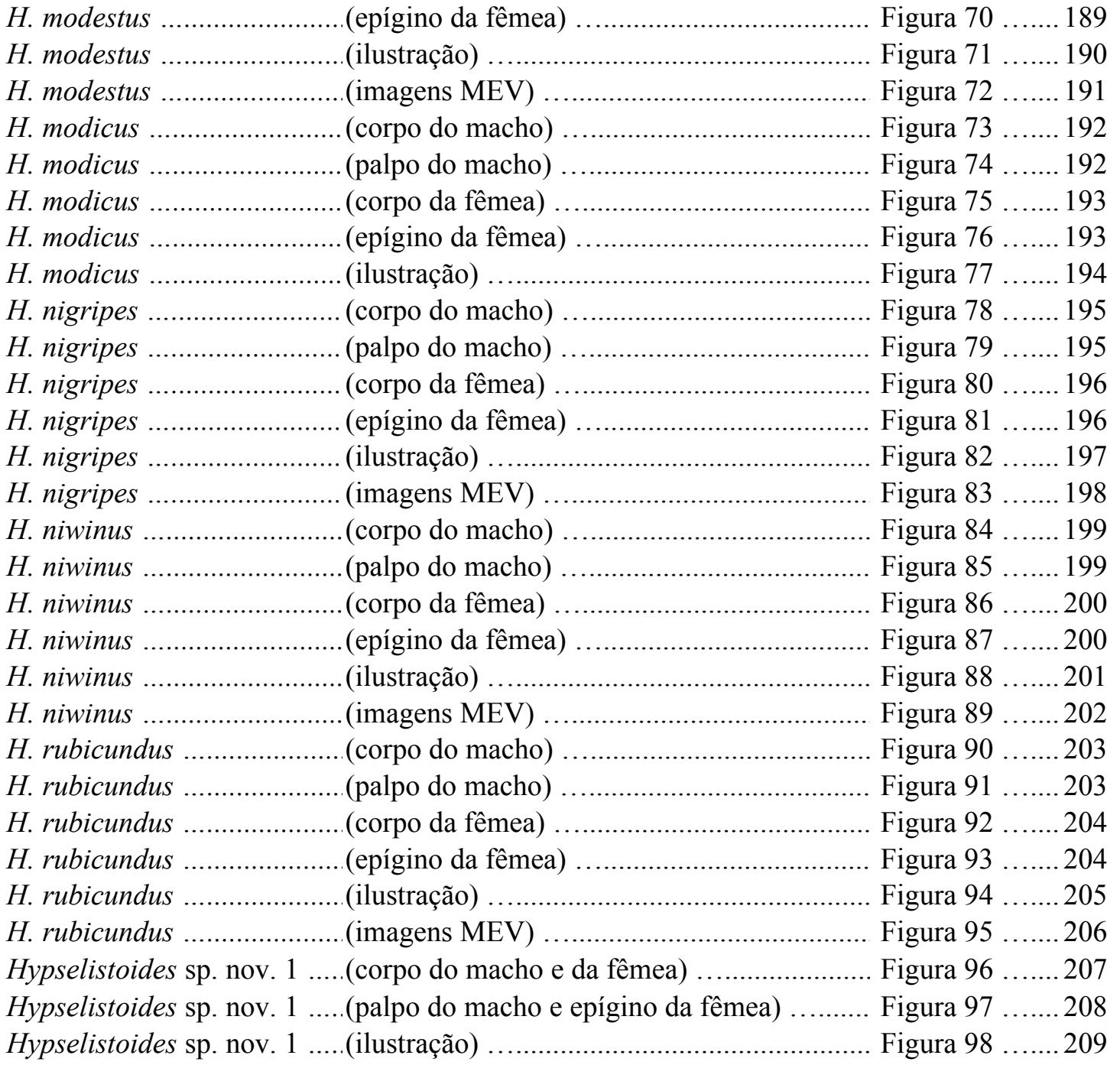

Gen. Sphecozone

S. melanocephala ...............(corpo da fêmea) ................................... Figura 4 _........ 147

S. melanocephala ...............(epígino da fêmea) .................................... Figura 5 .......... 147

S. nitens ...........................(corpo do macho) .................................... Figura 12 _...... 152

S. nitens ..........................(palpo do macho) ................................... Figura 13 _...... 152

S. nitens ...........................(corpo da fêmea) .................................... Figura 14 ....... 153

S. nitens ...........................(epígino da fêmea) .................................. Figura 15 ....... 153

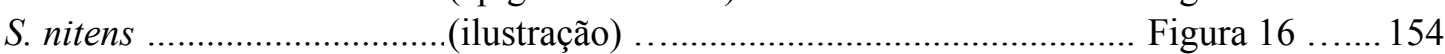

S. nitens .........................(imagens MEV) ...................................... Figura 17 ....... 155

S. rubescens .......................(ilustração) ............................................ Figura 10 ....... 150

S. rubescens .....................(imagens MEV) .................................. Figura 11 ....... 151

S. rubescens .......................(corpo do macho) .................................. Figura 6 ......... 148

S. rubescens ..................... (palpo do macho) ................................. Figura 7 ........ 148

S. rubescens ....................... (corpo da fêmea) ....................................... Figura 8 .......... 149

S. rubescens ....................... (epígino da fêmea) ................................... Figura 9 ......... 149 


\section{Resumo}

O gênero Sphecozone O. Pickard Cambridge, 1970 foi revisado. A hipótese obtida por análise cladística não o recupera como um grupo monofilético, e dois gêneros foram revalidados: Clitolyna Simon, 1894, para incluir a espécie-tipo Clitolyna fastibilis (Keyserling, 1886) comb. nov., e as espécies C. alticeps (Millidge, 1991) comb. nov., $C$. castanea (Millidge, 1991) comb. nov., C. crassa (Millidge, 1991) comb. nov., C. chumota (Miller, 2007) comb. nov., C. formosa (Millidge, 1991) comb. nov., C. gravis (Millidge, 1991) comb. nov., C. novaeteutoniae (Baert, 1987) comb. nov., C. personata (Simon, 1894) comb. nov., C. prativaga (Keyserling, 1886) comb. nov., C. rostrata (Millidge, 1991) comb. nov., C. rugosa (Millidge, 1991) comb. nov., C. spadicaria (Simon, 1894) comb. nov., C. tumidosa (Keyserling, 1886) comb. nov., C. varia (Millidge, 1991) comb. nov. e C. venialis (Keyserling, 1886) comb. nov., e Hypselistoides Tullgren, 1901, para incluir a espécie-tipo Hypselistoides bicolor (Nicolet, 1849) comb. nov., e as espécies $H$. altehabitans (Keyserling, 1886) comb. nov., H. capitatus (Millidge, 1991) comb. nov., H. corniculans (Millidge, 1991) comb. nov., H. cornutus (Millidge, 1991) comb. nov., $H$. crinitus (Millidge, 1991) comb. nov., H. diversicolor (Keyserling, 1886) comb. nov., $H$. ignigenus (Keyserling, 1886) comb. nov., H. labiatus (Keyserling, 1886) comb. nov., H. lobatus (Millidge, 1991) comb. nov., H. modestus (Nicolet, 1849) comb. nov., H. modicus (Millidge, 1991) comb. nov., H. nigripes (Millidge, 1991) comb. nov., H. niwinus (Chamberlin, 1916) comb. nov. e H. rubicundus (Keyserling, 1886). As espécies do gênero Moyosi Miller, 2007 foram transferidas para Clitolyna. O gênero Sphecozone conta, agora, somente com a espécie-tipo Sphecozone rubescens O. Pickard-Cambridge, 1871 e a espécie S. nitens Millidge, 1991. Um gênero novo foi proposto para acomodar Gen. nov. magnipalpis. Diagnoses e descrições atualizadas, imagens por microscopia eletrônica de varredura, imagens multi-focais e mapas de distribuição foram apresentadas. Uma espécies nova de Hypselistoides, duas de Clitolyna e duas do Gen. nov. foram descritas, assim como as fêmeas de C. gravis, C. tumidosa e H. lobatus.

Palavras-chave: Filogenia; Parcimonia; Aranhas; Neotrópicos; Erigoninae 


\section{Abstract}

The genus Sphecozone O. Pickard Cambridge, 1970 was revised. The hypothesis obtained by cladistic analysis does not recover it as a monophyletic group, and two genera were revalidated: Clitolyna Simon, 1894, to include the type species Clitolyna fastibilis (Keyserling, 1886) comb. nov., and the species C. alticeps (Millidge, 1991) comb. nov., C. castanea (Millidge, 1991) comb. nov., C. crassa (Millidge, 1991) comb. nov., C. chumota (Miller, 2007) comb. nov., C. formosa (Millidge, 1991) comb. nov., C. gravis (Millidge, 1991) comb. nov., C. novaeteutoniae (Baert, 1987) comb. nov., C. personata (Simon, 1894) comb. nov., C. prativaga (Keyserling, 1886) comb. nov., C. rostrata (Millidge, 1991) comb. nov., C. rugosa (Millidge, 1991) comb. nov., C. spadicaria (Simon, 1894) comb. nov., C. tumidosa (Keyserling, 1886) comb. nov., C. varia. (Millidge, 1991) comb. nov. and $C$. venialis (Keyserling, 1886) comb. nov., and Hypselistoides Tullgren, 1901, to include the type species Hypselistoides bicolor (Nicolet, 1849) comb. nov., and the species $H$. altehabitans (Keyserling, 1886) comb. nov., $H$. capitatus (Millidge, 1991) comb. nov., H. corniculans (Millidge, 1991) comb. nov., $H$. cornutus (Millidge, 1991) comb. nov., H. crinitus (Millidge, 1991) comb. nov., $H$. diversicolor (Keyserling, 1886) comb. nov., H. ignigenus (Keyserling, 1886) comb. nov., H. labiatus (Keyserling, 1886) comb. nov., H. lobatus (Millidge, 1991) comb. nov., $H$. modestus (Nicolet, 1849) comb. nov., H. modicus (Millidge, 1991) comb. nov., $H$. nigripes (Millidge, 1991) comb. nov., H. niwinus (Chamberlin, 1916) comb. nov. and $H$. rubicundus (Keyserling, 1886). Species of Moyosi Miller, 2007 were transferred to Clitolyna. The genus Sphecozone has now only the type species Sphecozone rubescens O. Pickard-Cambridge, 1871 and the species S. nitens Millidge, 1991. A new genus was proposed to accommodate Gen. nov. magnipalpis. Updated diagnoses and descriptions, scanning electron microscopy images, multi-focal images and distribution maps were presented. One new species of Hypselistoides, two of Clitolyna and two of Gen. nov. were described, as well as the females of C. gravis, C. tumidosa and H. lobatus.

Keywords: Phylogeny; Parcimony; Spiders; Neotropics; Erigoninae 


\section{Introdução}

Dentre as 117 famílias de aranhas, Linyphiidae Blackwall, 1859 é a segunda mais diversa, incluindo 4559 espécies descritas para o mundo (World Spider Catalog, 2018). São aranhas de pequeno porte que apresentam poucas variações morfológicas corporais, se comparada aos outros Araneoidea como Araneidae e Theridiidae, embora alguns machos apresentem modificações cefálicas peculiares (Millidge, 1991, figs. 701, 713; Hormiga, 2000, figs. 32-35; Frick \& Muff, 2009, figs. 9-11). São reconhecidas pela presença de estrias ou sulcos estridulatórios, na parte ectal das quelíceras, e por construírem teias em forma de lençol junto ao solo, apesar de pertencerem ao grupo de aranhas que produzem teias de forma orbicular (Coddington, 1986; Griswold et al., 1998; Harwood \& Obrycki, 2005).

Os linifídeos estão difundidos por todo o globo, mas são melhor conhecidos na Região Holártica (Tanasevitch, 2018). Mesmo com uma grande riqueza e largamente distribuídos, pouco se sabe a respeito de sua diversidade na Região Neotropical. Dos artigos publicados nos últimos 20 anos, cerca de 76\% referem-se a linifídeos da Europa, Ásia e América do Norte. Destes artigos, poucos se referem à biologia e filogenia, sendo a grande maioria limitada a estudos taxonômicos, com revisões de gêneros e descrições de espécies (Miller, 2005a, 2005b; Dupérré et al., 2006; Saaristo, 2007; Lasut et al., 2009; Xu et al., 2010; Tu \& Hormiga, 2010; Lemos e Brescovit, 2013; Rodrigues et al., 2013; Otto e Tanasevitch, 2015; Tanasevitch, 2017; Zhao e Li, 2017).

Mesmo que os estudos taxonômicos sejam predominantes, pesquisas quanto à filogenia de linifídeos têm crescido. Tentativas de descrever a história evolutiva e investigar a relação com outras famílias são antigas (Merrett, 1963; Millidge, 1988, 1993), mas somente a partir de Hormiga (1994a) é que a análise cladística ganhou importância. A monofilia de Linyphiidae é bem suportada em análises filogenéticas, sendo Pimoidae Wunderlich, 1986 seu grupo-irmão, e é sustentada por pelo menos cinco sinapomorfias: perda da apófise média e do condutor de Araneoidea, presença de um paracímbio intersegmental em forma de "U" ou "J", presença do radix e do supratégulo no palpo dos machos (Hormiga, 1994a, 1994b; Griswold et al., 1998; Miller \& Hormiga, 2004; Arnedo et al., 2009, Agnarson et al., 2013; Wheeler et al., 2016). 
A classificação supragenérica de Linyphiidae ainda é discutida e é dividida em sete subfamílias: Dubiaraneinae Millidge, 1993; Erigoninae Emerton, 1882; Ipainae Saaristo, 2007; Linyphiinae Blackwall, 1859; Micronetinae Hull, 1920; Mynogleninae Lehtinen, 1967 e Stemonyphantinae Wunderlich, 1986 (Tanasevitch, 2018). Destas, apenas Ipainae, Mynogleninae e Stemonyphantinae não apresentam registros para a Região Neotropical. Hipóteses filogenéticas corroboram a monofilia de Mynogleninae e Erigoninae, enquanto que a posição basal do gênero Stemonyphantes Menge, 1866 e a monofilia das demais subfamílias ainda é investigada (Hormiga, 2000; Miller \& Hormiga, 2004; Arnedo et al., 2009; Frick \& Scharff, 2014; Gavish-Regev et al., 2013).

A subfamília Erigoninae inclui atualmente 403 gêneros distribuídos mundialmente (Tanasevitch, 2018). Aranhas desta subfamília são caracterizadas pela ausência da unha tarsal no palpo da fêmea e a presença de uma ou mais apófises na tíbia do palpo dos machos (Miller \& Hormiga, 2004). Na Região Neotropical são registrados 58 gêneros (39 endêmicos para a região), dos quais 50 foram estudados por Miller (2007) em sua revisão dos Erigoninae Neotropicais.

O primeiro a propor uma hipótese filogenética para os gêneros e espécies de Erigoninae foi Hormiga (2000), que apresentou uma análise baseada em 43 táxons, sendo 31 erigonines, utilizando 73 caracteres morfológicos e comportamentais. Miller e Hormiga (2004) refizeram a análise adicionando 41 táxons, incluindo agora espécies Neotropicais. Caracteres foram acrescentados e modificados resultando em uma nova matriz de 176 caracteres. $\mathrm{O}$ resultado encontrado por estes autores confirmou a monofilia de Erigoninae, além de destacar dois grandes clados, um incluindo os gêneros Triplogyna Millidge, 1991, Laminacauda Millidge, 1985 e os "erigonines haplotraqueados", e outro incluindo Sciastes Bishop \& Crosby, 1938 e os "erigonines distais" (Miller \& Hormiga, 2004, fig. 4, clados 17 e 38 , respectivamente).

Um evento considerado evolutivamente importante dentre os Erigoninae Neotropicais, e encontrado no clado dos "erigonines distais", é a perda ou redução do paracímbio, uma estrutura esclerotizada ligada ao címbio e localizada na parte retrolateral do palpo dos machos de Araneoidea. A redução dessa estrutura, em Erigoninae, ocorreu em Ceratinopsis Emerton, 1882, Dolabritor Millidge, 1991, Gonatoraphis Millidge, 1991 e Tutaibo Chamberlin, 1916, enquanto que a perda ocorreu em Moyosi Miller, 2007, 
Psilocymbium Millidge, 1991 e Sphecozone O. P.-Cambridge, 1870. Hipótese filogenética de Miller \& Hormiga (2004) sugere que a perda do paracímbio ocorreu duas vezes independentemente em Psilocymbium e Sphecozone, e que, somados a Ceratinopsis, Dolabritor, Gonatoraphis, Intecymbium Miller, 2007 e Tutaibo, formariam um grupo intimamente relacionado. Apesar de Moyosi não estar incluído nestas análises, uma recente dissertação de mestrado (Lemos, 2013) sugere que o gênero esteja mais relacionado à Psilocymbium do que Sphecozone, baseado na perda do paracímbio.

Apesar destes estudos, a relação interna de Sphecozone ainda é desconhecida. O gênero foi descrito por Pickard-Cambridge (1870), para incluir a espécie-tipo S. rubescens. Baseando-se na morfologia do palpo dos machos, com presença do supratégulo, pela forma da divisão embólica e pela forma em $U$ invertido do reservatório espermático, Millidge (1985) inclui o gênero em Erigoninae, propondo uma relação com os gêneros Ceratinopsis Emerton, 1882 e Ceraticelus Simon, 1884. Ainda neste trabalho ele sinonimiza o gênero monotípico Hypselistoides Tullgren, 1901 com Sphecozone, transfere Ceratinopsis modesta (Nicolet, 1849) para $S$. modesta, e descreve uma espécie nova, S. ardens.

Uma nova revisão do gênero foi realizada por Millidge (1991), desta vez incluindo 18 espécies novas neotropicais, além de propor as transferências das espécies Ceratinopsis araeonciformis (Simon, 1895) e Typhistes personata (Simon, 1894) para Sphecozone. Neste trabalho, Millidge ainda rejeita a sinonímia de Ceratinella Emerton, 1882 e Ceratinopsis com Sphecozone, proposta por Wunderlich (1987), além de sugerir uma relação entre Sphecozone e os gêneros Brattia Simon, 1894, Ceratinopsis, Dolabritor Millidge, 1991, Gonathoraphis Millidge, 1991, Gymnocymbium Millidge, 1991, Psilocymbium Millidge, 1991 e Tutaibo Chamberlin, 1916, relações que foram confirmadas através da análise cladística de Miller e Hormiga (2004). Millidge (1993) ainda descreve S. magnipalpis para os Estados Unidos, sendo esta o único registro do gênero fora da região neotropical.

Além de Millidge, apenas Miller contribuiu para ampliar o conhecimento de Sphecozone. Ao revisar o gênero Brattia, Miller (2004) transfere todas as espécies neotropicais para Sphecozone, separando-as das espécies da África e Filipinas, as quais foram transferidas para outros gêneros. Um outro trabalho mais extenso, envolvendo Sphecozone, foi realizado por Miller em 2007, onde ele propôs a transferência de Clytolina 
Simon 1894 e Gymnocymbium, de duas espécies de Ceratinopsis e 6 de Erigone Audouin, 1826, além de sinonimizar 8 espécies de Sphecozone, duas de Erigone e uma de Ceratinopsis. Depois desta revisão, Sphecozone passou a incluir 34 espécies, onde 12 são conhecidas apenas por um de seus sexos, 5 somente por fêmeas e 6 por machos (Tabela 1). Miller e Hormiga (2004) realizando uma análise cladística da subfamília Erigoninae, seleciona 4 representantes do gênero Sphecozone para compor os terminais: Sphecozone rubescens, a espécie-tipo do gênero; Sphecozone bicolor (Nicolet, 1849), antiga espécietipo de Hypselistoides; S. spadicaria (Simon, 1894), espécie-tipo de Brattia; e S. crassa (Millidge, 1991), que apesar de não ter sido a espécie-tipo é a única representante de Gymnocymbium a apresentar os dois sexos descritos. Os resultados mostram Sphecozone como monofilético, grupo-irmão de Tutaibo, e suportado pela perda do paracímbio e crista do radix, e a origem do átrio (Miller e Hormiga, 2004), porém essa hipótese ainda é discutida. Miller e Hormiga (2004) e Miller (2007) questionam a determinação de Sphecozone como um gênero monofilético, sugerindo que a espécie S. rubescens seria morfologicamente incomum as demais espécies de Sphecozone analisadas. Os autores propõem ainda uma futura análise onde, caso se confirme a posição basal de $S$. rubescens e espécies semelhantes, pudesse formar um pequeno grupo associado ao gênero Hypselistoides, possivelmente revalidado. Esta tese teve como objetivos testar esta hipótese, sob um ponto de vista filogenético, incluindo todas as espécies descritas do gênero Sphecozone e prováveis espécies novas, além de realizar um novo estudo taxonômico do grupo, incluindo espécies que não foram avaliadas em recentes revisões, apresentando descrições e imagens atualizadas. 


\section{Material e Métodos}

\section{Descrições taxonômicas}

O formato das descrições segue a revisão taxonômica de Miller (2007). A presença de tricobótrio no metatarso IV (TmIV) e sua posição no metatarso I (TmI) segue Millidge (1980). Todas as medidas estão apresentadas em milímetros (mm), com exceção das fotomicrografias de varreduras, que estão em micrômetros $(\mu \mathrm{m})$. Para exame detalhado das estruturas dos palpos dos machos, estes foram expandidos em solução de $\mathrm{KOH}$ a 10\% conforme metodologia adaptada de Griswold (1993). Os epíginos das fêmeas foram dissecados e digeridos com auxílio de uma solução de pancreatina, conforme Álvarez-Padilla e Hormiga (2007).

Fotomicrografias de varredura foram realizadas utilizando microscópio eletrônico FEI Quanta 250 do Laboratório de Biologia Celular, do Instituto Butantan, para examinar detalhes das quelíceras, prossoma, pernas, fiandeiras de machos e fêmeas, além de epíginos das fêmeas e palpos dos machos. Fotografias digitais multifocais dos espécimes foram tiradas com auxílio de estereomicroscópio Leica MZ16A com câmera digital Leica DFC500 acoplada, e montadas com o programa Leica Application Suíte Versão 3.3.0.

As abreviações das estruturas foram utilizadas conforme Hormiga (1994b, 2000), Miller \& Hormiga (2004) e Miller (2007). Para auxiliar nas identificações das estruturas em imagens dos artigos referenciados, foram mantidas as abreviações originais, sendo aqui traduzidas apenas seu significado: A, átrio;AC, fúsulos da glândula aciniforme; AG, fúsulos da glândula agregada; AL, lóbulo anterior da placa dorsal do epígino; ALE, olhos laterais anteriores; ALS, fiandeira lateral anterior; AME, olhos médios anteriores; AMF, aba da margem anterior do címbio; AP, processo anterior da placa ventral do epígino; ARP, processo anterior do radix; AT, dente anterior do radix; AVC, apófise ventral do címbio; $\mathrm{BCE}$, base escavada do címbio; $\mathrm{BH}$, hematodoca basal; $\mathrm{BL}$, lóbulo basal do êmbolo; $\mathrm{CB}$, címbio; $\mathrm{CD}$, duto de copulação; $\mathrm{CG}$, sulco retrobasal do címbio; CL, column; CO, abertura de copulação; CRL, lóbulo retrolateral do címbio; CY, fúsulos da glândula cilíndrica; DP, placa dorsal do epígino; DAV, Depressão anterior da placa ventral; DLV, Depressão lateral da placa ventral; DSA, apófise distal suprategular; DT, dente distal da apófise prolateral da tíbia; DTA, apófise 
distal da tibia; DTS, esclerito tegular distal (Tutaibo); E, êmbolo; EA, apófise embólica; EBP, processo basal do êmbolo; EM, membrana embólica; FD, duto de fertilização; FL, fúsulos da glândula flageliforme; IM, membrana interna do epígino; LCR, lóbulo da cauda do radix; MAP, fúsulos da glândula ampularmaior; mAP, fúsulos da glândula ampular menor; PAT, apófise proximal do tégulo; PC, paracímbio; PI, fúsulos da glândula piriforme; PLE, olhos laterais posteriores; PLS, fiandeira lateral posterior; PME, olhos médio posteriores; PMS, fiandeira média posterior; PPD, Processo posterior dorsal do címbio; PT, protégulo; PTA, apófise prolateral da tibia; R, radix; RMP, processo retromediano do címbio; RR, crista do radix; RTA, apófise retrolateral da tíbia; S, espermateca; SPT, supratégulo; ST, subtégulo; T, tégulo; TA, apófise terminal; TmI, posição do tricobótrio no primeiro metatarso; TmIV, tricobótrio do quarto metatarso; TP, porção posterior do radix; VP, placa ventral do epígino; VTP, processo ventral da tíbia.

\section{Material examinado}

Foram examinados exemplares das seguintes instituições (siglas e curador entre parênteses): American Museum of Natural History, Nova Iorque (AMNH, L. Prendini); California Academy of Science, California (CAS, L. Esposito); Laboratório Especial de Coleções Zoológica, Instituto Butantan, São Paulo (IBSP, A. D. Brescovit); Museo Argentino de Ciencias Naturales Bernardino Rivadavia, Buenos Aires (MACN, C. Scioscia); Museo de Historia Natural, Universidad Mayor de San Marcos, Lima (MUSM, D. Silva Dávila); Museu de Ciências e Tecnologia, Pontifícia Universidade Católica do Rio Grande do Sul, Porto Alegre (MCTP, R. Teixeira); Museu de Ciências Naturais, Fundação Zoobotânica do Rio Grande do Sul, Porto Alegre (MCN, R. Ott); Museu de Zoologia, Universidade de São Paulo, São Paulo (MZSP, R. Pinto da Rocha); Museum of Comparative Zoology, Harvard University, Cambridge (MCZ, L. Leibensperger, G. Giribet); National Museum of Natural History, Smithsonian Institution, Washington, D.C. (USNM, J. Coddington), Centro de Coleções Taxonômicas da Universidade Federal de Minas Gerais, Belo Horizonte (UFMG, A. J. Santos).

Os exemplares utilizados para os estudos de caracteres, medidas e imagens, encontram-se listados abaixo. Além do material de empréstimo, algumas espécies, 
principalmente as com número limitado de exemplares, também tiveram seus dados baseados em recentes publicações (Hormiga, 2000; Miller \& Hormiga, 2004; Miller, 2007) e estão em destaque com asterisco.

* Grammonota pictilis (O. P.-Cambridge, 1875)

Canadá. Nova Escócia: Kentville $\left(45^{\circ} 04^{\prime} \mathrm{N} ; 64^{\circ} 31^{\prime} \mathrm{W}\right)$, 31.v.1957, C. Dondale col. (AMNH, $1 \delta^{\Uparrow} 5$ q). Estados Unidos, Nova York, Little Pond, Orange Co. $\left(41^{\circ} \mathrm{N} ; 74^{\circ} \mathrm{W}\right)$, 25.v.1920, S. C. Bishop col. (AMNH, $1 \delta^{\Uparrow} 5$ q).

*Ceratinopsis interpres (O. P-Cambridge, 1874)

Estados Unidos. Nova Hampshire: Hillsborough Co., Hollis, "Beaver Brook Assc." $\left(42^{\circ} 44^{\prime} \mathrm{N} ; 7^{\circ} 36^{\prime} \mathrm{W}\right), 26 . v .1977$, J. Coddington col. (USNM, 658, 202우).

*Dolabritor spineus Millidge, 1991

Colômbia. Cundinamarca: La Calera, Cerro del Chocolatero, 5km NE de Bogotá (440'N; 7359'W), 31.i.1996, G. Hormiga, J. Miller, J. Barriga, J.C. Bello, A. Sabogal col. (USNM, $2 \hat{\jmath} 4$ ).

*Gonatoraphis lysistrata Miller, 2007

Colômbia. Boyacá: S.F.F. Iguaque, perto da margem Laguna Iguaque (541'20,8”N; 73²6'7,0”W), 5-8.ii.1998, G. Hormiga, J. Coddington, J. Miller, V. Rodríguez col. (USNM 1034, 1035, 1ठ1).

*Intecymbium antarcticum (Simon, 1895)

Chile. Região de Los Lagos: Llanquihue, $7 \mathrm{~km} \mathrm{~N}$ de Ensenada $\left(41^{\circ} 07 ' \mathrm{~S} ; 72^{\circ} 32^{\prime} \mathrm{W}\right)$, 26.xi.1981, R. T. Schuh \& N. Platnick col. (AMNH, 19). Llanquihue, Lago Chapo, 34km E de Puerto Montt (41ํㄱ'S; 72³1'W), 24.xii.1984-2.ii.1985, S. \& J. Peck col. $\left(\mathrm{AMNH}, 1{ }^{\Uparrow}\right)$. Região de Magallanes: Esperanza Prov., Torres del Paine, perto de Refugio Pudeto $\left(51^{\circ} 14 ' \mathrm{~S} ; 7^{\circ} 30^{\prime} \mathrm{W}\right), 7 . x i i .2000$, J. Miller, I. Agnarsson col. (USNM, 1우). 
Moyosi prativaga (Keyserling, 1886)

Argentina. Misiones: Puerto Iguazú, Parque Nacional de Iguazú, Zona de Saltos, Islas (2541'S; 54²6'W), 8-15.ii.1995, M. J. Ramírez col. (MACN, 1ð2ㅇ), 8.xii.19906.I.1991, S. \& J. Peck col. (AMNH \#90-91, 1ð1ㅇ); Brasil. Rio Grande do Sul: Maquiné, FEPAGRO (29³9'S; 50¹2'W), 18-27.i.2002, Equipe Biota col. (IBSP 60099, 60107, 60328, 60632, 2ð2ㅇ).

*Psilocymbium acanthodes Miller, 2007

Argentina. Buenos Aires: Río Luján, FCGM (34²3'S; 58³6'W), 5.x.1993, M. Ramírez, A. Pérez col. (MACN 1028, $3 \overbrace{}^{\Uparrow} 3$ ㅇ) .

*Tutaibo phoeniceus O. Pickard-Cambridge, 1894

México. Chiapas: perto de Bochil $\left(17^{\circ} 00^{\prime} \mathrm{N} ; 92^{\circ} 54^{\prime} \mathrm{W}\right)$, 2.viii.1964, J. Shetterly col. (MCZ 61511, 2`ํㅇ), 5km de San Cristobal de Las Casas $\left(16^{\circ} 43^{\prime} \mathrm{N} ; 92^{\circ} 34^{\prime} \mathrm{W}\right), 27-$ 28.vii.1983, W. Maddison \& R. S. Anderson col. (MCZ 61488, 4ð3우).

Sphecozone altehabitans (Keyserling, 1886)

Peru. La Libertad: Los Alisos, (nr. Pataz), (8¹3'45.3"S; 77²2'22.2"W), 17.vi.1986, B. Roth col. (CAS 9076640, 3 ㅇ).

Sphecozone alticeps Millidge, 1991

Colômbia. Cauca: Puracé, Paramo Purace, 15km E Purace, (2¹6'29.6"N; 76²3'02.0"W), 20.x.1968, B. Malkin col. (AMNH 00326248, 1今, holótipo), 20.x.1968, B. Malkin col. (AMNH 00326249, 7q, parátipo).

Sphecozone bicolor (Nicolet, 1849)

Bolívia. Camargo: 16mi N of Camargo, S Bolivia, 20.ii.1951, Ross and Michelbacher col. (CAS 9076614, 19, CAS 9076629, 1ð). Chile. Región De La Araucanía (IX): Cautín Prov., Chacamo, NW Nueva Imperial and W Temuco, 17-23.ii.1981, L. E. Pena col. (AMNH 00326266, 3ð6우 1\#J, parátipo). Región Del Bío Bío (VIII): Concepción Prov., Periquillo, 22.xi.1992, T. Cekalovic col. (AMNH 00326267, 4ð13q). Región De 
Magallanes (XII): Magallanes Prov., Reserva Nacional Laguna Parrillar, 1-10.xii.2000, Miller, Agnarson col. (USNM, $5 \lesssim 34$ 우 1\#J).

Sphecozone capitata Millidge, 1991

Peru. Lambayeque: Hacienda Huacraruco, KP 522 (7¹8'22.0"S 78²6'14.5"W), 2227.iii.1958, KLK col. (MUSM 0507406, 1 , , parátipo). Cajamarca: San Juan, Hacienda Huacraruco, KP 522 (7¹8'22.0"S 78²6'14.5"W), 22-27.iii.1958, KLK col. (MUSM, $1 \hat{\jmath}$, holótipo).

Sphecozone castanea (Millidge, 1991)

Brasil. São Paulo: São Bernardo do Campo, Parque Estoril, (234ㄴ'S; 46³2'W), 28.ix02.x.2006, C. V. Janini et al. col. (IBSP 90164, 5ð4 9 ), São Paulo, Jardim Ângela,

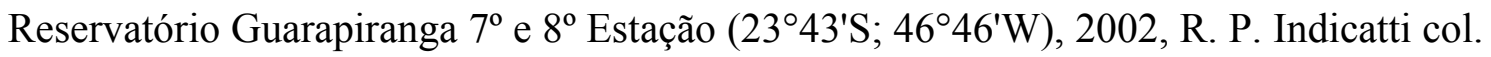

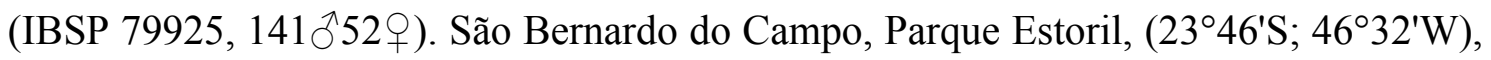
04-09.i.2007, C. V. Janini et al. col. (IBSP 116936, 2ð4우, IBSP 89964, 6ð1 das Cruzes, Parque Natural Municipal da Serra do Itapety, $\left(23^{\circ} 29^{\prime} \mathrm{S} ; 4^{\circ} 12^{\prime} \mathrm{W}\right)$, 13 18.x.2003, Equipe Biota col. (IBSP 55094, 2ㅇ). Itapevi, (23³3'S; 4702'W), iv.2000, Sem Coletor col. (IBSP 63190, 1ठ2; IBSP 63192, 29). Santo André, Reserva

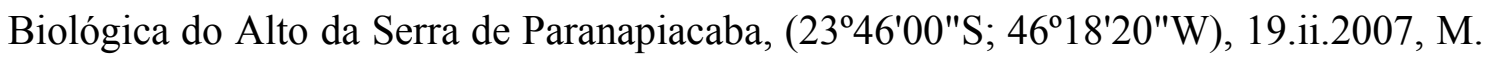
Uehara Prado col. (IBSP 143053, 2ð)).

Sphecozone corniculans Millidge, 1991

Colombia. Cundinamarca: Provincia del Sumapaz, Páramo de Sumapaz, $\left(4^{\circ} 25^{\prime} \mathrm{N}\right.$; 7406'W), 4-14 .x.1978, H. Sturn col. (MCZ 78/55, 1ð̋, holótipo). Argentina. Buenos Aires: Rio Abra Vieja, Isla Don Segismundo, Delta of Parana $\left(34^{\circ} 23^{\prime} \mathrm{S} ; 58^{\circ} 33^{\prime} \mathrm{W}\right)$, 6.i.1962, O. de Ferrariis col. (AMNH 326271, 1ð̄, holótipo).

Sphecozone cornuta Millidge, 1991

Argentina. Buenos Aires: Parque Pereya, (3450'S; 58¹0'W), 28.i.1962, O. de Ferrariis

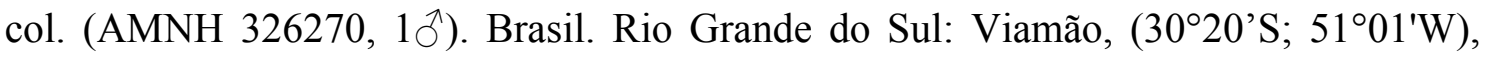
7.vii.1995, A. A. Lise col. (MCTP 18286, 1ð)., Caxias do Sul, Fazenda Souza, $\left(29^{\circ} 07^{\prime} \mathrm{S} ; 51^{\circ} 12^{\prime} \mathrm{W}\right), 5 . x i .1994$, L. Moura col. (MCN 26212, 1ठ). 
Sphecozone crassa (Millidge, 1991)

Brasil. Amazonas: São Gabriel da Cachoeira, Pico da Neblina, $\left(0^{\circ} 47^{\prime} \mathrm{N} ; 66^{\circ} 01^{\prime} \mathrm{W}\right)$, 8.x.1990, A. A. Lise et al. col. (MCTP 1376, 19).

Sphecozone crinita Millidge, 1991

Brasil. Santa Catarina: Rancho Queimado, (2740'S; 49¹3'W), 15-18.xi.1995, A. B.

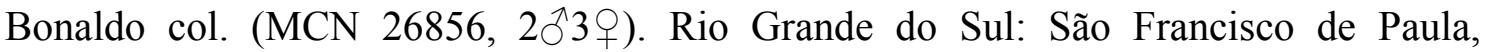
Potreiro Velho, $\left(2^{\circ} 24^{\prime}\right.$ S; 50¹9'W), i.2002, L. A. Bertoncello et al. col. (MCTP 25743,

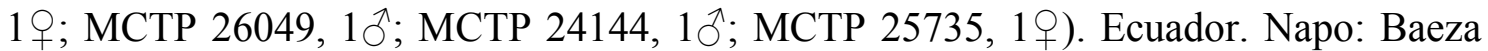
("Breza"), (0²7'S; 7753'W), 4.ii.1976, R. T. Schuh col. (AMNH 326261, 1ठ1ㅇ, parátipo).

Sphecozone diversicolor (Keyserling, 1886)

Brasil. Rio Grande do Sul: Cachoeira do Sul, (30¹3'S; 5251'W), 14.xii.1992, R. G.

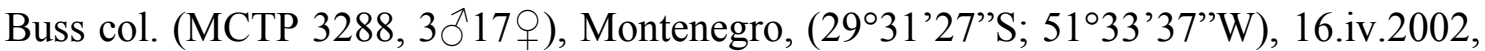
V. Wolf et al. col. (MCN 37074, 12§20+). São Paulo: Peruíbe, Estação Ecológica Juréia-Itatins, (24 33' 015"S; 47 13' 292"W), 02.xi.1995, R. Bertani \& O. Marques col. (IBSP 6353, 1ð2ㅇ). Rio de Janeiro: Santa Maria Madalena, $\left(21^{\circ} 57^{\prime} \mathrm{S} ; 42^{\circ} 01^{\prime} \mathrm{W}\right)$, vi.1960, M. Alvarenga col. (AMNH 326263, 2ð̂, parátipo).

Sphecozone fastibilis (Keyserling, 1886)

Brasil. Minas Gerais: Pains, $\left(20^{\circ} 21^{\prime} S\right.$; $\left.45^{\circ} 35^{\prime} \mathrm{W}\right), 15-27 . V I I .2013$, Equipe Carste col.

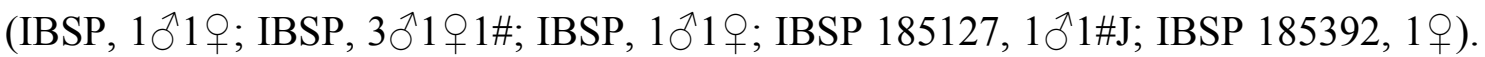

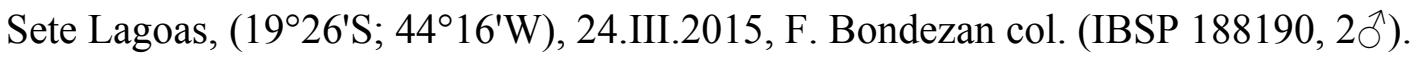

Sphecozone gravis (Millidge, 1991)

Brasil. Minas Gerais: Prudente de Morais, Fazenda Sapé, (19³0'; 447'W), 2.vi.2001, E. S. S. Álvares col. (UFMG 1159, 1ठ2ㅇ, parátipo). Mato Grosso do Sul: Brasilândia, Usina Hidrelétrica Engenheiro Sérgio Motta, $\left(21^{\circ} 18^{\prime} \mathrm{S} ; 52^{\circ} 01 \mathrm{~W}\right), 2000$, Equipe IBSP col. (IBSP 30832, 1ð). São Paulo: Assis, Parque Ecológico de Assis, (22³9'S; 50²5'W), 25-29.xi.2002, C. Firmo col. (IBSP 59136, 1§1우). Mato Grosso do Sul: 


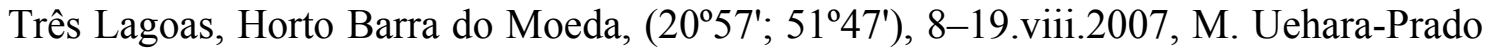
col. (UFMG 5682, $3 \overbrace{}^{\Uparrow} 1$ \%).

Sphecozone ignigena (Keyserling, 1886)

Brasil. Rio Grande do Sul: Viamão, (30²0’S; 5101'W), 25.xi.1994, A. A. Lise et al.

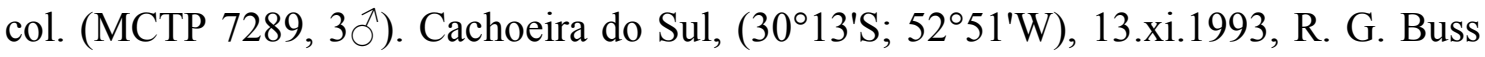

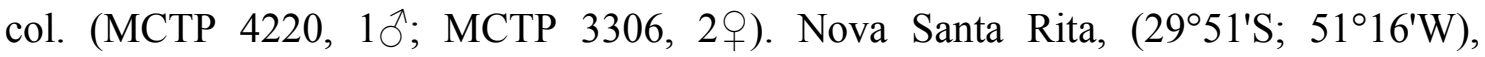
23.v.2009, A. Oliveira col. (MCTP 37274, 1 ㅇ).

Sphecozone labiata (Keyserling, 1886)

Brasil. Minas Gerais: Monte Verde, Trilha Pedra Partida, $\left(22^{\circ} 53^{\prime} \mathrm{S} ; 4^{\circ} 00^{\prime} \mathrm{W}\right), 21-$ 23.vii.1998, V. C. Onófrio col. (IBSP 20267, 16つ18). São Paulo: São Miguel

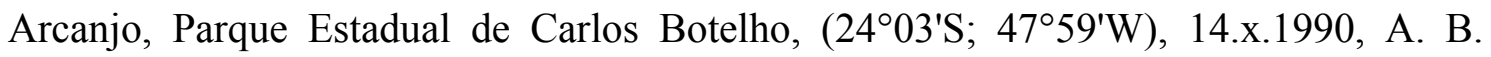
Bonaldo col. (MCN 20487, 4ð2 + ). Santa Catarina: Blumenau, Parque Natural Municipal "Nascentes do Garcia”, (2703'13.5"S; 4905'W), 21-28.I.2003, Equipe Biota col. (MCN 41117, 1ð1우).

Sphecozone lobata Millidge, 1991

Brasil. Rio Grande do Sul: Cidreira, (308'S; 50¹6'W), 20.ix.2003, J. A. M. Pinto col. (MCTP 37100, 1ð2ᄋ; MCTP 34065, 5ठ). Chile. Juan Fernandez Islands: Mas a Tierra

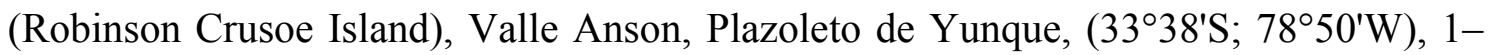
28.iv.1962, B. Malkin col. (AMNH 326273, 1ð̂, holótipo).

Sphecozone magnipalpis Millidge, 1993

Estados Unidos. Arizona: Santa Cruz Co., Santa Rita Mts., Madera Canyon, $\left(31^{\circ} 44^{\prime} 20.0^{\prime \prime} \mathrm{N} ; 110^{\circ} 53^{\prime} \mathrm{W}\right), 1-2 . v i i i .1952$, H. B. Leech and J. W. Green col. (CAS 16973, 1ठึ, holótipo).

Sphecozone melanocephala (Millidge, 1991)

Brasil. Rio de Janeiro: Teresópolis, $\left(22^{\circ} 23^{\prime} \mathrm{S} ; 4^{\circ} 01^{\prime} \mathrm{W}\right), 16 . i i i .1946$, H. Sick col. (AMNH 326268, 1q, holótipo). 
Sphecozone modesta (Nicolet, 1849)

Chile. Región De Los Lagos (X): Chiloé Prov., Chiloé, Río Pudeto and Puente Río Pudeto, (41 $\left.{ }^{\circ} 52^{\prime} \mathrm{S} ; 7^{\circ} 46^{\prime} \mathrm{W}\right), 28.1 i .1972$, T. Cekalovic col. (AMNH 326269, 21 $\delta^{\wedge} 65$ ㅇ). Bolivia. La Paz: Huatajata, Lago Titicaca, $\left(16^{\circ} 12^{\prime} \mathrm{S} ; 68^{\circ} 41^{\prime} \mathrm{W}\right)$, 8.viii.1993, A. D. Brescovit \& H. Höfer col. (MCN 23785, 1ðึ4우).

\section{Sphecozone modica Millidge, 1991}

Argentina. La Rioja: 5km E. Chilecito, (2908'S; 67²7'W), xii.1971, Lee Herman col. (AMNH 326247, 1§̂, holótipo). Brasil. Rio Grande do Sul: Triunfo, Parque Copesul de

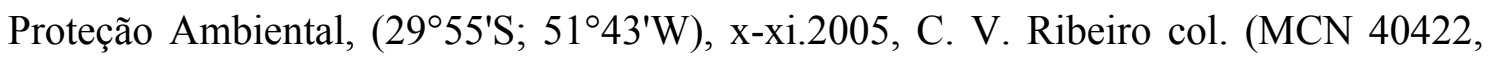

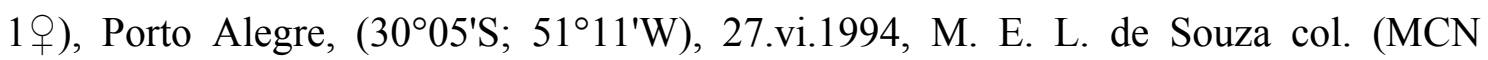

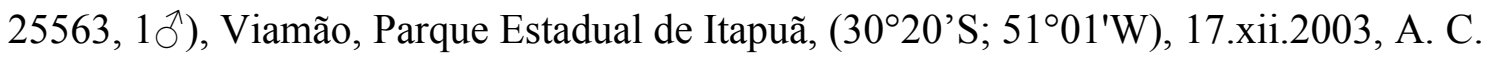
K. Ferreira col. (MCTP 20410, 1§), Cachoeirinha, Estação Experimental do Arroz, Irga $\left(30^{\circ} 00^{\prime} \mathrm{S} ; 51^{\circ} 12^{\prime} \mathrm{W}\right), 16 . x i .2004$, E. N. L. Rodrigues col. (MCN 39127, 1 ㅇ)

Sphecozone nigripes Millidge, 1991

Peru. La Libertad: Laguna Quishuar, (7³6'14.53"S; 77²5'12.47"W), iii.2011, C. Carranza col. (MUSM 0504452, $\left.1 \bigcirc^{\Uparrow}\right), 30 \mathrm{~km}$ south of Cajabamba, $\left(7^{\circ} 40^{\prime} \mathrm{S} ; 7^{\circ} 29^{\prime} \mathrm{W}\right)$, 20.i.1976, R. T \& J. C. Schuh col. (AMNH 326265, 1ð̄, parátipo). Lima: Bosque de

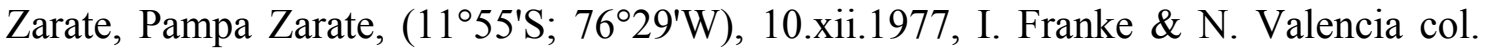

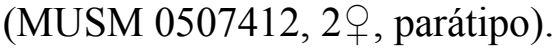

Sphecozone nitens Millidge, 1991

Brasil. Rondônia: Ouro Preto do Oeste, Campo Experimental da Embrapa, $\left(10^{\circ} 43^{\prime} \mathrm{S}\right.$; $62^{\circ} 15^{\prime}$ W), viii.2008-ix.2008, L. S. P. Trigueiro, C. A. D. Teixeira, L. A. P. Sallet, K. S. Serra col. (IBSP 124654, 19). Peru. Huánuco: Yuyapichis, Rio Yuyapichis, Rio Yuyapichis (09 37' S; 74 56' W), 29.i-26.ix.1983, M. Verhaagh col. (IBSP 23870, 1ठ). Junín: San Ramon, hotel "El Refugio", jardins (11'15.724"S; 75²1’28.621"W),

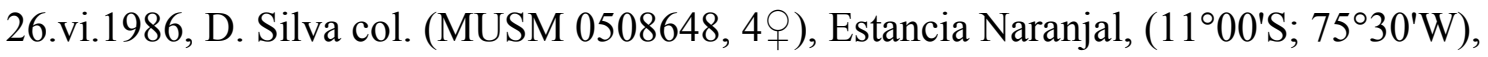
20-27.vii.1965, P. \& B. Wygodzinsky col. (AMNH 326264, 1ð1ㅇ). Madre de Dios:

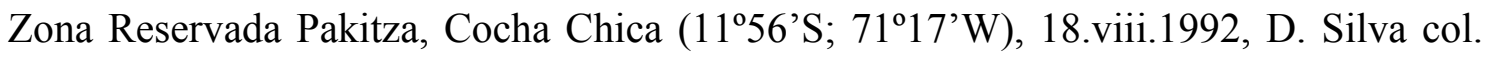

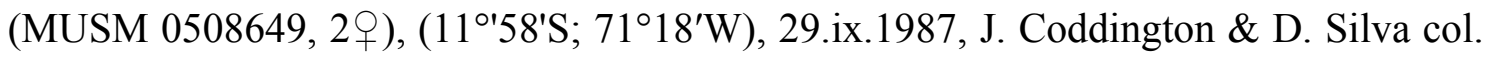




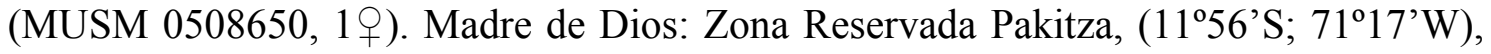
18.viii.1992, D. Silva col. (MUSM 0508651, 1 ). Pasco: Oxapampa, Abra Asirrodiro, (10³4'S; 75²3'W), 21.vi.1986, D. Silva col. (MUSM 0507411, 1 q, parátipo).

Sphecozone niwina (Chamberlin, 1916)

Chile. Región de Tarapacá (I): Tarapacá prov., Parinacota, (18²'S; 69¹6'W), 2 4.iv.1990, L. E. Pena col. (AMNH 326260, 2ð12 $q$ ). Peru. Pasco: Huayllay, Santuario de Huayllay, (1056'54,11"S; 76²18'45,5"W), 3.ix.2007, W. Paredes col. (MUSM

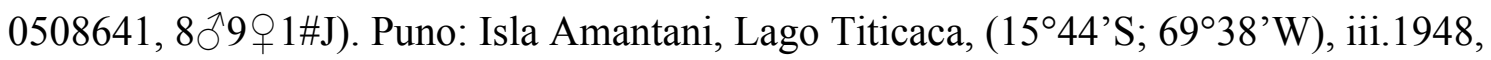

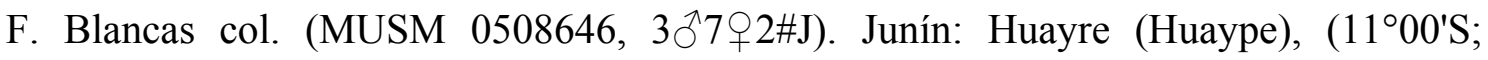
$\left.76^{\circ} 01^{\prime} \mathrm{W}\right), 21 . x .1963$, sem informação do cololetor (MUSM 0508647, 1ठ2ㅇ).

Sphecozone novaeteutoniae (Baert, 1987)

Brasil. Santa Catarina: São Cristóvão do Sul, Monte Alegre, $\left(27^{\circ} 17^{\prime} \mathrm{S} ; 5^{\circ} 25^{\prime} \mathrm{W}\right), 2001$ 2002, J. M. Moreira col. (IBSP 141271, 20⿱). Chapecó, (274'S; 52³8'W), vi-vii.2011, D. Baretta col. (IBSP 166724, 29). Campo Belo do Sul, Planalto, (2749'S; 5047'W), xii.2011-i.2012, D. Baretta col. (IBSP 166726, 1ð2우). Rio Grande do Sul: Vicente Dutra, $\left(27^{\circ} 08^{\prime} S ; 3^{\circ} 19^{\prime} \mathrm{W}\right)$, vi.2006, T. de Freitas col. (MCTP 19943, 3q; MCTP 19929, $\left.3{ }^{\Uparrow}\right)$. Sapiranga, $\left(29^{\circ} 38^{\prime} \mathrm{S} ; 5^{\circ} 59^{\prime} \mathrm{W}\right)$, 9.iv.2006, E. L. C. Silva col. (MCTP

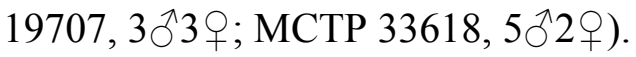

Sphecozone personata (Simon, 1894)

Brasil. Rio Grande do Sul: Maquiné, $\left(29^{\circ} 40^{\prime} \mathrm{S} ; 50^{\circ} 12^{\prime} \mathrm{W}\right)$, 3.viii.2008, E. N. L.

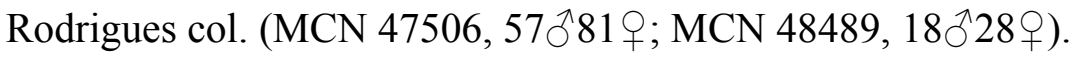

Sphecozone rostrata Millidge, 1991

Brasil. Rio Grande do Sul: Viamão, (30²0’S; 5101'W), 2.xii.1994, A. A. Lise et al.

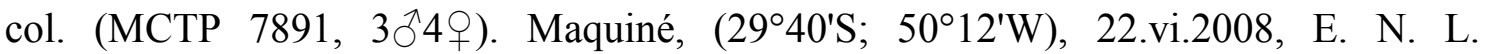

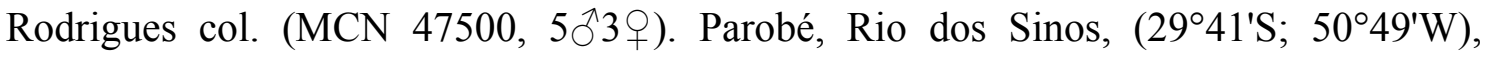
18.xii.2007, E. N. L. Rodrigues \& P. E. S. Rodrigues col. (MCN 48076, 6ð13ㅇ). 
Sphecozone rubescens O. Pickard-Cambridge, 1870

Brasil. Pernambuco: Araçoiaba, (747'S; 3506'W), 2009A. Costa col. (IBSP 168079,

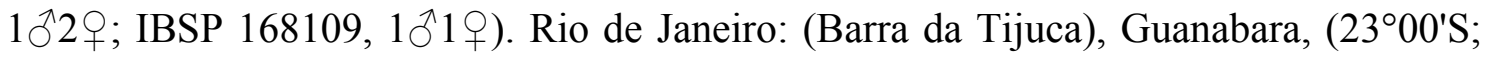
4321'W), vi.1971, T. McGrath col. (MCZ 61531, 2ð5 9 ). Rio Grande do Sul: Viamão, $\left(30^{\circ} 20^{\prime} \mathrm{S} ; 51^{\circ} 01^{\prime} \mathrm{W}\right), 22 . x i .1995$, A. A. Lise et al. col. (МCTP 8620, 1ð̊; MCTP 17923, 2ð; MCTP 17929, 5ठ).

Sphecozone rubicunda (Keyserling, 1886)

Peru. Cusco: La Convencion, Reserva Comunal Matsigenga, (12¹3'37.2"S; 73³1'59.7"W), 17.viii.2012, A. Asenjo col. (MUSM 0505325, 2ㅇ). Ayacucho: Puquio,

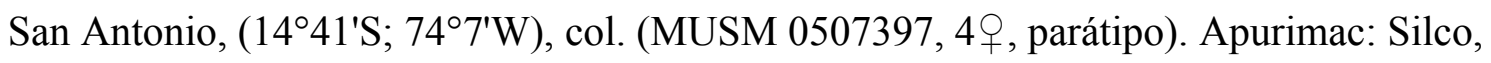
(14²4'54.0"S; 7256'46.7"W), 15.iii.2013, M. Cardenas col. (MUSM 0506141, 1ठ). Huánuco: Ambo, (10¹1'32.0"S; 76²1'04.9"W), 20.viii.2012, B. Medina col. (MUSM 0505343, 1万4우; MUSM 0505297, 1万1우).

*Sphecozone spadicaria (Simon, 1894):

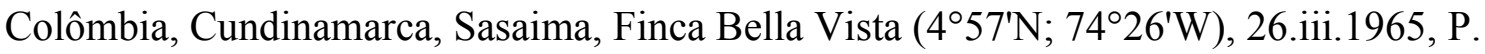
R. \& D. L. Craig col. (CAS, 1ठ1q), 27.v.1965, P. R. \& D. L. Craig col. (CAS, 1 + ). Venezuela, Mérida, El Vigia, Estrada La Victoria $\left(8^{\circ} 36^{\prime} \mathrm{N} ; 71^{\circ} 39^{\prime} \mathrm{W}\right), 22.1 i .1968$, P. \& B. Wygodzinsky col. (AMNH, $1 \jmath^{\jmath} 2$ ).

Sphecozone tumidosa (Keyserling, 1886)

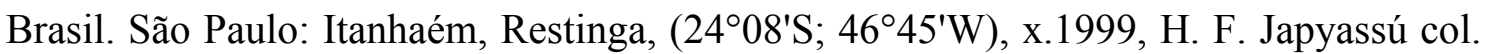

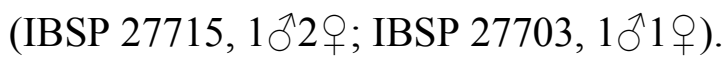

Sphecozone varia Millidge, 1991

Peru. Cusco: Machu Picchu, above ruins, (13ํํ'S; 72³6'W), 1-5.vii.1964, B. Malkin col. (AMNH 326252, 1 \% , holótipo). Wiñayhuaina, (1307'S; 72³4'W), 10.ii.1990, D. Silva col. (MUSM 0508652, 5q). 
Sphecozone venialis (Keyserling, 1886)

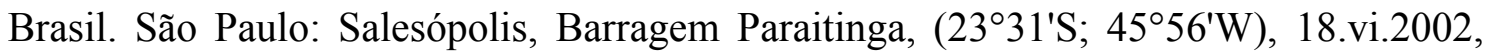
Equipe IBSP col. (IBSP 122500, $3 \precsim 2$; IBSP 38305, 4; IBSP 55195, 4ㅇ). Mogi das Cruzes, Distrito de Biritiba-Ussu, Manuel Ferreira (233' ${ }^{\prime}$; $\left.46^{\circ} 7^{\prime} \mathrm{W}\right)$, v.2001, E. Kashimata \& R. Martins col. (IBSP 56394, 1ð). Santos, Vale do Rio Jurubatuba, $\left(23^{\circ} 51^{\prime} \mathrm{S} ; 46^{\circ} 18^{\prime} \mathrm{W}\right)$, iii-xii.2007, Nogueira et al. col. (IBSP 125868, 1우 IBSP 125865, 1ठ; IBSP 127788, 1ठ; IBSP 125866, 1ठ).

\section{Clitolyna sp.nov.01}

Brasil. São Paulo: Mogi das Cruzes, Biritiba-Uçu, (233''s; 467'W), 12.v.1991, N. Silveira col. (MCN 21093, 1ठ). Rio Grande do Sul: Cambará do Sul, $\left(29^{\circ} 1^{\prime} \mathrm{S}\right.$; $\left.50^{\circ} 11^{\prime} W\right), 25 . x i .1993$, L. A. Moura col. (MCN 24273, 2ð1 1 , holótipo). Santa Catarina: Rancho Queimado, (2740'S; 49¹3'W), 8-12.x.1994, L. Moura col. (MCN 26259, 1 으, parátipo).

\section{Clitolyna sp.nov.02}

Brasil. Rio Grande do Sul: São Francisco de Paula, (29²6'S; 50³4'W), 12-15.vi.1997, R. Ott col. (MCTP 10038, 5ð12q, parátipo; MCTP 16331, 1ð̂1q, Holótipo). São Paulo: São Paulo, Parque Estadual da Cantareira, Núcleo Águas Claras (23 $25^{\prime} \mathrm{S} ; 46^{\circ}$ $37^{\prime}$ W), 02-07.ii.2005, F. U. Yamamoto col. (IBSP 76195, $3 \bigcirc^{\Uparrow} 2$ ㅇ, parátipo; IBSP 76303,

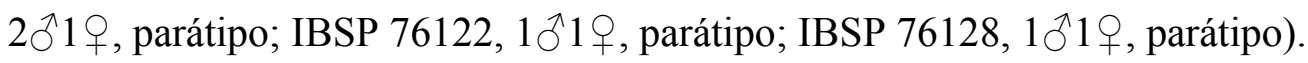

\section{Hypselistoides sp.nov.01}

Brasil. Rio Grande do Sul: São Francisco de Paula, CPCN Pró-Mata, (29²7'S; 50¹8'W), 8.iii.2002, R. Ott col. (MCN 39393, 6ð4우, Holótipo; MCN 39391, $9{ }^{\lambda} 5$ q 2 \#J, parátipo). Viamão, $\left(30^{\circ} 20^{\prime} \mathrm{S} ; 51^{\circ} 01^{\prime} \mathrm{W}\right)$, 12.viii.1994, A. A. Lise et al. col. (MCTP 9532, 1 q , parátipo; MCTP 9545, 2 q, parátipo; MCTP 8734, $3 \overbrace{}^{\Uparrow} 1$, , parátipo).

Gen.nov. sp.nov.01

Brasil. Rio Grande do Sul: Santana da Boa Vista, $\left(30^{\circ} 44^{\prime} \mathrm{S}\right.$; 53ำ1'W), 27-28.iv.2013,

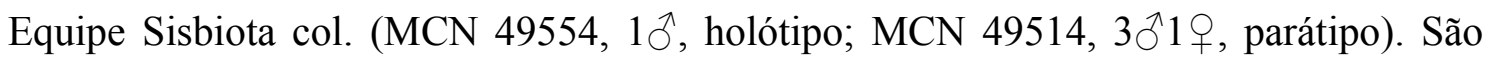
Borja, Reserva Biológica de São Donato, (2841'S; 5558'W), 10-24.vii.2012, M. M. da 
Silva col. (MCTP 36236, 12ð3우). Santana da Boa Vista, $\left(30^{\circ} 44^{\prime} \mathrm{S}\right.$; 531' $\left.\mathrm{W}\right), 27-$ 28.iv.2013, Equipe Sisbiota col. (MCN 49683, $6 \overbrace{}^{\Uparrow} 2$ 에J, parátipo).

Gen.nov. sp.nov.02

Brasil. Rio Grande do Sul: São Francisco de Paula, Potreiro Velho, (29²4'S; 50¹9'W), 21.x.2003, L. A. Bertoncello col. (MCTP 17649, 1§̂, holótipo). Santa Catarina:

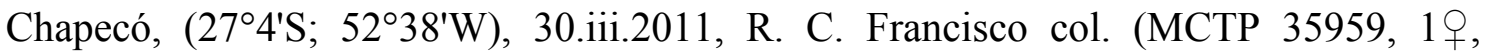
parátipo). Guatambú, (276'S; 5246'W), 13.vii.2009, R. C. Francisco col. (MCTP

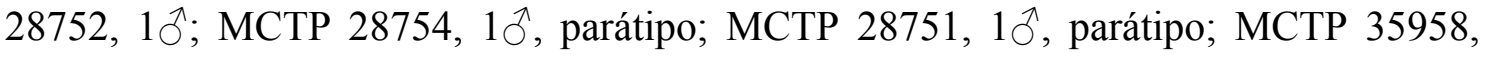
$3 \widehat{\jmath} 3$, , parátipo). 
Análise cladística

A matriz de dados, montada e editada utilizando os programas Calc do LibreOffice v.6.0 e Gedit v.3,18, contou com a maioria das espécies de Sphecozone, sendo que as espécies que apresentaram mais de 60\% de caracteres desconhecidos ("missing datas") foram retiradas da análise. São os casos de $S$. araeonciformis e $S$. longipes, espécies que não foram localizadas nas coleções em que estão depositadas (MNHN-Muséum National d'Histoire Naturelle, Paris, NHRS-Naturhistoriska riksmuseet, Estocolmo e MWNH-Museum Wiesbaden, Department of Natural Science, Wiesbaden) e, logo, não foi possível levantar seus caracteres, e $S$. altehabitans, $S$. melanocephala, $S$. varia e $S$. formosa, compostas somente por fêmeas, e que por não apresentarem machos, não possuem ao menos $57 \%$ do total de caracteres. Com isso, a matriz final apresentou o total de 77 caracteres e 41 táxons terminais (sendo 8 do grupo externo, 28 do grupo interno e 5 espécies novas).

Essa matriz foi então analisada através de uma busca heurísticas tradicional, utilizando-se o algoritmo TBR, por meio do programa TNT (versão 1.1), com os seguintes comandos: mult=tbr rep 200 hold 200. O valor do suporte de Bremer absoluto e relativo foi calculado utilizando, também, o programa TNT, com os seguintes comandos: sub $\mathbf{N}$ hold $\mathbf{N} x 1000 ;$ bb=tbr fillonly; unique*; bsupport; bsupport); (onde $\mathbf{N}=1$ à 13). A otimização dos caracteres foi realizada através do programa WinClada, versão 1.00.08. As árvores obtidas foram editadas no Inkscape v.0.92+devel. 


\section{Caracteres}

Foram utilizados 77 caracteres, sendo 36 relacionados ao palpo dos machos, 12 ao epígino das fêmeas, 23 à carapaça e pernas e 6 ao abdômen e fiandeiras, de ambos os sexos. A maioria dos caracteres que compõe a matriz foram baseados em Miller \& Hormiga (2004) com exceção de 14 caracteres novos, sendo 8 caracteres do palpo dos machos e 5 caracteres do epígino das fêmeas e 1 caráter da carapaça do macho, e estão representados na lista com asterisco. A matriz ainda conta com 13 caracteres multiestados, que foram tratados aqui como não-ordenados. Os caracteres ambíguos foram otimizados por ACCTRAN, de modo a favorecer a reversão ou perda secundária (Hormiga, 2000), com exceção do caráter 8 (Paracímbio), que para manter essa interpretação, foi otimizado por DELTRAN. Entre parênteses os valores dos índices e passos de cada caráter, na árvore de consenso (L, número de passos; CI, índice de consistência; RI, índice de retenção)

1- Processo retromediano do címbio (RMP), caráter 1 de Miller e Hormiga (2004). $(\mathrm{L}=2 ; \mathrm{CI}=0,5 ; \mathrm{RI}=0,5)$ :

(0) ausente (Clitolyna castanea)

(1) presente (Clitolyna venialis, Clitolyna crassa, Miller, 2007: 217, f. 162B)
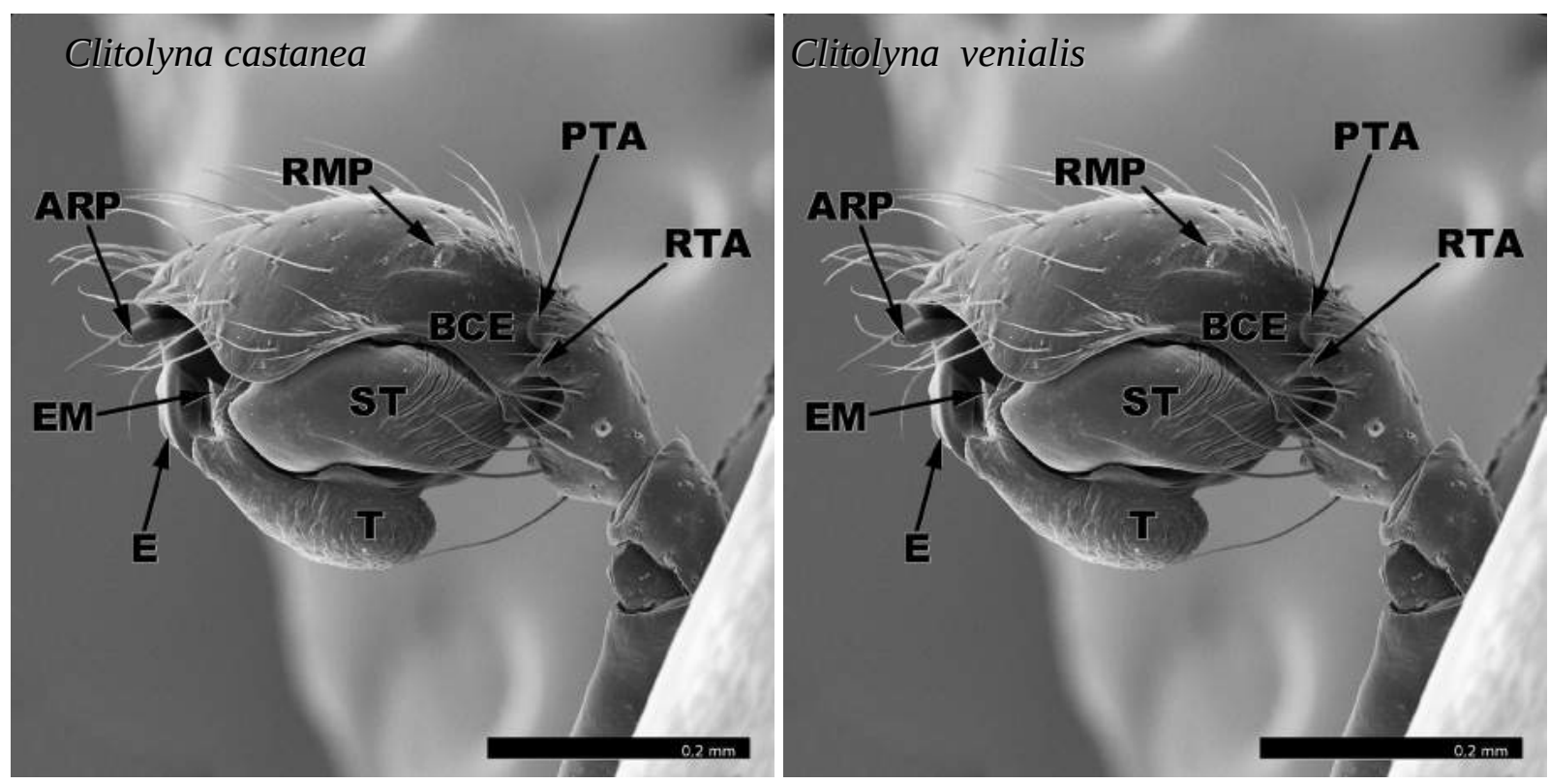
2- *Processo posterior dorsal do címbio $(\mathrm{PPD})(\mathrm{L}=2 ; \mathrm{CI}=0,5 ; \mathrm{RI}=0,5)$ :

A parte dorsal do címbio, na sua região mais proximal, pode apresentar uma projeção pontiaguda, em forma de espinho. Nas espécies analisadas neste estudo, essa projeção pode ser curta e estreita, como em S. alticeps, ou mais robusta e alongada, como em $S$. personata e $S$. rostrata.

(0) ausente (Clitolyna castanea)

(1) presente (Clitolyna personata)
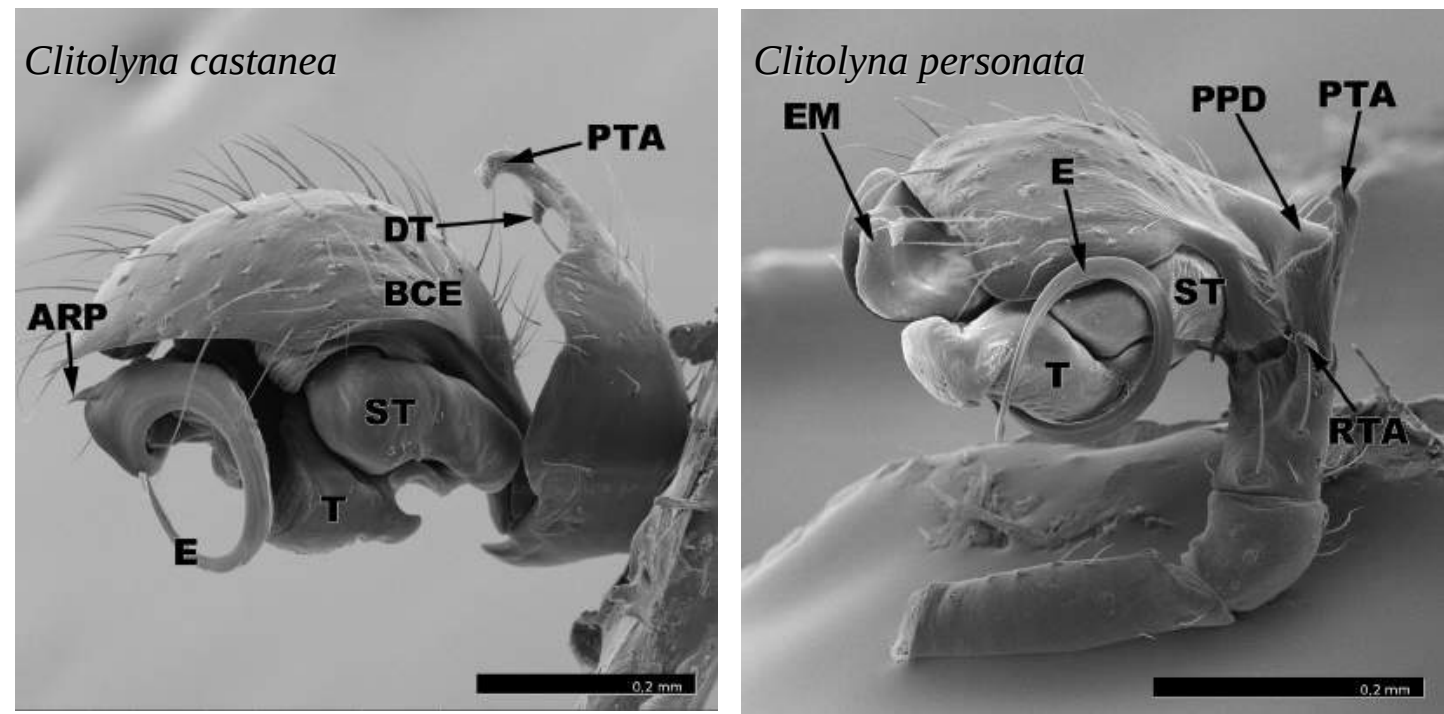

3- *Cerdas posterior dorsais do címbio $(\mathrm{L}=2 ; \mathrm{CI}=0,5 ; \mathrm{RI}=0,75)$ :

Na região dorsoproximal do címbio, algumas cerdas se destacam por serem mais grossas que as demais encontradas ao longo do címbio, e assemelhando mais à pequenos espinhos.

(0) tão grossas quanto as demais cerdas (Clitolyna castanea)

(1) mais grossas que as demais cerdas, como espinhos (Hypselistoides labiatus)

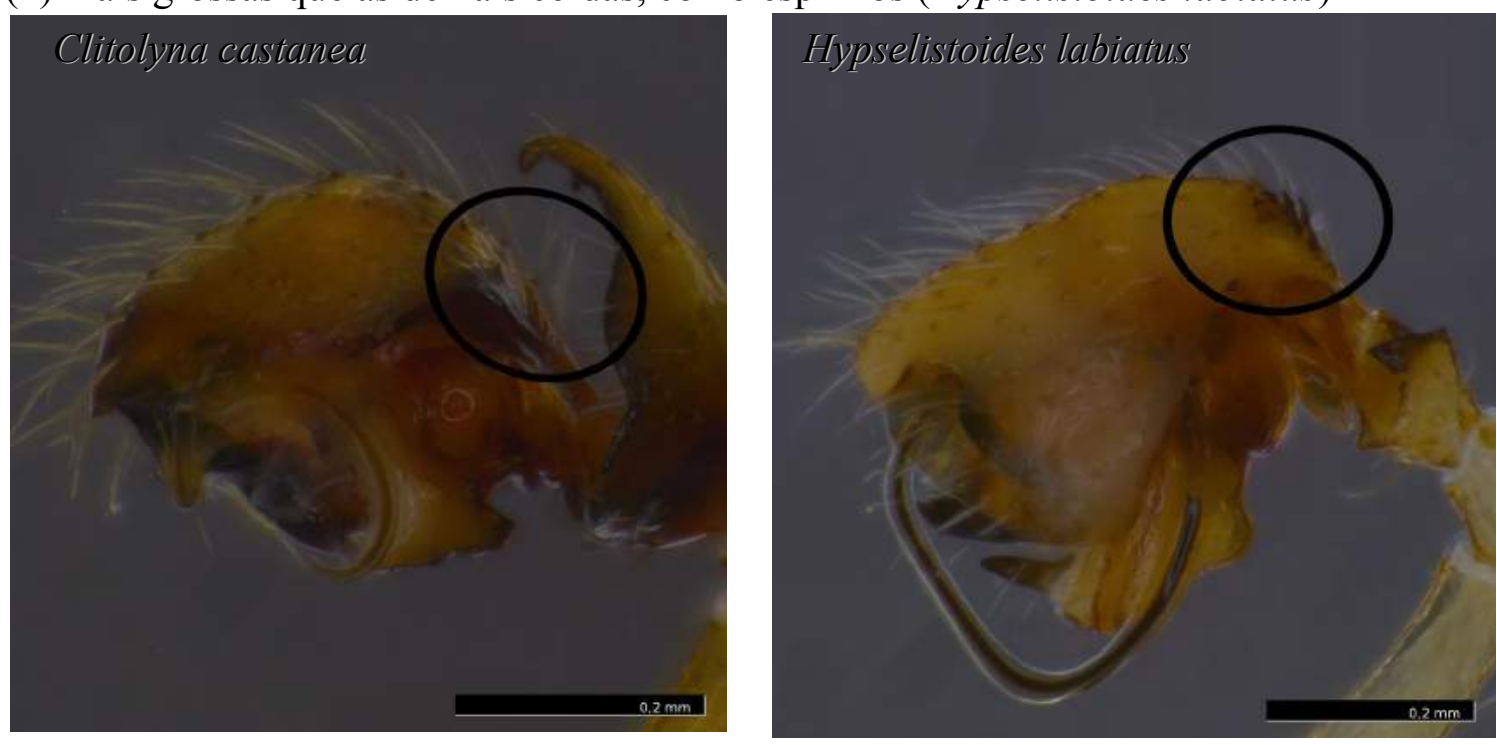


4- *Cerdas modificadas no címbio $(\mathrm{L}=1 ; \mathrm{CI}=1 ; \mathrm{RI}=1)$ :

Autapomorfia de S. lobata. Cerdas modificadas no palpo de Linyphiidae são raras, ocorrendo em poucas Erigoninae, como Pseudotyphistes (Miller, 2007: 73-75, f. 51A-H, 52F-G, 53A-D), por exemplo. Em S. lobata, as cerdas são bem diferente das de Pseudotyphistes, mais simples, porém mais frequentes (ocorrem pelo menos 4 na região dorso-retrolateral do címbio).

(0) ausente (Clitolyna castanea)

(1) presente (Hypselistoides lobatus)
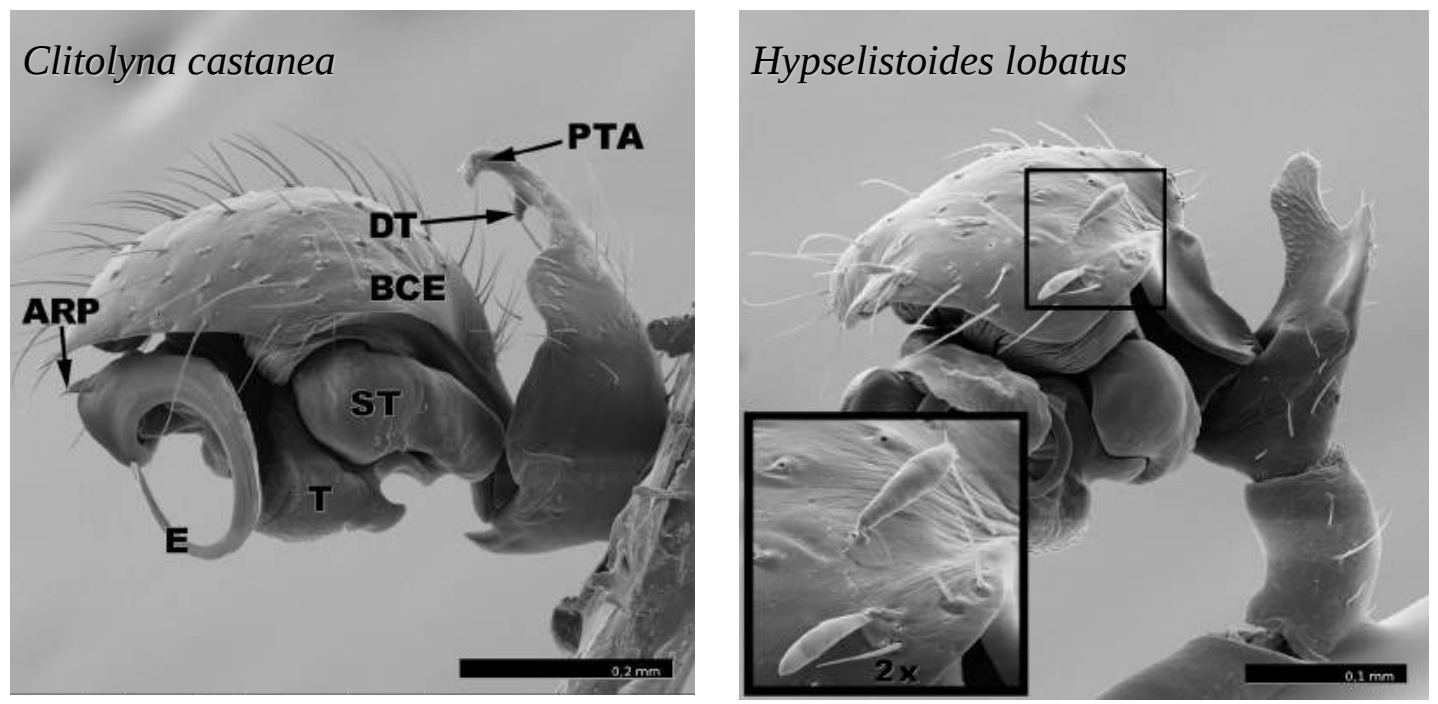

5- Sulco retrobasal do címbio (CG), caráter 7 de Miller e Hormiga (2004). ( $\mathrm{L}=4$;

$\mathrm{CI}=0,25 ; \mathrm{RI}=0,5)$ :

(0) ausente (Clitolyna castanea)

(1) presente (Clitolyna prativaga)
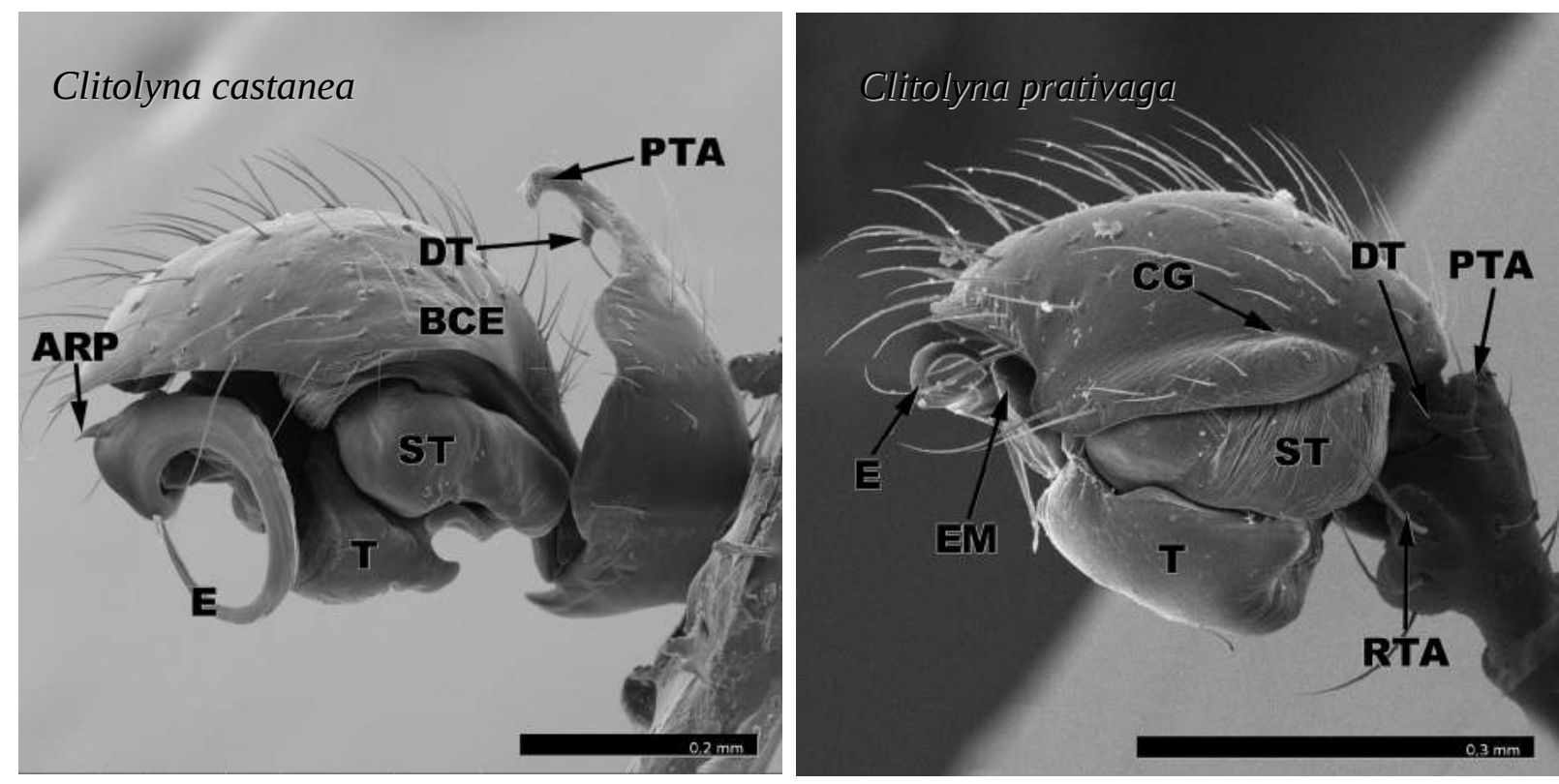
6- Base escavada do címbio (BCE), caráter 8 de Miller e Hormiga (2004). ( $\mathrm{L}=4$; $\mathrm{CI}=0,25 ; \mathrm{RI}=0,727)$ :

(0) ausente (Clitolyna fastibilis)

(1) presente (Hypselistoides rubicundus)
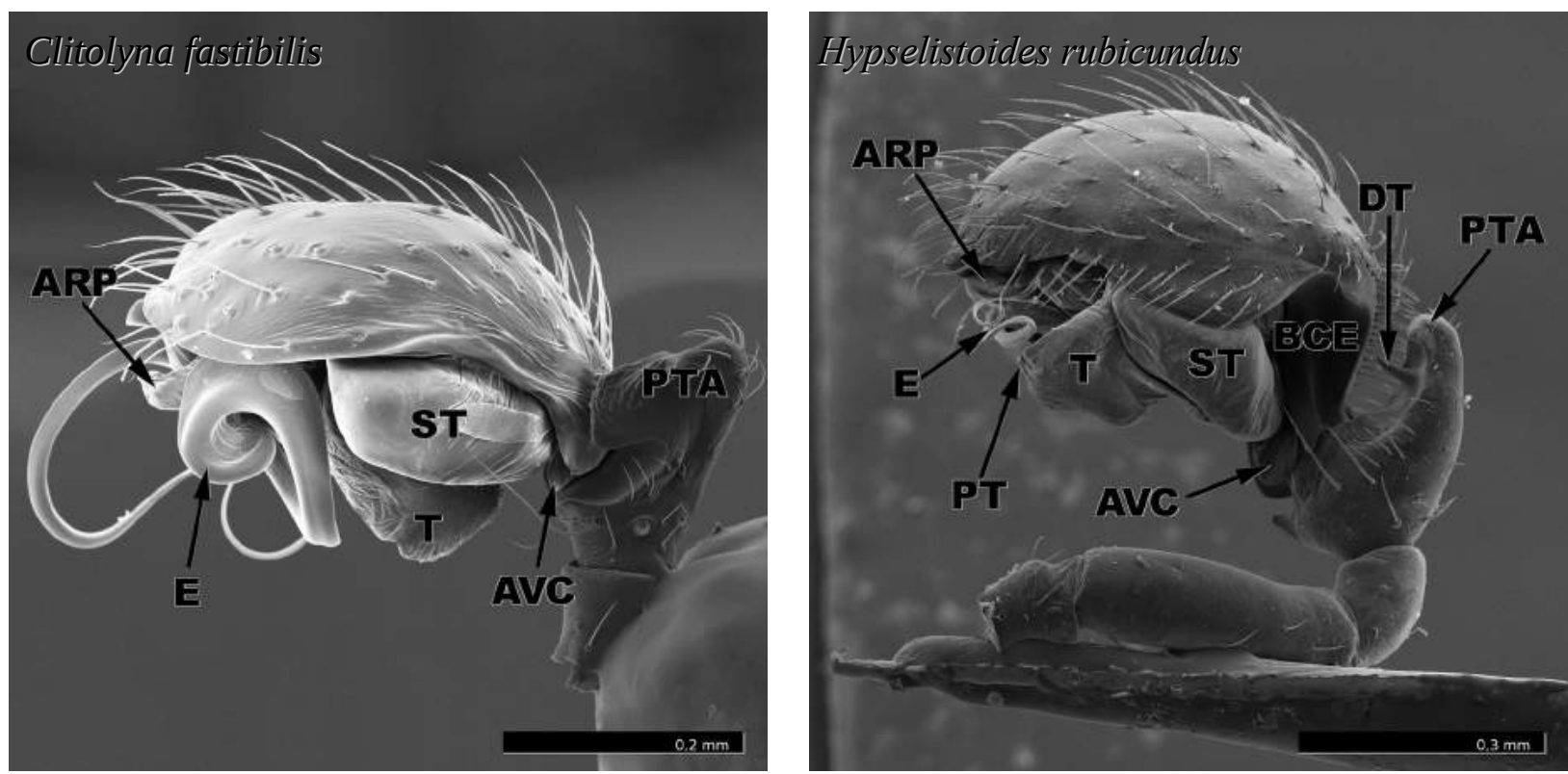

7- *Apófise ventral do címbio ( $\mathrm{L}=3 ; \mathrm{CI}=0,333 ; \mathrm{RI}=0,882)$ :

O címbio pode apresentar uma projeção na sua parte ventral, localizado na margem, próximo a tíbia.

(0) ausente (Clitolyna venialis)

(1) presente (Clitolyna fastibilis)
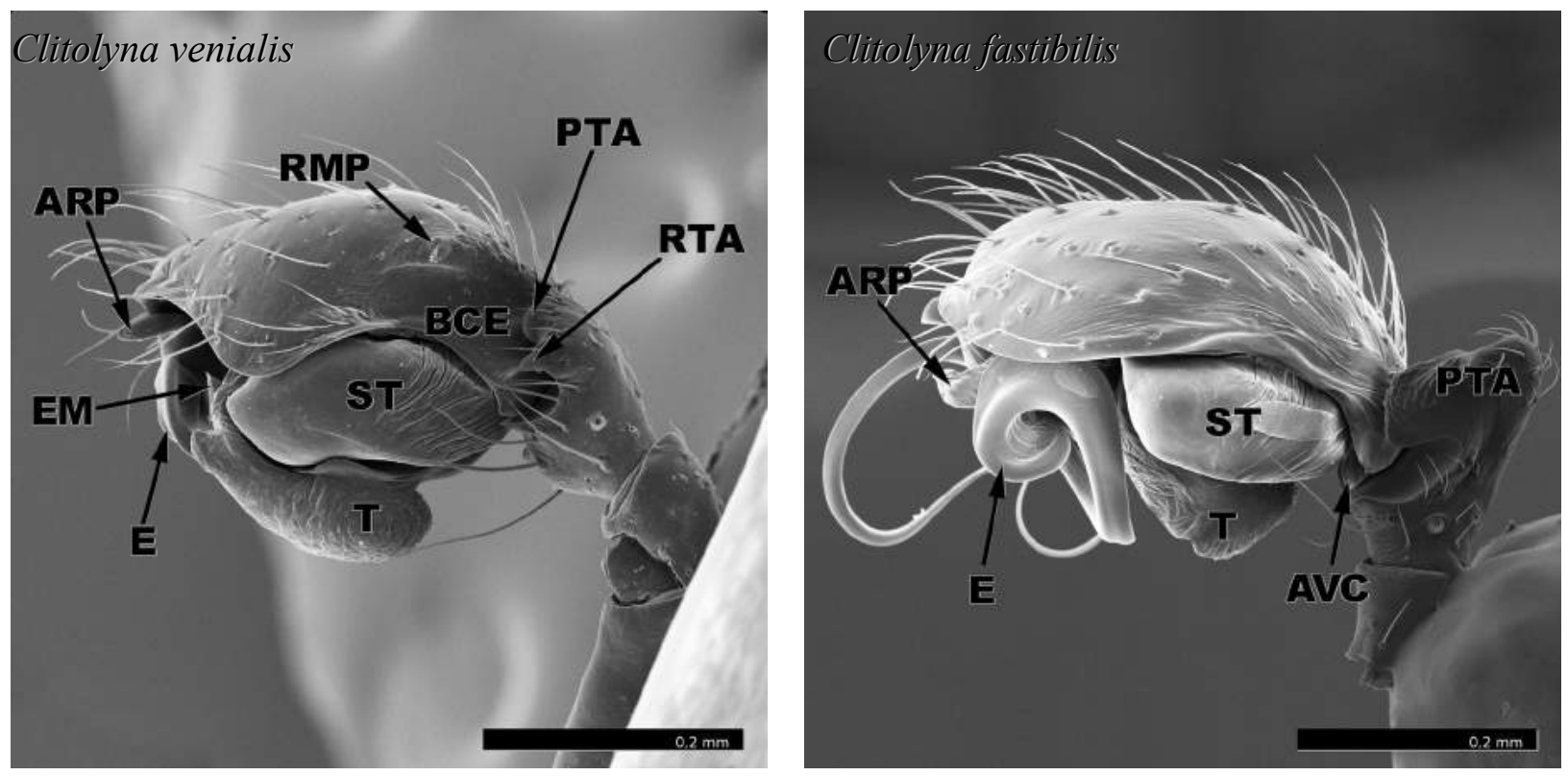
8- Paracímbio (PC), caráter 10 de Miller e Hormiga (2004). $(\mathrm{L}=4 ; \mathrm{CI}=0,25 ; \mathrm{RI}=0,625)$ :

Os caracteres relacionados ao paracímbio (carácter 8-11), presente nos estudos de Linyphiidae, foram retirados ou modificados por serem, grande parte deles, não aplicados. O caráter 9, forma do paracímbio, por exemplom possui em Miller e Hormiga (2004) 7 estados. Neste trabalho, foi reduzido para 3 estados.

(0) presente (Grammonota pictilis)

(1) ausente (Hypselistoides rubicundus)
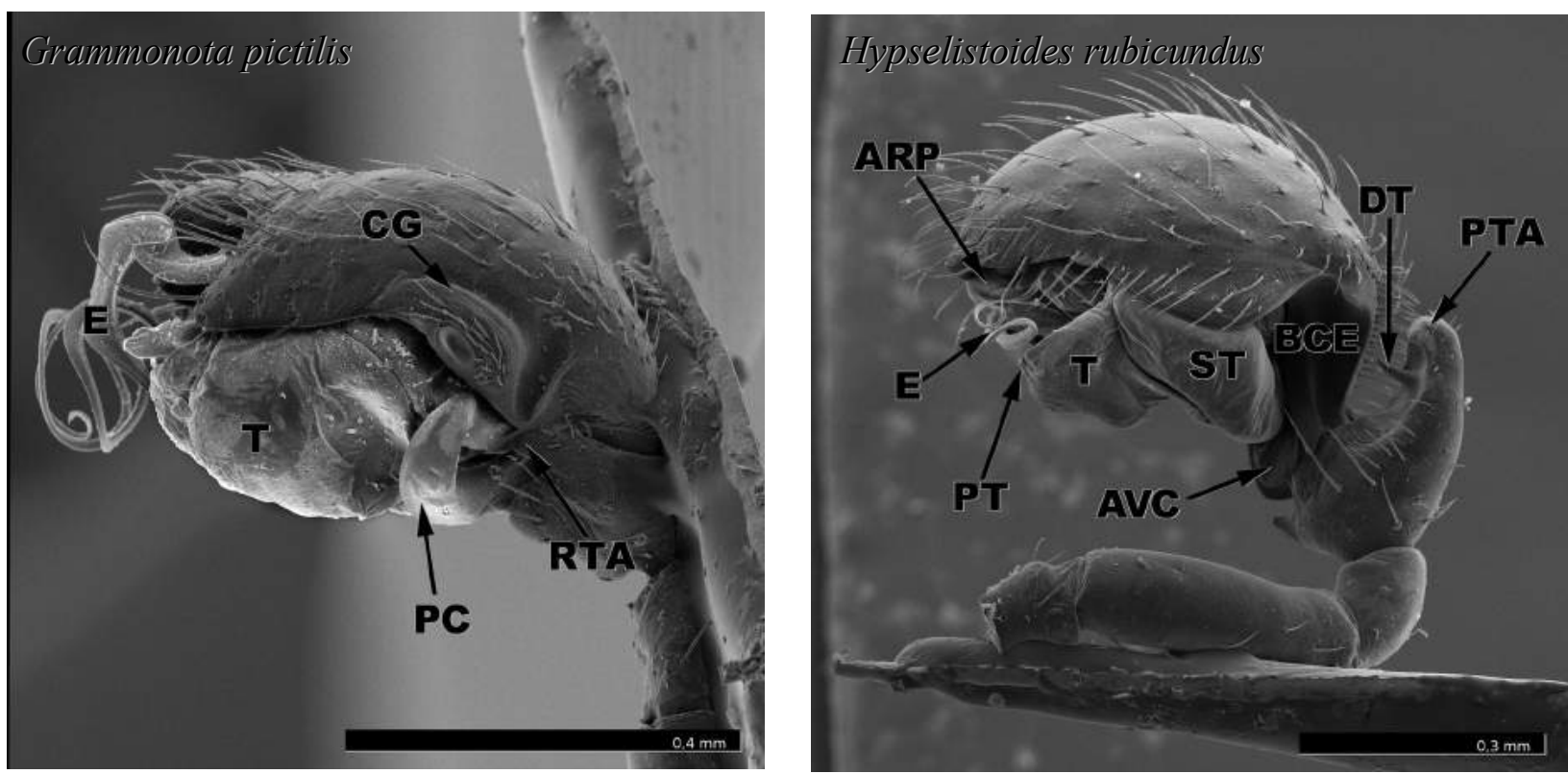

9- União do paracímbio, caráter 11 de Miller e Hormiga (2004). ( $\mathrm{L}=2 ; \mathrm{CI}=0,5 ; \mathrm{RI}=0,5)$ :

(0) intersegmental (Tutaibo phoeniceus, imagem adicional em Miller, 2007: 181, f. 140D)

(1) íntegro (Gen.nov. sp.nov.01)
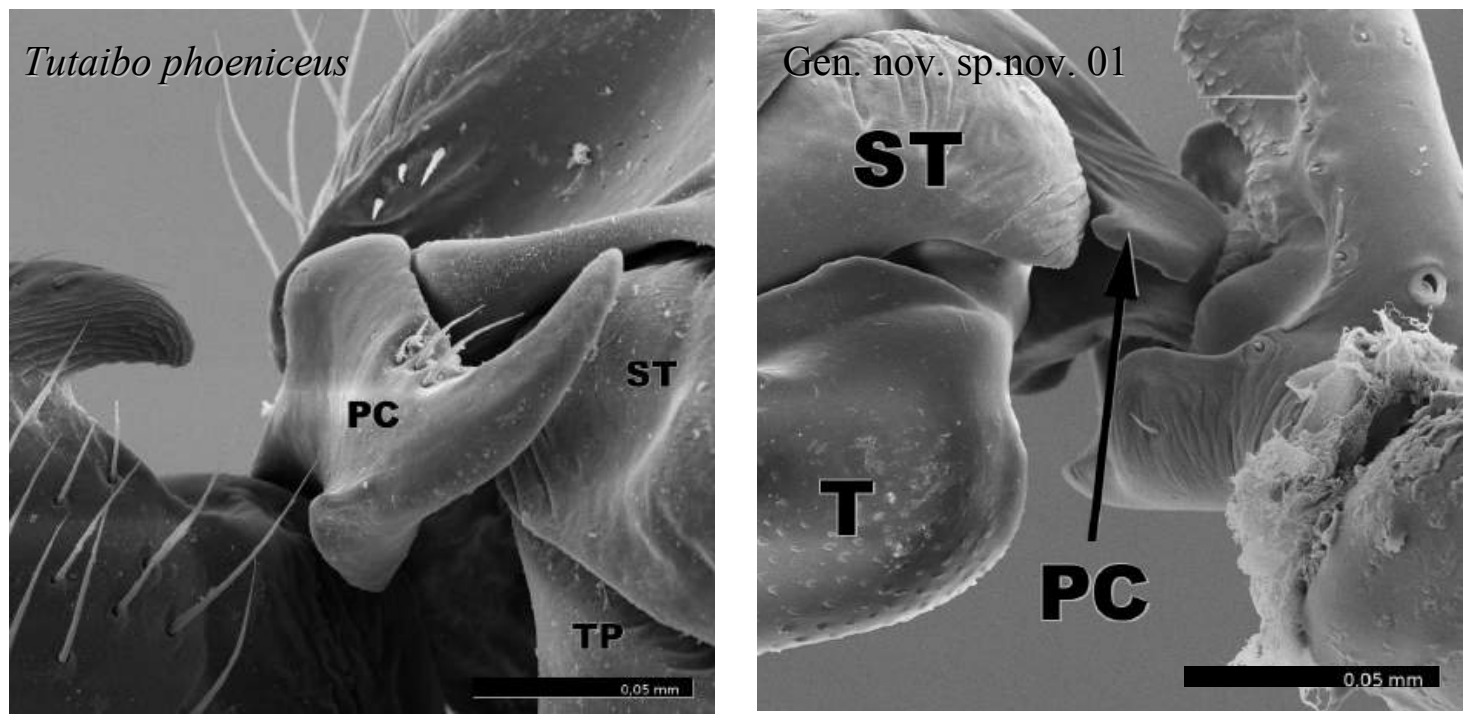
10- Forma do paracímbio, caráter 12 de Miller e Hormiga (2004). ( $\mathrm{L}=2 ; \mathrm{CI}=0,5$; $\mathrm{RI}=0,5)$ :

(0) forma de gancho (Tutaibo phoeniceus: Miller, 2007: 181, f. 140D)

(1) espiral (Grammonota pictilis)

(2) vestigial (Gen.nov. sp.nov.01)
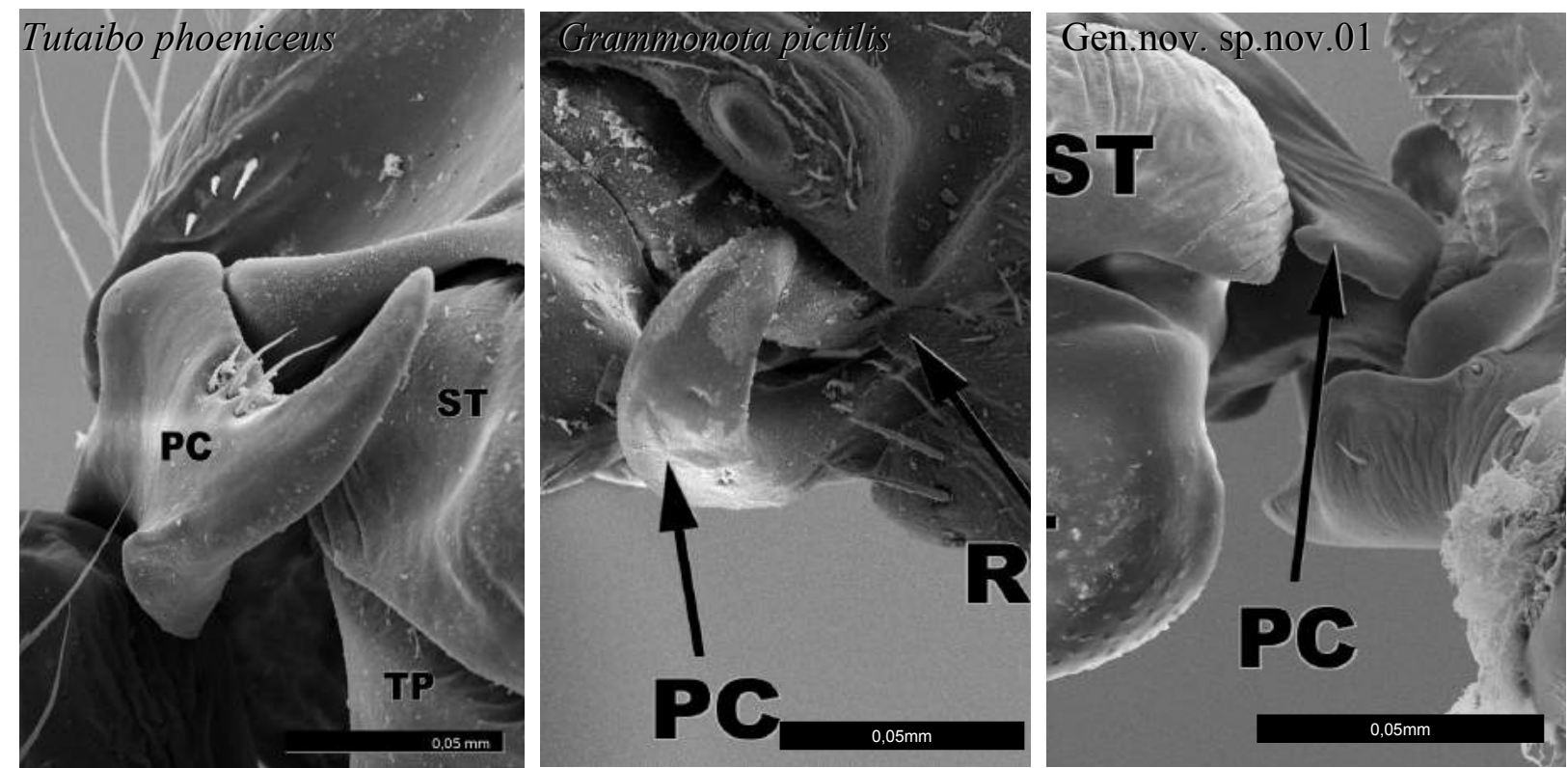

11- Base do paracímbio, caráter 14 de Miller e Hormiga (2004). (L=3; CI=0,667; $\mathrm{RI}=0,667)$ :

(0) sem cerdas (Gen.nov. sp.nov.01)

(1) com conjuntos de cerdas (Tutaibo phoeniceus, Miller, 2007: 181, f. 140D)
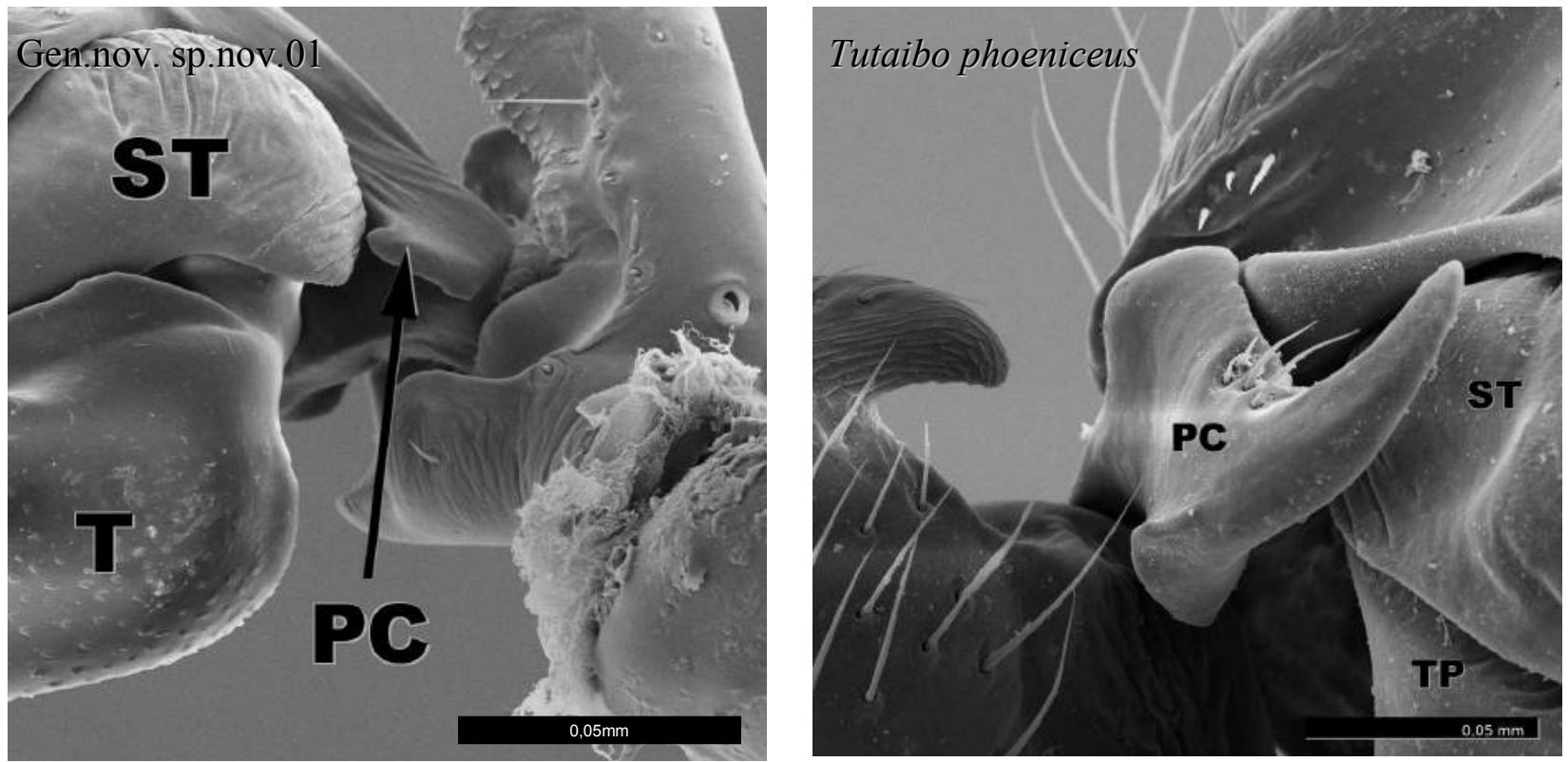
12- Protégulo (PT), caráter 16 de Miller e Hormiga (2004). ( $\mathrm{L}=4 ; \mathrm{CI}=0,25 ; \mathrm{RI}=0,5)$ :

(0) ausente (Clitolyna fastibilis)

(1) presente (Hypselistoides diversicolor)
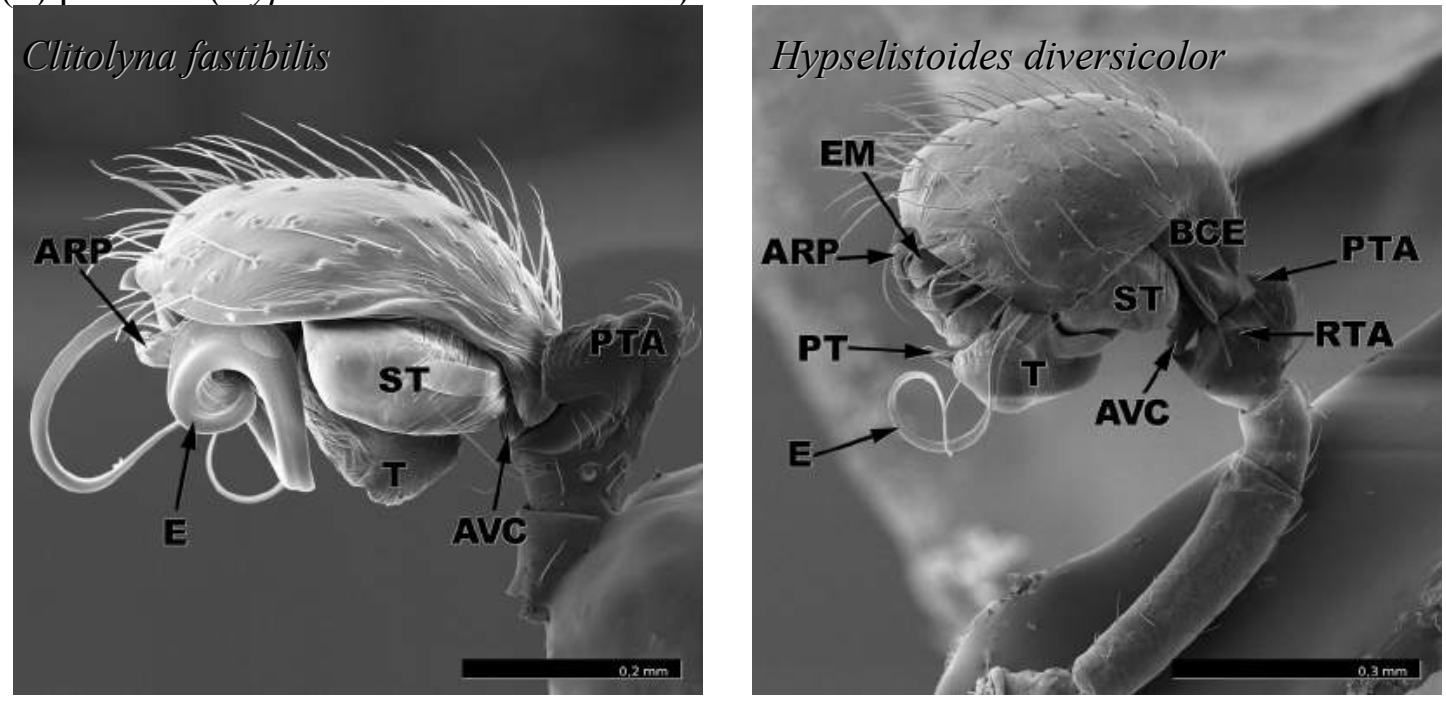

13- *Forma do protégulo $(\mathrm{L}=2 ; \mathrm{CI}=0,5 ; \mathrm{RI}=0,833)$ :

O protégulo é um saco membranoso localizado no tégulo, na parte antero-ventral (Hormiga, 2000; Miller e Hormiga 2004). A sua forma é muito discutida e sua presença dá suporte ambíguo a vários clados de Erigoninae (Miller \& Hormiga, 2004). Neste estudo foram incluídos dois caracteres relacionado à essa estrutura. Um relacionado às suas formas bem distintas, que podem ser discreta, curta, com base mais alargada, ou mais proeminete, muitas vezes bem alongada, em forma de espinho. Outro caráter (caráter 14) está relacionado à variação do nível de sua esclerotização, que vai do hialino à bem esclerotizada.

(0) tão larga quanto longa (Clitolyna personata)

(1) longo, em forma de espinho (Hypselistoides diversicolor)

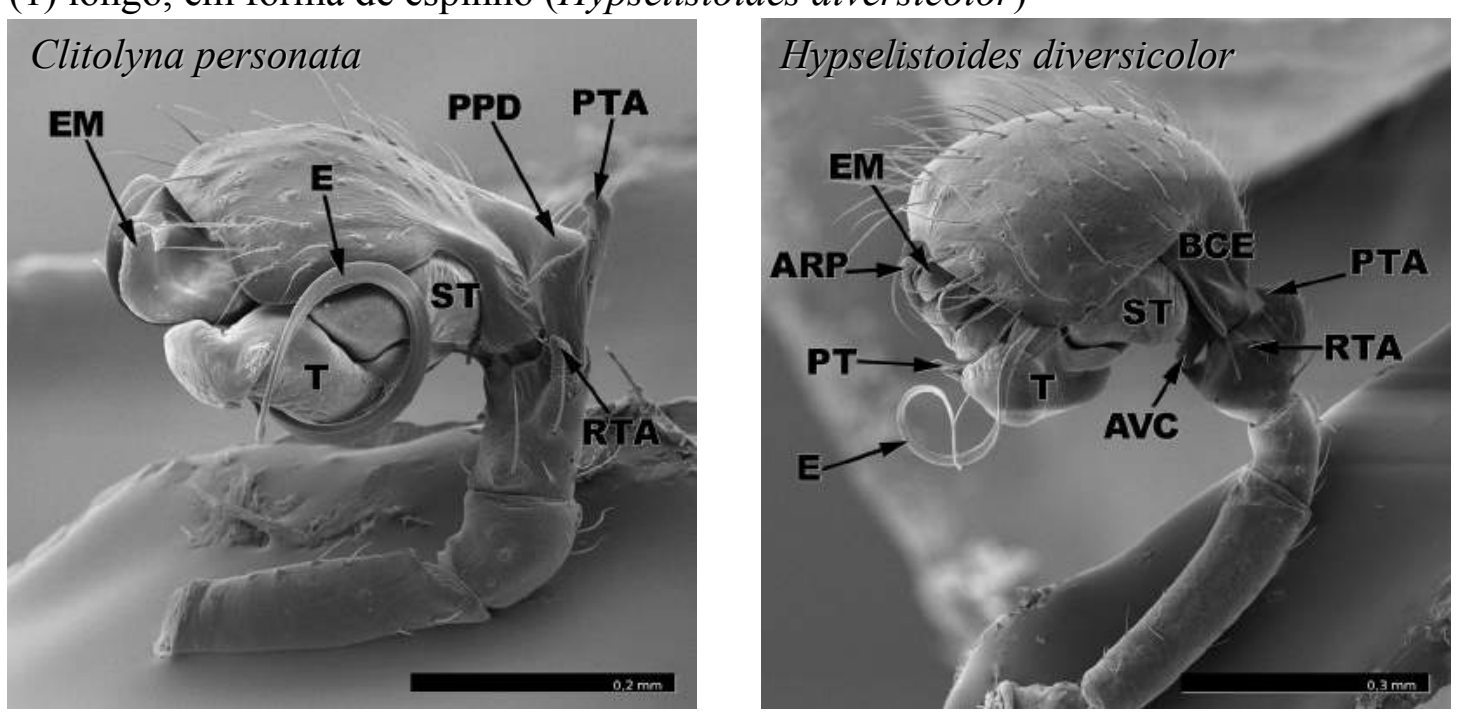


14- *Estrutura do protégulo $(\mathrm{L}=4 ; \mathrm{CI}=0,25 ; \mathrm{RI}=0,571)$ :

Ver caráter 13.

(0) hialina (Hypselistoides ignigenus)

(1) esclerotizada (Hypselistoides labiatus)
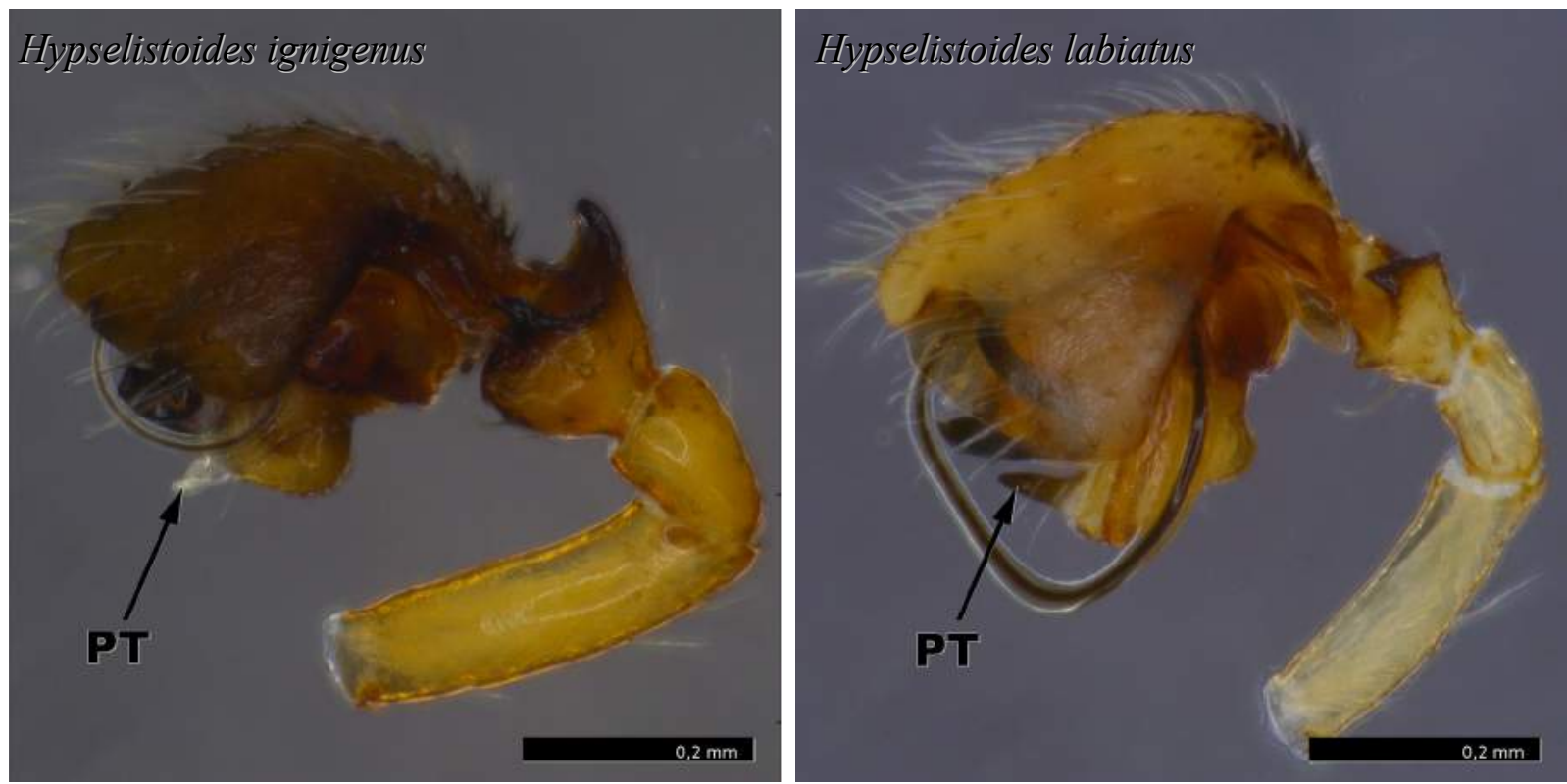

15- Papila do protégulo, caráter 17 de Miller e Hormiga (2004). ( $\mathrm{L}=2 ; \mathrm{CI}=0,5 ; \mathrm{RI}=0)$ :

(0) ausente (Hypselistoides diversicolor)

(1) presente (Clitolyna crassa, fig. 162B, Miller, 2007, p. 217)

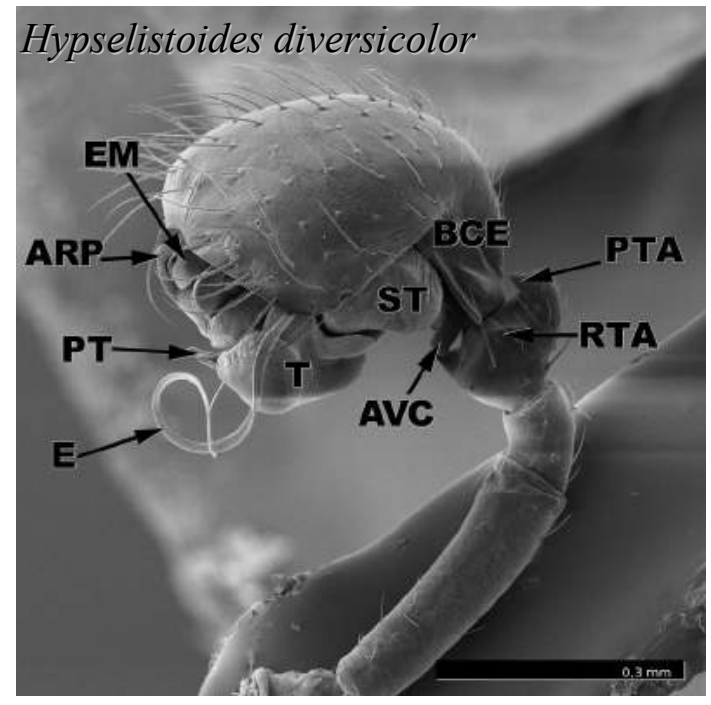

Clitolyna crassa (Miller, 2007)

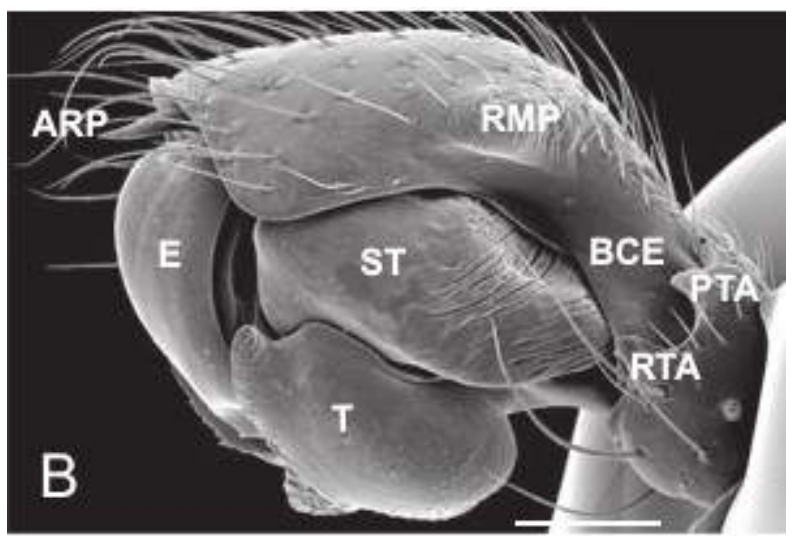


16- Forma da papila do protégulo $(\mathrm{L}=1 ; \mathrm{CI}=1 ; \mathrm{RI}=1)$ :

Caráter 18 de Miller e Hormiga (2004).

(0) forma de escama (Clitolyna crassa, fig. 162B, Miller, 2007, p. 217)

(1) forma alongada (Grammonota pictilis)

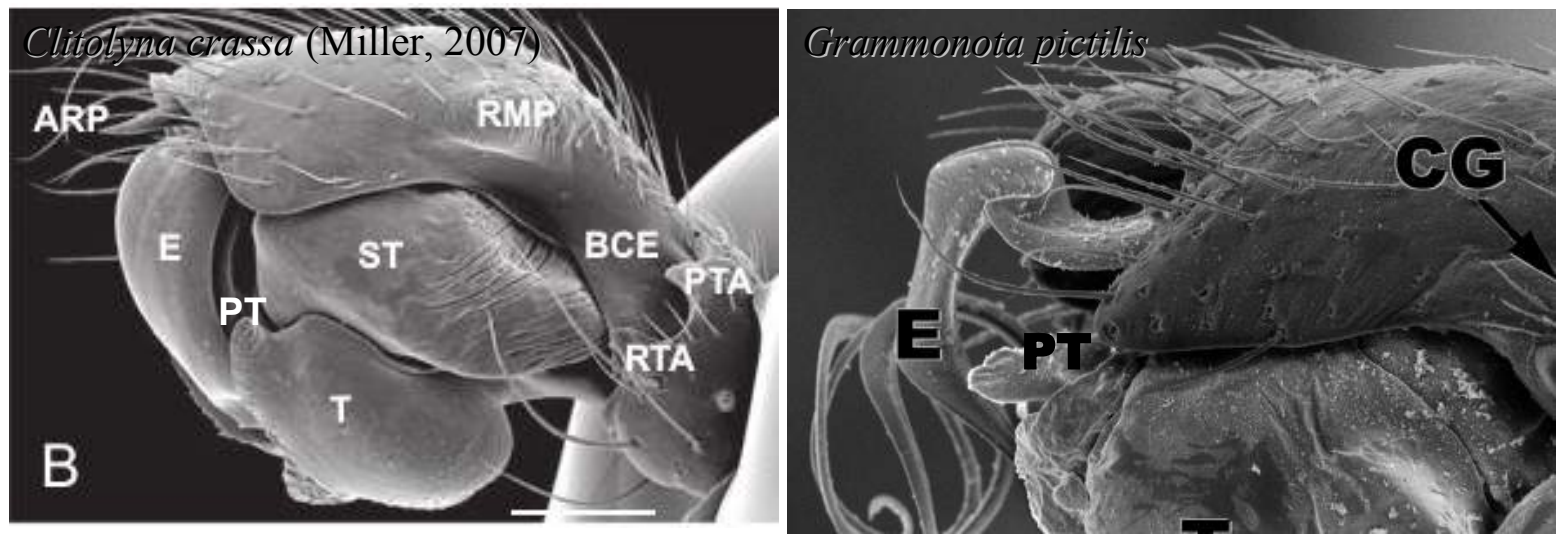

17- Papilas no tégulo (T), caráter 20 de Miller e Hormiga (2004). (L=4; CI=0,25; $\mathrm{RI}=0,4)$ :

(0) ausente (Sphecozone nitens)

(1) presente (Hypselistoides modestus)
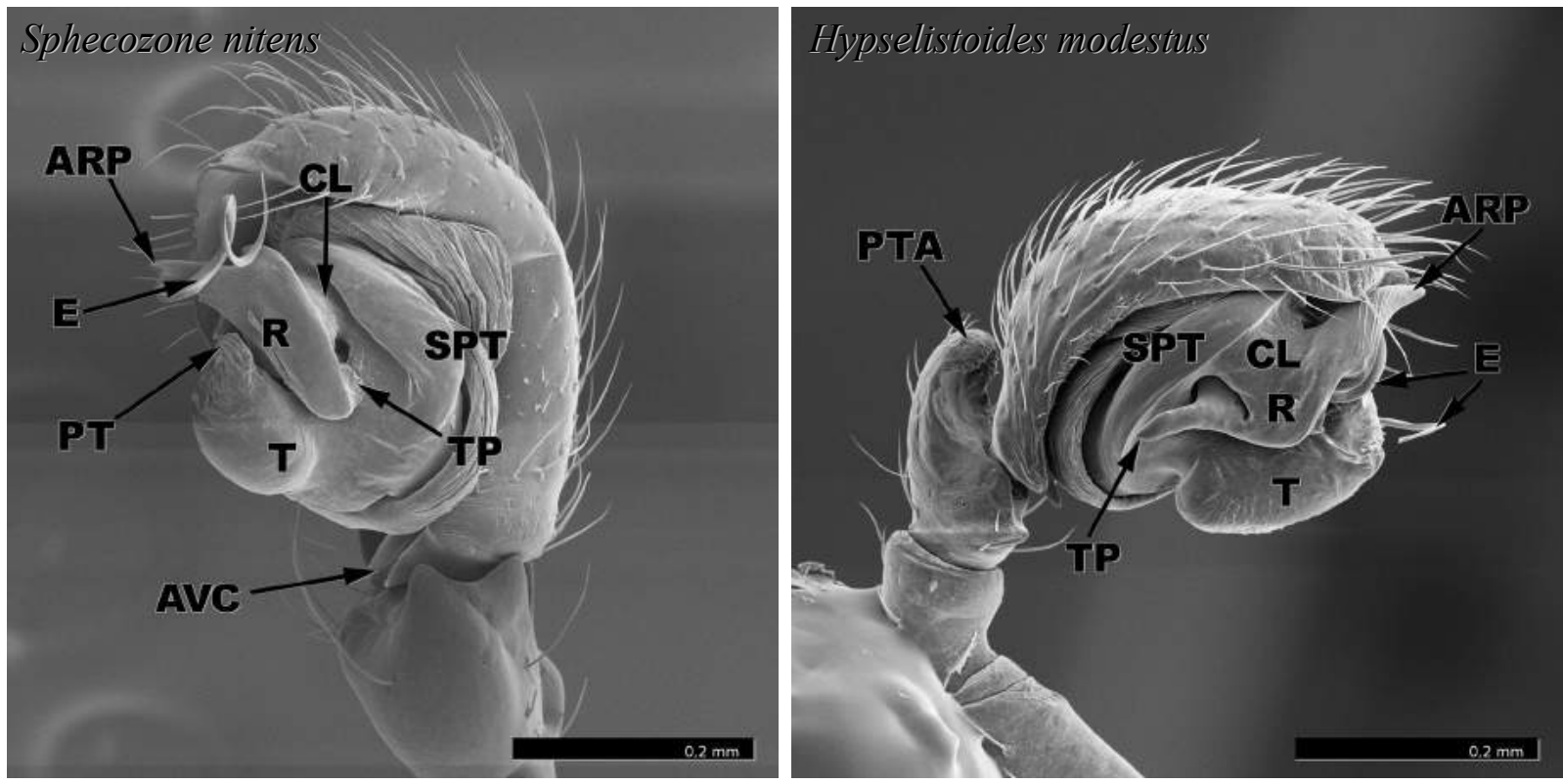
18- Textura do supratégulo (SPT), caráter 27 de Miller e Hormiga (2004). ( $\mathrm{L}=5 ; \mathrm{CI}=0,2$; $\mathrm{RI}=0,429)$ :

(0) liso (Hypselistoides modestus)

(1) estriado (Clitolyna fastibilis)
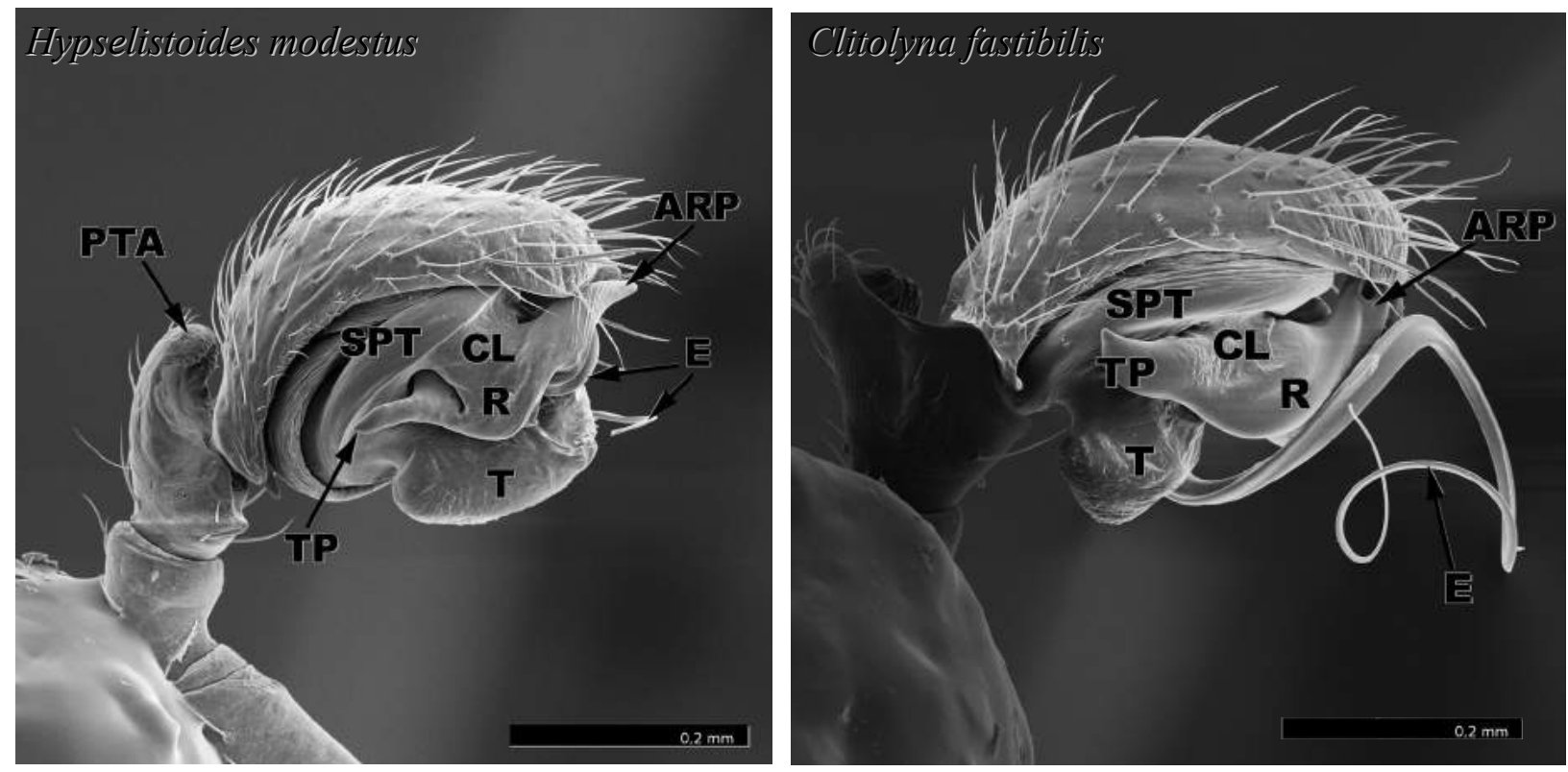

19- Apófise distal suprategular (DSA), caráter 29 de Miller e Hormiga (2004). ( $\mathrm{L}=4$; $\mathrm{CI}=0,25 ; \mathrm{RI}=0,786)$ :

(0) ausente (Hypselistoides modestus)

(1) presente (Clitolyna novaeteutoniae)
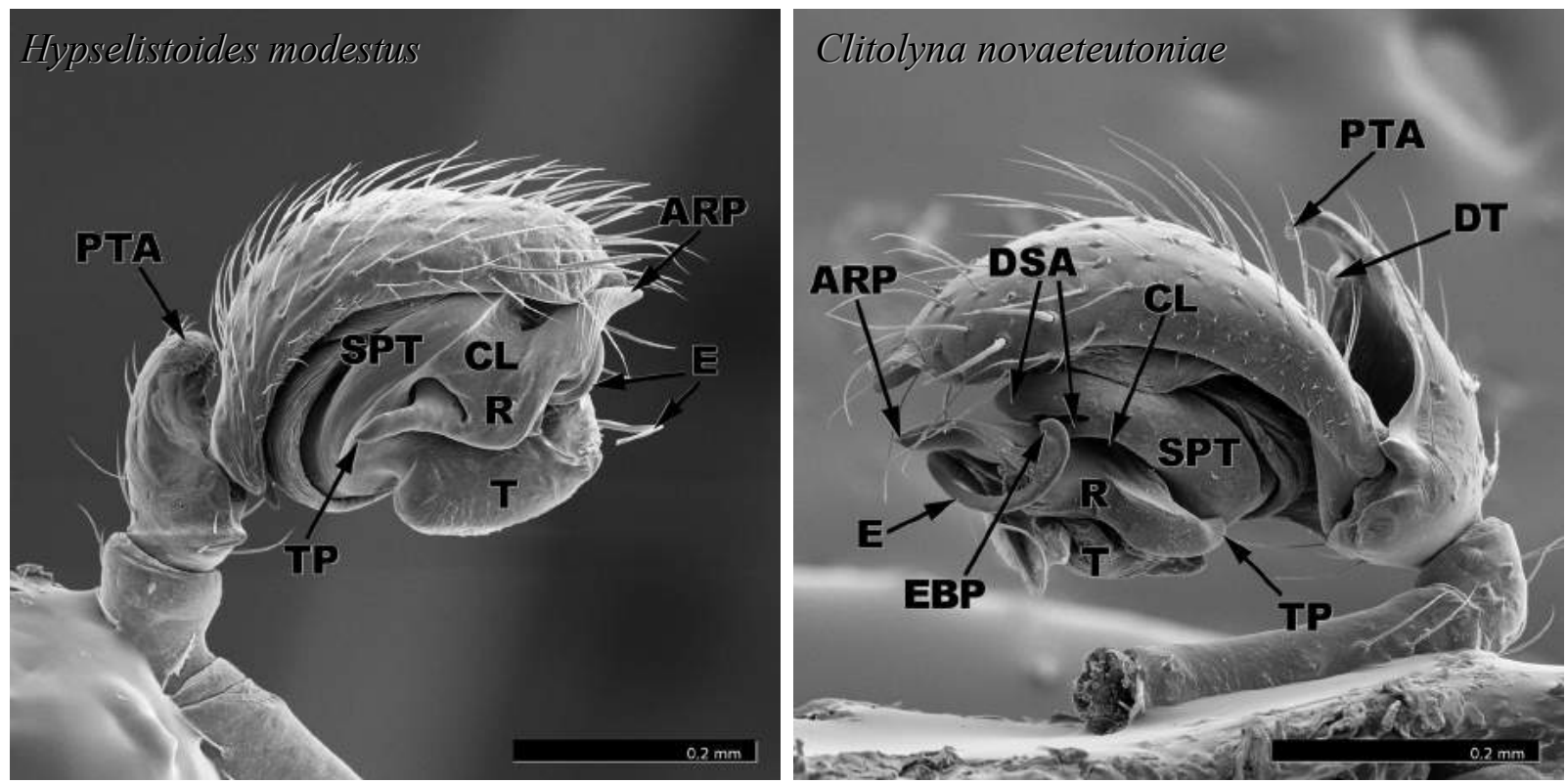
20- Orientação inicial da apófise distal suprategular (DSA), caráter 31 de Miller e Hormiga (2004). ( $\mathrm{L}=1 ; \mathrm{CI}=1 ; \mathrm{RI}=1)$ :

(0) estende-se distalmente além do supratégulo (Clytolina sp.nov.02)

(1) estende-se ventralmente do supratégulo (Clitolyna castanea)
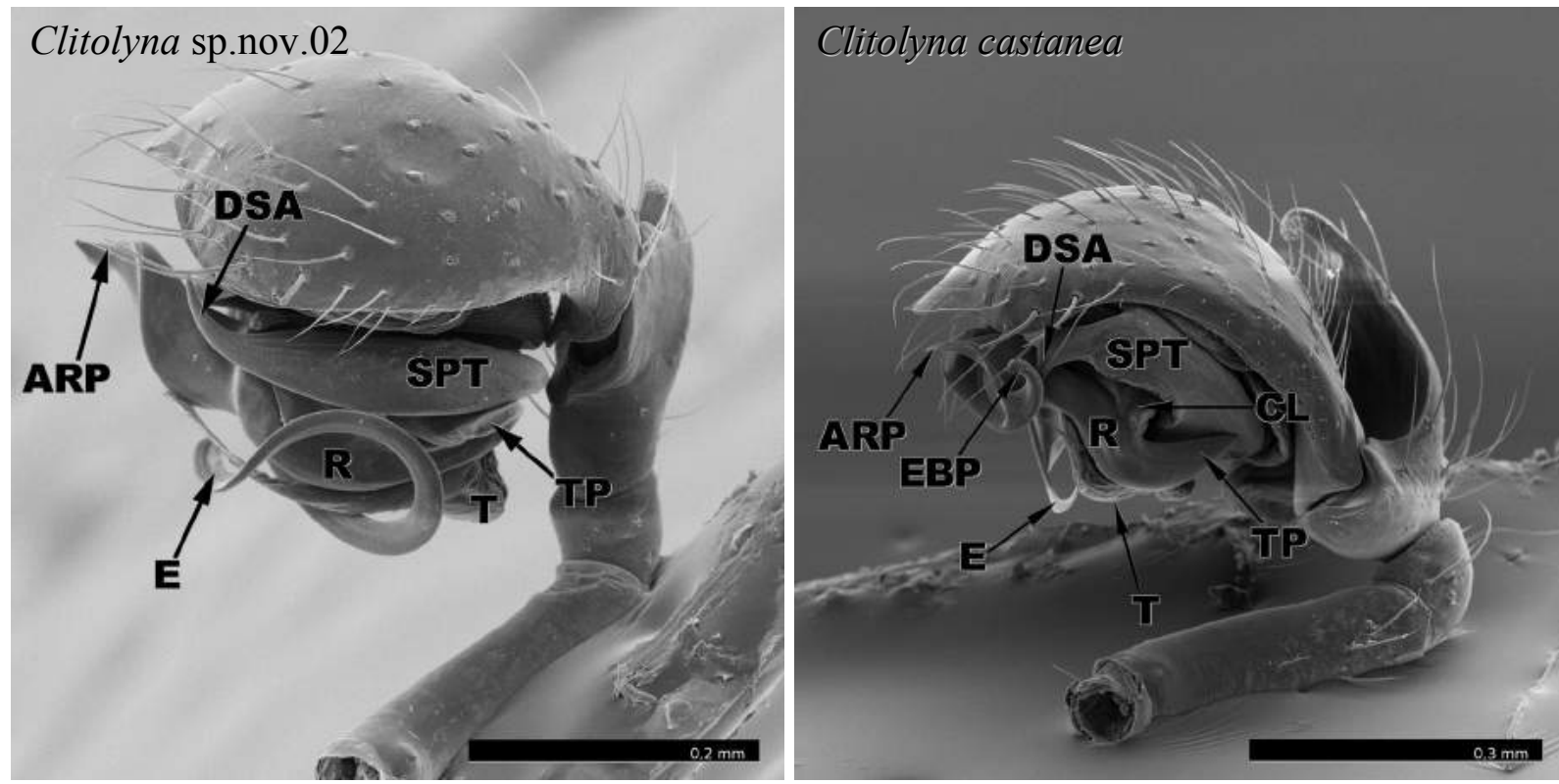

21- Membrana embólica $(\mathrm{L}=7 ; \mathrm{CI}=0,143 ; \mathrm{RI}=0,455)$ :

Caráter 40 de Miller e Hormiga (2004).

(0) ausente (Clytolina fastibilis)

(1) presente (Clitolyna venialis)
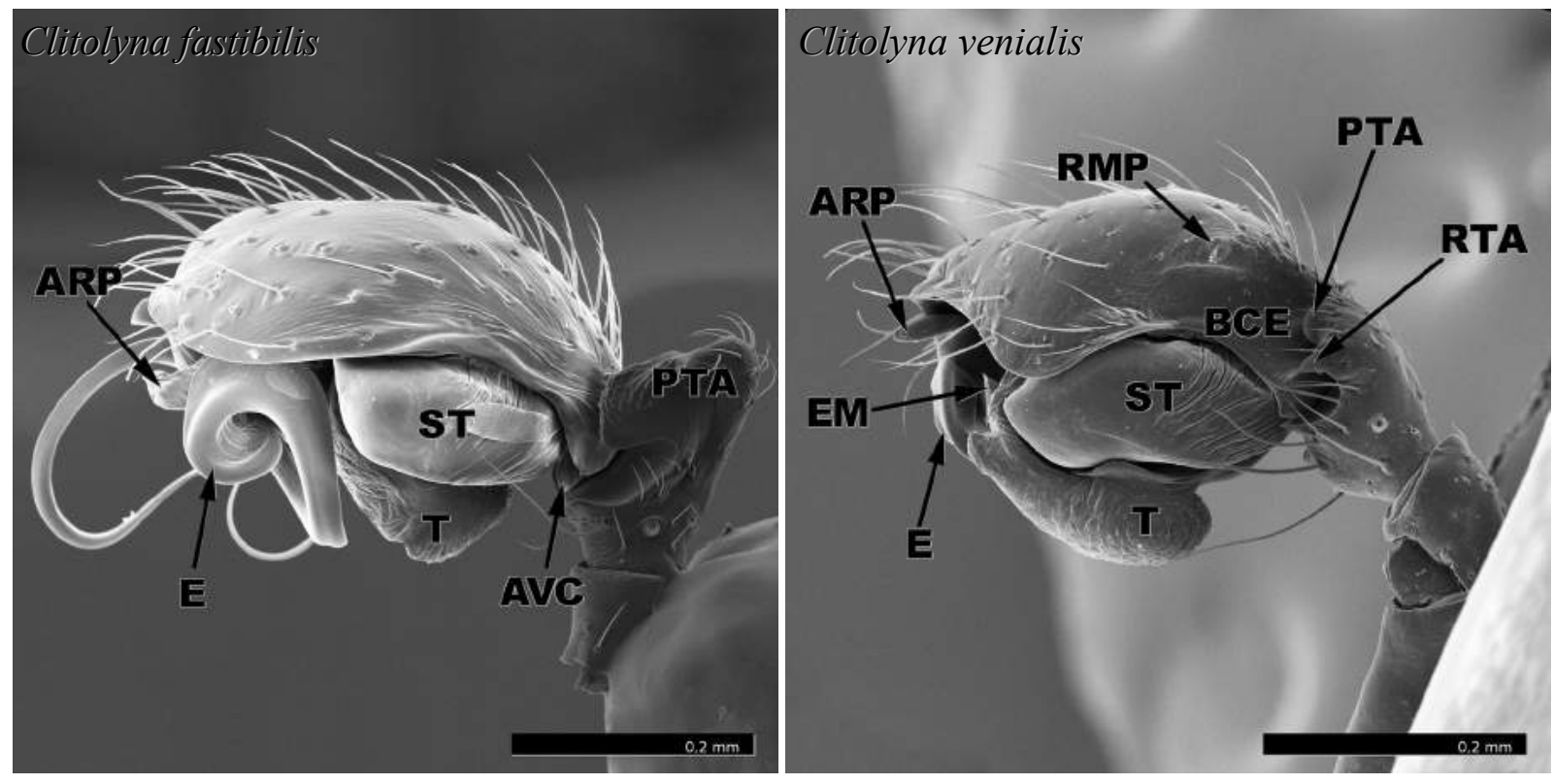
22- Disposição do êmbolo (E), Caráter 44 de Miller e Hormiga (2004). (L=3; CI=0,333; $\mathrm{RI}=0,333)$ :

(0) reto à curvado (Clitolyna prativaga)

(1) espiral (Clitolyna castanea)
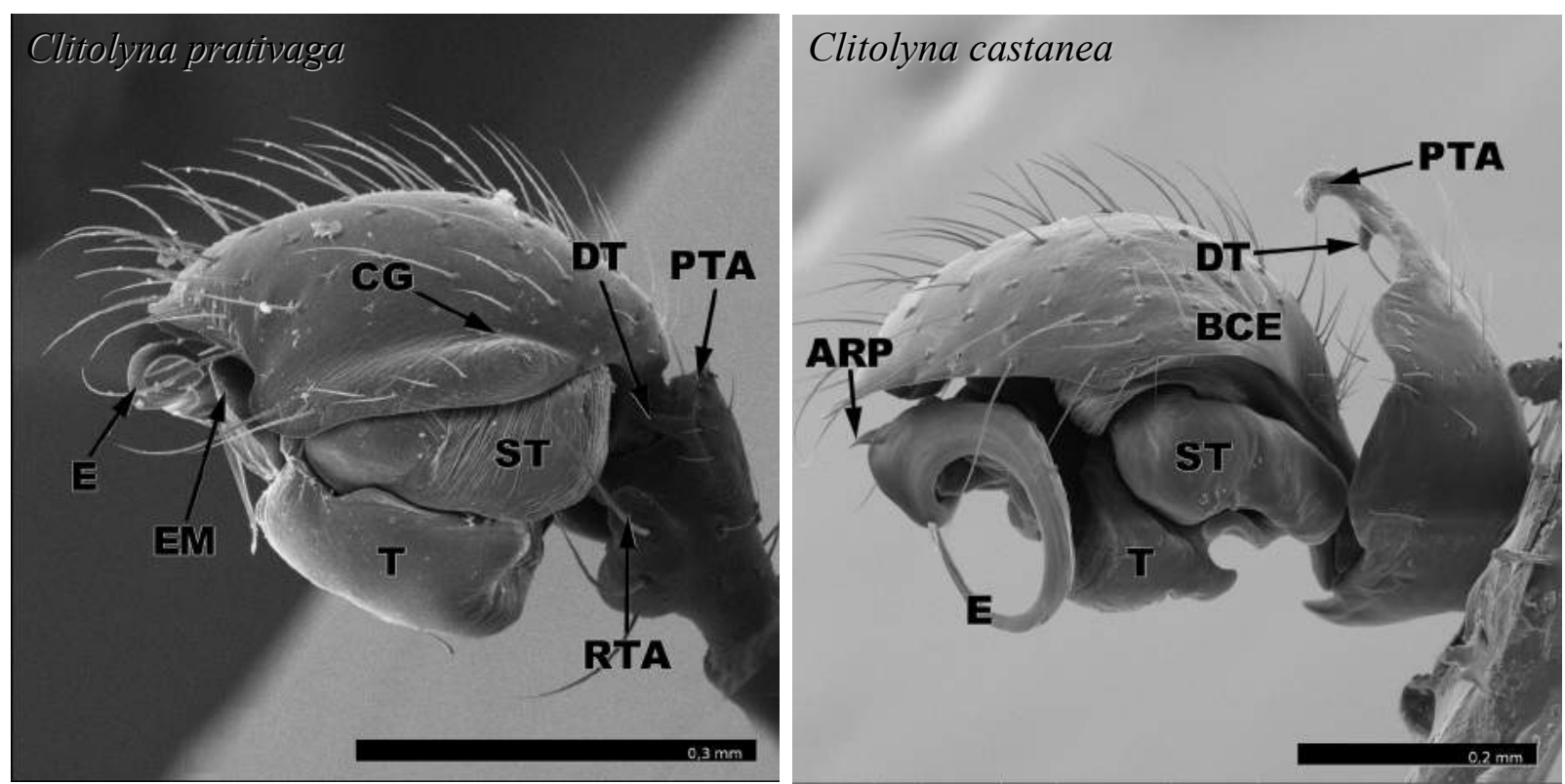

23- *Forma do êmbolo (E) ( $\mathrm{L}=4 ; \mathrm{CI}=0,25 ; \mathrm{RI}=0,5)$ :

O êmbolo (E) pode apresentar espessuras distintas em sua base, podendo ser mais delgado ou espesso.

(0) delgado (Clitolyna prativaga)

(1) espesso (Clitolyna fastibilis)
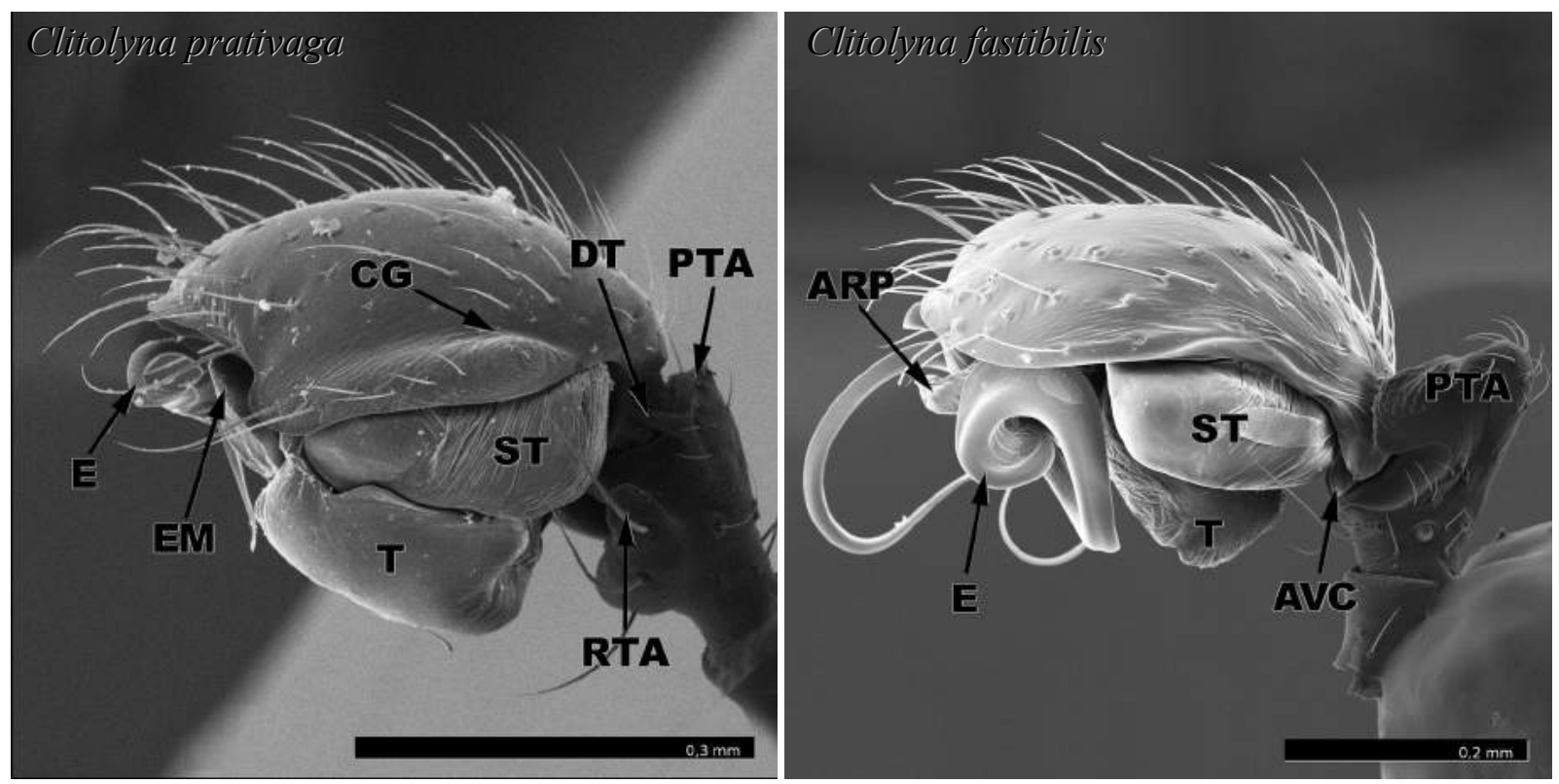
24- Ponta do êmbolo (E), caráter 45 de Miller e Hormiga (2004). ( $\mathrm{L}=5 ; \mathrm{CI}=0,2$; $\mathrm{RI}=0,692)$ :

(0) termina na abertura do êmbolo (Hypselistoides diversicolor)

(1) com uma projeção além da abertura do êmbolo (Clitolyna gravis)
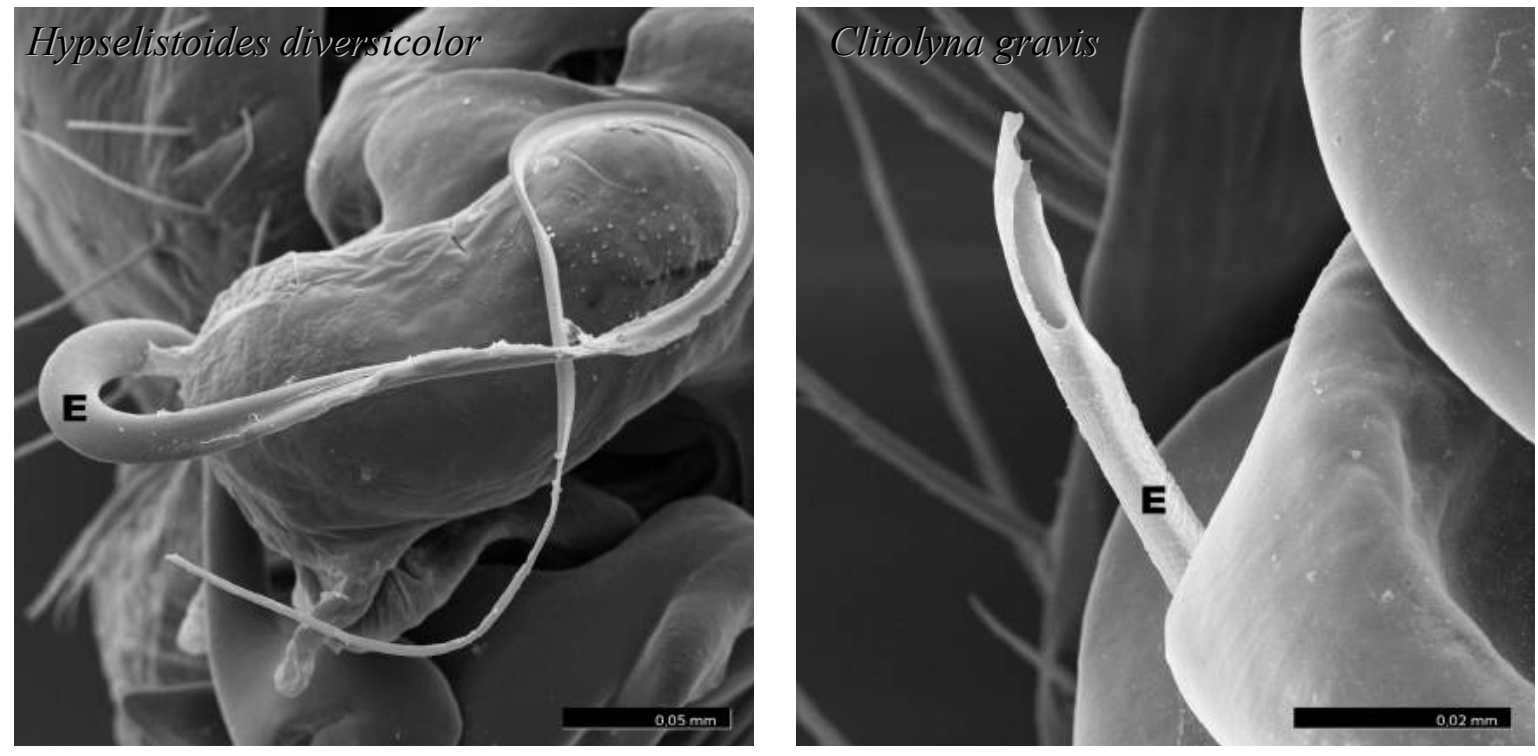

25- Processo basal do êmbolo (EBP), caráter 48 de Miller e Hormiga (2004). (L=6; $\mathrm{CI}=0,167 ; \mathrm{RI}=0,583)$ :

(0) ausente (Sphecozone nitens)

(1) presente (Clitolyna castanea)
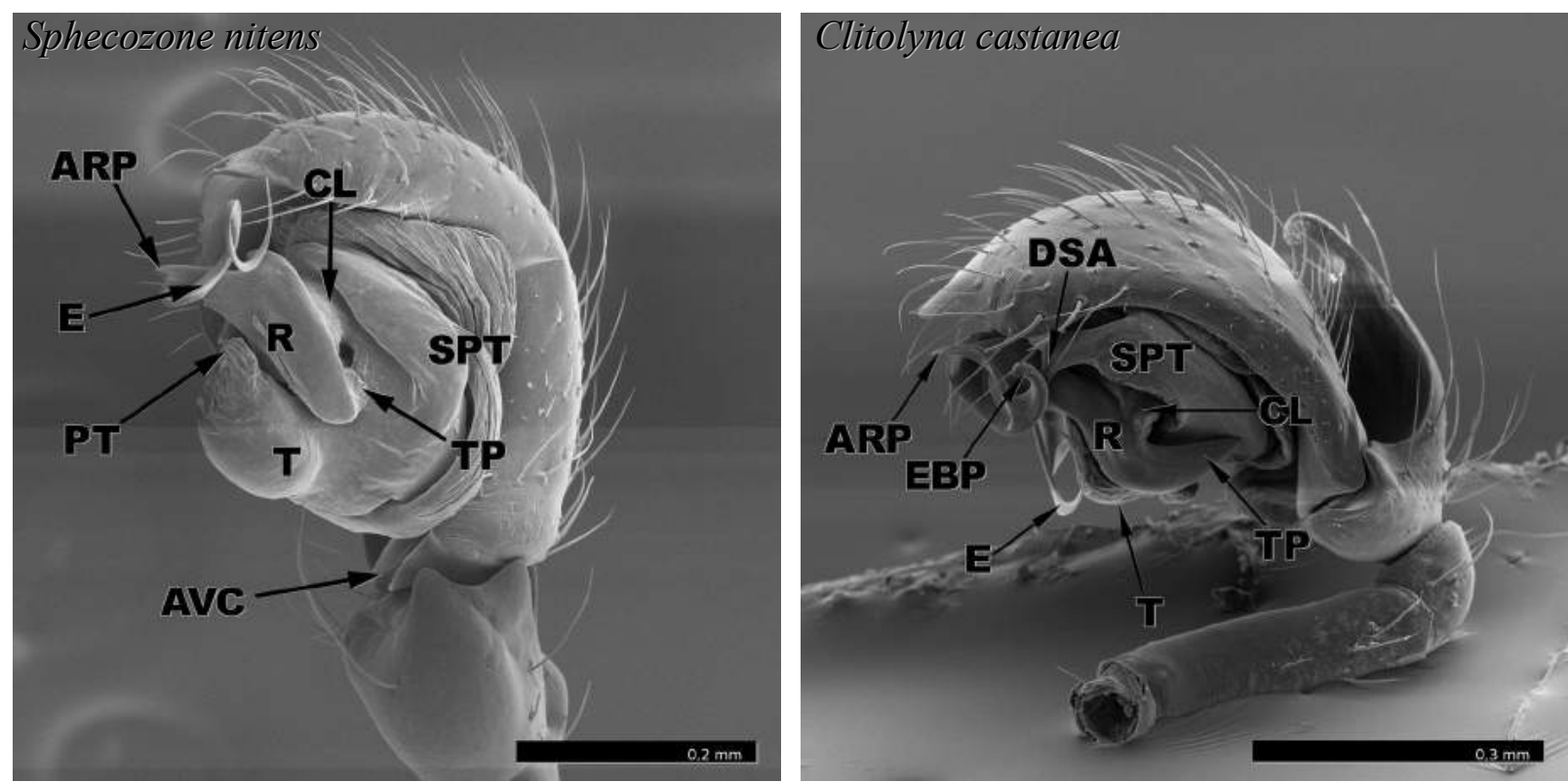
26- Forma da cauda do radix $(\mathrm{L}=5 ; \mathrm{CI}=0,2 ; \mathrm{RI}=0,5)$ :

Caráter 53 de Miller e Hormiga (2004).

(0) reto (Clitolyna fastibilis)

(1) espiral (Clitolyna prativaga)
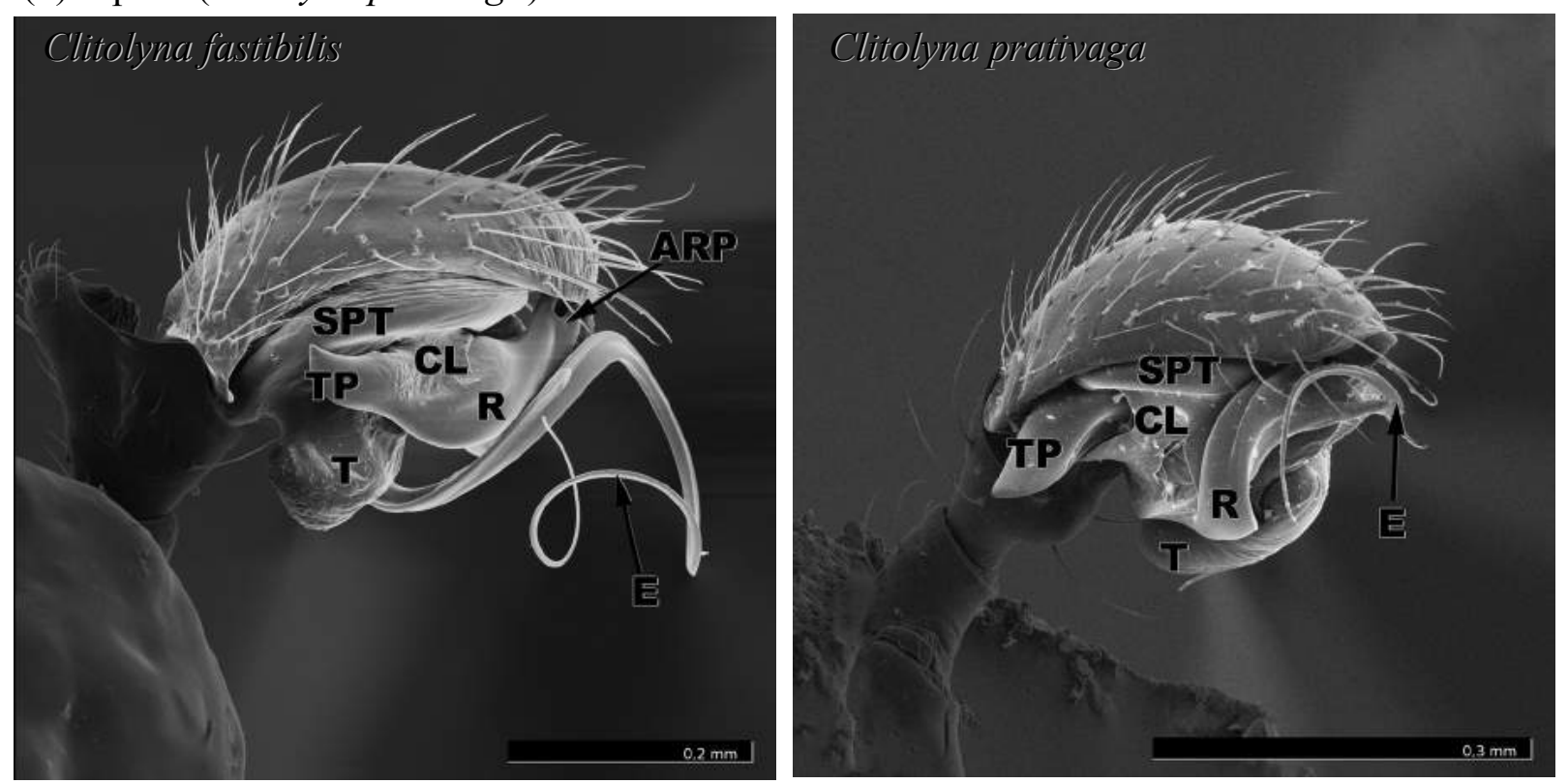

27- *Lóbulo na cauda do radix $(\mathrm{LCR})(\mathrm{L}=2 ; \mathrm{CI}=0,5 ; \mathrm{RI}=0,833)$ :

A cauda do radix pode apresentar uma região mais pronunciada dorsalmente, próximo ao column.

(0) ausente (Clitolyna castanea)

(1) presente (Hypselistoides diversicolor)
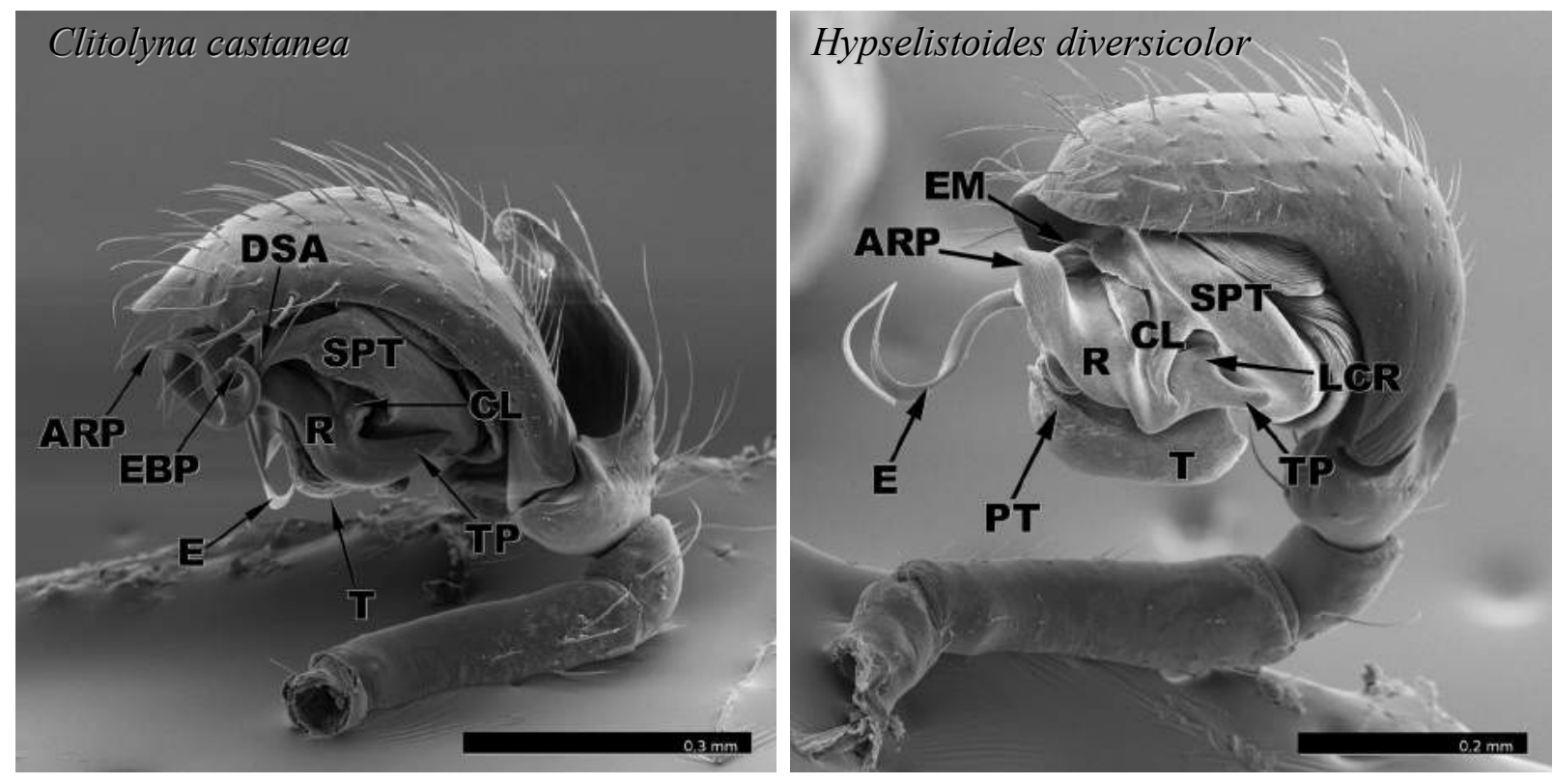
28- Processo anterior do radix (ARP), caráter 55 de Miller e Hormiga (2004). ( $\mathrm{L}=2$; $\mathrm{CI}=0,5 ; \mathrm{RI}=0,667)$ :

(0) ausente (Clitolyna prativaga)

(1) presente (Hypselistoides diversicolor)
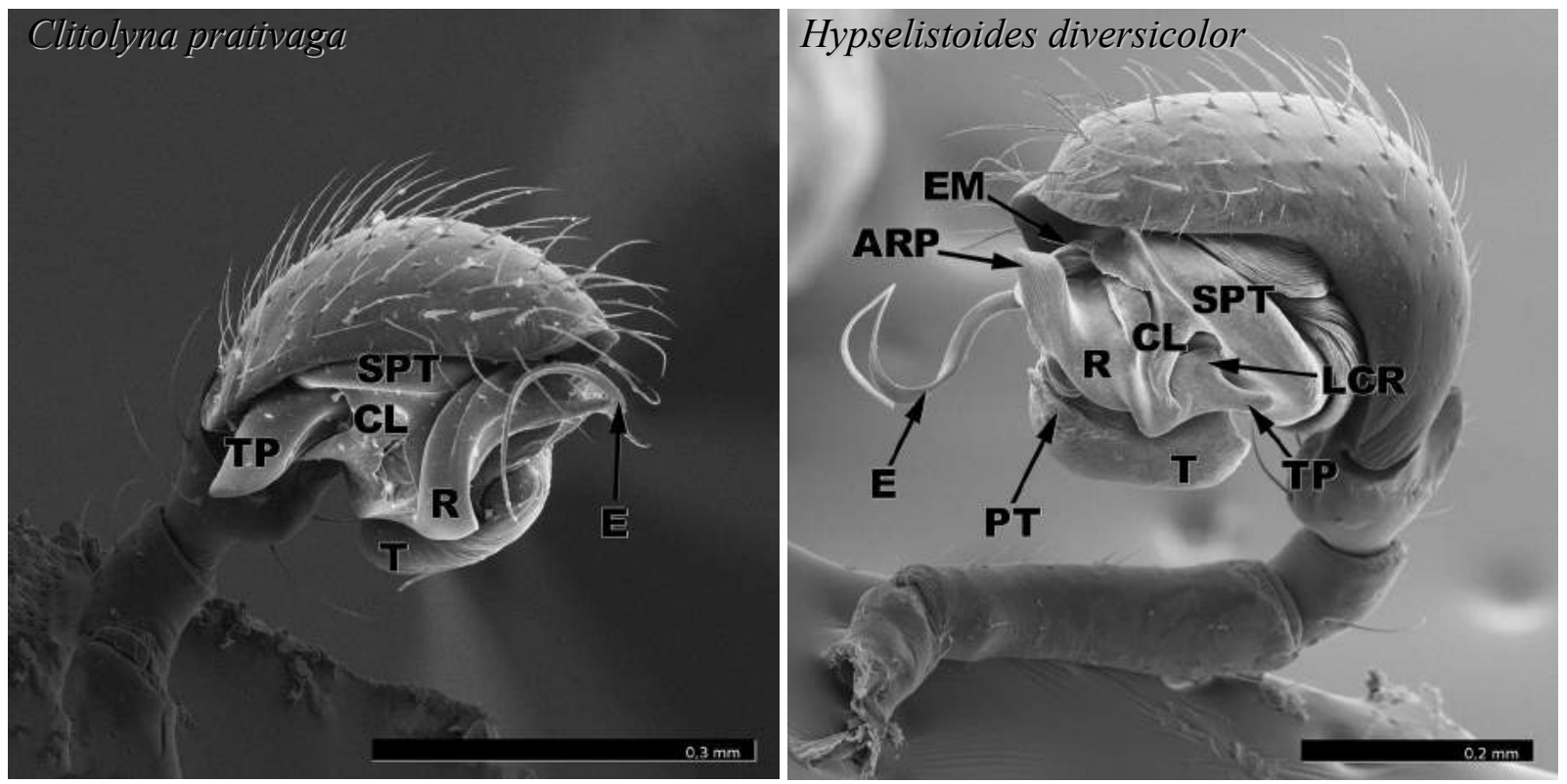

29- Dente mesal do radix $(\mathrm{L}=1 ; \mathrm{CI}=1 ; \mathrm{RI}=1)$ :

Caráter 58 de Miller e Hormiga (2004).

(0) ausente (Clitolyna fastibilis)

(1) presente (Hypselistoides diversicolor)

30- Crista do radix (RR) $(\mathrm{L}=3 ; \mathrm{CI}=0,333 ; \mathrm{RI}=0,714)$ :

Caráter 60 de Miller e Hormiga (2004).

(0) ausente (Hypselistoides diversicolor)

(1) presente (Tutaibo phoeniceus, Miller, 2007: 181, f. 140A) 
31- Tíbia do palpo do macho, apófise prolateral (PTA), caráter 67 de Miller e Hormiga (2004). ( $\mathrm{L}=2 ; \mathrm{CI}=0,5 ; \mathrm{RI}=0)$ :

(0) ausente (Hypselistoides corniculans)

(1) presente (Clitolyna castanea)
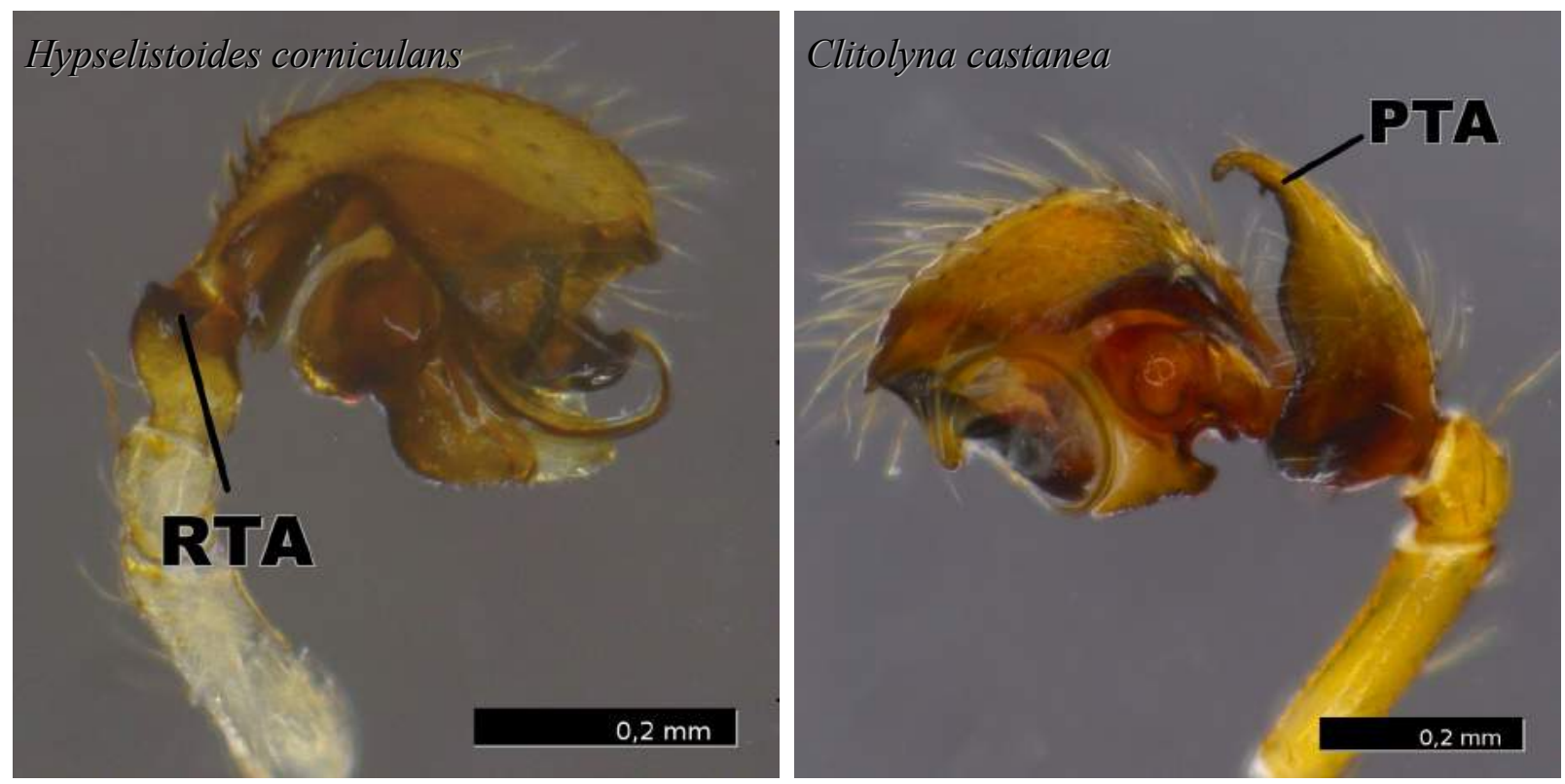

32- Orientação inicial da apófise prolateral (PTA), caráter 68 de Miller e Hormiga (2004). ( $\mathrm{L}=4 ; \mathrm{CI}=0,25 ; \mathrm{RI}=0,5)$ :

(0) perpendicular (Clitolyna castanea)

(1) distal (Sphecozone rubescens)
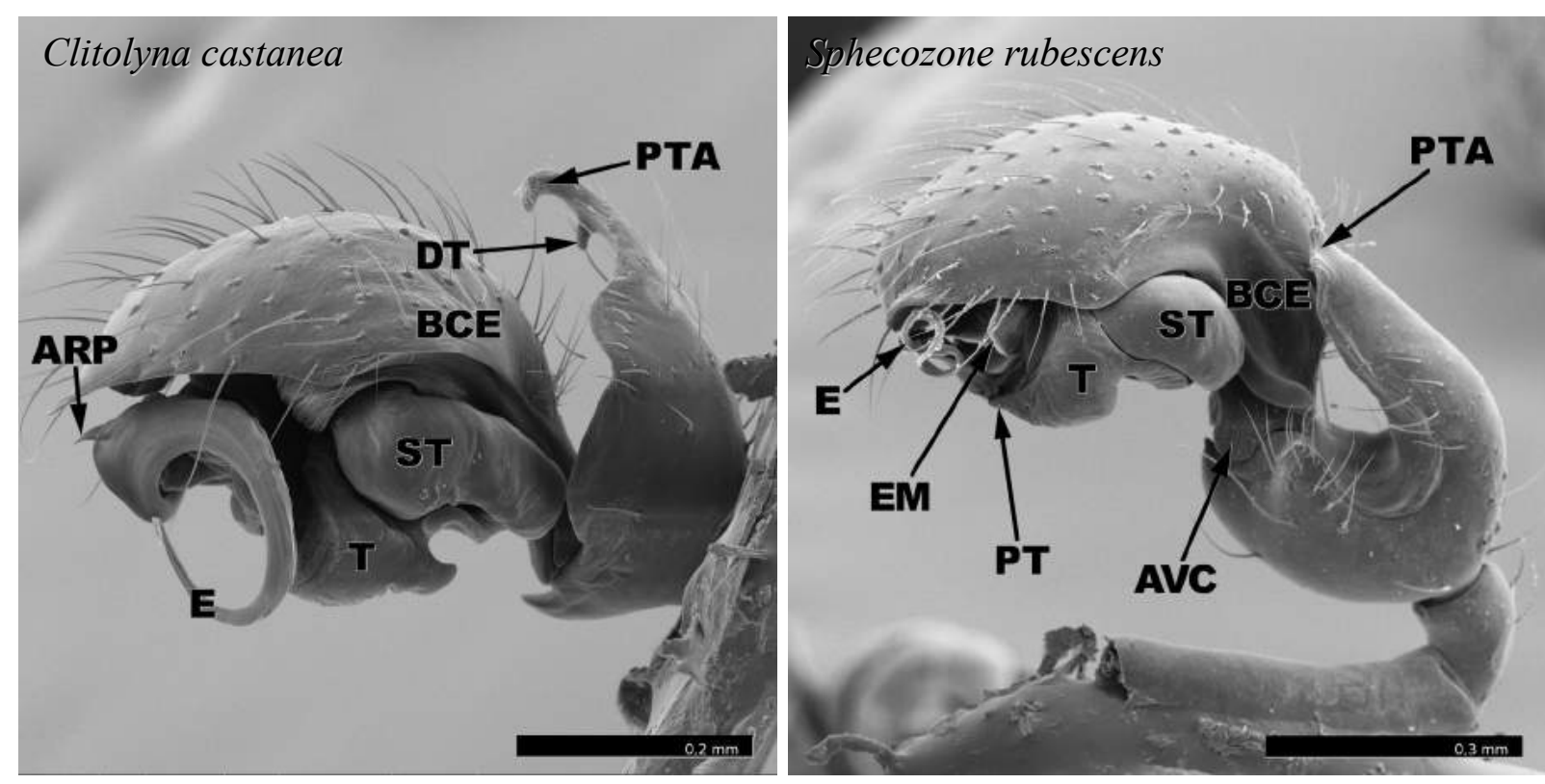
33- Dente distal da apófise prolateral $(\mathrm{L}=6 ; \mathrm{CI}=0,167 ; \mathrm{RI}=0,375)$ :

Caráter 69 de Miller e Hormiga (2004).

(0) ausente (Hypselistoides diversicolor)

(1) presente (Clitolyna castanea)

34- Tíbia do palpo do macho, apófise retrolateral $(\mathrm{L}=6 ; \mathrm{CI}=0,167 ; \mathrm{RI}=0,722)$ :

Caráter 70 de Miller e Hormiga (2004).

(0) ausente (Clitolyna castanea)

(1) presente (Hypselistoides diversicolor)
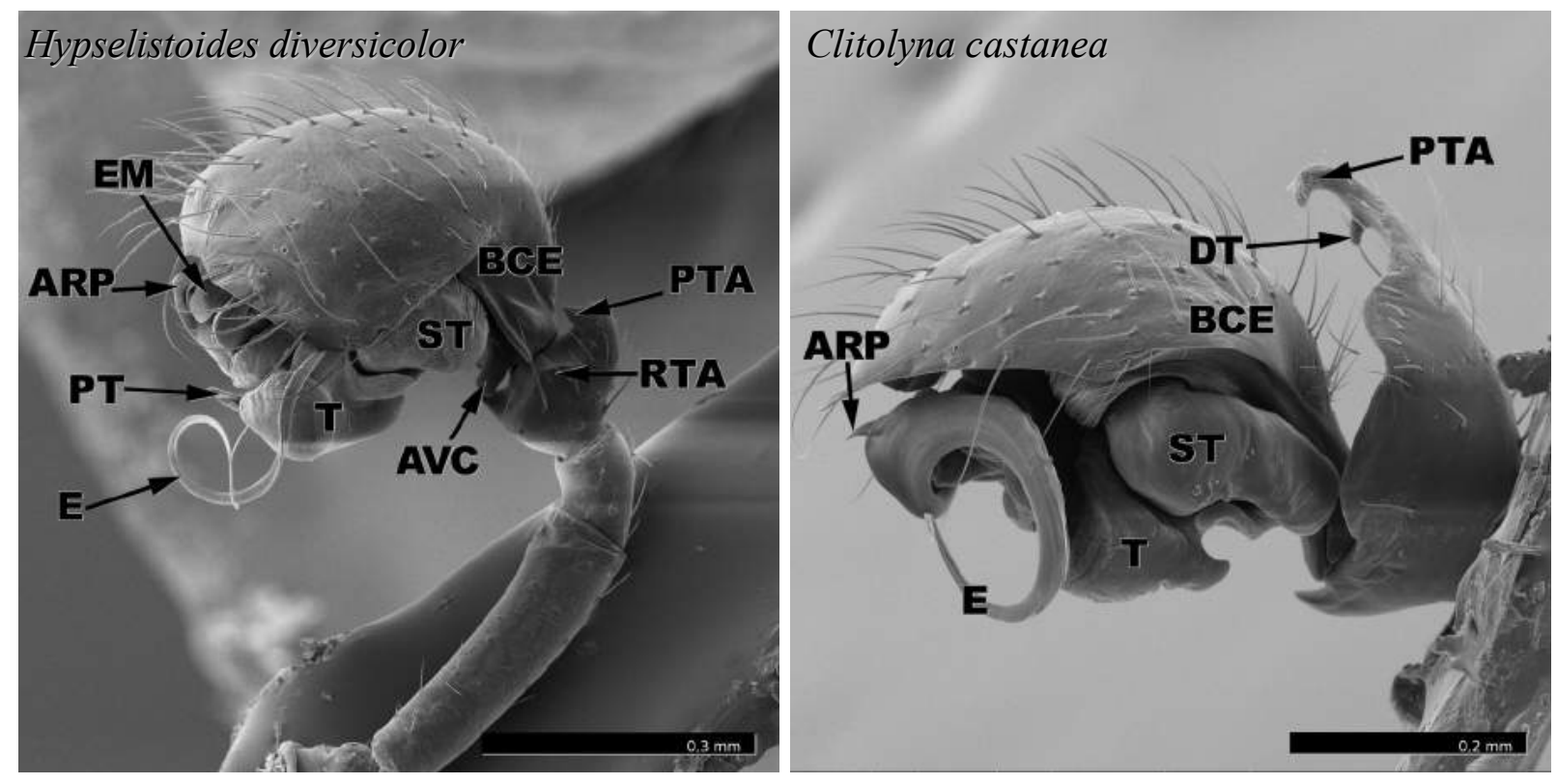
35- Tíbia do palpo do macho, processo ventral (VTP), caráter 72 de Miller e Hormiga (2004). ( $\mathrm{L}=5 ; \mathrm{CI}=0,2 ; \mathrm{RI}=0,333)$ :

(0) ausente (Clitolyna castanea)

(1) presente (Clitolyna rostrata)
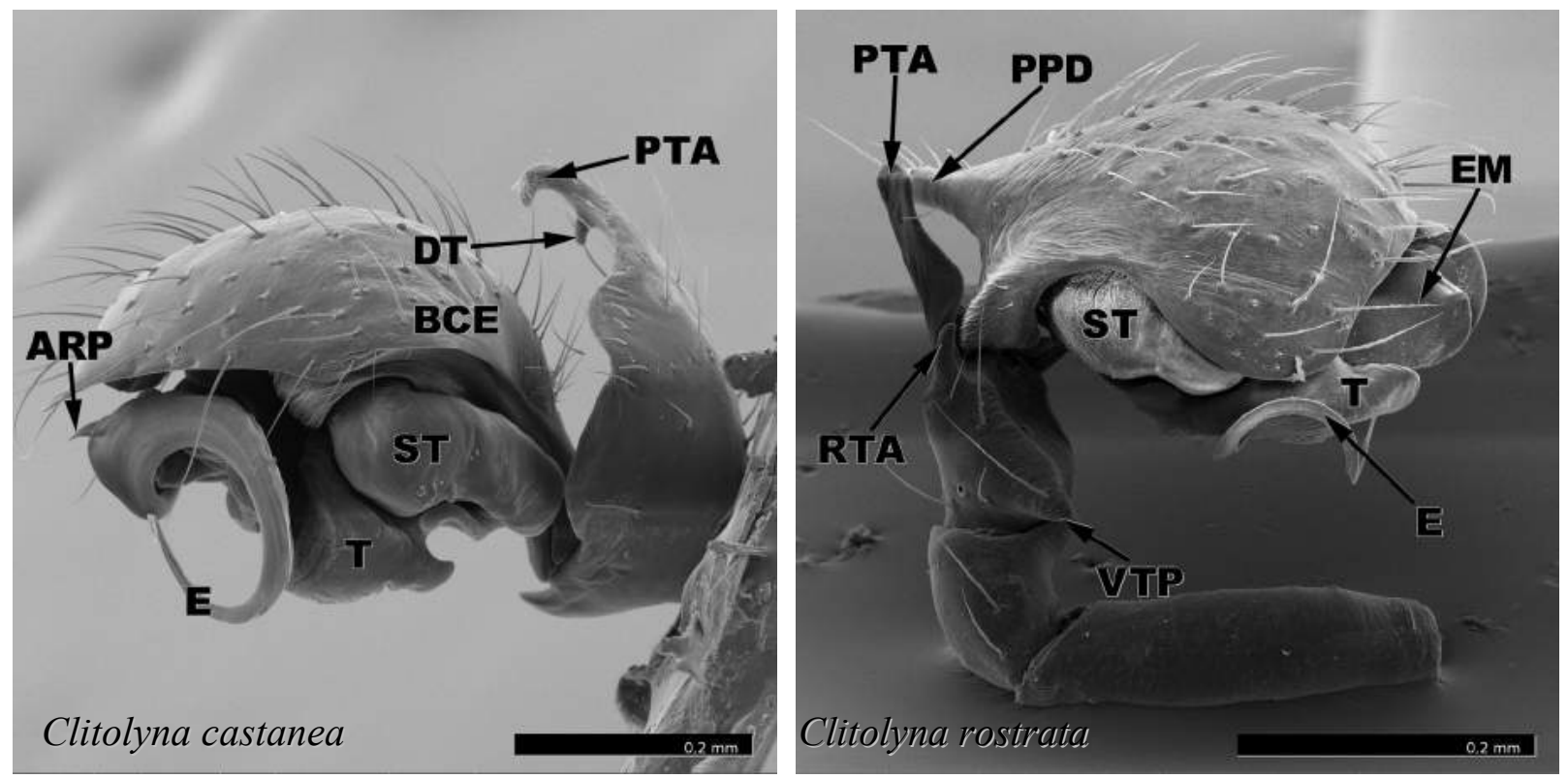

36- Tíbia do palpo do macho, tricobótrio prolateral ( $\mathrm{L}=6 ; \mathrm{CI}=0,167 ; \mathrm{RI}=0,615)$ :

Caráter 73 de Miller e Hormiga (2004).

(0) ausente (Hypselistoides diversicolor)

(1) presente (Clitolyna fastibilis)

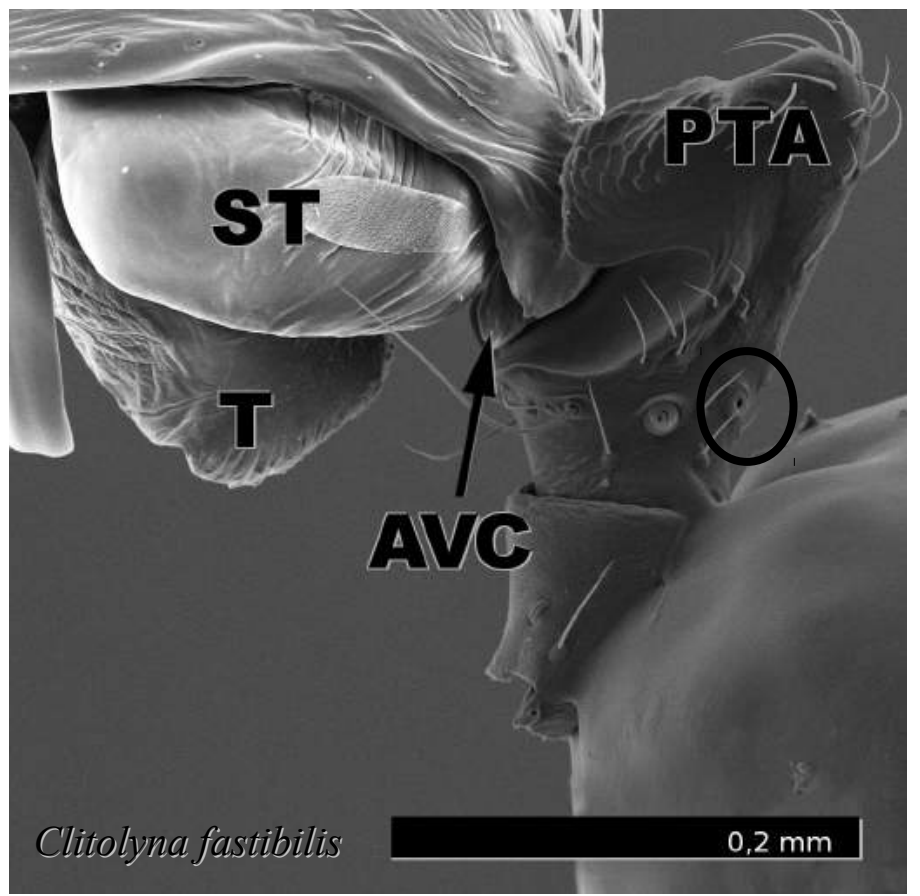


37- Lóbulo anterior da placa dorsal do epígino (AL), caráter 80 de Miller e Hormiga (2004). $(\mathrm{L}=2 ; \mathrm{CI}=0,5 ; \mathrm{RI}=0,667)$ :

(0) ausente (Psilocymbium acanthodes, Miller, 2007: 222, f. 167F)

(1) presente (Clitolyna novaeteutoniae)
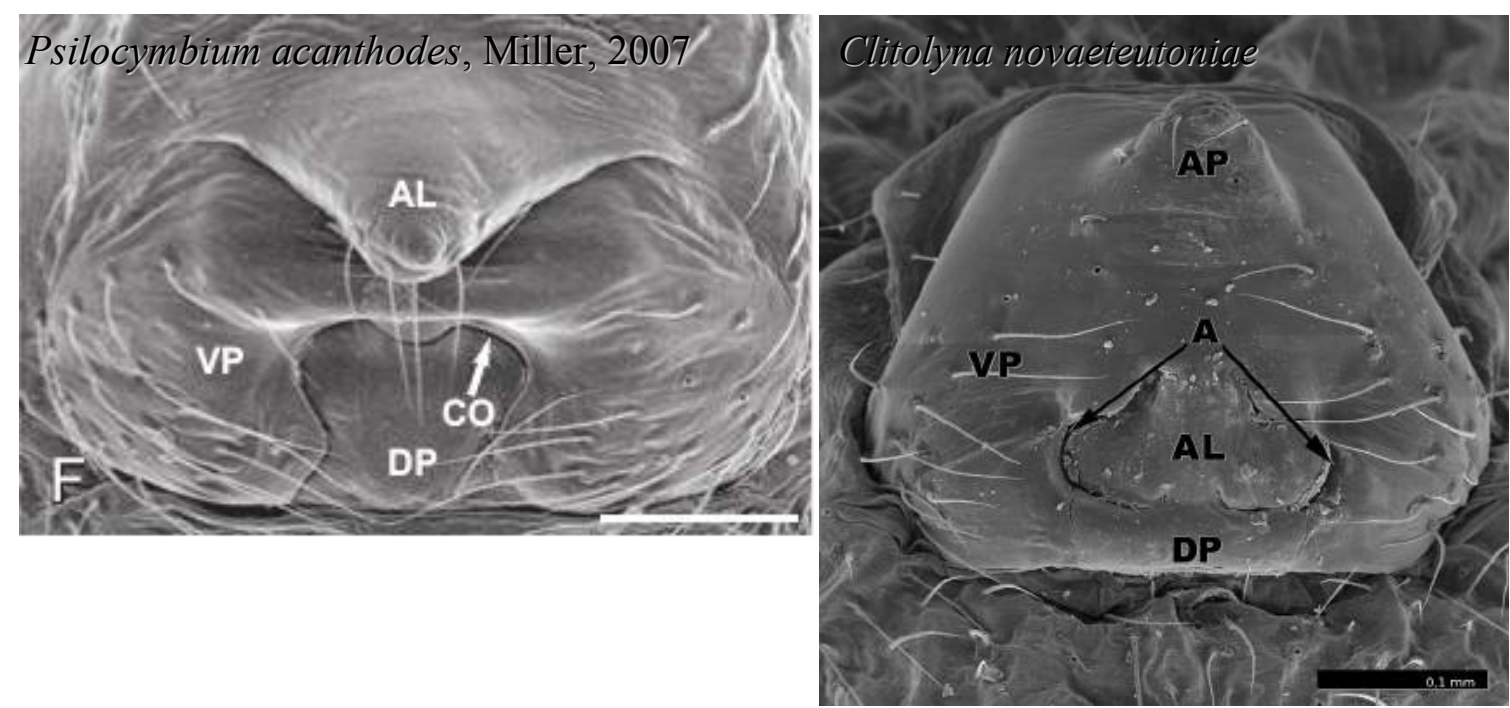

38- *Forma do lóbulo anterior da placa dorsal (AL) $(\mathrm{L}=2 ; \mathrm{CI}=0,5 ; \mathrm{RI}=0,5)$ :

A diferença entre a largura da placa dorsal (DP) e seu lóbulo anterior (AL) costumam ser discretas entre as fêmeas analisadas neste trabalho. Em raras exceções, essa diferença por ser o dobro, com o lóbulo sendo muito mais larga que a placa dorsal.

(0) tão larga quanto a placa dorsal (Clitolyna novaeteutoniae)

(1) pelo menos 2x mais larga (Clitolyna fastibilis)
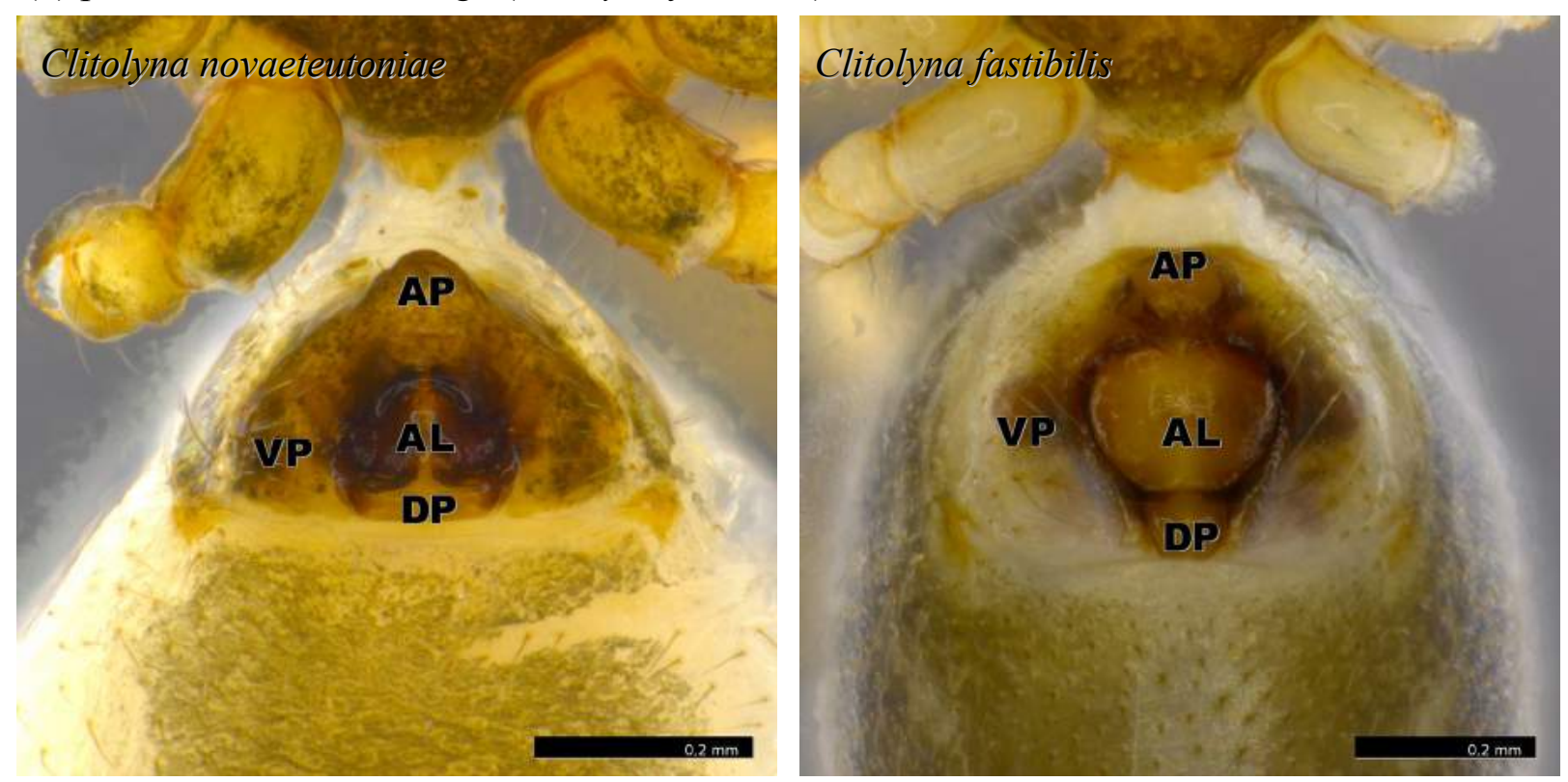
39- Processo anterior da placa ventral do epígino (AP), caráter 88 de Miller e Hormiga (2004). ( $\mathrm{L}=6 ; \mathrm{CI}=0,167 ; \mathrm{RI}=0,545)$ :

(0) ausente (Hypselistoides diversicolor)

(1) presente (Clitolyna novaeteutoniae)
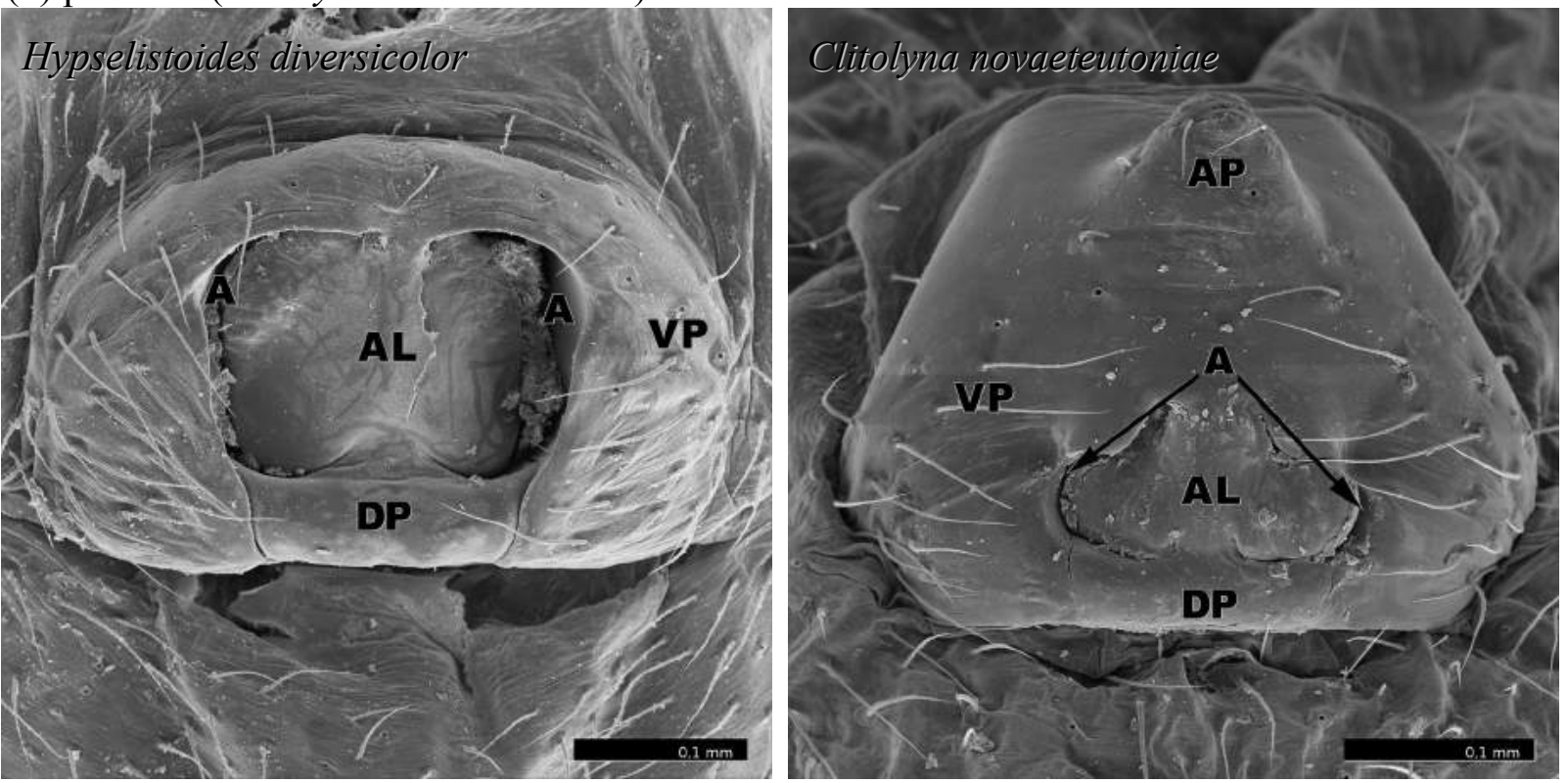

40- *Depressão anterior da placa ventral $(\mathrm{DAV})(\mathrm{L}=2 ; \mathrm{CI}=0,5 ; \mathrm{RI}=0,5)$ :

A placa ventral pode apresentar dois tipo de depressões, anterior e lateral (caráter 41). Os dois tipos de depressões podem não estar relacionados, já que a depressão anterior, nos três casos observados (Clitolyna gravis, Clitolyna personata e S. rostrata), apresentou grânulos, o que faz suspeitar uma origem glandular.

(0) ausente (Hypselistoides diversicolor)

(1) presente (Clitolyna gravis)
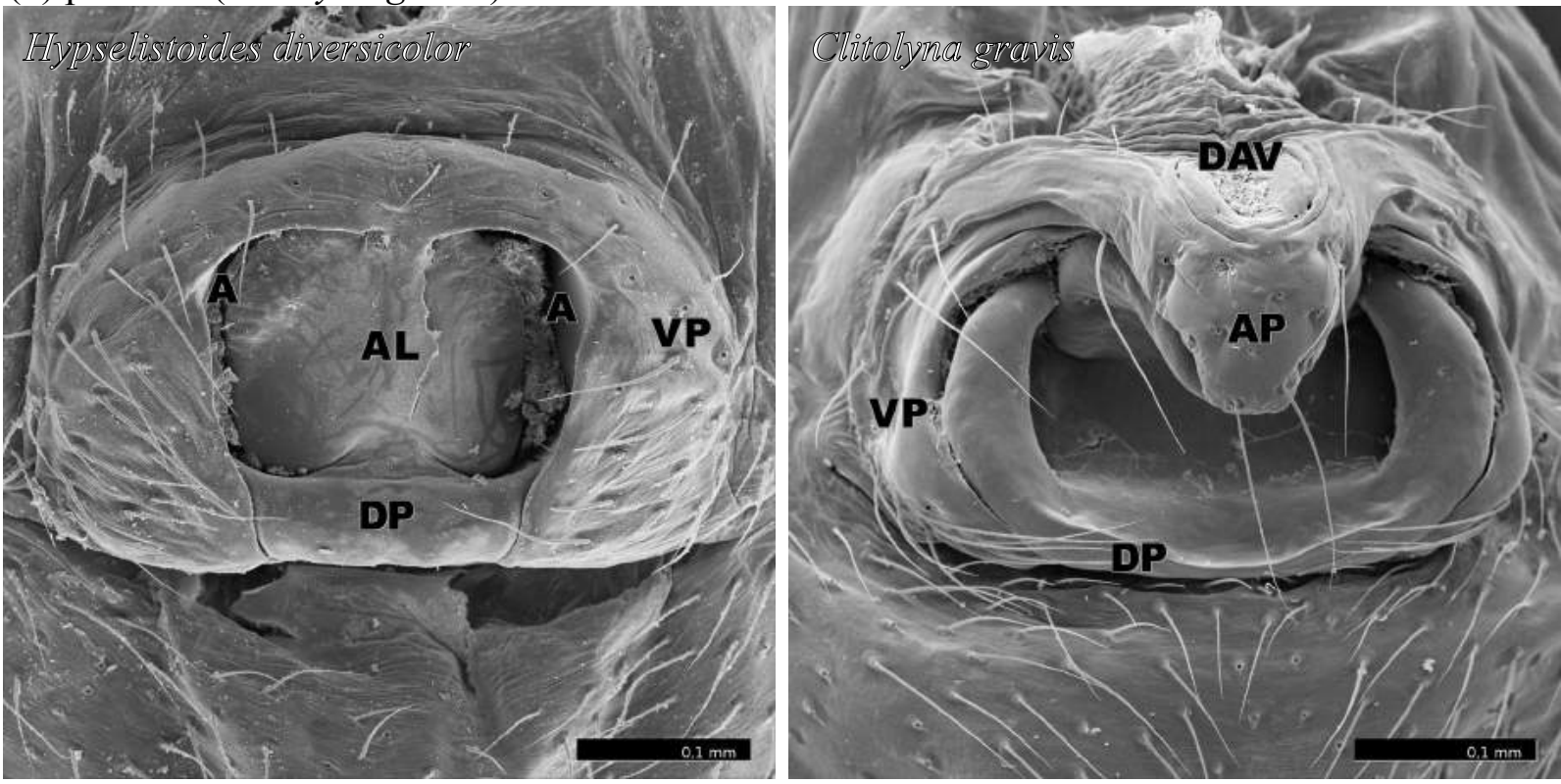
41- *Depressão lateral da placa ventral $(\mathrm{L}=2 ; \mathrm{CI}=0,5 ; \mathrm{RI}=0,857)$ :

Ver caráter 41.

(0) ausente (Hypselistoides diversicolor)

(1) presente (Hypselistoides niwinus)
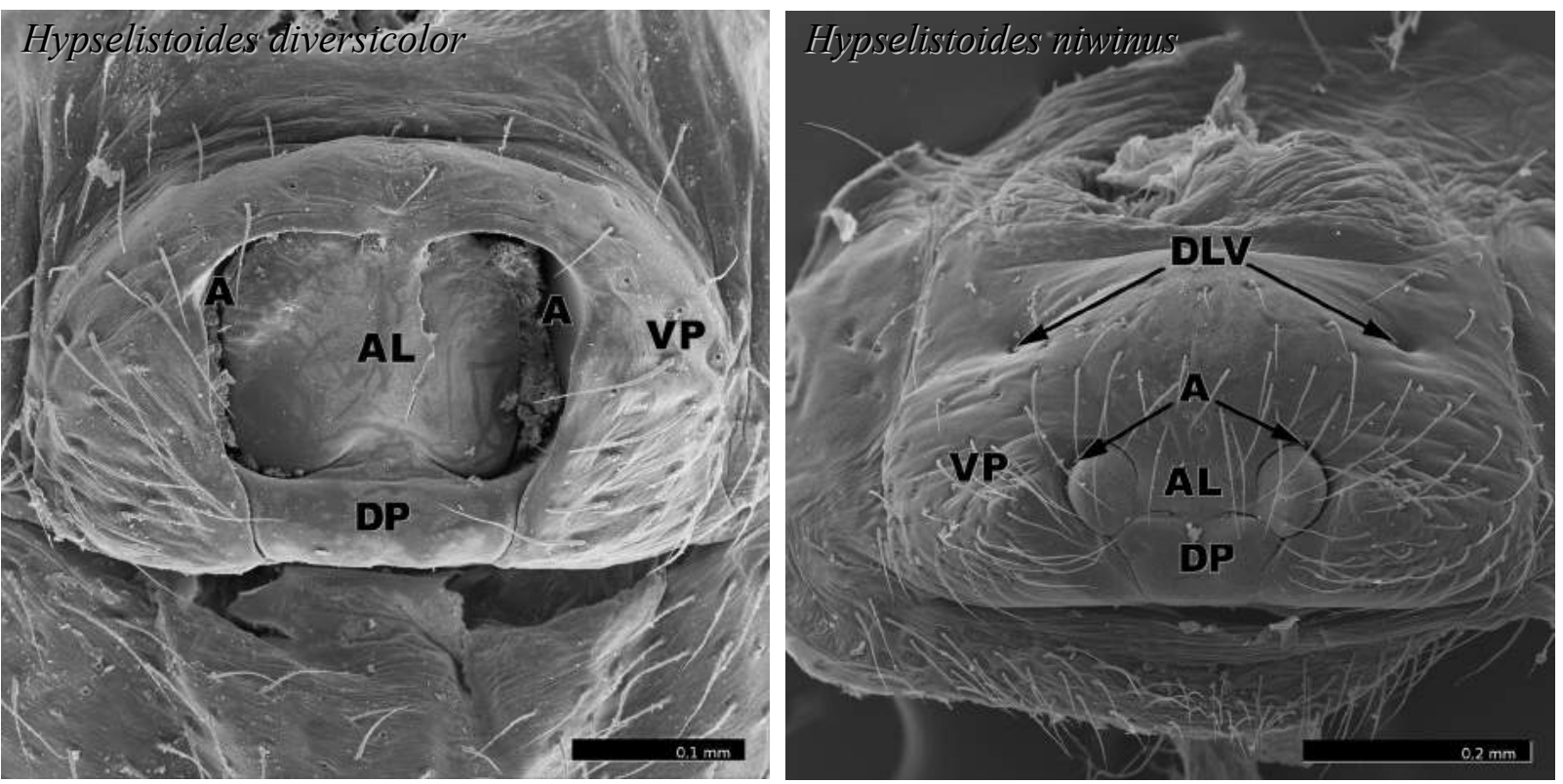

42- Átrio (A), caráter 92 de Miller e Hormiga (2004). ( $\mathrm{L}=3 ; \mathrm{CI}=0,333 ; \mathrm{RI}=0)$ :

(0) ausente (Tutaibo phoeniceus: Miller, 2007: 181, f. 140F)

(1) presente (Clitolyna novaeteutoniae)
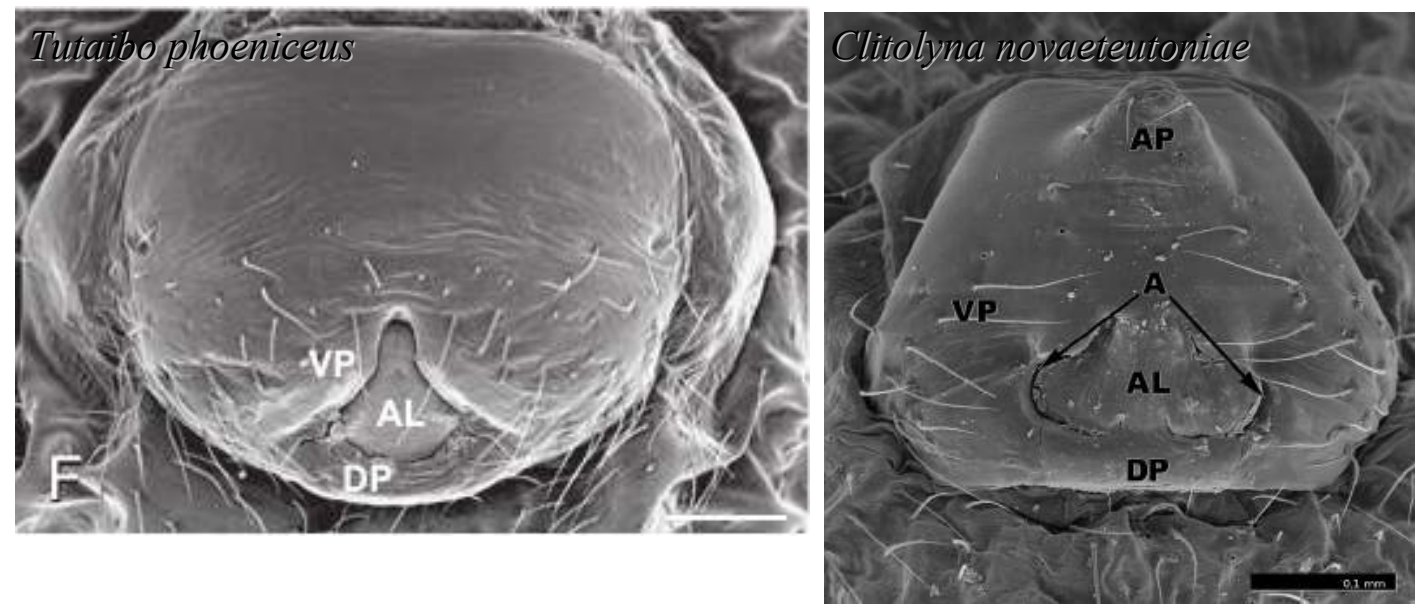
43- *Forma do átrio $(\mathrm{L}=6 ; \mathrm{CI}=0,333 ; \mathrm{RI}=0,429)$ :

(0) curvo (Hypselistoides ignigenus)

(1) sinuoso (Clitolyna novaeteutoniae)

(2) reto (Hypselistoides diversicolor)
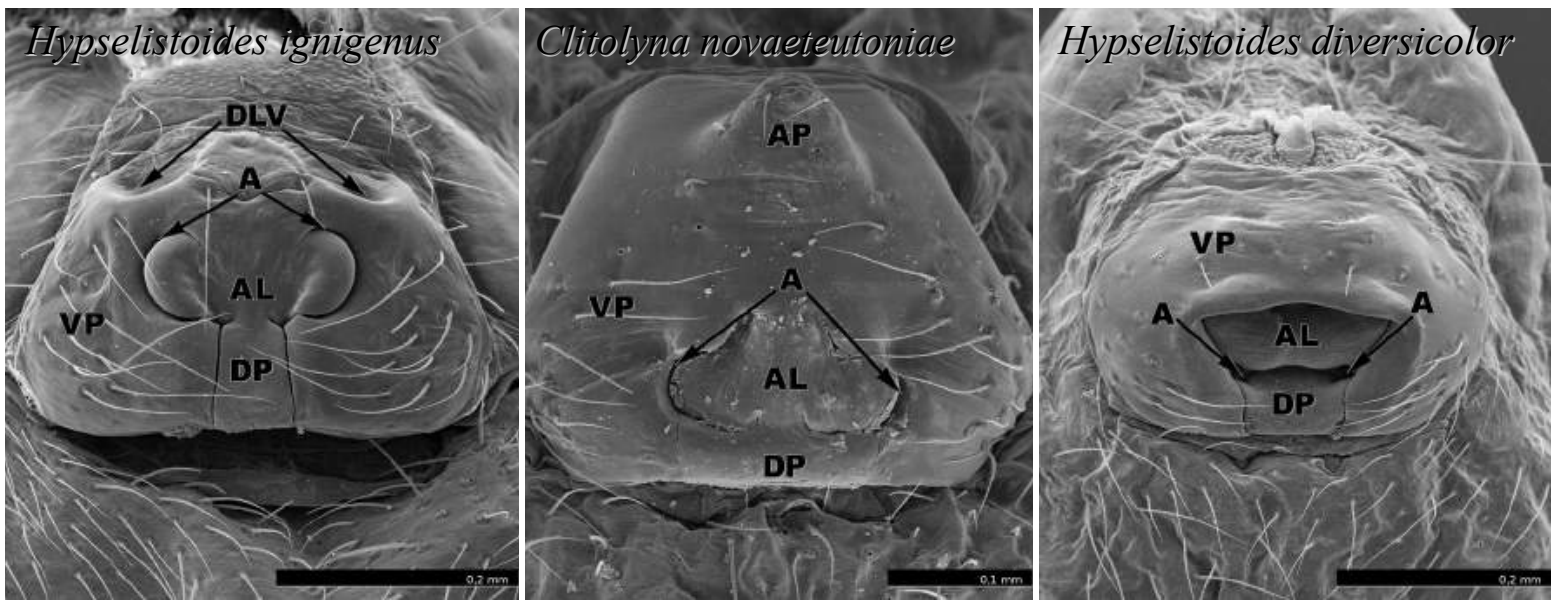

44- Orientação da placa dorsal do epígino, caráter 93 de Miller e Hormiga (2004). (L=1; $\mathrm{CI}=1 ; \mathrm{RI}=1)$ :

(0) posição da placa dorsal inteiramente dorsal à placa ventral (Ceratinopsis interpres)

(1) placa dorsal estendendo-se anteriormente (Clitolyna novaeteutoniae)

45- Membrana interna (IM), caráter 96 de Miller e Hormiga (2004).(L=3; CI=0,333;

$\mathrm{RI}=0,667)$ :

(0) ausente (Hypselistoides diversicolor)

(1) presente (Clitolyna novaeteutoniae)
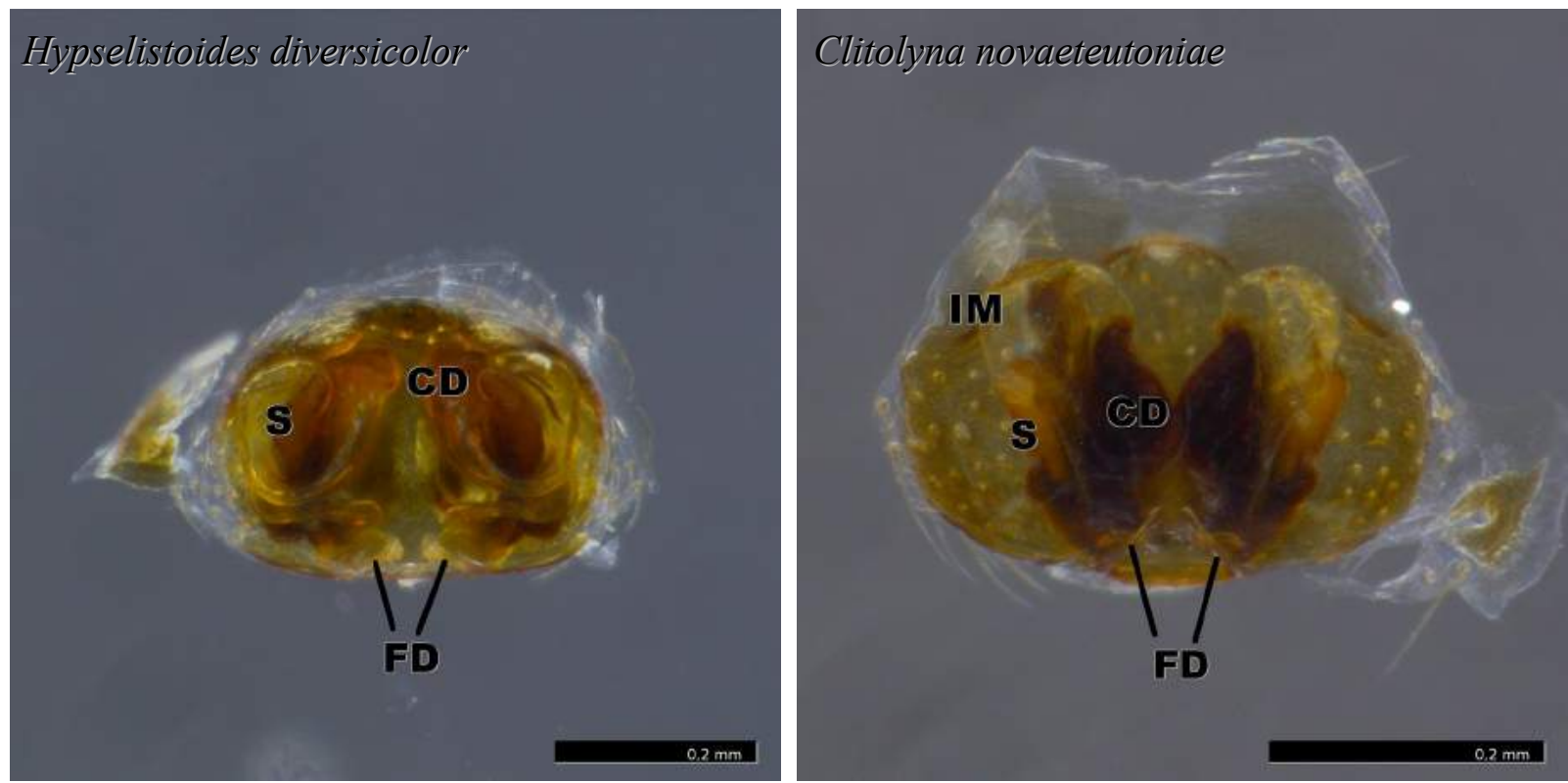
46- Forma da espermateca (S), caráter 98 de Miller e Hormiga (2004). ( $\mathrm{L}=10$; $\mathrm{CI}=0,2$; $\mathrm{RI}=0,5)$ [escala $0,2 \mathrm{~mm}]$ :

(0) redondo para levemente ovalado (Hypselistoides niwinus)

(1) fortemente ovalado (Clitolyna novaeteutoniae)

(2) muito longo e curvado (Hypselistoides modicus)
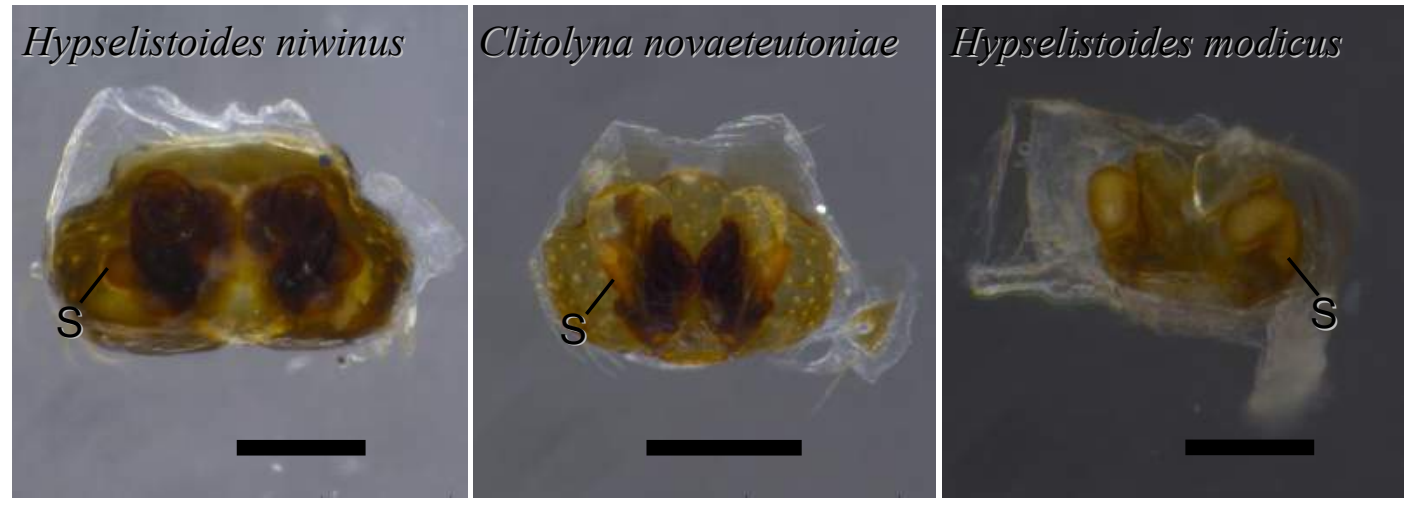

47- *Posição da espermateca ( $\mathrm{L}=9 ; \mathrm{CI}=0,222 ; \mathrm{RI}=0,667)$ [escala $0,2 \mathrm{~mm}$ ]:

(0) dorsal, em relação ao duto copulatório (Hypselistoides niwinus)

(1) lateral, em relação ao duto copulatório (Clitolyna novaeteutoniae)

(2) envolvido pelo duto copulatório (Clitolyna personata)
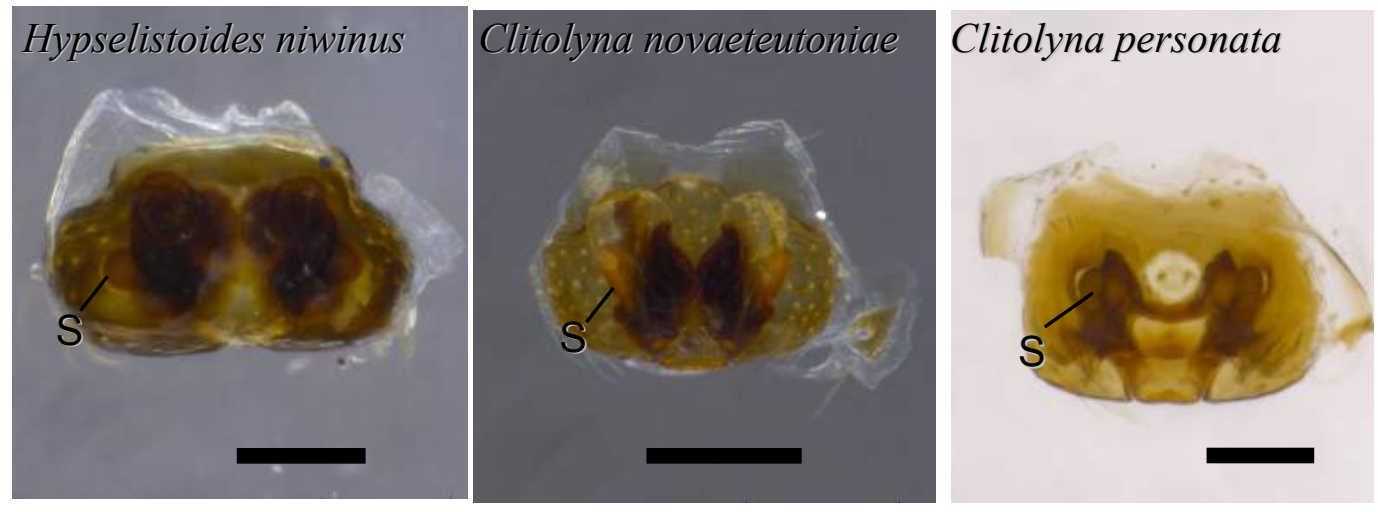

48- Orientação do duto de fertilização, caráter 99 de Miller e Hormiga (2004). (L=2; $\mathrm{CI}=0,5 ; \mathrm{RI}=0,8)$ :

(0) posterior (Clitolyna novaeteutoniae)

(1) mesal (Hypselistoides modicus) 
49- Região cefálica no macho ( $\mathrm{L}=7 ; \mathrm{CI}=0,143 ; \mathrm{RI}=0,625)$ :

Problemas na matriz original de Miller \& Hormiga (2004) já foram reportados e resolvidos por Dupérré \& Paquin (2007), Frick \& Muff (2009) e Frick et al. (2010), e envolvia trocas de estados e discordâncias na codificação dos caracteres de determinados táxons.

O caráter "região cefálica dos machos", apresentou incoerências quanto sua descrição. Aparentemente simples, os estados permitiam codificar as espécies em não elevado (0) e elevado (1). No entanto, comparando os dados na matriz de Miller \& Hormiga (2004), algumas espécies tiveram suas codificações duvidosas. Em relação aos táxons analisados neste estudo, os autores codificaram somente $P$. acanthodes, como tendo a região elevada. Porém, observando as imagens de Miller (2007), S. rubescens e H. bicolor, também parece ter a região elevada (figs 156A, p.211; 159D, p.214; 175E, p.230; 141D, p.182). Algumas ilustrações referentes a outros táxons (por exemplo Areoncus, Gonatium, Hypselocara, codificados como elevados) podem ser conferidas em Hormiga (2000, figs 32B, D, E) para comparação.

Esse caráter não apresenta nenhuma descrição em Miller \& Hormiga (2004), apenas referências à imagens e artigos. Recorrendo à sua bibliografia, foi consultado Hormiga (2000) para maiores informações. Neste artigo ele descreve:

"Those linyphiids in which the cephalic region is not entirely raised have relatively low lateral eyes (close to the margin of the cephalothorax), which is the araneoid plesiomorphic condition. When the entire cephalic region is raised, the lateral eyes are raised higher (relative to the margin of the cephalothorax), which is the apomorphic condition."

Hormiga (2000), no entanto, não informa qual a relação ou proporção desta distância. Não se sabe ao certo se esse caráter em particular foi mal definido, ou se houve um problema na codificação entre $H$. bicolor e $S$. rubescens, por parte dos autores originais. Sendo assim, para este estudo, essas espécies foram reinterpretadas como tendo a região cefálica elevada.

(0) não elevado (Hypselistoides modestus)

(1) elevado (Hypselistoides capitatus) 
50- *Forma da elevação da região cefálica $(\mathrm{L}=6 ; \mathrm{CI}=0,167 ; \mathrm{RI}=0,286)$ :

Além da altura da região cefálica, outra diferença é a forma como ela se eleva. Pode ser suave, com um ângulo mais aberto, ou abrupta, com a região cefálica e a região toráxica formando um ângulo de quase $90^{\circ}$

(0) suave (Hypselistoides ignigenus)

(1) abrupta (Hypselistoides capitatus)

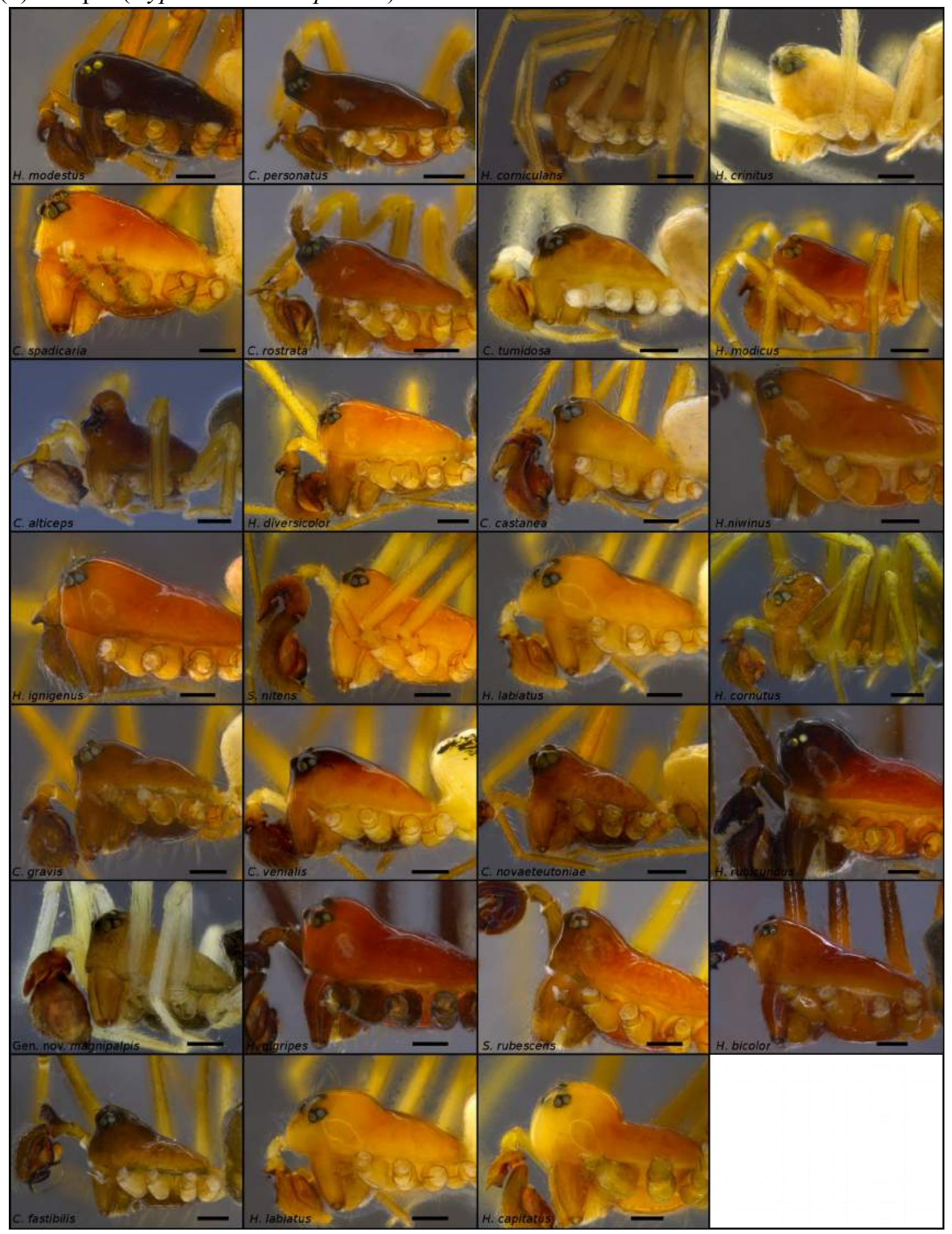


51- Lóbulo cefálico nos OMP no macho, caráter 102 de Miller e Hormiga (2004). (L=2; $\mathrm{CI}=0,5 ; \mathrm{RI}=0)$ :

(0) ausente (Clitolyna novaeteutoniae)

(1) presente (Clitolyna alticeps)

52- Lóbulo cefálico pós-OMP no macho, caráter 103 de Miller e Hormiga (2004). (L=1; $\mathrm{CI}=1 ; \mathrm{RI}=1)$ :

(0) ausente (Clitolyna novaeteutoniae)

(1) presente (Grammonota pictilis)

53- Lóbulo cefálico entre OMA-OMP no macho, caráter 104 de Miller e Hormiga (2004). ( $\mathrm{L}=1 ; \mathrm{CI}=1 ; \mathrm{RI}=1)$ :

(0) ausente (Clitolyna novaeteutoniae)

(1) presente (Clitolyna personata)
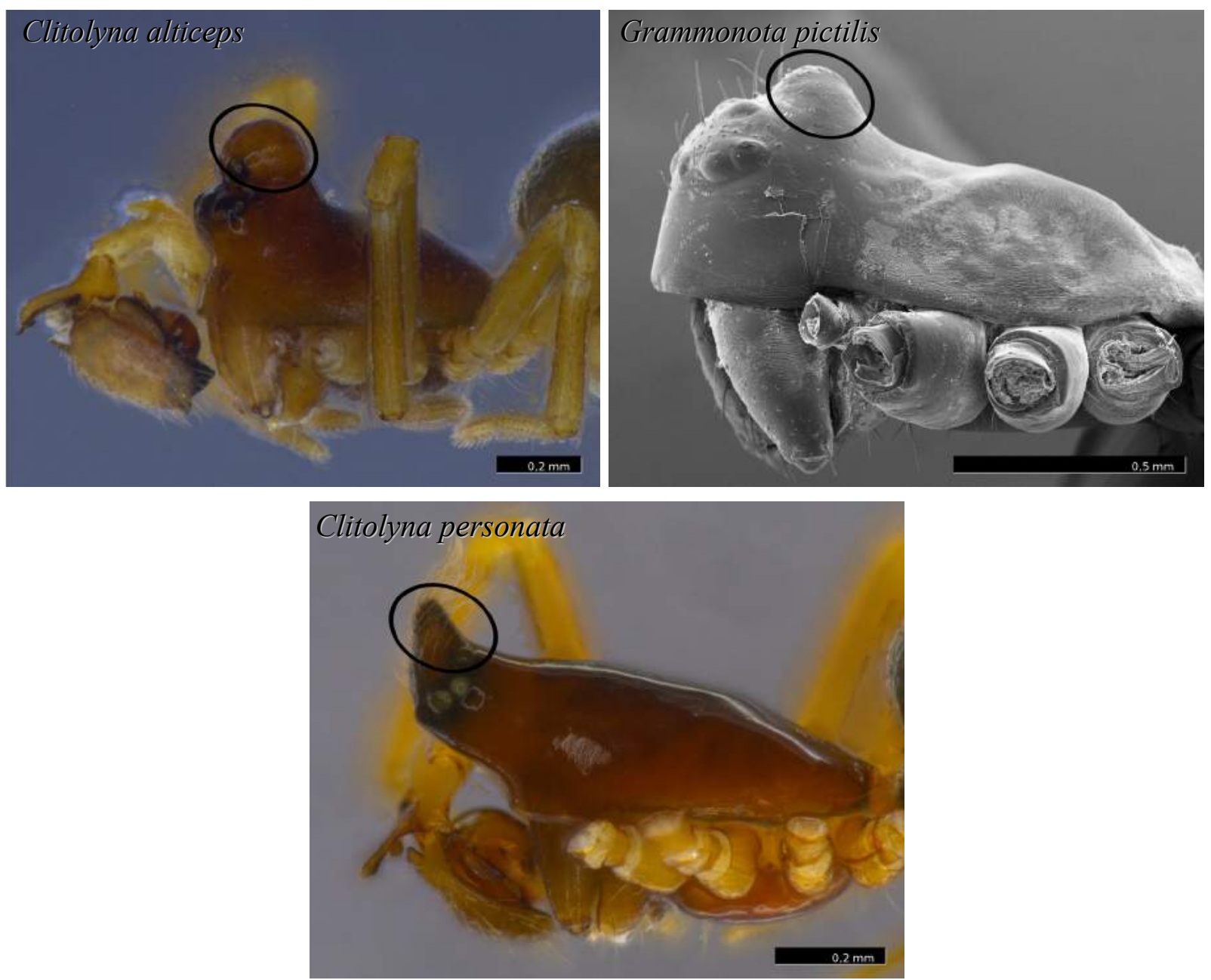
54- Orifício cefálico no macho, caráter 109 de Miller e Hormiga (2004). (L=1; CI=1; $\mathrm{RI}=1)$ :

(0) ausente (Clitolyna novaeteutoniae)

(1) presente (Dolabritor spineus: Miller, 2007, p. 235, f. 179A)
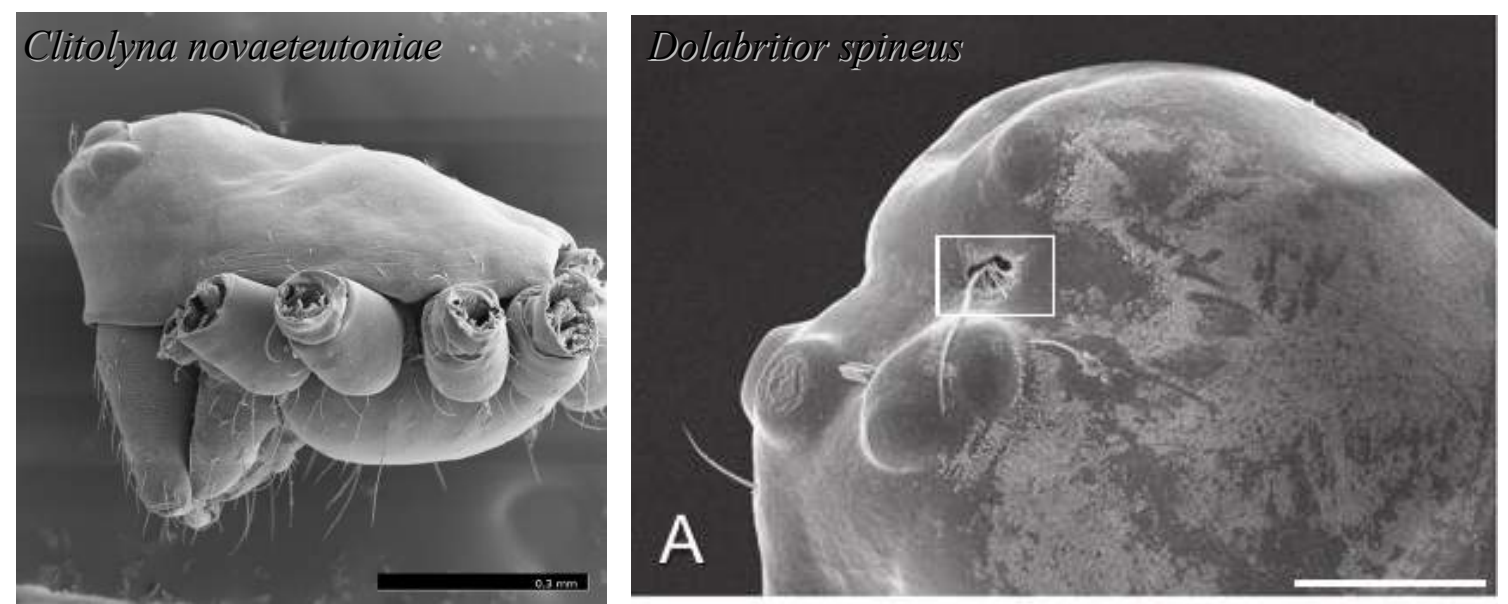

55- Poros cuticulares cefálicos no macho, caráter 110 de Miller e Hormiga (2004). $(\mathrm{L}=5 ; \mathrm{CI}=0,2 ; \mathrm{RI}=0,636)$ :

(0) raro (Clitolyna novaeteutoniae)

(1) comum (Hypselistoides lobatus)
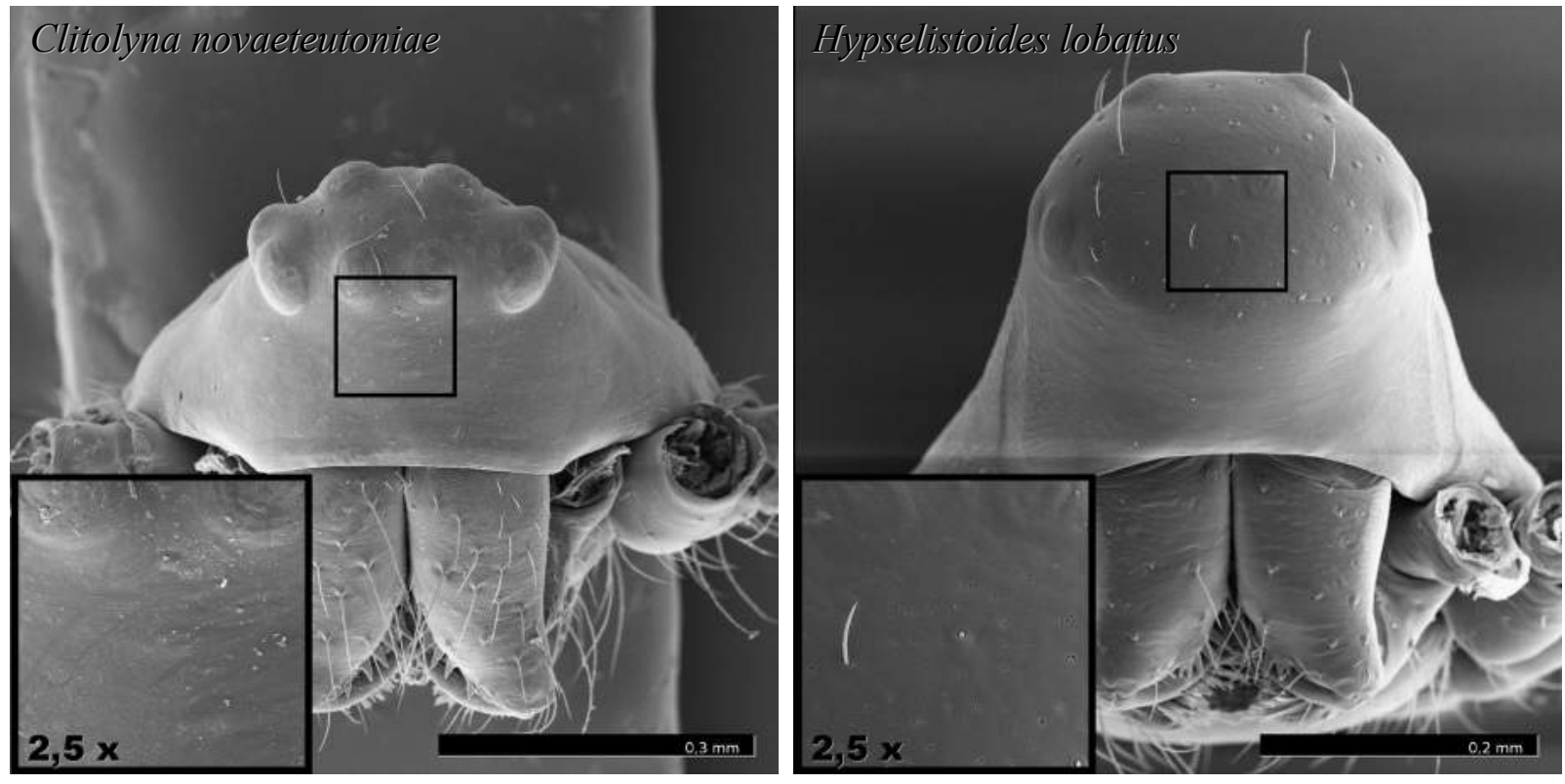
56- Textura do clípeo do macho, caráter 112 de Miller e Hormiga (2004). ( $\mathrm{L}=2 ; \mathrm{CI}=0,5$; $\mathrm{RI}=0)$ :

(0) suave (Clitolyna novaeteutoniae)

(1) como escamas (Gonatoraphis lysistrata)

57- Estrias estridulatórias da quelícera do macho, caráter 117 de Miller e Hormiga (2004). ( $\mathrm{L}=8 ; \mathrm{CI}=0,25 ; \mathrm{RI}=0)$ :

(0) rugosas (Clitolyna novaeteutoniae)

(1) como escamas (Hypselistoides modestus)

(2) sobrepostos (Sphecozone nitens)

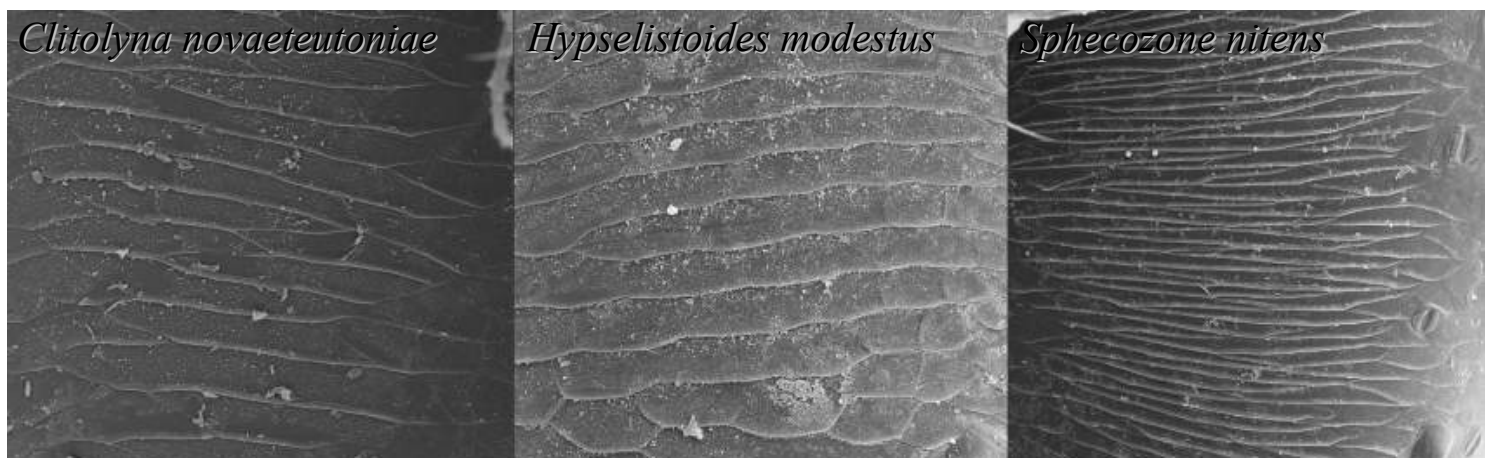

58- Fileira de estrias estridulatórias na quelícera dos machos, caráter 118 de Miller e Hormiga (2004). ( $\mathrm{L}=7 ; \mathrm{CI}=0,429 ; \mathrm{RI}=0,692)$ :

(0) ampla e igualmente espaçadas (Clitolyna novaeteutoniae)

(1) comprimidas proximalmente (Clitolyna sp.nov.02)

(2) comprimidas distalmente (Hypselistoides lobatus)

(3) comprimidas e igualmente espaçadas (Clitolyna personata)

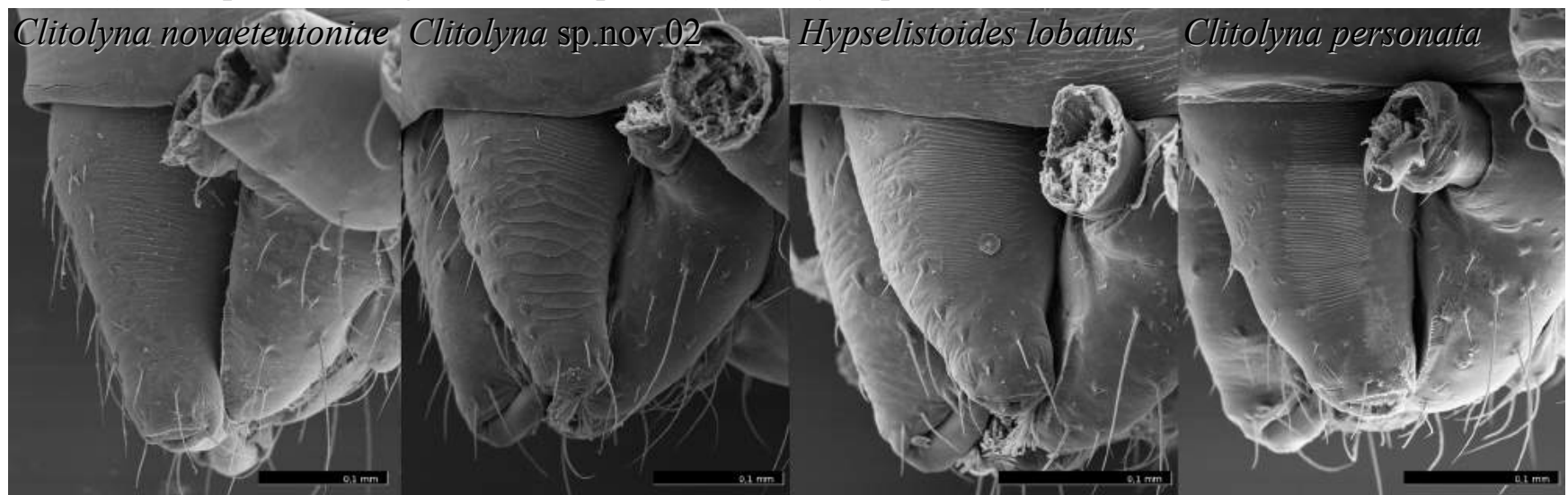


59- Veios auxiliares das estrias estridulatórias, caráter 119 de Miller e Hormiga (2004).

$(\mathrm{L}=4 ; \mathrm{CI}=0,25 ; \mathrm{RI}=0,4)$ :

(0) ausente (Clitolyna novaeteutoniae)

(1) presente (Hypselistoides modestus)
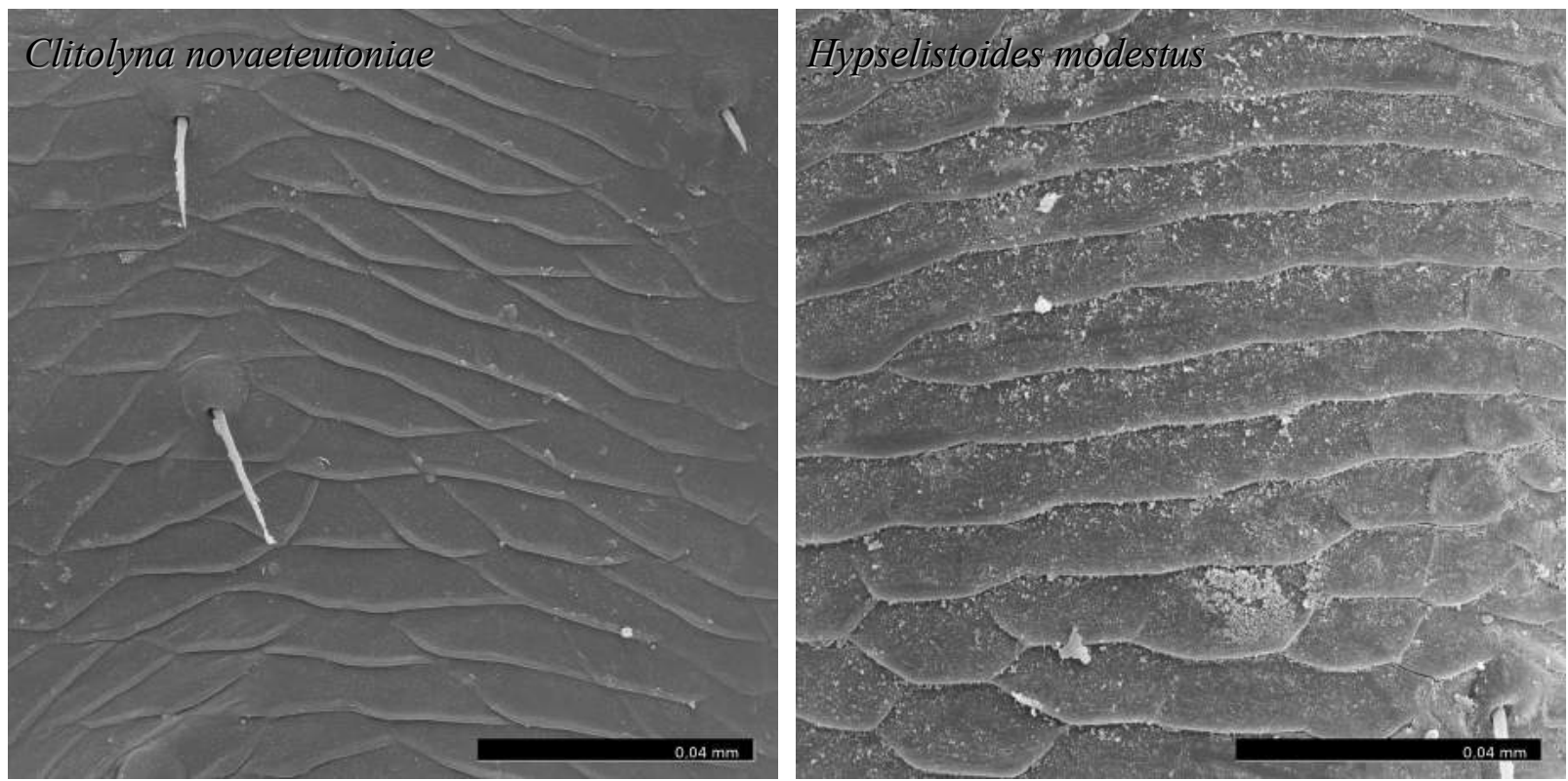

60- Dentes da margem retrolateral da quelícera da fêmea, caráter 123 de Miller e Hormiga (2004). ( $\mathrm{L}=2 ; \mathrm{CI}=0,5 ; \mathrm{RI}=0)$ :

(0) três (Tutaibo phoeniceus)

(1) quatro ou mais (Clitolyna novaeteutoniae)

61- Macroseta dorsomesal proximal do tarso do palpo da fêmea, caráter 127 de Miller e Hormiga (2004). $(\mathrm{L}=8 ; \mathrm{CI}=0,125 ; \mathrm{RI}=0,462)$ :

(0) presente (Clitolyna novaeteutoniae)

(1) ausente (Sphecozone rubescens)

62- Macroseta dorsomesal distal do tarso do palpo da fêmea, caráter 128 de Miller e Hormiga (2004). ( $\mathrm{L}=5 ; \mathrm{CI}=0,2 ; \mathrm{RI}=0,636)$ :

(0) presente (Sphecozone rubescens)

(1) ausente (Clitolyna novaeteutoniae) 
63- Macroseta dorsoectal proximal do tarso do palpo da fêmea, caráter 129 de Miller e Hormiga (2004). ( $\mathrm{L}=6 ; \mathrm{CI}=0,167 ; \mathrm{RI}=0,688)$ :

(0) presente (Sphecozone nitens)

(1) ausente (Clitolyna novaeteutoniae)

64- Macroseta dorsoectal distal do tarso do palpo da fêmea, caráter 130 de Miller e Hormiga (2004). ( $\mathrm{L}=5 ; \mathrm{CI}=0,2 ; \mathrm{RI}=0,733)$ :

(0) presente (Sphecozone rubescens)

(1) ausente (Clitolyna novaeteutoniae)

65- Macroseta ventromesal do tarso do palpo da fêmea, caráter 131 de Miller e Hormiga (2004). ( $\mathrm{L}=6 ; \mathrm{CI}=0,5 ; \mathrm{RI}=0)$ :

(0) zero

(1) dois (Hypselistoides nigripes)

(2) três (Clitolyna novaeteutoniae)

(3) quatro (Sphecozone rubescens)

(4) cinco ou seis (Hypselistoides niwinus)

66- Macroseta ventroectal do tarso do palpo da fêmea, quantidade, caráter 132 de Miller e Hormiga (2004). ( $L=7 ; \mathrm{CI}=0,429 ; \mathrm{RI}=0,429)$ :

(0) um (Gen.nov. sp.nov.01)

(1) dois (Clitolyna novaeteutoniae)

(2) três (S. spadicaria)

(3) quatro (Clitolyna sp.nov.01)

67- Macroseta dorsal proximal da tíbia I, caráter 136 de Miller e Hormiga (2004). (L=3; $\mathrm{CI}=0,333 ; \mathrm{RI}=0)$ :

(0) ausente (Clitolyna sp.nov.01)

(1) presente (Clitolyna novaeteutoniae)

68- Macroseta dorsal proximal da tíbia II, caráter 138 de Miller e Hormiga (2004). $(\mathrm{L}=2 ; \mathrm{CI}=0,5 ; \mathrm{RI}=0)$ :

(0) ausente (Hypselistoides lobatus)

(1) presente (Clitolyna novaeteutoniae) 
69- Macroseta dorsal proximal da tíbia III, caráter 140 de Miller e Hormiga (2004). $(\mathrm{L}=3 ; \mathrm{CI}=0,333 ; \mathrm{RI}=0)$ :

(0) ausente (Hypselistoides lobatus)

(1) presente (Clitolyna novaeteutoniae)

70- Macroseta dorsal proximal da tíbia IV, caráter 142 de Miller e Hormiga (2004). $(\mathrm{L}=2 ; \mathrm{CI}=0,5 ; \mathrm{RI}=0)$ :

(0) ausente (Clitolyna novaeteutoniae)

(1) presente (Hypselistoides lobatus)

71- Tricobótrio no metatarso IV, caráter 152 de Miller e Hormiga (2004). (L=6; $\mathrm{CI}=0,167 ; \mathrm{RI}=0,286)$ :

(0) ausente (Clitolyna novaeteutoniae)

(1) presente (Sphecozone rubescens)

72- Textura do pulmão nos machos, caráter 154 de Miller e Hormiga (2004). (L=8; $\mathrm{CI}=0,25 ; \mathrm{RI}=0,6)$ :

(0) rugoso

(1) sulcado (Clitolyna venialis)

(2) escamado (Hypselistoides niwinus)

(3) suave (Hypselistoides ignigenus)
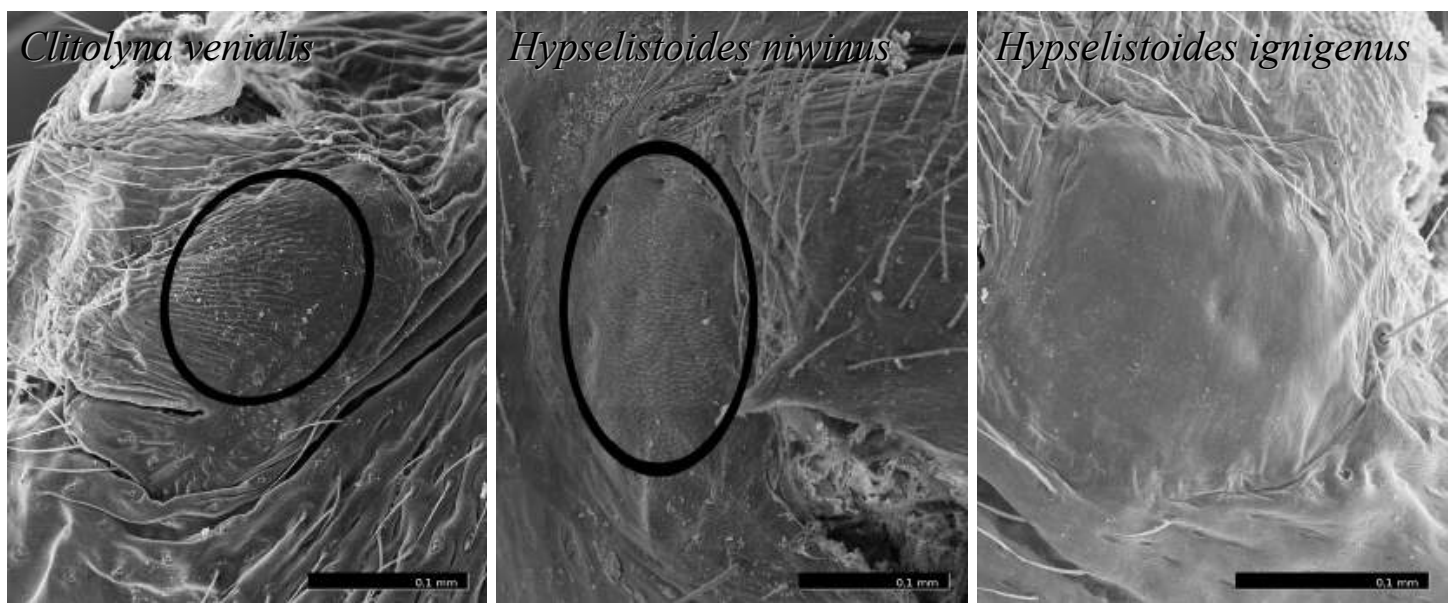
73- Fúsulos da glândula aciniforme da fiandeira médio posterior da fêmea, caráter 162 de Miller e Hormiga (2004). ( $\mathrm{L}=3 ; \mathrm{CI}=0,333 ; \mathrm{RI}=0,6)$ :

(0) ausente

(1) um (Clitolyna novaeteutoniae)

(2) dois (Hypselistoides niwinus)

(3) três

(4) quatro
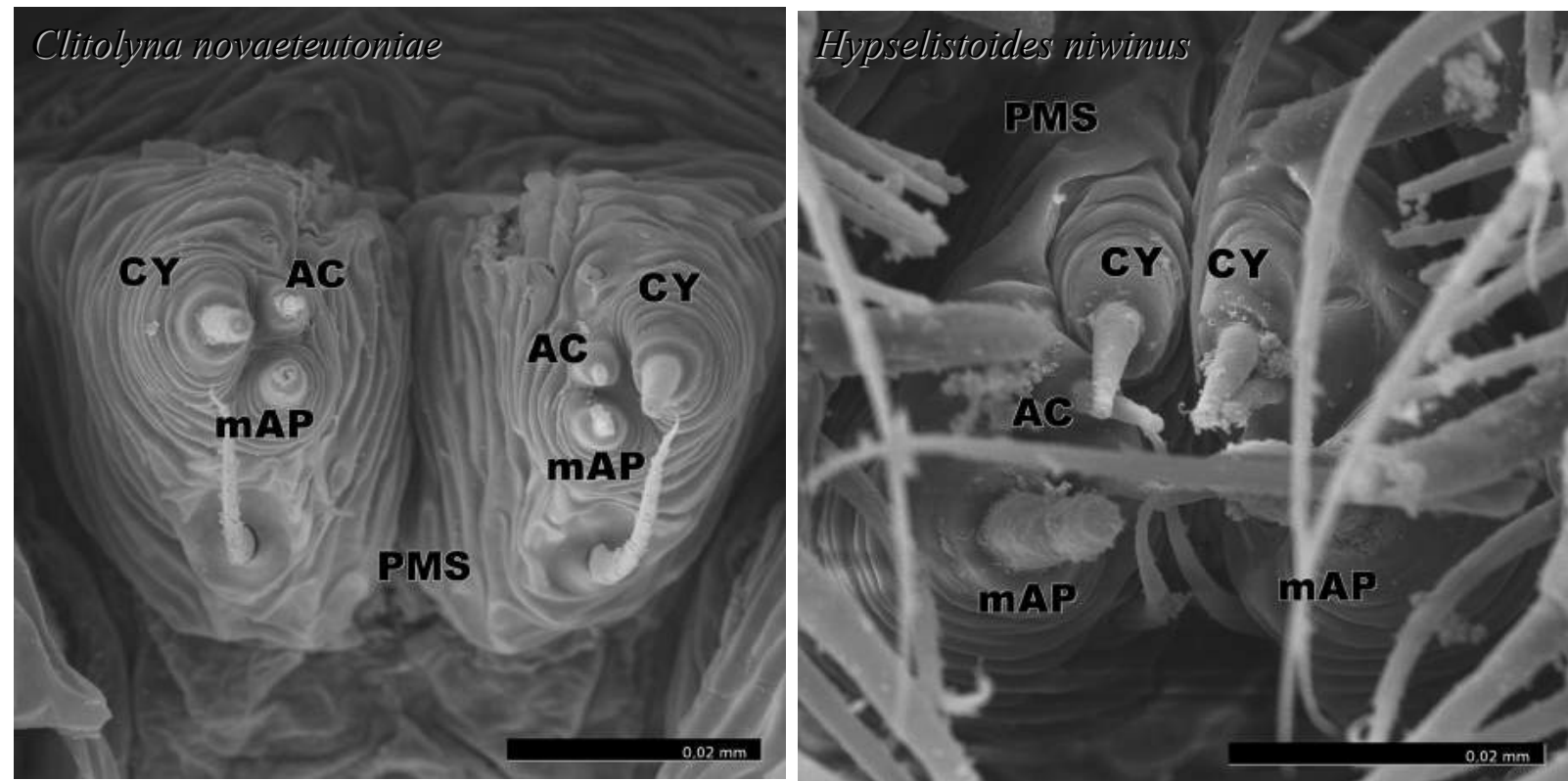

74- Fúsulos da glândula aciniforme da fiandeira lateral posterior da fêmea, caráter 165 de Miller e Hormiga (2004). ( $\mathrm{L}=7$; $\mathrm{CI}=0,143 ; \mathrm{RI}=0,5)$ :

(0) 1-5 (Clitolyna personata)

(1) 6 a mais (Clitolyna novaeteutoniae)
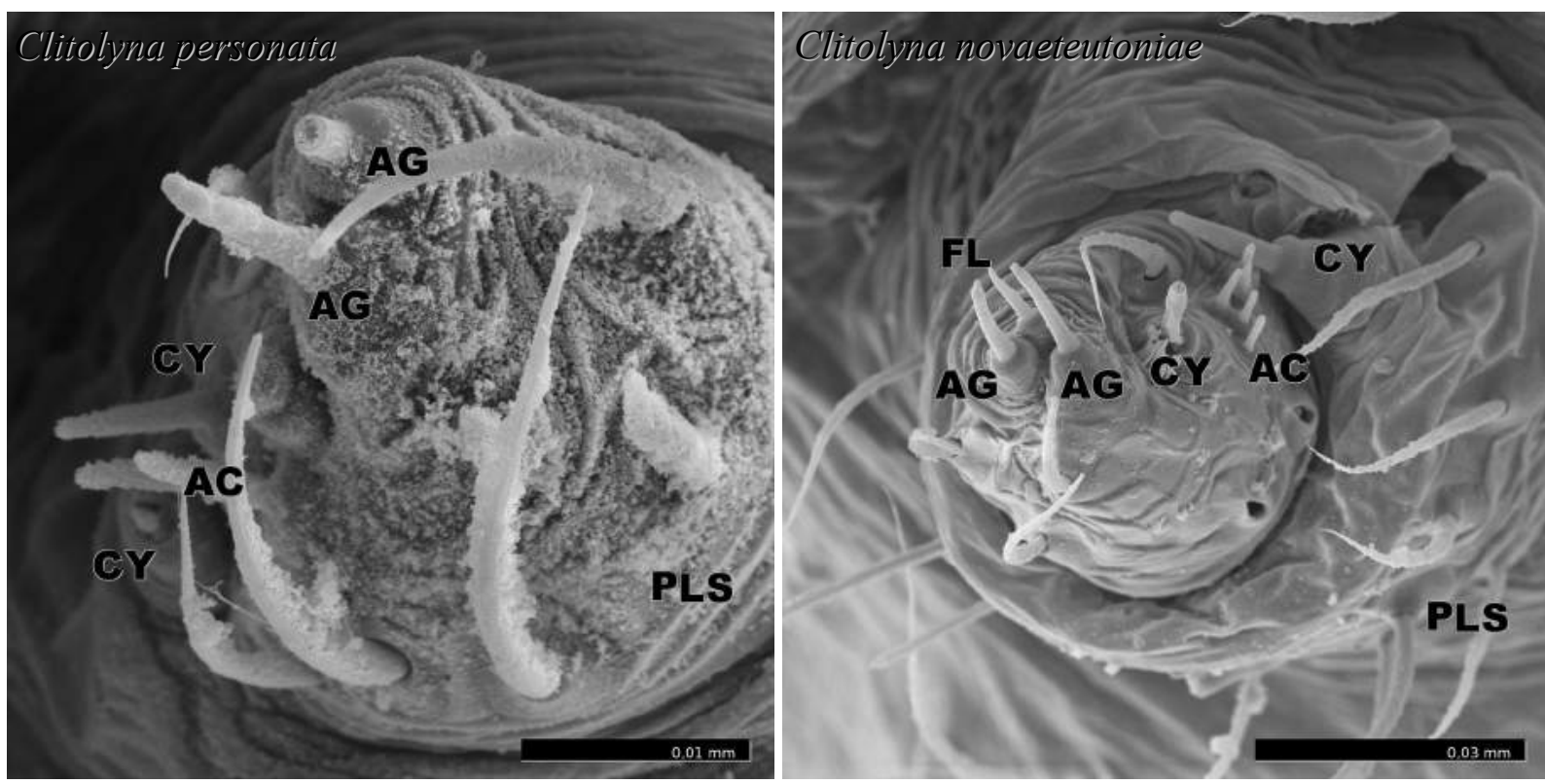
75- Trio de fúsulos das glândulas agregados-flageliforme na fiandeira lateral posterior dos machos, caráter 166 de Miller e Hormiga (2004). ( $\mathrm{L}=1 ; \mathrm{CI}=1 ; \mathrm{RI}=1)$ :

(0) ausente (Clitolyna personata)

(1) presente (Clitolyna novaeteutoniae)
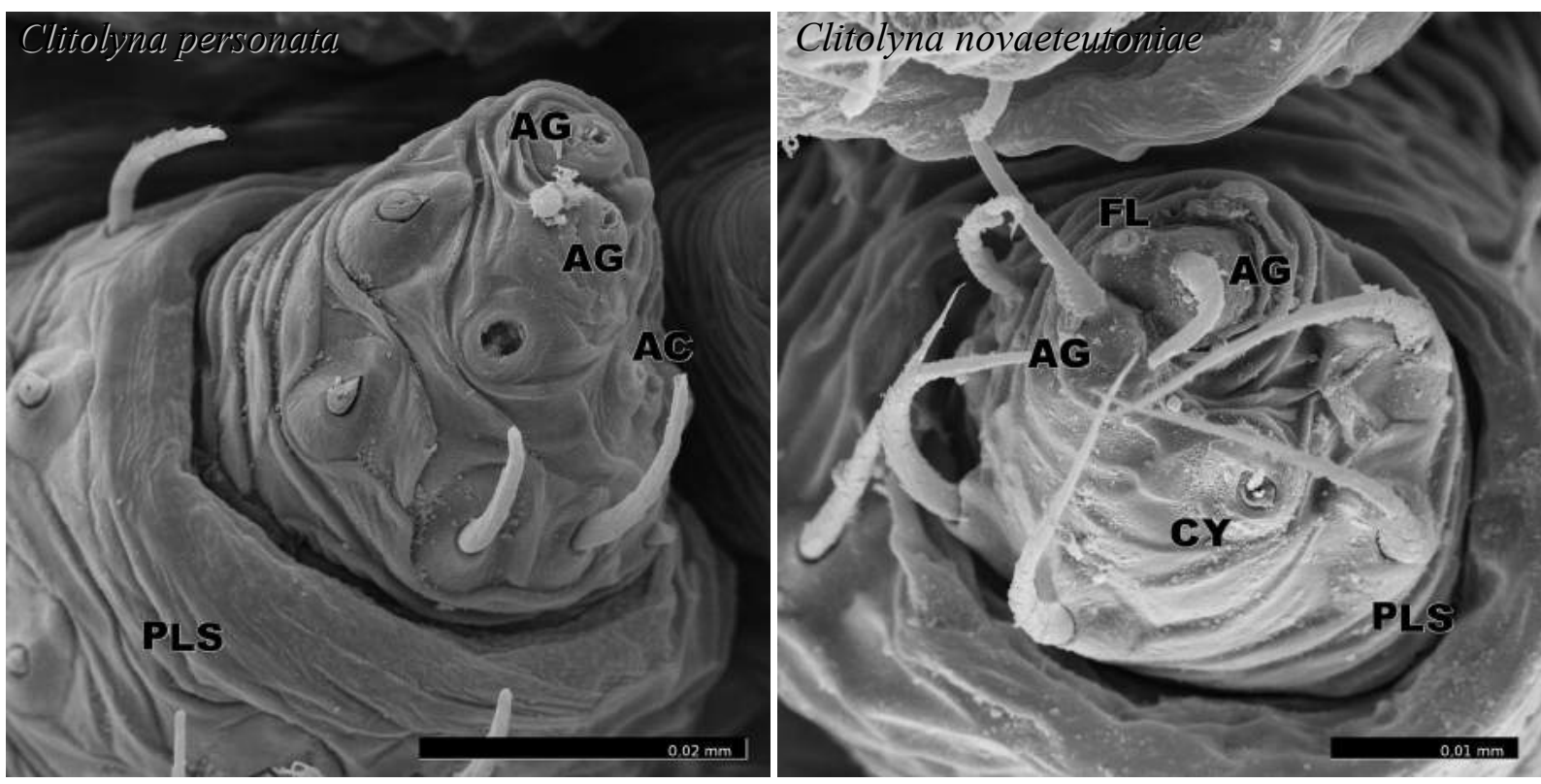

76- Fúsulo da glândula agregada da fiandeira lateral posterior da fêmea, caráter 167 de Miller e Hormiga (2004). ( $\mathrm{L}=2 ; \mathrm{CI}=0,5 ; \mathrm{RI}=0)$ :

(0) dois (Clitolyna novaeteutoniae)

(1) um (Clitolyna gravis)
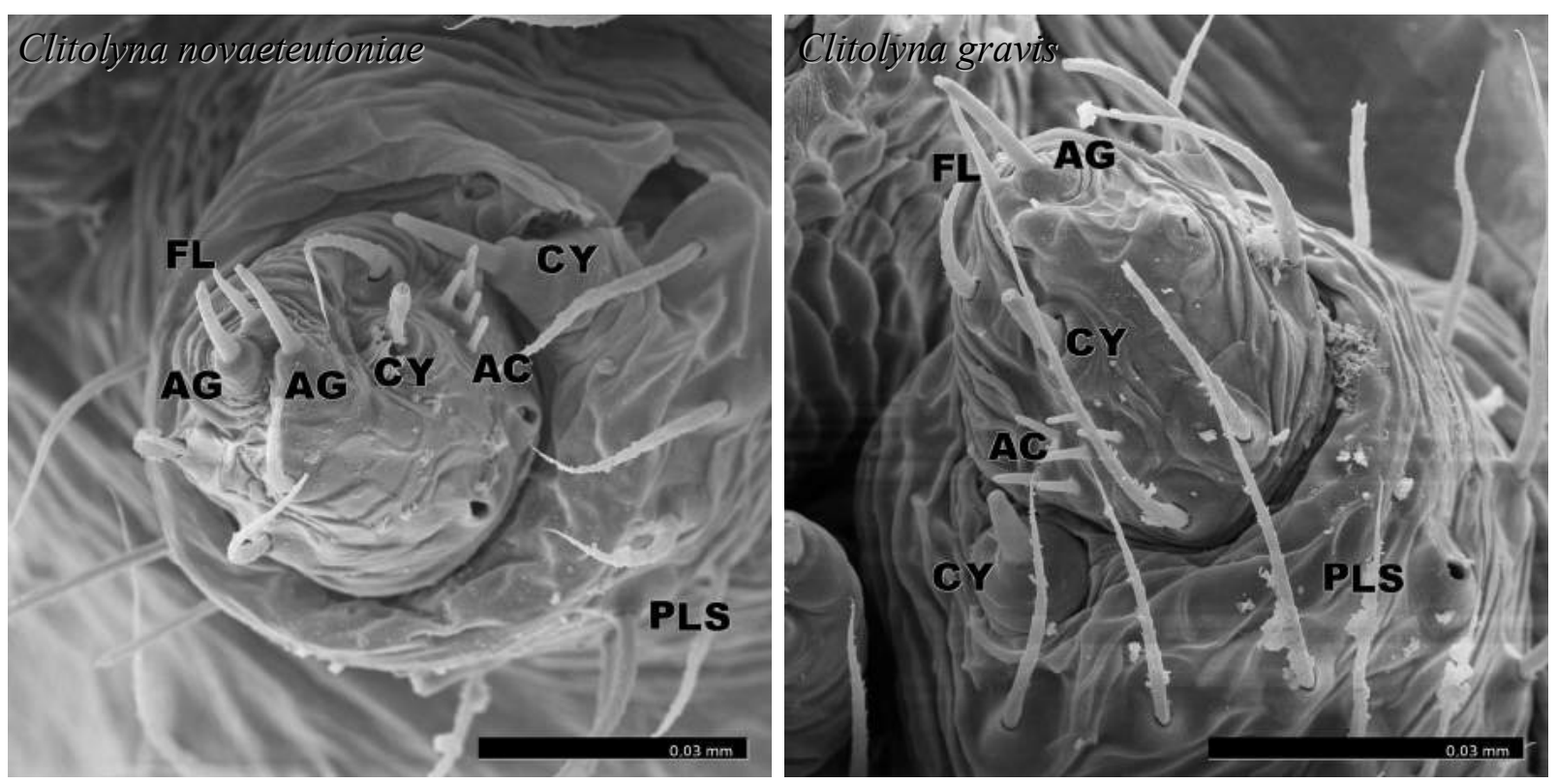
77- Fúsulo da glândula flageliforme da fiandeira lateral posterior da fêmea, caráter 168 de Miller e Hormiga (2004). ( $\mathrm{L}=2 ; \mathrm{CI}=0,5 ; \mathrm{RI}=0)$ :

(0) presente (Clitolyna novaeteutoniae)

(1) ausente

(2) com nódulo (Clitolyna personata)
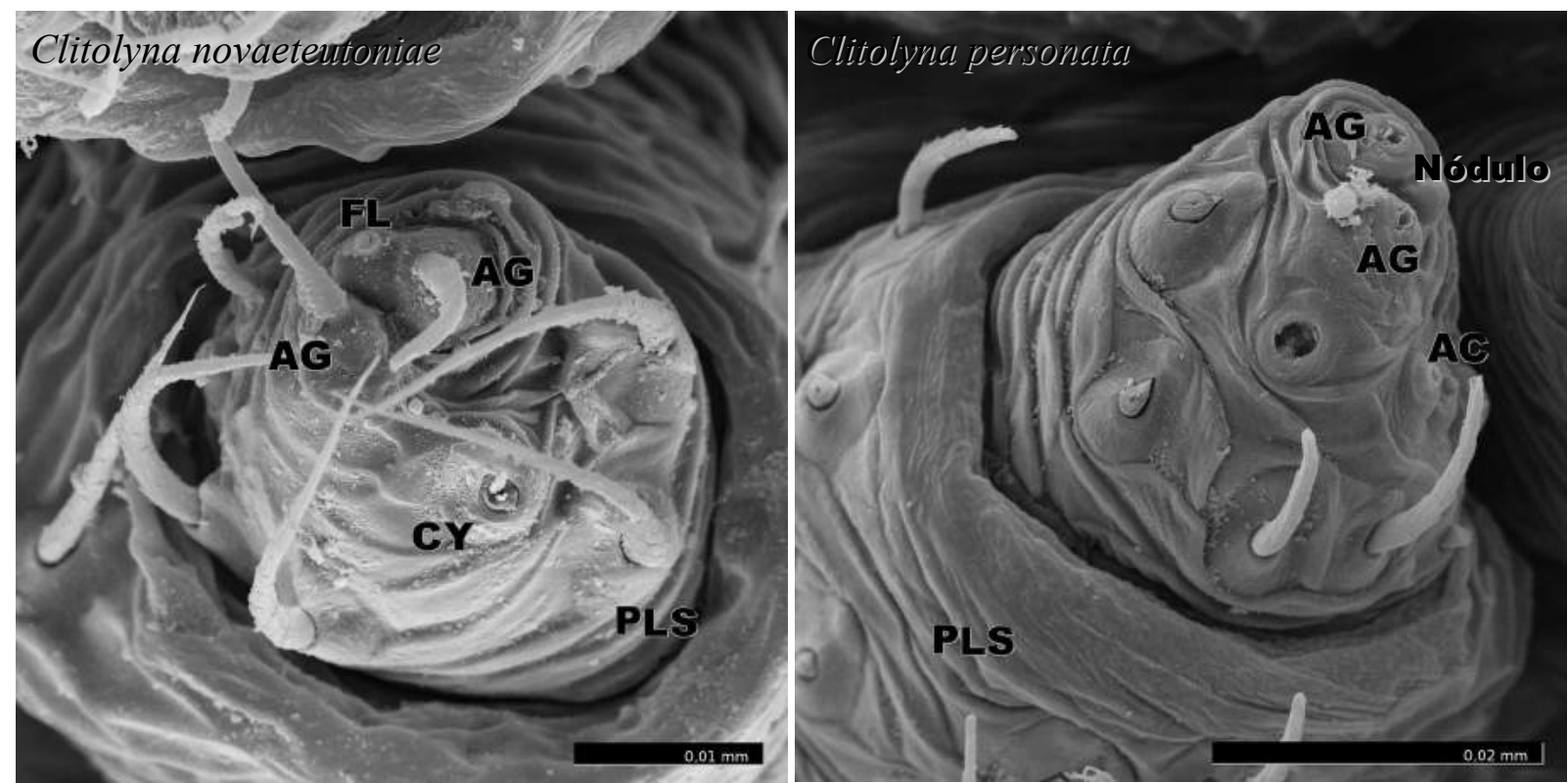


\section{Resultados}

O resultado apresentou apenas duas árvores mais parcimoniosas com 294 passos $(\mathrm{IC}=0,30 ; \mathrm{IR}=0,57)$ (Figura 1). Embora as árvores contenham muitas homoplasias $\mathrm{e}$ poucos ramos suportados por sinapomorfias exclusivas, as topologias obtidas estão bem resolvidas, o que gerou uma árvore de consenso com poucas politomias, mostrando apenas uma tricotomia em cada um dos clados 28 e 31 (Figuras 2 e 3 ).

A árvore escolhida para otimização e estudo da evolução dos caracteres está representada na figura 3. Esta topologia foi escolhida por apresentar Sphecozone nigripes, S. niwina e S. rubicunda (clado 29), espécies muito semelhantes morfologicamente (Figuras 78-95) e de distribuição muito próxima e restrita aos Andes (Mapas 2A e 3), como grupo monofilético.

A topologia apresentada mostra Psilocymbium acanthodes como grupo irmão de todos os outros táxons analisados (clado 2), o que contrasta consideravelmente da hipótese obtida por Miller \& Hormiga (2004), em que aparece como grupo irmão de Dolabritor spineus e Gonathoraphis lysistrata. Desta vez, D. spineus e G. lysistrata aparecem como grupo-irmão de Intecymbium antarcticum, formando o clado 3, sustentado pelo paracímbio fundido (caráter 9, estado 1), ponta do êmbolo com uma projeção além de sua abertura (caráter 24, estado 1), perda do processo basal do êmbolo (caráter 25, estado 0) e pela presença de 3 macrosetas ventromesais no tarso do palpo da fêmea (caráter 65, estado 2), com Bremer absoluto igual a 2 e relativo, 33. No clado 5 (Bremer absoluto 1 e relativo 20), a espécie Ceratinopsis interpres, assim como na hipótese de Miller e Hormiga (2004), continua sendo grupo irmão dos gêneros Tutaibo e Sphecozone, representados no clado 6 (Bremer absoluto 1 e relativo 20). No entanto, as relações entre esses dois gêneros tiveram mudanças.

O clado 7, sustentado por 4 sinapomorfias (Bremer absoluto 1 e relativo 20), é composto por 14 espécies sendo uma delas Moyosi prativaga, espécie-tipo do gênero Moyosi que, até então, não havia sido incluída em análises filogenéticas. Neste clado, encontra-se também a espécie Sphecozone spadicaria, antes espécie-tipo do gênero Brattia, S. crassa, espécie-tipo de Gymnocymbium, e S. fastibilis, espécie-tipo de Clitolyna, estes 3 gêneros, sinônimos júnior de Sphecozone (Figura 3). Por conta desse grupo não estar intimamente relacionado com a espécie-tipo $S$. rubescens, sugere-se a transferência 
das espécies que compõem o clado para um dos sinônimos júnior a ser revalidado. Prevalecendo a Lei da prioridade, propõe-se a revalidação do gênero Clitolyna Simon, 1984: 673, à Brattia Simon 1894: 674. O gênero revalidado passa a ter como sinapomorfias a perda do paracímbio (caráter 8 , estado1), perda da membrana embólica (caráter 21, estado 0), presença de apófise retrolateral (caráter 34, estado 1) e fileira de estrias estridulatórias na quelícera dos machos ampla e igualmente espaçadas (caráter 58, estado 0).

As relações internas de Clytolina apresenta $C$. crassa como grupo irmão de Clitolyna sp. nov. 02 (C. alticeps ((C. prativaga (C. gravis (C. spadicaria (C. castanea, $C$. novaeteutoniae $)))(((C$. fastibilis, $C$. sp. nov. 01$)(C$. tumidosa, $C$. venialis $))(C$. personata C. rostrata)))). As espécies C. spadicaria, C. castanea e C. novaeteutoniae, que pertenciam ao gênero Brattia, formam um grupo monofilético dentro de Clitolyna, sustentado pela presença da membrana embólica (caráter 21, estado 1), perda da apófise retrolateral da tíbia do palpo do macho (caráter 34, estado 0 ), região cefálica do macho não elevado (caráter 49, estado 0), estrias estridulatórias da quelícera do macho rugosas (caráter 57, estado 0) e forma do átrio do epígino da fêmea sinuoso (caráter 43, estado 1), uma sinapomorfia exclusiva do grupo. Esse grupo é, por sua vez, grupo irmão de C. gravis, antiga espécie-tipo de Gymnocymbium, que completa o clado 12, grupo irmão de $C$. prativaga, antiga espécie-tipo de Moyosi.

Outro clado importante dentro de Clitolyna apresenta a espécie-tipo do gênero, $C$. fastibilis que, junto com a espécie nova Clitolyna sp. nov. 01 e o grupo (C. tumidosa, $C$. venialis) formam o clado 17, sustentado por 3 sinapomorfias. A relação das espécies $C$. personata e C. rostrata apresentam um forte suporte, sustentado por 10 sinapomorfias, sendo duas exclusivas, e se relacionando com o clado 17.

No outro grande clado (20), as antigas espécies de Sphecozone estão separadas em 3 gêneros distintos. O clado 26, composta por 15 espécies, apresenta a espécie $S$. bicolor, antes espécie-tipo de Hypeslistoides (Figura 3), e é sustentado por 3 sinapomorfias: presença da apófise ventral do címbio (caráter 7, estado 1) e do processo basal do êmbolo (caráter 25, estado 1), e perda do paracímbio (caráter 8, estado 1). Propõe-se aqui transferir as espécies desse clado para este gênero que será, também, revalidado, corroborando a hipótese de Miller e Hormiga (2004) e Miller (2007). 
As relações interna de Hypselistoide apresentam 3 grandes grupos. Na árvore de consenso, o clado 29 representadas pelas espécies $H$. nigripes, $H$. niwinus e H. rubicundus, apresenta-se colapsada. Outra politomia dentro de Hypselistoides apresenta as espécies $H$. capitatus, H. modestus e H. lobatus $+H$. modicus. Este clado, por sua vez, é grupo irmão de $H$. cornutus(H. labiatus(H. diversicolor(H. ignigenus(H. corniculans, H. crinitus)))), um dos poucos clados a apresentar um alto valor de suporte, sustentado pelas sinapomorfias como cerdas posterior dorsal do címbio mais grossas, como espinhos (caráter 3, estado 1, sinapomorfia exclusiva), forma do protégulo alongado (caráter 13, estado 1), presença do lóbulo na cauda do radix (caráter 37 , estado 1) e dente mesal do radix (caráter 29 , estado 1 , sinapomorfia exclusiva), presença da apófise retrolateral tíbia do palpo do macho (caráter 34, estado 1), e pela espermateca envolvido pelo duto copulatório (caráter 47, estado 2).

Gen. nov. magnipalpis e as duas espécies novas formam um grupo morfologicamente distinto das espécies de Hypselistoides, principalmente por apresentar um paracímbio. Apesar do baixo suporte e as homoplasias sustentando o clado, serão transferidas para um gênero novo. Este grupo ainda precisa de mais estudos, já que o Gen. nov. magnipalpis apresenta somente o macho descrito, e os dados apresentados na matriz contém muitos caracteres desconhecidos (missing data).

De todas as espécies analisadas, apenas $S$. rubescens (espécie-tipo) e S. nitens, permaneceram como Sphecozone e, assim como na hipótese de Miller e Hormiga (2004), Tutaibo continua sendo seu grupo irmão. O suporte de Sphecozone é alto, sendo um dos poucos a apresentar um bom valor de Bremer absoluto e relativo (5/71, respectivamente), apesar das homoplasias. O gênero possui, agora, como sinapomorfias presença de apófise ventral do címbio (caráter 7 , estado 1), perda do paracímbio (caráter 8 , estado 1) e papilas no tégulo (caráter 17 , estado 0 ), cauda do radix reta (caráter 26 , estado 0 ), perda do tricobótrio prolateral da tíbia do palpo do macho (caráter 36, estado 0), forma do epígino fortemente ovalado (caráter 46, estado 1), e presença do tricobótrio no metatarso IV (caráter 71, estado 1). 


\section{Discussão}

O resultado apresentado possibilita escolher dentre 3 hipóteses quanto à nova relação do gênero Sphecozone. A primeira seria a revalidação dos gêneros Clitolyna para o clado 15, Brattia para o clado 11 e Hypselistoides para o clado 26. Essa opção corrobora alguns argumentos levantados por Miller (2007) como, por exemplo, a afirmação de que a antiga espécie-tipo de Gymnocymbium, C. gravis, poderia não ser congenérica à outra espécie de Gymnocymbium. Nos resultados, pode-se observar que C. crassa não está intimamente relacionado à $C$. gravis. Outro ponto levantado seria a proposta de uma relação entre as espécies $C$. fastibilis e $C$. personata, e que também teriam a posição dentro de Sphecozone contestada (Miller, 2007). O clado 15 mantêm as duas espécies dentro do mesmo gênero, e não as relacionam à Sphecozone.

O problema dessa interpretação, no entanto, seria a quantidade de gêneros novos monotípicos a serem validados, no caso as espécies Clitolyna crassa, Clitolyna sp. nov. 02 e Clitolyna alticeps. Além disso, mesmo que os gêneros criados nesta hipótese formem grupos mais exclusivos, ainda existe o problema das grandes variações morfológicas presentes, principalmente nos palpos dos machos, o que é um dos pontos mais discutidos por Miller e Hormiga (2004) e Miller (2007). Por exemplo, há uma grande diferença nos palpos de C. fastibilis (Anexo E, Figs. 114, 117, 118) e C. venialis (Anexo E, Figs. 164, 167, 168). Também pode-se observar grandes diferenças no epígino das fêmeas de $C$. spadicaria (Anexo E, Figs. 153, 154) e C. gravis (Anexo E, Figs. 124-126).

A segunda hipótese seria a transferência de todas as espécies, incluindo Tutaibo phoeniceus e Gen. nov. para Sphecozone. Essa proposta também parece não ser ideal, primeiro pelas diferenças taxonômicas, as espécies desses dois gêneros possuem epíginos das fêmeas e palpos dos machos bem distintos, e o que mais chama atenção é a presença do paracímbio em Tutaibo e Gen. nov., ausente em Sphecozone. Como já comentado, Miller e Hormiga (2004) e Miller (2007) dão grande importância para essas diferenças das estruturas sexuais, que os levaram a questionar a monofilia de Sphecozone. Além disso, Wunderlich (1987) já havia proposto incluir, porém neste caso o gênero Ceratinopsis, em Sphecozone (tal como Tutaibo e o Gen. nov., os machos de Ceratinopsis também possui palpos com paracímbio). Essa proposta foi rejeitada por Millidge (1991), justamente devido às diferenças morfológicas da genitália. Outro ponto negativo para esta proposta é 
porque o gênero Tutaibo possui mais 9 espécies que ficaram fora da análise, incluindo a sua espécie-tipo T. debilipes Chamberlin, 1916, ou seja, sugerir uma transferência de gênero baseada numa filogenia que apresenta somente uma espécie representativa do gênero, esta não sendo sequer a espécie-tipo, talvez não seja a melhor opção.

Ainda que as diferenças morfológicas das genitálias ainda sejam evidentes, a terceira hipótese, que foi a escolhida, é uma opção que permite separar de Sphecozone as espécies ditas como atípicas por Miller (2007), revalidando o gênero Clitolyna (clado 7) e Hypselistoides (clado 28), corroborando todas as opções de agrupamento proposto por Miller e Hormiga (2004) e Miller (2007), e também permite que apenas um gênero novo (Gen. nov.) seja proposto, além de manter Tutaibo como um gênero válido e grupo irmão de Sphecozone. 


\section{Conclusão}

- O resultado das análises não recuperaram Sphecozone como um grupo monofilético, corroborando as hipóteses apresentadas por Miller e Hormiga (2004) e Miller (2007);

- Foram revalidados os gênero Hypselistoides Tullgren, 1901 e Clitolyna Simon, 1894;

- Um gênero novo será proposto para acomodar as espécies Gen. nov. magnipalpis (Millidge, 1993), Gen. nov. sp. nov. 01 e Gen. nov. sp. nov. 02. 


\title{
Resultados taxonômicos
}

\author{
FAMÍLIA LINYPHIIDAE Blackwall, 1859 \\ Subfamília Erigoninae Emerton, 1882 \\ Gênero Sphecozone O. Pickard-Cambridge, 1871
}

(Figs. 04-17, Mapa 1)

Sphecozone O. Pickard-Cambridge, 1870: 733. Millidge, 1985: 66-68. Millidge, 1991:

165-166. Miller, 2007: 185. Espécie tipo Sphecozone rubescens O. Pickard-Cambridge, 1870.

Espécie-tipo: Sphecozone rubescens O. Pickard-Cambridge, 1871

Diagnose: O gênero é diagnosticado pelos seguintes conjuntos de caracteres: Presença de uma apófise ventral do címbio, perda de paracímbio e papilas no tégulo, forma reta da cauda do radix, perda do tricobótrio prolateral da tíbia do palpo do macho, epígino fortemente ovalado, e presença de tricobótrio no metatarso IV.

Descrição: Machos com comprimento total de 2,05-2,53 . Carapaça 1,01-1,11 de comprimento, 0,70-0,79 de largura, alaranjada com a região cefálica escura e elevada. Esterno 0,57-0,64 de comprimento, 0,49-0,51 de largura, alaranjado. Clípeo 0,22-0,25 de altura. Quelícera com 5-6 dentes promarginais e 4 retromarginais. Abdômen branco com manchas escuras próximas às fiandeiras. Pernas amareladas, podendo ser mais escuras na região distal dos artículos. Distância entre coxa IV 0,92 vezes sua largura. TmI 0,33. TmIV presente.

Fêmeas com comprimento total de 2,10-3,29. Carapaça 0,89-1,33 de comprimento, 0,620,86 de largura. Esterno 0,63-0,70 de comprimento, 0,58 de largura. Clípeo 0,25 de altura. Quelícera com 5-6 dentes promarginais e 5 retromarginais. Padrões do abdômen, esterno, carapaça e pernas como no macho, mas com a região cefálica não elevada na fêmea. Distância entre coxa IV 1,09 vezes sua largura. TmI 0,28-0,31.

Espécies: Sphecozone rubescens O. Pickard-Cambridge, 1870, Sphecozone nitens 
Millidge, 1991, Sphecozone araeonciformis (Simon, 1895) (insertae sedis), S. longipes (Strand, 1908) (insertae sedis) e S. melanocephala (Millidge, 1991) (insertae sedis).

Nota: Duas espécies não puderam ser localizadas até o final desta tese. São os casos de Sphecozone araeonciformis (Simon, 1895) e S. longipes (Strand, 1908) depositados no Muséum National d'Histoire Naturelle, Paris, França (MNHN), Naturhistoriska riksmuseet, Estocolmo, Suécia (NHRS) e Museum Wiesbaden, Department of Natural Science, Wiesbaden, Alemanha (MWNH). As descrições antigas contêm poucas informações que possa ajudar a levantar caracteres para a matriz de dados utilizadas na análise filogenética, ou até mesmo suficientes para uma revisão taxonômica. Ao contrário de S. longipes, cuja descrição original, que carece de ilustrações, é única presente na literatura, $S$. areonciformis apresenta uma revisão mais recente, elaborada por Millidge (1991). Porém as ilustrações pouco ajudam a apontar caracteres relevantes. A fêmea de S. areonciformis foi descrita como Ceratinopsis lineata Tullgren, 1901 e posteriormente tranferida para Ceratinopsis areonciformis por Roewer (1942) e Bonnet (1956). Pelas descrições de Tullgren, a fêmea lembra Hypselistoides bicolor (Nicolet, 1849) comb. nov., pela coloração escura e tamanho do corpo, e pela localização do espécime, na Patagônia, Chile. Porém, a ilustração sugere que o epígino apresenta um processo anterior da placa ventral, e mostra uma margem entre a placa ventral e o lóbulo anterior da placa dorsal em forma de "M", o que difere do epígino de H. bicolor e grupos relacionados. O macho, com ilustração elaborado por Millidge (1991), aparenta ser diferente das espécies revisadas nesta tese, se assemelhando mais aos palpos de Psylocymbium.

Já a espécie $S$. melanocephala, foi analisada e fotografada (fig. 04-05) porém seu epígino se mostrou atípico comparadas às espécies examinadas neste trabalho (fig.05). Originalmente descrita para Brattia, seu epígino não apresenta membrana interna, como as demais fêmeas que compunham o gênero, além de não apresentar uma placa dorsal, comum em todas as espécies revisadas neste trabalho. O macho também não é conhecido, e por ter mais de $60 \%$ dos caracteres não conhecidos, essas espécies não foi incluída na análise cladística, impossibilitando saber sua posição.

Até que essas espécies sejam localizadas, ou até que novos espécimes sejam encontrados, S. areonciformis, S. longipes e $S$. melanocephala serão consideradas aqui como insertae sedis. 
Distribuição: Argentina, Bolívia, Brasil, Colômbia, Equador, Paraguai e Peru (Mapa 1)

Sphecozone rubescens O. Pickard-Cambridge, 1870

Figs. 6-11, Mapa 1

Sphecozone rubescens O. Pickard-Cambridge, 1870: 733, pl. 44, fig. 2 (macho e duas

fêmeas síntipos de Santa Fé, Minas Gerais, Brasil, depositado no HEC [Hope Entomological Collections, Oxford, Reino Unido], não examinado). Simon, 1894: 673.

Petrunkevitch, 1911: 270; 1928: 132. Roewer, 1942: 710. Bonnet, 1958: 4118. van Helsdingen, 1979: 410, figs 8-11.

Erigone nigrianus Keyserling, 1886: 222, pl. 19, fig. 279 (macho e fêmea do Rio de Janeiro, Brasil, não examinado).

Erigone vegeta Keyserling, 1891: 241-242, fig. 184 (fêmea holótipo do Rio Grande do Sul, Brasil, depositado no BMNH [Natural History Museum, Londres, Reino Unido], não examinado).

Ceratinopsis nigriana. Simon, 1894: 645. Bonnet, 1956: 1020. Roewer, 1942: 706.

Ceratinopsis nigrianus. Simon, 1897a: 2. Petrunkevitch, 1911: 225. Mello-Leitão, 1919: 469.

Sphecozone rubescens. Millidge, 1985: 68, figs 260-264.

Sphecozone rubescens. Millidge 1991: 171-172, figs 726-728.

Sphecozone rubescens. Miller, 2007: 187, f. 142E, 144A-B, E-F, H, 145, 155A-F, 156AE, $157 \mathrm{~A}-\mathrm{E}$.

Diagnose: Machos de S. rubescens lembram os de $S$. nitens pela forma da apófise prolateral da tíbia ampla e direcionada distalmente. Diferenciam-se de $S$. nitens pelo tamanho da tíbia em relação ao címbio, ligeiramente menor em S. nitens (Figs. 7, 10, 11, 13, 16, 17). Fêmeas de $S$. rubescens lembram as de $S$. nitens, pela forma quadrada do epígino e pela espermateca alongada, posicionada lateralmente aos dutos copulatórios. Distinguem-se de $S$. nitens pela forma mais quadrada da placa dorsal e pela forma da espermateca, ligeiramente mais longa em $S$. nitens (Figs. 9-11, 15-17).

Descrição: Macho (da Barra da Tijuca, Guanabara, Brasil) e fêmea (da Serra dos Órgãos, 
Rio de Janeiro, Brasil) com descrição e ilustrações em Miller, 2007. Imagens adicionais: Fig. 6-11.

Variação: Machos ( $\mathrm{n}=10)$ : Comprimento total 2,63-2,92 (média 2,71); comprimento da carapaça 1,02-1,11 (média 1,05); largura da carapaça 0,70-0,79 (média 0,74); comprimento do fêmur I 1,09-1,31 (média 1,21).

Fêmeas $(n=10)$ : Comprimento total 2,54-3,29 (média 2,96); comprimento da carapaça 1,13-1,33 (média 1,21); largura da carapaça 0,73-0,86 (média 0,81); comprimento do fêmur I 1,20-1,53 (média 1,31).

Distribuição: Argentina, Brasil, Colômbia e Equador. (Mapa 1)

Material examinado: COLÔMBIA. META: Puerto Lleras, Lomalinda, $\left(3^{\circ} 18^{\prime} \mathrm{N}\right.$; 732'ㄴ), ii.1989, V. \& B. Roth col., (CAS 9076626, 19). EQUADOR. CHIMBORAZO: 30mi SW of Alausi, ( $\left.2^{\circ} 13^{\prime} \mathrm{S} ; 7^{\circ} 50^{\prime} \mathrm{W}\right), 14.1 i .1955$, E. I. Schiingler \& E. S. Ross col., (CAS 9076627, 19). BRASIL. PARAÍBA: Indepencia (Amparo?), (7³6’'S; 370’ W), $1911 \mathrm{~W}$.

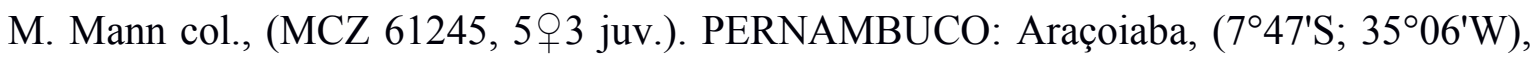
2009A. Costa col., (IBSP 168074-168077, 168079-168084, 168086-168129, 21ðึ40). GOIAS: Goiania, (16²41'S; 49¹5'W), 12.vii.1957, B. Malkin col., (CAS 9076632, 1q).

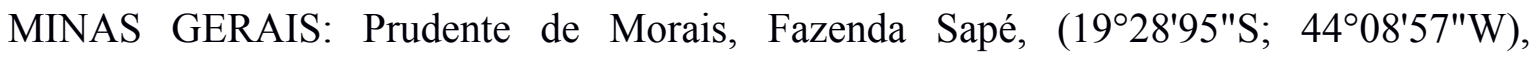

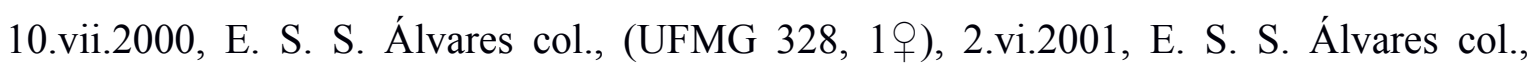
(UFMG 5482, 2ㅇ). Belo Horizonte, Campus da UFMG, (1952'S; 435' W), 22.ii.2000, E.

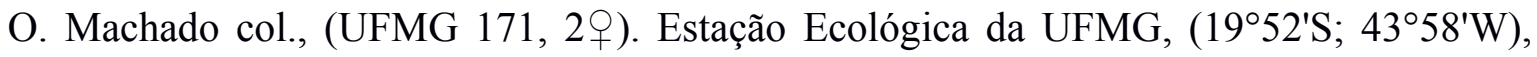
10-23.i.2001, E. S. S. Álvares \& E. O. Machado col., (UFMG 66, 39 ), v.1999, E. S. S. Álvares col., (UFMG 67, 4q), iii-vii.2000, E. S. S. Álvares col., (UFMG 1133, 1ठ1 ), 17-21.iii.2000, E. S. S. Álvares col., (UFMG 71, 2ð). Itabirito, Sítio Recanto das Rosas, (2014'S; 4347'W), i.2004, E. O. Machado col., (UFMG 1862, 2ð19). Juiz de Fora, Reserva Biológica Municipal Poço D'Anta, (2145'37.8"S; 43¹9'10.2"W), 2-3.iv.2011, G. H. F. Azevedo \& A. J. Santos col., (UFMG 5321, 4). RIO DE JANEIRO: Rio de Janeiro,

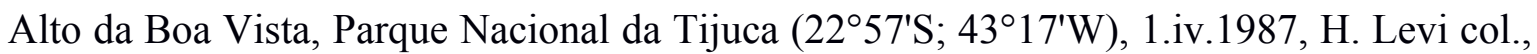

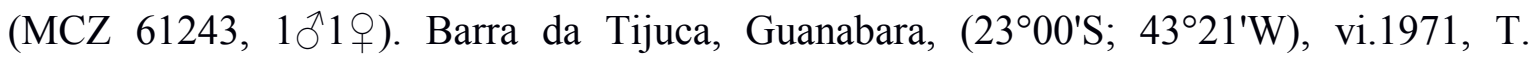
McGrath col., (MCZ 61531, 2ð5ㅇ), 16.iv.1965, H. Levi col., (MCZ 61244, 1ठึ). RIO 
GRANDE DO SUL: Marau, $\left(28^{\circ} 27^{\prime} \mathrm{S} ; 5^{\circ} 15^{\prime} \mathrm{W}\right), 30.1 i i .1991$, F. A. Rodogheri col., (MCTP 965, 19). Canela, (29²1'S; 5049'W), 6.vi.1966, A. A. Lise col., (MCZ 61254, 19). São Francisco de Assis, (29²7'S; 5501'W)11-12.v.2013, Equipe Sisbiota col., (MCN 49463, 49630, 49648, $3{ }^{\Uparrow} 2{ }^{2} 1$ juv.). Tainhas, (29²4'S; 50¹9'W), 31.vii.2003, E. L. C. Silva col., (MCTP 19821, 1ㅇ). Xangri-lá, Praia do Remanso, (2949'S; 5003'W), 10-11.x.1992, D. Rossa col., (MCTP 2913, 1ठ). Glorinha, (2952’S; 5048’W), 24.x.1998, A. C. K. Ferreira col., (MCTP 10354, 1 q 1 juv.). Osório, (2952'S; 50¹5'W), 11.xi.1990, C. N. Nunes col., (MCTP 422, 1ठ). Mariluz, (2955'S; 5006'W), 7.ix.1991, R. O. Júnior col., (MCTP 4323,

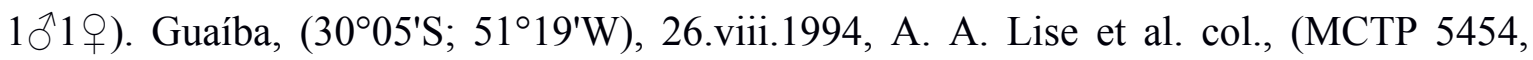
1 + ), 02.i.1995, A. A. Lise et al. col., (MCTP 8499, 1ðึ1 ), 17.iii.1995, A. A. Lise et al.

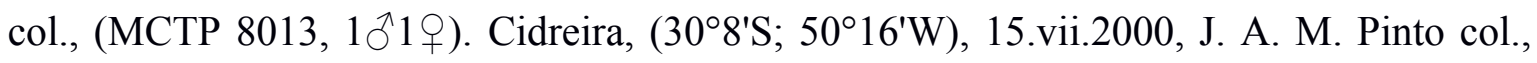
(MCTP 37523, 1). Viamão, (30²0’S; 5101'W), 22.xi.1995, A. A. Lise et al. col.,

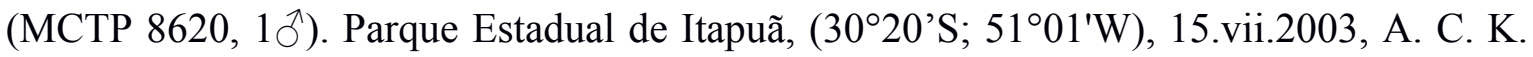
Ferreira col., (MCTP 17919, 1§), 29.vii.2003, A. C. K. Ferreira col., (MCTP 17917, 1ठ), 28.viii.2003, A. C. K. Ferreira col., (MCTP 17911, 17921, 17926, 3ð), 22.ix.2003, A. C. K. Ferreira col., (MCTP 17912, 17918, 17922, 17925, 3 3q), 21.x.2003, A. C. K. Ferreira col., (MCTP 17920, 1ठ), 22.x.2003, A. C. K. Ferreira col., (MCTP 17923, 2§), 18.xi.2003, A. C. K. Ferreira col., (MCTP 17927, 17929, 5ð1우), 17.xii.2003, A. C. K. Ferreira col., (MCTP 17913, 17924, 29), 10.ii.2004, A. C. K. Ferreira col., (MCTP 17914, 19), 9.iii.2004, A. C. K. Ferreira col., (MCTP 17930, 1§), 30.iv.2004, A. C. K. Ferreira

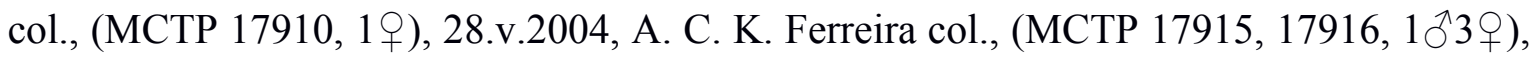
12.vi.2004, A. C. K. Ferreira col., (MCTP 17928, 1§ึ). Caçapava do Sul, (30³0'S;

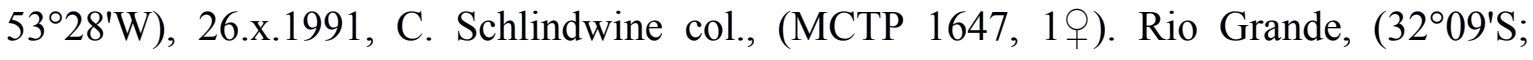
$52^{\circ} 16^{\prime} \mathrm{W}$ ), vi.2005, F. A. P. dos Santos col., (MCTP 21867, 1q). ARGENTINA. TUCUMÁN: San Pedro de Colalao, 4 km south-west of San Pedro de Colalao, $\left(26^{\circ} 14^{\prime} \mathrm{S}\right.$; 65³0'W), 16.xii.1971, L. Herman col., (AMNH , 1ㅇ).

\section{Sphecozone nitens Millidge, 1991}

Figs. 12-17, Mapa 1

Sphecozone nitens Millidge, 1991: 167, f. 708 (fêmea holótipo de Abra Asirrodiro, Oxapampa, Pasco, Peru, depositado no MUSM, não examinado). 
Sphecozone nitens. Miller, 2007: 189, f. 142F, 144C-D, G.

Material tipo examinado: PERU. PASCO: Oxapampa, Abra Asirrodiro, (10³4'S; 75²3'W), 21.vi.1986, D. Silva col., (MUSM 507411, 19, parátipo).

Diagnose: Ver diagnose em $S$. rubescens.

Descrição: Macho (de Estancia Naranjal, San Ramon, Junin, Peru) e fêmea (Yantzaza, Zamora Chinchipe, Ecuador) com descrições e ilustrações em Miller, 2007, pp. 189-190, f. 142F, 144C-D, G. Imagens adicionais: Fig. 12-17.

Variação: Fêmeas ( $\mathrm{n}=9$ ): Comprimento total 2,10-2,79 (média 2,41); comprimento da carapaça 0,89-1,05 (média 0,97); largura da carapaça 0,62-0,78 (média 0,72); comprimento do fêmur I 1,05-1,17 (média 1,12).

Distribuição: Bolívia, Brasil, Equador e Peru (Mapa 1).

Material examinado: EQUADOR. NAPO: Oriente, Misuagualli (Misahuallí), ( $1^{\circ} 02^{\prime} \mathrm{S}$;

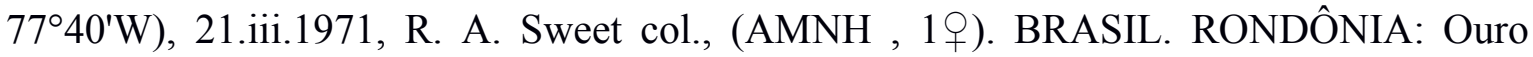
Preto do Oeste, Campo Experimental da Embrapa, (10 $\left.{ }^{\circ} 43^{\prime} \mathrm{S} ; 6^{\circ} 15^{\prime} \mathrm{W}\right)$, viii.2008-ix.2008, L. S. P. Trigueiro, C. A. D. Teixeira, L. A. P. Sallet, K. S. Serra col., (IBSP 124653, 124654, 29). PERU. HUÁNUCO: Tingo Maria, (9¹9'S; $\left.76^{\circ} 01^{\prime} \mathrm{W}\right)$, 18.xii.1954, E. I. Schiingler \& E. S. Ross col., (CAS 9076638, 19). Yuyapichis, Rio Yuyapichis, (09² 37' S; $74^{\circ} 56^{\prime}$ W), 29.i-26.ix.1983, M. Verhaagh col., (IBSP 23870, 1ð̋). JUNÍN: San Ramón,

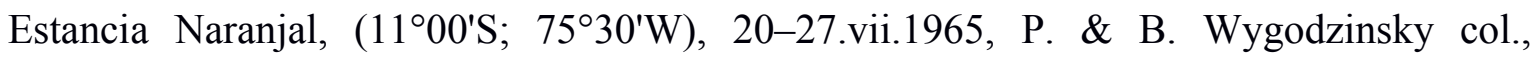

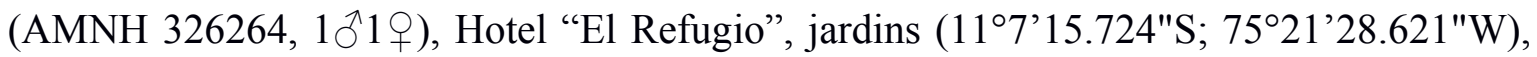
26.vi.1986, D. Silva col., (MUSM 508648, 4). MADRE DE DIOS: Zona Reservada

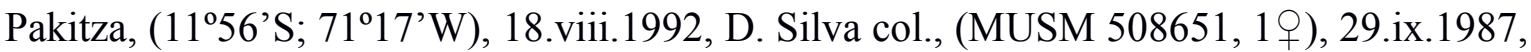

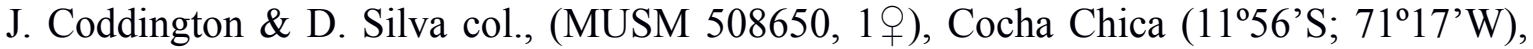
18.viii.1992, D. Silva col., (MUSM 508649, 29). BOLIVIA. LA PAZ: lower end Inca Trail from La Cumbre to Chairo, (nr. La Paz), (16²28'10.5"S; 6804'W), 22.ix.1988, V. D. \& B. Roth col., (CAS 9076620, 1ठ゙). 


\section{Hypselistoides Tullgren, 1901 Revalidado \\ Figs. 18-98, Mapa 2-6}

Hypselistoides Tullgren, 1901: 202. Millidge, 1985: 66. Espécie tipo e designação original Hypselistoides affinis Tullgren, 1901.

Espécie-tipo: Hypselistoides bicolor (Nicolet, 1849).

Diagnose: O gênero é diagnosticado pelos seguintes conjuntos de caracteres: presença de apófise ventral do címbio e perda do paracímbio.

Descrição: Macho com comprimento total de 1,47-2,64. Carapaça 0,66-1,12 de comprimento, 0,55-0,86 de largura, alaranjada, com a região cefálica escura. Esterno 0,331,16 de comprimento, 0,40-0,89 de largura, alaranjado. Clípeo 0,14-0,36 de altura. Quelícera com 5-6 dentes promarginais e 4-5 retromarginais. Abdômen branco à cinza escuro ou cinza escuro para preto. Pernas de coloração marrom escura ou amareladas. TmI 0,23-0,47. TmIV presente ou ausente. Címbio do palpo com cavidade basal. Tégulo apresenta um protégulo e papilas, o supratégulo apresenta uma apófise distal. Êmbolo longo, em espiral. Membrana embólica está presente, radix apresenta processo anterior robusto. Tíbia com apófise prolateral, dente distal presente. Tíbia com um tricobótrio prolateral e um retrolateral.

Fêmea com comprimento total de 1,19-2,79. Carapaça 0,55-1,13 de comprimento, 0,500,92 de largura, alaranjada. Esterno 0,33-1,22 de comprimento, 0,35-0,95 de largura, alaranjado. Clípeo 0,08-0,27 de altura. Quelícera com 6 dentes promarginais e 5 retromarginais. Abdômen branco, com ou sem manchas escuras na porção posterior. Pernas de coloração marrom escura alaranjadas a amareladas. TmI 0,28-0,58. TmIV ausente. Palpo apresenta de uma a nenhuma macroseta dorsomesal, uma a nenhuma macroseta dorsoectal, uma a três macrosetas ventromesais e uma a três ventroectais. Epígino proeminente. Placa ventral inteira ou com cavidades ou invaginações laterias. Átrios curvados. Dutos de fertilização orientados mesalmente. Dutos copulatório não encapsulado, espermateca arredondada ou ovalada.

Espécies: Hypselistoides altehabitans (Nicolet, 1849), H. bicolor (Nicolet, 1849) comb. 
nov., H. capitatus (Millidge, 1991) comb. nov., H. corniculans (Millidge, 1991) comb. nov., H. cornutus (Millidge, 1991) comb. nov., H. crinitus (Millidge, 1991) comb. nov., H. diversicolor (Keyserling, 1886) comb. nov., H. ignigenus (Keyserling, 1886) comb. nov., H. labiatus (Keyserling, 1886) comb. nov., H. lobatus (Millidge, 1991) comb. nov., H. modestus (Nicolet, 1849) comb. nov., H. modicus (Millidge, 1991) comb. nov., $H$. nigripes (Millidge, 1991) comb. nov., H. niwinus (Chamberlin, 1916) comb. nov., $H$. rubicundus (Keyserling, 1886) comb. nov., Hypselistoides sp.nov.01.

Distribuição: Argentina, Bolívia, Brasil, Colômbia, Chile, Equador, Peru e Uruguai. (Mapa 2-6)

\section{Hypselistoides bicolor (Nicolet, 1849) comb. nov.}

Figs. 21-25, Mapa 2

Linyphia bicolor Nicolet, 1849: 524, pl. 5, fig.12 (dois síntipos machos, 13 síntipos fêmeas de Valdivia, Região de Los Lagos, Chile, depositado no MNHN [Muséum National d'Histoire Naturelle, Paris, França], não examinado).

Hypselistoides affinis Tullgren, 1901: 202-203, pl. 15, fig. 9 (síntipo fêmea de Lagatovia, Chile, depositado no NHRM [Naturhistoriska riksmuseet, Stockholm, Suécia], não examinado).

Sphecozone affinis. Millidge 1985: 70-71, figs 256, 266.

Sphecozone ardens Millidge, 1985: 69-70, figs 274-279 (holótipo macho male de NE de Nueva Imperial e O de Temuco, Chacamo, Cautín, Chile, depositado no AMNH). Sphecozone bicolor. Miller, 2007: 190-193.

Material tipo examinado: CHILE. REGIÓN DE LA ARAUCANÍA (IX): Cautín Prov., Chacamo, NW Nueva Imperial e W Temuco, (38³5'S; 7302'W), 17-23.ii.1981, L. E. Pena col., (AMNH, 1ð̄, holótipo). REGIÓN DEL BÍOBÍO (VIII): Concepción Prov., Tomé, (36³6'S; 7256'W), 12.xii.1982, T. Cekalovic col., (AMNH, 1ठ16 juv., parátipo). Caledonia, E de Mulchen, (37²4'S; $\left.72^{\circ} 13^{\prime} \mathrm{W}\right), 10-15 . i 1.1981$, L. E. Pena col., (AMNH, 1q, parátipo). REGIÓN DE LA ARAUCANÍA (IX): Cautín Prov., Chacamo, NW Nueva Imperial e W Temuco, (38³5'S; 7302'W), 17-23.ii.1981, L. E. Pena col., 


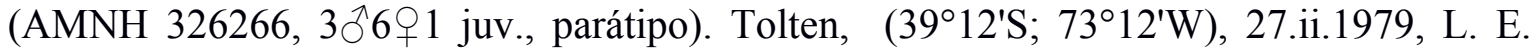
Pena col., (AMNH, 1q, parátipo). Cautín Prov., Villarrica, $\left(39^{\circ} 17^{\prime} \mathrm{S} ; 7^{\circ} 13^{\prime} \mathrm{W}\right), 27-$ 28.ii.1979, L. E. Pena col., (AMNH, 1, parátipo). REGIÓN DE LOS LAGOS (X): Osorno Prov., P.N. Puyehue, Volcán Casa Blanca, (4045'S; 73¹2'W), 20-25.ii.1982, A. Newton \& M. Thayer col., (AMNH, $4{ }^{\Uparrow} 1$ juv., parátipo).

Diagnose: Machos de $H$. bicolor se assemelham aos de $H$. nigripespor apresentarem um processo basal do êmbolo. Diferencia-se de $H$. nigripes por apresentar a região cefálica com uma elevação mais suave (Figs. 21, 22, 25). Fêmeas de H. bicolor se assemelham com as de $H$. rubicundus e $H$. niwinus, por apresentar o lóbulo anterior da placa dorsal mais larga que longa, e pelas depressões laterias da placa ventral. Se diferencia de $H$. rubicundus e $H$. nigripes, que possuem uma placa ventral retangular, e de $H$. niwinus, que possui uma invaginação anterolateral menos pronunciada, com a região anterior da placa ventral mais larga (Figs. 24, 25).

Descrição: Macho e fêmea da Reserva Nacional Laguna Parrillar, Magallanes, Chile. Descrição em Miller, 2007, pp. 190-193. Imagens adicionais: Fig. 21-25.

Variação: Machos ( $\mathrm{n}=10)$ : Comprimento total 1,857-2,649 (média 2,235); comprimento da carapaça 0,887-1,126 (média 0,974); largura da carapaça 0,72-0,861 (média 0,783); comprimento do fêmur I 0,873-1,413 (média 1,167).

Fêmeas $(\mathrm{n}=10)$ : Comprimento total 2,273-2,792 (média 2,577); comprimento da carapaça 0,971-1,135 (média 1,028); largura da carapaça 0,82-0,929 (média 0,865); comprimento do fêmur I 0,918-1,421 (média 1,218).

Distribuição: Argentina, Bolívia e Chile (Mapa 2).

Material examinado: BOLÍVIA. CAMARGO: 16mi $\mathrm{N}$ de Camargo, $\mathrm{S}$ de Bolivia, (20³8'S; 65¹2'W), 20.ii.1951, Ross and Michelbacher col., (CAS 9076614, 9076629,

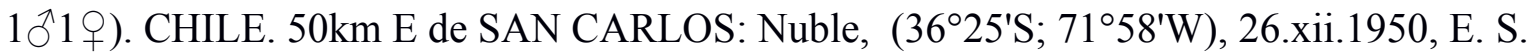
Roth e Michelbacher col., (CAS 9076500, 19). REGIÓN DEL BÍOBÍO (VIII): Concepción Prov., Periquillo, (36²4'S; 7302'W), 22.xi.1992, T. Cekalovic col., (AMNH 
326267, 4ð13 ). REGIÓN DE LA ARAUCANÍA (IX): Cautín Prov., Pucon, Lago Villarrica, (39 $\left.16^{\prime} \mathrm{S} ; 7^{\circ} 58^{\prime} \mathrm{W}\right)$, 14.xii.1988, V. \& B. Roth col., (CAS 9076642, 5ð13 1 juv.). PUCON: (10mi NE of Pucon), (39 $\left.16^{\prime} \mathrm{S} ; 7^{\circ} 58^{\prime} \mathrm{W}\right), 12.1 .1951$, Ross and Michelbacher col., (CAS 9076643, 19). REGIÓN DE LOS LAGOS (X): Valdivia, 1820km NW Neltume, (39¹6'S; 71 $\left.{ }^{\circ} 58^{\prime} \mathrm{W}\right), 25 . x i .1988$, V. \& B. Roth col., (CAS 9076621,

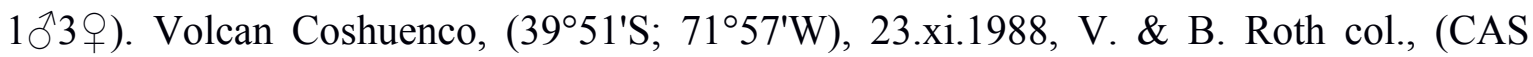
9076636, 29). Provincia Panquipulli, Los Lagos, (39³8'S; 72²0'W), 23.xi.1988, V. \& B. Roth col., (CAS 9076502, 2ㅇ). 30km S of Valdívia, (3949'S; 73¹1'W), 13.I.1951, Ross and Michelbacher col., (CAS 9076505, 191 juv.). Osorno Prov., Pocutrihue ("Pocatrihue"), (40³2'S; 7342'W), 26-28.iii.1968, L. Peña col., (MCZ 61529, 19). P.N. Puyehue, Antillanca, (40 $\left.46^{\prime} \mathrm{S} ; 7^{\circ} 12^{\prime} \mathrm{W}\right), 12 . x i i .2000-21 . i .2001$, Miller, Agnarson, Alvarez, Coddingotn, Hormiga col., (USNM, 1 4 juv.). Provincia de Llanquihue, $2-3 \mathrm{~km}$

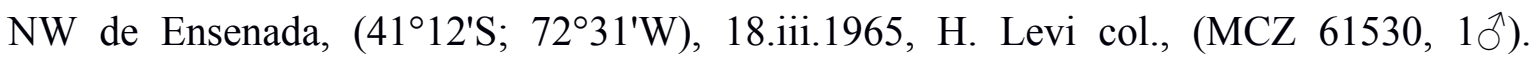
REGIÓN DE MAGALLANES (XII): Magallanes Prov., Reserva Nacional Laguna

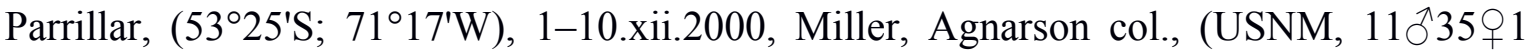
juv.). ARGENTINA. NEUQUÉN: Parque Nacional Lanín, $2 \mathrm{~km}$ NW Nonthué, $\left(40^{\circ} 08^{\prime S}\right.$; 71³8'W), 20-24.ii.1999, S. L. Heydon \& J. M. Ledford col., (CAS 9076613, 19). San Martin, (40¹0'S; 71²1'W), 20-21.xi.1988, V. \& B. Roth col., (CAS 9076624, 49). San Martin de los Andes, (4009'S; 71¹9'W), 20-21.xi.1988, V. \& B. Roth col., (CAS 9076622, 19). RIO NEGRO: Parque Nacional Nahuel Huapi, Puerto Blest, (41 02'S; 7149'W), 22.ii.1999, S. L. Heydon \& J. M. Ledford col., (CAS 9076617, 1ठ). TIERRA DEL FUEGO: Bahia San Sebastian, Pta de Arenas, (53¹7'S; 68²7'W), 20.iv.1971, O. S. Flint \& G. F. Hevel col., (USNM, $1 \delta^{\widehat{T}} 5$ 1 juv.).

\section{Hypselistoides altehabitans (Keyserling, 1886) comb. nov.}

Figs. 18-20, Mapa 3.

Erigone altehabitans Keyserling, 1886: 202-203, fig. 262 (fêmea de Montana di Naucho, Peru, depositado no MZPW [Polish Academy of Science, Museum and Institute of Zoology, Varsóvia, Polônia, ex-PAINZ]). Petrunkevitch, 1911: 232.

Sphecozone pulchra Millidge, 1991: 169, fig. 710 (fêmea holótipo de Laguna Manochogui, Pataz, La Libertad, Peru, depositado no MUSM) 
Sphecozone altehabitans. Miller, 2007: 193, f. 146E.

Material tipo examinado: PERU. LA LIBERTAD: Patáz, Laguna Manochogui (8¹1'36.5"S; 77¹7'11.4"W), 19, 28-29.vii.1987, B. Leon col. (MUSM, holótipo de Sphecozone pulchra).

Diagnose: Fêmeas de $H$. altehabitans lembram as de $H$. nigripes e $H$. rubicundus pela forma do epígino, sem a invaginação anterolateral na porção anterior da placa ventral. Diferem-se de $H$. nigripes e $H$. rubicundos por apresentar a placa ventral mais arredondada na margem anterior (Figs. 19-20). Macho desconhecido.

Descrição: Macho desconhecido.

Fêmea (holótipo de Laguna Manochogui, Pataz, La Libertad, Peru). Descrição em Miller, 2007, pp.193-194. Imagens adicionais: Fig. 18-20.

Variações: Fêmeas $(n=3)$ : Comprimento total 1,75-2,08 (média 1,93); comprimento da capapaça 0,57-0,66 (média 0,62); largura da carapaça 0,52-0,53 (média 0,52); comprimento do fêmur I 0,76-0,83 (média 0,80).

Distribuição: Apenas para Peru. (Mapa 3).

Material examinado: PERU. LA LIBERTAD: Los Alisos, (nr. Pataz) (8¹3'45.3"S; $\left.77^{\circ} 22^{\prime} 22.2^{\prime \prime} \mathrm{W}\right), 3$ + $, 17 . v i .1986, \mathrm{~B}$. Roth col. (CAS 9076640).

Hypselistoides nigripes (Millidge, 1991) comb. nov.

Figs. 78-83, Mapa 2.

Sphecozone nigripes Millidge, 1991: 169, f. 716-719 (holótipo macho de Cajabamba, Cajamarca, Peru, depositado no AMNH).

Sphecozone nigripes. Miller, 2007: 187.

Material tipo examinado: PERU. CAJAMARCA: sul de Cajabamba, ( $\left.7^{\circ} 10^{\prime} \mathrm{S} ; 78^{\circ} 31^{\prime} \mathrm{W}\right)$, 
20.i.1976, R. T \& J. C. Schuh col., (AMNH 1§̄, holótipo). LIMA: Bosque de Zarate, Pampa Zarate, $\left(11^{\circ} 55^{\prime} \mathrm{S} ; 7^{\circ} 29^{\prime} \mathrm{W}\right), 10 . x i i .1977$, I. Franke \& N. Valencia col., (MUSM

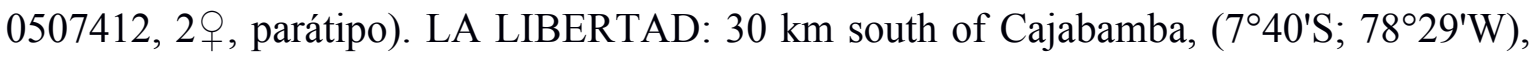
20.i.1976, R. T \& J. C. Schuh col., (AMNH 326265, 1ठ̋, parátipo).

Diagnose: Machos de H. nigripes lembram os de H. bicolor e Hypselistoides sp.nov.01 por apresentarem o processo basal do êmbolo. Diferenciam-se de Hypselistoides sp.nov.01 pela ausência de um processo ventral da tíbia do palpo e de $H$. bicolor por apresentar uma elevação da região cefálica abrupta (Figs. 78, 79, 82, 83). Fêmeas de H. nigripes se assemelham com de H. rubicundus, H. niwinus e $H$. bicolor, por apresentar o lóbulo anterior da placa dorsal mais larga que longa, e pelas depressões laterias da placa ventral. Se diferenciam de $H$. niwinus e $H$. bicolor, que possuem uma invaginação anterolateral pronunciada, e $H$. rubicundus, que possuem uma placa ventral menos retangular que em $H$. nigripes (Figs. 81-83).

Descrição: Macho (parátipo; AMNH 326265) de Cajabamba, La Libertad, Peru. Comprimento total 2,55. Carapaça 1,01 de comprimento, 0,83 de largura, alaranjada, com a região cefálica elevada. Esterno 0,58 de comprimento, 0,58 de largura, alaranjado. Clípeo 0,27 de altura. Quelícera com 6 dentes promarginais e 5 retromarginais. Abdômen cinza escuro para preto. Diâmetro dos olhos e distância: OMA 0,05; OLA 0,06; OMP 0,05; OLP 0,06. Distância entre os OMA 0,67 vezes seu diâmetro, distância entre os OMP 1,48 vezes seu diâmetro, distância entre OMA-OLA 1,21 vezes o diâmetro do OLA, distância entre OMP-OLP 1,30 vezes o diâmetro do OLP. Distância entre coxa IV 1,08 vezes sua largura. Fórmula das pernas I-II-IV-III. Fêmur I/II/III/IV 1,17/1,06/0,94/1,22; patela I 0,24; tíbia I 1,18; metatarso I 0,81 ; tarso I 0,63. Pernas de coloração marrom escura. Fêmur/patela/tíbia/címbio do palpo 0,37/0,16/0,25/0,50. TmI 0,34. TmIV ausente. Címbio do palpo com cavidade basal. Tégulo apresenta um protégulo e papilas, o supratégulo apresenta uma apófise distal. Divisão embólica apresenta êmbolo longo, em espiral, com uma projeção na sua abertura. Uma membrana embólica está presente, o radix apresenta processo anterior robusto. Tíbia possui apenas uma apófise prolateral, com dente distal presente. Conta também com um tricobótrio prolateral e um retrolateral. (Figs. 78-79, 8283). 
Fêmea (parátipo; MUSM 0507412) de Pampa Zarate, Bosque de Zarate, Lima, Peru. Comprimento total 3,10. Carapaça 1,18 de comprimento, 1,01 de largura. Esterno 0,75 de comprimento, 0,70 de largura. Clípeo 0,27 de altura. Quelícera com 6 dentes promarginais e 5 retromarginais. Padrões do abdômen, esterno e carapaça como no macho, mas com a região cefálica não elevada na fêmea. Diâmetro dos olhos e distância: OMA 0,05; OLA 0,05; OMP 0,04; OLP 0,05. Distância entre os OMA 0,79 vezes seu diâmetro, distância entre os OMP 1,54 vezes seu diâmetro, distância entre OMA-OLA 1,56 vezes o diâmetro do OLA, distância entre OMP-OLP 1,77 vezes o diâmetro do OLP. Distância entre coxa IV 1,31 vezes sua largura. Fórmula das pernas I-II-IV-III. Fêmur I/II/III/IV 1,41/1,33/1,21/1,57; patela I 0,32; tíbia I 1,28; metatarso I 1,12; tarso I 0,80. Pernas como no macho. Fêmur/patela/tíbia/tarso do palpo 0,42/0,15/0,32/0,48. TmI 0,35. TmIV ausente. Palpo com duas macrosetas ventromesal e três ventroectal. Epígino proeminente, apresenta lóbulo anterior da placa dorsal dividido pela placa ventral em duas circunferências. Placa ventral com duas pequenas cavidades laterias. Átrios arredondados. Dutos de fertilização orientados mesalmente. Dutos copulatório não encapsulado, espermateca arredondada. (Figs. 80-81, 82-83).

Variação: $\operatorname{Machos}(\mathrm{n}=2)$ : Comprimento total 2,48-2,52 (média 2,50); comprimento da carapaça 0,99-1,03 (média 1,01); largura da carapaça 0,83-0,84 (média 0,83); comprimento do fêmur I 0,97-1,17 (média 1,07).

Fêmeas ( $\mathrm{n}=2$ ): Comprimento total 2,87-2,96 (média 2,91); comprimento da carapaça 1,111,26 (média 1,19); largura da carapaça 0,99-1,04 (média 1,01); comprimento do fêmur I 1,31-1,36 (média 1,34).

Distribuição: Peru (Cajamarca, La Libertad, Lima). (Mapa 2A).

Material examinado: PERU. LA LIBERTAD: Laguna Quishuar, (7³6'20.47"S;

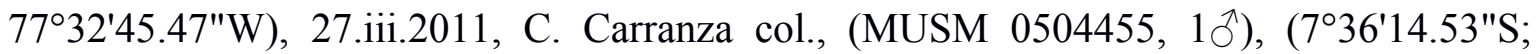
77²5'12.47"W), iii.2011, C. Carranza col., (MUSM 0504452, 1ðึ). LIMA: Bosque de Zarate, Pampa Zarate, (11 $\left.{ }^{\circ} 55^{\prime} \mathrm{S} ; 7^{\circ} 29^{\prime} \mathrm{W}\right), 30 . i v .1978$, I. Franke \& N. Valencia col., (MUSM 0508675, 2 9 juv.). 
Hypselistoides niwinus (Chamberlin, 1916) comb. nov.

Figs. 84-89, Mapa 3.

Erigone niwina Chamberlin, 1916: 235, pl. 17, f. 4 (holótipo fêmea e 3 fêmeas parátipos de Urubamba, Cuscu, Peru, depositado no MCZ).

Erigone taibo Chamberlin, 1916: 234, pl. 17, f. 5 (holótipo fêmea e fêmea parátipo de Urubamba, Cuscu, Peru, depositado no MCZ, não examinado).

Sphecozone aurantia Millidge, 1991: 171, f. 720 (holótipo fêmea, com 2 fêmeas parátipos, de Camino al Illimani, La Paz, Bolívia, depositado no AMNH)

Sphecozone niwina. Miller, 2007: 195, f. 142I, 147C-D, G, I.

Material tipo examinado: PERU. CUSCO: Urubamba, (13ํำ'S; $\left.72^{\circ} 06^{\prime} \mathrm{W}\right)$, iv.1911, Yale Peruvian Expedition col., (MCZ 22323, 19, holótipo). Bolívia. LA PAZ: Pedro Domingo Murillo, Camino al Illimani, (16 $35^{\prime}$ S; 67²7'W), 25.xii.1975, L. E. Pena col., (AMNH,

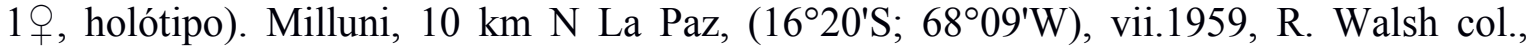
(AMNH, 2 , , parátipo). Pedro Domingo Murillo, Camino al Illimani, (16 $\left.36^{\circ} \mathrm{S} ; 67^{\circ} 47^{\prime} \mathrm{W}\right)$, 25.xii.1975, L. E. Pena col., (AMNH, 2q, parátipo). Campero, $\left(17^{\circ} 27^{\prime} \mathrm{S} ; 68^{\circ} 57^{\prime} \mathrm{W}\right), 13-$

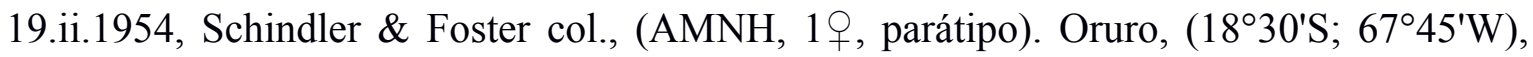
24.i.1976, N. Chlamar col., (AMNH, 29, parátipo).

Diagnose: Machos de $H$. niwinus lembram os de $H$. rubicundus pela presença de um dente distal na apófise prolateral da tíbia, se diferenciando de $H$. rubicundus por apresentar o dente menor, mais discreto (Figs. 85, 88, 89). Fêmeas de $H$. niwinus se assemelham com H. rubicundus, $H$. nigipes e H. bicolor, por apresentarem o lóbulo anterior da placa dorsal mais larga que longa, e pelas depressões laterias da placa ventral. Se diferenciam de $H$. rubicundus e $H$. nigripes, que possuem uma placa ventral mais retangular, e de $H$. bicolor, por apresentarem uma invaginação anterolateral na placa ventral menos pronunciada (Figs. 87-89).

Descrição: Macho e fêmea de Parinacota, Tarapacá, Chile com descrições e ilustrações em Miller, 2007, 195-196, f. 142I, 147C-D, G, I. Imagens adicionais: Fig. 84-89. 
Variação: $\operatorname{Machos}(\mathrm{n}=10)$ : Comprimento total 2,25-2,78 (média 2,49); comprimento da carapaça 1,02-1,24 (média 1,11); largura da carapaça 0,80-1,01 (média 0,86); comprimento do fêmur I 0,89-1,13 (média 0,97).

Fêmeas $(\mathrm{n}=10)$ : Comprimento total 2,94-3,98 (média 3,20); comprimento da carapaça 1,17-1,36 (média 1,25); largura da carapaça 0,97-1,14 (média 1,02); comprimento do fêmur I 0,89-1,47 (média 1,12).

Distribuição: Bolívia, Chile e Peru. (Mapa 3).

Material examinado: PERU. LA LIBERTAD: Patáz, Manachaqui, ( $\left.7^{\circ} 47^{\prime} \mathrm{S} ; 7^{\circ} 35^{\prime} \mathrm{W}\right)$, 22.iii.1988, D. Silva col., (MUSM 508644, $3 \bigcirc^{\Uparrow} 14 \uparrow 1$ juv.). ANCASH: Callejon de Huaylas, ( $9^{\circ} 16^{\prime}$ S; $\left.77^{\circ} 07^{\prime} \mathrm{W}\right)$, viii.1988, V. \& B. Roth col., (CAS 9076633, 3 9 ). PASCO: Huayllay, Santuario de Huayllay, (1056'54,11"S; 76¹8'45,5"W), 3.ix.2007, W. Paredes col.,

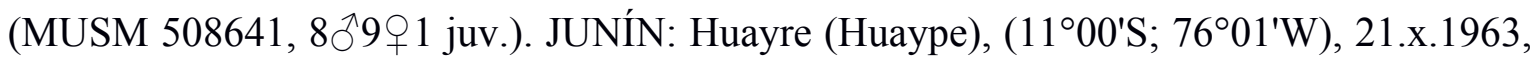

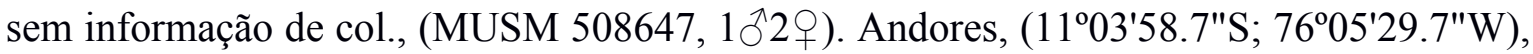
19.iii.2007, G. Alvares \& W. Paredes col., (IBSP 73273, 4ㅇ). Ondores, Bajo Piedras,

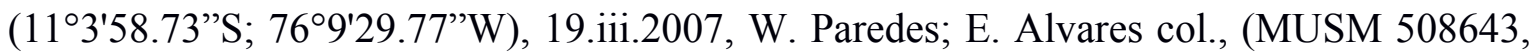

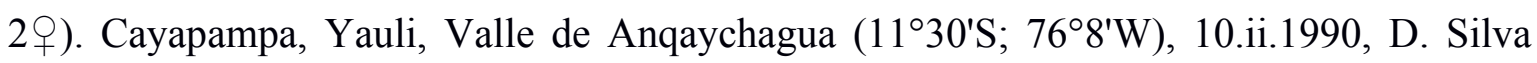

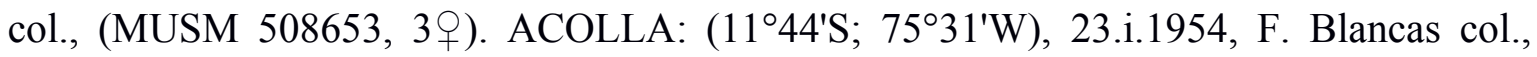
(MUSM 508645, 4 ㅇ juv.). CUSCO: Rumicollca, (13³7’S; 71²’'W), 27.vi.1983, M. del Castillo col., (MUSM 508640, 76ㅇ). Chumbivilcas, Quebrada Casanuma, (14²9'8”S; 7149'36”W), vi.2013, Luz Huerto S. col., (MUSM 506869, 19). LA RAYA: (14²9'S; 71 ${ }^{\circ} 02^{\prime} \mathrm{W}$ ), 1.ili.1951, Ross and Michelbacher col., (CAS 9076637, 2q). PUNO: Melgar Antauta, (14¹4'11”S; 70¹9'57’W), 19-21.ix.2011, B. Medina col., (MUSM 506943, 3 +). Isla Amantani, Lago Titicaca, (1544’S; 69³8’W), iii.1948, F. Blancas col., (MUSM

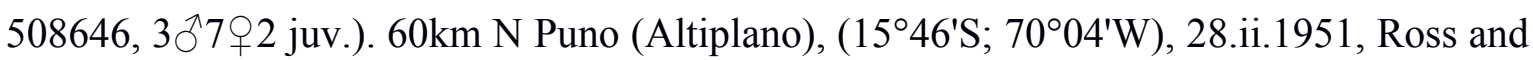
Michelbacher col., (CAS 9076639, 19). Juli, (16²12'S; 69²7'W), 2.ix.1997, J. Ochoa col.,

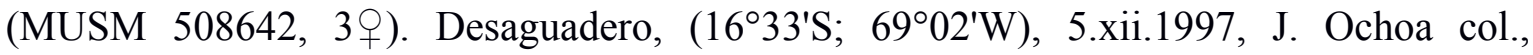
(MUSM 508659, 19). CHILE. REGIÓN DE TARAPACÁ (I): Tarapacá prov., Parinacota,

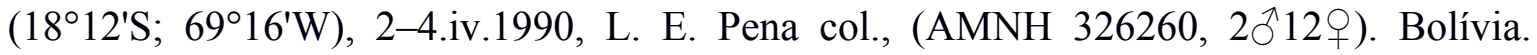
ORURO: Sajama, Lagunas, (18¹3'12.4”S; 68 55'54.2”W), 12.xi.2005, W. Paredes col., (MUSM 508660, 192 juv.). PONGO: (16 19 'S; 6757'W), iv.1921, W. W. Mann col., (USNM, 1). 
Hypselistoides rubicundus (Keyserling, 1886) comb. nov.

Figs. 90-95, Mapa 3.

Erigone rubicunda Keyserling, 1886: 205-207, fig. 265 (macho lectótipo de Amable María, Peru, depositado no MZPW [Polish Academy of Science, Museum and Institute of Zoology, Varsóvia, Polônia, ex-PAINZ], não examinado).

Ceratinopsis rubicunda. Simon, 1894: 645.

Sphecozone fuscipes Millidge, 1991: 171, figs 721-725 (macho holótipo de San Antonio, Puquio, Ayacucho, Peru, depositado no MUSM, não examinado).

Sphecozone rubicunda. Miller, 2007: 194, f. 142H, 147A-B, E-F, H.

Material tipo examinado: PERU. AYACUCHO: Puquio, San Antonio, (1441'S; 74²'W), (MUSM 0507397, 4웅 parátipo).

Diagnose: Machos de $H$. rubicundus lembram os de $H$. niwinus pela presença de um dente distal na apófise prolateral da tíbia, se diferenciando de $H$. niwinus por apresentar o dente mais robusto (Figs. 91, 94, 95). Fêmeas de H. rubicundus se assemelham as de H. niwinus, H. nigipes e H. bicolor, por apresentar o lóbulo anterior da placa dorsal mais larga que longa, e pelas depressões laterias da placa ventral. Se diferenciam de $H$. bicolor e $H$. niwinus, que possuem uma invaginação anterolateral da placa ventral, e de $H$. nigripes, que possuem a placa ventral mais retangular (Figs.93-95) .

Descrição: Macho (de Junín, Peru) e fêmea (de Amable María, Peru, paralectótipo) com descrições e ilustrações em Miller, 2207: 194, f. 142H, 147A-B, E-F, H. Imagens adicionais: Fig. 90-95.

Variação: Machos ( $\mathrm{n}=7$ ): Comprimento total 2,33-3,03 (média 1,86); comprimento da carapaça 0,96-1,33 (média 0,79); largura da carapaça 0,70-0,92 (média 0,57); comprimento do fêmur I 0,95-1,14 (média 1,06).

Fêmeas $(n=10)$ : Comprimento total 2,53-3,34 (média 2,86); comprimento da carapaça 0,95-1,21 (média 1,08); largura da carapaça 0,76-1,04 (média 0,92); comprimento do 
fêmur I 0,90-1,23 (média 1,08).

Distribuição: Peru. Mapa 3.

Material examinado: PERU. HUÁNUCO: Ambo, (1009'S; 76²2'W), 18.viii.2012, B. Medina col., (MUSM 0505297, 1ठ1), 16.viii.2012, B. Medina col., (MUSM 0505293, 1우), 20.viii.2012, B. Medina col., (MUSM 0505343, 1§4우). PASCO: Huariaca, (10²6'36.1"S; 76²11'14.4"W), 15.ix.1954, E. I. Schiingler \& E. S. Ross col., (CAS 9076635, 1ðึ). CUSCO: La Convencion, Reserva Comunal Matsigenga, (12¹3'37.2"S; 73³1'59.7"W), 17.viii.2012, A. Asenjo col., (MUSM 0505325, 2ㅇ). Salkantay, (13²0'02.4"S; 72³2'W), 10.vii.1983, G. C. Hunter col., (CAS 9076634, 10َ). Espinar,

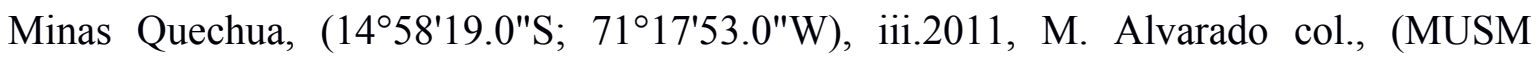
0503460, $2{ }^{\Uparrow} 2$ q 2 juv.). APURIMAC: Abancay, Cotarusi, (14 $\left.15^{\prime} 17.1^{\prime \prime S} ; 73^{\circ} 12^{\prime} 20.1^{\prime \prime W}\right)$, 5.vii.2013, M. Cardenas col., (MUSM 0506236, $3 q 1$ juv.). Silco, (14²4'54.0"S; 7256'46.7"W), 15.iii.2013, M. Cardenas col., (MUSM 0506141, 1ठ). SAN MARTIN:

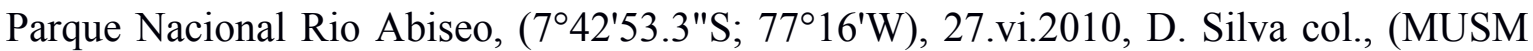
0501625, 2ð19). ANCASH: Parque Nacional Huascarán, Laguna Parón, (859'43.0"S; 77²0'41.0"W), 16.v.2010, L. Figueroa, R. Pinto-da-Rocha \& D. Silva D. col., (MUSM 0503168, 1ㅇ).

Hypselistoides capitatus (Millidge, 1991) comb. nov.

Figs. 26-30, Mapa 2B.

Sphecozone capitata Millidge, 1991: 169, f. 711-715. (Macho holótipo e fêmea parátipo de Lambayeque, Huacraruco, Peru, depositado no MUSM)

Material tipo examinado: PERU. CAJAMARCA: San Juan, Hacienda Huacraruco, (7¹7'S; 78²9'W), 1今̄, 22-27.iii.1958, KLK col. (MUSM-sem tombo, holótipo); LAMBAYEQUE: Hacienda Huacraruco, (6²8'S; 7953'W), 19, 22-27.iii.1958, KLK col. (MUSM 0507406, parátipo).

Diagnose: Machos de $H$. capitatus se diferenciam de todos os Hypselistoides por 
apresentar uma apófise prolateral perpendicular, alta e com uma projeção dorsal (Figs. 27, 30). Fêmeas se diferenciam das demais espécies de Hypselistoides por apresentar a margem posterior da placa ventral em forma de " $\mathrm{M}$ " e placa dorsal muito mais larga que alta (Figs. 29, 30).

Descrição: Macho (Holótipo; MUSM) de Hacienda Huacraruco, San Juan, Cajamarca, Peru. Comprimento total 2,36. Carapaça 1,16 de comprimento, 0,88 de largura, alaranjada, possui região cefálica elevada. Esterno 0,60 de comprimento, 0,63 de largura, alaranjado. Clípeo 0,36 de altura. Quelícera com 6 dentes promarginais e 5 retromarginais. Abdômen apresenta coloração bege (material pouco conservado). Diâmetro dos olhos e distância: OMA 0,03; OLA 0,05; OMP 0,05; OLP 0,05. Distância entre os OMA 1,13 vezes seu diâmetro, distância entre os OMP 2,55 vezes seu diâmetro, distância entre OMA-OLA 2,26 vezes o diâmetro do OLA, distância entre OMP-OLP 1,47 vezes o diâmetro do OLP. Distância entre coxa IV 0,98 vezes sua largura. Fórmula das pernas I-II-IV-III. Fêmur I/II/III/IV 1,56/1,39/1,16/1,4; patela I 0,24; tíbia I 1,43; metatarso I 1,31; tarso I 0,62. Pernas alaranjadas. Fêmur/patela/tíbia/címbio do palpo 1/1/1/1. TmI 0,47. TmIV ausente. Palpo com cavidade basal do címbio presente, tégulo com protégulo e papilas, supratégulo liso, êmbolo é longo, espiral, com uma projeção que se estende além de sua abertura. radix liso, apresenta processo anterior robusto. Tíbia somente com apófise prolateral, apresenta um tricobótrio prolateral e um retrolateral. (Figs. 26-27, 30)

Fêmea (Parátipo; MUSM 0507406) de mesma localidade do macho. Comprimento total 3,36. Carapaça 1,22 de comprimento, 0,95 de largura, de coloração castanha. Esterno 0,71 de comprimento, 0,67 de largura, castanho. Clípeo 0,25 de altura. Quelícera com 6 dentes promarginais e 5 retromarginais. Abdômen bege escuro. Diâmetro dos olhos e distância: OMA 0,04; OLA 0,05; OMP 0,06; OLP 0,05. Distância entre os OMA 0,92 vezes seu diâmetro, distância entre os OMP 1,26 vezes seu diâmetro, distância entre OMA-OLA 1,43 vezes o diâmetro do OLA, distância entre OMP-OLP 1,21 vezes o diâmetro do OLP. Distância entre coxa IV 1,05 vezes sua largura. Fórmula das pernas I-II-IV-III. Fêmur I/II/III/IV 1,60/1,53/1,35/1,73; patela I 0,33; tíbia I 1,51; metatarso I 1,17; tarso I 0,74. Pernas alaranjadas. Fêmur/patela/tíbia/címbio do palpo 0,40/0,15/0,28/0,49. TmI 0,58. TmIV ausente. Palpo apresenta três macrosetas ventromesal e duas ventroectal. Epígino apresenta uma placa dorsal muito mais larga que comprida. Placa ventral simples, sem 
processos, átrios curvado. Duto copulatório não encapsulado, duto de fertilização tem orientação mesal. Espermateca arredondada. (Figs. 28-30).

Distribuição: Apenas para Peru. (Mapa 2B).

Material examinado: Somente o material tipo.

Hypselistoides modestus (Nicolet, 1849) comb. nov.

Figs. 67-72, Mapa 2B.

Theridion modestum Nicolet, 1849: 526, pl. 5, f. 15. (uma fêmea lectótipo e 2 fêmeas paralectótipos do Chile, depositado no $\mathrm{MNHN}$, não examinado).

Theridion distinctum Nicolet, 1849: 527 (uma fêmea lectótipo e 2 fêmeas paralectótipos do Chile, depositado no MNHN, não examinado).

Theridium weyenberghi Holmberg, 1876: 14 (fêmea de Buenos Aires, Argentina, MNHN, não examinado).

Erigone modesta. Keyserling, 1886: 229, pl. 19, f. 284.

Ceratinopsis modesta. Simon, 1896: 65.

Ceratinopsis distincta. Simon, 1896: 65. Levi, 1967: 19, f. 43-44 (f).

Ceratinopsis modesta. Levi, 1967: 19, f. 45-47 (f).

Sphecozone modesta. Millidge, 1985: 69, f. 267-273. Miller, 2007: 187, 201, f. 134.

Diagnose: Machos de $H$. modestus se assemelham à $H$. capitatus, $H$. lobatus e $H$. modicus pela forma do êmbolo estreito, curvado e mais curto que nas demais espécies de Hypselistoides. Se diferencia dessas espécies pela ausência de processo ventral da tíbia, presente em $H$. lobatus e $H$. modicus, e pelo processo dorsal da apófise prolateral em $H$. capitatus (Figs. 68, 71, 72). Fêmeas de H. modestus se assemelham com as de H. capitatus, H. lobatus e H. modicus pela orientação mesal do duto de fertilização, diferenciando-se pela forma da espermateca, estreita e alongada (Figs.70-72).

Descrição: Macho (AMNH 326269) de Puente Río Pudeto, Río Pudeto, Chiloé, Región De Los Lagos (X), Chile. Comprimento total 2,05. Carapaça 0,93 de comprimento, 0,73 de 
largura. Esterno 0,52 de comprimento, 0,52 de largura, carapaça e esterno de coloração marrom escuro. Clípeo 0,18 de altura. Quelícera com 6 dentes promarginais e 5 retromarginais. Abdômen amarelado, com mancha preta próximo às fiandeiras. Diâmetro dos olhos e distância: OMA 0,04; OLA 0,05; OMP 0,05; OLP 0,06. Distância entre os OMA 0,59 vezes seu diâmetro, distância entre os OMP 0,85 vezes seu diâmetro, distância entre OMA-OLA 0,96 vezes o diâmetro do OLA, distância entre OMP-OLP 1,03 vezes o diâmetro do OLP. Distância entre coxa IV 1,36 vezes sua largura. Fórmula das pernas III-IV-III. Fêmur I/II/III/IV 0,72/0,68/0,62/0,79; patela I 0,24; tíbia I 0,63; metatarso I 0,52; tarso I 0,38. Pernas alaranjadas. Fêmur/patela/tíbia/címbio do palpo 0,27/0,14/0,07/0,34. TmI 0,47. TmIV ausente. Palpo com cavidade basal do címbio presente, tégulo com protégulo e papilas, supratégulo liso. Êmbolo longo, espiral e achatado, com uma projeção que se estende além de sua abertura. radix liso, apresenta processo anterior robusto. Tíbia somente com apófise prolateral, apresenta um tricobótrio prolateral e um retrolateral. (Figs. 67-68, 71-72).

Fêmea (AMNH 326269) de mesma localidade do macho. Comprimento total 3,01. Carapaça 1,10 de comprimento, 0,92 de largura. Esterno 0,65 de comprimento, 0,64 de largura, carapaça e esterno com o mesmo padrão de coloração do macho. Clípeo 0,21 de altura. Quelícera com 6 dentes promarginais e 5 retromarginais. Abdômen amarelado com manchas pretas circulares na lateral, manchas pretas próximo às fiandeiras que se liga à uma linha longitudinal que se estende pelo dorso até a metade posterior. Diâmetro dos olhos e distância: OMA 0,04; OLA 0,06; OMP 0,07; OLP 0,06. Distância entre os OMA 0,79 vezes seu diâmetro, distância entre os OMP 0,57 vezes seu diâmetro, distância entre OMA-OLA 0,95 vezes o diâmetro do OLA, distância entre OMP-OLP 1,07 vezes o diâmetro do OLP. Distância entre coxa IV 1,46 vezes sua largura. Fórmula das pernas III-IV-III. Fêmur I/II/III/IV 0,88/0,84/0,77/1,06; patela I 0,33; tíbia I 0,79; metatarso I 0,62; tarso I 0,48. Pernas alaranjadas, mais escuras na parte distal dos Fêmures, nas patelas e tibias. Fêmur/patela/tíbia/tarso do palpo 0,31/0,09/0,21/0,38. TmI 0,45. TmIV ausente. Palpo apresenta três macrosetas ventromesal e duas ventroectal. Epígino apresenta uma placa dorsal quadrada com lóbulo anterior. Placa ventral simples, sem processos, átrios curvado, mais reto na sua base. Duto copulatório não encapsulado, duto de fertilização tem orientação mesal. Espermateca oval e estreita. (Figs. 69-72). 
Variação: $\operatorname{Machos}(\mathrm{n}=10)$ : Comprimento total 1,72-2,20 (média 2,03); comprimento da carapaça 0,85-0,95 (média 0,91); largura da carapaça 0,71-0,77 (média 0,74); comprimento do fêmur I 0,67-0,81 (média 0,76 ).

Fêmeas $(\mathrm{n}=10)$ : Comprimento total 2,66-3,37 (média 2,86); comprimento da carapaça 0,89-1,16 (média 1,02); largura da carapaça 0,80-0,95 (média 0,87); comprimento do fêmur I 0,80-0,89 (média 0,85).

Obs.: As manchas no abdômen podem variar entre os indivíduos. Machos e fêmeas podem apresentar as manchas pretas longitudinais e pontos pretos pelo abdômen, como estas também podem estar ausentes. Manchas pretas próximas às fiandeiras é um padrão constante.

Distribuição: Argentina (Chubut, Larioja, Neuquén), Bolívia (La Paz), Brasil (Rio Grande do Sul) e Chile (Araucania, Coquimbo, Bíobío, Los Lagos, Valparaíso, Santiago e Zapallar). Mapa 2B.

Material examinado: BOLIVIA. LA PAZ: Huatajata, Lago Titicaca, (16 $\left.16^{\circ}{ }^{\prime} \mathrm{S} ; 68^{\circ} 41^{\prime} \mathrm{W}\right)$, 8.viii.1993, A. D. Brescovit \& H. Höfer col., (MCN 23785, 1ð4우). BRASIL. RIO GRANDE DO SUL: Cambará do Sul, (29¹'S; 50¹1'W), iv.2005, M. V. Petry et al. col.,

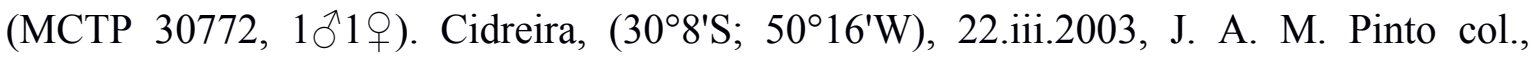
(MCTP 34090, 2ð), 27.vii.2003, J. A. M. Pinto col., (MCTP 34123, 1ð). Capivari do Sul, (3008'S; 50³0'W), 14.i.2009, L. Fritz col., (MCN 45952, 19). Rio Grande, Estação Ecológica do Taim, (3244'S; 52³4'W), 9.iv.1986, M. A. L. Marques col., (MCN 14914, 1ठ), 10.iv.1986, M. Rosenau col., (MCN 14982, 19). CHILE. ZAPALLAR: (32³3'S; 71 $\left.{ }^{\circ} 27^{\prime} \mathrm{W}\right), 27 . x i .1950$, Ross and Michelbacher col., (CAS9076501, 9076503, 20).

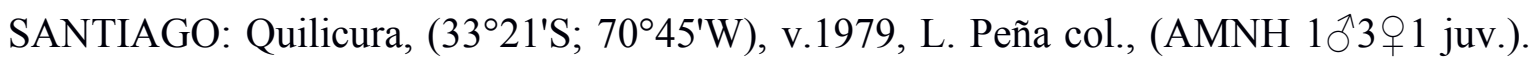

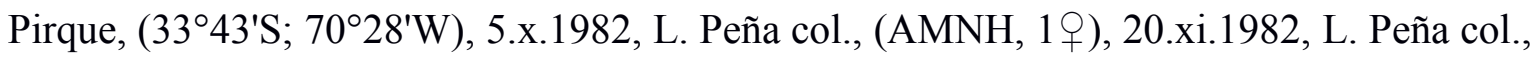
(AMNH 1 1 1 juv.), 30.xi.1982, L. Peña col., (AMNH, 11). REGIÓN DE LOS LAGOS (X): Chiloé Prov., Chiloé, Río Pudeto, Puente Río Pudeto, (4152'S; 7346'W), 28.ii.1972, T. Cekalovic col., (AMNH 326269, 21 đ̋5 
Hypselistoides lobatus (Millidge, 1991) comb. nov.

Figs. 61-66, Mapa 2B.

Sphecozone lobata Millidge, 1991: 176, f. 747-749, 753 (holótipo macho de Plazoleto de

Yunque, Valle Anson, Mas a Tierra, Arquipélago Juan Fernandez, Chile, depositado no AMNH).

Material tipo examinado: CHILE. ARQUIPÉLAGO JUAN FERNÁNDEZ: Mas a Tierra

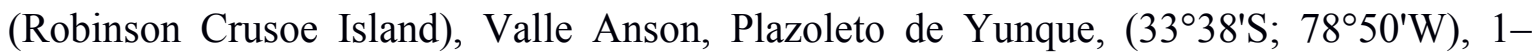
28.iv.1962, B. Malkin col., (AMNH 326273, 1ð̂, holótipo).

Diagnose: Machos de H. lobatus lembram os de $H$. modicus pela presença de um processo ventral da tíbia do palpo. Diferencia-se de H. modicus pela presença de cerdas modificadas na região retrolateral do címbio (Figs. 62, 65, 66). Fêmeas se assemelham às de $H$. modicus pela forma alongada e curvada da espermateca e a placa dorsal alargada. Diferenciam-se de H. modicus pela forma do processo anterior da placa ventral, mais proeminente em H. lobatus (Figs.64-66).

Descrição: Macho (Holótipo; AMNH 326273) de Plazoleto de Yunque, Valle Anson, Mas a Tierra, Arquipélago Juan Fernandez, Chile. Comprimento total 1,49. Carapaça 0,73 de comprimento, 0,57 de largura, alaranjada, com região cefálica elevada. Esterno 0,36 de comprimento, 0,34 de largura, alaranjada, com bordas escuras. Clípeo 0,25 de altura. Quelícera com 6 dentes promarginais e 5 retromarginais. Abdômen de coloração bege. Diâmetro dos olhos e distância: OMA 0,03; OLA 0,04; OMP 0,04; OLP 0,04. Distância entre os OMA 0,87 vezes seu diâmetro, distância entre os OMP 2,60 vezes seu diâmetro, distância entre OMA-OLA 2,36 vezes o diâmetro do OLA, distância entre OMP-OLP 2,40 vezes o diâmetro do OLP. Distância entre coxa IV 1,35 vezes sua largura. Fórmula das pernas I-II-IV-III. Fêmur I/II/III/IV 0,45/0,42/0,35/0,50; patela I 0,17; tíbia I 0,36; metatarso I 0,31; tarso I 0,28. Pernas amareladas. Fêmur/patela/tíbia/címbio do palpo 0,27/0,15/0,09/0,30. TmI 0,40. TmIV ausente. Palpo apresenta cavidade basal do címbio, protégulo pequeno e papilas no tégulo. O supratégulo apresenta estrias. A membrana embólica está presente, o êmbolo é longo e em espiral, apresenta uma projeção que se 
estende além de sua abertura. O radix é liso, apresenta processo anterior robusto. Tíbia com apófise prolateral da tíbia e retrolateral, apresenta um tricobótrio prolateral e um retrolateral. (Figs. 61-62, 65-66).

Fêmea (MCTP 34064) de Cidreira, Rio Grandedo Sul, Brasil. Comprimento total 1,25. Carapaça 0,51 de comprimento, 0,48 de largura, com tonalidades mais escuras que do macho, apresenta coloração castanha com mancha escura na região cefálica. Esterno 0,30 de comprimento, 0,36 de largura, castanho com bordas escuras. Clípeo 0,09 de altura. Quelícera com 6 dentes promarginais e 5 retromarginais. Abdômen de coloração bege escuro. Diâmetro dos olhos e distância: OMA 0,03; OLA 0,04; OMP 0,05; OLP 0,04. Distância entre os OMA 0,31 vezes seu diâmetro, distância entre os OMP 0,82 vezes seu diâmetro, distância entre OMA-OLA 0,71 vezes o diâmetro do OLA, distância entre OMP-OLP 0,77 vezes o diâmetro do OLP. Distância entre coxa IV 1,68 vezes sua largura. Fórmula das pernas I-II-IV-III. Fêmur I/II/III/IV 0,37/0,34/0,29/0,38; patela I 0,15; tíbia I 0,28; metatarso I 0,21; tarso I 0,22. Pernas alaranjadas. Fêmur/patela/tíbia/tarso do palpo 0,17/0,08/0,09/0,17. TmI 0,37. TmIV ausente. Palpos com macrosetas dorsoectal proximal e dorsoectal distal, apresenta 3 macrosetas ventromesal e 2 ventroectal. Epígino complaca dorsal larga, átrios curvados, em forma de "C". Duto copulatório encapsulado, membrana interna (IM) presente, espermateca oval e encurvada. (Figs. 63, 64, 66).

Variação: Machos ( $\mathrm{n}=10)$ : Comprimento total 1,19-1,6 (média 1,33); comprimento da carapaça 0,58-0,67 (média 0,63); largura da carapaça 0,44-0,53 (média 0,49); comprimento do fêmur I 0,37-0,45 (média 0,41).

Fêmeas ( $\mathrm{n}=4)$ : Comprimento total 1,33-1,57 (média 1,45); comprimento da carapaça $0,57-$ 0,64 (média 0,59); largura da carapaça 0,49-0,55 (média 0,52); comprimento do fêmur I 0,41-0,45 (média 0,43).

Obs.: Devido ao estado de conservação do holótipo, os demais machos analisados apresentam uma coloração mais escura, se assemelhando à tonalidades da fêmea, aqui descrita.

Distribuição: Brasil (Rio Grande do Sul), Chile (Arquipélago Juan Fernández). Mapa 2B.

Material examinado: BRASIL. RIO GRANDE DO SUL: Cidreira, (30 $\left.8^{\prime} \mathrm{S} ; 50^{\circ} 16^{\prime} \mathrm{W}\right)$, 
17.v.2003, J. A. M. Pinto col. (MCTP 22069, 34065, 34066, 37091, 37093, 37095, 10§)), 31.v.2003, J. A. M. Pinto col., (MCTP 34091, 1ð), 14.vi.2003, J. A. M. Pinto col., (MCTP 34045, 34076, 34089, 37133, 7ð), 28.vi.2003, J. A. M. Pinto col., (MCTP 34068, 34071, 34075, 34087, 6ठ1ㅜ), 7.vii.2003, J. A. M. Pinto col., (MCTP 34144, 1ठ̋), 12.vii.2003, J. A. M. Pinto col., (MCTP 34116, 37099, 37102, 37107, 9ð2ㅇ) 27.vii.2003, J. A. M. Pinto col., (MCTP 37090, 37101, 37105, 4ठ), 10.viii.2003, J. A. M. Pinto col., (MCTP 37103, 37215, 8§), 24.viii.2003, J. A. M. Pinto col., (MCTP 34155, 37092, 37094, 37097, 6§), 20.ix.2003, J. A. M. Pinto col., (MCTP 34149, 34167, 37096, 37100, 14ð2우).

Hypselistoides modicus (Millidge, 1991) comb. nov.

Figs. 73-77, Mapa 2B.

Sphecozone modica Millidge, 1991: 177, f. 750-752, 754-755 (macho holótipo e fêmea parátipo de Chilecito, La Rioja, Argentina, depositado no AMNH.)

Sphecozone modica. Miller, 2007: 187.

Material tipo examinado: ARGENTINA. LA RIOJA: 5km E. Chilecito, $\left(29^{\circ} 08^{\prime} \mathrm{S}\right.$; $\left.67^{\circ} 27^{\prime} \mathrm{W}\right)$, xii.1971, Lee Herman col., (AMNH 326247, 1今, holótipo).

Diagnose: Machos de $H$. modicus lembram os de $H$. lobatus pela presença de um processo ventral da tíbia do palpos do macho. Se diferenciam de H. modicus pela ausência de cerdas modificadas na região retrolateral do címbio (Figs. 74, 77). Fêmeas se assemelham às de H. lobatus pela forma alongada e curvada da espermateca e a placa dorsal alargada. Diferencia-se de $H$. lobatus pela forma do processo anterior da placa ventral, mais discreto em H. modicus (Figs.76, 77).

Descrição: Macho (Holótipo; AMNH 326247) de Chilecito, La Rioja, Argentina. Comprimento total 1,47. Carapaça 0,66 de comprimento, 0,55 de largura, castanho, com região cefálica sutilmente elevada. Esterno 0,33 de comprimento, 0,40 de largura, alaranjado. Clípeo 0,14 de altura. Quelícera com 6 dentes promarginais e 5 retromarginais. Abdômen bege. Diâmetro dos olhos e distância: OMA 0,03; OLA 0,05; OMP 0,05; OLP 0,05. Distância entre os OMA 0,51 vezes seu diâmetro, distância entre os OMP 0,91 vezes 
seu diâmetro, distância entre OMA-OLA 0,81 vezes o diâmetro do OLA, distância entre OMP-OLP 0,89 vezes o diâmetro do OLP. Distância entre coxa IV 1,62 vezes sua largura. Fórmula das pernas I-II-IV-III. Fêmur I/II/III/IV 0,45/0,40/0,36/0,49; patela I 0,16; tíbia I 0,35; metatarso I 0,29; tarso I 0,27. Pernas alaranjadas. Fêmur/patela/tíbia/címbio do palpo 0,22/0,11/0,09/0,30. TmI 0,35. TmIV ausente. Címbio do palpo apresenta cavidade basal. Tégulo com papilas, supratégulo liso. Êmbolo alongado, cilíndrico e em espiral, radix apresenta processo anterior robusto. Tíbia com apófise prolateral e ventral, possui um tricobótrio prolateral e um retrolateral. (Figs. 73-74, 77).

Fêmea (MCN 404221) do Parque Copesul de Proteção Ambiental, Triunfo, Rio Grande do Sul, Brasil. Comprimento total 1,19. Carapaça 0,55 de comprimento, 0,50 de largura, alaranjada. Esterno 0,55 de comprimento, 0,50 de largura, alaranjado com bordas escurecidas. Clípeo 0,08 de altura. Quelícera com 6 dentes promarginais e 5 retromarginais. Abdômen bege. Diâmetro dos olhos e distância: OMA 0,04; OLA 0,04; OMP 0,05; OLP 0,06. Distância entre os OMA 0,51 vezes seu diâmetro, distância entre os OMP 0,67 vezes seu diâmetro, distância entre OMA-OLA 0,55 vezes o diâmetro do OLA, distância entre OMP-OLP 0,58 vezes o diâmetro do OLP. Distância entre coxa IV 1,58 vezes sua largura. Fórmula das pernas I-II-IV-III. Fêmur I/II/III/IV 0,42/0,37/0,32/0,43; patela I 0,14; tíbia I 0,32; metatarso I 0,27; tarso I 0,26. Pernas amareladas. Fêmur/patela/tíbia/tarso do palpo 0,15/0,06/0,11/0,19. TmI 0,41. TmIV ausente. Palpo com 3 macrosetas ventromesal e 2 ventroectal. Epígino proeminente, apresenta placa dorsal mais larga do que longa. Átrios curvados, em forma de " $\mathrm{C}$ ". Duto copulatório não encapsulado, duto de fertilização orientado mesalmente. Espermateca oval, muito longa e curvada dorsalmente. (Figs. 75-77).

Variação: Machos ( $\mathrm{n}=3$ ): Comprimento total 1,07-1,23 (média 1,17); comprimento da carapaça $0,5-0,60$ (média 0,58 ); largura da carapaça $0,46-0,48$ (média 0,48 ); comprimento do fêmur I 0,35-0,37 (média 0,35).

Fêmeas ( $\mathrm{n}=2$ ): Comprimento total 1,19-1,34 (média 1,26); comprimento da carapaça 0,550,58 (média 0,56); largura da carapaça 0,46-0,50 (média 0,48); comprimento do fêmur I $0,38-0,42$ (média 0,41 ).

Distribuição: Argentina (La Rioja) e Brasil (Rio Grande do Sul). Mapa 2B. 
Material examinado: BRASIL. RIO GRANDE DO SUL: Triunfo, $\left(29^{\circ} 55^{\prime} \mathrm{S} ; 5^{\circ} 43^{\prime} \mathrm{W}\right)$, 2.xii.2010, E. N. L. Rodrigues col., (MCN 47610, 1ठ), x-xi.2005, C. V. Ribeiro col., (MCN 40422, 1q). Cachoeirinha, Estação Experimental do Arroz, Irga $\left(30^{\circ} 00^{\prime} \mathrm{S}\right.$;

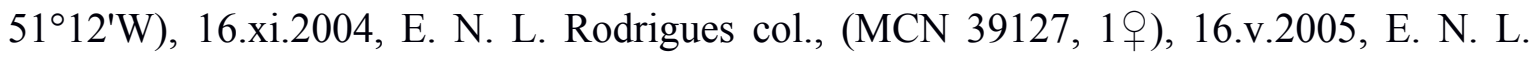

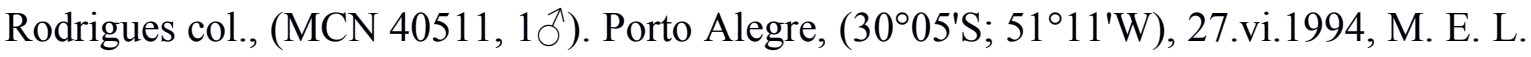
de Souza col., (MCN 25563, 1§̂). Viamão, Parque Estadual de Itapuã, (30²0’S; 5101'W), 17.xii.2003, A. C. K. Ferreira col., (MCTP 20410, 1今).

\section{Hypselistoides cornutus (Millidge, 1991) comb. nov.}

Figs. 34-36, Mapa 4.

Sphecozone cornuta Millidge, 1991: 177, f. 761-764 (Macho holótipo de Isla Don Segismundo, Rio Abra Vieja, Buenos Aires, Argentina).

Sphecozone cornuta. Miller, 2007: 186, 187.

Material tipo examinado: ARGENTINA. BUENOS AIRES: Rio Abra Vieja, Isla Don

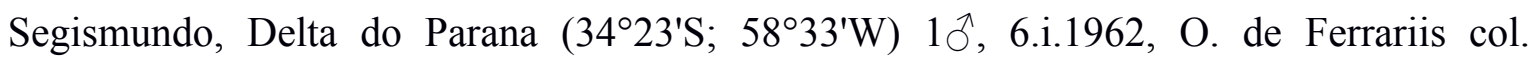
(AMNH 326271, holótipo).

Diagnose: Machos de $H$. cornutus se assemelham aos de $H$. labiatus, $H$. diversicolor, $H$. ignigenus, $H$. corniculans e $H$. crinitus pela forma alongada, semelhante à espinho, do protégulo do palpo. Se diferenciam de $H$. diversicolor, $H$. ignigenus, $H$. corniculans e $H$. crinitus pela estrutura esclerotizada do protégulo, e de H. labiatus, pela ausência de uma apófise prolateral da tíbia (Figs. 35, 36). Fêmea desconhecida.

Descrição: Macho (Holótipo; AMNH 00326271) de Isla Don Segismundo, Rio Abra Vieja, Buenos Aires, Argentina. Comprimento total 1,85. Carapaça 0,81 de comprimento, 0,59 de largura, castanha, com manchas escuras difundindo à partir do centro da região torácica. Região cefálica elevada, com cerdas na região ocular. Esterno 0,44 de comprimento, 0,44 de largura, castanho escuro. Clípeo 0,15 de altura. Quelícera com 5 dentes promarginais e 4 retromarginais. Abdômen preto, com pequenas manchas 
amareladas na região do pulmão e fiandeiras. Diâmetro dos olhos e distância: OMA 0,04; OLA 0,06; OMP 0,07; OLP 0,06. Distância entre os OMA 0,55 vezes seu diâmetro, distância entre os OMP 0,95 vezes seu diâmetro, distância entre OMA-OLA 1,19 vezes o diâmetro do OLA, distância entre OMP-OLP 1,06 vezes o diâmetro do OLP. Distância entre coxa IV 1,19 vezes sua largura. Fórmula das pernas I-II-IV-III. Fêmur I/II/III/IV 0,62/0,58/0,52/0,63; patela I 0,19 ; tíbia I 0,52 ; metatarso I 0,47 ; tarso I 0,35 . Pernas alaranjadas. Fêmur/patela/tíbia/címbio do palpo 0,28/0,10/0,09/0,36. TmI 0,27. TmIV ausente. Palpo com cavidade basal do címbio (BCE), protégulo longo e esclerotisado. Supratégulo liso, sem apófises. Êmbolo longo, em espiral, radix apresenta processo anterior robusto. Tíbia apresenta uma apófise retrolateral (RTA), possui um tricobótrio prolateral e com um tricobótrio retrolateral. (Figs. 34-36).

Fêmea desconhecida.

Variação: $\operatorname{Machos}(\mathrm{n}=3$ ): Comprimento total 1,73-2,31 (média 2,05); comprimento da carapaça 0,85-0,93 (média 0,88); largura da carapaça 0,62-0,72 (média 0,67); comprimento do fêmur I 0,64-1,02 (média 0,79).

Distribuição: Buenos Aires, Argentina, e Rio Grande do Sul, Brasil (Mapa 4).

Material examinado: ARGENTINA. BUENOS AIRES: Parque Pereya $\left(34^{\circ} 50^{\prime} \mathrm{S}\right.$; $\left.58^{\circ} 10^{\prime} \mathrm{W}\right), 28.1 .1962, \mathrm{O}$. de Ferrariis col., (AMNH 326270, 1ð). BRASIL. RIO GRANDE

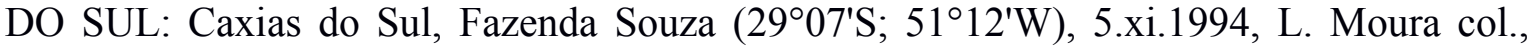

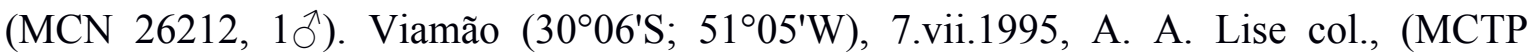
$\left.18286,1{ }^{\Uparrow}\right)$.

Hypselistoides labiatus (Keyserling, 1886) comb. nov.

Figs. 55-60, Mapa 4.

Erigone labiata Keyserling, 1886: 272, fig. 321 (macho e duas fêmeas síntipos de Blumenau, Brasil, depositado no BMNH [Natural History Museum, Londres, Reino Unido], não examinado).

Sphecozone labiata (Keyserling, 1886). Miller, 2007: 200, f. 149C-F, H. 
Diagnose: Machos de H. labiatus se assemelham aos de H. cornutus, H. diversicolor, $H$. ignigenus, $H$. corniculans e $H$. crinitus pela forma alongada, semelhante a espinho, do protégulo do palpo. Se diferenciam de $H$. diversicolor, $H$. ignigenus, $H$. corniculans e $H$. crinitus pela estrutura esclerotizada do protégulo, e de $H$. cornutus, pela presença de uma apófise prolateral da tíbia (Figs. 56, 59, 60). Fêmeas assemelham-se com as de $H$. diversicolor, $H$. ignigena, $H$. crinita e Hypselistoides sp.nov.01 pelas espermatecas envolvidas pelos dutos de copulação, diferenciando-se na forma das espermatecas, mais grossas em H. labiatus (Figs. 58-60).

Descrição: Macho síntipo e fêmea de Blumenau, Brasil com descrições e ilustrações em Miller, 2007, 200, f. 149C-F, H. Imagens adicionais Figs. 55-60.

Variação: $\operatorname{Machos}(\mathrm{n}=10)$ : Comprimento total 1,78-2,20 (média 2,02); comprimento da carapaça 0,84-1,01 (média 0,91); largura da carapaça 0,57-0,70 (média 0,64); comprimento do fêmur I 0,88-1,20 (média 1,03).

Fêmeas $(\mathrm{n}=10)$ : Comprimento total 2,06-2,31 (média 2,18); comprimento da carapaça 0,84-0,96 (média 0,91); largura da carapaça 0,64-0,71 (média 0,67); comprimento do fêmur I 0,92-1,15 (média 1,03).

Distribuição: Registro para Sudeste e Sul do Brasil (Mapa 4).

Material examinado: BRASIL. MINAS GERAIS: Monte Verde, Trilha Pedra Partida,

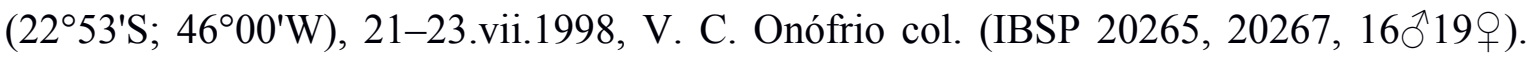
SÃO PAULO: São Luiz do Paraitinga, Parque Estadual da Serra do Mar, Núcleo Santa

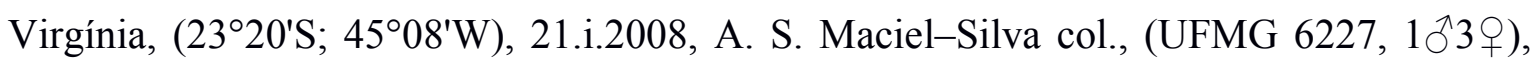
15.viii.2008, A. S. Maciel-Silva col., (UFMG 5596, 1ठ). Ubatuba, Parque Estadual da Serra do Mar, $\left(23^{\circ} 25^{\prime}\right.$ S; 4505'W), xi.1996, L. S. Rocha col., (IBSP 7678, 1ㅇ). Santo André, Paranapiacaba, Estação Biológica do Alto da Serra, $\left(23^{\circ} 46^{\prime} \mathrm{S} ; 46^{\circ} 18^{\prime} \mathrm{W}\right)$, 27.vii.1999, F. S. Cunha col., (IBSP 23965, 1 q). Bertioga, Trilha do rio Itatinga, (2346'S; 46 $06^{\prime}$ W), vii.2000, M. S. C. Morinicol., (IBSP 62384, 19). São Miguel Arcanjo, Parque Estadual de Carlos Botelho, (2403'S; 4759'W), 14.x.1990, A. B. Bonaldo col., (MCN 


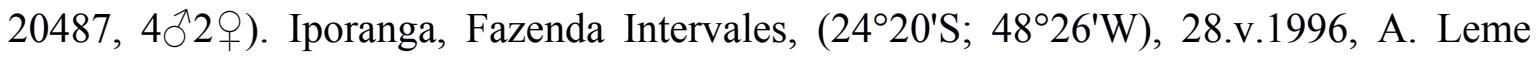
col., (IBSP 8099, 19). PARANÁ: Antonina, Reserva Natural Rio Cachoeira, (2518'S; 4841'W), 26.ix.2005, F. Raub col., MCN 45631, 45642, 44750, $2 \overbrace{}^{\Uparrow} 1$ ㅇ juv.). São José dos Pinhais, (253' S; 49¹2'W), 29.ix.1986, Equipe PROFAUPAR col., (MCN 20509, 19). SANTA CATARINA: Blumenau, Parque Natural Municipal "Nascentes do Garcia", (2703'13.5"S; 4905'W), 21-28.I.2003, Equipe Biota col., (MCN 41117, IBSP 71983, 1§่2 $)$. RIO GRANDE DO SUL: São Francisco de Paula, $\left(29^{\circ} 24^{\prime} \mathrm{S} ; 5^{\circ} 19^{\prime} \mathrm{W}\right), 21-$ 24.iii.1995, A. A. Lise col., (MCTP 11966, 3ð4), 25-28.vii.1996, A. A. Lise et al. col.,

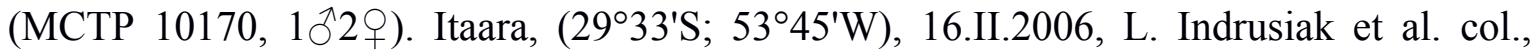
(MCTP 21546, 19). Arroio Teixeira, (2941'S; 4959'W), 15.xi.1985, F. Quadros col., (MCTP 33691, 19). Guaíba, (3005'S; 51ํ1' W), 1.i.1991, A. B. Bonaldo col., (MCN 20695, 1q).

Hypselistoides diversicolor (Keyserling, 1886) comb. nov.

Figs. 43-48, Mapa 5.

Erigone diversicolor Keyserling, 1886: 271, fig. 320 (fêmea holótipo de Blumenau, Brasil, depositado no BMNH [Natural History Museum, Londres, Reino Unido], não examinado). Petrunkevitch, 1911: 234. Mello-Leitão, 1927: 400. Roewer, 1954b: 1496. Bonnet, 1956: 1763.

Ceratinopsis diversicolor. Mello-Leitão, 1941: 15. Platnick, 2004.

Sphecozone cristata Millidge, 1991: 173, figs 729, 730, 735, 736. (macho holótipo de Itu, São Paulo, Brasil, depositado no AMNH). Platnick, 1993: 353; 2004.

Sphecozone diversicolor. Miller, 2007: 196, f. 148A-E, 151A.

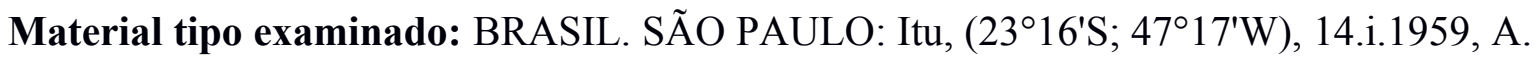
M. Nadler col., (AMNH, 1§, holótipo).

Diagnose: Machos de $H$. diversicolor se assemelham aos $H$. ignigenus, $H$. corniculans e H. crinitus pela forma membranosa do protégulo alongado do palpo, se diferenciando dessas espécies pelas ausência de cerdas em forma de espinhos na parte posterior dorsal do címbio (Figs. 44, 47, 48). Epíginos das fêmeas de H. diversicolor lembram as de H. labiata 
e H. crinita, pela espermateca fortemente alongada, envolto dos dutos copulatórios. Se diferenciam de H. labiata e H. crinita por apresentar o átrio mais reto (Figs. 46-48).

Descrição: Macho e fêmea de Cordilheira, Cachoeira do Sul, Rio Grande do Sul, Brasil. Descrição em Miller, 2007, pp.196-198, f. 148A-E, 151A. Imagens adicionais Figs. 4348 .

Variação: $\operatorname{Machos}(\mathrm{n}=10)$ : Comprimento total 1,84-2,37 (média 2,07); comprimento da carapaça 0,83-1,02 (média 0,91); largura da carapaça 0,66-0,76 (média 0,71); comprimento do fêmur I 0,77-0,98 (média 0,91).

Fêmeas $(\mathrm{n}=10)$ : Comprimento total 1,85-2,61 (média 2,18); comprimento da carapaça 0,74-1,11 (média 0,89); largura da carapaça 0,62-0,79 (média 0,70); comprimento do fêmur I 0,84-1,08 (média 0,92).

Distribuição: Registro para as regiões Sul e Sudeste do Brasil, e sul do Uruguai (Mapa 5).

Material examinado: RIO DE JANEIRO: Santa Maria Madalena, (21 $\left.{ }^{\circ} 57^{\prime} \mathrm{S} ; 42^{\circ} 01^{\prime} \mathrm{W}\right)$, vi.1960, M. Alvarenga col., (AMNH 326263, 20̄, Parátipo). Material adicional: SÃO PAULO: Mogi das Cruzes, Distrito de Biritiba-Ussu, Manuel Ferreira (233' $\mathrm{S}$; $\left.46^{\circ} 07^{\prime} \mathrm{W}\right)$, v.2001, E.Kashimata \& R. Martins col., (IBSP 56377, 56456, 2q). Peruíbe, Estação Ecológica Juréia-Itatins, $\left(24^{\circ} 33^{\prime} 01,5^{\prime \prime} \mathrm{S} ; \quad 4^{\circ} 13^{\prime} 29,2^{\prime \prime} \mathrm{W}\right), \quad 02 . x i .1995, \quad$ R.Bertani \& O.Marques col., (IBSP 6353, 1ठ2ㅇ). PARANÁ: Antonina, Reserva Natural Rio

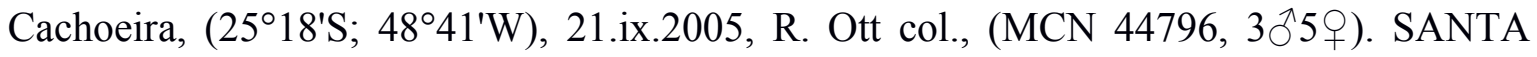

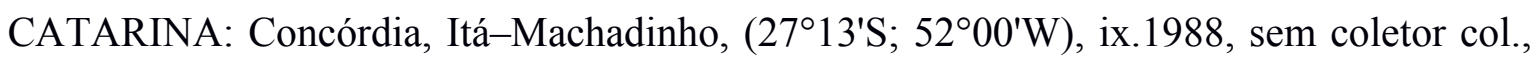
(MCTP 911, $3 \overbrace{}^{\Uparrow} 1$ \%). Itá, Rio Uruguai, $\left(27^{\circ} 17^{\prime} \mathrm{S} ; 52^{\circ} 18^{\prime} \mathrm{W}\right)$, v.1988, Eq. Itá-Machadinho col., (MCTP 899, 1ठ2q1 juv.). RIO GRANDE DO SUL: Machadinho, Rio Apuaê

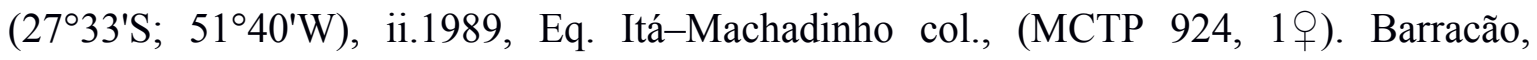
(274'S; 51²7'W), ix.1988, Eq. Itá-Machadinho col., (MCTP 920, 1q). São Francisco de Paula, (29²4'S; 50¹9'W), 25-28.vii.1996, A. A. Lise et al. col., (MCTP 10558, 1q), 1.ix.1996, A. A. Lise et al. col., (MCTP 10576, 39), 28.v.1999, F. Diefenthaeler col., (MCTP 15309, 1ठ), 23.i.1956, S. Correa col., (MCTP 4551, 2ð7q). Montenegro,

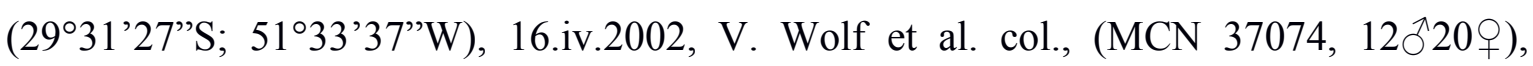


5.ix.2002, V. Wolf et al. col., (MCN 37190, $28 \overbrace{}^{\lambda} 25$ 우 juv.), 8.x.2002, V. Wolf et al. col., (MCN 37218, 28ð43ㅇ), 15.x.2002, V. Wolf et al. col., (MCN 37208, $17 \precsim 29+$ ). Capão da Canoa, Capão Novo, (29³9'S; 5001'W), 17-18.iv.1993, A. A. Lise col., (MCTP 3151, 2+). Viamão, Estação Experimental Secrataria da Agricultura, (3002'S; $\left.51^{\circ} 1^{\prime} \mathrm{W}\right)$, 7.x.1991, M. C. de Paula col., (MCTP 2852, $1 \overbrace{}^{\Uparrow} 1$ juv.), 7.vii.1995, A. A. Lise et al. col., (MCTP 16375, 19), 12.viii.1994, A. A. Lise et al. col., (MCTP 5287, 1ठ). Viamão,

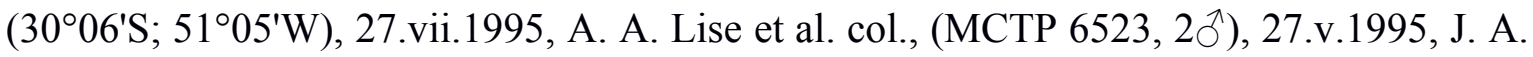
M. Pinto col., (MCTP 6065, 1ठ), 11.vii.1992, R. G. Buss col., (MCTP 3280, 1ठ)), 27.viii.1992, R. G. Buss col., (MCTP 3295, 497 juv.), 29.viii.1992, R. G. Buss col., (MCTP 3304, 6ð5ㅇ), 17.x.1992, R. G. Buss col., (MCTP 3303, 4ð6ㅇ), 27.x.1992, R. G. Buss col., (MCTP 3281, $1 \lesssim 6 q 1$ juv.), 14.xii.1992, R. G. Buss col., (MCTP 3287, 3288, 4ð23ㅇ 1 juv.), 27.xii.1992, R. G. Buss col., (MCTP 7281, 3ð), 18.v.1993, R. G. Buss col., (MCTP 3984, 4576, 3ðึ41 juv.), 30.xi.1993, R. G. Buss col., (MCTP 4246, 1ठ10), 30.xii.1993, R. G. Buss col., (MCTP 4352, 4353, 3ð̊69). URUGUAI. LAVALLEJA: Arequita, Cerro Arequita, (34 $\left.17^{\prime} \mathrm{S} ; 5^{\circ} 16^{\prime} \mathrm{W}\right)$, 05.xii.1997, A.D.Brescovit col., (IBSP $\left.14453,1{ }^{\Uparrow}\right)$.

\section{Hypselistoides ignigenus (Keyserling, 1886) comb. nov.}

Figs. 49-54, Mapa 5.

Erigone ignigena Keyserling, 1886: 268, fig. 316 (macho holótipo do Rio Grande do Sul ("Rio Grande"), Brasil, depositado no BMNH [Natural History Museum, Londres, Reino Unido]).

Sphecozone tincta Millidge, 1991: 174-175, figs 731, 732, 737 (macho holótipo de

Pelotas, Brasil, depositado no AMNH). Rodrigues, 2005: 103-105, f. 1-11.

Sphecozone ignigena. Miller, 2007: 198, f. 148A-B, G, 151B.

Material tipo examinado: BRASIL. RIO GRANDE DO SUL: Pelotas, $\left(31^{\circ} 46^{\prime} \mathrm{S}\right.$; 52²2'W), xii.1960, C. Biezanko col., (AMNH, 1ð̄, holótipo).

Diagnose: Machos de $H$. ignigena se assemelham aos de $H$. diversicolor, $H$. corniculans e H. crinita pela forma alongada e hialina do protégulo do palpo. Se diferencia dessas 
espécies por apresentar uma apófise retrolateral em forma de espinho e apófise prolateral mais alto, distalmente com forma de gancho (Figs. 50, 53, 54). Fêmeas de $H$. ignigena se diferenciam das demais especies de Hypselistoides por apresentar a placa dorsal mais longa do que larga (Figs. 52-54).

Descrição: Macho e fêmea (do Rio Grande do Sul, Brasil). Descrição em Rodrigues, 2005, páginas 103-105, figuras 1-11 (como S. Tincta), e em Miller, 2007, páginas 198-200, figuras 148A-B, G, 151B. Imagens adicionais figs. 49-54.

Variação: $\operatorname{Machos}(\mathrm{n}=10)$ : Comprimento total 1,78-2,26 (média 2,03); comprimento da carapaça 0,89-1,13 (média 1,02); largura da carapaça 0,68-0,82 (média 0,74); comprimento do fêmur I 0,91-0,98 (média 0,95).

Fêmeas $(\mathrm{n}=10)$ : Comprimento total 2,27-2,98 (média 2,63); comprimento da carapaça 0,94-1,20 (média 1,09); largura da carapaça 0,75-1,01 (média 0,85); comprimento do fêmur I 0,95-1,37 (média 1,06).

Distribuição: Registro para regiões Sudeste e Sul do Brasil (Mapa 5).

Material examinado: BRASIL. MINAS GERAIS: Ouro Preto, Parque Estadual de Itacolomi, (20²6'S; 4327'W), 11-13.iv.2008, K. P. Santos et al. col., (UFMG 2196, 1 q). SÃO PAULO: São Paulo, Parque da Previdência, (233''"S; 46²4'W), 12.xii.2000, F. S. Cunha et alcol., (IBSP 26294, 2`3+). RIO GRANDE DO SUL: Torres, $\left(29^{\circ} 20^{\prime} \mathrm{S}\right.$;

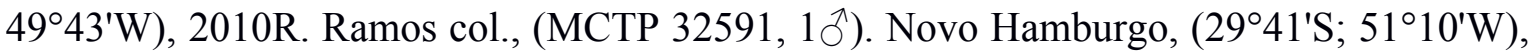

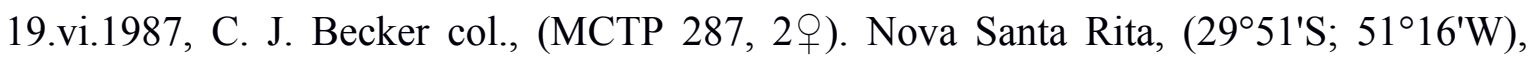
23.v.2009, A. Oliveira col., (MCTP 37274, 19). Eldorado do Sul, Parque Estadual Delta do Jacuí, Fazenda Kramm (2958’S; 51¹8’W), 29.x.1998, L. A. Moura col., (MCN 30401, 5ㅇ). Guaíba, (3005'S; 51¹9'W), 3.x.1995, A. A. Lise et al. col., (MCTP 9179, 10), 24.x.1995, A. A. Lise et al. col., (MCTP 9045, 1ㅇ). Cidreira, (308'S; 50¹6'W), 12.vii.2003, J. A. M. Pinto col., (MCTP 37117, 1 ㅇ). Cachoeira do Sul, 18.v.1992, R. G. Buss col., (MCTP 3986, 1ठ゚), 10.x.1992, R. G. Buss col., (MCTP 3297, 19), 14.x.1992, R. G. Buss col., (MCTP 3292, 1ठ), 13.xi.1993, R. G. Buss col., (MCTP 4220, 1ठ), 30.xi.1993, R. G. Buss col., (MCTP 4245, 19), 2.xii.1992, R. G. Buss col., (MCTP 3306, 
2ㅇ). Viamão, Parque Estadual de Itapuã, (30²0’S; $\left.51^{\circ} 01^{\prime} \mathrm{W}\right)$, 9.iii.2004, A. C. K. Ferreira col., (MCTP 20376, 1ठ), 15.vii.2003, A. C. K. Ferreira col., (MCTP 20350, 1q), 25.viii.1995, A. A. Lise et al. col., (MCTP 7559, 19), 25.xi.1994, A. A. Lise et al. col., (MCTP 7286, 7289, 3ð5), 22.xi.1995, A. A. Lise et al. col., (MCTP 8621, 2q), 15.xii.1995, A. A. Lise et al. col., (MCTP 8797, 9027, 2ð1).

Hypselistoides corniculans (Millidge, 1991) comb. nov.

Figs. 31-33, Mapa 6.

Sphecozone corniculans Millidge, 1991: 166, f. 695-697 (Macho holótipo de Paramo de

Sumapaz, Espec, Colombia, 3600-4000m, depositado no MCZ).

Sphecozone corniculans. Miller, 2007: 186, 187.

Material tipo examinado: COLOMBIA. CUNDINAMARCA: Provincia del Sumapaz,

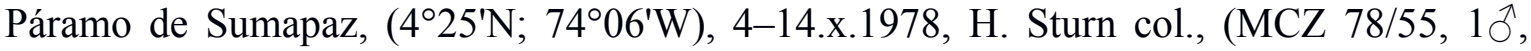
holótipo).

Diagnose: Machos de H. corniculans se assemelham aos de H. diversicolor, H. ignigena e H. crinita pela forma alongada e hialina do protégulo do palpo. Se diferencia dessas espécies por não apresentar uma apófise prolateral (Figs. 32, 33). Fêmeas desconhecidas.

Descrição: Macho (Holótipo; MCZ 78/55) de Páramo de Sumapaz, Provincia del Sumapaz, Cundinamarca, Colômbia. Comprimento total 1,48. Carapaça 0,66 de comprimento, 0,59 de largura, alaranjada. Esterno 0,41 de comprimento, 0,44 de largura, castanho claro com bordas escuras. Clípeo 0,14 de altura. Quelícera com 6 dentes promarginais e 5 retromarginais. Abdômen amarelado, com mancha preta longitudinal, na região dorsal e em volta da fiandeira. Diâmetro dos olhos e distância: OMA 0,03; OLA 0,04; OMP 0,04; OLP 0,04. Distância entre os OMA 0,66 vezes seu diâmetro, distância entre os OMP 1,38 vezes seu diâmetro, distância entre OMA-OLA 1,13 vezes o diâmetro do OLA, distância entre OMP-OLP 1,23 vezes o diâmetro do OLP. Distância entre coxa IV 1,55 vezes sua largura. Fórmula das pernas I-II-IV-III. Fêmur I/II/III/IV $0,65 / 0,56 / 0,49 / 0,64$; patela I 0,17 ; tíbia I 0,53 ; metatarso I 0,46 ; tarso I 0,36 . Pernas 
alaranjadas. Fêmur/patela/tíbia/címbio do palpo 0,26/0,08/0,08/0,35. TmI 0,44. TmIV ausente. Palpo apresenta cavidade basal do címbio, protégulo e papilas no tégulo. Supratégulo liso, não apresenta apófises. Êmbolo longo, em espiral, radix apresenta processo anterior robusto. Tíbia apresenta somente pófise retrolateral (RTA), sem tricobótrio prolateral e com 1 tricobótrio retrolateral. Figs. 31-33.

Fêmea desconhecida.

Distribuição: Conhecido somente pela localidade do tipo (Mapa 6).

Material examinado: somente o material tipo

Hypselistoides crinitus (Millidge, 1991) comb. nov.

Figs. 37-42, Mapa 6.

Sphecozone crinita Millidge, 1991: 167, f. 704-707 (Macho holótipo, com uma fêmea e um macho parátipo, de Baeza (Breza), Napo, Ecuador)

Sphecozone crinita. Miller, 2007: 186, 187.

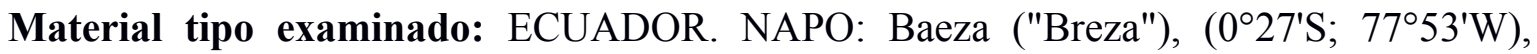
4.ii.1976, R. T. Schuh col., (AMNH, 1ठ, holótipo), 4.ii.1976, R. T. Schuh col., (AMNH 326261, $1 \bigcirc^{\Uparrow} 1$, parátipo).

Diagnose: Machos de $H$. crinita se assemelham aos de $H$. ignigena pela forma alongada e hialina do protégulo do palpo e pela presença de uma apófise retrolateral e apófise prolateral, diferenciando-se pela forma discreta das apófises em H. crinita (Figs. 38, 41, 42). Fêmeas de $H$. crinita se assemelham às de $H$. labiata e $H$. diversicolor pelas espermatecas fortemente alongadas e envolvidas pelos duto de copulação, se diferenciando de $H$. labiata e $H$. diversicolor pela forma da depressão lateral da placa ventral, mais discreta em $H$. crinita (Figs. 40-42).

Descrição: Macho (Parátipo; AMNH 326261) de Baeza (Breza), Napo, Ecuador. Comprimento total 1,72. Carapaça 0,74 de comprimento, 0,57 de largura, de coloração 
amarelada, região cefálica ligeiramente mais escura. Esterno 0,40 de comprimento, 0,44 de largura, marrom claro, com bordas mais escuras. Clípeo 0,20 de altura. Quelícera com 5 dentes promarginais e 4 retromarginais. Abdômen amarelado (material em mau estado de conservação). Diâmetro dos olhos e distância: OMA 0,04; OLA 0,05; OMP 0,05; OLP 0,06. Distância entre os OMA 0,67 vezes seu diâmetro, distância entre os OMP 1,33 vezes seu diâmetro, distância entre OMA-OLA 0,76 vezes o diâmetro do OLA, distância entre OMP-OLP 0,79 vezes o diâmetro do OLP. Distância entre coxa IV 1,38 vezes sua largura. Fórmula das pernas I-II-IV-III. Fêmur I/II/III/IV 0,71/0,69/0,52/0,70; patela I 0,16; tíbia I 0,62; metatarso I 0,60 ; tarso I 0,39. Pernas de coloração amarelada. Fêmur/patela/tíbia/címbio do palpo 0,22/0,10/0,09/0,40. TmI 0,23. TmIV ausente. Palpo com cavidade basal do címbio. Protégulo presente, papilas presentes no tégulo, supratégulo liso, apresentando uma apófise lisa. Membrana embólica presente, êmbolo longo em espiral, radix liso, apresenta processo anterior robusto. Tíbia com apófise prolateral, apresenta dente distal, apófise retrolateral da tíbia presente. Tíbia com um tricobótrio prolateral e um retrolateral. (Figs. 37-38, 41-42).

Fêmea (Parátipo; AMNH 326261) de mesma localidade do macho. Comprimento total 1,82. Carapaça 0,71 de comprimento, 0,59 de largura, com tons alaranjado. Esterno 0,39 de comprimento, 0,45 de largura, alaranjado, com bordas escuras. Clípeo 0,13 de altura. Quelícera com 5 dentes promarginais e 4 retromarginais. Abdômen amarelado, mais escuro que o do macho, com mancha preta ao redor das fiandeiras. Diâmetro dos olhos e distância: OMA 0,03; OLA 0,06; OMP 0,06; OLP 0,06. Distância entre os OMA 0,50 vezes seu diâmetro, distância entre os OMP 0,84 vezes seu diâmetro, distância entre OMA-OLA 0,65 vezes o diâmetro do OLA, distância entre OMP-OLP 0,64 vezes o diâmetro do OLP. Distância entre coxa IV 1,72 vezes sua largura. Fórmula das pernas III-IV-III. Fêmur I/II/III/IV 0,72/0,67/0,56/0,74; patela I 0,17; tíbia I 0,58; metatarso I 0,61; tarso I 0,38. Pernas alaranjadas. Fêmur/patela/tíbia/tarso do palpo 0,22/0,09/0,14/0,28. TmI 0,28. TmIV ausente. Palpo apresenta macrosetas dorsomesal distal, 2 macrosetas ventromesal e 1 ventroectal. Epígino apresenta duas pequenas depressões laterais na parte distal da placa ventral. Os átrios são curvados, em forma de "C". Espermateca de forma oval. (Figs. 39-42).

Variação: $\operatorname{Machos}(\mathrm{n}=2)$ : Comprimento total 1,63-1,73 (média 1,68); comprimento da 
carapaça 0,80-0,81 (média 0,81); largura da carapaça 0,63-0,66 (média 0,64); comprimento do fêmur I 0,66-0,69 (média 0,68).

Fêmeas $(n=3)$ : Comprimento total 1,71-2,05 (média 1,86); comprimento da carapaça 0,76-0,86 (média 0,81); largura da carapaça 0,58-0,66 (média 0,63); comprimento do fêmur I 0,66-0,74 (média 0,71).

Obs.: Material em melhor estado de conservação, carapaças tem tonalidades alaranjadas mais escuras, os abdômens mais amarelados possuem manchas pretas longitudinais na parte dorsal e ao redor das fiandeiras

Distribuição: Conhecida para Equador e região Sul do Brasil (Mapa 6).

Material examinado: BRASIL. SANTA CATARINA: Rancho Queimado, $\left(27^{\circ} 40^{\prime} \mathrm{S}\right.$; 49¹3'W), 15-18.xi.1995, A. B. Bonaldo col., (MCN 26856, $2{ }^{\jmath} 3$ \% ). RIO GRANDE DO SUL: São Francisco de Paula, Potreiro Velho, (29²4'S; 50¹9'W), vii.2001, L. A. Bertoncello et al. col., (MCTP 26049, 1ð), ix.2001, L. A. Bertoncello et al. col., (MCTP 25735, 19), i.2002, L. A. Bertoncello et al. col., (MCTP 25743, 19), v.2002, L. A. Bertoncello et al. col., (MCTP 24144, 1§).

Hypselistoides sp.nov.01 Rodrigues, Lemos, Brescovit, in prep.

Figs. 96-98, Mapa 2A.

Material tipo examinado: BRASIL. RIO GRANDE DO SUL: São Francisco de Paula, Potreiro Velho, $\left(29^{\circ} 24^{\prime} \mathrm{S} ; 50^{\circ} 19^{\prime} \mathrm{W}\right), 1{ }^{\Uparrow} 1$ +, $3 . v .2000$, J. Ketterl col. (MCTP 16331, holótipo). BRASIL, SÃO PAULO: São Paulo, Parque Estadual da Cantareira, Núcleo

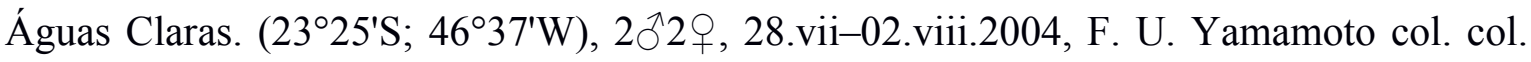
(IBSP 76122; 76128, parátipo), 2ð19, 12-17.v.2005, F. U. Yamamoto col. col. (IBSP 76303, parátipo), $3 \partial^{\circledR} 2$ q, 02-07.ii.2005, F. U. Yamamoto col. col. (IBSP 76195, parátipo). SANTA CATARINA: Siderópolis $\left(28^{\circ} 34^{\prime} \mathrm{S} ; 4^{\circ} 31^{\prime} \mathrm{W}\right), 4{ }^{\Uparrow} 1$ ㅇ, 08.vii.2006, R. A. Teixeira col. (IBSP 84826, parátipo). RIO GRANDE DO SUL: São Francisco de Paula (29²6'S;

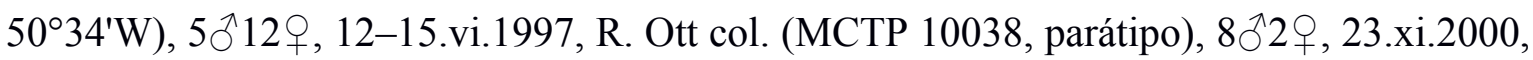
R. Ott et al. col. (MCTP 19064, parátipo). 
Diagnosis: Machos de Hypselistoides sp.nov.01 se assemelham aos de $H$. nigripes e $H$. bicolor por apresentarem um processo basal do êmbolo. Diferencia-se dessas espécies por possuir um processo ventral da tibia do palpo (Figs. 97, 98). Fêmeas de Hypselistoides sp.nov.01 lembram às de $H$. labiata, $H$. diversicolor, $H$. ignigena e $H$. crinitus pela forma do epígino, que possuem as espermatecas envolvidos pelos dutos copulatórios. Diferenciam-se destas espécies pela forma da arredondada espermateca (Figs. 97, 98).

Descrição: Macho (Holótipo; MCTP 16331) de São Francisco de Paula, Rio Grande do Sul. Comprimento total 1,63. Carapaça 0,73 de comprimento, 0,61 de largura, alaranjado com manchas escuras na região cefálica. Esterno 0,43 de comprimento, 0,41 de largura, laranja com borda amarronzada. Abdômen amarelado mancha preta na parte dorsal, perto das fiandeiras. Clípeo 0,13 de altura. Quelícera com 0,24 de comprimento. Diâmetro dos olhos e distância: OMA 0,04; OLA 0,07; OMP 0,07; OLP 0,06. OMA-OMA: 0,03. OMPOMP: 0,04, OMA-OLA: 0,04, OMP-OLP: 0,05. Olhos agrupados em uma região levemente elevada. Distância entre as coxas IV 0,15. Fórmula da perna I-IV-II-III. Fêmur I/II/III/IV $\quad 0,72 / 0,61 / 0,54 / 0,73 ;$ patela $\mathrm{I} / \mathrm{II} / \mathrm{III} / \mathrm{IV} \quad 0,2 / 0,18 / 0,18 / 0,15 ;$ tíbia $\mathrm{I} / \mathrm{II} / \mathrm{III} / \mathrm{IV}$ 0,67/0,55/0,46/0,66; metatarso I/II/III/IV 0,52/0,48/0,42/0,52; tarso I/II/III/IV 0,45/0,41/0,32/0,36. Comprimento total da perna I/II/III/IV 2,56/2,23/1,92/2,42. Pernas com todos os segmentos amarelados. Fêmur/patela/tíbia/címbio do palpo 0,22/0,1/0,18/0,35. TmI 0,28. TmIV presente. Tíbia com um tricobótrio retrolateral, apófise prolateral da tíbia em forma de gancho, com pequenos dentes na margem. Címbio com uma carena dorsal na região proximal. Pequeno protégulo e tégulo com pequenas papilas. Cauda do radix estreito e em espiral. Membrana embólica e processo anterior do radix presente. Êmbolo longo, fino e espiral. (Figs. 96-98).

Fêmea (Parátipo; MCTP 16331), mesma localidade do macho. Comprimento total 1,72. Carapaça 0,71 de comprimento, 0,6 de largura. Esterno 0,45 de comprimento, 0,43 de largura. Padrão de coloração do abdômen, carapaça e esterno como no macho. Clípeo 0,12 de altura. Quelícera 0,26 de altura. Diâmetro dos olhos e distância: OMA 0,03; OLA 0,06; OMP 0,06; OLP 0,05. OMA-OMA: 0,03, OMP-OMP: 0,04, OMA-OLA: 0,04, OMPOLP: 0,04 . Região cefálica não elevada como no macho. Distância entre coxa IV 0,16. Fórmula da perna I-IV-II-III. Fêmur I/II/III/IV 0,68/0,67/0,6/0,72; patela I/II/III/IV 0,21/0,2/0,19/0,16; tíbia I/II/III/IV 0,63/0,58/0,49/0,66; metatarso I/II/III/IV 
0,52/0,49/0,43/0,51; tarso I/II/III/IV 0,44/0,42/0,32/0,37. Comprimento total da perna I/II/III/IV 2,48/2,36/2,03/2,42. Padrão de coloração da perna como no macho. Fêmur/patela/tíbia/tarso do palpo 0,23/0,07/0,17/0,21. TmI 0,28. TmIV presente. Epígino com átrios curvados. Lóbulo anterior da placa dorsal tão larga quanto a placa dorsal. Dutos copulatórios esclerotizados, dutos de fertilização originando da parte posterior da espermateca, percorre mesalmente. Espermateca oval (Figs. 96-98).

Variação: Machos ( $\mathrm{n}=10)$ : Comprimento total $1,61-1,87$; comprimento da carapaça $0,61-$ 0,76; largura da carapaça 0,54-0,58; Comprimento fêmur I 0,69-0,73.

Fêmeas $(n=10)$ : Comprimento total $1,65-2,13$; comprimento da carapaça $0,71-0,78$; largura da carapaça $0,56-0,67$; Comprimento fêmur I 0,71-0,81.

Distribuição: Registro para Sudeste e Sul do Brasil (Mapa 2A).

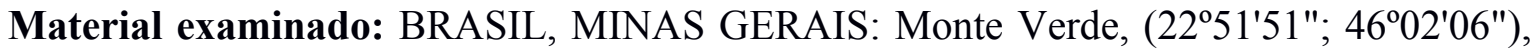
2ᄋ, 17-18.xi.2001, A.D.Brescovit et al col. (IBSP 31863). RIO DE JANEIRO: Volta

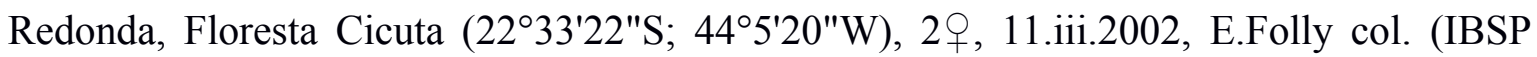
39603). SÃO PAULO: São Paulo, Parque Estadual da Cantareira, Núcleo Águas Claras. $\left(23^{\circ} 25^{\prime} \mathrm{S} ; 46^{\circ} 37^{\prime} \mathrm{W}\right), 60{ }^{\wedge} 11$,, $02-07 . i i .2005$, F. U. Yamamoto col. col. (IBSP 7618876194; 76196-76198; 76200-76223; 76312-76323), 50ð8ㅇ, 12-17.v.2005, F. U. Yamamoto col. col. (IBSP 73483; 76262-76302; 76304-76308; 76311), 21§13，1419.xi.2004, F. U. Yamamoto col. col. (IBSP 76158-76187), 35 ${ }^{\uparrow} 9$ \% , 28.vii-02.viii.2004, F. U. Yamamoto col. col. (IBSP 73481; 76113-76121; 76123; 76124; 76126; 76127; 76129; 76132-76135; 76137-76144; 76146; 76147; 76149-76151; 76153; 76154; 76156; $76309 ; 76310)$; Mogi das Cruzes, Parque Natural Municipal da Serra do Itapety $\left(23^{\circ} 28^{\prime} \mathrm{S}\right.$; $\left.46^{\circ} 9^{\prime} \mathrm{W}\right), 1 \partial^{\top}, 13-18 . x .2003$, Equipe Biota col. (IBSP 55115); Iporanga, Parque Estadual

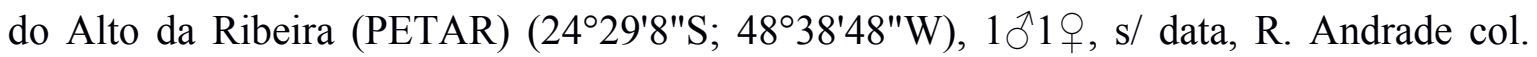
(IBSP 29346; 29350), 1ठ̄, 02.v.2002, R. Andrade col. (IBSP 44801). SANTA CATARINA: Ilhota, Morro do Baú, (2648’29”S; 4857’19”W), 20, 4.ii.1996, A. B.

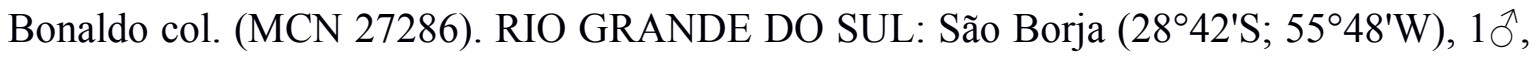
2006, R. Camargo col. (IBSP 70327). São Francisco de Paula, Barragem Passo do Inferno (2916'28"S; 5044'6"W), 2へ, 20-22.iii.2001, R. Ott col. (MCN 33766). São Francisco de 
Paula, Potreiro Velho $\left(29^{\circ} 24^{\prime} \mathrm{S} ; 50^{\circ} 19^{\prime} \mathrm{W}\right), 3{ }^{\wedge} 2$, $25 . x .2000$, R. Ott et al. col. (MCTP 19058; 19063), 1ð2q, 2.i.2001, R. Ott et al. col. (MCTP 19065), 2q, 3.iii.2001, R. Ott et al. col. (MCTP 19067), 3 , , 7.iv.2001, R. Ott et al. col. (MCTP 19068), 1q, 14.ix.2001, R. Ott et al. col. (MCTP 19074), 1q, 7.vii.2001, R. Ott et al. col. (MCTP 19072), 1ð̂, 9.viii.2001, R. Ott et al. col. (MCTP 19059), 10̂, 11.x.2001, R. Ott et al. col. (MCTP 19075), 19, 14.iv.2002, R. Ott et al. col. (MCTP 19060), 3 q, 18.v.2002, R. Ott et al. col. (MCTP 19071). Canela (29²0'S; 5047'W), 3ㅇ, 10.ix.2005, M. Barros et al. col. (MCN

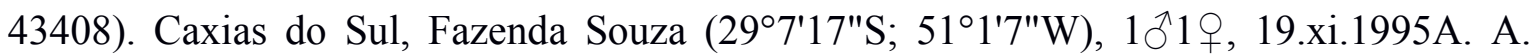
Lise et al. col. (MCTP 9133). 


\section{Clitolyna Simon, 1894 Revalidado}

Figs. 99-187, Mapa 7-10

Clitolyna Simon, 1894: 673. Espécie tipo e designação original Erigone fastibilis Keyserling, 1886.

Brattia Simon, 1894: 673-674. Baert, 1987: 261-262. Millidge, 1991: 179. Espécie tipo e designação original Brattia spadicaria Simon, 1894.

Gymnocymbium Millidge, 1991: 184. Espécie-tipo por designação original Gymnocymbium grave Millidge, 1991.

Espécie-tipo: Clitolyna fastibilis (Keyserling, 1886) comb. nov.

Diagnose: O gênero é diagnosticado pelos seguintes conjunto de caracteres: perda do paracímbio e da membrana embólica. Presença de uma apófise retrolateral da tíbia do palpo do macho, perdida em C. spadicaria, C. castanea, C. novaeteutoniae e C. fastibilis. Fileira de estrias estridulatórias na quelícera dos machos distribuídas ampla e igualmente entre si, complrimidas e igualmente espaçada em C. personata, C. rostrata, C. tumidosa, C. venialis e Clitolyna sp.nov.01, e comprimidas proximalmente em Clitolyna sp.nov.02

Descrição: Macho com comprimento total de 1,40-2,10. Carapaça 0,67-0,77 de comprimento, 0,48-0,73 de largura, castanha escura, região cefálica muito elevada. Esterno 0,41-0,78 de comprimento, 0,42-0,66 de largura, castanho escuro. Clípeo 0,170,24 de altura. Quelícera com 6-5 dentes promarginais e 5-4 retromarginais. Abdômen bege escuro. Distância entre coxa IV 1,22-1,54 vezes sua largura. Pernas amareladas, com mancha branca na tíbia, próximo à patela. TmI 0,25-0,57. TmIV presente. Fêmea com comprimento total de 1,86-2,45. Carapaça 0,71-0,91 de comprimento, 0,62-0,75 de largura, castanha escura. Esterno 0,45-0,54 de comprimento, 0,46-0,55 de largura, castanho escuro. Clípeo 0,14-0,23 de altura. Quelícera com 5-6 dentes promarginais e 4-5 retromarginais. Abdômen com coloração bege escuro à amarelado, apresentando ou não manchas escuras ao redor da fiandeira. Distância entre coxa IV 1,60-1,87 vezes sua largura. Pernas amareladas à alaranjadas, com ou sem manchas claras. TmI 0,21-0,54 TmIV presente ou ausente. 
Espécies: Clitolyna alticeps (Millidge, 1991) comb. nov., C. castanea (Millidge, 1991) comb. nov., C. crassa (Millidge, 1991) comb. nov., C. chumota (Miller, 2007) comb. nov., C. fastibilis (Keyserling, 1886) comb. nov., C. formosa (Millidge, 1991) comb. nov., C. gravis (Millidge, 1991) comb. nov., C. novaeteutoniae (Baert, 1987) comb. nov., C. personata (Simon, 1894) comb. nov., C. prativaga (Keyserling, 1886) comb. nov., $C$. rostrata (Millidge, 1991) comb. nov., C. rugosa (Millidge, 1991) comb. nov., C. spadicaria (Simon, 1894) comb. nov., C. tumidosa (Keyserling, 1886) comb. nov., $C$. varia (Keyserling, 1886) comb. nov., C. venialis (Keyserling, 1886) comb. nov., Clitolyna sp.nov.01, Clitolyna sp.nov.02. Clitolyna electa Crosby, 1905 (nomen dubium, ver Miller, 2007: 187).

Distribuição: Argentina, Bolívia, Brasil, Colômbia, Equador, Peru, Trinidad e Tobago e Venezuela

Clitolyna fastibilis (Keyserling, 1886) comb. nov.

Figs. 113-118, Mapa 8.

Erigone fastibilis Keyserling, 1886: 217-218, fig. 274 (macho holótipo de Serre Vermelle (Serra Vermelha?), Minas Gerais, Brasil, depositado no BMNH [Natural History Museum, Londres, Reino Unido], não examinado).

Clitolyna fastibilis. Simon, 1894: 673.

Clitolina fastibilis. Petrunkevitch, 1928: 129.

Sphecozone fastibilis. Miller, 2007: 208, f. 154A-E.

Diagnose: C. fastibilis Diferencia-se de outras espécies de Clitolyna, exceto Clitolyna sp.nov.01, pela forma da região cefálica dos machos, elevada abruptamente e com fortes cerdas na região ocular. Diferencia-se de Clitolyna sp.nov.01 pela forma da apófise prolateral, mais longa, e curvada distalmente em C. fastibilis (Figs. 114, 117, 118). Fêmeas de C. fastibilis lembram as de Clitolyna sp.nov.01, por apresentar o lóbulo anterior da placa dorsal pelo menos 2x mais larga que a placa dorsal. Difere-se de Clitolyna sp.nov.01 pela forma do lóbulo anterior da placa dorsal, mais arredondado em C. fastibilis (Figs. 
$116-118)$.

Descrição: Macho de Viamão, Rio Grande do Sul, Brasil e fêmea de Cachoeira do Sul, Rio Grande do Sul, Brasil. Descrição em Miller, 2007, pp.208-211, f. 154A-E. Imagens adicionais: Fig. 113-118.

Variação: $\operatorname{Machos}(\mathrm{n}=10)$ : Comprimento total 1,82-2,08 (média 1,95); comprimento da carapaça 0,71-0,79 (média 0,76); largura da carapaça 0,58-0,72 (média 0,65); comprimento do fêmur I 0,91-1,05 (média 0,97).

Fêmeas ( $\mathrm{n}=4)$ : Comprimento total 2,04-2,35 (média 2,21); comprimento da carapaça 0,740,80 (média 0,77 ); largura da carapaça $0,61-0,68$ (média 0,25 ); comprimento do fêmur I 0,92-1,05 (média 0,98).

Distribuição: Registro para Argentina (Misiones), Brasil (Minas Gerais, Santa Catarina, Rio Grande do Sul). (Mapa 8).

Material examinado: BRASIL. MINAS GERAIS: Pains, $\left(20^{\circ} 21^{\prime} \mathrm{S} ; 4^{\circ} 35^{\prime} \mathrm{W}\right), 07 / \mathrm{X} / 2014$, F. Bondezan et al col., (IBSP 187740, 29), 12/IX/2013, Equipe Spelayon col. (IBSP 185127, 185392, 185613, 185628, 185614, 6ð1ㅇ juv.), 15-27/VII/2013, Equipe Carste col., (IBSP, $5 ð 3 q 1$ juv.), XII/2015, F. Bondezan col., (IBSP 187090, 187095, 2ð⿱). Sete

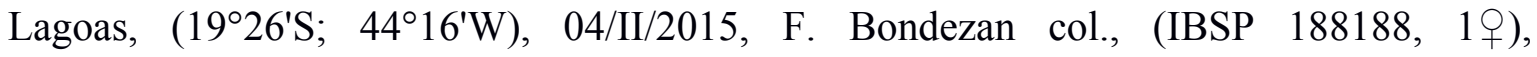
24/III/2015, F. Bondezan col., (IBSP 188190, 2ð). SANTA CATARINA: Concórdia, Parque Estadual Fritz Plaumann, $\left(27^{\circ} 13^{\prime} \mathrm{S} ; 52^{\circ} 00^{\prime} \mathrm{W}\right)$, x.2005-vii.2006, J. Griss col., (MCN 42185, 1§). RIO GRANDE DO SUL: Cachoeira do Sul, Porteira Sete, $\left(30^{\circ} 13^{\prime} \mathrm{S}\right.$; 5251'W), 25.v.1993, R. G. Buss col., (MCTP 4002, 1 ㅇ). Gravataí, (2957'S; 5055'W), 24.xi.1998, M. Kratina col., (MCN 29782, 1ठ̋). Júlio de Castilhos, Barragem de Itaúba, $\left(29^{\circ} 09^{\prime} \mathrm{S} ; 53^{\circ} 41^{\prime} \mathrm{W}\right), 22 . x .1998$, L. A. Moura col., (MCN 31068, 1ठ). Triunfo, Parque Copesul de Proteção Ambiental, (2955'S; 5143'W), 7.vi.2005, R. Ott col., (MCN 39936, $1 \overbrace{}^{\lambda})$ 
Clitolyna crassa (Millidge, 1991) comb. nov.

Figs. 110-112, Mapa 7A.

Gymnocymbium crassum Millidge, 1991: 184-186, f. 800-802 (macho holótipo de Sinop, Mato Grosso, Brasil, depositado no AMNH).

Gymnocymbium propinquum Millidge, 1991: 186, f. 804, 807 (fêmea holótipo de Jacareacanga, Pará, Brazil, in AMNH).

Sphecozone crassa. Miller \& Hormiga, 2004: 413, f. 19F. Miller, 2007a: 205, f. 151E, $153 \mathrm{~A}-\mathrm{B}, \mathrm{E}, \mathrm{G}-\mathrm{H}, 162 \mathrm{~A}-\mathrm{F}, 163 \mathrm{~A}-\mathrm{F}$.

Material tipo examinado: BRASIL. PARÁ: Jacareacanga ("Jacazeacanga"), (6²'S' 57²5'W), x.1959, M. Alvarenga col. (AMNH, holótipo). MATO GROSSO: Sinop,

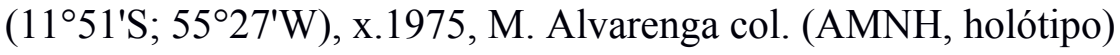

Diagnose: Espécies de C. crassa lembram as de $C$. venialis e $C$. Tumidosa pela presença de um processo retromediano no címbio do palpo dos machos. Diferenciam-se de $C$. venialis e $C$. Tumidosa pela ausência de uma membrana embólica (Fig. 112). Fêmeas de $C$. crassa lembram as de C. Tumidosa, C. venialis e C. formosa pela espermateca arredondada, localizadas lateralmente aos dutos de copulação. Diferenciam-se de $C$. Tumidosa e C. venialis, pela forma do átrio, mais reto em C. crassa, e curvado em $C$. Tumidosa e C. venialis. Diferem-se de C. formosa pela margem entre a placa ventral e o lóbulo anterior da placa dorsal, mais curvado em C. crassa (Figs. 111, 112).

Descrição: Macho (da Parque Nacional Cordillera de los Picachos, Caquetá, Colombia). Descrição em Miller, 2007, pp. 205-206. magens adicionais Fig. 112.

Fêmea (mesma localidade). Descrição em Miller, 2007, pp. 205-206. Imagens adicionais Figs. 110-112.

Variação: Fêmea $(\mathrm{n}=1)$ : Comprimento total 2,32; comprimento da carapaça 0,78; largura da carapaça 0,68 ; comprimento do fêmur I 0,96.

Distribuição: Conhecida para Amazônia colombiana e brasileira (Mapa 7A). 
Material examinado: BRASIL. AMAZONAS: São Gabriel da Cachoeira, Pico da Neblina, (047'N; 6601'W), 8.x.1990, A. A. Lise et al. col., (MCTP 1376, 1 \%).

\section{Clitolyna formosa (Millidge, 1991) comb. nov.}

Figs. 119-120, Mapa 7A.

Gymnocymbium formosum Millidge, 1991: 186, figs 803, 805-806 (Fêmea holótipo de Baños, Ecuador, depositado no AMNH).

Sphecozone formosa. Miller, 2007a: 207, f. 151F, 165.

Material tipo examinado: EQUADOR. TUNGURAHUA: Baños, $\left(1^{\circ} 23^{\prime} \mathrm{S}, 78^{\circ} 25^{\prime} \mathrm{W}\right)$, 2.v.1939, W. M. Clarke-MaCintyre col., (AMNH 326259, 1 \%, holótipo).

Diagnose: Fêmea de C. formosa possui o epígino semelhante ao de C. crassa diferenciando-se dela pela margem entre a placa ventral e o lóbulo anterior da placa dorsal, mais reta em C. formosa (Figs. 120). O macho não é conhecido.

Descrição: Macho desconhecido.

Fêmea (holótipo) de Baños, Equador. Descrição em Miller, 2007, pp. 207-208, f. 151F, 165. Imagens adicionais Figs. 119-120.

Distribuição: Somente a localidade-tipo (Mapa 7A).

Material examinado: somente o tipo.

Clitolyna alticeps (Millidge, 1991) comb. nov.

Figs. 99-103, Mapa 7A.

Sphecozone alticeps Millidge, 1991: 167, f. 698-703 (macho holótipo e 7 fêmeas parátipos de Paramo Purace, Cauca, Colombia, depositado no AMNH). 
Material tipo examinado: COLÔMBIA, CAUCA: Puracé, Paramo Purace, $15 \mathrm{~km} \mathrm{E}$ Purace $\left(2^{\circ} 16^{\prime} 29.6^{\prime \prime} \mathrm{N} ; 7^{\circ} 23^{\prime} 02.0^{\prime \prime} \mathrm{W}\right), 1{ }^{\wedge}, 20 . x .1968$, B. Malkin col. (AMNH 00326248, holótipo); 7ㅇ, 20.x.1968, B. Malkin col. (AMNH 00326249, parátipo).

Diagnose: Machos de C. alticeps lembram os de C. personata e C. rostrata, pela projeção dorsal do címbio e pela apófise prolateral da tíbia, perpendicular e alta. Diferem-se de $C$. personata e $C$. rostrata por apresentarem a projeção mais curta que em $C$. personata e $C$. rostrata (Figs. 100, 103). Fêmeas se diferenciam de todas as outras espécies de Clitolyna pela forma da espermateca, muito longa e curvada (Figs. 102).

Descrição: Macho (Holótipo; AMNH 00326248) de Puracé, Cauca, Colômbia. Comprimento total 1,63. Carapaça 0,68 de comprimento, 0,65 de largura, coloração castanha escura, região cefálica muito elevada. Esterno 0,41 de comprimento, 0,42 de largura, castanho escuro. Clípeo 0,24 de altura. Quelícera com 5 dentes promarginais e 4 retromarginais. Abdômen com coloração bege escuro. Diâmetro dos olhos e distância: OMA 0,02; OLA 0,03; OMP 0,04; OLP 0,02. Distância entre os OMA 1,48 vezes seu diâmetro, distância entre os OMP 2,97 vezes seu diâmetro, distância entre OMA-OLA 1,38 vezes o diâmetro do OLA, distância entre OMP-OLP 1,57 vezes o diâmetro do OLP. Olhos médio posteriores separados dos demais por um estrangulamento na região cefálica. Distância entre coxa IV 1,54 vezes sua largura. Fórmula das pernas I-II-IV-III. Fêmur I/II/III/IV 0,59/0,56/0,48/0,63; patela I 0,17; tíbia I 0,49; metatarso I 0,42; tarso I 0,34. Pernas amareladas, com mancha branca na tíbia, próximo à patela. Fêmur/patela/tíbia/címbio do palpo 0,31/0,17/0,09/0,33. TmI 0,57. TmIV presente. Palpo com processo posterior dorsal do címbio. Tégulo sem protégulo, apresenta papilas. Supratégulo liso, com apófise distal. Êmbolo espiral, estreito. radix com processo anterior. Tíbia do palpo do macho com apófise prolateral longo e apófise retrolateral em forma de dente. Apresenta um tricobótrio prolateral (Figs. 99-100, 103).

Fêmea (Parátipo; AMNH 00326249) de Puracé, Cauca, Colômbia. Comprimento total 1,93. Carapaça 0,71 de comprimento, 0,62 de largura,coloração como a do macho, região cefálica normal, não elevada como no macho. Esterno 0,42 de comprimento, 0,46 de largura. Clípeo 0,14 de altura. Quelícera com 5 dentes promarginais e 4 retromarginais. Abdômen como no macho. Diâmetro dos olhos e distância: OMA 0,02; OLA 0,04; OMP 
0,04; OLP 0,03. Distância entre os OMA 0,72 vezes seu diâmetro, distância entre os OMP 1,36 vezes seu diâmetro, distância entre OMA-OLA 0,69 vezes o diâmetro do OLA, distância entre OMP-OLP 0,94 vezes o diâmetro do OLP. Distância entre coxa IV 1,67 vezes sua largura. Fórmula das pernas I-II-IV-III. Fêmur I/II/III/IV 0,61/0,53/0,45/0,58; patela I 0,21 ; tíbia I 0,43 ; metatarso I 0,40 ; tarso I 0,33 . Coloração das pernas como no macho. Fêmur/patela/tíbia/tarso do palpo 0,22/0,08/0,15/0,25. TmI 0,54. TmIV presente. Tarso do palpo da fêmea com macroseta dorsomesal proximal. Epígino com átrio reto, espermateca muito longa e curvada, posicionada lateralmente em relação ao duto copulatório. Duto de fertilização orientado posteriormente. (Figs. 101-102).

Variação: Fêmeas (n=6): Comprimento total 1,68-1,83 (média 1,47); comprimento da carapaça 0,64-0,69 (média 0,66); largura da carapaça 0,57-0,61 (média 0,59); comprimento do fêmur I 0,54-0,57 (média 0,56).

Distribuição: Conhecido apenas para Colômbia (Mapa 7A).

Material examinado: somente os tipos.

Clitolyna prativaga (Keyserling, 1886, 269) comb. nov.

Figs. 139-144.

Erigone prativaga Keyserling, 1886:269, fig. 318 (fêmea holótipo de Blumenau, Brasil, de BMNH [Natural History Museum, Londres, Reino Unido], não examinado). Moyosi prativaga. Miller, 2007.

Diagnose: Machos de C. prativaga se diferenciam de outros Clitolyna, exceto C. chumota, por não apresentarem o processo anterior do radix no palpo dos machos. Diferenciam-se de C. chumota pela forma da apófise retrolateral, com margem mais reta em C. prativaga, mais pontiaguda em C. chumota (Figs. 140, 143, 144). Fêmeas Diferenciam-se de outras Clitolyna, exceto C. chumota e C. rugosa, pela posição dorsal da espermateca em relação ao duto de copulação (lateral ou envolvida pelo duto em outras espécies). Distinguem-se de C. chumota e C. rugosa pelo comprimento da placa dorsal, sendo mais estreita em C. 
prativaga que em C. chumota e C. rugosa (Figs. 142-144).

Descrição: Macho e fêmea (parátipos de Parque Nacional de Iguazú, Misiones, Argentina) com descrição e ilustrações em Miller, 2007, pp. 217-219, f. 151H, 169, 170A, B, F. Imagens adicionais: Fig. 139-144.

Variação: $\operatorname{Machos}(\mathrm{n}=10)$ : Comprimento total 1,54-1,64 (média 1,61); comprimento da carapaça 0,74-0,72 (média de 0,728); largura da carapaça 0,60-0,64 (média 0,62); comprimento do fêmur I 0,72-0,84 (média 0,78 ).

Fêmeas $(\mathrm{n}=10)$ : Comprimento total $1,48-2,18$ (média 1,76); comprimento da carapaça 0,66-0,78 (média 0,74), largura da carapaça 0,58-0,76 (média 0,66); comprimento do fêmur I 0,64-0,98 (média 0,84).

Distribuição: Argentina e regiões Sul, Sudeste e Centro-Oeste do Brasil.

Material examinado: ARGENTINA, MISIONES: Puerto Iguazú, Parque Nacional de Iguazú, Area Cataratas $\left(25^{\circ} 40^{\prime} \mathrm{S} ; 54^{\circ} 27^{\prime} \mathrm{W}\right)$ 1ㅇ $11-16 / \mathrm{X} / 1999$. M. J. Ramírez \& L.

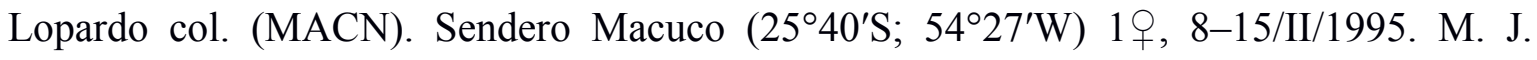

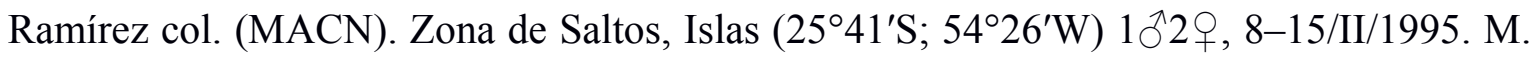

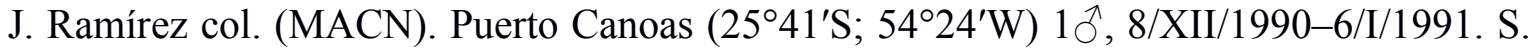
\& J. Peck col. (AMNH \#90-91); Puerto Libertad, Saltos del Uruguai, (255'' S; 54²36'W) 3ㅇ, 23-25/II/1997. M. J. Ramírez col. (MACN ); BRASIL, MATO GROSSO DO SUL: Brasilândia, Usina Hidrelétrica Sergio Motta, Fazenda Cisalpina (2115'S; 51 $\left.56^{\prime} \mathrm{W}\right)$ 4ð3ㅇ, 08-12/VIII/2000. Equipe IBSP col. (IBSP 30633; 30640; 30642; 30646; 30860;

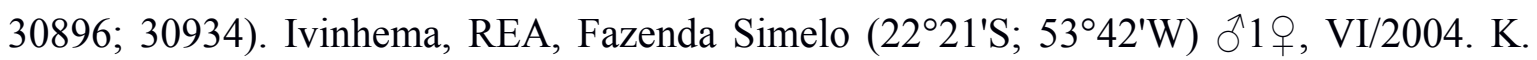
Anjos col. (IBSP 125116). PARANÁ. Antonina, Reserva Natural do Rio Cachoeira, (2520’S; 48³9’W) 1q, 22/X/2005. H. Höfer col. (MCN 45925); Foz do Iguaçu, Parque

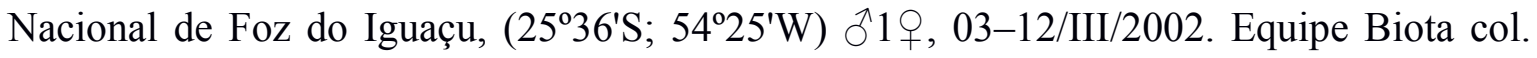

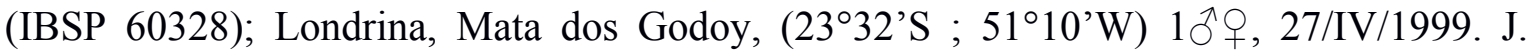

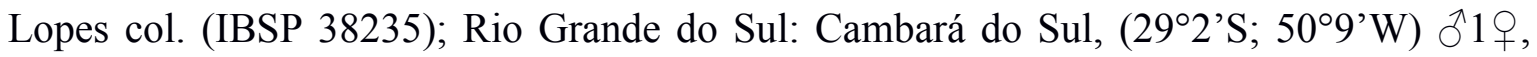
11-13/IV/1994. Bonaldo \& Moura col. (MCN 25513); Derrubadas, Parque Estadual do

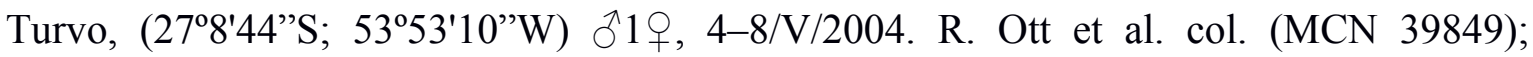


Maquiné, FEPAGRO, $\left(29^{\circ} 39^{\prime} \mathrm{S} ; 50^{\circ} 12^{\prime} \mathrm{W}\right) 2{ }^{\wedge} 6$ \% , 18-27/I/2002. Equipe Biota col. (IBSP 60099; 60101; 60107; 60108; 60113; 60114; 60632; 60639); São Francisco de Paula,

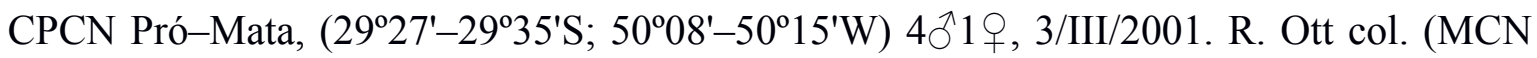

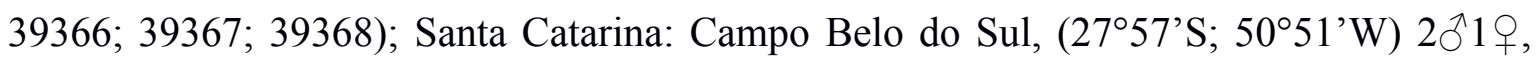
14-18/XI/2007. T. G. Pinto col. (MCN 44275; 44276); Chapecó, (2705'S ; 52³1'W) $2{ }^{\Uparrow} 1$ +, 2008 . R. Francisco col. (IBSP 122326; 122350; 122383); Ilhota, Morro do Baú,

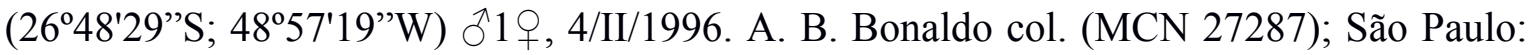

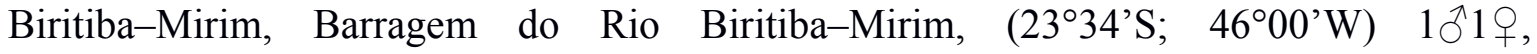
30/VII/2004. Equipe IBSP col. (IBSP 119855; 119856); Itapevi, (233’'S; 4657’ W) §119, I-XII/1999. C. Bertim \& V. Onófrio col. (IBSP 122076); Mogi das Cruzes, $\left(23^{\circ} 30^{\prime} \mathrm{S} ; 4^{\circ} 11^{\prime}\right.$ W) $2{ }^{\Uparrow} 4$ +, $03-10 / \mathrm{V} / 2001$. E. K. Kashimata \& R. Martins col. (IBSP 74243; 75249; 75251; 75265); mesma localidade, Parque das Neblinas, (2344'52”S; 4609'44”W) Љ1 1 , 11/II/2006. M. Uehara-Prado col. (IBSP 143194); mesma localidade,

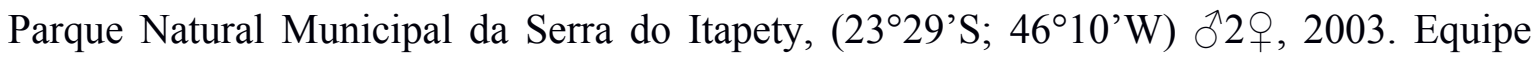
Biota col. (IBSP 54616; 68563); Salesópolis, Barragem do Rio Paraitinga, (23³3'S; $\left.45^{\circ} 56^{\prime} \mathrm{W}\right){ }^{\Uparrow} 1+$, 18-25/VI/2002. Equipe IBSP col. (IBSP 147324); Santo André, Reserva

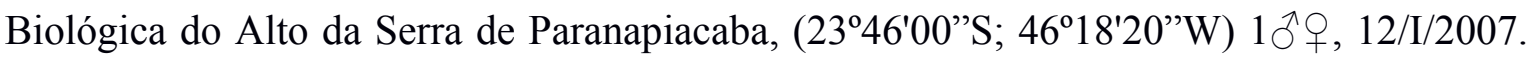
M. Uehara-Prado col. (IBSP 143104); São Bernardo dos Campos, Parque Estoril,

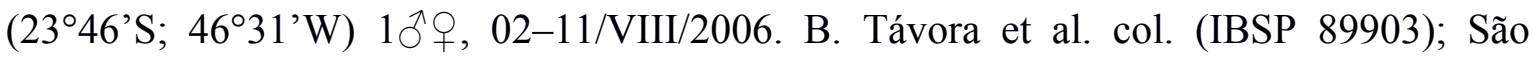
Paulo, Reservatório de Guarapiranga, Jardim Ângela, Parque Ilha dos Eucaliptos $\left(23^{\circ} 44^{\prime} \mathrm{S}\right.$; $\left.46^{\circ} 44^{\prime} \mathrm{W}\right) 1 \delta^{\Uparrow} 1$,, $6-12 / \mathrm{XI} / 1999$. R. P. Indicatti et al. col. (IBSP 132307; 132308); Teodoro Sampaio, Parque Estadual do Morro do Diabo, $\left(22^{\circ} 31^{\prime} \mathrm{S} ; 52^{\circ} 18^{\prime} \mathrm{W}\right) 2{ }^{\Uparrow} 7 q, 24-31 / \mathrm{III} / 2003$. Equipe Biota col. (IBSP 60204; 60205; 60212; 60214; 60216; 60217; 60219; 60220).

\section{Clitolyna chumota (Miller, 2007) comb. nov.}

Figs. $184-189$

Moyosi chumota Miller, 2007: 219, fig. 151I, 170C-E, G, 171 (macho holótipo de Essequibo River, Upper Takutu Upper Essequibo Region, Guyana de USNM, examinado. 
Material tipo examinado: GUYANA. UPPER TAKUTU-UPPER ESSEQUIBO REGION: Gunns Strip, bank of Essequibo river, (1'36'45.7'N; 58³8'14.6”W), 615/VII/1999. J. A. Coddington, G. Hormiga, J. Miller, I. Agnarsson, M. Kuntner col. (USNM 1037; 1038; 1039, 15○118 , parátipos).

Diagnose: Machos de C. chumota se diferenciam de outros Clitolyna, exceto C. prativaga, por não apresentarem o processo anterior do radix no palpo dos machos. Diferenciam-se de C. prativaga pela forma da apófise retrolateral, com margem mais pontiaguda em $\mathrm{C}$. chumota, mais reta em C. prativaga (Figs. 185, 188, 189). Fêmeas Diferenciam-se de outras Clitolyna, exceto C. prativaga e C. rugosa, pela posição dorsal da espermateca em relação ao duto de copulação (lateral ou envolvida pelo duto em outras espécies). Distinguem-se de C. prativaga pelo comprimento da placa dorsal, sendo mais estreita em C. prativaga. Distinguem-se de C. rugosa pela forma da margem anterior do lóbulo da placa dorsal, que apresenta uma curva mais acentuada em C. rugosa, levemente curvada em C. chumota (Figs. 187-189).

Descrição: Macho e fêmea (de Gunn's Strip, $42.2 \mathrm{~km} \mathrm{~S}$, Guyana). Descrições em Miller, 2007, pp. 219-220, f. 151I, 170C-E, G, 171. Imagens complementares: Figs. 184-189

Variação: Macho ( $\mathrm{n}=10$ ): Comprimento total 1,34-1,50 (média 1,40); comprimento da carapaça $0,60-0,65$ (média 0,62 ), largura da carapaça $0,5-0,55$ (média 0,52 ); comprimento do fêmur I 0,65-0,71 (média 0,68).

Fêmeas $(\mathrm{n}=10)$ : Comprimento total 1,36-1,62 (média 1,49); comprimento da carapaça 0,56-0,63 (média 0,60), largura da carapaça 0,50-0,55 (média 0,53); comprimento do fêmur I 0,57-0,65 (média 0,62).

Distribuição: Conhecido apenas da localidade tipo (fig. 171, Miller, 2007, p.226).

Material examinado: somente o tipo. 
Clitolyna rugosa (Millidge, 1991) comb. nov.

Fig. 169, 170H, 176A (Miller, 2007, pp. 220-221)

Sphecozone rugosa Millidge, 1991: 177-178, figs 765, 766 (fêmea holótipo de Punta

Larga, Buenos Aires, Argentina, depositado em AMNH]. Platnick, 1993: 354; 2004.

Moyosi rugosa: Miller, 2007: 220.

Material examinado: ARGENTINA. BUENOS AIRES: Buenos Aires, Punta Larga (3449’S, 5759’W), 23.ii.1972 (Lee Herman, AMNH, \#948, 19, holótipo).

Diagnose: Fêmeas Diferenciam-se de outras Clitolyna, exceto C. prativaga e C. chumota, pela posição dorsal da espermateca em relação ao duto de copulação (lateral ou envolvida pelo duto em outras espécies). Distinguem-se de C. prativaga pelo comprimento da placa dorsal, sendo mais estreita em C. prativaga. Distinguem-se de C. chumota pela forma da margem anterior do lóbulo da placa dorsal, que apresenta uma curva levemente curvada em C. chumota, mais acentuada em C. rugosa (Figs. ).

Descrição: Macho desconhecido. Fêmea (de Punta Larga, Buenos Aires, Argentina). Descrições em Miller, 2007, pp. 220-221, f. 169, 170H, 176A.

Distribuição: Conhecido apenas da localidade tipo (fig. 169, Miller, 2007, p.226).

Material examinado: somente o tipo.

Clitolyna gravis (Millidge, 1991) comb. nov.

Figs. 121-126, Mapa 10.

Gymnocymbium grave Millidge, 1991: 184, f. 797-799 (Macho holótipo de Crevaux, Río Pilcomayo, Tarija, Bolívia, depositado no AMNH). Platnick, 1993: 283; 2004.

Sphecozone gravis. Miller, 2007: 208, f. 153C-D, F.

Material tipo examinado: BOLÍVIA. TARIJA: Gran Chaco, Crevaux, Río Pilcomayo, 


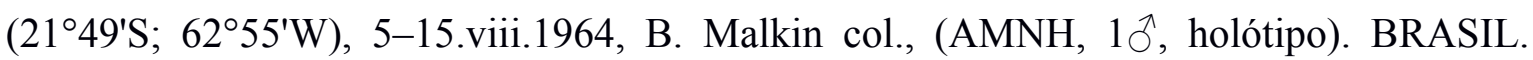

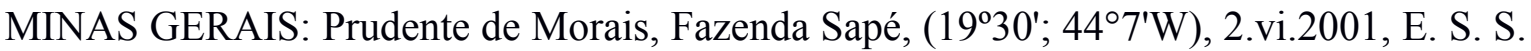
Álvares col., (UFMG 1159, 1ð2ๆ)

Diagnose: Machos de C. gravis diferem-se de outras espécies de Clitolyna por apresentarem uma apófise distal do supratégulo do palpo longo e robusto, orientado ventralmente (Figs. 122, 125, 126). Fêmeas de C. gravis diferem-se de outras Clitolyna pela forma ampla do lóbulo anterior da placa dorsal e por apresentarem uma depressão anterior, próximo ao processo anterior da placa ventral (Figs. 124-126).

Descrição: Macho (de Crevaux, Río Pilcomayo, Tarija, Bolívia). Descrição em Miller, 2007, p. 208, f. 153C-D, F. Imagens adicionais 121-122, 125-126.

Fêmea (Parátipo; UFMG 1159) de Fazenda Sapé, Prudente de Morais, Minas Gerais, Brasil. Comprimento total 1,86. Carapaça 0,76 de comprimento, 0,61 de largura, com tons de castanho escuro. Esterno 0,45 de comprimento, 0,47 de largura, castanho escuro. Clípeo 0,11 de altura. Quelícera com 6 dentes promarginais e 5 retromarginais. Abdômen amarelado, com mancha preta ao redor da fiandeira. Diâmetro dos olhos e distância: OMA 0,05; OLA 0,06; OMP 0,07; OLP 0,06. Distância entre os OMA 0,44 vezes seu diâmetro, distância entre os OMP 0,61 vezes seu diâmetro, distância entre OMA-OLA 0,55 vezes o diâmetro do OLA, distância entre OMP-OLP 0,62 vezes o diâmetro do OLP. Distância entre coxa IV 1,18 vezes sua largura. Fórmula das pernas I-II-IV-III. Fêmur I/II/III/IV $0,91 / 0,81 / 0,70 / 0,93$; patela I 0,22 ; tíbia I 0,85 ; metatarso I 0,75 ; tarso I 0,54 . Pernas alaranjadas. Fêmur/patela/tíbia/tarso do palpo 0,26/0,08/0,17/0,28. TmI 0,21. TmIV ausente. Palpo apresenta três macrosetas ventromesal e três ventroectal. Epígino amplo e escavado, apresenta lóbulo anterior da placa dorsal largo, processo anterior da placa ventral muito proeminente. Duto copulatório não encapsulado, espermateca de forma oval e alongada. (Figs. 123-126).

Variação: $\operatorname{Machos}(\mathrm{n}=10)$ : Comprimento total 1,44-1,98 (média 1,81); comprimento da carapaça 0,72-0,80 (média 0,75); largura da carapaça 0,59-0,66 (média 0,62); comprimento do fêmur I 0,83-1,07 (média 0,99).

Fêmeas $(\mathrm{n}=10)$ : Comprimento total 1,45-1,84 (média 1,74); comprimento da carapaça 
0,63-0,77 (média 0,71); largura da carapaça 0,55-0,63 (média 0,59); comprimento do fêmur I 0,86-1,04 (média 0,96).

Obs.: apesar da revisão de Miller (2007) não contar com o abdômen do macho, o padrão da coloração é semelhante entre os dois sexos, ou seja, a carapaça pode apresentar a região cefálica mais escura em alguns indivíduos e o abdômem pode variar de um amarelo mais claro à um bege mais escuro, porém sempre apresentam uma mancha preta próximo às fiandeiras.

Distribuição: Bolívia (Tarija) e Brasil (Minas Gerais, São Paulo) (Mapa 10).

Material examinado: BRASIL. MINAS GERAIS: Taiobeiras, $\left(15^{\circ} 48^{\prime} \mathrm{S} ; 42^{\circ} 13^{\prime} \mathrm{W}\right), 08$ 16.iv.2002, Equipe Biota col., (IBSP 59975-59980, 60658, $2 ð 8$ 1 1 juv.). Belo Horizonte, Fundação Zoobotânica, (1951'S; 4400'W), 05-12.x.1999, J. C. R. Fontenelle col., (IBSP 41241, 19). MATO GROSSO DO SUL: Três Lagoas, Horto Barra do Moeda, (2057'; 514'), 8-19.viii.2007, M. Uehara-Prado col., (UFMG 5682, 3ð1ㅇ), ii-iii.2008, M. Uehara-Prado col., (UFMG 5680, 1ð2ㅇ). Brasilândia, Usina Hidrelétrica Engenheiro Sérgio Motta, $\left(21^{\circ} 18\right.$ 'S; 5201W)08-12.viii.2000, Equipe IBSP col., (IBSP 30832, 30839, 30849, 30609, 30901, 30904, 30922, 30930, 30936, 9ð1ㅇ), 15-19.viii.2000, J. P. Guadanucci \& C. Fukushima col., (IBSP 35405, 35407, 35411, 3^1우). Ivinhema, REA, (22 $\left.2^{\circ} 8^{\prime} \mathrm{S} ; 53^{\circ} 49^{\prime} \mathrm{W}\right)$, vi.2004, K. Anjos col., (IBSP 125110, 125119, 125121, 125132,

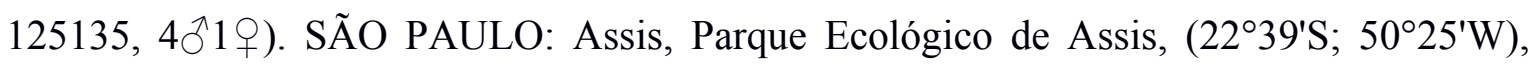
25-29.xi.2002, C. Firmo col., (IBSP 59134, 59136, 59137, 2ð2ㅇ).

Clitolyna spadicaria (Simon, 1894, 674) comb. nov.

Figs. 151-154, Mapa 10.

Brattia spadicaria Simon, 1894a: 674 (seis machos e seis fêmeas síntipos de Caracas, Venezuela, depositado no MNHN [Muséum National d'Histoire Naturelle, Paris, França], não examinado).

Brattia spadicaria. Baert, 1987: 262, f. 1-6. Millidge, 1991: 179, f. 767-772.

Sphecozone spadicaria. Miller, 2004: 529, f. 1-11. Miller \& Hormiga, 2004: 414, f. 18E. Miller, 2007: 201, f. 150A-E, 151C, 160A-F, 161A-F. 
Diagnose: Machos de C. spadicaria lembram os de $C$. novaeteunoniae, $C$. castanea e Clitolyna sp.nov.02, pela ausência da apófise retrolateral da tíbia do palpo. Diferem-se de C. novateutoniae e C. castanea, pela forma da apófise prolateral, mais curta e estreita que em $C$. novaeteutoniae e $C$. castanea, e ausência de um dente distal. Diferem-se de Clitolyna sp.nov.02, pela forma simples do tégulo (Figs. 152, 154). Fêmeas de $C$. spadicaria lembram as de $C$. novaeteutoniae, $C$. castanea e $C$. gravis por apresentarem uma membrana interna no epígino, diferenciando-se dessas espécies pela forma do processo anterior da placa ventral curto e discreto (Figs. 153, 154).

Descrição: Macho e fêmea (de Finca Bella Vista, Sasaima, Cundinamarca, Colômbia) com descrições e ilustrações em Miller, 2007: 201, f. 150A-E, 151C, 160A-F, 161A-F. Imagens adicionais. Fig. 151-154.

Distribuição: Colômbia, Trinidade e Tobago e Venezuela (Mapa 10).

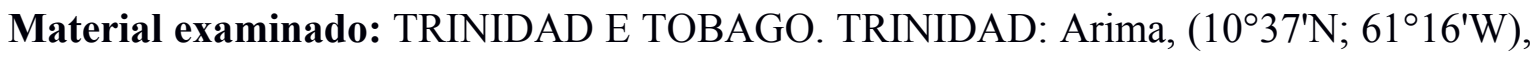
29.vi.1999, J. Miller col., (USNM, 10ึ). COLÔMBIA. CUNDINAMARCA: Sasaima, Finca Bella Vista, (457'N; 74²6'W), 26.iii.1965, P. R. \& D. L. Craig col., (CAS 9076619, 1ठ1ㅇ), 27.v.1965, P. R. \& D. L. Craig col., (CAS 9076615, 1 q 8 juv.).

Clitolyna castanea (Millidge, 1991) comb. nov.

Figs. 104-109, Mapa 10.

Brattia castanea Millidge, 1991: 180, f. 776-780, 782 (Macho holótipo, com duas fêmeas e três machos parátipos, da Universidade de São Paulo, Sao Paulo, Brasil, depositano no MCZ, não examinado).

Sphecozone castanea. Miller, 2007: 186, 187.

Diagnose: Machos de C. castanea assemelham-se aos de C. novaeteunoniae, pela forma da apófise prolateral, muito alargada e alta, apresentando um dente distal. Diferem-se de C. novaeteutoniae por apresentarem a apófise distal do supratégulo não bífido, como em 
C. novaeteutoniae (Figs. 105, 108, 109). Fêmeas de C. castanea lembram as de $C$. novaeteutoniae, C. spadicaria e $C$. gravis por apresentarem uma membrana interna no epígino e um processo anterior da placa ventral, diferenciando-se de $C$. novaeteutoniae, $C$. spadicaria e $C$. gravis pela forma do processo anterior da placa ventral robusta e de base alargada, delgada e proeminente em $C$. novaeteutoniae e $C$. gravis, discreta em $C$. spadicaria (Figs. 107, 109).

Descrição: Macho (IBSP 116936) do Parque Estoril, São Bernardo do Campo, São Paulo, Brasil. Comprimento total 1,70. Carapaça 0,78 de comprimento, 0,66 de largura, alaranjada, com região cefálica levemente acastanhada. Esterno 0,43 de comprimento, 0,44 de largura, castanho. Clípeo 0,17 de altura. Quelícera com 6 dentes promarginais e 5 retromarginais. Abdômen amarelado, com manchas escuras próximo às fiandeiras. Diâmetro dos olhos e distância: OMA 0,04; OLA 0,06; OMP 0,06; OLP 0,06. Distância entre os OMA 0,64 vezes seu diâmetro, distância entre os OMP 0,66 vezes seu diâmetro, distância entre OMA-OLA 0,76 vezes o diâmetro do OLA, distância entre OMP-OLP 0,62 vezes o diâmetro do OLP. Distância entre coxa IV 1,22 vezes sua largura. Fórmula das pernas I-II-IV-III. Fêmur I/II/III/IV 0,85/0,79/0,65/0,89; patela I 0,21; tíbia I 0,79; metatarso I 0,68; tarso I 0,53. Pernas alaranjadas. Fêmur/patela/tíbia/címbio do palpo 0,68/0,25/0,28/0,68. TmI 0,25. TmIV ausente. Palpo com cavidade basal do címbio presente, protégulo e papilas presentes no tégulo, supratégulo liso, apresentando uma apófise lisa, membrana embólica e processo basal embólico presente, êmbolo em espiral, com uma projeção que se estende além de sua abertura. radix liso, apresenta processo anterior robusto. Apófise prolateral da tíbia presente, com dente distal, apófise retrolateral da tíbia presente, tíbia apresenta 1 tricobótrio retrolateral. (Figs. 104-105, 108-109).

Fêmea (IBSP 116936) de mesma localidade do macho. Comprimento total 2,10. Carapaça 0,79 de comprimento, 0,75 de largura. Esterno 0,49de comprimento, 0,46 de largura, coloração e forma da carapaça e esterno como a do macho. Clípeo 0,17 de altura. Quelícera com 6 dentes promarginais e 5 retromarginais. Padrão do abdômen como no macho. Diâmetro dos olhos e distância: OMA 0,04; OLA 0,06; OMP 0,06; OLP 0,06. Distância entre os OMA 0,48 vezes seu diâmetro, distância entre os OMP 0,71 vezes seu diâmetro, distância entre OMA-OLA 0,91 vezes o diâmetro do OLA, distância entre OMP-OLP 0,59 vezes o diâmetro do OLP. Distância entre coxa IV 1,11 vezes sua largura. Fórmula 
das pernas I-II-IV-III. Fêmur I/II/III/IV 0,98/0,88/0,75/1,01; patela I 0,24; tíbia I 0,86; metatarso I 0,73; tarso I 0,57. Pernas como as do macho. Fêmur/patela/tíbia/tarso do palpo 0,30/0,11/0,20/0,34. TmI 0,27. TmIV ausente. Palpo da fêmea apresenta macrosetas dorsomesal distal, dorsoectal proximal, dorsoectal distal. Apresenta 3 macrosetas ventromesais e 2 ventroectais. Epígino muito proeminente, átrios curvado, mais arredondado na sua base. Duto copulatório sinuoso, membrana interna presente. Espermateca de forma oval. (Figs. 106-107, 109)

Variação: Machos ( $\mathrm{n}=10$ ): Comprimento total 1,71-2,01 (média 1,84); comprimento da carapaça 0,77-0,91 (média 0,82); largura da carapaça 0,65-0,76 (média 0,71); comprimento do fêmur I 0,85-0,93 (média 0,89).

Fêmeas $(\mathrm{n}=10)$ : Comprimento total 1,77-2,15 (média 1,95); comprimento da carapaça 0,78-0,93 (média 0,84); largura da carapaça 0,65-0,79 (média 0,71); comprimento do fêmur I 0,85-0,96 (média 0,91).

Distribuição: Região Sudeste e norte da região Sul do Brasil (Mapa 10).

Material examinado: BRASIL. MINAS GERAIS: São Roque de Minas, Parque Nacional da Serra da Canastra, (20¹3'S; 46 $\left.26^{\prime} \mathrm{W}\right), 15-25 . v i i .1997$, C. P. Nogueira col., (IBSP

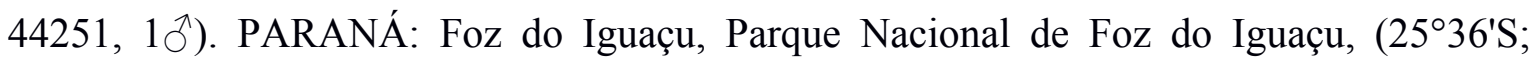
54²5'W), 03-12.iii.2002, Equipe Biota col., (IBSP 60647, 10ึ). Tijucas do Sul, Lagoa, Morro do Cabral $\left(25^{\circ} 55^{\prime} \mathrm{S} ; 4^{\circ} 11^{\prime} \mathrm{W}\right)$, ix.2000, J. Ricetti col., (IBSP 39034, $1 \bigcirc^{\Uparrow} 3$ + $)$. SÃO

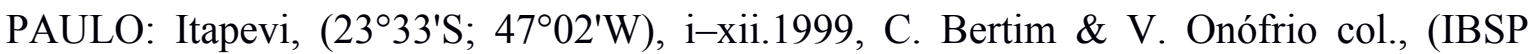

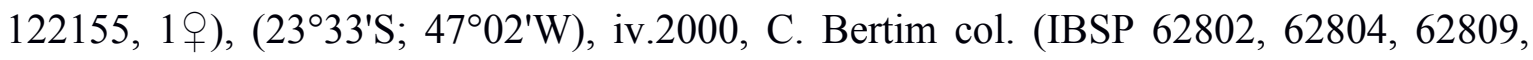

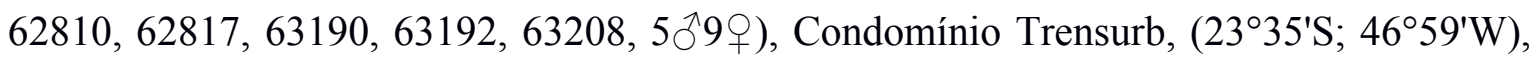
i.2000, V. Onofrio \& D. M. Battesti col., (IBSP 133261, 1ठ). Mairiporã, Parque Estadual

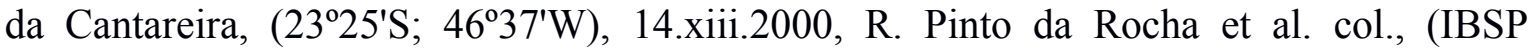
127768, 1q), viii.2000, R. Pinto da Rocha et al. col., (IBSP 127769, 1q). Mogi das Cruzes, Parque das Neblinas, (2344'52"S; 4609'44"W), 01.xi.2005, M. Uehara Prado col., (IBSP 143193, 1ठ), 01.xii.2005, M. Uehara Prado col., (IBSP 143192, 19), 03.i.2006, M. Uehara Prado col., (IBSP 142901,142904, 2ð), 11.ii.2001, M. Uehara Prado col., (IBSP 142903, 1ㅇ), Parque Natural Municipal da Serra do Itapety, $\left(23^{\circ} 29^{\prime} \mathrm{S} ; 46^{\circ} 12^{\prime} \mathrm{W}\right) 1^{1}-$ 
18.x.2003, Equipe Biota col. (IBSP 54590, 54660, 55086, 55091, 55092, 55094, 55096, 55099, 55116, $685597 \widehat{\jmath} 13$ ) ), v-vi.2003, P. A. M. Goldoni col. (IBSP 68556, 68557, $993912 \widehat{\jmath} 1$ 우). Santo André, Reserva Biológica do Alto da Serra de Paranapiacaba, (234ㅇ'00"S; 46²18'20"W), 11.i.2007, M. Uehara Prado col., (IBSP 143054,143057, 1ठ1ㅜ), 16.v.2007, M. Uehara Prado col., (IBSP 143073, 143081, 1ð1ㅇ), 17.v.2005, M. Uehara Prado col., (IBSP 143079, 1ठ), 17.v.2007, M. Uehara Prado col., (IBSP 143056, 1우), 17.xi.2006, M. Uehara Prado col., (IBSP 143068, 143070, 143071, 143076, 143077, 143080, 6ð1ㅇ), 18.ii.2007, M. Uehara Prado col., (IBSP 143059, 143065, 143066, 1ð2ㅇ), 19.ii.2007, M. Uehara Prado col., (IBSP 143053, 2ð), 19.iii.2007, M. Uehara Prado col., (IBSP 143055, 143069, 1ठ1ㅇ), 19.xii.2006, M. Uehara Prado col., (IBSP 143051, 143052, 143062, 143063, 143064, 2`7우), 20.iii.2007, M. Uehara Prado col., (IBSP 143075, 1ठ). São Bernardo do Campo, Parque Estoril, $\left(23^{\circ} 46^{\prime} \mathrm{S} ; 4^{\circ} 32^{\prime} \mathrm{W}\right), 28.1 \mathrm{x}-$ 02.x.2006, B. Távora et al. col., 15-29.xii.2006, B. Távora et al. col., (IBSP 116848, 1ठ), (IBSP 116415, 1ठ), 31.i-07.ii.2007, B. Távora et al. col., (IBSP 116862, 1ð), 0510.iv.2007, B. Távora et al. col., (IBSP 116922, 1ð1ㅇ), 15-19.xii.2007, B. Távora et al. col.(IBSP 116918, 117844, 1ð1)., 02-07.vi.2006, C. V. Janini et al. col., (IBSP 81301, 1ठ), 02-07.vi.2006, C. V. Janini et al. col., (IBSP 81303, 81305, 81308, 81312, 81314, 81315, 89844-89875, 89877-89888, 89890-89893, 89895-89900, 89916, 89974, 96ð27우), 02-11.viii.2006, C. V. Janini et al. col., (IBSP 81306, 81309, 89901, 89904,

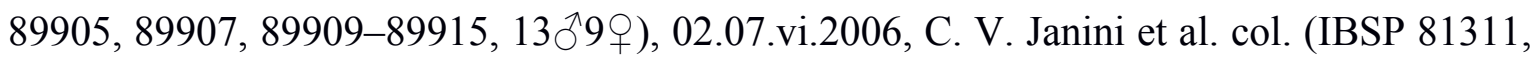
2§), 04-09.i.2007, C. V. Janini et al. col. (IBSP 116883-116885, 116893-116896, 116900, 116902, 116927, 116928, 116934-116936, 43ठ22+9), 04-09.i.2008, C. V. Janini et al. col., (IBSP 116850-116852, 116854, 116856, 116857, 116859, 116860, 116863116865, 116867-116871, 116873-116875, 116877, 116881, 116882, 116904, 116907116909, 116914, 116917, 116919-116921, 116924, 116925, 116929, 116930, 116940, 116943, 116944, 116946, 116947, 116949, 116951, 116952, 116957-116959, 116961, 116967, 116971-116976, 116982-116984, 116986-116988, 145ð56ㅇ), 05-10.iv.2006, C. V. Janini et al. col. (IBSP 80335, 81299, 81307, 89908, 89917, 89919, 89921, 8992389928, 89931, 89933, 89934, 89940, 89941, 89943, 89944, 89946, 89949, 89950, 89951, 89953, 89956, 89958, 90361, 90363, 35ð7우), 05-10.iv.2007, C. V. Janini et al. col.(IBSP 116878, 119732, 2ð), 15-19.xii.2006, C. V. Janini et al. col.(IBSP 116938, 116954,

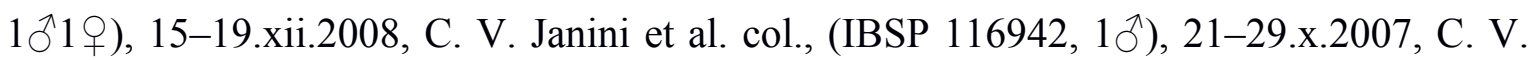


Janini et al. col.(IBSP 116849, 116855, 116916, 116955, 5ð2ㅇ), 21.29.x.2007, C. V. Janini et al. col.(IBSP 116890, 1ठ), 26.vi-02.vii.2007, C. V. Janini et al. col.(IBSP 116853, 116861, 116872, 116879, 116897, 116903, 116905, 116950, 116953, 116962 , 116970, 116979, 116980, 119730, 12ð10우), 26.vi-02.vii.2008, C. V. Janini et al. col., (IBSP 116977, 1ठ), 26.vi-02.viii.2008, C. V. Janini et al. col., (IBSP 116978, 1 ), 26.vi03.ix.2007, C. V. Janini et al. col., (IBSP 116963, 2ð2市), 26.vi.02.vii.2007, C. V. Janini et al. col., (IBSP 116901, 1ठ), 26.vi.02.viii.2007, C. V. Janini et al. col., (IBSP 116932, 2 q), 27.viii-03.ix.2007, C. V. Janini et al. col., (IBSP 116876, 116891, 116892, 116911116913, 116915, 116933, 116937, 116956, 5つ7우), 28.ix-02.x.2006, C. V. Janini et al. col., (IBSP 81271, 81300, 81313, 89960, 89961, 89963, 89964, 89965, 89968, 8997189973, 89975, 89977, 89981-89990, 89992, 89994, 89996-89999, 90141-90143, 90145, 90147, 90149, 90151, 90153, 90154, 90156-90158, 90160-90165, 90167-90169, 90171, 90173, 90174, 90176, 90177, 90180, 90181, 90184-90188, 90190-90193, 90195, 9019890200, 90204, 90207, 90208, 90210, 90214, 90216-90219, 116960, 158ð42ㅇ), 31.i07.ii.2007, C. V. Janini et al. col., (IBSP 116866, 116887, 116888, 116898, 116926,

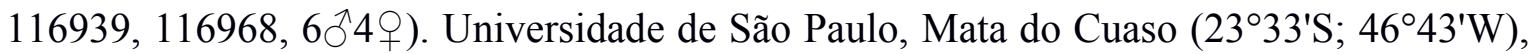
16-23.iv.1999, D. F. Candiani col., (IBSP41937, 19), 16-23.viii.1999, D. F. Candiani col., (IBSP42034, 2§), v.2001, Equipe USP col., (IBSP41799, 1§). Reservatório Guarapiranga

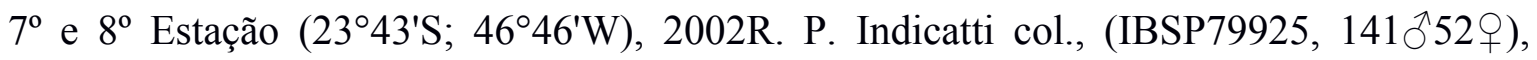

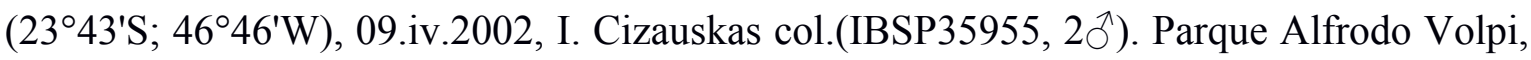

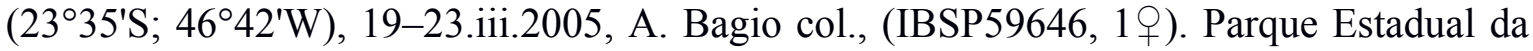

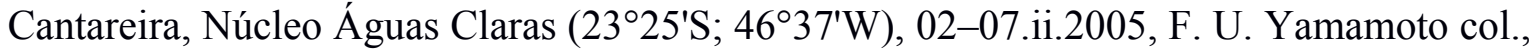
(IBSP 73472, 73473, 4ð1ㅇ), 14-19.xi.2004, F. U. Yamamoto col., (IBSP 73474, 1ठ), 28.vii-02.viii.2004, F. U. Yamamoto col., (IBSP 73468-73470, 73480, 73482, 76145, $76148,76155,6 \AA 4$ ).

Clitolyna novaeteutoniae (Baert, 1987, 265) comb. nov.

Figs. 127-132, Mapa 10.

Brattia novaeteutoniae Baert, 1987: 265, f. 7-13 (holótipo macho, 7 macho e 19 fêmeas parátipos de Nova Teutonia, Santa Catarina, Brasil, depositado no IRSNB [Institut Royal des Sciences Naturelles de Belgique, Bruxelas, Bélgica], não examinado). 
Brattia novaeteutoniae. Millidge, 1991: 180, f. 781, 783-784.

Sphecozone novaeteutoniae. Miller, 2007: 187.

Diagnose: Machos de C. novaeteutoniae lembram os de C. castanea, pela forma da apófise prolateral, muito alargada e longa, apresentando um dente distal. Diferem-se de $C$. castanea por apresentarem a apófise distal do supratégulo bífido, normal em C. castanea (Figs. 128, 131, 132). Fêmeas de $C$. novaeteutoniae lembram as de $C$. castanea, $C$. spadicaria e C. gravis por apresentarem uma membrana interna no epígino e um processo anterior da placa ventral, diferenciando-se de $C$. castanea, $C$. spadicaria e $C$. gravis pela forma do processo anterior da placa ventral delgada e proeminente, sendo robusta e de base alargada em C. castanea, discreta em $C$. spadicaria e direcionada posteriormente em $C$. gravis (Figs. 130-132).

Descrição: Macho (IBSP 141271) de Monte Alegre, São Cristóvão do Sul, Santa Catarina, Brasil. Comprimento total 1,58. Carapaça 0,67 de comprimento, 0,59 de largura, acastanhada. Esterno 0,39 de comprimento, 0,42 de largura, castanho escuro. Clípeo 0,15 de altura. Quelícera com 6 dentes promarginais e 5 retromarginais. Abdômen amarelado com mancha escura ao redor da fiandeira que se estende por todo ventre. Diâmetro dos olhos e distância: OMA 0,06; OLA 0,06; OMP 0,06; OLP 0,05. Distância entre os OMA 0,23 vezes seu diâmetro, distância entre os OMP 0,64 vezes seu diâmetro, distância entre OMA-OLA 0,46 vezes o diâmetro do OLA, distância entre OMP-OLP 0,57 vezes o diâmetro do OLP. Distância entre coxa IV 1,25 vezes sua largura. Fórmula das pernas III-IV-III. Fêmur I/II/III/IV 0,78/0,70/0,58/0,76; patela I 0,19; tíbia I 0,77; metatarso I 0,62; tarso I 0,47. Pernas alaranjadas. Fêmur/patela/tíbia/címbio do palpo 0,23/0,10/0,16/0,30. TmI 0,24. TmIV ausente. Címbio do palpo com cavidade basal. Tégulo com papilas, supratégulo liso, apresentando uma apófise distal bífida. Membrana embólica presente, êmbolo em espiral, com uma projeção na abertura, apresenta processo basal embólico. Radix liso, apresenta processo anterior robusto. Tíbia com apófise prolateral, apresenta um dente distal. Apresenta somente um tricobótrio retrolateral. (Figs. $127-128,131-132)$.

Fêmea (IBSP 166724) de Chapecó, Santa Catarina, Brasil. Comprimento total 1,94. Carapaça 0,72 de comprimento, 0,60 de largura. Esterno 0,42 de comprimento, 0,46 de 
largura. Clípeo 0,11 de altura. Quelícera com 6 dentes promarginais e 5 retromarginais. Padrão do abdômen, esterno e carapaça como no macho. Diâmetro dos olhos e distância: OMA 0,05; OLA 0,07; OMP 0,06; OLP 0,07. Distância entre os OMA 0,50 vezes seu diâmetro, distância entre os OMP 0,73 vezes seu diâmetro, distância entre OMA-OLA 0,45 vezes o diâmetro do OLA, distância entre OMP-OLP 0,62 vezes o diâmetro do OLP. Distância entre coxa IV 1,30 vezes sua largura. Fórmula das pernas I-II-IV-III. Fêmur I/II/III/IV 0,84/0,75/0,62/0,84; patela I 0,21; tíbia I 0,78; metatarso I 0,65; tarso I 0,49. Pernas como no macho. Fêmur/patela/tíbia/tarso do palpo 0,22/0,09/0,16/0,27. TmI 0,30. TmIV ausente. Tarso do palpo com macroseta dorsomesal distal, dorsoectal proximal e distal. Apresenta 3 macrosetas ventromesais e 2 ventroectais. Epígino muito proeminente, apresenta um processo anterior da placa ventral elevado e robusto. Átrios sinuoso. Membrana interna presente, espermateca de forma de ovalada. Duto de fertilização orientado anteriormente. (Figs. 129-132).

Variação: $\operatorname{Machos}(\mathrm{n}=10)$ : Comprimento total 1,52-1,91 (média 1,72); comprimento da carapaça 0,66-0,80 (média 0,72); largura da carapaça 0,58-0,64 (média 0,61); comprimento do fêmur I 0,76-0,85 (média 0,81).

Fêmeas $(\mathrm{n}=10)$ : Comprimento total 1,79-2,38 (média 1,98); comprimento da carapaça 0,66-0,81 (média 0,76); largura da carapaça 0,60-0,72 (média 0,66); comprimento do fêmur I 0,80-0,94 (média 0,87).

Distribuição: Registro para região Sul do Brasil (Mapa 10).

Material examinado: PARANÁ: Foz do Iguaçu, Parque Nacional de Foz do Iguaçu, (253'' S; 54²5'W), 03-12.iii.2002, Equipe Biota col., (IBSP 60311, 60313, 60316,

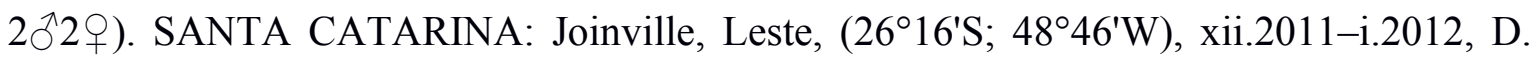
Baretta col., (IBSP 166725, 1ㅇ). Chapecó, (27²'S; 52³8'W), vi-vii.2011, D. Baretta col., (IBSP 166724, 29), 2008, R. Francisco col., (IBSP 122332, 1ठ̋). São Cristóvão do Sul, Monte Alegre, (27¹7'S; 50²5'W), 2001-2002, J. M. Moreira col., (IBSP 141230, 141241, 141248, 141271, 141294, 141315, 141336, 10ð1 9 ). Lages, Santa Terezinha do Salto, (274' $\mathrm{S}$; 50³0'W), xii.2011-i.2012, D. Baretta col., (IBSP 166727, 1q). Campo Belo do

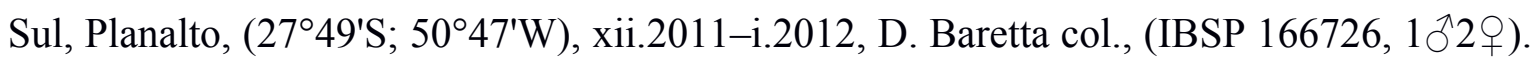




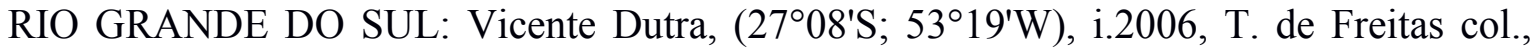
(MCTP 19926, $3 \hat{\delta}$ ), v.2006, T. de Freitas col., (MCTP 19928, 1ठ), vi.2006, T. de Freitas col., (MCTP 19929, 19943, 3ð3\%), vii.2006, T. de Freitas col., (MCTP 19930, 3ठ̂).

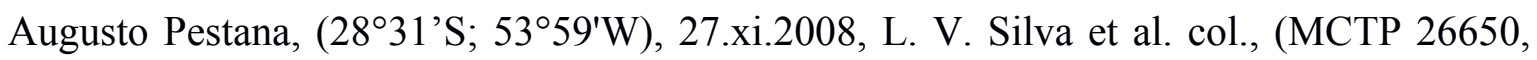
4ð1우), 27.xii.2008, L. V. Silva et al. col., (MCTP 26652, 26654, 2ठ), 10.i.2009, L. V. Silva et al. col., (MCTP 27407, 1ठ), 21.iii.2009, L. V. Silva et al. col., (MCTP 27409, 1ठ), 12.xi.2009, L. V. Silva et al. col., (MCTP 27410, 2ð). Cambará do Sul, Aparados da Serra, (29¹1'S; 5006'W), 14.iv.2013, Equipe Sisbiota col., (MCN 49420, 1ㅇ). São Francisco de Assis, (2927'S; 5501'W), iv-v.2013, Equipe Sisbiota col., (MCN 49417, 2ð), 28.iv.2013, Equipe Sisbiota col., (MCN 49628, 1ð), 11-12.v.2013, Equipe Sisbiota col., (MCN 49645, 49657, 23). Potreiro Velho, (29²4'S; 50¹9'W), 3.xi.1998, J. Ketterl col., (MCTP 15375, 1ठ). Sapiranga, (29³8'S; 5059'W), 14.ix.2005, E. L. C. Silva col., (MCTP 33618, 33625, 7ð2市), 22.ii.2006, E. L. C. Silva col., (MCTP 28536, 6ð3 9.iv.2006, E. L. C. Silva col., (MCTP 19707, 3ð3ㅇ). Cachoeira do Sul, Alto dos Casemiros, (30¹3'S; 5251'W), 26.ix.1992, R. G. Buss col., (MCTP 3291, 1우).

\section{Clitolyna personata (Simon, 1894) comb. nov.}

Figs. 133-138, Mapa 9.

Typhistes personatus Simon, 1894: 672, f. 748-749 (síntipos macho e fêmea do sul do Brasil, depositado no MNHN [Muséum National d'Histoire Naturelle, Paris, França], não examinado).

Sphecozone personata. Millidge, 1991: 175, f. 739-742. Miller, 2007: 187. Rodrigues, Ott \& Mendonça, 2012: 61, f. 6-19.

Diagnose: Machos de C. personata lembram os de C. alticeps e C. rostrata, pela projeção dorsal do címbio e pela apófise prolateral da tíbia, perpendicular e longo. Diferem-se de $C$. alticeps, pelo tamanho da projeção do címbio, robusto e longo em $C$. personata, e de $C$. rostrata pela forma do lóbulo cefálico entre OMA-OMP, cônico em C. personata, estreito e alongado em C. rostrata (Figs. 133, 134, 137, 138). Fêmeas de C. personata lembram as de C. rostrata e de Clitolyna sp.nov.02, pela localização das espermatecas, envolvidas pelos dutos de copulação. Diferenciam-se de C. rostrata pelas espermatecas, mais 
alongadas em $C$. personata. Diferenciam-se de Clitolyna sp.nov.02 pela forma do lóbulo anterior da placa dorsal, mais alarga que alta em Clitolyna sp.nov.02, sendo tão larga quanto longa em C. personata (Figs. 136-138).

Descrição: Macho e fêmea (de Maquiné, Rio Grande do Sul, Brasil) com descrição e informações em Rodrigues, Ott \& Mendonça, 2012: 61, f. 6-19. Imagens adicionais: Fig. $133-138$.

Variação: $\operatorname{Machos}(\mathrm{n}=10)$ : Comprimento total 1,40-1,69 (média 1,59); comprimento da carapaça 0,67-0,82 (média 0,77); largura da carapaça 0,49-0,55 (média 0,53); comprimento do fêmur I 0,46-0,57 (média 0,50).

Fêmeas $(\mathrm{n}=10)$ : Comprimento total 1,33-1,67 (média 1,45); comprimento da carapaça 0,52-0,65 (média 0,59); largura da carapaça 0,48-0,53 (média 0,50); comprimento do fêmur I 0,40-0,49 (média 0,44).

Distribuição: Região Sul do Brasil e São Paulo (Mapa 9).

Material examinado: BRASIL. SÃO PAULO: Biritiba Mirim, Barragem do Rio Biritiba, $\left(23^{\circ} 37^{\prime} \mathrm{S} ; 4^{\circ} 04^{\prime} \mathrm{W}\right), 10 . \mathrm{V} .2003$, Equipe IBSP col., (IBSP 147066, 1ठ). SANTA CATARINA: Arabutã, BR-283, Rio Jacutinga $\left(27^{\circ} 11^{\prime} \mathrm{S} ; 52^{\circ} 09^{\prime} \mathrm{W}\right)$, ix.1988, Eq. ItáMachadinho col., (MCTP 919, 19). Ilha do Arvoredo, (27²16'S; 48²1'W), 15-16.x.1993, A. A. Lise col., (MCTP 4028, 1ठ). Itá, Rio Uruguai, $\left(27^{\circ} 17^{\prime} \mathrm{S} ; 52^{\circ} 18^{\prime} \mathrm{W}\right)$, xii.1988, Eq. Itá-Machadinho col., (MCTP 902, 10). Rancho Queimado, $\left(27^{\circ} 40^{\prime} \mathrm{S} ; 49^{\circ} 13^{\prime} \mathrm{W}\right), 13-$ 15.i.1995, A. B. Bonaldo col., (MCN 26422, 19), 8-10.v.1995, Equipe Laboratório de Aracnologia col., (MCTP 9091, 19). RIO GRANDE DO SUL: Machadinho, Usina

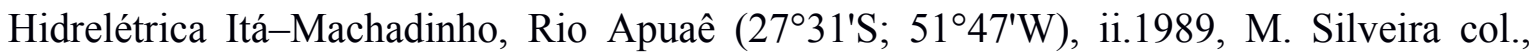
(MCTP 923, 1§ึ). São Francisco de Paula, (29²4'S; 50¹9'W), 1-4.v.1997, A. A. Lise col., (MCTP 14527, 1ðึ), 31.vii.2003, E. L. C. Silva col., (MCTP 19824, + juv.). Sapiranga, (29³8'S; 5059'W), 29-30.x.2005, E. L. C. Silva col., (MCTP 17429, 1ठㅇ).

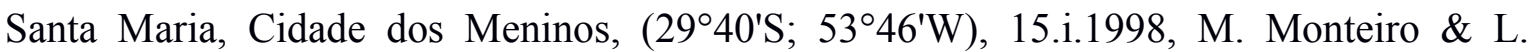
Indrusiak col., (MCTP 38188, 19). São Marcos, (2944'S; 5346'W), 23.iv.1999, J.

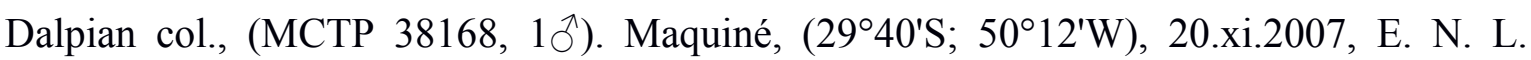


Rodrigues col., (MCN 47507, 18 45), 3.viii.2008, E. N. L. Rodrigues col., (MCN

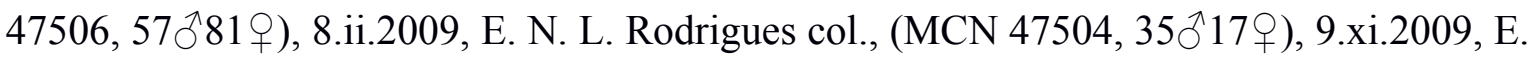
N. L. Rodrigues col., (MCN 47502, 20 $\overbrace{}^{\circledR} 49$ \%). Rio Maquiné, (2940'S; 50¹1'W), 27.i.2008, E. N. L. Rodrigues col., (MCN 48489, $18 \overbrace{}^{\circledR} 28$ ㅇ). Cachoeira do Sul, (30¹3'S; 52॰51'W), 20.x.1994, R. G. Buss col., (MCTP 6862, 1ठ).

Clitolyna rostrata (Millidge, 1991) comb. nov.

Figs. 145-150, Mapa 9.

Sphecozone rostrata Millidge, 1991: 175, f. 743-746 (holótipo macho de Encruzilhada, Bahia, Brasil, depositado no AMNH). Miller, 2007: 187. Rodrigues, Ott \& Mendonça, 2012: 60, f. $1-5$.

Material tipo examinado: BRASIL. BAHIA: Encruzilhada (Enerigilhada), (15³1'S; 4054'W), xii.1973, M. Alvarenga col., (AMNH 326246, 1ठ, holótipo).

Diagnose: Machos de C. rostrata lembram os de C. alticeps e C. personata, pela projeção dorsal do címbio e pela apófise prolateral da tíbia, perpendicular e alta. Diferem-se de $C$. alticeps, pelo tamanho da projeção do címbio, robusto e longo em C. rostrata. Difere-se de C. personata pela forma lóbulo cefálico entre OMA-OMP, estreito e alongado em $C$. rostrata, cônico em C. personata (Figs. 145, 146, 149, 150). Fêmeas de C. rostrata lembram as de $C$. personata e de Clitolyna sp.nov.02, pela localização das espermatecas, envolvidas pelos dutos de copulação. Diferenciam-se de C. personata e Clitolyna sp.nov.02 pelas espermatecas mais arredondadas (Figs. 148-150).

Descrição: Macho e fêmea (de Maquiné, Rio Grande do Sul, Brasil) com descrição e informações em Rodrigues, Ott \& Mendonça, 2012: 61, f. 6-19. Imagens adicionais: Fig. $145-150$.

Variação: Machos ( $\mathrm{n}=10)$ : Comprimento total 1,36-1,64 (média 1,49); comprimento da carapaça 0,62-0,72 (média 0,68); largura da carapaça 0,51-0,55 (média 0,54); comprimento do fêmur I 0,44-0,54 (média 0,48). 
Fêmeas $(\mathrm{n}=10)$ : Comprimento total 1,37-1,68 (média 1,51); comprimento da carapaça 0,54-0,61 (média 0,58); largura da carapaça 0,50-0,55 (média 0,52); comprimento do fêmur I 0,43-0,51 (média 0,47).

Distribuição: Brasil (Bahia e Rio Grande do Sul) (Mapa 9).

Material examinado: BRASIL. RIO GRANDE DO SUL: Terra de Areias, $\left(29^{\circ} 34^{\prime} \mathrm{S}\right.$; 5003'W), 27.xii.2001, E. L. C. Silva col., (MCTP 19839, 4§ึ), 23.xi.2002, E. L. C. Silva col., (MCTP 19840, 3 \% ). Maquiné, (2940'S; 50¹2'W), 9.v.2008, E. N. L. Rodrigues col., (MCN 47519, $3 \lesssim 3$ †), 22.vi.2008, E. N. L. Rodrigues col., (MCN 47500, $5 ð 3$ ). Parobé, Rio dos Sinos, (2941'S; 5049'W), 18.xii.2007, E. N. L. Rodrigues \& P. E. S. Rodrigues col., (MCN 48076, 6ð13 9 ). Glorinha, São João, (2952’S; 5048’W), 14.vii.2000, A. B. Bonaldo col., (MCN 33049, 2ð17ㅇ). Viamão, (30²0’S; 5101'W), 7.vii.1995, A. A. Lise col., (MCTP 18285, 1ठ), 19.viii.1994, A. A. Lise et al. col., (MCTP 5318, 1ठ), 25.xi.1994, A. A. Lise et al. col., (MCTP 8489, 1§4우), 2.xii.1994, A. A. Lise et al. col., (MCTP 7891, 8129, 3ð5ㅇ), 24.iii.1995, A. A. Lise et al. col., (MCTP 8712, 1ð), 12.v.1995, A. A. Lise et al. col., (MCTP 8431, 1§), 23.vi.1995, A. A. Lise et al. col., (MCTP 9109, 9110, 1§1우), 15.xii.1995, A. A. Lise et al. col., (MCTP 9026, 2q), 23.i.1996, A. A. Lise et al. col., (MCTP 9228, 9229, $3 \hat{\jmath} 1$ 9), iv.2002, L. E. C. Schneider col., (MCTP 13734, 13745, 1ð1우), 8.xii.1992, M. Cunha col., (MCTP 2816, 5ð1우).

\section{C. tumidosa (Keyserling, 1886, 220) comb. nov.}

Figs. 155-159, Mapa 7B.

Erigone tumidosa Keyserling, 1886: 220, pl. 19, fig. 277 (macho holótipo de Serra

Vermelha (Serre Vermelle?), Brasil, depositado no BMNH [Natural History Museum, Londres, Reino Unido], não examinado).

Ceratinopsis tumidosa. Simon, 1894: 645.

Sphecozone tumidosa. Miller, 2007: 205, f. 152D-E.

Diagnose: Machos de C. tumidosa lembram os de C. venialis e C. crassa pela presença de um processo retromediano no címbio do palpo. Diferenciam-se de C. crassa pela presença 
de membrana embólica (Figs. 156, 159). Fêmeas de C. crassa lembram as de C. tumidosa e C. venialis pelas espermatecas arredondadas, localizadas lateralmente aos dutos de copulação. Diferenciam-se de C. crassa, pela forma do átrio, curvada em C. tumidosa, reto em C. crassa (Fig. 158).

Descrição: Macho (de Serra Vermelha (Serre Vermelle), Brasil) com descrições e ilustrações em Miller, 2007: 205, f. 152D-E. Imagens adicionais figs. 155-156, 159.

Fêmea (IBSP 27715) de Itanhaém, São Paulo, Brasil. Comprimento total 1,96. Carapaça 0,71 de comprimento, 0,61 de largura, castanha, com região cefálica preta. Esterno 0,43 de comprimento, 0,43 de largura, marrom escuro. Clípeo 0,13 de altura. Quelícera com 6 dentes promarginais e 5 retromarginais. Abdômen amarelado com mancha escura ao redor das fiandeiras e redor das fiandeiras e longitudinalmente no dorso. Diâmetro dos olhos e distância: OMA 0,04; OLA 0,04; OMP 0,04; OLP 0,04. Distância entre os OMA 0,63 vezes seu diâmetro, distância entre os OMP 1,28 vezes seu diâmetro, distância entre OMA-OLA 0,95 vezes o diâmetro do OLA, distância entre OMP-OLP 1,17 vezes o diâmetro do OLP. Distância entre coxa IV 1,41 vezes sua largura. Fórmula das pernas III-IV-III. Fêmur I/II/III/IV 0,77/0,71/0,64/0,87; patela I 0,20; tíbia I 0,62; metatarso I 0,63; tarso I 0,39. Pernas amareladas. Fêmur/patela/tíbia/tarso do palpo 0,25/0,10/0,13/0,29. TmI 0,35. TmIV ausente. Epígino com processo anterior da placa ventral. Apresenta par de átrio curvo. Forma do espermateca arredondada, levemente ovalada, posicionada lateralmente em relação ao duto copulatório. Duto de fertilização com orientado para parte posterior. (Figs. 157-158).

Variação: $\operatorname{Machos}(\mathrm{n}=1)$ : Comprimento total 1,65; comprimento da carapaça 0,73 ; largura da carapaça 0,62; comprimento do fêmur I 0,74.

Fêmeas ( $\mathrm{n}=2$ ): Comprimento total 1,71-1,87 (média 1,79); comprimento da carapaça 0,660,73 (média 0,69); largura da carapaça 0,57-0,64 (média 0,61); comprimento do fêmur I 0,76-0,83 (média 0,79).

Obs.: A coloração do abdômen pode variar de amarelo claro para bege escuro, apresentando uma mancha de longitudinal mais escura, ocupando grande parte dorsal do abdômen, como também apresentar mancha restrita ao redor das fiandeiras 
Distribuição: Brasil (Minas Gerais e São Paulo) (Mapa 7B).

Material examinado: BRASIL. SÃO PAULO: Itanhaém, (2408'S; 4645'W), x.1999, H. F. Japyassú col., (IBSP 27703, 27715, 2ð3 9 ).

Clitolyna venialis (Keyserling, 1886, 270) comb. nov.

Figs. 163-168, Mapa 7B.

Erigone venialis Keyserling, 1886: 270, pl. 21, fig. 319 (macho e fêmea síntipos do Rio de Janeiro, Brasil, depositado no BMNH [Natural History Museum, Londres, Reino Unido], não examinado).

Sphecozone nigriceps Millidge, 1991: 175, f. 733, 734, 738. (macho holótipo do Jardim Botânico, Água Funda, São Paulo, São Paulo, Brasil, depositado no AMNH).

Sphecozone venialis. Miller, 2007: 203, f. 151D, 152A-C.

Material tipo examinado: BRASIL. SÃO PAULO: São Paulo, Água Funda, Jardim Botânico, (23³8'S; 46³7'W), 7.vii.1962, A. F. Archer col., (AMNH, 10̂, holótipo).

Diagnose: Espécies de C. venialis lembram as de C. Tumidosa e C. crassa pela presença de um processo retromediano no címbio do palpo dos machos. Diferenciam-se de $C$. crassa pela presença de uma membrana embólica (Figs. 164, 167, 168). Fêmeas de $C$. venialis lembram as de C. Tumidosa e C. crassa pelas espermatecas arredondadas, localizadas lateralmente aos dutos de copulação. Diferenciam-se de C. crassa pela forma do átrio, curvada em C. Tumidosa, reto em C. crassa (Figs. 166-168).

Descrição: Descrição: Macho e fêmea (de San Pedro, Cruce Caballero, Misiones, Argentina) com descrições e ilustrações em Miller, 2207: 194, f. 142H, 147A-B, E-F, H. Imagens adicionais: Fig. 163-168.

Variação: Machos ( $\mathrm{n}=10)$ : Comprimento total 1,75-2,03 (média 1,89); comprimento da carapaça 0,71-0,84 (média 0,78); largura da carapaça 0,69-0,75 (média 0,71); comprimento do fêmur I 0,89-1,04 (média 0,96). 
Fêmeas $(\mathrm{n}=10)$ : Comprimento total 1,84-2,37 (média 2,15); comprimento da carapaça 0,68-0,87 (média 0,76); largura da carapaça 0,54-0,71 (média 0,66); comprimento do fêmur I 0,86-1,07 (média 0,99).

Distribuição: Argentina (Misiones e Tucumán), Bolívia (Potosí), Brasil (Mato Grosso do Sul e regiões Sudeste e Sul), Peru (Amazonas e Madre de Dios) (Mapa 7B).

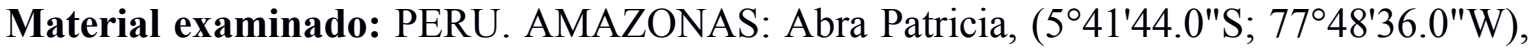
sem informação de dataM. Alvarado, R. Pinto-da-Rocha \& D. Silva D. col., (MUSM 0506687, 19). MADRE DE DIOS: Zona Reservada Pakitza, (11 $\left.{ }^{\circ} 58^{\prime} \mathrm{S} ; 7^{\circ} 18^{\prime} \mathrm{W}\right)$, 10.vii.1991, D. Silva col., (MUSM 0508663, 19). BOLIVIA. POTOSI: Potosi, (19³2'S; 654' W), Ross e Michelbacher col., (CAS 9076616, 19). BRASIL. MATO GROSSO DO SUL: Três Lagoas, Horto Barra do Moeda, (2057'; 51 $\left.{ }^{\circ} 47^{\prime}\right)$, iii.2009, M. Uehara-Prado col., (UFMG 5683, 1§). MINAS GERAIS: Ouro Preto, Parque Estadual de Itacolomi, (20²6'S; 4327'W), 11-13.iv.2008, K. P. Santos et al. col., (UFMG 2198, 2392, 2 9).

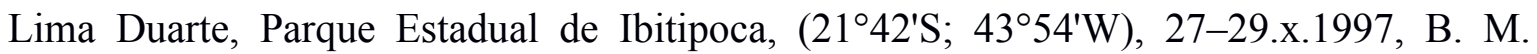
Souza col., (IBSP 23806, 1ठ). Santa Rita de Ibitipoca, Parque Estadual de Ibitipoca, (21ㄴ2'S; 435' W), vi.1998, A. Oliveira e B. M. Souza col., (IBSP 21472, 1ㅇ). RIO DE JANEIRO: Itatiaia, (22²9'46.0"S; 44³3'48.0"W), 09-13.vi.2001, H. F. Japyassu col.,

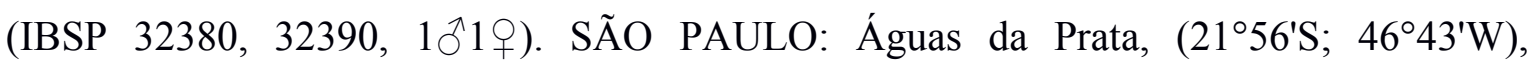
11.iv.1998, V. C. Onófrio col., (IBSP 17513, 19). São José do Barreiro, Parque Nacional da Serra da Bocaina, (2244'S; 44³6'W), 22-25.vii.2006, F. U. Yamamoto col., (IBSP

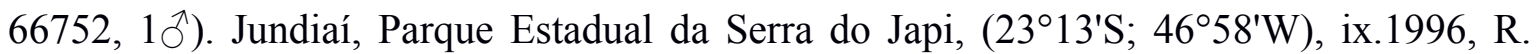
Lima col., (IBSP 7246, 19), 11.viii.2000, R. Pinto da Rocha et al. col., (IBSP 127784, 127786, 127790, 127796, 127799, 1ð4ㅇ), 29.x.2000, R. Pinto da Rocha et al. col., (IBSP 127787, 127791, 127797, 127798, 4), 10.xi.2000, R. Pinto da Rocha et al. col., (IBSP 127783, 127785, 127795, $1 \jmath^{3}$ \%), 29.xi.2000, R. Pinto da Rocha et al. col., (IBSP 127789, 127794, 29), 13.xii.2000, R. Pinto da Rocha et al. col., (IBSP 127788, 1ठ), 20.xii.2000, R. Pinto da Rocha et al. col., (IBSP 127800, 19), 21.xii.2000, R. Pinto da Rocha et al. col.,

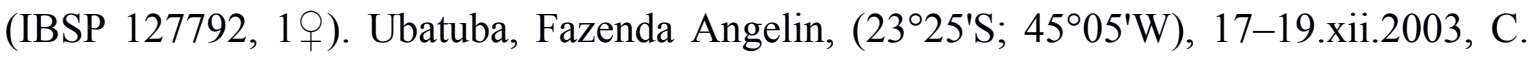
Rheims \& R. Indicatti col., (IBSP 52249, 2 + $)$. Salesópolis, Barragem Paraitinga, (2331'S; $\left.45^{\circ} 56^{\prime} \mathrm{W}\right), 18 . v i .2002$, Equipe IBSP col., (IBSP 122500, $3{ }^{\top} 2$ ) ). Parque Nascentes do Rio 
Tietê, (2334'S; 4544'W), 1997, R. Martins col., (IBSP 20201, 1 + ). Estação Biológica de

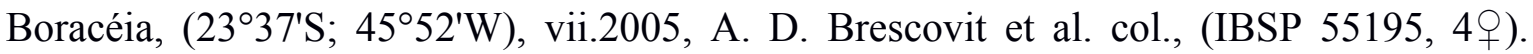

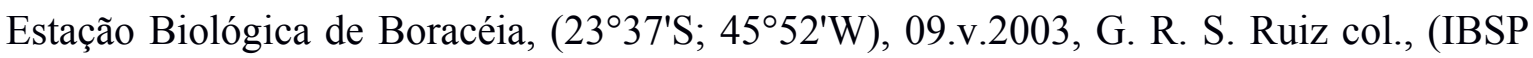
38305, 4ㅇ). Mogi das Cruzes, Distrito de Biritiba-Ussu, Manuel Ferreira (233' S; $46^{\circ} 7^{\prime}$ W)v.2001, E. Kashimata \& R. Martins col., (IBSP 56335, 56394, 56447, 56454, 56586, 56587, $5 \jmath^{\Uparrow} 3$ ㅇ). Santo André, Reserva Biológica do Alto da Serra de Paranapiacaba,

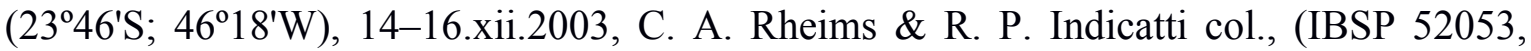
2ð1우), 27.x.2007, Equipe Butantan col., (IBSP 88566, 1ठ), 28.x.2007, Equipe Butantan col., (IBSP 88549, 1). Bertioga, Trilha do rio Itatinga, $\left(23^{\circ} 46 ' \mathrm{~S} ; 46^{\circ} 06^{\prime} \mathrm{W}\right)$, vii.2000, M. S. C. Morini col., (IBSP 62374, 1ठ). Santos, Vale do Rio Jurubatuba, (2351'S; $\left.46^{\circ} 18^{\prime} \mathrm{W}\right)$ iii-xii.2007, Nogueira et al. col., (IBSP 125865-125870, 125873-125879, 5ठ1). Iporanga, Fazenda Intervales, (2420'S; 48²6'W), vii.1996, A. Leme col., (IBSP 8134,

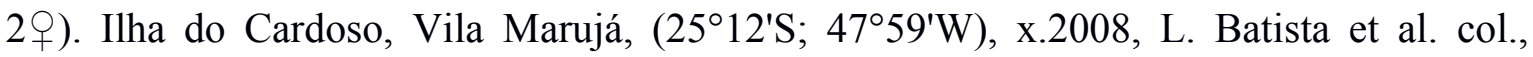
(IBSP 119829, 1ㅇ). PARANÁ: Almirante Tamandaré, $\left(25^{\circ} 18^{\prime} \mathrm{S} ; 4^{\circ} 18^{\prime} \mathrm{W}\right)$, 24.viii.84, E. C. Costa col., (MCTP 12565, 19). Curitiba, $\left(25^{\circ} 28^{\prime} \mathrm{S} ; 4^{\circ} 15^{\prime} \mathrm{W}\right)$, 9.i.1963, Blake \& Cochran col., (USNM, 1q). SANTA CATARINA: Seara, Distrito de Nova Teutônia, $\left(27^{\circ} 07^{\prime} \mathrm{S} ; 52^{\circ} 21^{\prime} \mathrm{W}\right), 4 . i i .2008$, M. O. Gonzaga \& A. J. Santos col., (UFMG 5542, 1 ㅇ), $13-$ 15.x.2006, E. L. C. Silva et al. col., (MCTP 28709, 1ðึ). RIO GRANDE DO SUL: Derrubadas, Parque Estadual do Turvo, $\left(27^{\circ} 20^{\prime} \mathrm{S} ; 5^{\circ} 10^{\prime} \mathrm{W}\right), 11-18.1 .2002$, Equipe Biota

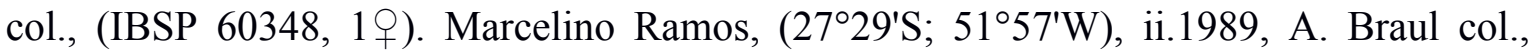

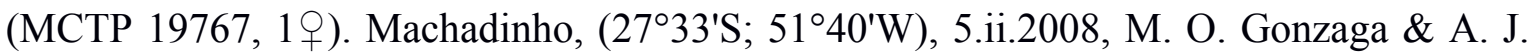

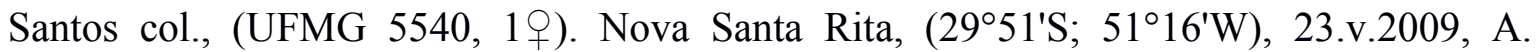
Oliveira col., (MCTP 37297, 3 9 ). Cidreira, (308'S; 50¹6'W), 20.ix.2003, J. A. M. Pinto col., (MCTP 37119, 19). ARGENTINA. TUCUMÁN: Cerro San Xavier, (2649’S; 65¹3'W), 11.ii.1951, Ross and Michelbacher col., (CAS 9076625, 19).

Clitolyna varia (Keyserling, 1886) comb. nov.

Figs. 160-162, Mapa 8.

Sphecozone varia Millidge, 1991: 220, pl. 19, fig. 277 (fêmea holótipo de Machu Picchu, Cusco, Peru, depositado no AMNH).

Sphecozone varia. Miller, 2007: 187. 
Material tipo examinado: PERU. CUSCO: Machu Picchu, $\left(13^{\circ} 09^{\prime} \mathrm{S} ; 72^{\circ} 36^{\prime} \mathrm{W}\right), 1-$ 5.vii.1964, B. Malkin col., (AMNH 326252, 19, holótipo).

Diagnose: Fêmea de C. varia lembra a de Clitolyna sp.nov.01, pela forma do duto de copulação, que possui uma forma laminar próxima a região da espermateca. Diferencia-se pela forma da placa dorsal muito mais larga que longa em C. varia (Figs. 161, 162).

Descrição: Macho desconhecido.

Fêmea (Holótipo; AMNH 326252) de Machu Picchu, Cusco, Peru. Comprimento total 2,45. Carapaça 0,91 de comprimento, 0,75 de largura, marrom escuro, com região cefálica preta. Esterno 0,54 de comprimento, 0,55 de largura, marrom, com bordas escuras. Clípeo 0,23 de altura. Quelícera com 5 dentes promarginais e 4 retromarginais. Abdômen bege escuro. Diâmetro dos olhos e distância: OMA 0,06; OLA 0,05; OMP 0,04; OLP 0,05. Distância entre os OMA 0,37 vezes seu diâmetro, distância entre os OMP 2,31 vezes seu diâmetro, distância entre OMA-OLA 0,74 vezes o diâmetro do OLA, distância entre OMP-OLP 0,77 vezes o diâmetro do OLP. Distância entre coxa IV 1,61 vezes sua largura. Fêmur I/II/III/IV 1,12/1,06/0,97/1,20; patela I 0,25; tíbia I 0,94; metatarso I 0,92; tarso I 0,51. Pernas amarronzadas, mais amareladas na base dos fêmures. Fêmur/patela/tíbia/tarso do palpo 0,32/0,11/0,27/0,36. TmI 0,82. TmIV ausente. Epígino com um par de átrio curvado, lóbulo anterior da placa dorsal apresentando margem anterior em "M". Dutos de copulação esclerotizados, dutos de fertilização originados da parte posterior da espermateca, se dirigindo mesalmente. Espermatecas ovais. (Figs. 160-162).

Variação: Fêmeas ( $\mathrm{n}=5$ ): Comprimento total 2,38-2,71 (média 2,53); comprimento da carapaça 0,93-0,98 (média 0,95); largura da carapaça 0,82-0,87 (média 0,85); comprimento do fêmur I 1,12-1,16 (média 1,14).

Distribuição: Registro para Peru (Mapa 8).

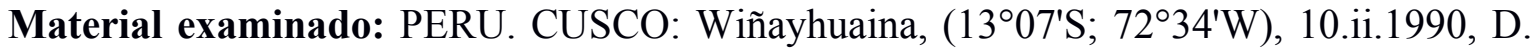
Silva col., (MUSM 0508652, 5ㅇ). 
Clitolyna sp.nov.01 Rodrigues, Lemos e Brescovit, in prep

Figs. 169-171, Mapa 8.

Material tipo examinado: BRASIL. RIO GRANDE DO SUL: Cambará do Sul, $\left(29^{\circ} 1^{\prime S}\right.$; 50¹1'W), 25.xi.1993, L. A. Moura col., (MCN 24273, 2ð11, holótipo). SANTA

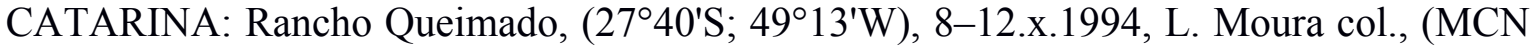
26259, 1 \% , parátipo).

Diagnose: Clitolyna sp.nov.01 Diferencia-se de outras espécies de Clitolyna, exceto $C$. fastibilis, pela forma da região cefálica dos machos, elevada abruptamente e com fortes cerdas na região ocular. Diferencia-se de C. fastibilis pela forma da apófise prolateral, mais curta e truncada em Clitolyna sp.nov.01 (Figs. 170, 171). Fêmeas de Clitolyna sp.nov01 lembram as de C. fastibilis, por apresentar o lóbulo anterior da placa dorsal pelo menos $2 \mathrm{x}$ mais larga que a placa dorsal. Difere-se de C. fastibilis pela forma do lóbulo anterior da placa dorsal, mais ovalada em Clitolyna sp.nov.01 (Figs. 170-171).

Descrição: Macho (Holótipo; MCN 24273) de Cambará do Sul, Rio Grande do Sul, Brasil. Comprimento total 2,02. Carapaça 0,88 de comprimento, 0,7 de largura, amareladas com mancha escura na região cefálica, estendendo em uma linha até a região torácica. Esterno 0,49 de comprimento, 0,52 de largura, amarelada com bordas escuras. Abdômen 1,27 de comprimento, 0,8 de largura and 0,83 de altura, amarelada com mancha preta na parte dorsal e próximo às fiandeiras. Clípeo 0,36 de altura. Quelícieras 0,33 de comprimento. Diâmetro e distância dos olhos: OMA 0,04; OLA 0,06; OMP 0,04; OLP 0,04. OMAOMA: 0,02. OMP-OMP: 0,12. OMA-OLA: 0,06, OMP-OLP: 0,02. Olhos agrupados em uma região elevada da região cefálica, com grossas cerdas na área ocular. Distância entre coxas IV 0,2. Fórmula das pernas IV-I-II-III. Fêmur I/II/III/IV 0,98/0,91/0,78/1,01; patela I/II/III/IV 0,2/0,23/0,18/0,23; tíbia I/II/III/IV 0,83/0,78/0,57/0,85; metatarso I/II/III/IV 0,75/0,67/0,54/0,75; tarso I/II/III/IV 0,44/0,39/0,39/0,41. Comprimento total da perna I/II/III/IV 3,2/2,98/2,46/3,25. Pernas amarelo escuro, mais claras na região proximal de cada segmento. Fêmur/patela/tíbia/címbio do palpo 0,36/0,23/0,23/0,46. Fórmula das macrosetas dorsais da tíbia 1-1-1-1. TmI 0.63. TmIV ausente. A patela apresenta um pequeno grupo de projeções na sua parte dorsal. Tíbia com um tricobótrio retrolateral, 
apófise prolateral da tíbia achatada dorsalmente, com 2 projeções, com dentículos em sua margem. Tégulo com papilas. Cauda do radix espiral. Membrana embólica presente. Processo anterior do radix presente. Êmbolo curto, largo, espiral. (Figs. 169-171).

Fêmea (Parátipo; MCN 24273) de mesma localidade do macho. Comprimento total 1,92. Carapaça 0,72 de comprimento, 0,59 de largura. Esterno 0,44 de comprimento, 0,49 de largura. Abdômen 1,35 de comprimento, 0,85 de largura, 0,91 de altura. Padrão da carapaça, esterno e abdômen como no macho. Clípeo 0,13 de altura. Quelícieras 0,39 de comprimento. Diâmetro e distância dos olhos: OMA 0,05; OLA 0,04; OMP 0,06; OLP 0,04, OMA-OMA: 0,02, OMP-OMP: 0,08, OMA-OLA: 0,04, OMP-OLP: 0,04. Olhos agrupados em região cefálica discretamente elevada. Distância entre coxas IV 0,18. Fórmula das pernas IV-I-II-III. Fêmur I/II/III/IV 0,93/0,83/0,75/1,01; patela I/II/III/IV 0,26/0,23/0,23/0,23; tíbia I/II/III/IV 0,78/0,72/0,57/0,8; metatarso I/II/III/IV 0,75/0,65/0,54/0,8; tarso I/II/III/IV 0,44/0,41/0,36/0,44. Comprimento total da perna I/II/III/IV 3,16/2,82/2,42/3,28. Padrão das pernas como no macho. Fêmur/patela/tíbia/tarso do palpo 0,31/0,1/0,18/0,31. Fórmula das macrosetas dorsal da tíbia 1-1-1-1. TmI 0,70, TmIV ausente. Epígino com um par de átrio curvado, lóbulo anterior da placa dorsal duas vezes mais larga que a placa dorsal. Dutos de copulação esclerotizados, dutos de fertilização originados da parte posterior da espermateca, se dirigindo mesalmente. Espermatecas ovais. (Figs. 169F-J, 170E-F, 171C-D).

Variação: $\operatorname{Machos}(\mathrm{n}=2)$ : Comprimento total 1,96-1,97; comprimento da carapaça 0,78 0.79 ; largura da carapaça $0,67-0,69$; comprimento do fêmur I 0,88-0,95.

Fêmeas $(n=2)$ : Comprimento total 1,82-2,11; comprimento da carapaça $0,61-0,74$; largura da carapaça 0,61-0,64; comprimento do fêmur I 0,89-0,97.

Distribuição: Brasil (São Paulo, Santa Catarina e Rio Grande do Sul) (Mapa 8).

Material examinado: BRASIL. SÃO PAULO: Mogi das Cruzes, Biritiba-Uçu, $\left(23^{\circ} 38^{\prime} \mathrm{S}\right.$; 467'W), 12.v.1991, N. Silveira col., (MCN 21093, 1ठึ). RIO GRANDE DO SUL: Cambará do Sul, (29¹'S; 50¹1'W), 11-13.iv1994, A. B. Bonaldo col., (MCN 25466, 1 q). 
Clitolyna sp.nov.02 Rodrigues, Lemos, Brescovit, in prep.

Figs. 172-174, Mapa 7A.

Material tipo examinado: BRASIL, RIO GRANDE DO SUL: São Francisco de Paula, Potreiro Velho $\left(29^{\circ} 26^{\prime} \mathrm{S} ; 50^{\circ} 34^{\prime} \mathrm{W}\right), 1^{\Uparrow} 1$ ㅇ, 3.v.2000, J. Ketterl col. (MCTP 16331, holótipo). BRASIL, SÃO PAULO: São Paulo, Parque Estadual da Cantareira, Núcleo

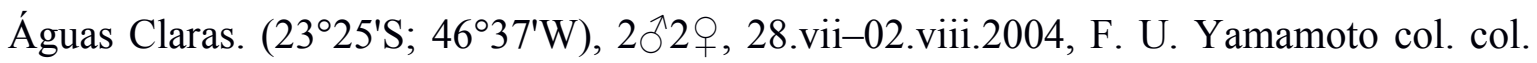
(IBSP 76122; 76128, parátipos), 2ð1우 12-17.v.2005, F. U. Yamamoto col. col. (IBSP 76303, parátipo), $3 ð 2$ ㅇ, 02-07.ii.2005, F. U. Yamamoto col. col. (IBSP 76195, parátipo). Santa Catarina: Siderópolis $\left(28^{\circ} 34^{\prime} \mathrm{S} ; 49^{\circ} 31^{\prime} \mathrm{W}\right), 4{ }^{\Uparrow} 1$ 웅 08.vii.2006, R. A. Teixeira col. (IBSP 84826, parátipo). RIO GRANDE DO SUL: São Francisco de Paula (29²6'S; 50³4'W), 5ð112 +, 12-15.vi.1997, R. Ott col. (MCTP 10038, parátipo), 8ð2q, 23.xi.2000, R. Ott et al. col. (MCTP 19064, parátipo).

Diagnose: Machos de Clitolyna sp.nov.02 Diferenciam-se dos de outras espécies por apresentar o tégulo do palpo muito amplo, em forma de crista (Figs. 173, 174). Fêmeas lembram C. personata e C. rostrata pela forma como a espermateca está envolvido pelo duto de copulação. Diferenciam-se de C. personata e C. rostrata por apresentar o lóbulo anterior da placa dorsal mais alargada que em C. personata e C. rostrata (Figs. 173, 174).

Descrição: Macho (Holótipo; MCTP 16331) de Potreiro Velho, São Francisco de Paula, Rio Grande do Sul, Brasil. Comprimento total 1,63. Carapaça 0,73 de comprimento, 0,61 de largura, alaranjado com mancha marrom na região cefálica. Esterno 0,43 de comprimento, 0,41 de largura, alaranjadas com margem marrom. Abdômen 0,91 de comprimento, 0,53 de largura e 0,48 de altura, amarelado com pequena mancha preta na parte dorsal, perto das fiandeiras. Clípeo 0,13 de altura. Quelícieras 0,24 de comprimento. Diâmetro e distância dos olhos: OMA 0.04; OLA 0.07; OMP 0.07; OLP 0.06. OMAOMA: 0.03. OMP-OMP: 0.04, OMA-OLA: 0.04, OMP-OLP: 0.05. Olhos agrupados numa região ocular elevada. Distância entre coxas IV 0,15. Fórmula das pernas I-IV-IIIII. Fêmur I/II/III/IV 0,72/0,61/0,54/0,73; patela I/II/III/IV 0,2/0,18/0,18/0,15; tíbia I/II/III/IV 0,67/0,55/0,46/0,66; metatarso I/II/III/IV 0,52/0,48/0,42/0,52; tarso I/II/III/IV 0,45/0,41/0,32/0,36. Comprimento total da perna I/II/III/IV 2,56/2,23/1,92/2,42. Pernas 
com todos os segmentos amarelados. Fêmur/patela/tíbia/címbo do palpo 0,22/0,1/0,18/0,35. TmI 0,28. TmIV presente. Tíbia com um tricobótrio retrolateral, apófise prolateral da tíbia em forma de gancho, com dentículos na margem. Címbio com uma carena dorsal na região proximal. Pequeno protégulo com papilas. Tégulo com pequenas papilas. Cauda do radix estreita e em espiral. Membrana embólica e processo anterior do radix presente. Êmbolo comprido, fino e espiral. (Figs. 172-174).

Fêmea (Parátipo; MCTP 16331), mesma localidade do macho. Comprimento total 1,72. Carapaça 0,71 de comprimento, 0,6 de largura. Esterno 0,45 de comprimento, 0,43 de largura. Abdômen 0,94 de comprimento, 0,6 de largura e 0,6 de altura. Padrão do abdômen, carapaça e esterno como no macho. Clípeo 0,12 de altura. Quelícieras 0,26 de comprimento. Diâmetro e distância dos olhos: OMA 0,03; OLA 0,06; OMP 0,06; OLP 0,05. OMA-OMA: 0,03, OMP-OMP: 0,04, OMA-OLA: 0,04, OMP-OLP: 0,04. Região cefálica não elevada como no macho. Distância entre coxas IV 0,16. Fórmula das pernas IIV-II-III. Fêmur I/II/III/IV 0,68/0,67/0,6/0,72; patela I/II/III/IV 0,21/0,2/0,19/0,16; tíbia I/II/III/IV 0,63/0,58/0,49/0,66; metatarso I/II/III/IV 0,52/0,49/0,43/0,51; tarso I/II/III/IV 0,44/0,42/0,32/0,37. Comprimento total da perna I/II/III/IV 2,48/2,36/2,03/2,42. Padrão das pernas como no macho. Fêmur/patela/tíbia/tarso do palpo 0,23/0,07/0,17/0,21. TmI 0,28. TmIV presente. Epígino com par de átrios curvos. Lóbulo anterior da placa dorsal tão largo quanto a placa dorsal. Duto de copulação esclerotizado, dutos de fertilização de origem posterior da espermateca, direciona-se mesalmente. Espermatecas ovais. (Figs. 172-174).

Variação: Machos $(n=10)$ : Comprimento total $1,61-1,87$; comprimento da carapaça $0,61-$ 0,76; largura da carapaça 0,54-0,58; comprimento do fêmur I 0,69-0,73.

Fêmeas $(\mathrm{n}=10)$ : Comprimento total $1,65-2,13$; comprimento da carapaça $0,71-0,78$; largura da carapaça $0,56-0,67$; comprimento do fêmur I $0,71-0,81$.

Distribuição: Registro para Sudeste e Sul do Brasil (Mapa 7A).

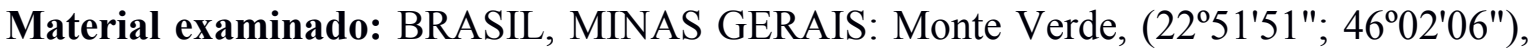
2ᄋ, 17-18.xi.2001, A.D.Brescovit et al col. (IBSP 31863). RIO DE JANEIRO: Volta

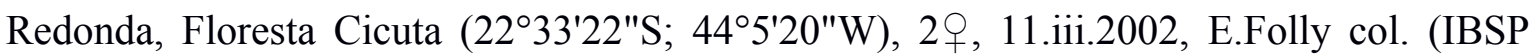


39603). SÃO PAULO: São Paulo, Parque Estadual da Cantareira, Núcleo Águas Claras. $\left(23^{\circ} 25^{\prime} \mathrm{S} ; 46^{\circ} 37^{\prime} \mathrm{W}\right), 60{ }^{\wedge} 11$,, $02-07 . i i .2005$, F. U. Yamamoto col. col. (IBSP 7618876194; 76196-76198; 76200-76223; 76312-76323), 50^8ㅇ, 12-17.v.2005, F. U. Yamamoto col. col. (IBSP 73483; 76262-76302; 76304-76308; 76311), 21ð13ㅇ, $14-$ 19.xi.2004, F. U. Yamamoto col. col. (IBSP 76158-76187), 35 ${ }^{\Uparrow} 9$ ㅇ, 28.vii-02.viii.2004, F. U. Yamamoto col. col. (IBSP 73481; 76113-76121; 76123; 76124; 76126; 76127; 76129; 76132-76135; 76137-76144; 76146; 76147; 76149-76151; 76153; 76154; 76156; 76309; 76310); Mogi das Cruzes, Parque Natural Municipal da Serra do Itapety $\left(23^{\circ} 28^{\prime} \mathrm{S}\right.$; $\left.46^{\circ} 9^{\prime} \mathrm{W}\right), 1 \partial^{\top}, 13-18 . x .2003$, Equipe Biota col. (IBSP 55115); Iporanga, Parque Estadual

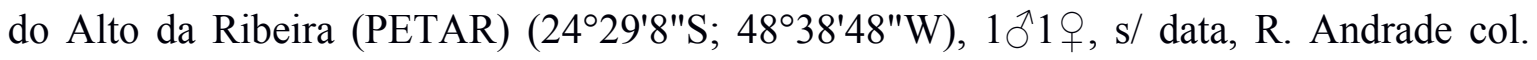
(IBSP 29346; 29350), 1ठ̄, 02.v.2002, R. Andrade col. (IBSP 44801). SANTA CATARINA: Ilhota, Morro do Baú, (2648’29”S; 4857'19”W), 20̂, 4.ii.1996, A. B. Bonaldo col. (MCN 27286). RIO GRANDE DO SUL: São Borja $\left(28^{\circ} 42^{\prime} \mathrm{S} ; 55^{\circ} 48^{\prime} \mathrm{W}\right), 1 \widehat{O}^{\hat{\prime}}$, 2006, R. Camargo col. (IBSP 70327). São Francisco de Paula, Barragem Passo do Inferno (29¹6'28"S; 5044'6"W), 2ð, 20-22.iii.2001, R. Ott col. (MCN 33766). São Francisco de Paula, Potreiro Velho $\left(29^{\circ} 24^{\prime} \mathrm{S} ; 50^{\circ} 19^{\prime} \mathrm{W}\right), 3{ }^{\circledR} 2$,, $25 . x .2000$, R. Ott et al. col. (MCTP 19058; 19063), 1ð2q, 2.i.2001, R. Ott et al. col. (MCTP 19065), 2q, 3.iii.2001, R. Ott et al. col. (MCTP 19067), 3ㅇ, 7.iv.2001, R. Ott et al. col. (MCTP 19068), 1q, 14.ix.2001, R. Ott et al. col. (MCTP 19074), 1q, 7.vii.2001, R. Ott et al. col. (MCTP 19072), 1ð̂, 9.viii.2001, R. Ott et al. col. (MCTP 19059), 1ô, 11.x.2001, R. Ott et al. col. (MCTP 19075), 19, 14.iv.2002, R. Ott et al. col. (MCTP 19060), 3 q, 18.v.2002, R. Ott et al. col. (MCTP 19071). Canela (29²0'S; 5047'W), 3ㅇ, 10.ix.2005, M. Barros et al. col. (MCN

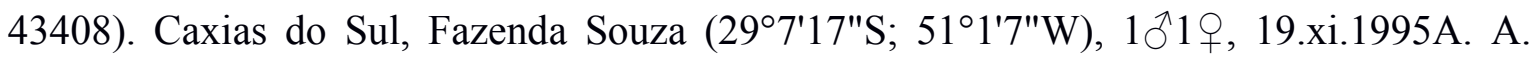
Lise et al. col. (MCTP 9133). 
Gen. nov.

Figs. 175-183, Mapa 11.

Espécie-tipo: Gen.nov. magnipalpis (Millidge, 1993)

Diagnose: O gênero é diagnosticado pelos seguintes conjuntos de caracteres: Perda do protégulo, fileira de estrias estridulatórias na quelícera dos machos comprimidas distalmente e apresentando veios auxiliares, uma macroseta ventroectal do tarso do palpo da fêmea.

Descrição: Machos com comprimento total de 1,46-1,69. Carapaça 0,62-0,78 de comprimento, 0,48-0,66 de largura, de coloração amarelada à marrom escuro. Esterno 0,35-0,43 de comprimento, 0,37-0,42 de largura. Clípeo 0,22-0,23 de altura. Abdômen acinzentado à amarelado claro com ou sem manchas escuras. Pernas amareladas. Distância entre coxa IV 1,03 vezes sua largura. TmI 0,44-0,68. TmIV ausente. Fêmea com comprimento total de 1,69-1,8. Carapaça 0,64-0,71 de comprimento, 0,53-0,60 de largura. Esterno 0,32-0,39 de comprimento, 0,38-0,41 de largura. Clípeo 0,14 de altura. Padrões do abdômen, esterno, carapaça e pernas como no macho. Distância entre coxa IV 0,19mm. TmI 0,42-0,44. TmIV ausente.

Espécies: Gen.nov. magnipalpis, Gen.nov. sp.nov.01, Gen.nov. sp.nov.02.

Distribuição: Registro para sul do Brasil e Sul dos Estados Unidos.

Gen.nov. magnipalpis (Millidge, 1993)

Figs. 175-177, Mapa 11B.

Sphecozone magnipalpis Millidge, 1993: 168, f. 1-4 (holótipo macho de Santa Rita Mts., Madera Co., Arizona, Estados Unidos, depositado no CAS).

Sphecozone magnipalpis Millidge, 1993. Miller, 2007: 187.

Material tipo examinado: ESTADOS UNIDOS. ARIZONA: Santa Cruz Co., Santa Rita 
Mts., Madera Canyon, (31ํ4'N; 11053'W), 1-2.viii.1952, H. B. Leech e J. W. Green col., (CAS 16973, 1ठ, holótipo).

Diagnose: Distingue-se de outras espécies do Gen.nov. pela forma do paracímbio, alongado, em forma de gancho (Figs 176, 177). Fêmea desconhecida.

Descrição: Macho (Holótipo; CAS 16973) de Madera Canyon, Santa Rita Mts., Santa Cruz Co., Arizona, Estados Unidos. Comprimento total 1,69. Carapaça 0,78 de comprimento, 0,66 de largura, amarelado, com manchas pretas difundidos pelo dorso, à partir do centro da região torácica. Região cefálica com manchas escuras. Esterno 0,43 de comprimento, 0,42 de largura, amarelo escuro com bordas pretas. Clípeo 0,23 de altura. Quelícera com 5 dentes promarginais e 3 retromarginais. Abdômen acinzentado. Diâmetro dos olhos e distância: OMA 0,03; OLA 0,05; OMP 0,05; OLP 0,04. Distância entre os OMA 0,69 vezes seu diâmetro, distância entre os OMP 1,09 vezes seu diâmetro, distância entre OMA-OLA 0,79 vezes o diâmetro do OLA, distância entre OMP-OLP 1,18 vezes o diâmetro do OLP. Distância entre coxa IV 1,03 vezes sua largura. Fórmula das pernas III-IV-III. Fêmur I/II/III/IV 0,67/0,59/0,48/0,68; patela I 0,18; tíbia I 0,57; metatarso I 0,44; tarso I 0,37. Pernas amareladas. Fêmur/patela/tíbia/címbio do palpo 0,31/0,13/0,13/0,41. TmI 0,68. TmIV ausente. Palpo apresenta um paracímbio estreito fundido ao címbio. O êmbolo de comprimento e espiral é achatado, e o radix possui um processo anterior alongado e pontiagudo. A tíbia apresenta uma apófise prolateral e ventral muito largos, e apenas um tricobótrio presente na face retrolateral (Figs. 175-177).

Distribuição: Estados Unidos (Arizona) (Mapa 11B).

Material examinado: Somente o holótipo.

Gen.nov. sp.nov.01 Rodrigues, Lemos, Brescovit, in prep.

Figs. 178-180, Mapa 11A.

Material tipo: BRASIL. RIO GRANDE DO SUL: Santana da Boa Vista, $\left(30^{\circ} 44^{\prime} \mathrm{S}\right.$; 53ำ1'W), 10̂, 27-28.iv.2013, Equipe Sisbiota col. (MCN 49554, holótipo). BRASIL. RIO 


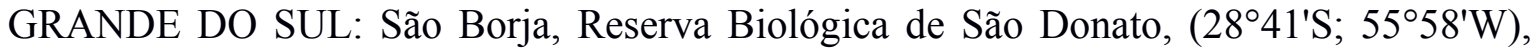
2ð̄, 11-25.x.2012, M. M. da Silva col. (MCTP 36988, parátipo). São Francisco de Paula, Potreiro Velho, $\left(29^{\circ} 24^{\prime} \mathrm{S} ; 50^{\circ} 19^{\prime} \mathrm{W}\right), 3{ }^{\lambda}, 22 . i x .2003$, L. A. Bertoncello et al. col. (MCTP 17657, parátipo). Santana da Boa Vista, $\left(30^{\circ} 44^{\prime} \mathrm{S} ; 53^{\circ} 11^{\prime} \mathrm{W}\right), 9{ }^{\nearrow} 3$ 91 juv., 27-28.iv.2013, Equipe Sisbiota col. (MCN 49514; 49683, parátipo).

Diagnosis: Assemelha-se à Gen.nov. sp.nov.02 pelo paracímbio vestigial presente no palpo e pela apófise prolatera, alongada perpendicularmente à tibia do palpo. Distingue-se de Gen.nov. sp.nov.02 pela forma do processo distal da apófise prolateral da tíbia do palpo. Em Gen.nov. sp.nov.01 ela possui forma de espinho e está direcionado dorsalmente, enquanto que em Gen.nov. sp.nov.02 o processo possui forma de "T" e está direcionado anteriormente (Figs. 179,180). As fêmeas se assemelham pela forma do lóbulo anterior da placa dorsal, amplo e com margens curvas. Diferenciam-se pela forma dos dutos copulatórios, longos e espiralados na Gen.nov. sp.nov.01 e mais curtos e curvos na Gen.nov. sp.nov.02 (Figs. 179).

Descrição: Macho (Holótipo; MCN 49554). Comprimento total 1,65. Carapaça 0,71 de comprimento, 0,56 de largura, marrom escuro. Esterno 0,35 de comprimento, 0,37 de largura, marrom escuro. Abdômen 0,98 de comprimento, 0,6 de largura e 0,68 de altura, amarelado com manchas escuras próximo às fiandeiras, estendendo ventralmente e dorsalmente. Clípeo 0,22 de altura. Quelícera 0,21 de comprimento. Diâmetro e distância dos olhos: OMA 0,03; OLA 0,05; OMP 0,04; OLP 0,04. OMA-OMA: 0,02, OMP-OMP: 0,1, OMA-OLA: 0,08, OMP-OLP: 0,06. Olhos em uma elevação da região cefálica, com várias cerdas entre a área ocular. Distância entre coxas IV 0,17. Fórmula das pernas I-IVII-III. Fêmur I/II/III/IV 0,61/0,53/0,43/0,59; patela I/II/III/IV 0,17/0,17/0,16/0,14; tíbia I/II/III/IV 0,52/0,45/0,34/0,52; metatarso I/II/III/IV 0,47/0,41/0,33/0,47; tarso I/II/III/IV 0,37/0,31/0,21/0,34. Comprimento total da perna I/II/III/IV 2,14/1,87/1.47/2,06. Pernas amareladas. Fêmur/patela/tíbia/címbio do palpo 0,27/0,14/0,17/0,28. TmI 0,44. TmIV ausente. Tíbia com um tricobótrio retrolateral e um prolateral, margem da apófise prolateral da tíbia com dentículos. Tégulo com papilas. Cauda do radix espiral. Membrana embólica e processo anterior do radix presente. Êmbolo comprido e espiral. (Figs. 178180). 
Fêmea (Parátipo; MCN 49514) de Santana da Boa Vista, Rio Grande do Sul, Brasil. Comprimento total 1,53. Carapaça 0,65 de comprimento, 0,55 de largura. Esterno 0,32 de comprimento, 0,38 de largura. Abdômen 0,95 de comprimento, 0,66 de largura e 0,64 de altura, padrão do abdômen, carapaça e esterno como no macho. Clípeo 0,14 de altura. Quelícera 0,2 de comprimento. Diâmetro e distância dos olhos: OMA 0,04; OLA 0,06; OMP 0,05; OLP 0,05. OMA-OMA: 0,02, OMP-OMP: 0,05, OMA-OLA: 0,03, OMPOLP: 0,03. Região cefálica não elevada como no macho. Distância entre coxas IV 0,19. Fórmula das pernas I-IV-II-III. Fêmur I/II/III/IV 0,54/0,51/0,42/0,59; patela I/II/III/IV 0,18/0,16/0,15/0,15; tíbia I/II/III/IV $0,48 / 0,42 / 0,32 / 0,49 ; \quad$ metatarso I/II/III/IV 0,42/0,39/0,31/0,41; tarso I/II/III/IV 0,34/0,27/0,26/0,29. Comprimento total da perna I/II/III/IV 1,96/1,75/1,46/1,93. Pernas como no macho. Fêmur/patela/tíbia/tarso do palpo 0,19/0,08/0,15/0,21. TmI 0,42. TmIV ausente. Epígino com par de átrios curvados. Lóbulo anterior da placa dorsal tão largo quanto a placa dorsal. Duto de copulação esclerotizado, dutos de fertilização de origem posterior da espermateca, direciona-se mesalmente. Espermatecas arredendodas. (Figs. 178-179).

Variação: Machos $(\mathrm{n}=10)$ : Comprimento total 1,46-1,68; comprimento da carapaça 0,62 0,71 ; largura da carapaça $0,49-0,56$; comprimento do fêmur I 0,48-0,62.

Fêmeas $(n=3)$ : Comprimento total 1,7-1,8; comprimento da carapaça 0,64-0,69; largura da carapaça $0,53-0,6$; comprimento do fêmur I 0,6-0,68.

Distribuição: Brasil (Santa Catarina, Rio Grande do Sul) (Mapa 11A).

Material examinado: BRASIL, SANTA CATARINA: Governador Celso Ramos, Palma das Gaivotas, (27²0'S; $\left.48^{\circ} 32^{\prime} \mathrm{W}\right), 1{ }^{\lambda}, 1-24 . i 1.1994$, L. A. Moura col. (MCN 25221). RIO

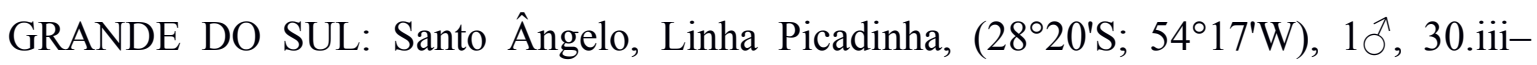
4.iv.2004, F. D'Agostini col. (MCTP 22611). São Borja, Reserva Biológica de São Donato,

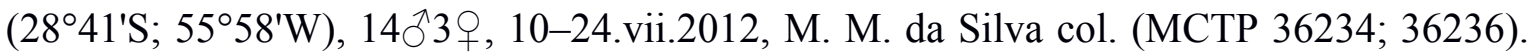
São Francisco de Paula, Potreiro Velho, (29²4'S; 50¹9'W), 1○̂, 29.vii.2003, L. A. Bertoncello et al. col. (MCTP 17659), 1ठ઼, 28.viii.2003, L. A. Bertoncello et al. col.

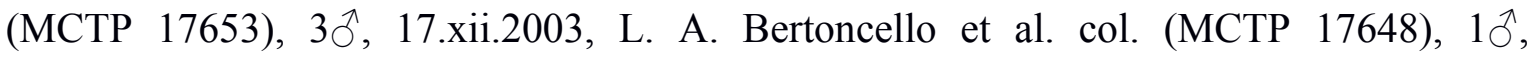
13.i.2004, L. A. Bertoncello et al. col. (MCTP 17651), 2ð̂, 9.iii.2004, L. A. Bertoncello et 
al. col. (MCTP 17655). Cidreira, Dunas, (306'S; 50¹0'W), 10, 31.v.2003, J. A. M. Pinto col. (MCTP 37104), 1ð̄, 10.viii.2003, J. A. M. Pinto col. (MCTP 37098). Santana da Boa Vista, (3044'S; 531' W), $10{ }^{\AA} 2$ juv., 27-28.iv.2013, Equipe Sisbiota col. (MCN 49646; 49601; 49600).

Gen.nov. sp.nov.02 Rodrigues, Lemos, Brescovit, in prep.

Figs. 181-183, Mapa 11B.

Material tipo: BRASIL. RIO GRANDE DO SUL: São Francisco de Paula, Potreiro Velho, (29²4'S; 50¹9'W), 1ð̂, 21.x.2003, L. A. Bertoncello col. (MCTP 17649, holótipo). BRASIL, SANTA CATARINA: Guatambú, $\left(27^{\circ} 6^{\prime} \mathrm{S} ; 52^{\circ} 46^{\prime} \mathrm{W}\right), 1{ }^{\lambda}, 23.1 x .2008$, R. C. Francisco col. (MCTP 28751, parátipo), 1ðૈ, 27.iv.2009, R. C. Francisco col. (MCTP 28754, parátipo); Chapecó, $\left(27^{\circ} 4^{\prime} \mathrm{S} ; 52^{\circ} 38^{\prime} \mathrm{W}\right), 1$ q, 30.iii.2011, R. C. Francisco col.

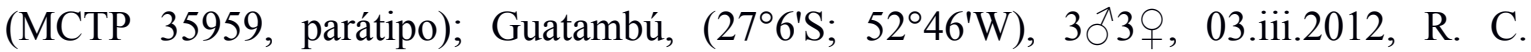
Francisco col. (MCTP 35958, parátipo), 2̧̂, 10.v.2012, R. C. Francisco col. (MCTP 35957, parátipo).

Diagnose: ver Gen.nov. sp.nov.01

Descrição: Macho (Holótipo; MCTP 17649) de Potreiro Velho, São Francisco de Paula, Rio Grande do Sul, Brasil. Comprimento total 1,69. Carapaça 0,74 de comprimento, 0,52 de largura, marrom escuro. Esterno 0,37 de comprimento, 0,38 de largura, marrom escuro. Abdômen 0,86 de comprimento, 0,59 de largura e 0,62 de altura, branco com manchas pretas perto das fiandeiras, estendendo ventral e dorsalmente. Clípeo 0,18 de altura. Quelícera 0,23 de comprimento. Diâmetro e distância dos olhos: OMA 0,04; OLA 0,05; OMP 0,04; OLP 0,04, OMA-OMA: 0,03, OMP-OMP: 0,09, OMA-OLA: 0,08, OMPOLP: 0,07. Olhos em uma elevação da região cefálica, com várias cerdas na área ocular. Distância entre coxas IV 0,14. Fórmula das pernas I-IV-II-III. Fêmur I/II/III/IV 0,58/0,51/0,42/0,59; patela I/II/III/IV $0,17 / 0,13 / 0,15 / 0,14$; tíbia $\quad$ I/II/III/IV 0,52/0,44/0,36/0,53; metatarso I/II/III/IV 0,46/0,38/0,37/0,48; tarso I/II/III/IV 0,35/0,27/0,26/0,32. Comprimento total da perna I/II/III/IV 2,08/1,73/1,56/2,06. Pernas amareladas. Fêmur/patela/tíbia/címbio do palpo 0,17/0,13/0,17/0,24. TmI 0,45. TmIV 
ausente. Tíbia com um tricobótrio retrolateral e um prolateral, apófise prolateral da tíbia com dentículos na sua margem. Tégulo com papilas. Cauda do radix espiral. Membrana embólica e processo anterior do radix presente. Êmbolo espiral. (Figs. 181, 183).

Fêmea (Parátipo; MCTP 35959) de Chapecó, Santa Catarina, Brasil. Comprimento total 1,69. Carapaça 0,66 de comprimento, 0,57 de largura. Esterno 0,39 de comprimento, 0,41 de largura. Abdômen 1,06 de comprimento, 0,84 de largura and 0,69 de altura. Padrão da carapaça e esterno como no macho. Abdômen branco com mancha escura próximo às fiandeiras, extendendo ventralmente. Clípeo 0,14 de altura. Quelícera 0,26 de comprimento. Diâmetro e distância dos olhos: OMA 0,04; OLA 0,05; OMP 0,05; OLP 0,04, OMA-OMA: 0,01, OMP-OMP: 0,04, OMA-OLA: 0,05, OMP-OLP: 0,05. Região cefálica não elevada como no macho. Distância entre coxas IV 0,19. Fórmula das pernas IIV-II-III. Fêmur I/II/III/IV 0,63/0,55/0,49/0,66; patela I/II/III/IV 0,17/0,15/0,15/0,14; tíbia I/II/III/IV 0,56/0,46/0,34/0,55; metatarso I/II/III/IV 0,45/0,42/0,35/0,46; tarso I/II/III/IV 0,39/0,34/0,26/0,32. Comprimento total da perna I/II/III/IV 2,2/1,92/1,59/2,13. Pernas como no macho. Fêmur/patela/tíbia/tarso do palpo 0,2/0,09/0,15/0,2. TmI 0,44. TmIV ausente. Epígino com par de átrio curvos. Lóbulo anterior da placa dorsal tão largo quanto a placa dorsal. Dutos copulatórios esclerotizados, dutos de fertilização originando da parte posterior da espermateca, direcionando-se mesalmente. Espermatecas ovais. (Figs. 181, 182).

Variação: Machos ( $\mathrm{n}=10)$ : Comprimento total $1,45-1,76$; comprimento da carapaça $0,64-$ 0,73; largura da carapaça 0,49-0,54; comprimento do fêmur I 0,55-0,64.

Fêmeas $(\mathrm{n}=2)$ : Comprimento total 1,68-1,79; comprimento da carapaça $0,64-0,71$; largura da carapaça $0,53-0,55$; comprimento do fêmur I 0,61-0,68.

Distribuição: Região Sul do Brasil (Santa Catarina, Rio Grande do Sul) (Mapa 11B).

Material examinado: BRASIL, SANTA CATARINA: Chapecó, $\left(27^{\circ} 4^{\prime} \mathrm{S} ; 52^{\circ} 38^{\prime} \mathrm{W}\right), 1 \mathrm{\delta}^{\lambda}$, 1.vii.2008, R. C. Francisco col. (MCTP 28750). Guatambú, $\left(27^{\circ} 6^{\prime} \mathrm{S} ; 52^{\circ} 46^{\prime} \mathrm{W}\right), 1 \mathrm{\delta}^{\Uparrow}$, 12.xii.2003, R. C. Francisco col. (MCTP 37843), 1ð, 27.iv.2009, R. C. Francisco col. (MCTP 28753), 1ठ, 13.vii.2009, R. C. Francisco col. (MCTP 28752), 1ठ, 4.ix.2009, R. C. Francisco col. (MCTP 28755). RIO GRANDE DO SUL: Rio dos Índios, $\left(27^{\circ} 15^{\prime} \mathrm{S}\right.$; 
52 52'W), 1ठ, 11.ix.2013, R. C. Francisco col. (MCTP 37824); São Borja, Reserva

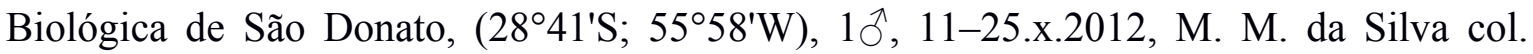
(MCTP 37013); São Francisco de Paula, Potreiro Velho, (29²4'S; 50¹9'W), 6 $\overbrace{}^{\wedge}$, 13.i.2004, L. A. Bertoncello et al. col. (MCTP 17658), 1ठ, 10.ii.2004, L. A. Bertoncello et al. col. (MCTP 17650), 1ð, 30.iv.2004, L. A. Bertoncello col. (MCTP 17654)., 1ð, 14.v.2004, L. A. Bertoncello col. (MCTP 17660); Cidreira, (30 $\left.8^{\prime} \mathrm{S} ; 50^{\circ} 16^{\prime} \mathrm{W}\right), 2{ }^{\lambda}$, 21.iii.2004, J. A. M. Pinto col. (MCTP 22172). 


\section{Referências Bibliográficas}

Agnarsson, I., Coddington, J. A., Kuntner, M. (2013). Systematics Progress in the study of spider diversity and evolution. In D. Penney (Ed.), Spider Research in the $21 \mathrm{st}$ Century trends perspectives (pp. 58-111). Manchester, UK: Siri Scientific Press.

Álvarez-Padilla, F., \& Hormiga, G. (2007). A protocol for digesting internal soft tissues and mounting spiders for scanning electron microscopy. The Journal of Arachnology, $35(3), 538-542$.

Arnedo, M. A., Hormiga, G., Scharff, N. (2009). Higher-level phylogenetics of linyphiid spiders (Araneae, Linyphiidae) based on morphological and molecular evidence. Cladistics, 25(3), 1-32.

Coddington, J. A. (1986). The Genera of the Spider Family Theridiosomatidae. Smithsonian Contributions to Zoology, 422(422), 1-96.

Dupérré, N., Paquin, P., Buckle, D. J. (2006). Have you seen my mate? Descriptions of unknown sexes of some North American species of Linyphiidae and Theridiidae (Araneae). Journal of Arachnology, 34, 142-158.

Frick, H., Muff, P. (2009). Revision of the genus Caracladus with the description of Caracladus zamoniensis spec. nov.(Araneae, Linyphiidae, Erigoninae). Zootaxa, 1982, $1-37$.

Frick, H., Scharff, N. (2014). Phantoms of Gondwana? - phylogeny of the spider subfamily Mynogleninae (Araneae: Linyphiidae). Cladistics, 30(1), 67-106.

Gavish-Regev, E., Hormiga, G., Scharff, N. (2013). Pedipalp sclerite homologies and phylogenetic placement of the spider genus Stemonyphantes (Linyphiidae, Araneae) and its implications for linyphiid phylogeny. Invertebrate Systematics, 27(1), 38-52.

Griswold, C. E. (1993). Investigations into the phylogeny of the Lycosoid spiders and their kin (Arachnida: Araneae, Lycosoidea). Smithsonian Contributions to Zoology, (539), $1-39$. 
Griswold, C. E., Coddington, J. A., Hormiga, G., Scharff, N. (1998). Phylogeny of the orbweb building spiders (Araneae, Orbiculariae: Deinopoidea, Araneoidea). Zoological Journal of the Linnean Society, 123, 1-99.

Harwood, J. D., Obrycki, J. J. (2005). Web-Construction Behavior of Linyphiid Spiders (Araneae, Linyphiidae): Competition and Co-Existence Within a Generalist Predator Guild. Journal of Insect Behavior, 18(5), 593-607.

Hormiga, G. (1993). Implications of the phylogeny of Pimoidae for the systematics of linyphiid spiders (Araneae, Araneoidea, Linyphiidae). Memoirs of the Queensland Museum 33: 533-542.

Hormiga, G. (1994a). Cladistics and the comparative morphology of linyphiid spiders and their relatives (Araneae, Araneoidea, Linyphiidae). Zoological Journal of the Linnean Society, 111, 1-71.

Hormiga, G. (1994b). A revision and cladistic analysis of the spider family Pimoidae (Araneoidea:Araneae). Smithsonian Contributions to Zoology, (549), 1-104.

Hormiga, G. (2000). Higher level phylogenetics of erigonine spiders (Araneae, Linyphiidae, Erigoninae). Smithsonian Contributions to Zoology, 609(609), 1-160.

Hormiga, G. (2002). Orsonwelles, a new genus of giant linyphiid spiders (Araneae) from the Hawaiian Islands. Invertebrate Systematics 16: 369-448.

Hormiga, G. (2003). Weintrauboa, a new genus of pimoid spiders from Japan and adjacent islands, with comments on the monophyly and diagnosis of the family Pimoidae and the genus Pimoa (Araneoidea, Araneae). Zoological Journal of the Linnean Society 139: $261-281$

Lasut, L., Marusik, Y. M., Frick, H. (2009). First description of the female of the spider Savignia zero Eskov, 1988 (Araneae: Linyphiidae). Zootaxa, 2267, 65-68.

Lemos, R. Y. (2013). Revisão e análise cladística das espécies do gênero Moyosi Miller, 2007 (Araneae, Linyphiidae, Erigoninae). Dissertação (Mestrado em Ciências, na área de Zoologia) - Instituto de Biociências, Universidade de São Paulo. São Paulo, p. 143

Lemos, Y., Brescovit, A. D. (2013). New species of the spider genus Exocora Millidge, 1991 (Araneae: Linyphiidae) from Brazil. Zootaxa, 3599(3), 261-278. 
Merrett, P. (1963). The palpus of male spiders of the family Linyphiidae. Proceedings of the Zoological Society of London, 140(3), 347-467.

Miller, J. A. (2004). The genus Brattia beyond South America (Araneae, Linyphiidae). Journal of Arachnology, 32, 526-538.

Miller, J. A. (2005a). Cave adaptation in the spider genus Anthrobia (Araneae, Linyphiidae, Erigoninae). Zoologica Scripta, 34, 565-592.

Miller, J. A. (2005b). A redescription of Porrhomma cavernicola Keyserling (Araneae, Linyphiidae) with notes on Appalachian troglobites. Journal of Arachnology, 33, 426438.

Miller, J. A. (2007). Review of Erigoninae spider genera in the Neotropics (Araneae: Linyphiidae, Erigoninae). Zoological Journal of the Linnean Society, 149, 1-263.

Miller, J. A., Hormiga, G. (2004). Clade stability and the addition of data: a case study from erigonine spiders (Araneae: Linyphiidae, Erigoninae). Cladistics, 20, 385-442.

Millidge, A. F. (1980). The erigonine spiders of North America. Part 1. Introduction and taxonomic background (Araneae: Linyphiidae). Journal of Arachnology, 8, 97-107.

Millidge, A. F. (1985). Some linyphiid spiders from South America (Araneae, Linyphiidae). American Museum Novitates, (2836), 1-78.

Millidge, A. F. (1988). The relatives of the Linyphiidae: phylogenetic problems at the family level (Araneae). Bulletin of the British Arachnological Society, 7(9), 253-268.

Millidge, A. F. (1991). Further linyphiid spiders (Araneae) from South America. Bulletin of the American Museum of Natural History, (205), 1-199.

Millidge, A. F. (1993). A North American species of the genus Sphecozone OP-Cambridge, 1870 (Araneae: Linyphiidae). Bulletin of the British Arachnological Society, 9(5), 168.

Otto, S., Tanasevitch, A. V. (2015). A new species of Incestophantes Tanasevitch, 1992 from the high mountains of the Caucasus Major (Arachnida: Aranei: Linyphiidae). Arthropoda Selecta, 24(1), 107-112.

Rodrigues, E. N. L., Lemos, Y., Brescovit, A. D. (2013). A new species and new records of linyphiid spiders (Araneae: Linyphiidae) from Amazonas, Brazil. Zoologia (Curitiba), 30(3), 338-342. 
Saaristo, M. I. (2007). A new subfamily of linyphiid spiders based on a new genus created for the keyserlingi-group of the genus Lepthyphantes (Aranei: Linyphiidae). Arthropoda Selecta, 16(1), 33-42.

Tanasevitch, A. V. (2017). New species and new records of linyphiid spiders from the IndoMalayan Region (Araneae, Linyphiidae). Zootaxa, 4227(3), 325-346.

Tanasevitch, A. V. 2013. Linyphiid spiders of the world, online no site http://old.cepl.rssi.ru/bio/tan/linyphiidae, acessado em 28/05/2018

Tu, L., Hormiga, G. (2010). The female genitalic morphology of “micronetine” spiders (Araneae, Linyphiidae). Genetica, 138, 59-73.

Wheeler, W. C., Coddington, J. A ., Crowley, L. M., Dimitrov, D., Goloboff, P. A., Griswold, C. E., Hormiga, G., Prendini, L., Ramírez,M. J., Sierwald, P., AlmeidaSilva, L., Alvarez-Padilla, F., Arnedo, M. A., Benavides, L. R., Benjamin, S. P., Bond, J. E., Grismado, C. J., Hasanf, E., Hedin, M., Izquierdo, M. A., Labarque, F. M., Ledford, J., Lopardo, L., Maddison, W. P., Miller, J. A., Piacentini, L. N., Platnick, N. I., Polotow, D., Silva-Dávila, D., Scharff, N., Szűts, T., Ubick, D., Vink, C. J., Wood, H. M., Zhang, J. (2016). The spider tree of life: Phylogeny of Araneae based on targetgene analyses from an extensive taxon sampling. Cladistics, 1-43.

World Spider Catalog (2018). World Spider Catalog. Natural History Museum Bern, online no site http://wsc.nmbe.ch, versão 19.0, acessado em 28/05/2018

Wunderlich, J. (1987a). Die Spinnen der Kanarischen Inseln und Madeiras: Adaptive Radiation, Biogeographie, Revisionen und Neubeschreibungen. Triops Langen, 435 pp.

Xu, X., Liu, J. \& Chen, J. (2010). Ambengana Millidge \& Russell-Smith, 1992, a synonym of Nerience Blackwall, 1833 (Araneae, Linyphiidae). ZooKeys 52: 1-8.

Zhao, Q., Li, S. (2017). Callosa gen. n., a new troglobitic genus from southwest China (Araneae, Linyphiidae). ZooKeys, 703, 109-128. 


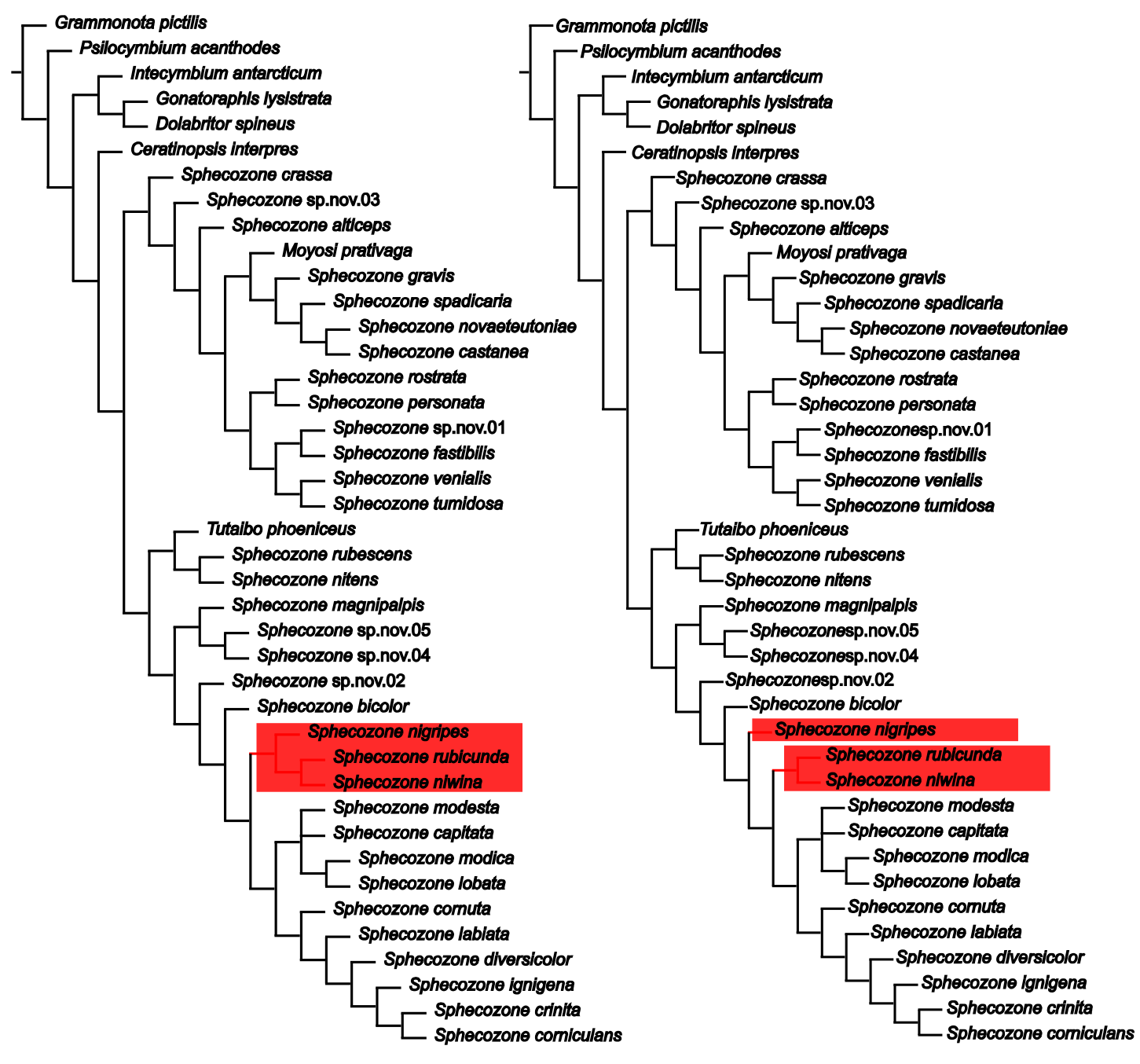

Figura 1. As duas árvores mais parcimoniosas encontradas por busca heurística tradicional, com 294 passos (IC=0,30; IR=0,57). Áreas avermelhadas indicam os clados que não foram mantidos nas duas topologias. 


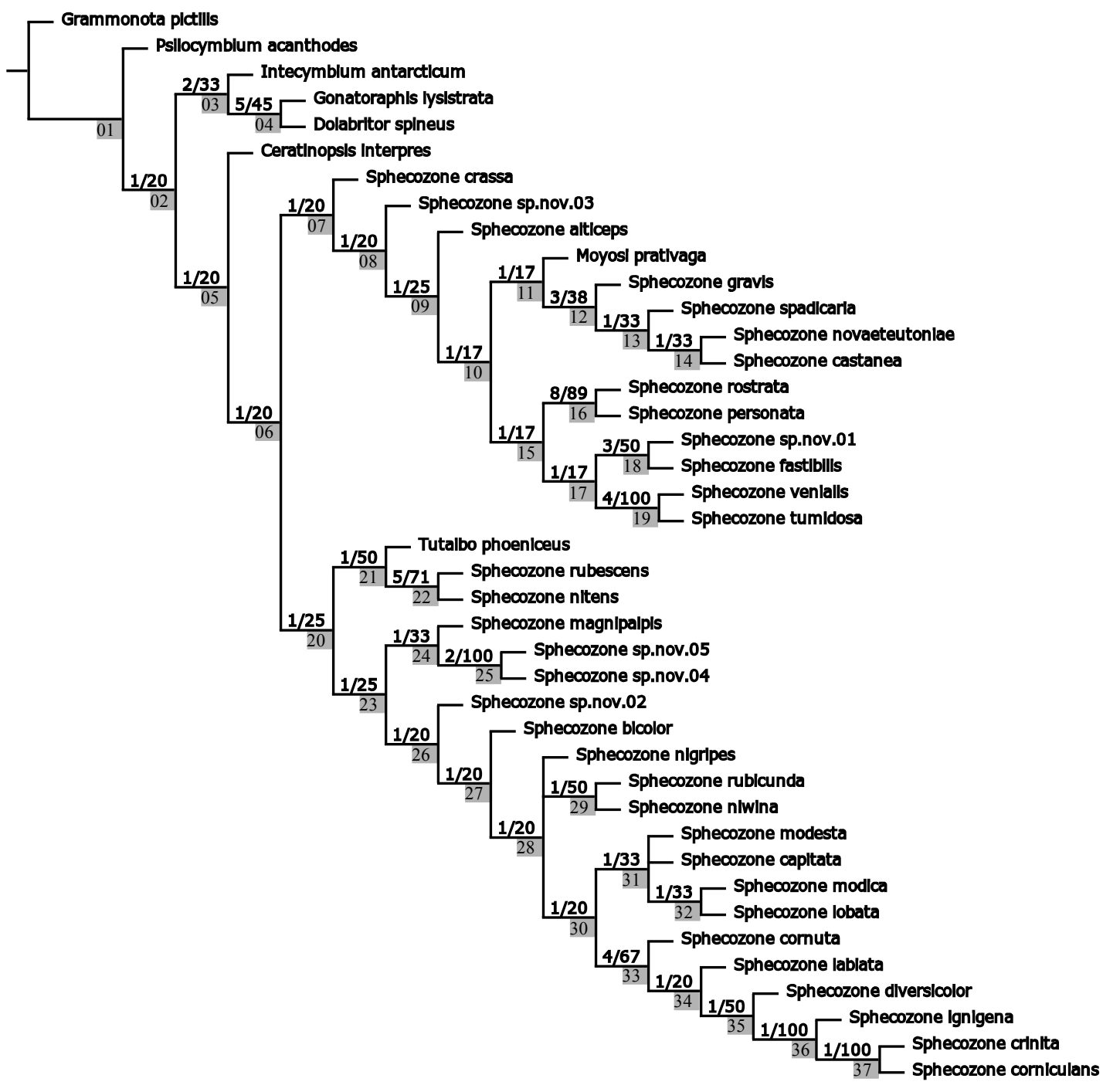

Figura 2. Consenso estrito das duas árvores mais parcimoniosas. Números acima dos ramos indicam o valor do suporte de Bremer (absoluto/relativo). Números dentro dos retângulos cinzas indicam números dos nós. 


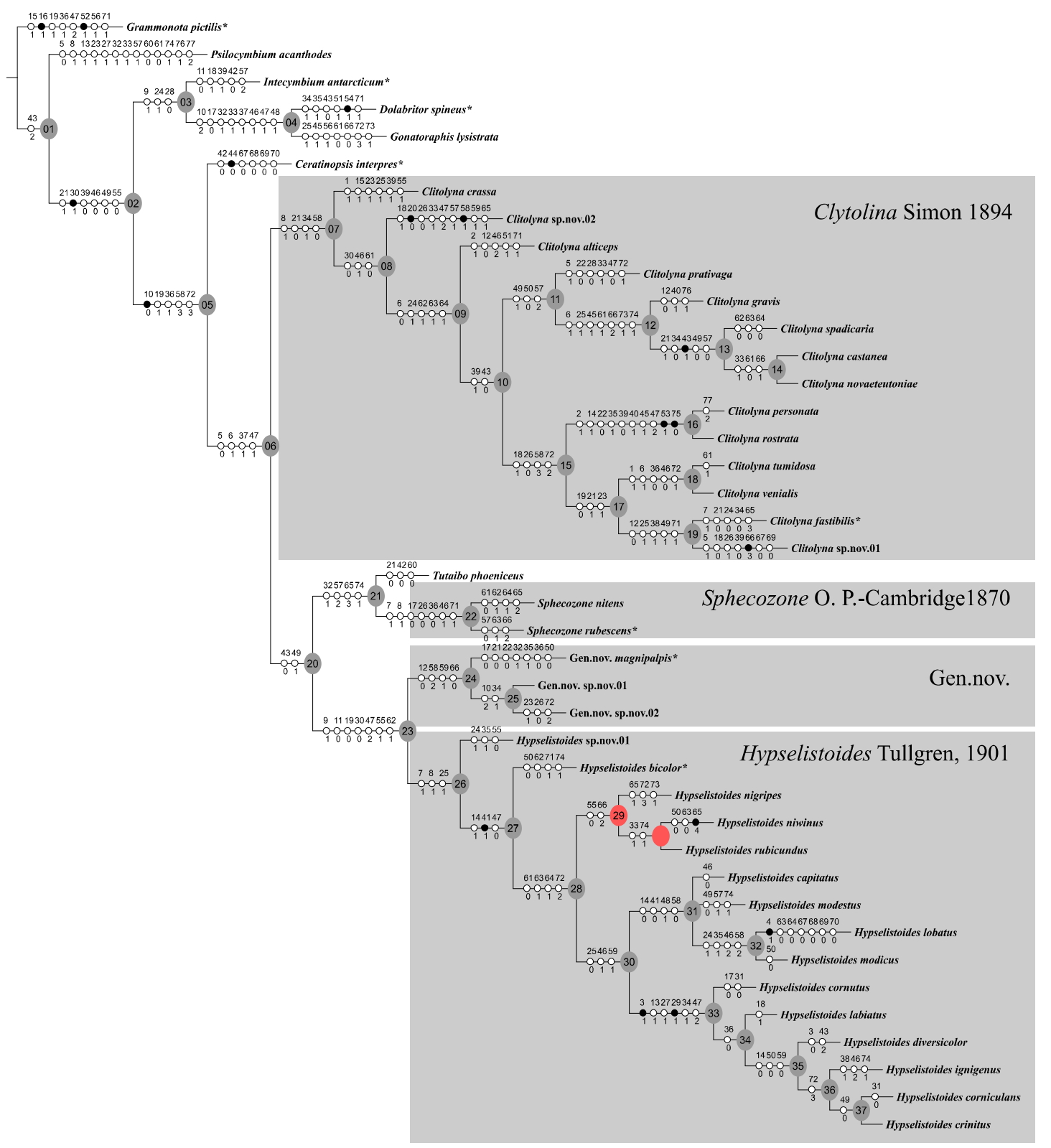

Figura 3. Árvore escolhida para otimização dos caracteres. Os pontos pretos indicam as sinapomorfias exclusivas e os pontos brancos as homoplasias. Números nos círculos cinzas indicam o número do ramos. Círculos rosas indicam ramos que não foram recuperados na outra topologia. Asteriscos indicam espécies-tipo. 


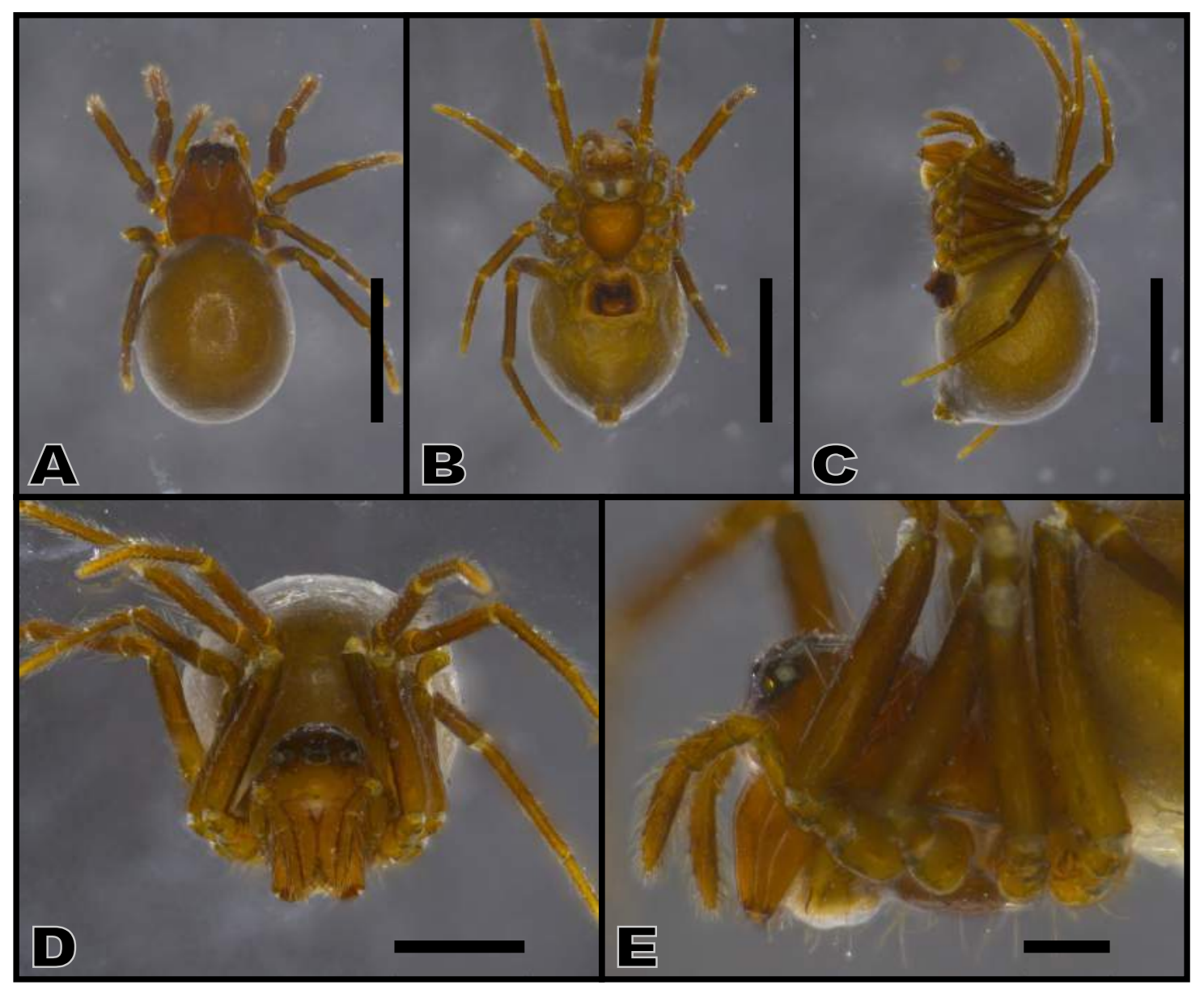

Figura 4. Sphecozone melanocephala, A-E, corpo da fêmea. A, dorsal; B, ventral; C, lateral; D, frontal; E, detalhe da região cefálica. Escala A-C, 1,0mm; D, 0,5mm; E, $0,2 \mathrm{~mm}$.

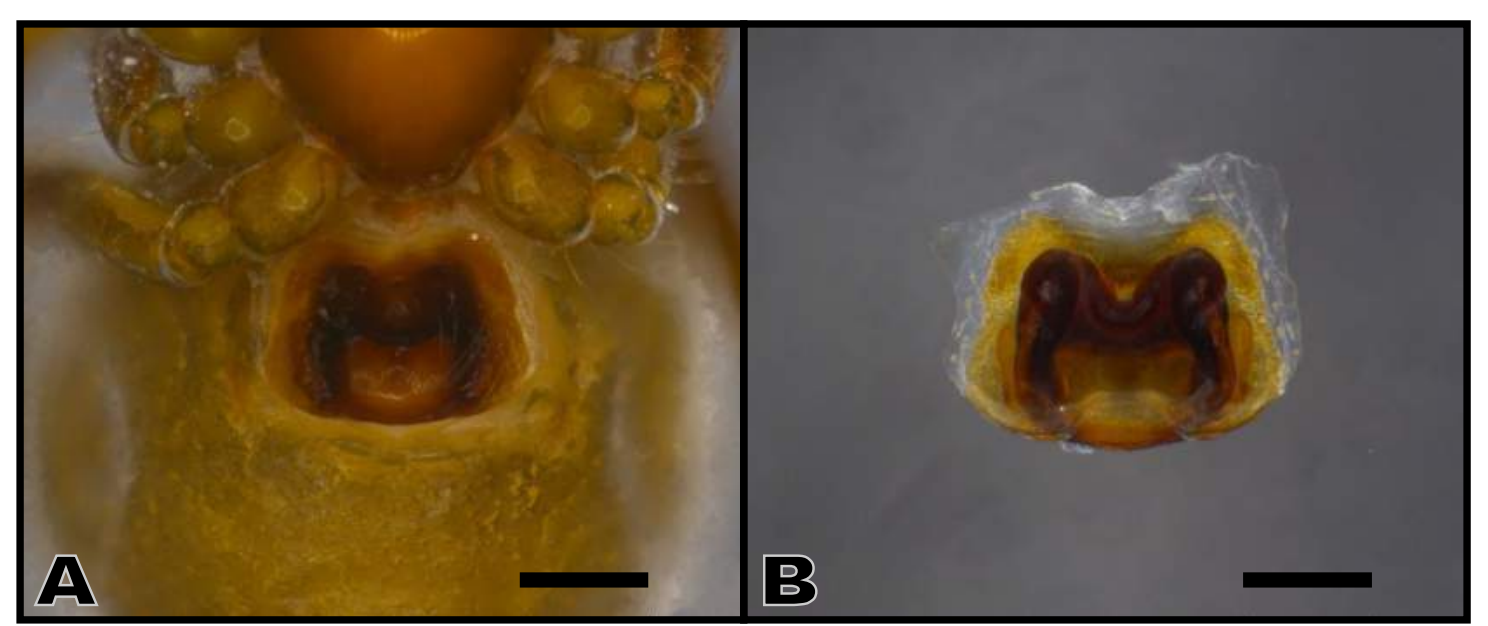

Figura 5. Sphecozone melanocephala, A-B, epígino da fêmea. A, ventral; B, dorsal. Escala $0,2 \mathrm{~mm}$ 


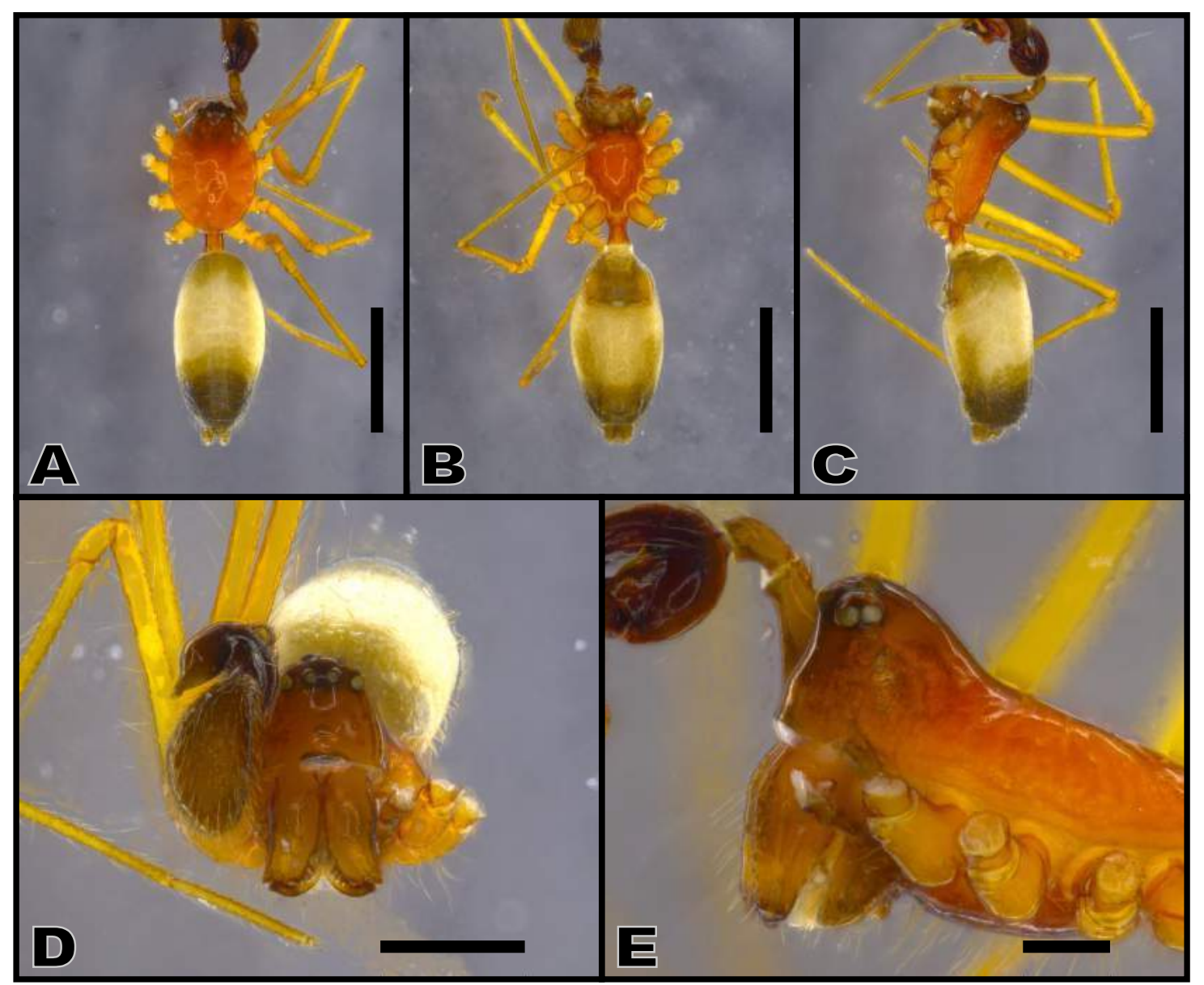

Figura 6. Sphecozone rubescens, A-E, corpo do macho. A, dorsal; B, ventral; C, lateral; D, frontal; E, detalhe da região cefálica. Escala A-C, 1,0mm; D, 0,5mm; E, 0,2mm.

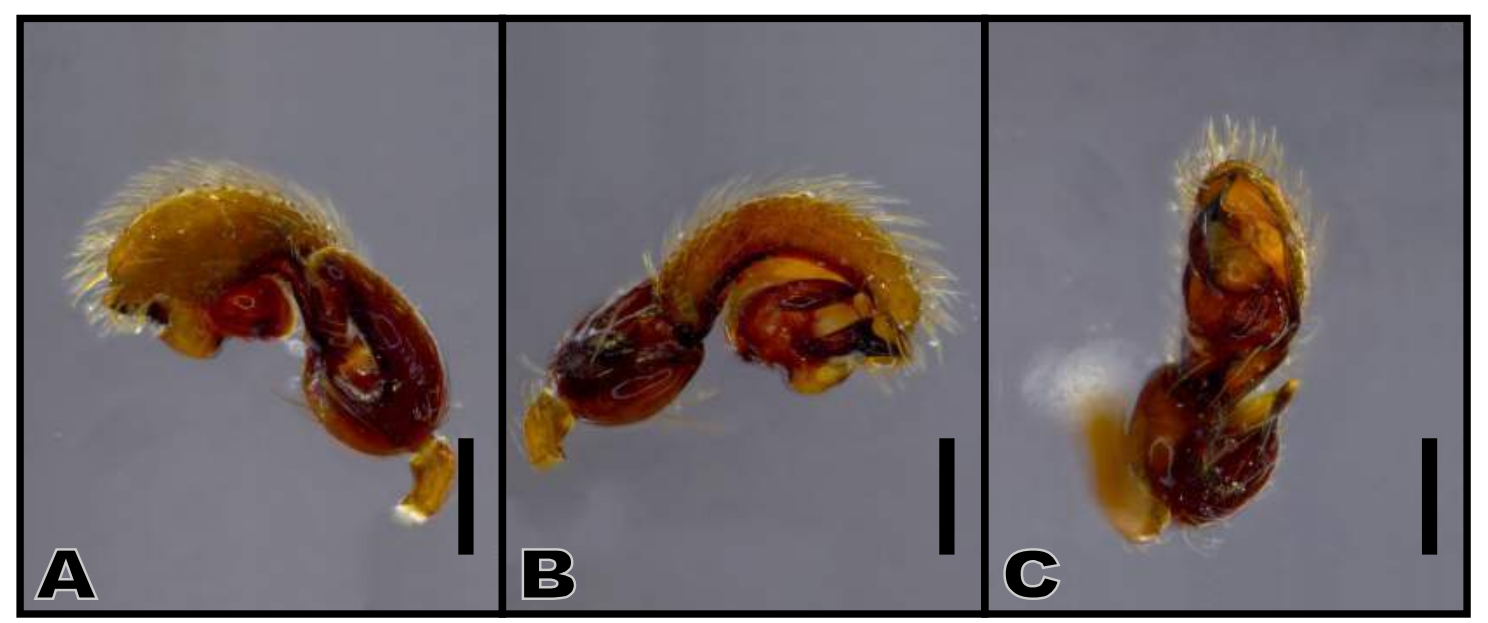

Figura 7. Sphecozone rubescens, A-C, palpo do macho. A, retrolateral; B, prolateral; C, ventral. Escala 0,2mm. 


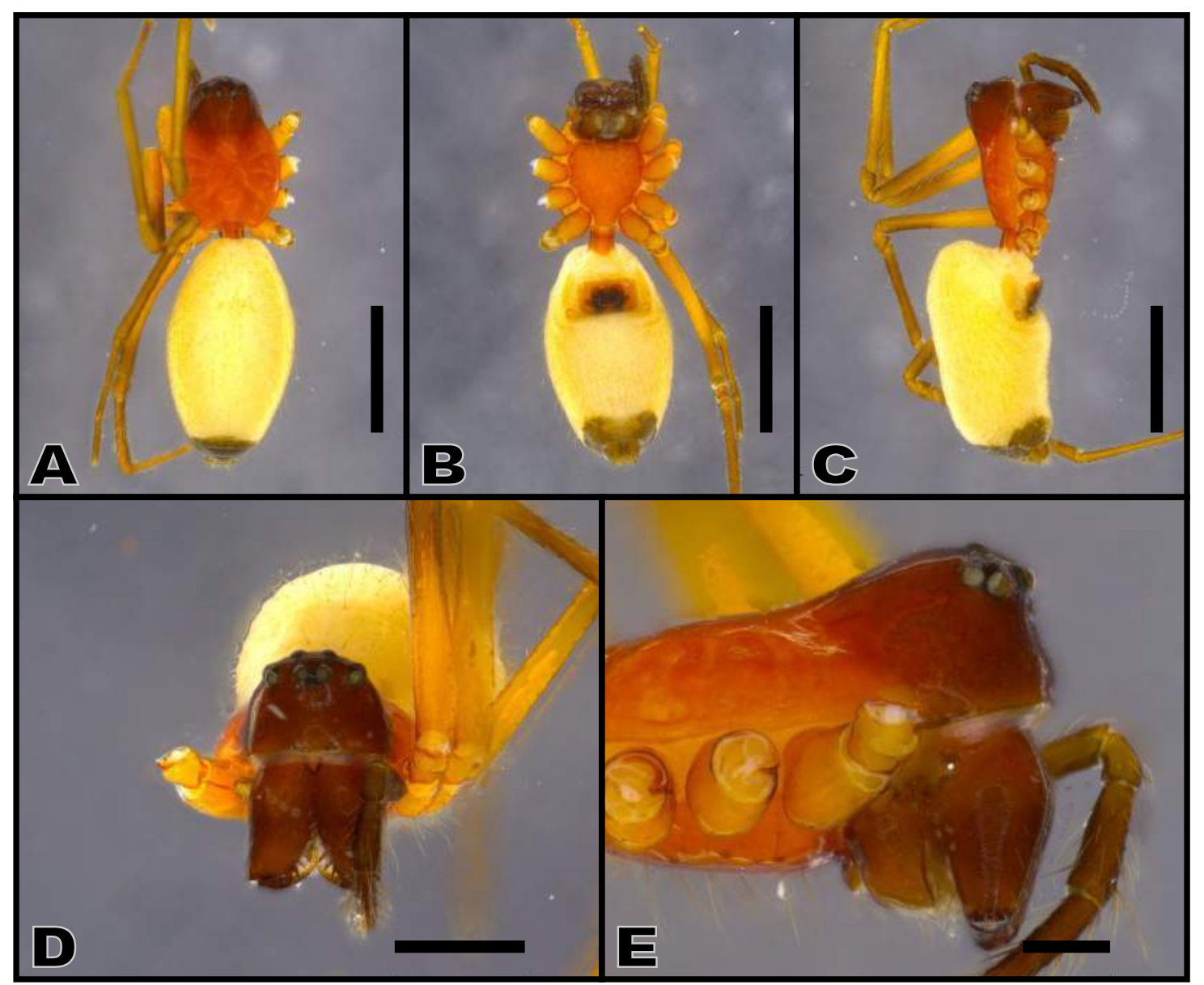

Figura 8. Sphecozone rubescens, A-E, corpo da fêmea. A, dorsal; B, ventral; C, lateral; D, frontal; E, detalhe da região cefálica. Escala A-C, 1,0mm; D, 0,5mm; E, 0,2mm.

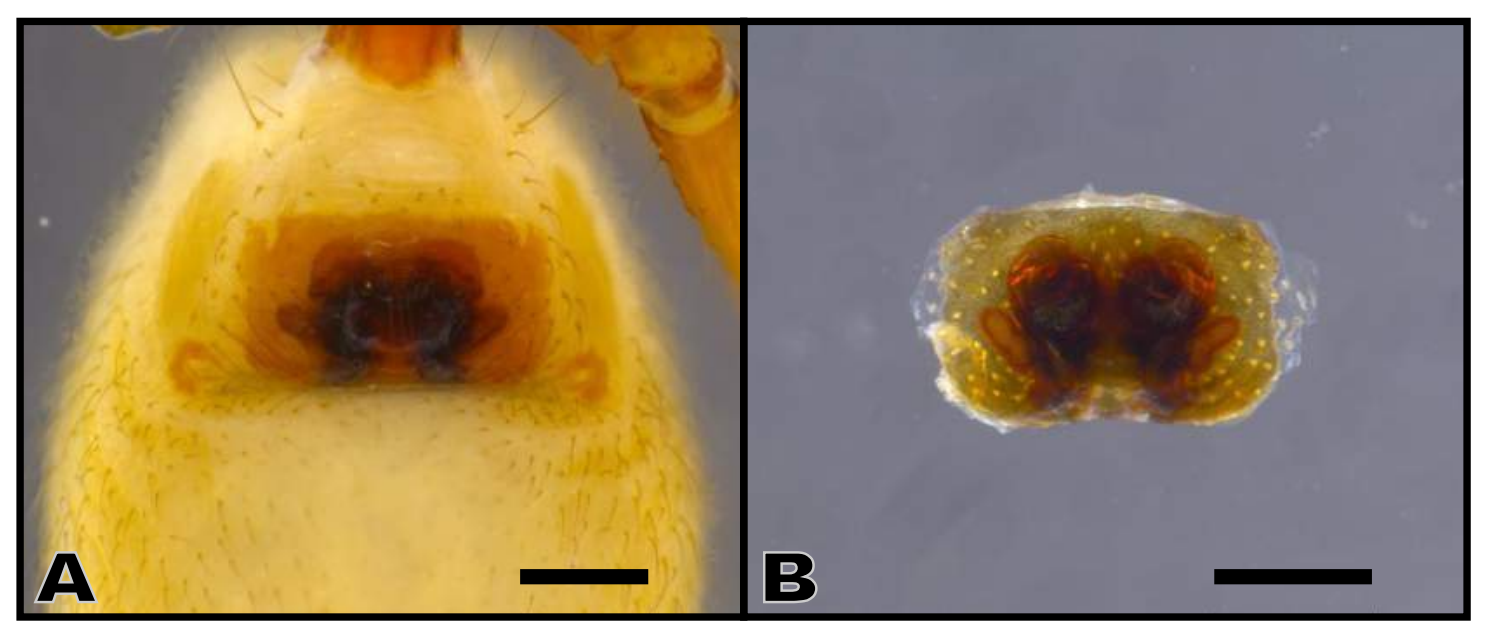

Figura 9. Sphecozone rubescens, A-B, epígino da fêmea. A, ventral; B, dorsal. Escala $0,2 \mathrm{~mm}$. 

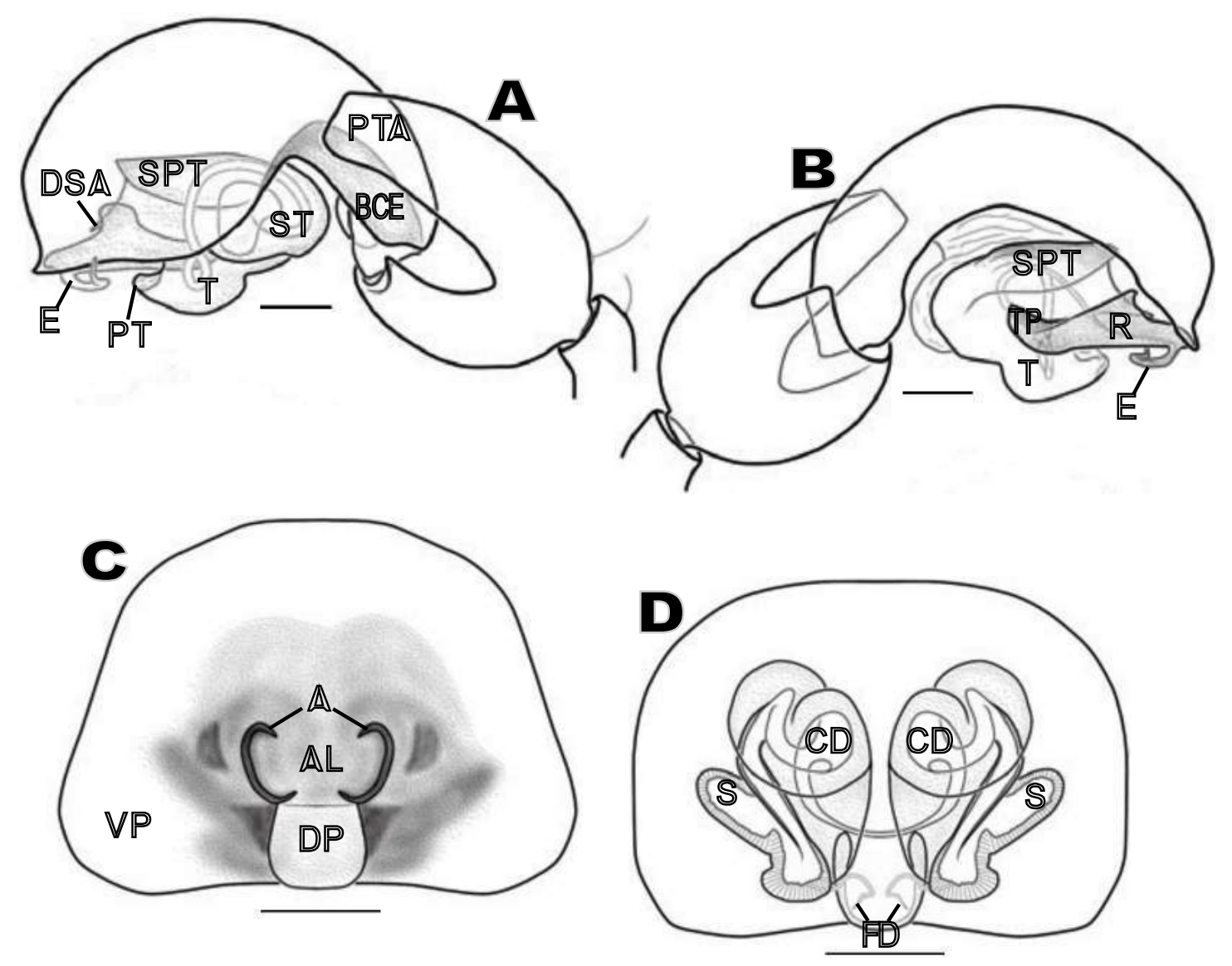

Figura 10. Sphecozone rubescens, A-B, palpo do macho; C, epígino da fêmea. A, retrolateral; B, prolateral; C, ventral; D, dorsal. Escala 0,1mm. A, átrio; AL, lóbulo anterior da placa dorsal do epígino; BCE, excavação basal do címbio; CD, duto de copulação; DP, placa dorsal do epígino; DSA, apófise distal suprategular; E, êmbolo; FD, duto de fertilização; PT, protégulo; PTA, apófise prolateral da tíbia; R, radix; S, espermateca; SPT, supratégulo; ST, subtégulo; T, tégulo; TP, cauda do radix; VP, placa ventral do epígino. 


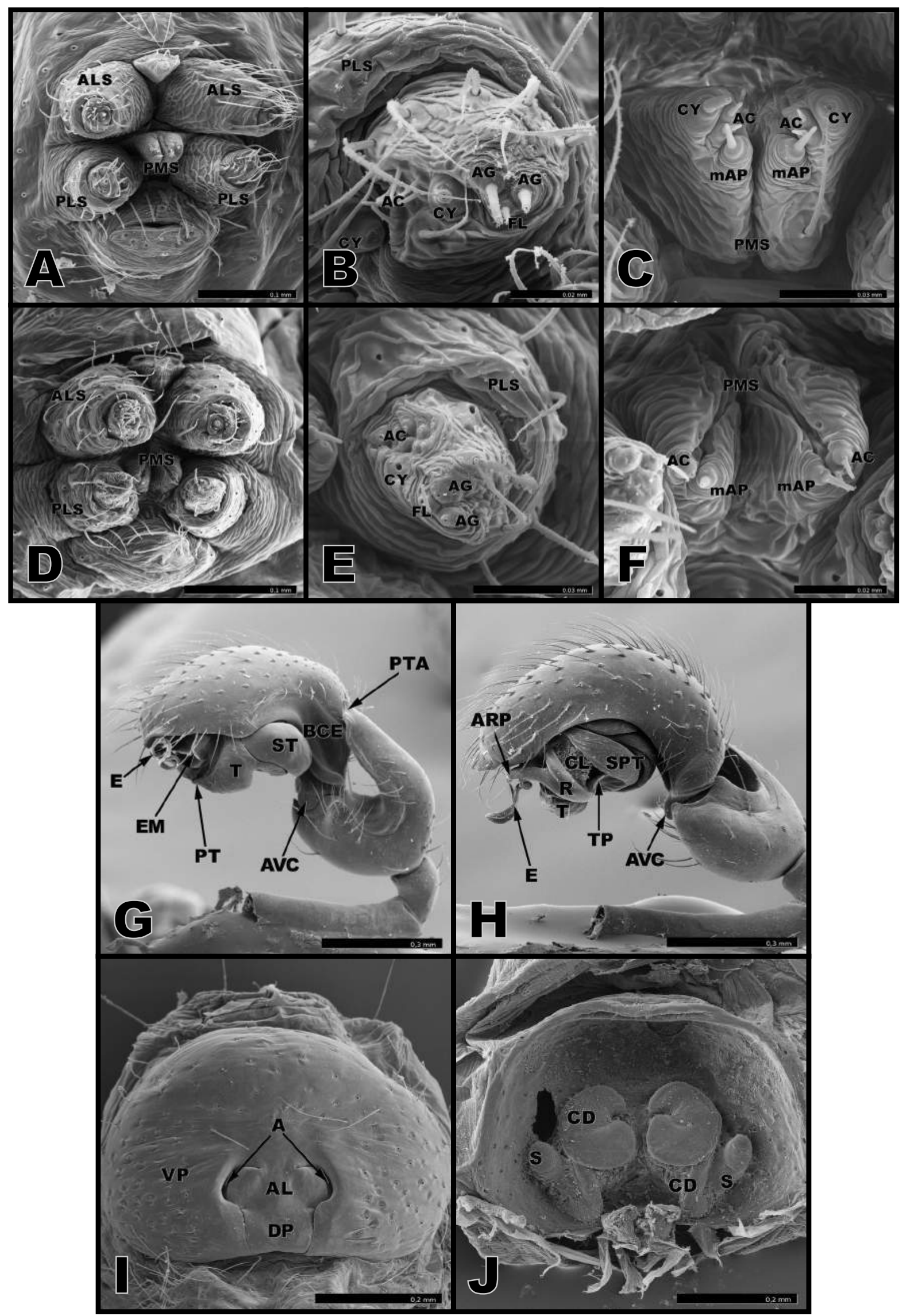

Figura 11. Sphecozone rubescens. A-C, fiandeiras da fêmea; D-F, fiandeiras do macho; G-H, palpo do macho; I-J, epígino da fêmea. A e D, vista geral. B e E, detalhe do PLS. $\mathrm{C}$ e F, detalhe do PMS. G, vista retrolateral. H, prolateral. I, vista dorsal. J, vista ventral. 


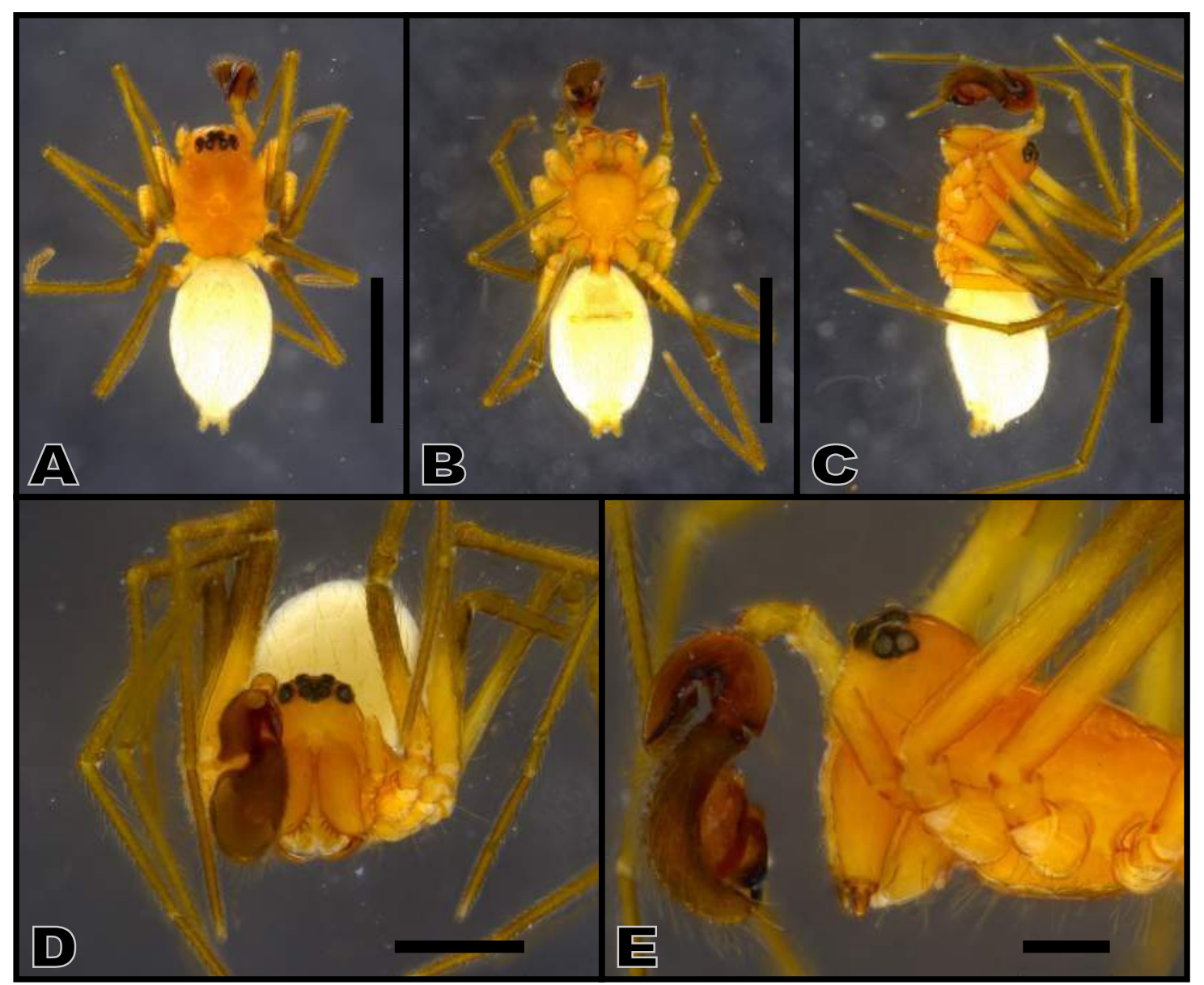

Figura 12. Sphecozone nitens, A-E, corpo do macho. A, dorsal; B, ventral; C, lateral; D, frontal; E, detalhe da região cefálica. Escala A-C, 1,0mm; D, 0,5mm; E, 0,2mm.

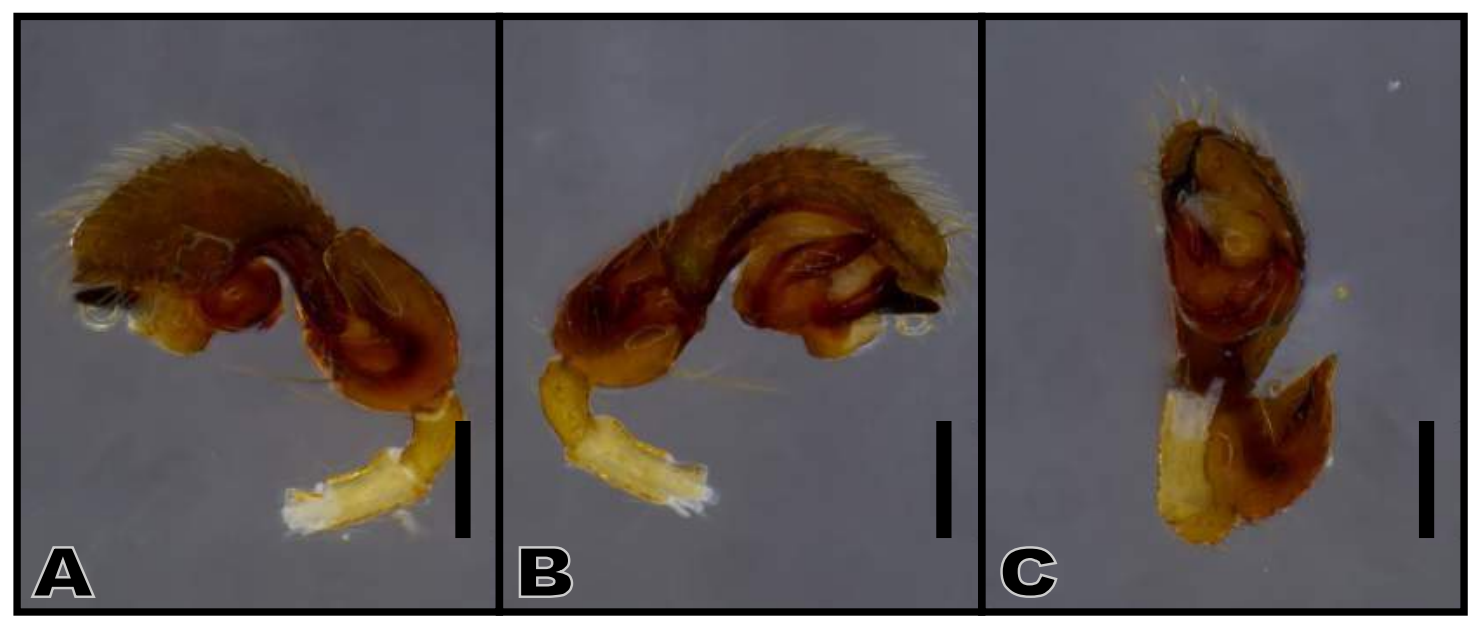

Figura 13. Sphecozone nitens, A-C, palpo do macho. A, retrolateral; B, prolateral; C, ventral. Escala 0,2mm. 


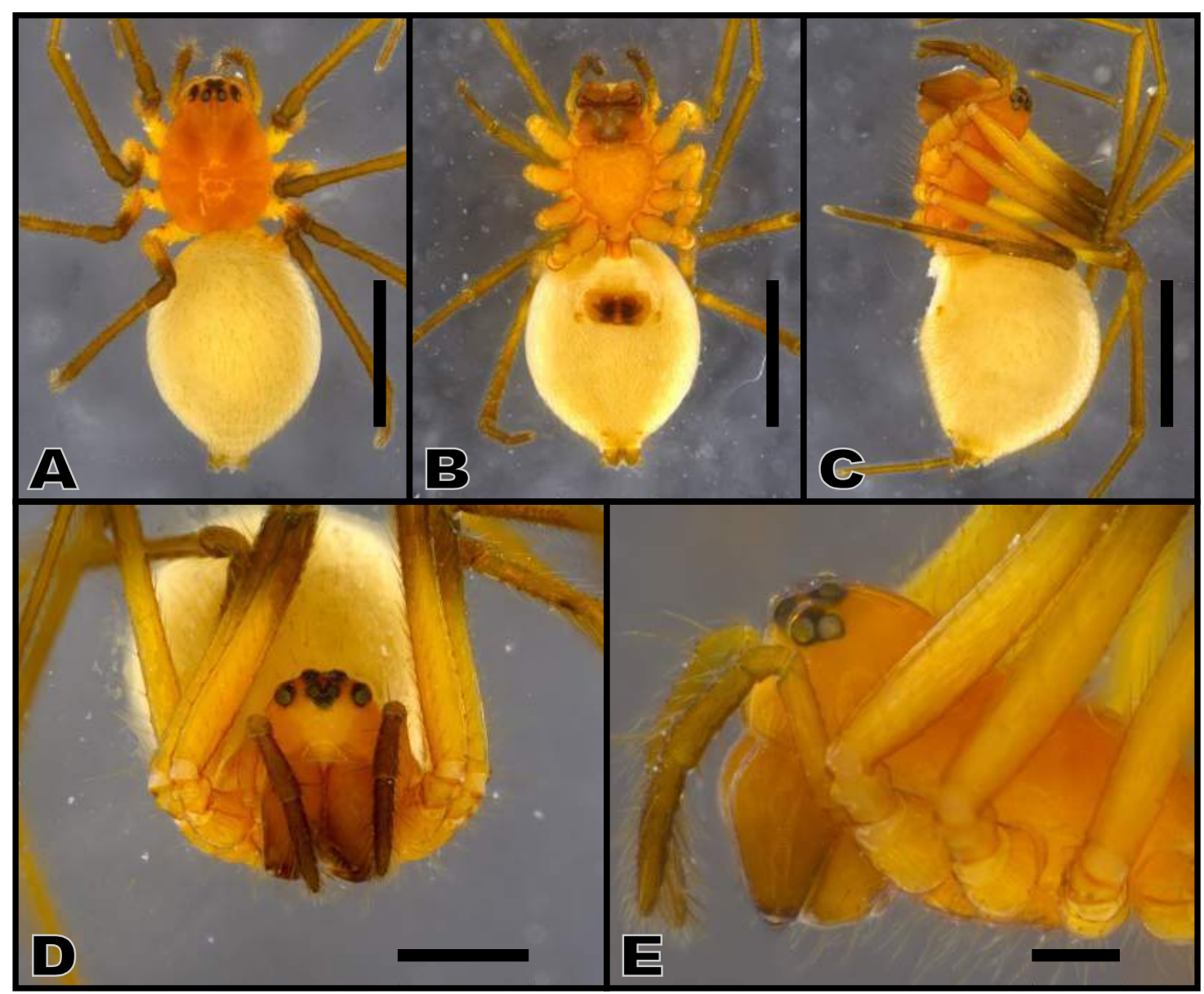

Figura 14. Sphecozone nitens, A-E, corpo da fêmea. A, dorsal; B, ventral; C, lateral; D, frontal; E, detalhe da região cefálica. Escala A-C, 1,0mm; D, 0,5mm; E, 0,2mm.

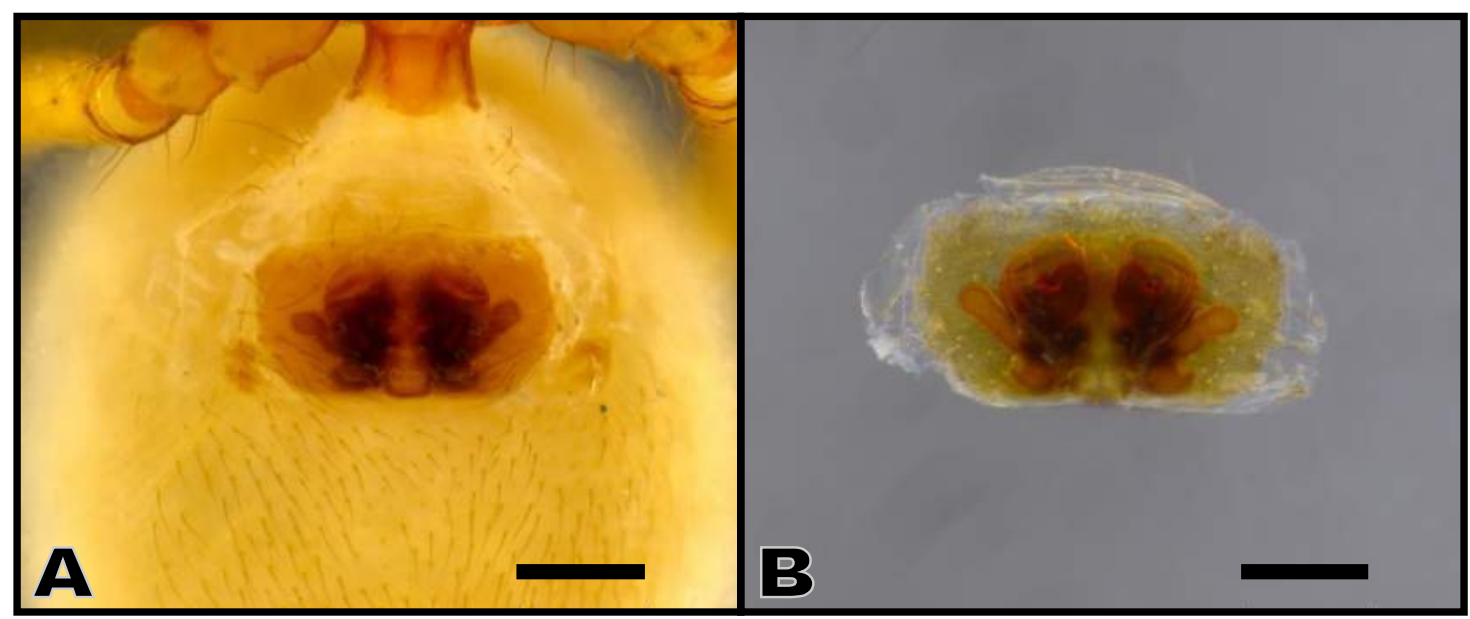

Figura 15. Sphecozone nitens, A-B, epígino da fêmea. A, ventral; B, dorsal. Escala $0,2 \mathrm{~mm}$. 


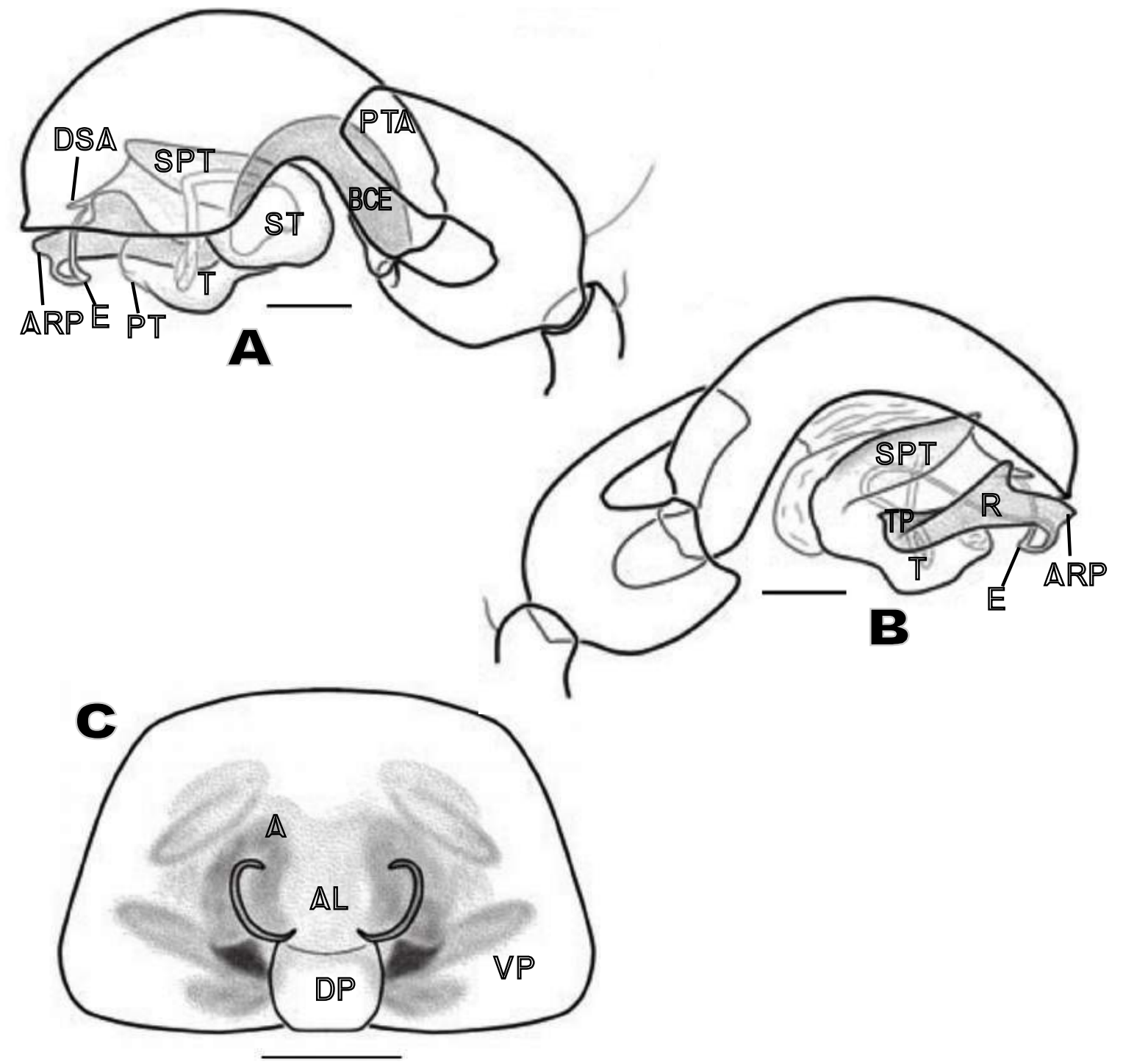

Figura 16. Sphecozone nitens, A-B, palpo do macho; C, epígino da fêmea. A, retrolateral; B, prolateral; C, ventral. Escala 0,1mm. A, átrio; AL, lóbulo anterior da placa dorsal do epígino; ARP, processo anterior do radix; BCE, excavação basal do címbio; DP, placa dorsal do epígino; DSA, apófise distal suprategular; E, êmbolo; PT, protégulo; PTA, apófise prolateral da tíbia; R, radix; SPT, supratégulo; ST, subtégulo; T, tégulo; TP, cauda do radix; VP, placa ventral do epígino. Ilustração de Miller, 2007. 


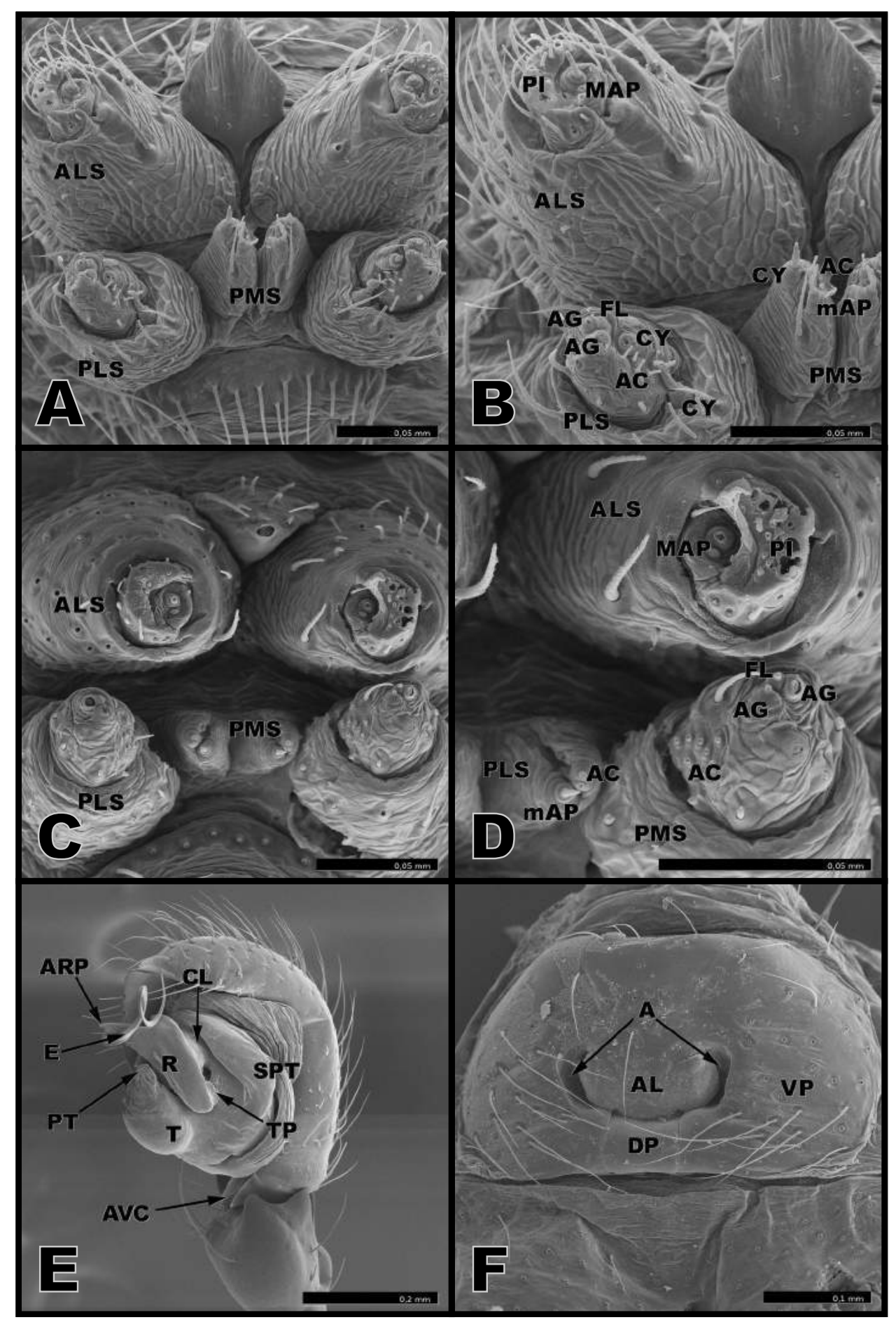

Figura 17. Sphecozone nitens. A-B, fiandeiras da fêmea; $\mathrm{C}-\mathrm{D}$, fiandeiras do macho; $\mathrm{E}-$ $\mathrm{F}$, palpo do macho; $\mathrm{G}-\mathrm{H}$, epígino da fêmea. A e $\mathrm{C}$, vista geral. $\mathrm{B}$ e $\mathrm{D}$, detalhes da fiandeira. E, vista prolateral. $\mathrm{F}$, vista ventral. 


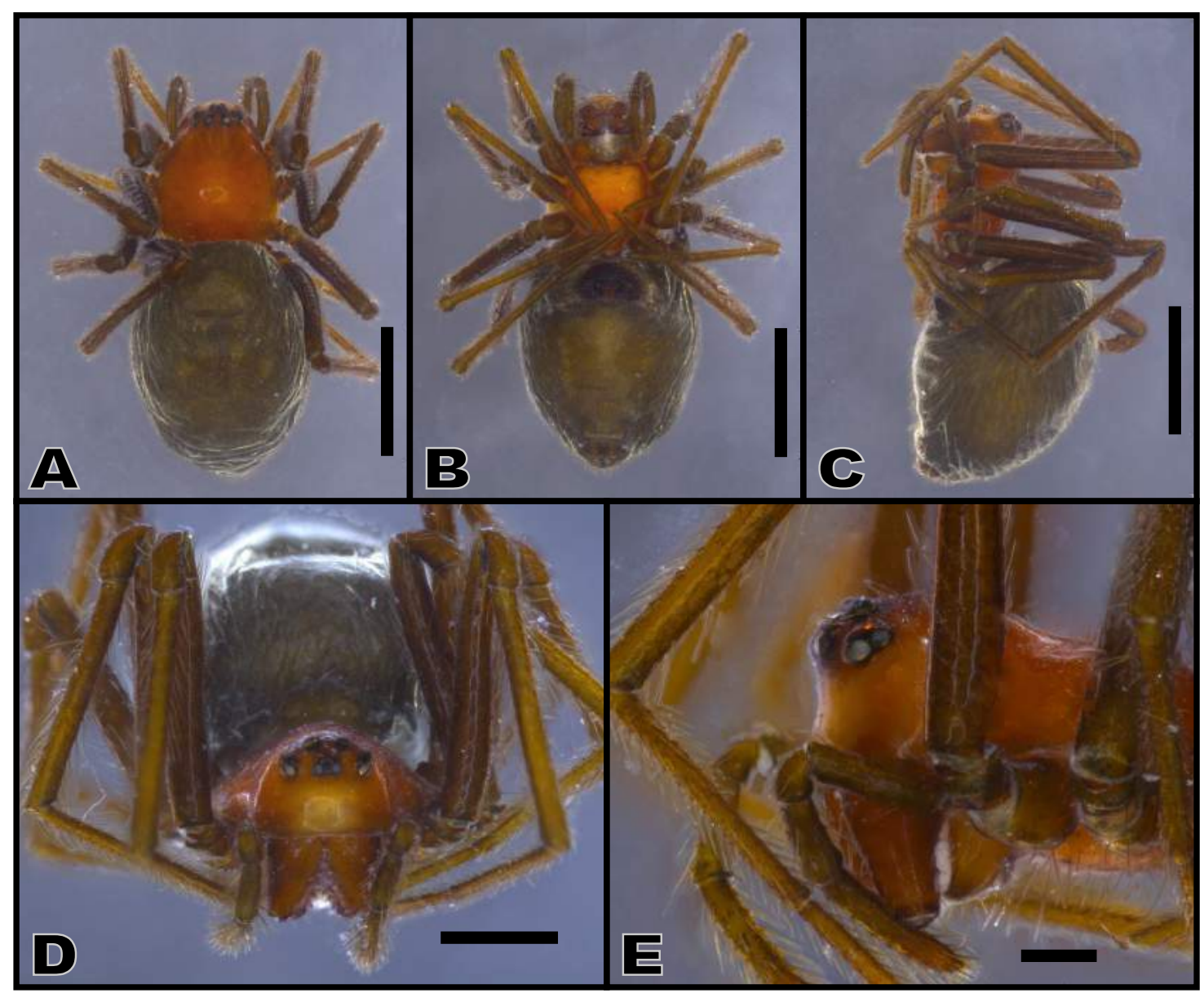

Figura 18. Hypselistoides altehabitans, A-E, corpo da fêmea. A, dorsal; B, ventral; C, lateral; D, frontal; E, detalhe da região cefálica. Escala A-C, 1,0mm; D-E 0,2mm.

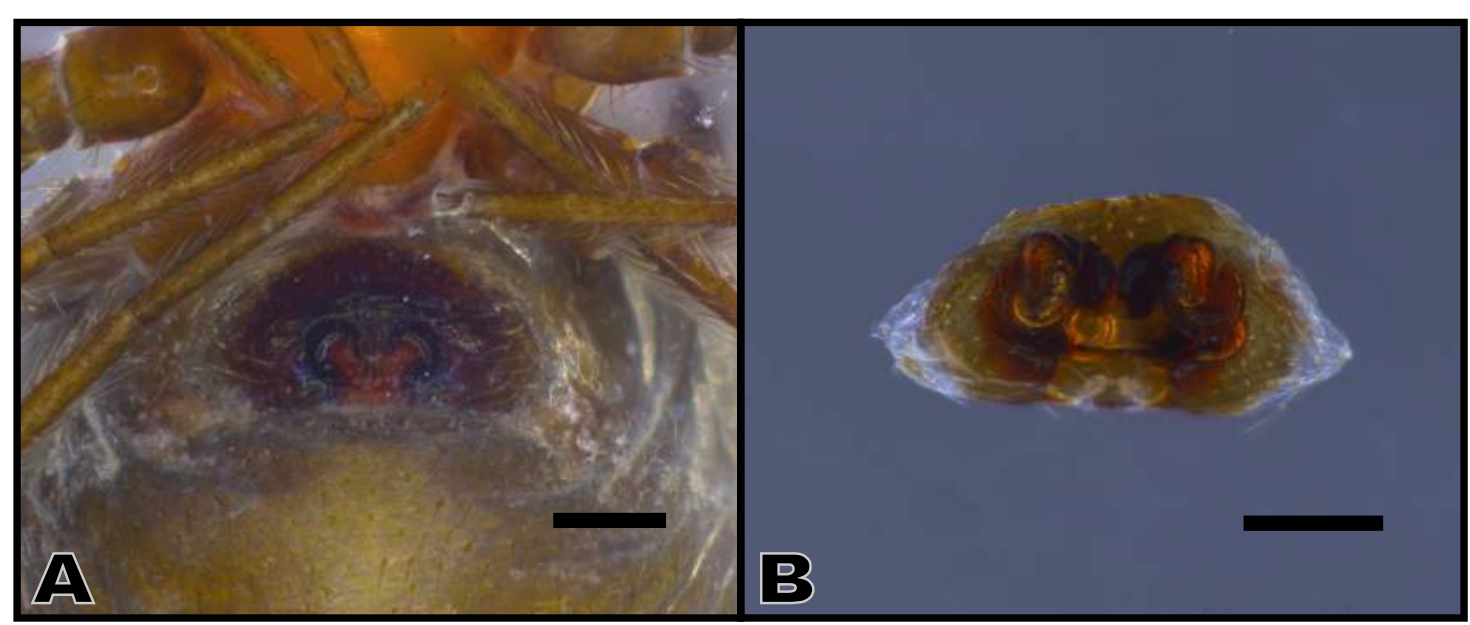

Figura 19. Hypselistoides altehabitans, A-B, epígino da fêmea. A, retrolateral; B, prolateral; C, ventral; D, ventral; E, dorsal. Escala 0,2mm. 


\section{$\mathbf{A}$}

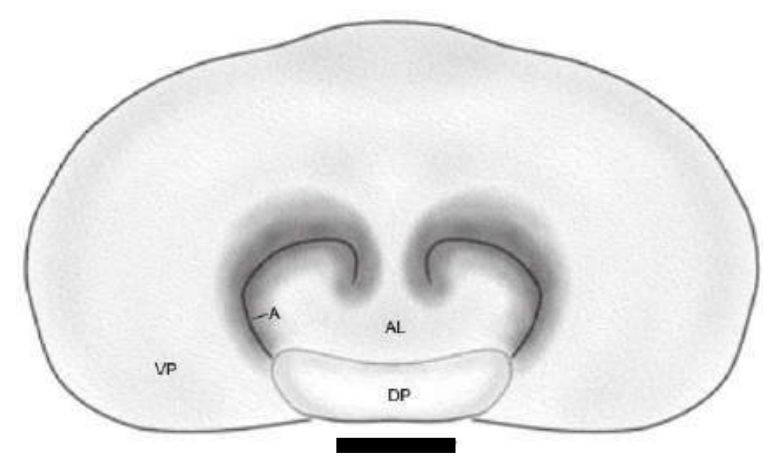

Figura 20. Hypselistoides altehabitans, A, epígino da fêmea, ventral. Escala 0,1mm. A, átrio; AL, lóbulo anterior da placa dorsal do epígino; CD, duto de copulação; CO, abertura de copulação; DP, placa dorsal do epígino; FD, duto de fertilização; S, espermateca; VP, placa ventral do epígino. Ilustração de Miller, 2007. 


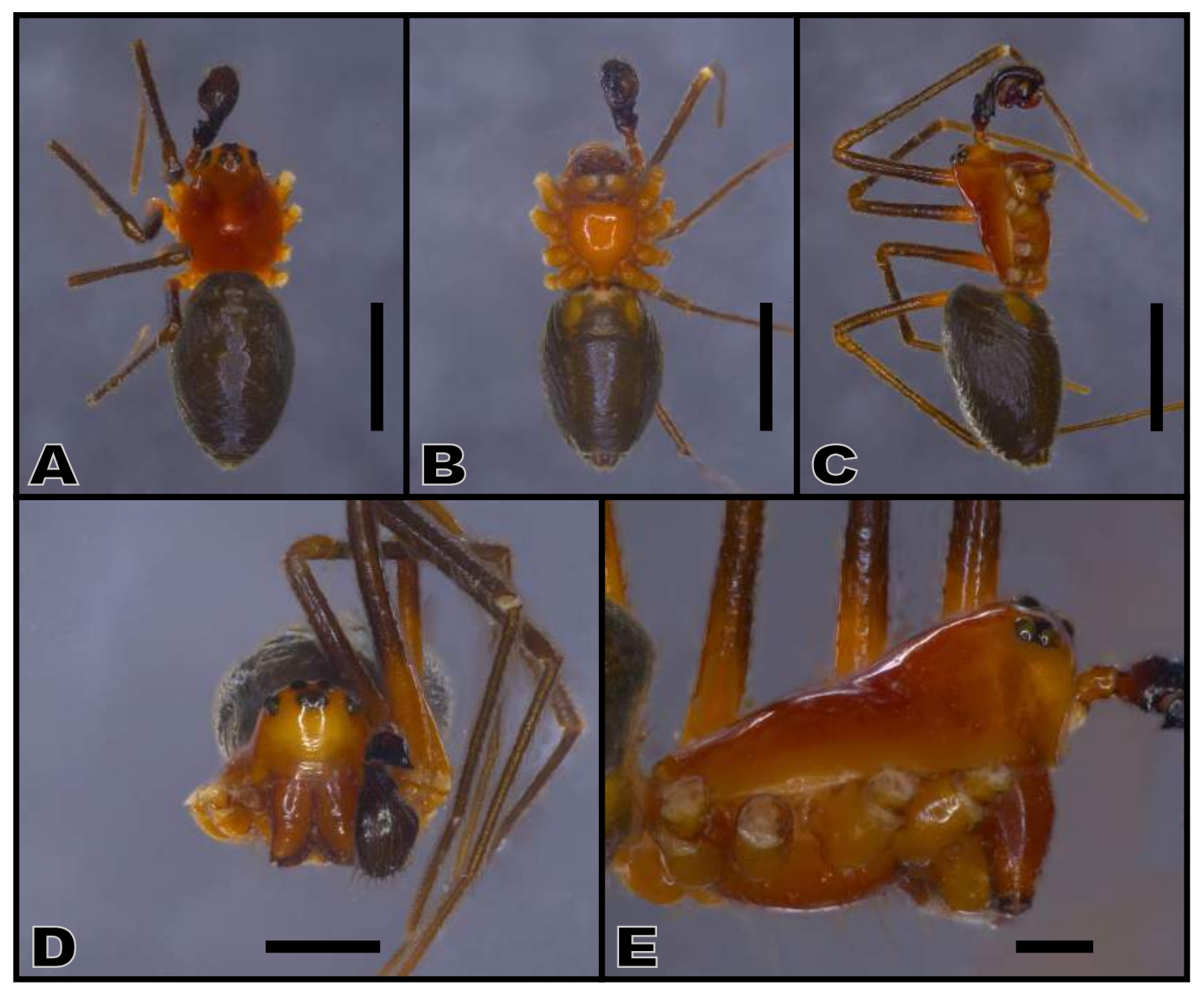

Figura 21. Hypselistoides bicolor, A-E, corpo do macho. A, dorsal; B, ventral; C, lateral; D, frontal; E, detalhe da região cefálica. Escala A-C, 1,0mm; D, 0,5mm; E, $0,2 \mathrm{~mm}$.

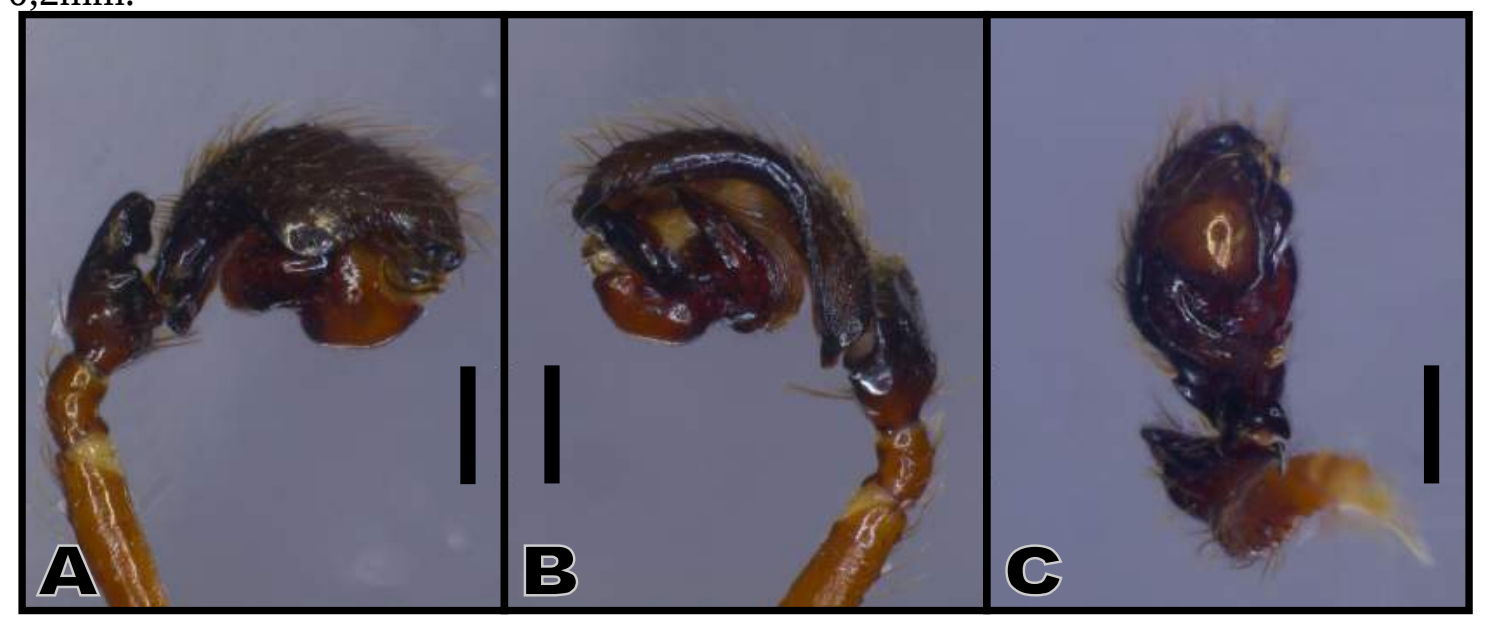

Figura 22. Hypselistoides bicolor, A-C, palpo do macho. A, retrolateral; B, prolateral; C, ventral. Escala $0,2 \mathrm{~mm}$. 


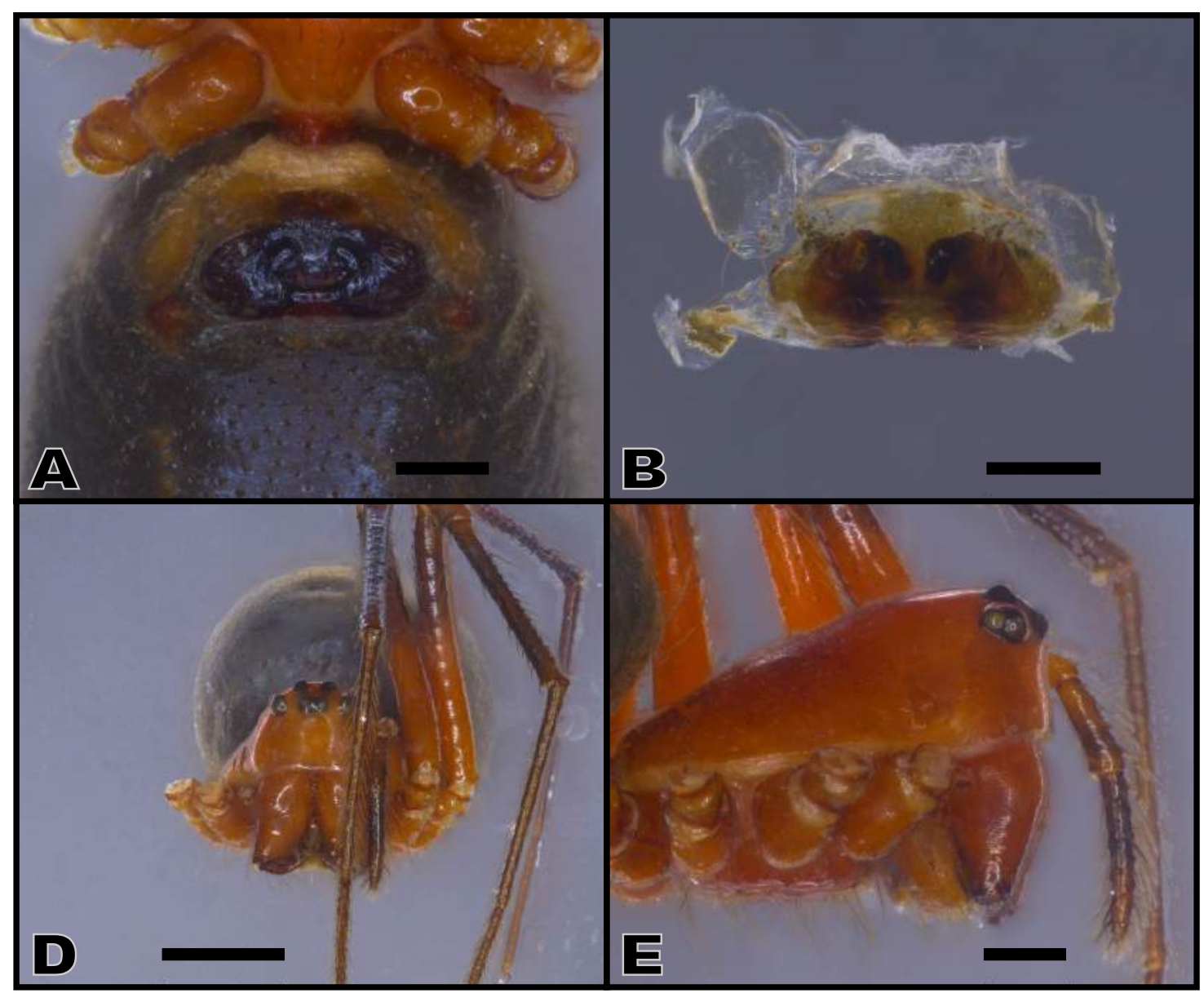

Figura 23. Hypselistoides bicolor, A-E, corpo da fêmea. A, dorsal; B, ventral; C, lateral;

D, frontal; E, detalhe da região cefálica. Escala A-C, 1,0mm; D, 0,5mm; E, 0,2mm.

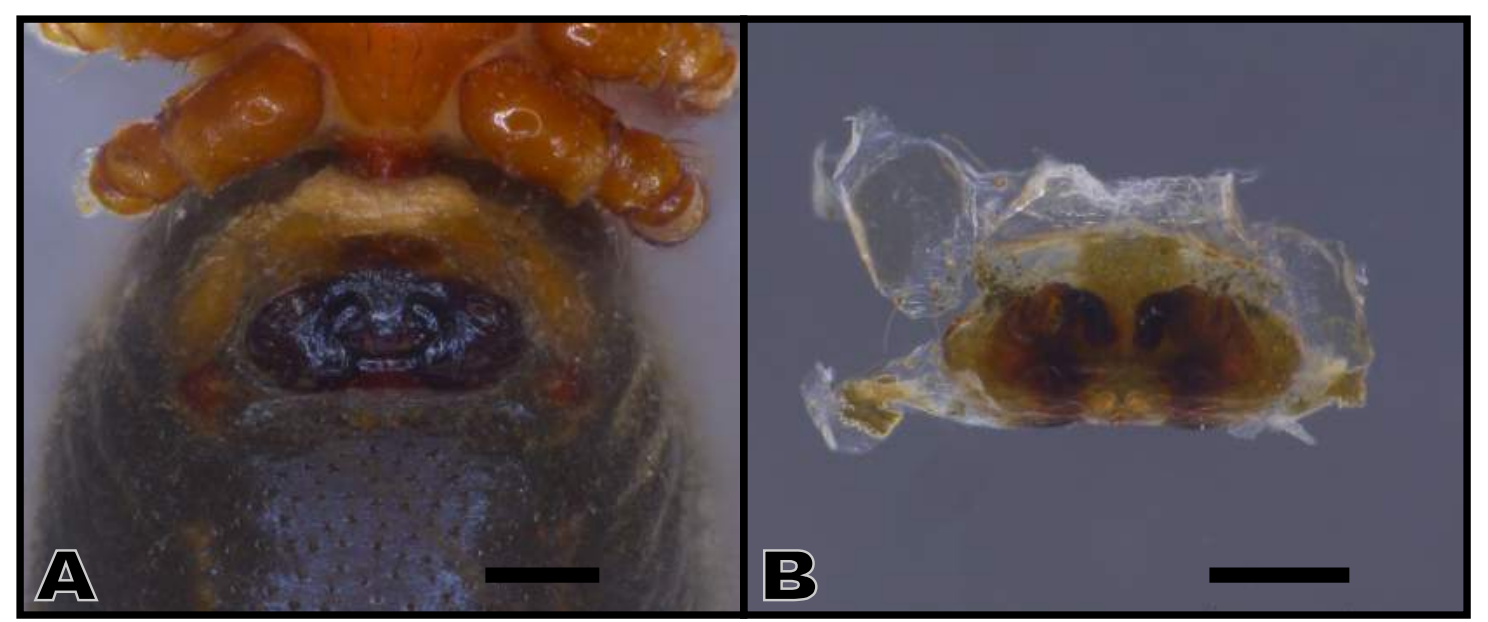

Figura 24. Hypselistoides bicolor, A-B, epígino da fêmea. A, ventral; B, dorsal. Escala $0,2 \mathrm{~mm}$. 


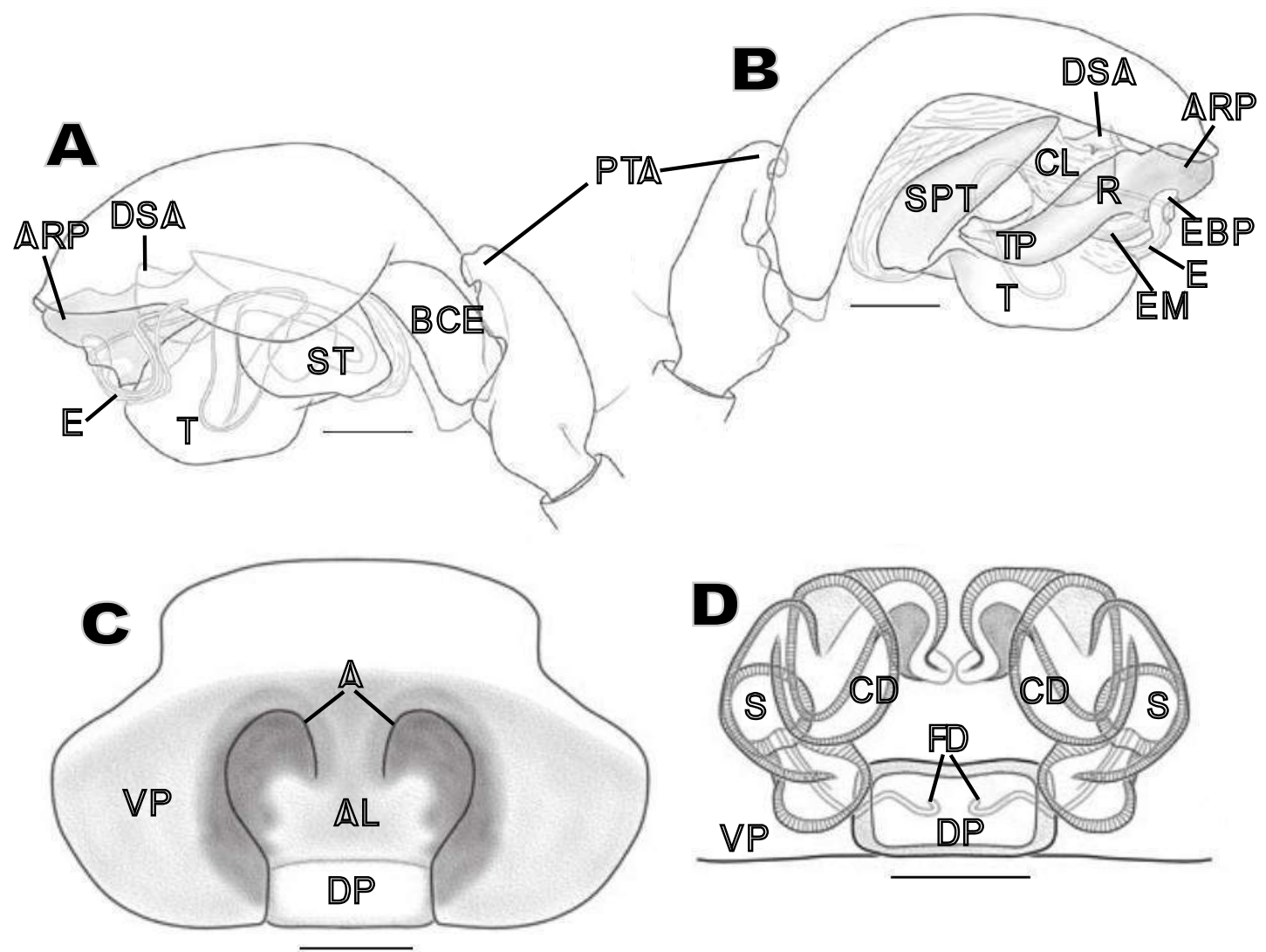

Figura 25. Hypselistoides bicolor, A-B, palpo do macho; C-D, epígino da fêmea. A, retrolateral; B, prolateral; C, ventral; D, dorsal. Escala 0,2mm. A, átrio; AL, lóbulo anterior da placa dorsal do epígino; ARP, processo anterior do radix; BCE, excavação basal do címbio; CD, duto de copulação; CL, column; DP, placa dorsal do epígino; DSA, apófise distal suprategular; E, êmbolo; EBP, processo basal do êmbolo; EM, membrana embólica; FD, duto de fertilização; PTA, apófise prolateral da tíbia; R, radix; S, espermateca; SPT, supratégulo; ST, subtégulo; T, tégulo; TP, cauda do radix; VP, placa ventral do epígino. Ilustração de Miller, 2007. 


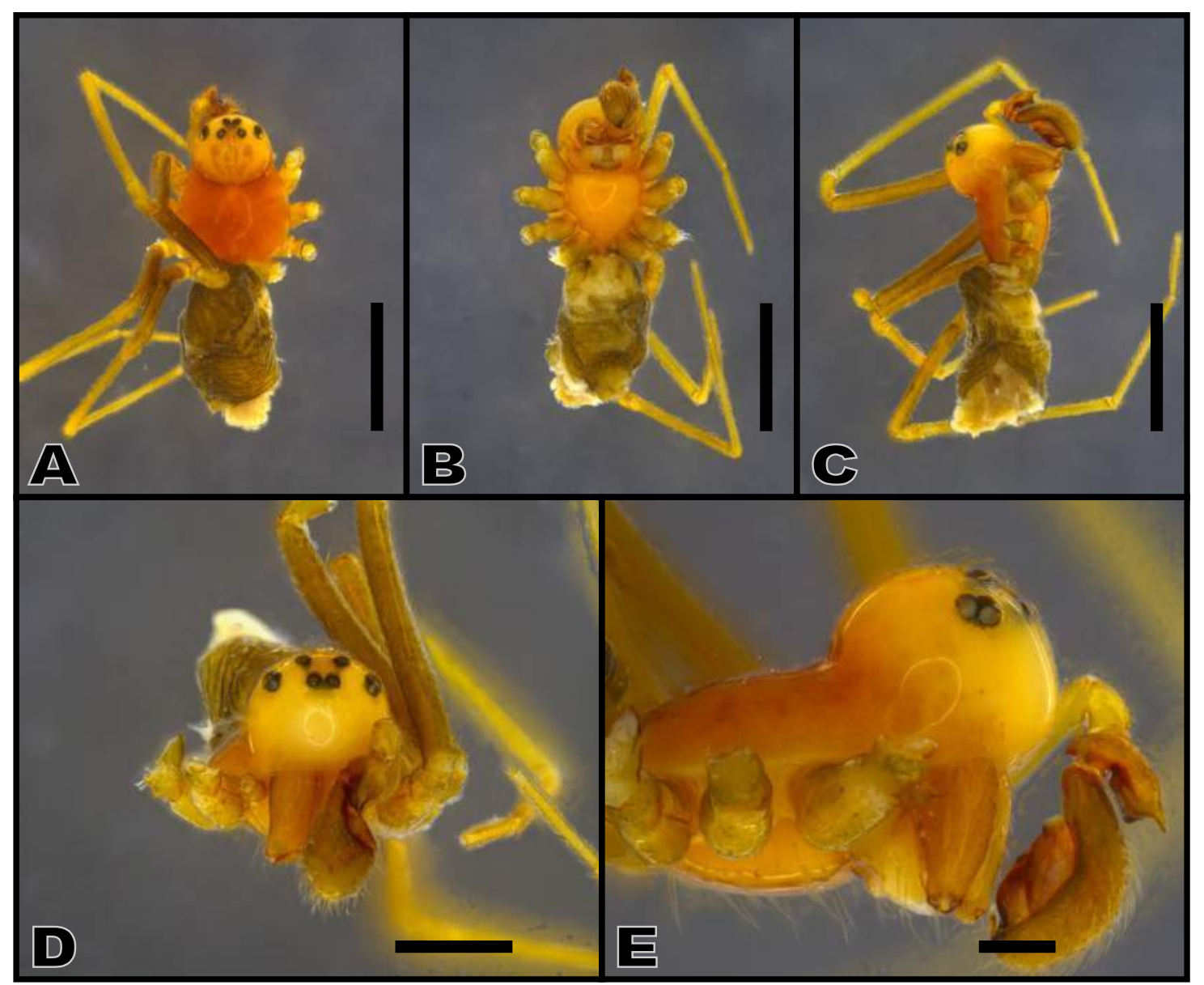

Figura 26. Hypselistoides capitatus, A-E, corpo do macho. A, dorsal; B, ventral; C, lateral; D, frontal; E, detalhe da região cefálica. Escala A-C, 1,0mm; D, 0,5mm; E, $0,2 \mathrm{~mm}$.

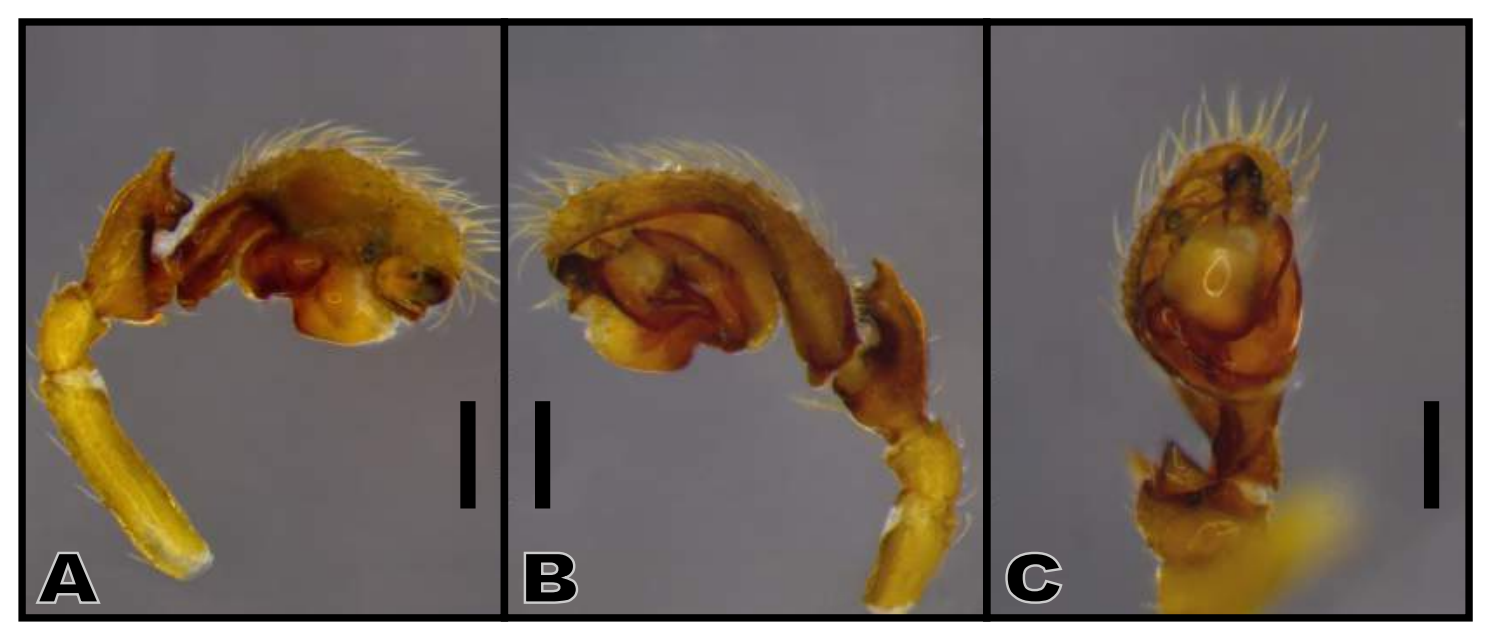

Figura 27. Hypselistoides capitatus, A-C, palpo do macho. A, retrolateral; B, prolateral; C, ventral. Escala 0,2mm. 


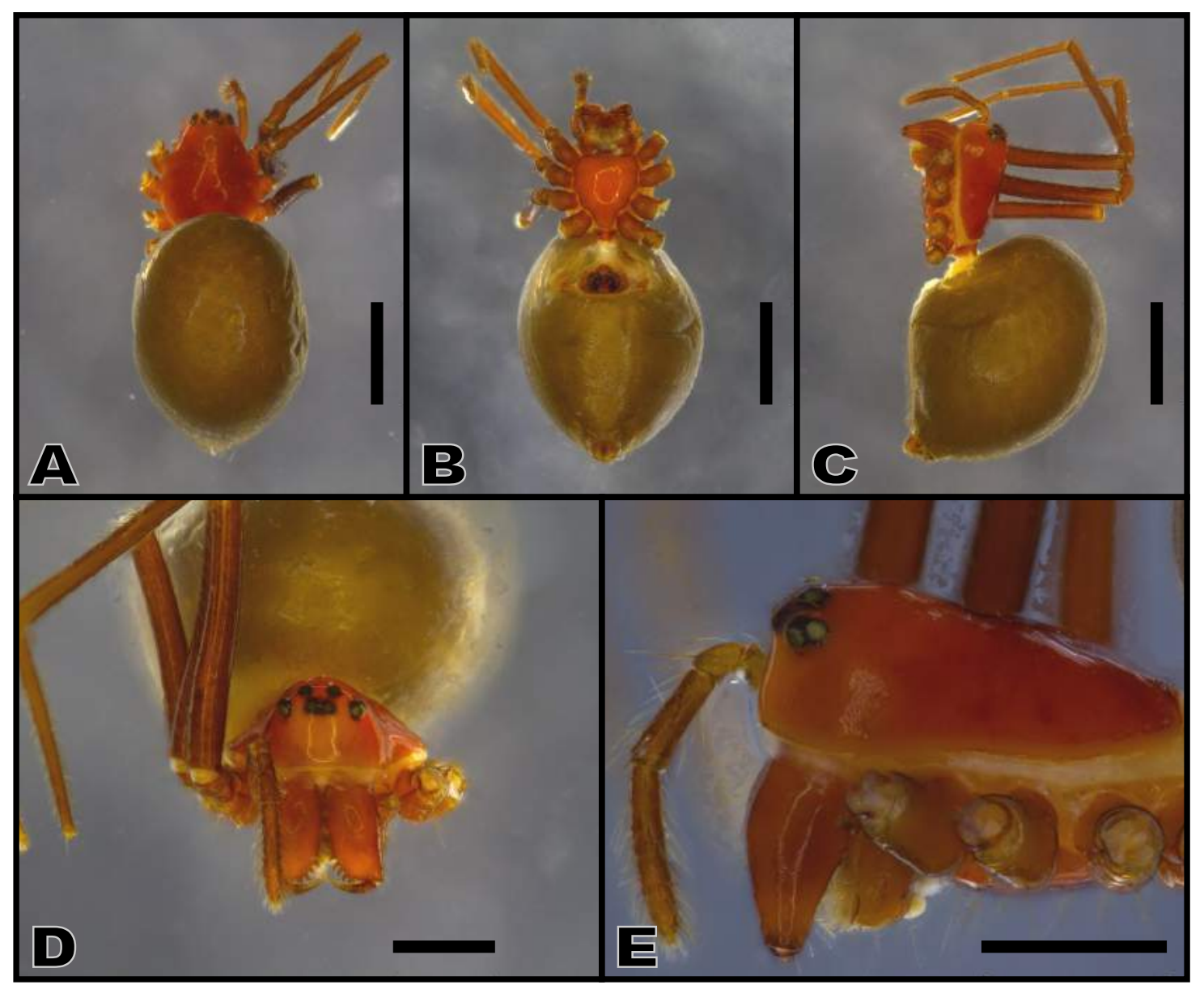

Figura 28. Hypselistoides capitatus, A-E, corpo da fêmea. A, dorsal; B, ventral; C, lateral; D, frontal; E, detalhe da região cefálica. Escala A-C, 1,0mm; D-E, 0,5mm.

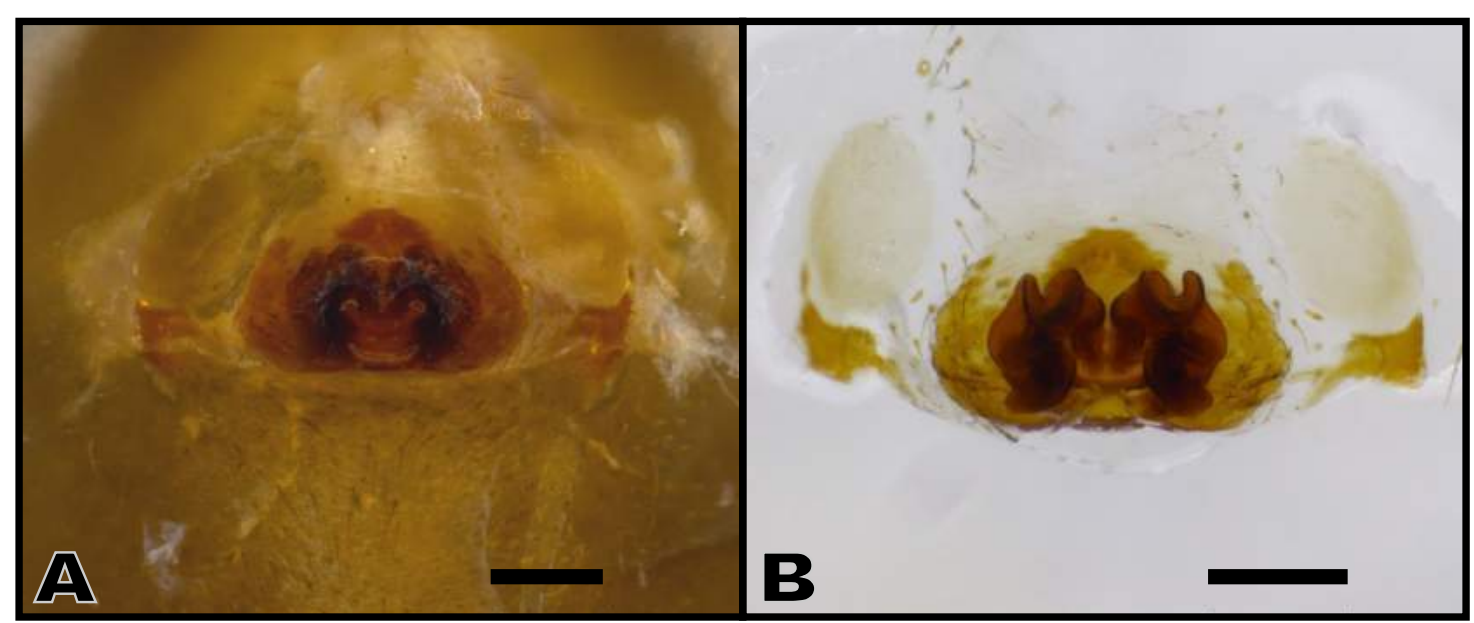

Figura 29. Hypselistoides capitatus, A-B, epígino da fêmea. A, ventral; B, dorsal. Escala 0,2mm. 


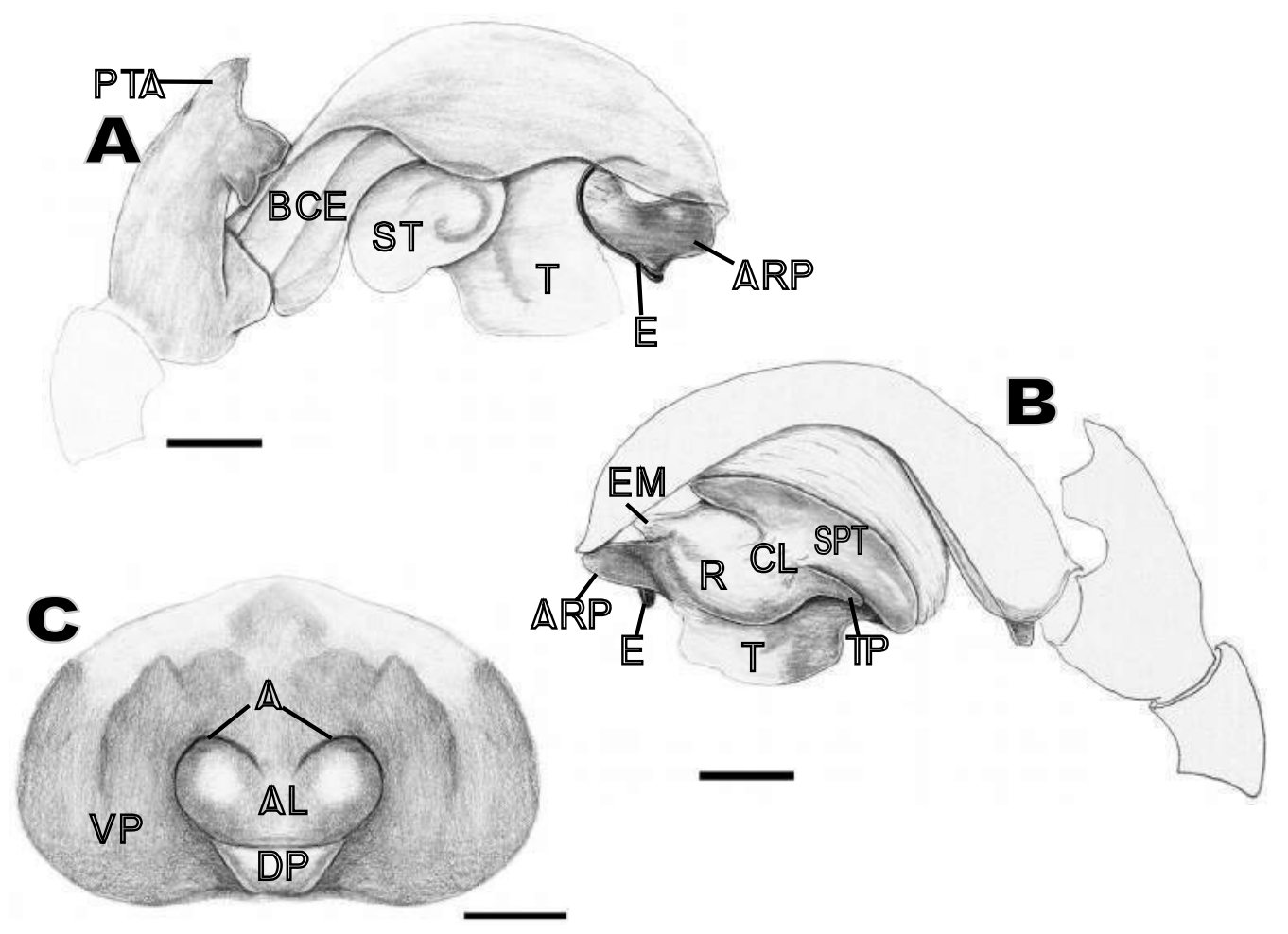

Figura 30. Hypselistoides capitatus, A-B, palpo do macho; C, epígino da fêmea. A, retrolateral; B, prolateral; C, ventral. Escala 0,1mm. A, átrio; AL, lóbulo anterior da placa dorsal do epígino; ARP, processo anterior do radix; BCE, excavação basal do címbio; CL, column; DP, placa dorsal do epígino; E, êmbolo; EM, membrana embólica; PTA, apófise prolateral da tíbia; R, radix; SPT, supratégulo; ST, subtégulo; T, tégulo; TP, cauda do radix; VP, placa ventral do epígino. 


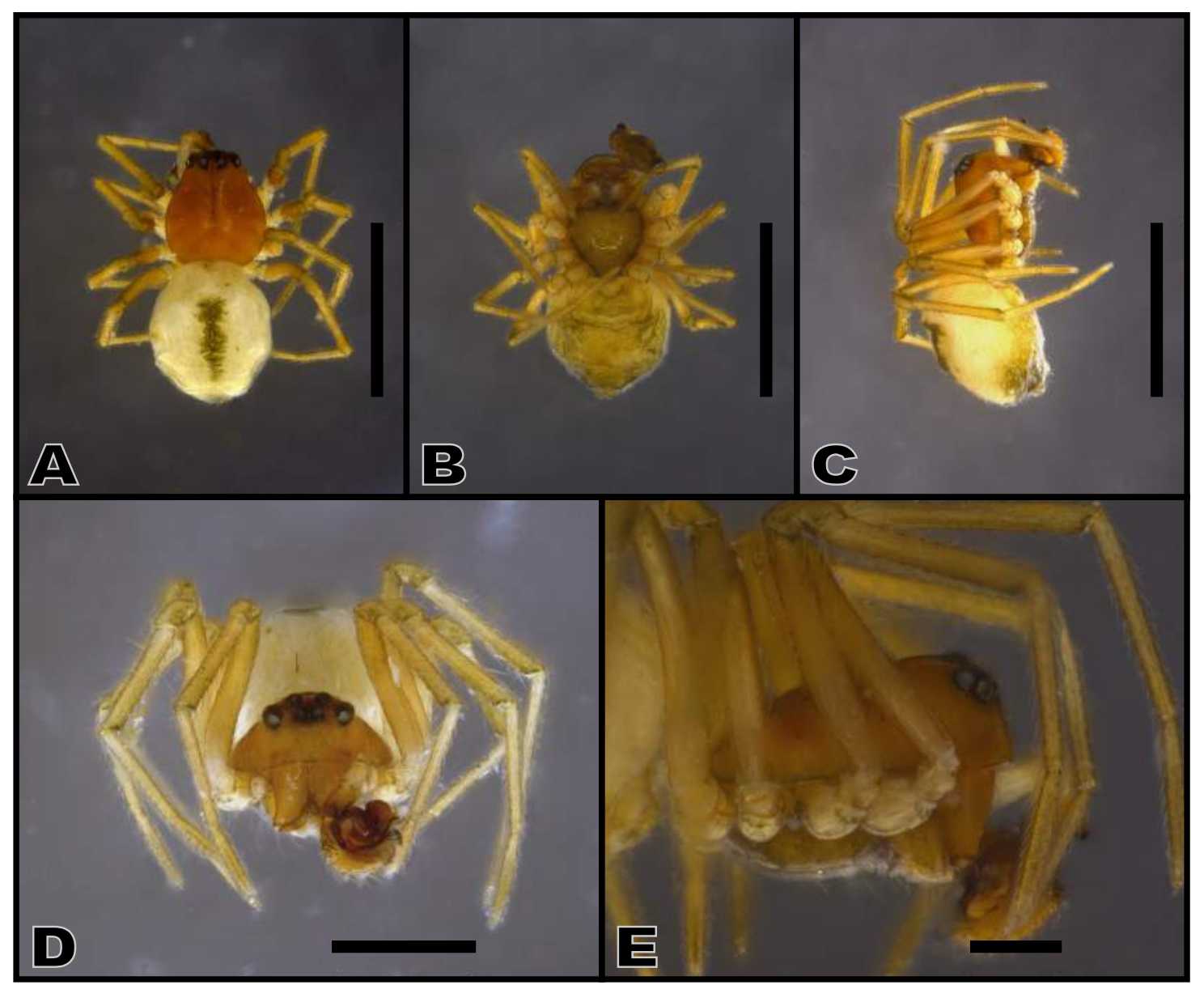

Figura 31. Hypselistoides corniculans, A-E, corpo do macho. A, dorsal; B, ventral; C, lateral; D, frontal; E, detalhe da região cefálica. Escala A-C, 1,0mm; D, 0,5mm; E, $0,2 \mathrm{~mm}$.

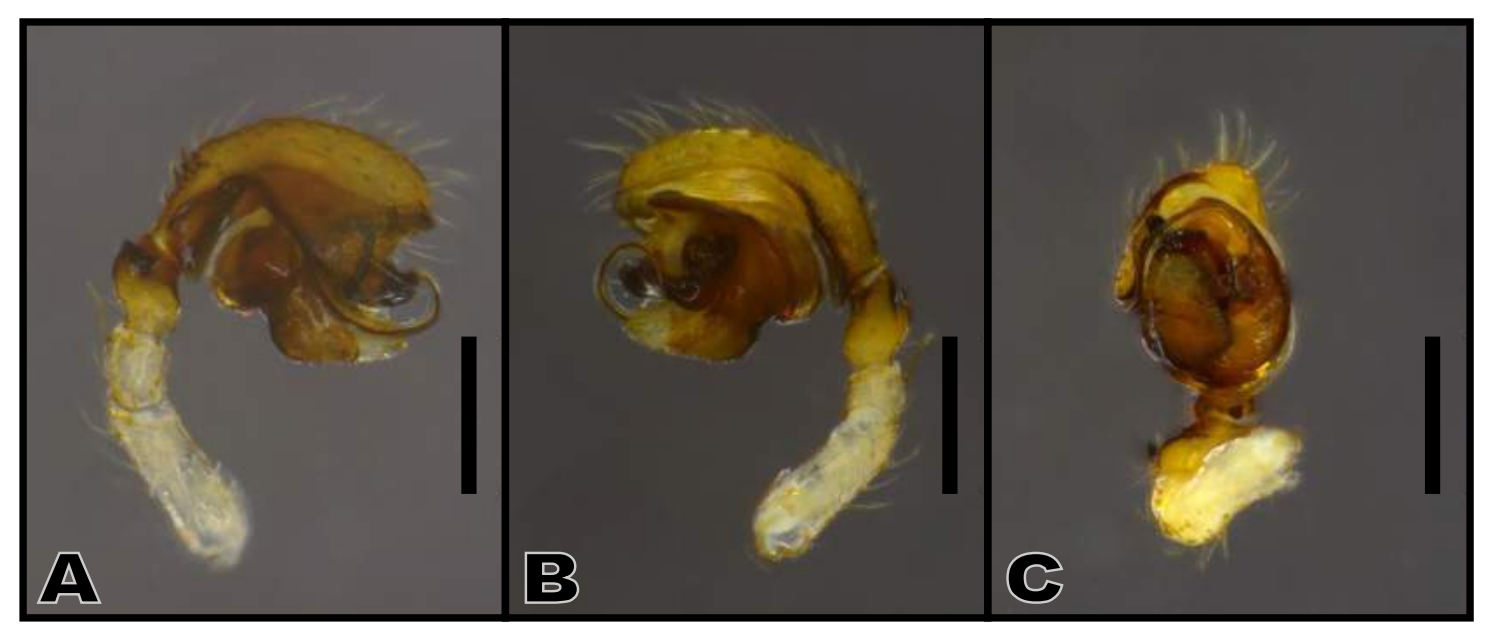

Figura 32. Hypselistoides corniculans, A-C, palpo do macho. A, retrolateral; B, prolateral; C, ventral. Escala 0,2mm. 


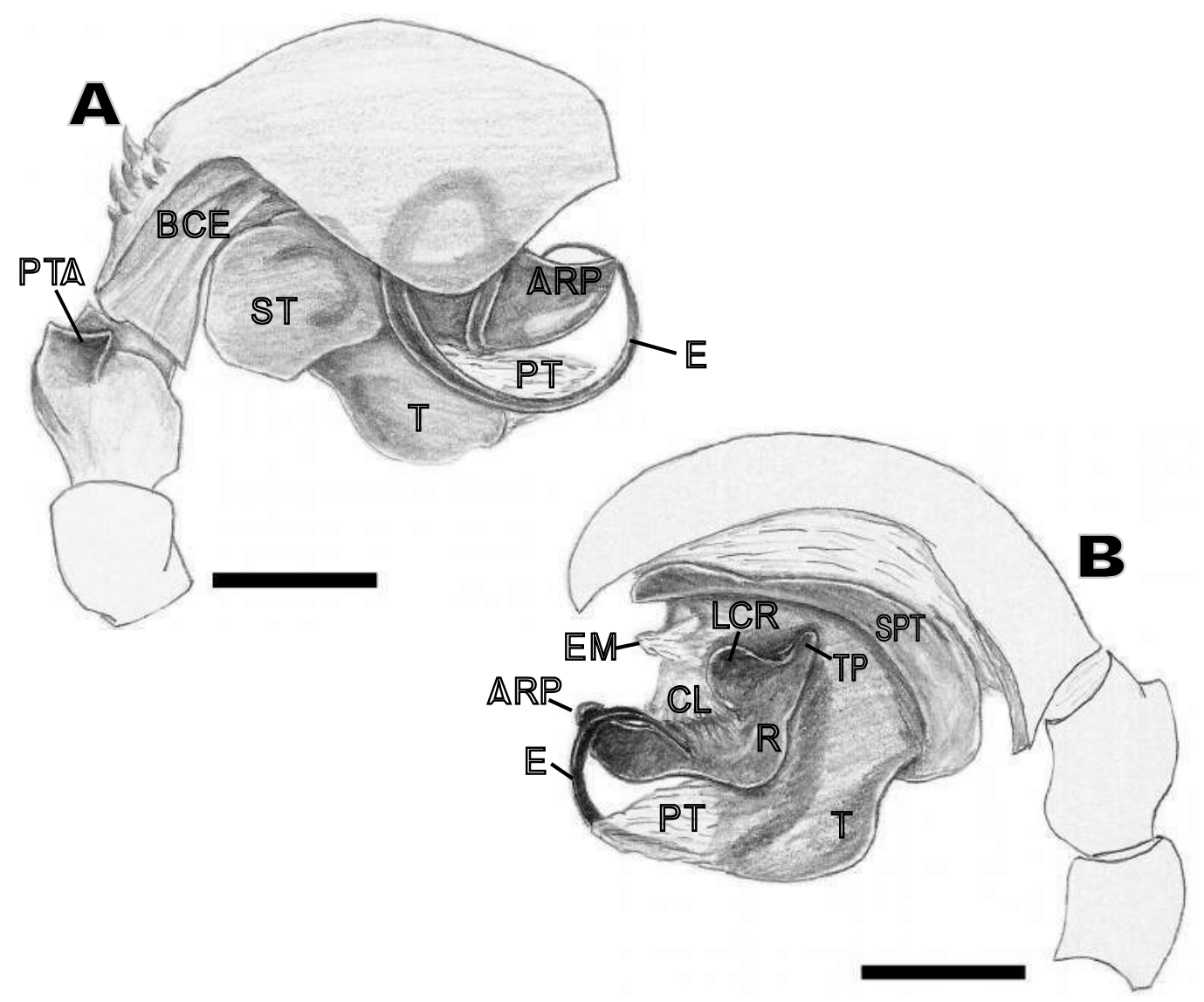

Figura 33. Hypselistoides corniculans, A-B, palpo do macho. A, retrolateral; B, prolateral. Escala 0,1mm. ARP, processo anterior do radix; BCE, excavação basal do címbio; CL, column; E, êmbolo; EM, membrana embólica; LCR, lóbulo da cauda do radix; PT, protégulo; PTA, apófise prolateral da tíbia; R, radix; SPT, supratégulo; ST, subtégulo; T, tégulo; TP, cauda do radix. 


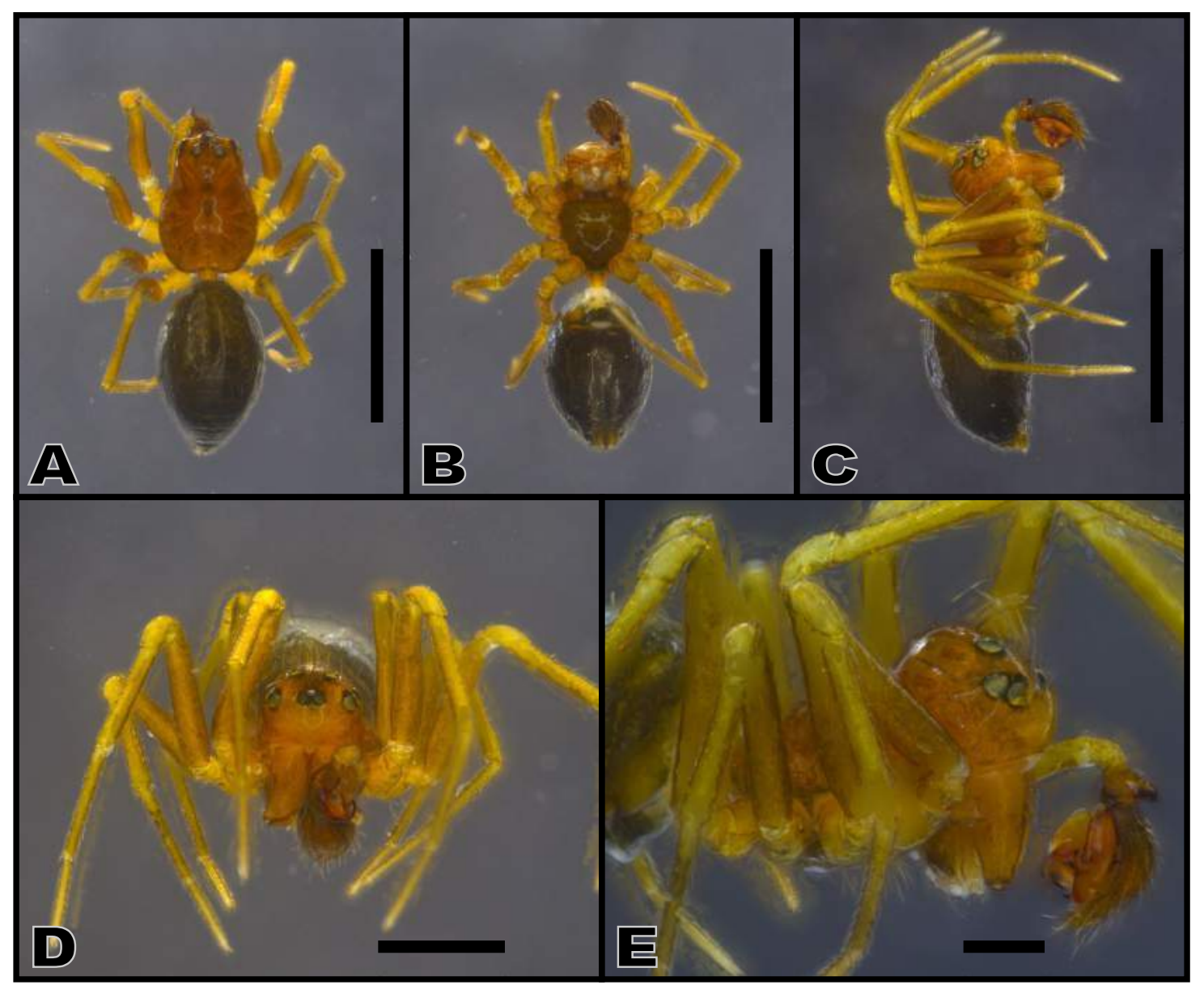

Figura 34. Hypselistoides cornutus, A-E, corpo do macho. A, dorsal; B, ventral; C, lateral; D, frontal; E, detalhe da região cefálica. Escala A-C, 1,0mm; D, 0,5mm; E, $0,2 \mathrm{~mm}$.

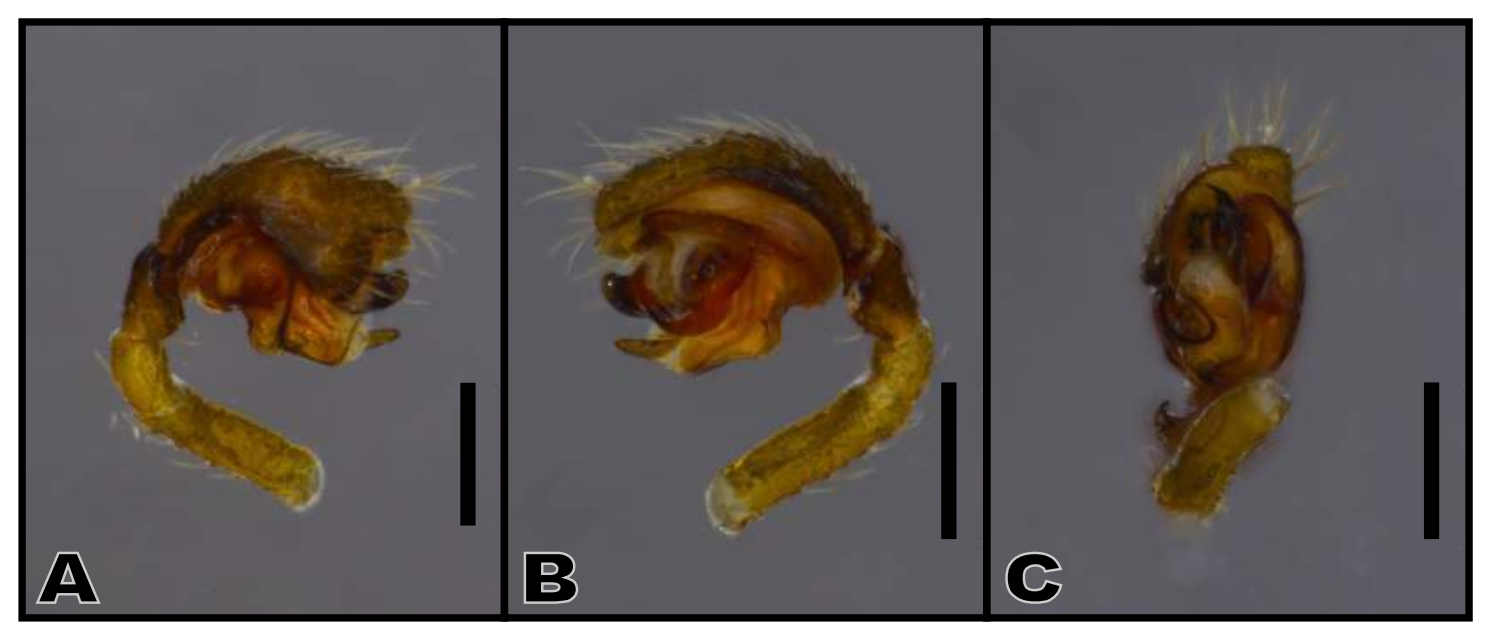

Figura 35. Hypselistoides cornutus, A-C, palpo do macho. A, retrolateral; B, prolateral; C, ventral. Escala 0,2mm. 


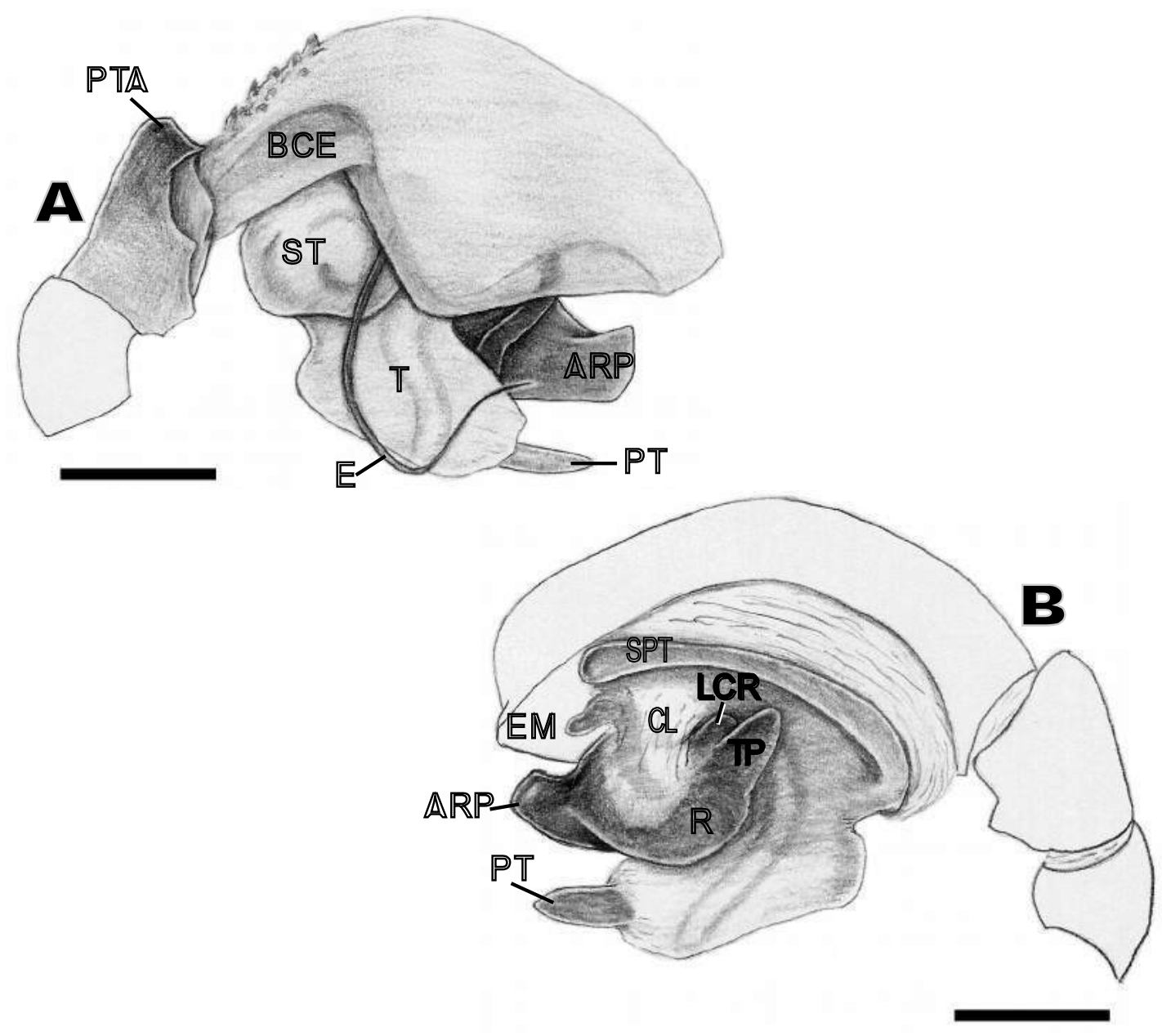

Figura 36. Hypselistoides cornutus, A-B, palpo do macho. A, retrolateral; B, prolateral. Escala 0,1mm. ARP, processo anterior do radix; BCE, excavação basal do címbio; CL, column; E, êmbolo; EM, membrana embólica; LCR, lóbulo da cauda do radix; PT, protégulo; PTA, apófise prolateral da tíbia; R, radix; SPT, supratégulo; ST, subtégulo; T, tégulo; TP, cauda do radix. 


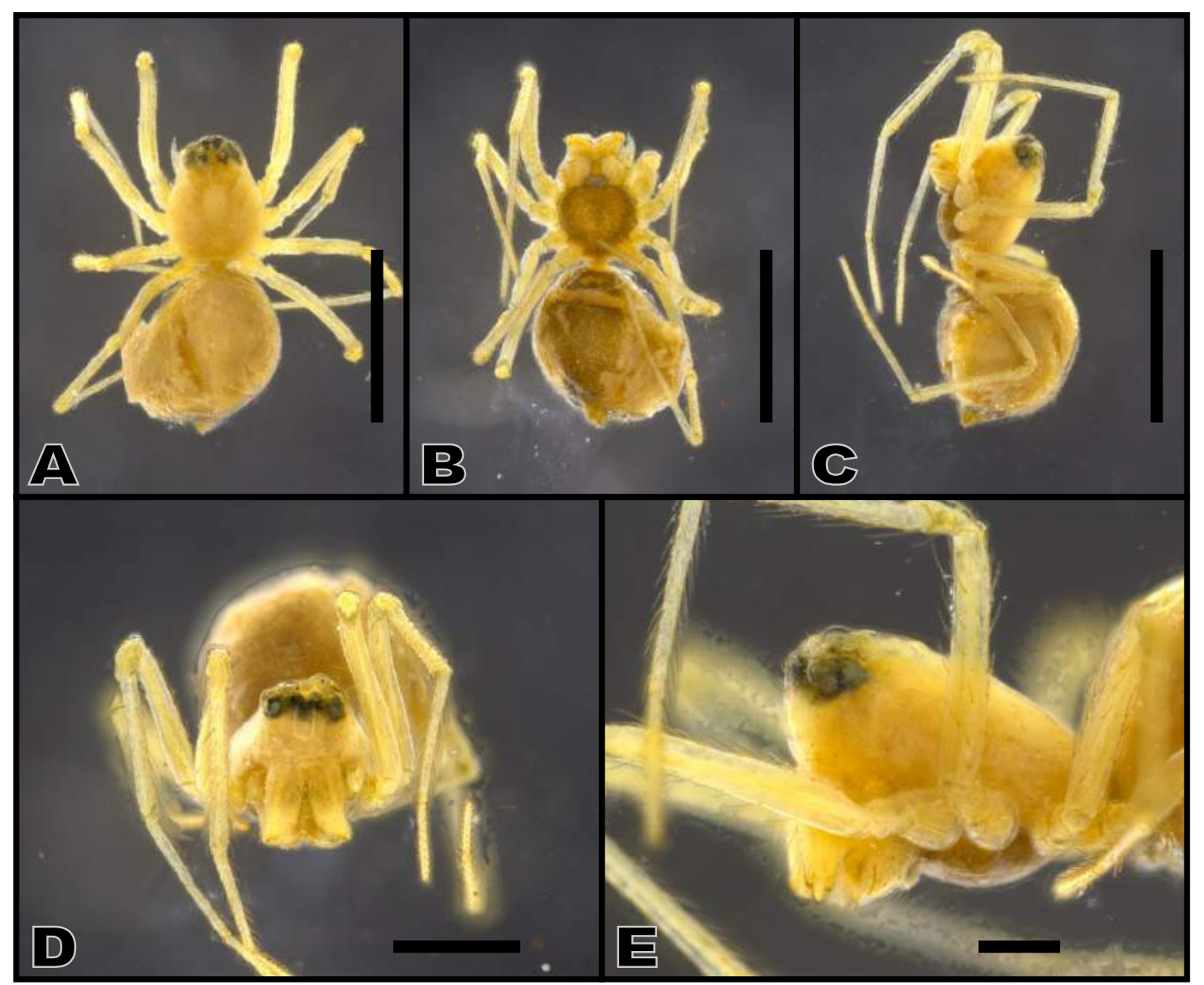

Figura 37. Hypselistoides crinitus, A-E, corpo do macho. A, dorsal; B, ventral; C, lateral; D, frontal; E, detalhe da região cefálica. Escala A-C, 1,0mm; D, 0,5mm; E, $0,2 \mathrm{~mm}$.

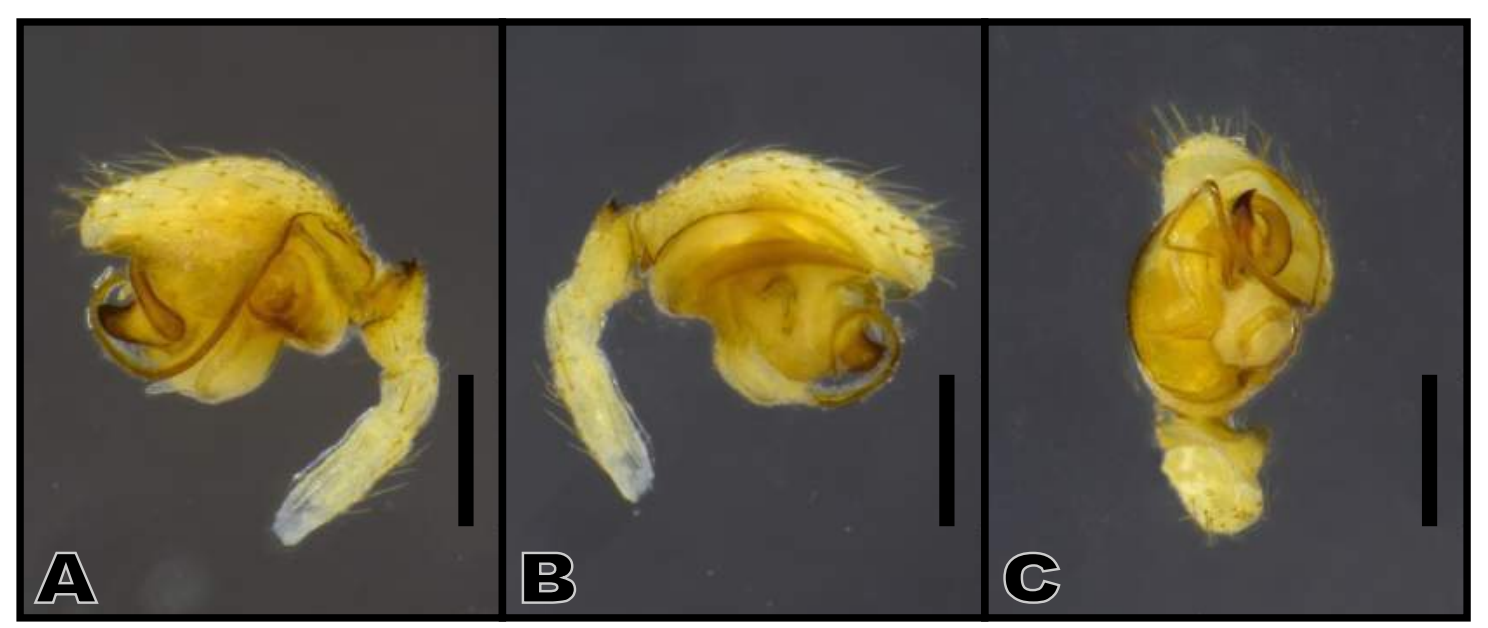

Figura 38. Hypselistoides crinitus, A-C, palpo do macho. A, retrolateral; B, prolateral; C, ventral. Escala 0,2mm. 


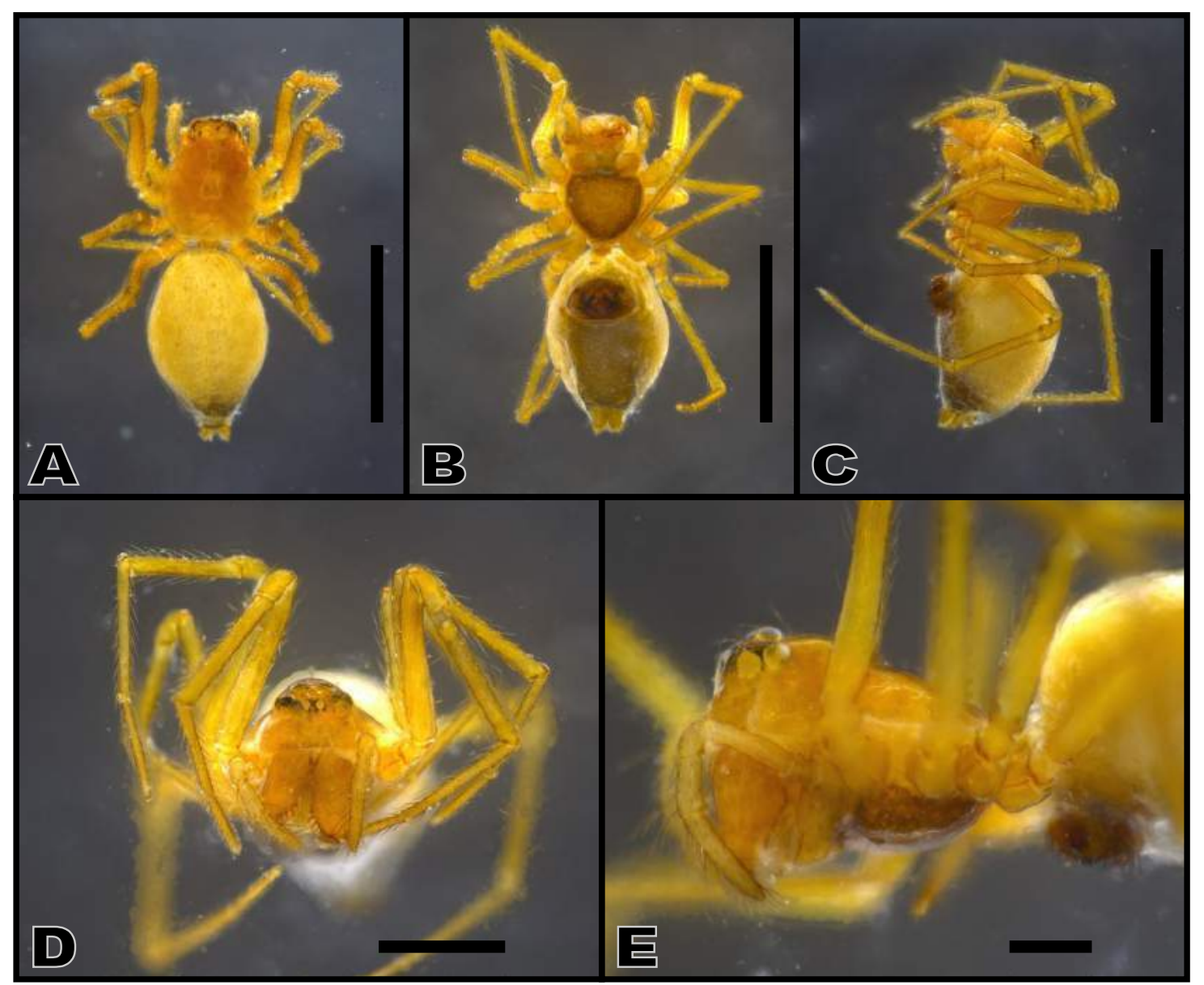

Figura 39. Hypselistoides crinitus, A-E, corpo da fêmea. A, dorsal; B, ventral; C, lateral; D, frontal; E, detalhe da região cefálica. Escala A-C, 1,0mm; D, 0,5mm; E, $0,2 \mathrm{~mm}$.

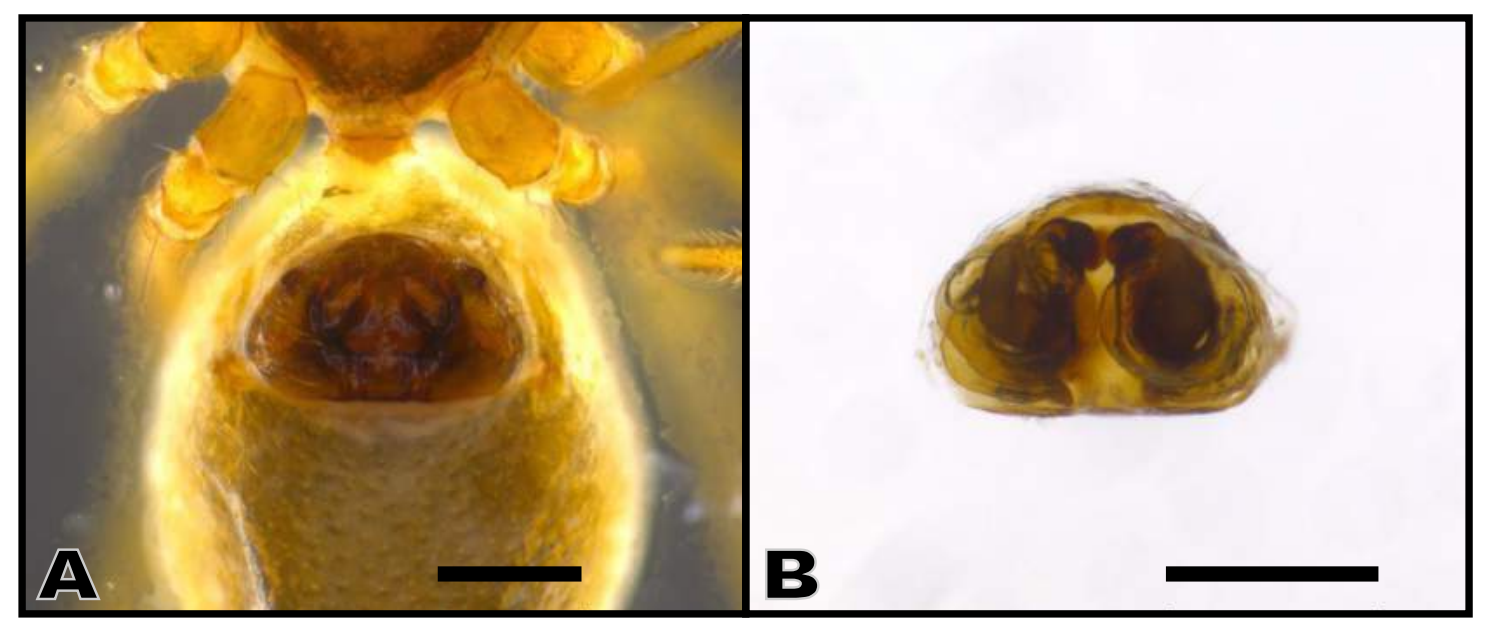

Figura 40. Hypselistoides crinitus, A-B, epígino da fêmea. A, ventral; B, dorsal. Escala $0,2 \mathrm{~mm}$ 


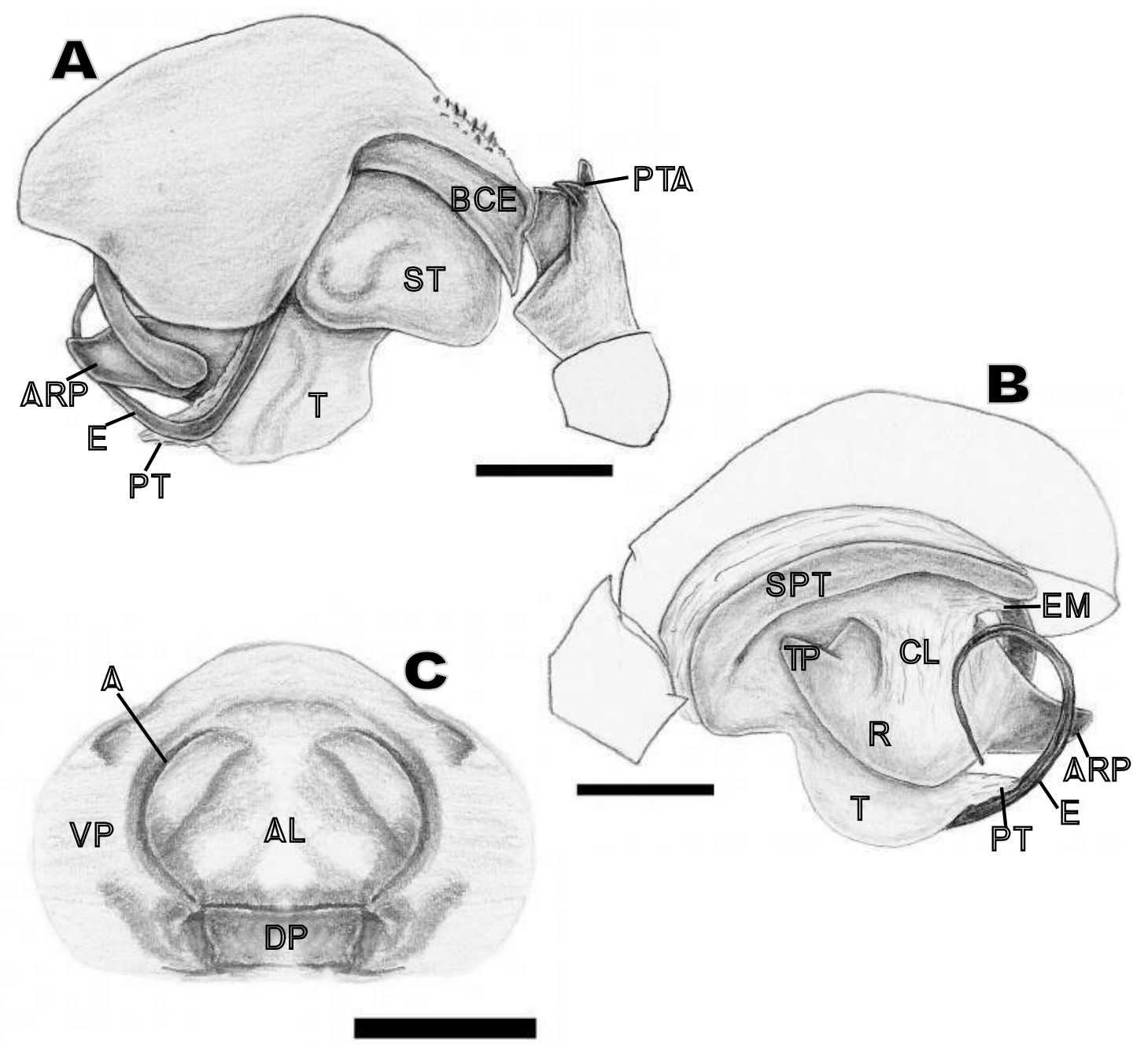

Figura 41. Hypselistoides crinitus, A-B, palpo do macho; C, epígino da fêmea. A, retrolateral; B, prolateral; C, ventral. Escala 0,1mm. A, átrio; AL, lóbulo anterior da placa dorsal do epígino; ARP, processo anterior do radix; BCE, excavação basal do címbio; CL, column; DP, placa dorsal do epígino; E, êmbolo; EM, membrana embólica; PT, protégulo; PTA, apófise prolateral da tíbia; Rradix; SPT, supratégulo; ST, subtégulo; T, tégulo; TP, cauda do radix; VP, placa ventral do epígino. 


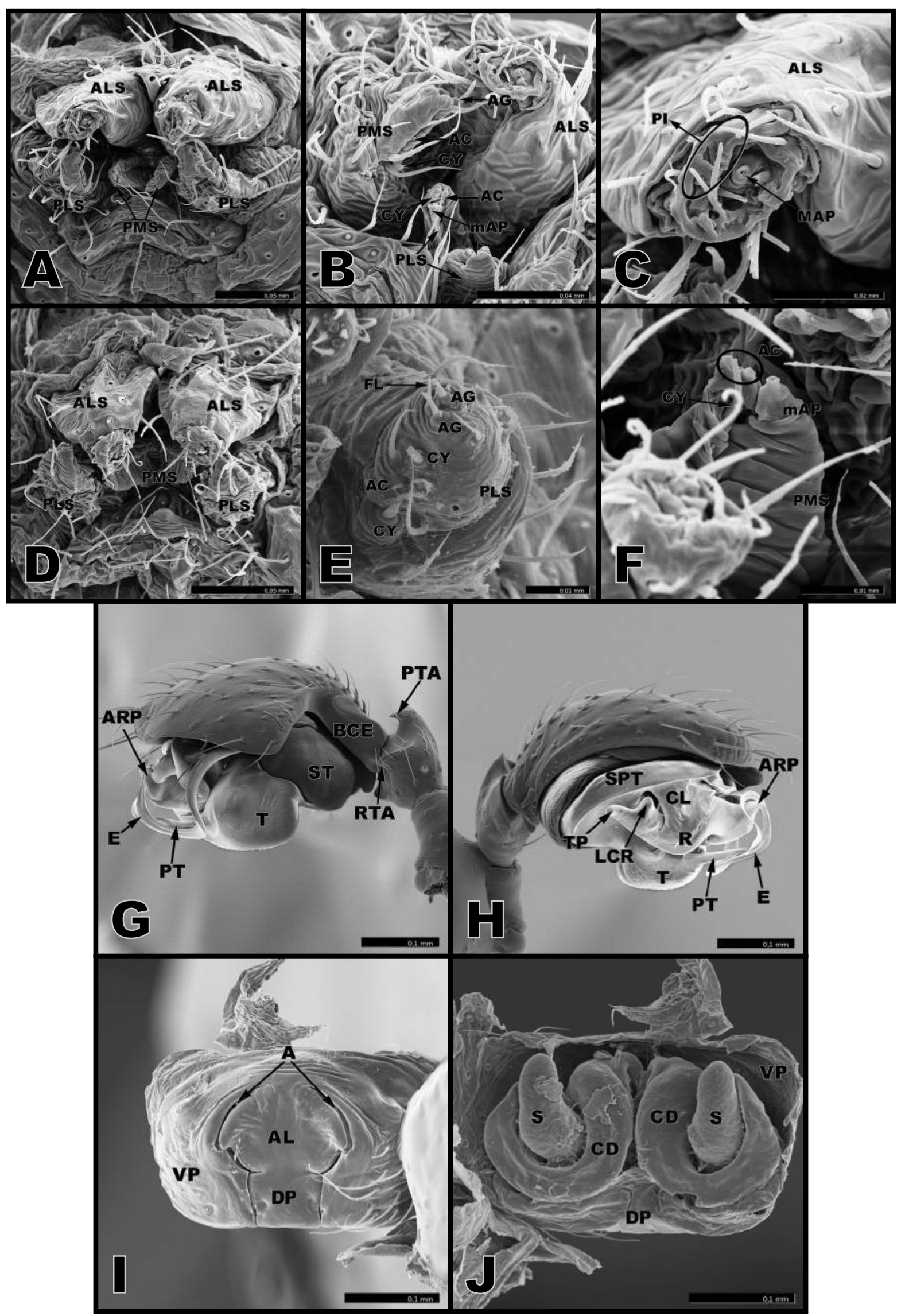

Figura 42. Hypselistoides crinitus. A-C, fiandeiras da fêmea; D-F, fiandeiras do macho; G-H, palpo do macho; I-J, epígino da fêmea. A e D, vista geral. B detalhes do PLS e PMS. C, detalhe do ALS. E, detalhe do PLS. F, detalhe do PMS. G, vista retrolateral. H, prolateral. I, vista dorsal. J, vista ventral. 


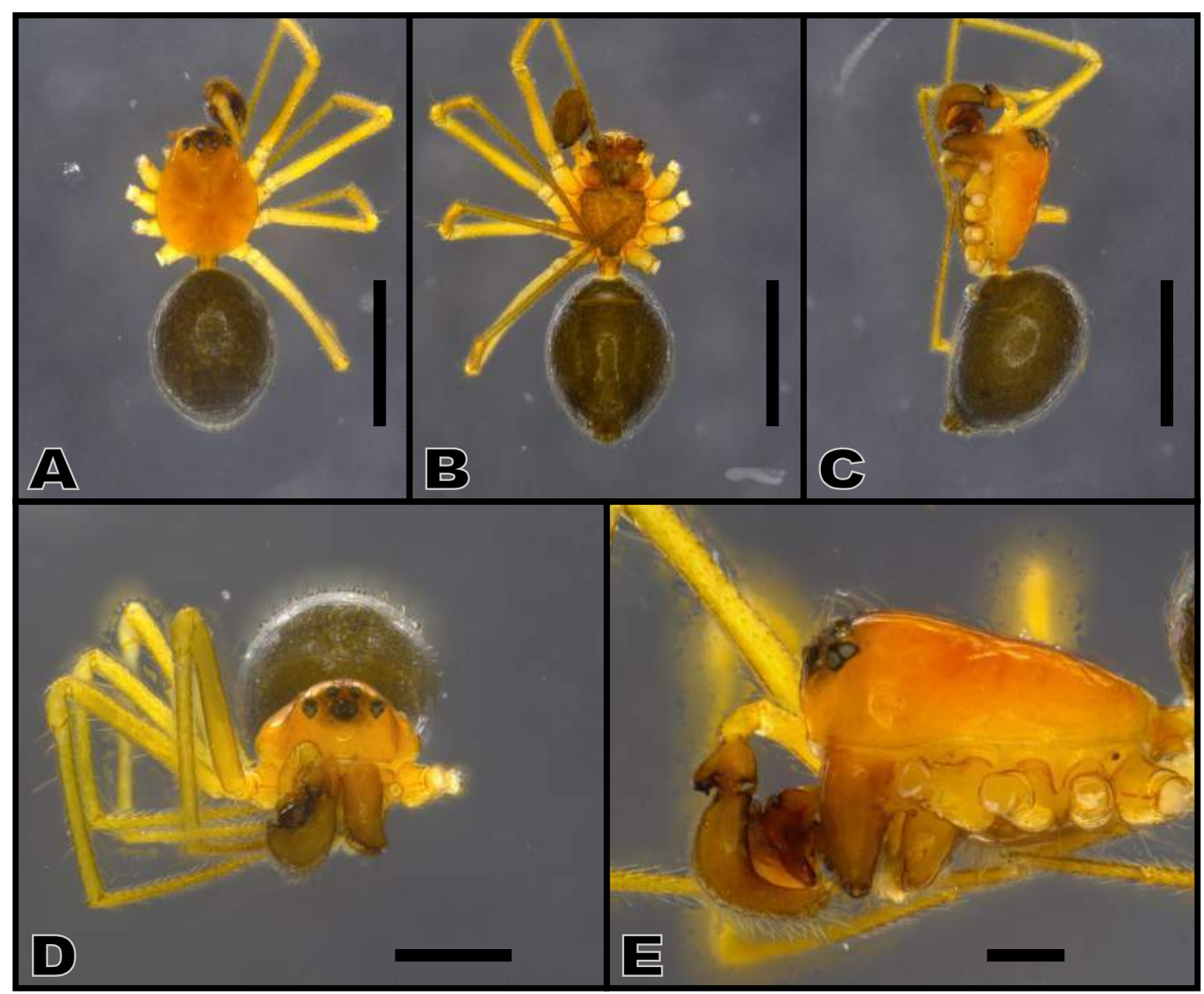

Figura 43. Hypselistoides diversicolor, A-E, corpo do macho. A, dorsal; B, ventral; C, lateral; D, frontal; E, detalhe da região cefálica. Escala A-C, 1,0mm; D, 0,5mm; E, $0,2 \mathrm{~mm}$.

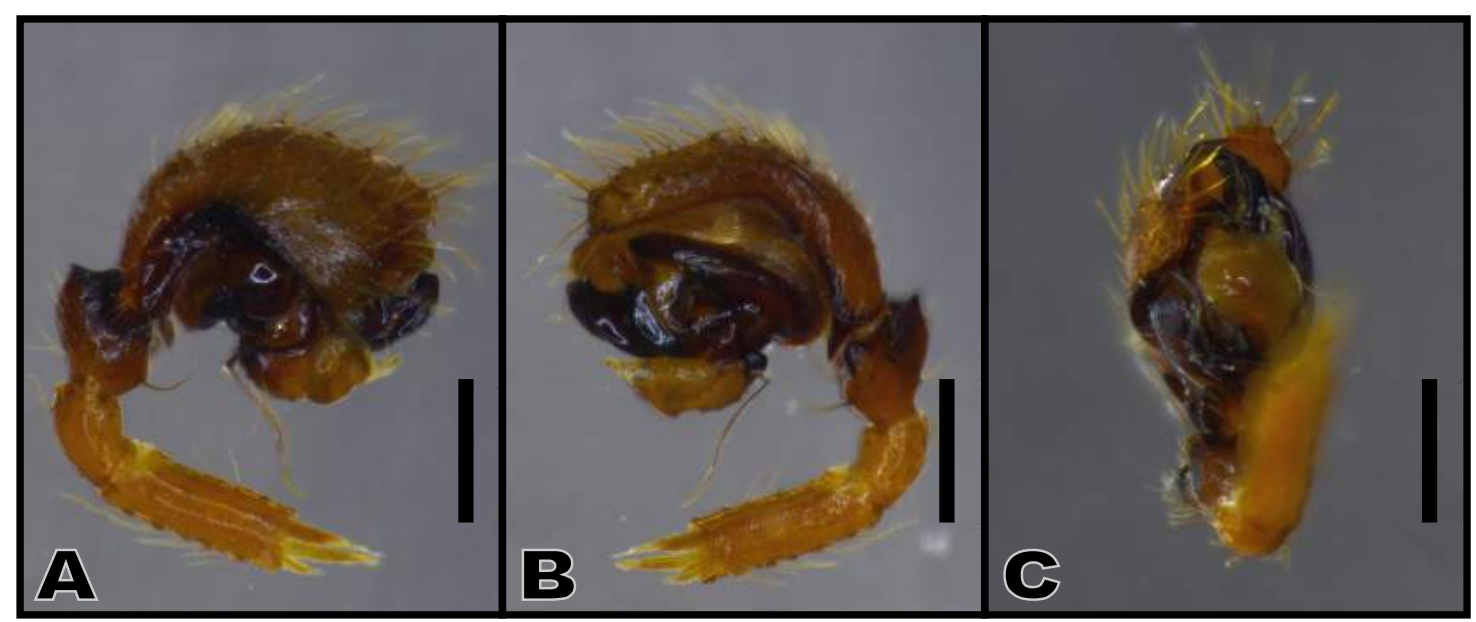

Figura 44. Hypselistoides diversicolor, A-C, palpo do macho. A, retrolateral; B, prolateral; C, ventral. Escala 0,2mm. 


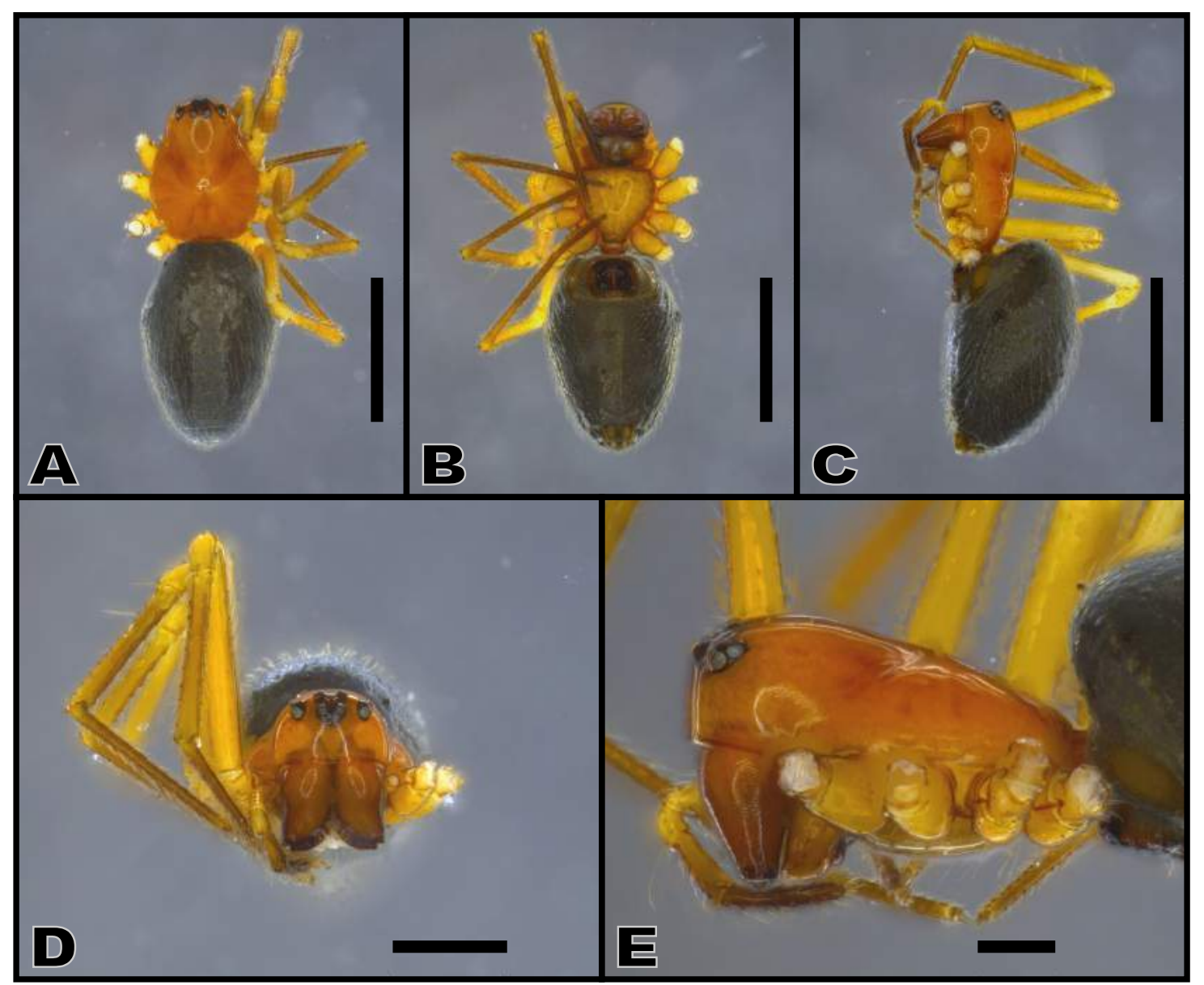

Figura 45. Hypselistoides diversicolor, A-E, corpo da fêmea. A, dorsal; B, ventral; C, lateral; D, frontal; E, detalhe da região cefálica. Escala A-C, 1,0mm; D, 0,5mm; E, $0,2 \mathrm{~mm}$.

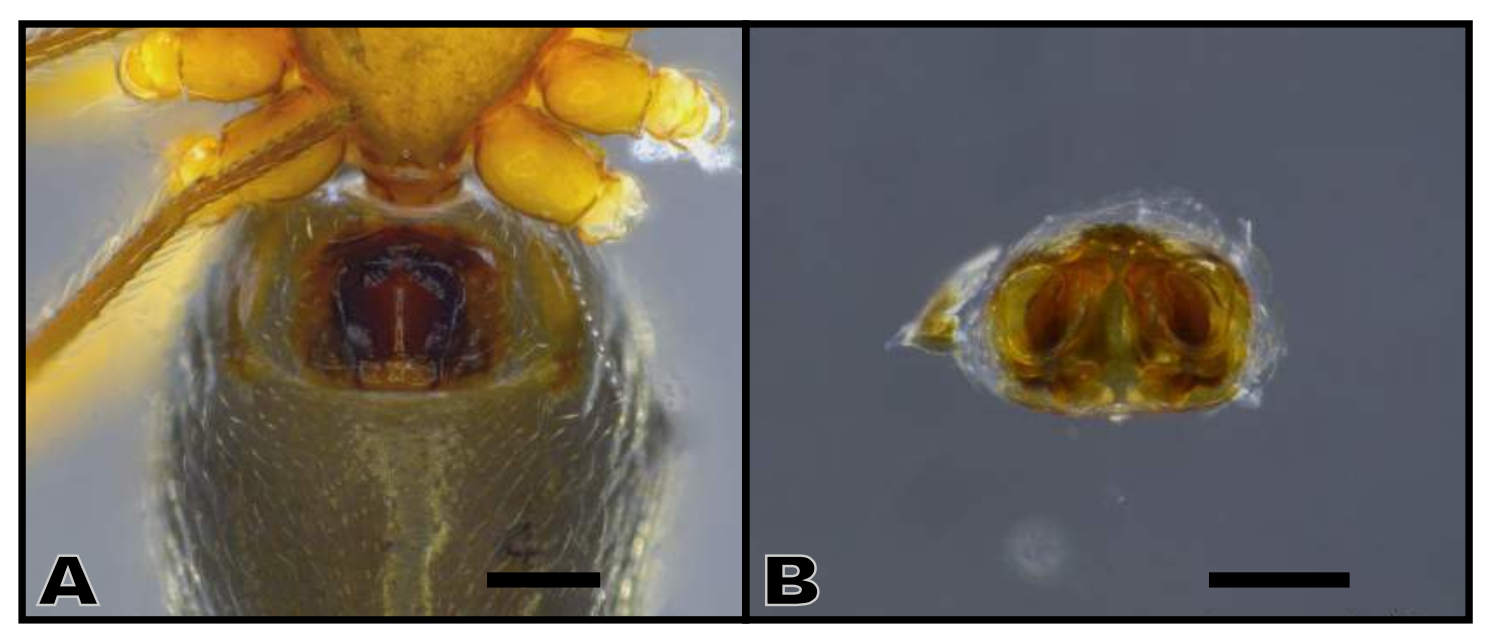

Figura 46. Hypselistoides diversicolor, A-B, epígino da fêmea. A, ventral; B, dorsal. Escala 0,2mm. 

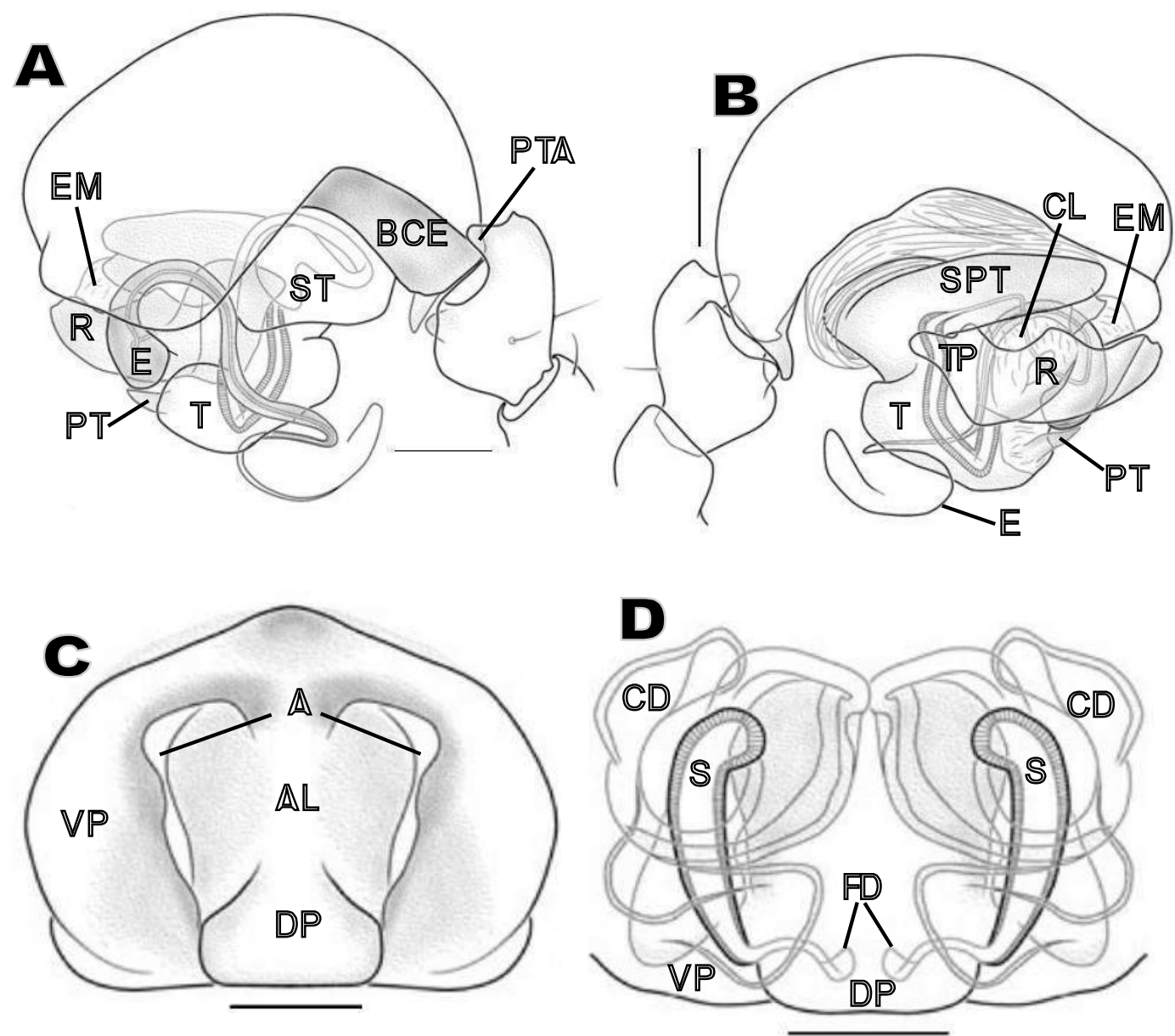

Figura 47. Hypselistoides diversicolor, A-B, palpo do macho; C-D, epígino da fêmea. A, retrolateral; B, prolateral; C, ventral; D, dorsal. Escala 0,1mm. A, átrio; AL, lóbulo anterior da placa dorsal do epígino; BCE, cavidade basal do címbio; CD, duto de copulação; CL, column; DP, placa dorsal do epígino; E, êmbolo; EM, membrana embólica; FD, duto de fertilização; PT, protégulo; PTA, apófise prolateral da tíbia; R, radix; S, espermateca; SPT, supratégulo; ST, subtégulo; T, tégulo; TP, cauda do radix; VP, placa ventral do epígino. Ilustração de Miller, 2007. 


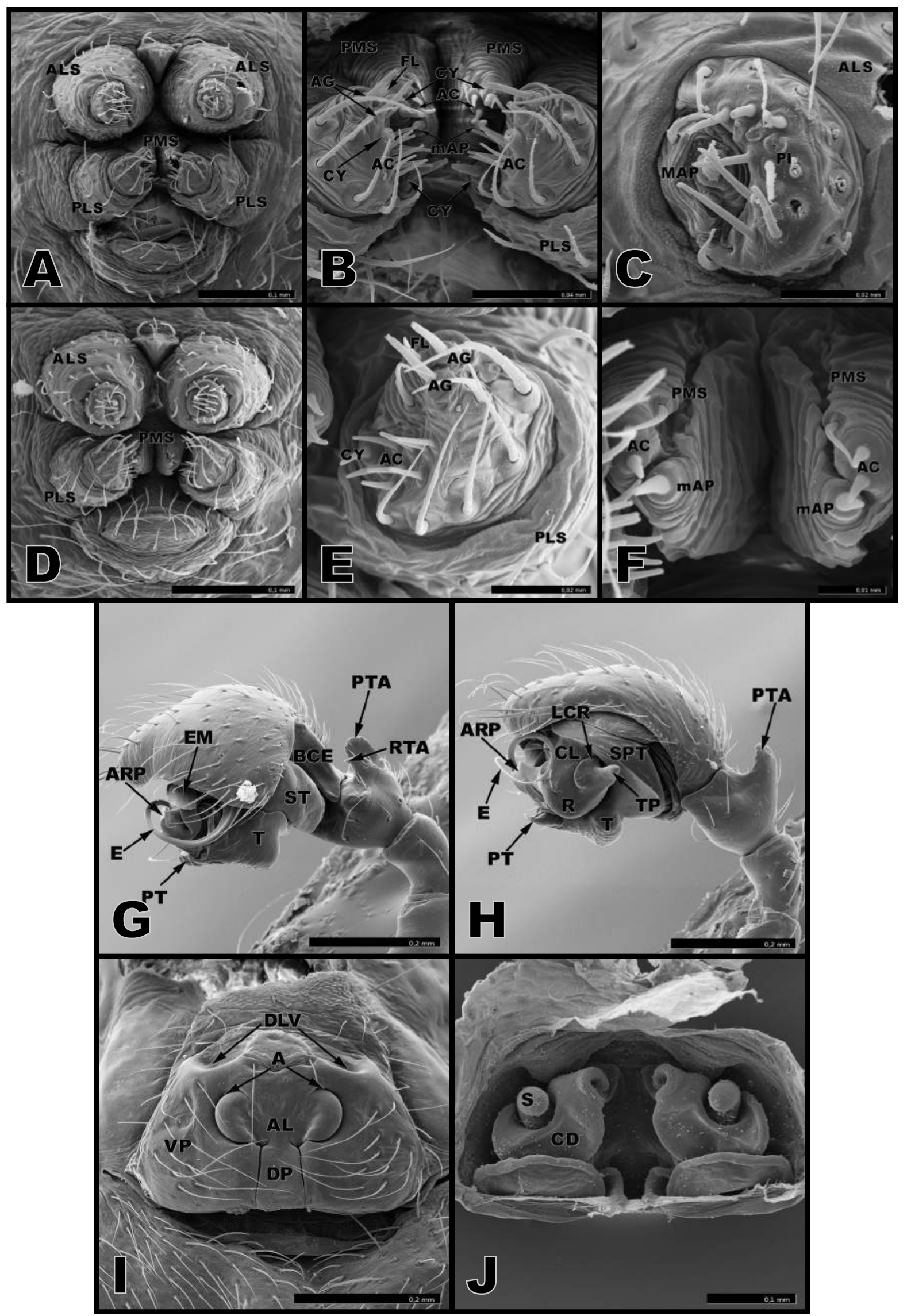

Figura 48. Hypselistoides diversicolor. A-C, fiandeiras da fêmea; D-F, fiandeiras do macho; G-H, palpo do macho; I-J, epígino da fêmea. A e D, vista geral. B, detalhes do PLS e PMS. C, detalhe do ALS. E, detalhe do PLS. F, detalhe do PMS. G, vista retrolateral. H, prolateral. I, vista dorsal. J, vista ventral. 


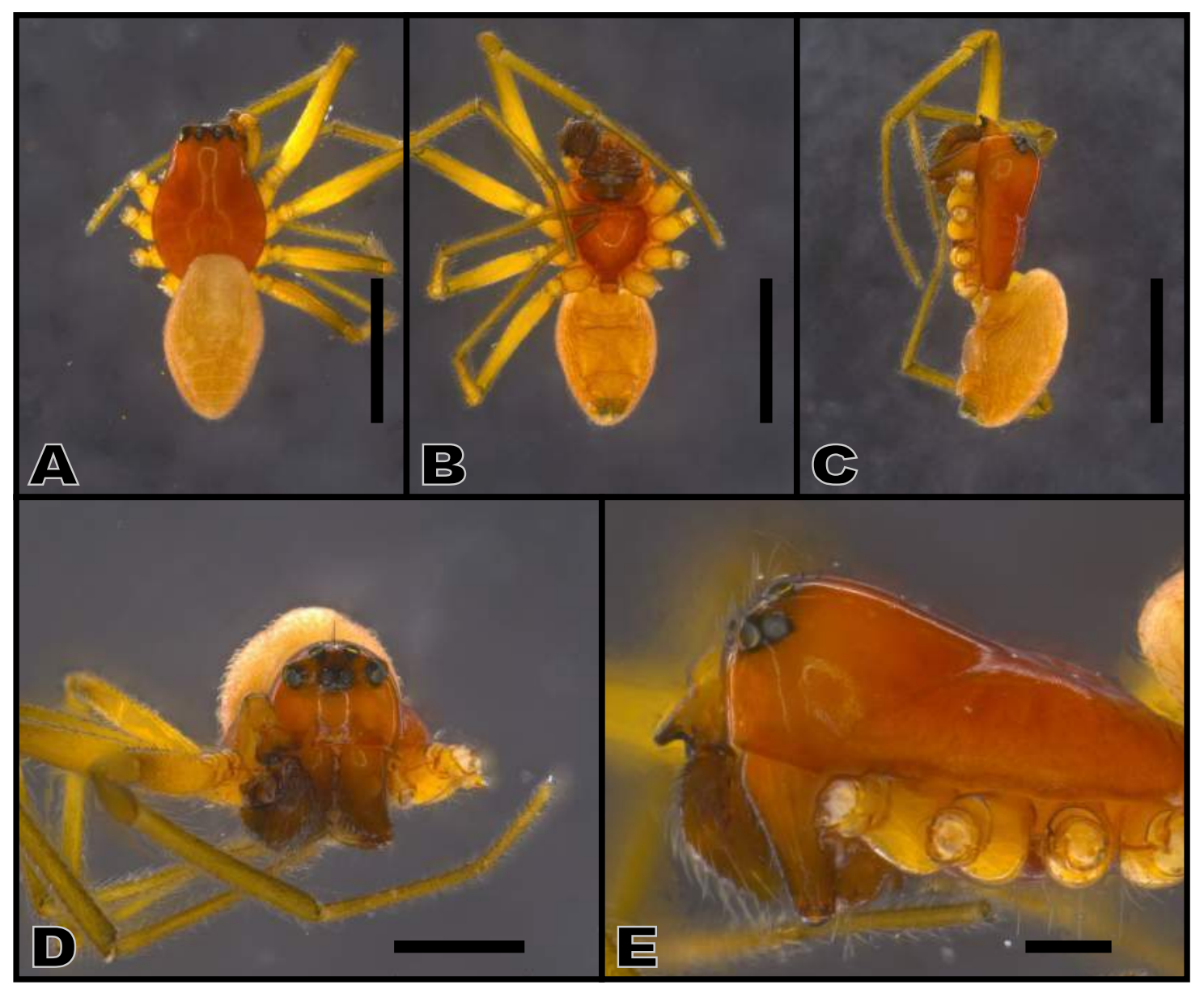

Figura 49. Hypselistoides ignigenus, A-E, corpo do macho. A, dorsal; B, ventral; C, lateral; D, frontal; E, detalhe da região cefálica. Escala A-C, 1,0mm; D, 0,5mm; E, $0,2 \mathrm{~mm}$.

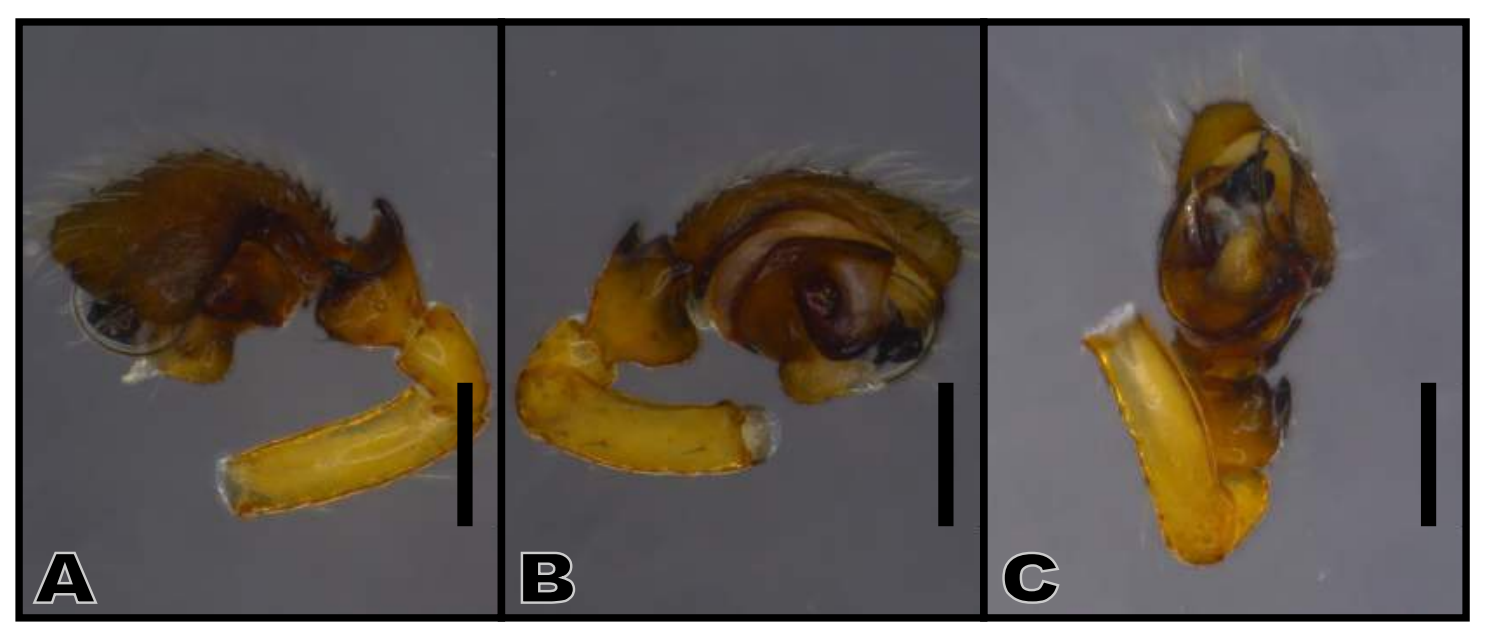

Figura 50. Hypselistoides ignigenus, A-C, palpo do macho. A, retrolateral; B, prolateral; C, ventral. Escala 0,2mm. 


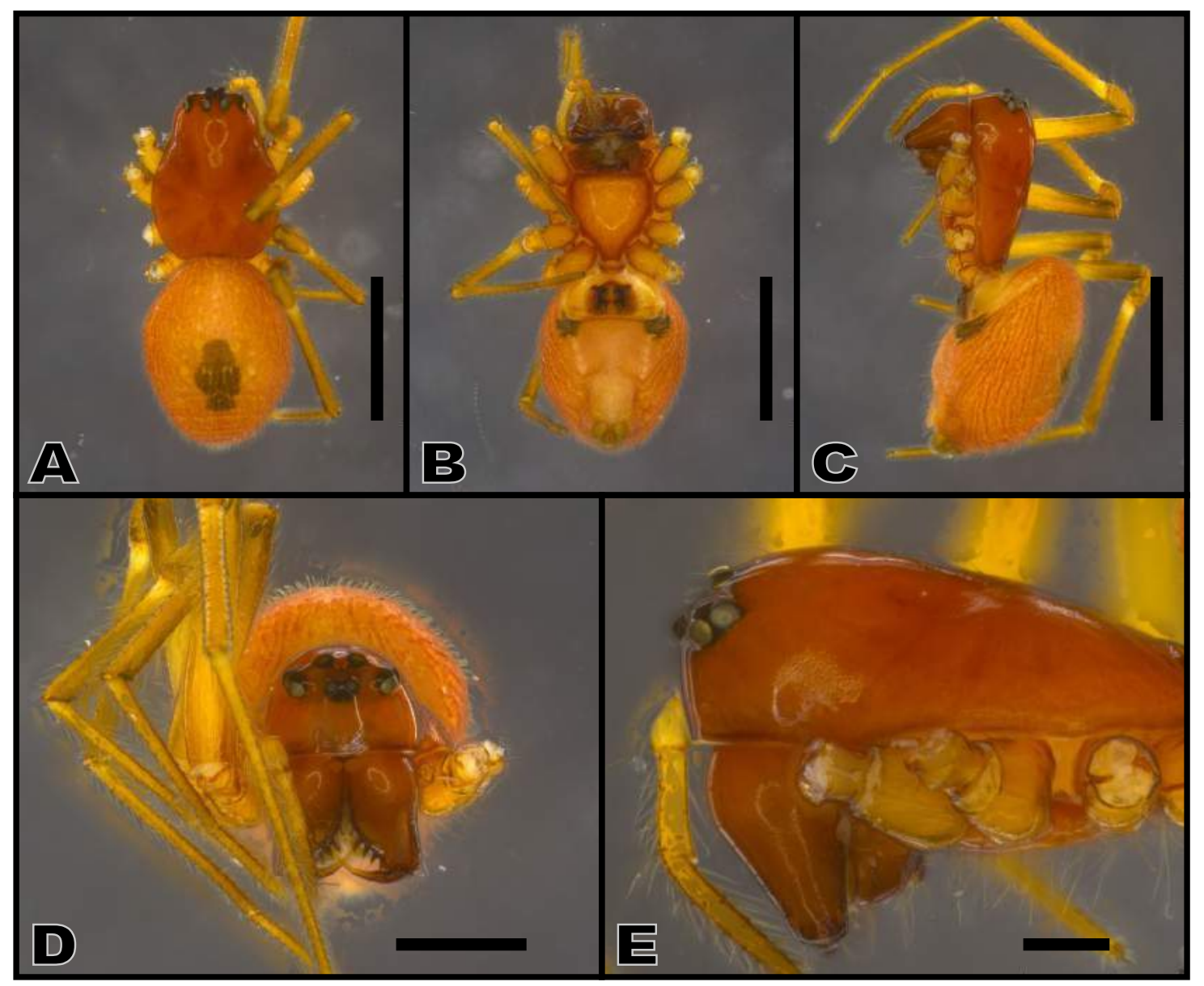

Figura 51. Hypselistoides ignigenus, A-E, corpo da fêmea. A, dorsal; B, ventral; C, lateral; D, frontal; E, detalhe da região cefálica. Escala A-C, 1,0mm; D, 0,5mm; E, $0,2 \mathrm{~mm}$.

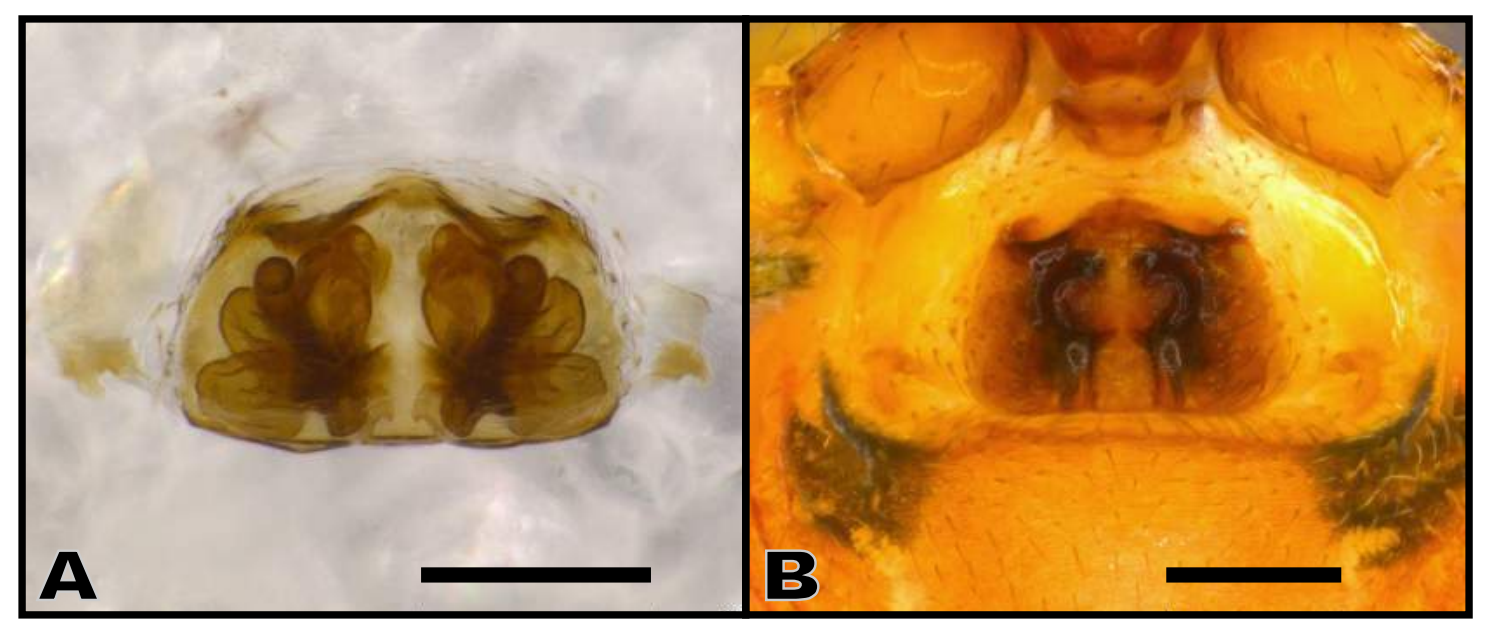

Figura 52. Hypselistoides ignigenus, A-B, epígino da fêmea. A, ventral; B, dorsal. Escala 0,2mm. 

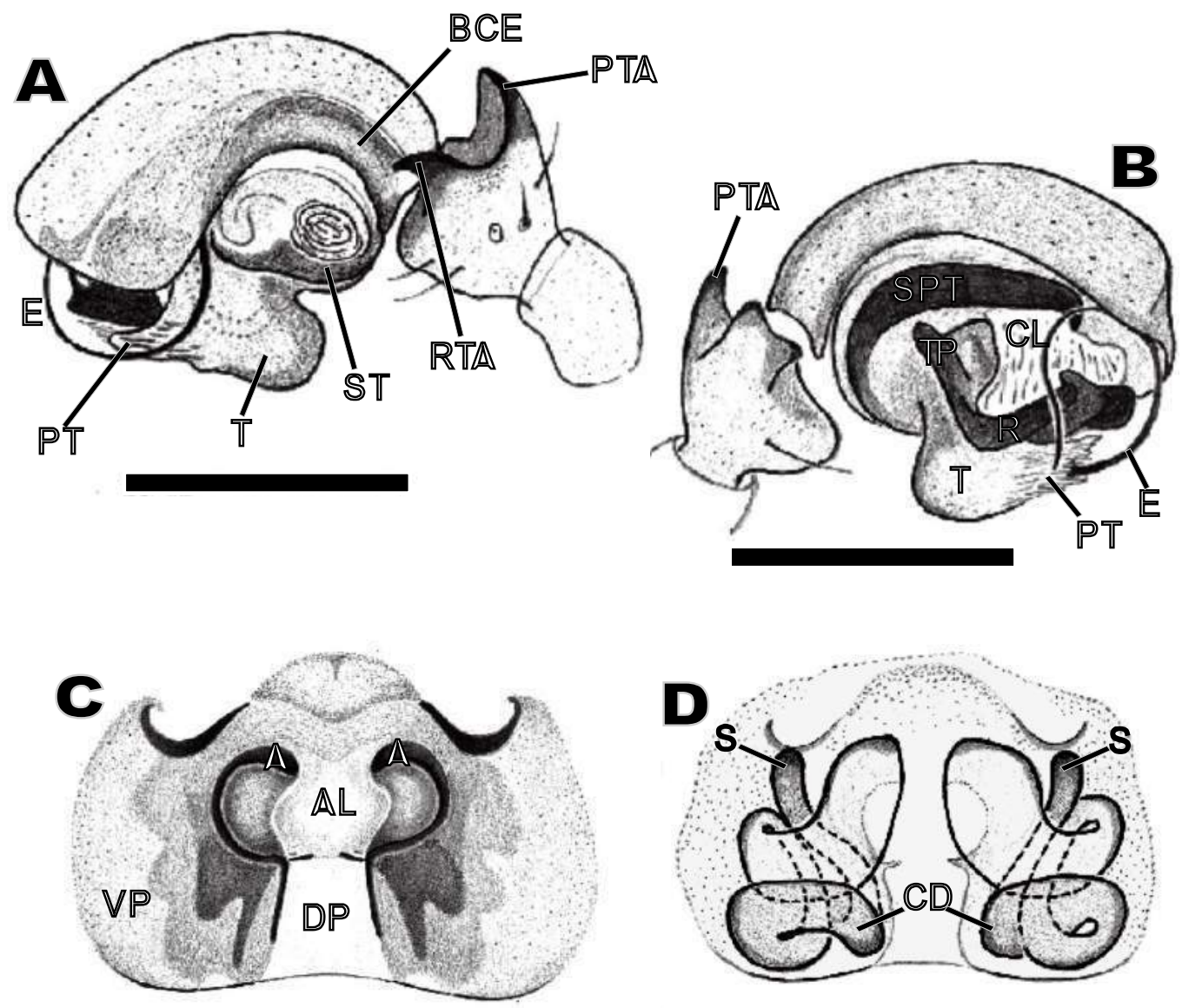

Figura 53. Hypselistoides ignigenus, A-B, palpo do macho; C, epígino da fêmea. A, retrolateral; B, prolateral; C, ventral. Escala 0,25mm. A, átrio; AL, lóbulo anterior da placa dorsal do epígino; BCE, excavação basal do címbio; CD, duto de copulação; CL, column; DP, placa dorsal do epígino; E, êmbolo; PT, protégulo; PTA, apófise prolateral da tíbia; R, radix; RTA, apófise retrolateral da tíbia; S, espermateca; SPT, supratégulo; ST, subtégulo; TP, cauda do radix; T, tégulo; VP, placa ventral do epígino. Ilustração de Rodrigues, 2005. 


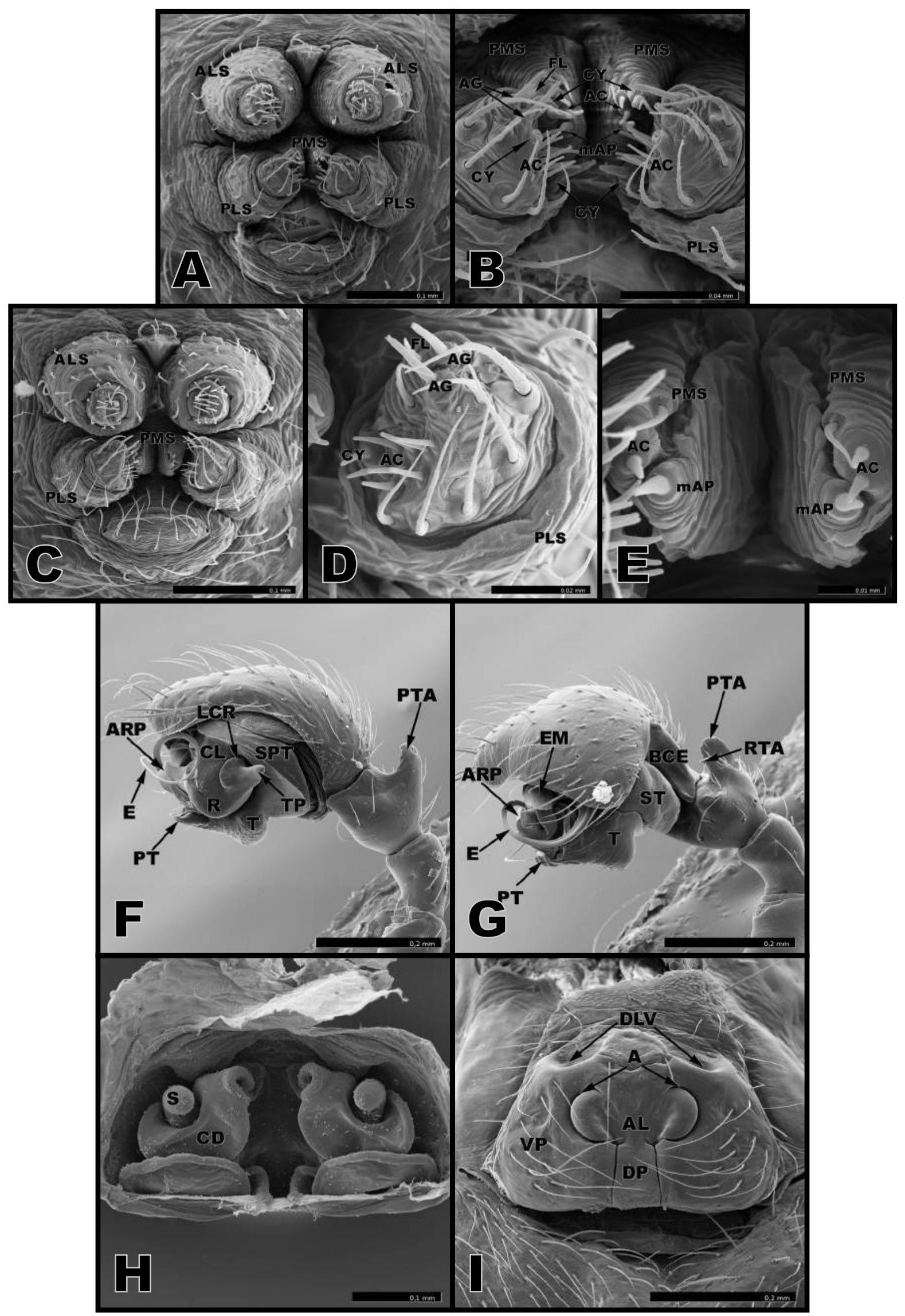

Figura 54. Hypselistoides ignigenus. $\mathrm{A}-\mathrm{B}$, fiandeiras da fêmea; $\mathrm{C}-\mathrm{E}$, fiandeiras do macho; $\mathrm{F}-\mathrm{G}$, palpo do macho; $\mathrm{H}-\mathrm{I}$, epígino da fêmea. A e C, vista geral. $\mathrm{B}$, detalhe dos PLS e PMS. D, detalhe do PLS. E, detalhe do PMS. F, vista retrolateral. G, vista prolateral. H, vista dorsal. I vista ventral. 


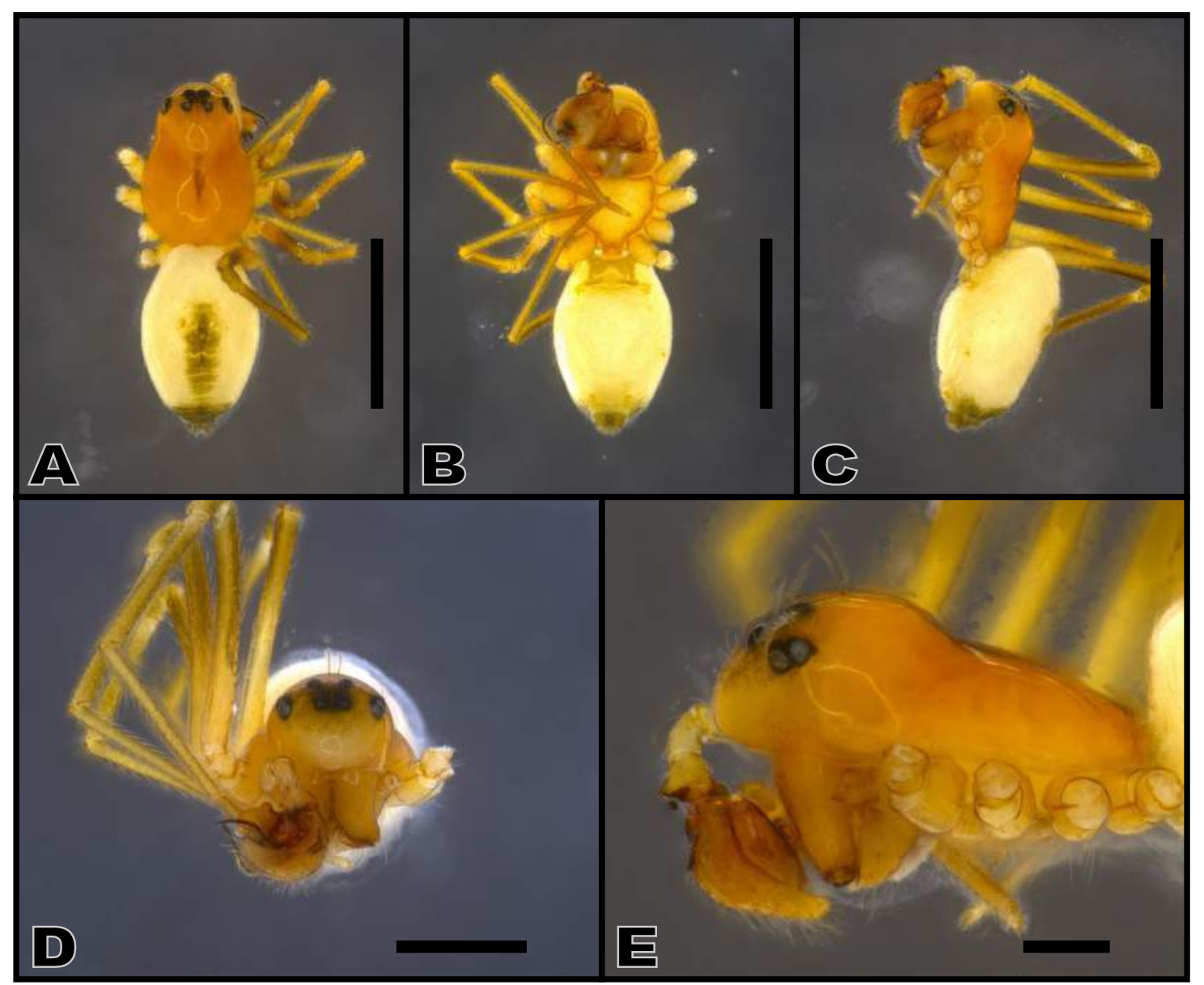

Figura 55. Hypselistoides labiatus, A-E, corpo do macho. A, dorsal; B, ventral; C, lateral; D, frontal; E, detalhe da região cefálica. Escala A-C, 1,0mm; D, 0,5mm; E, $0,2 \mathrm{~mm}$.

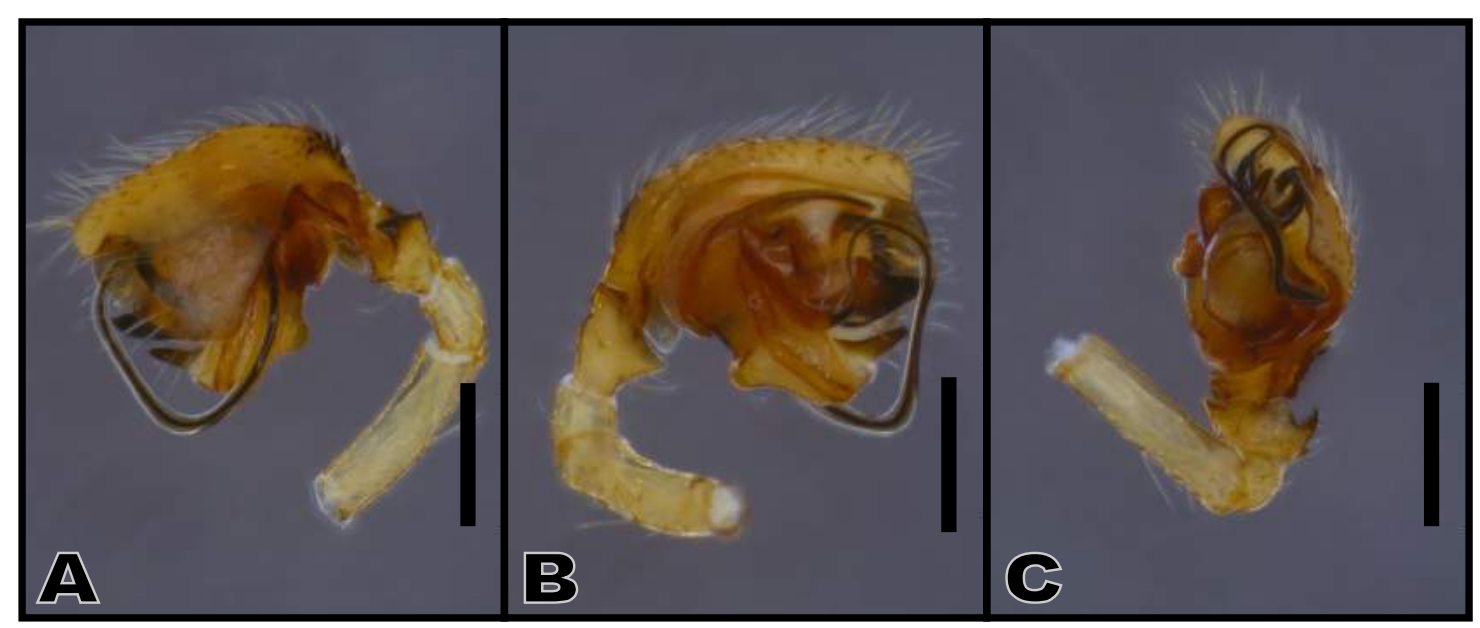

Figura 56. Hypselistoides labiatus, A-C, palpo do macho. A, retrolateral; B, prolateral; C, ventral. Escala 0,2mm. 


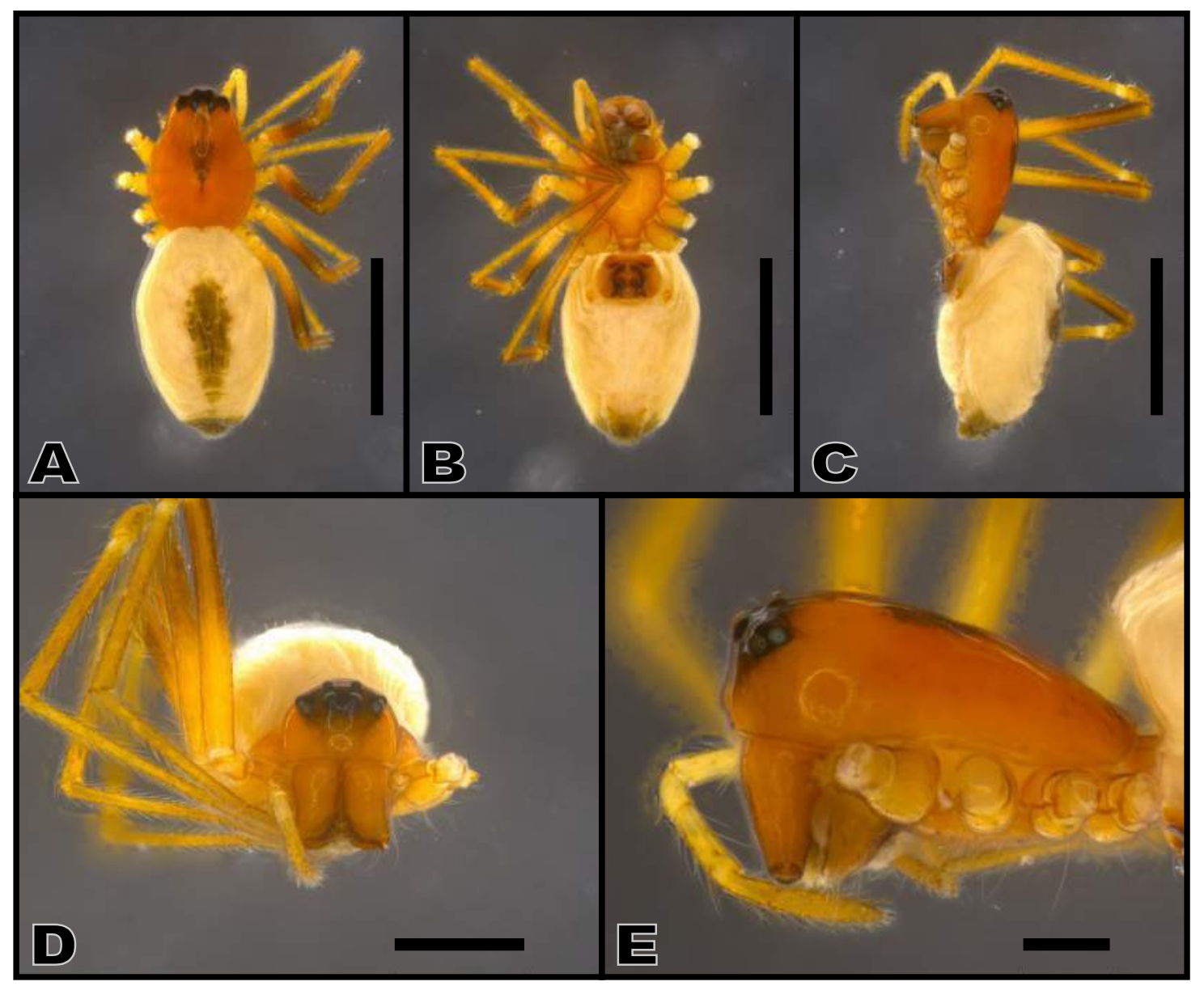

Figura 57. Hypselistoides labiatus, A-E, corpo da fêmea. A, dorsal; B, ventral; C, lateral; D, frontal; E, detalhe da região cefálica. Escala A-C, 1,0mm; D, 0,5mm; E, $0,2 \mathrm{~mm}$.

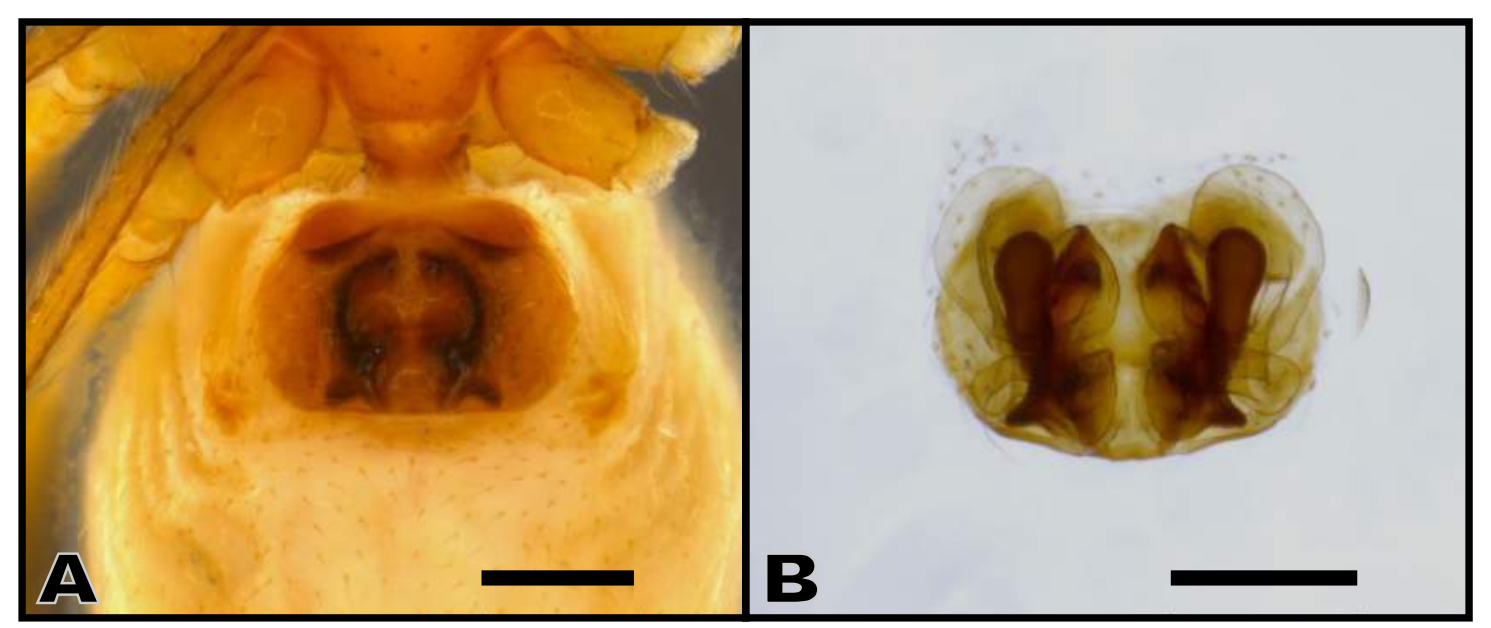

Figura 58. Hypselistoides labiatus, A-B, epígino da fêmea. A, ventral; B, dorsal. Escala $0,2 \mathrm{~mm}$ 

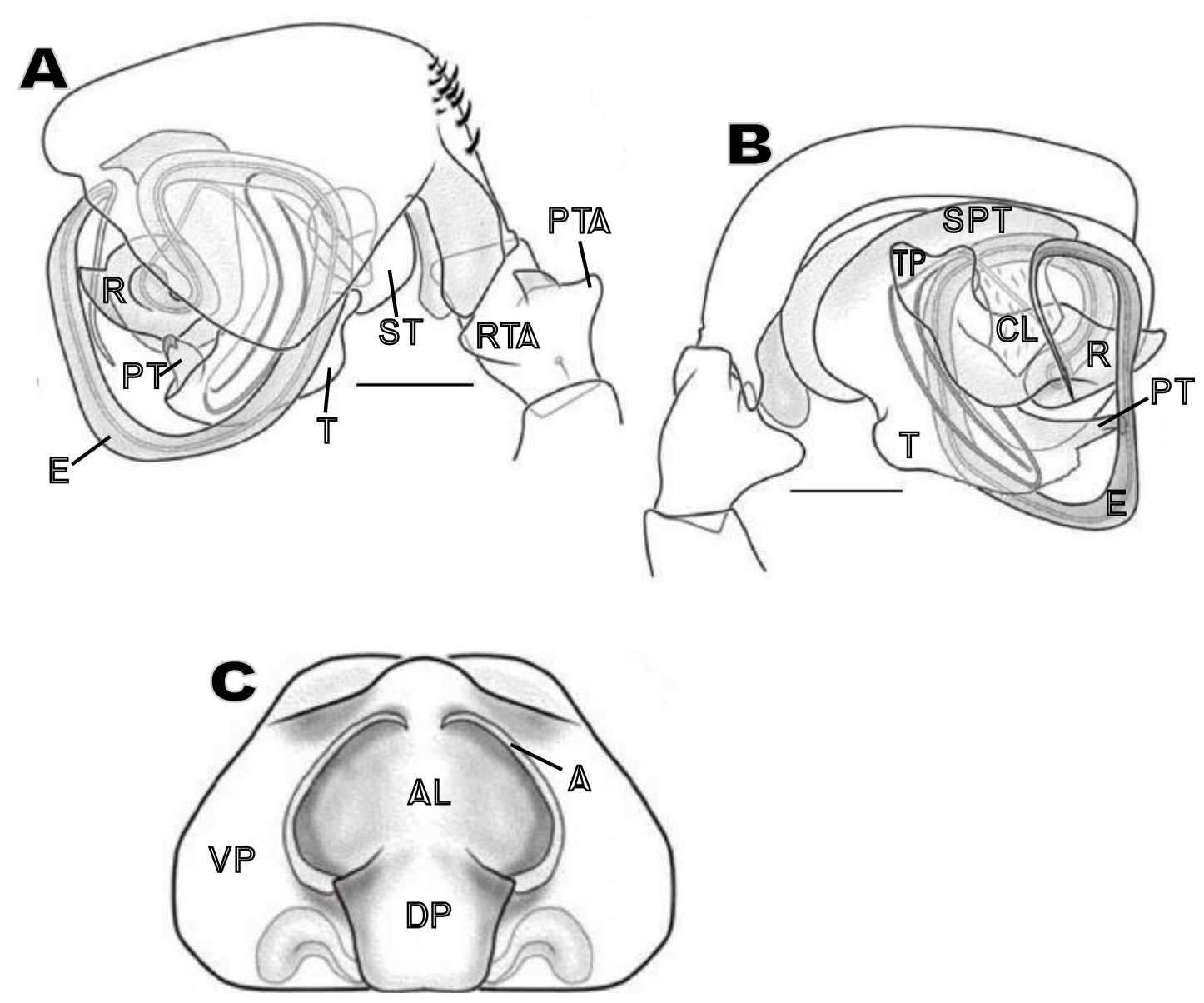

Figura 59. Hypselistoides labiatus, A-B, palpo do macho; C, epígino da fêmea. A, retrolateral; B, prolateral; C, ventral. Escala 0,1mm. A, átrio; AL, lóbulo anterior da placa dorsal do epígino; CL, column; DP, placa dorsal do epígino; E, êmbolo; PT, protégulo; PTA, apófise prolateral da tíbia; R, radix; RTA, apófise retrolateral da tíbia; SPT, supratégulo; ST, subtégulo; T, tégulo; TP, cauda do radix; VP, placa ventral do epígino. Ilustração de Miller, 2007. 


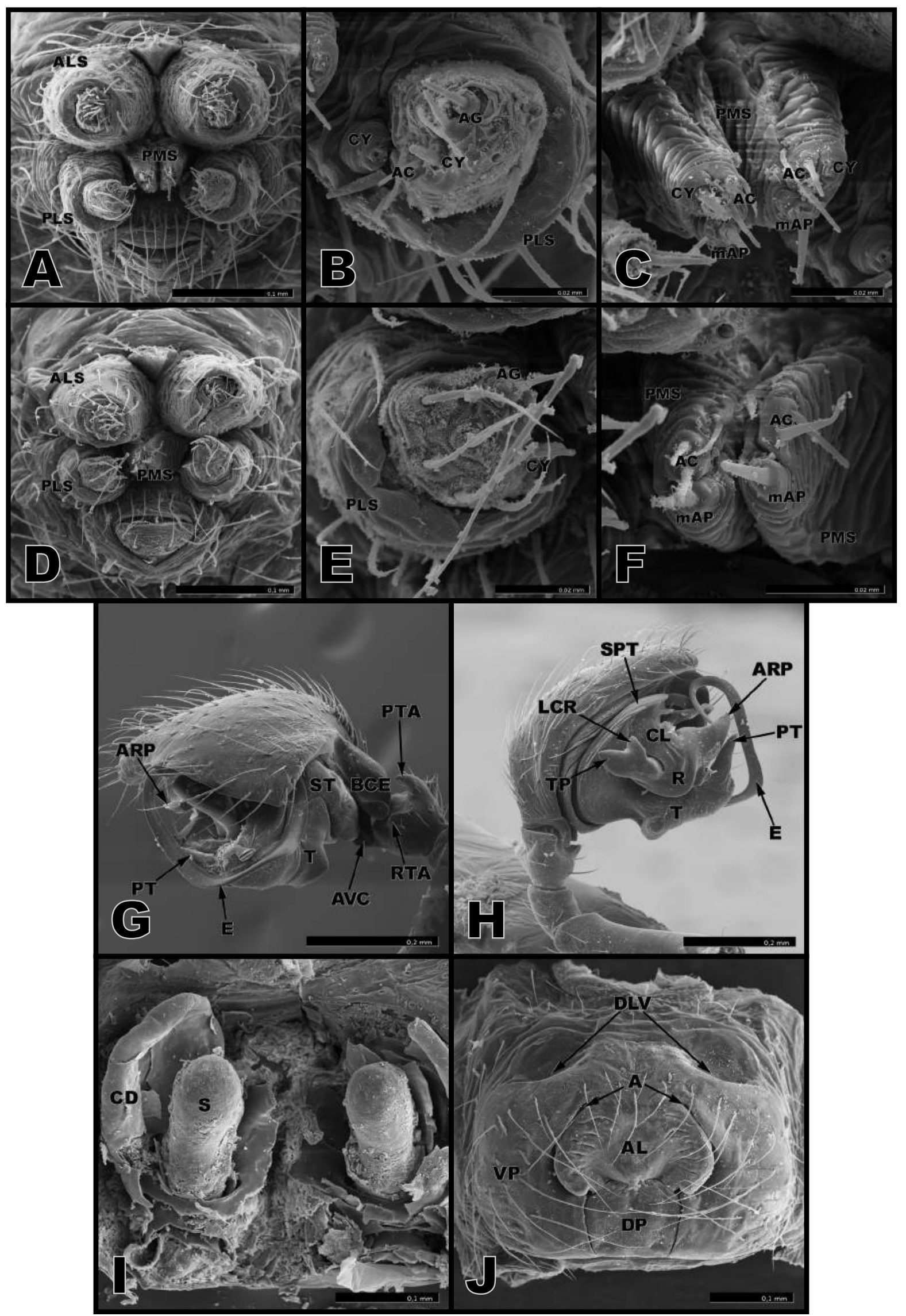

Figura 60. Hypselistoides labiatus. A-C, fiandeiras da fêmea; D-F, fiandeiras do macho; G-H, palpo do macho; I-J, epígino da fêmea. A e D, vista geral. B e E, detalhe do PLS. C e F, detalhe do PMS. G, vista retrolateral. H, vista prolateral. I, vista dorsal. J vista ventral. 


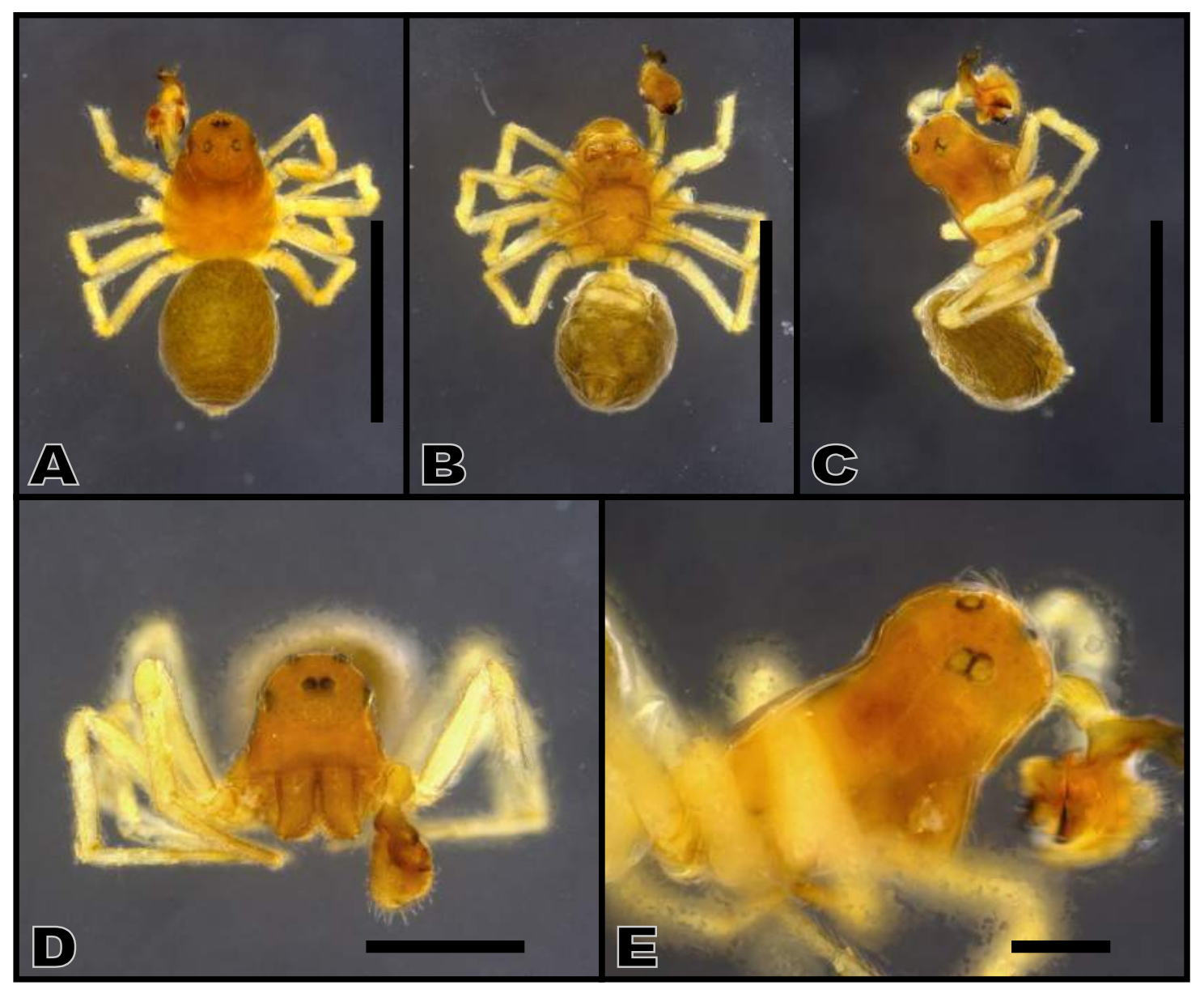

Figura 61. Hypselistoides lobatus, A-E, corpo do macho. A, dorsal; B, ventral; C, lateral; D, frontal; E, detalhe da região cefálica. Escala A-C, 1,0mm; D, 0,5mm; E, $0,2 \mathrm{~mm}$.

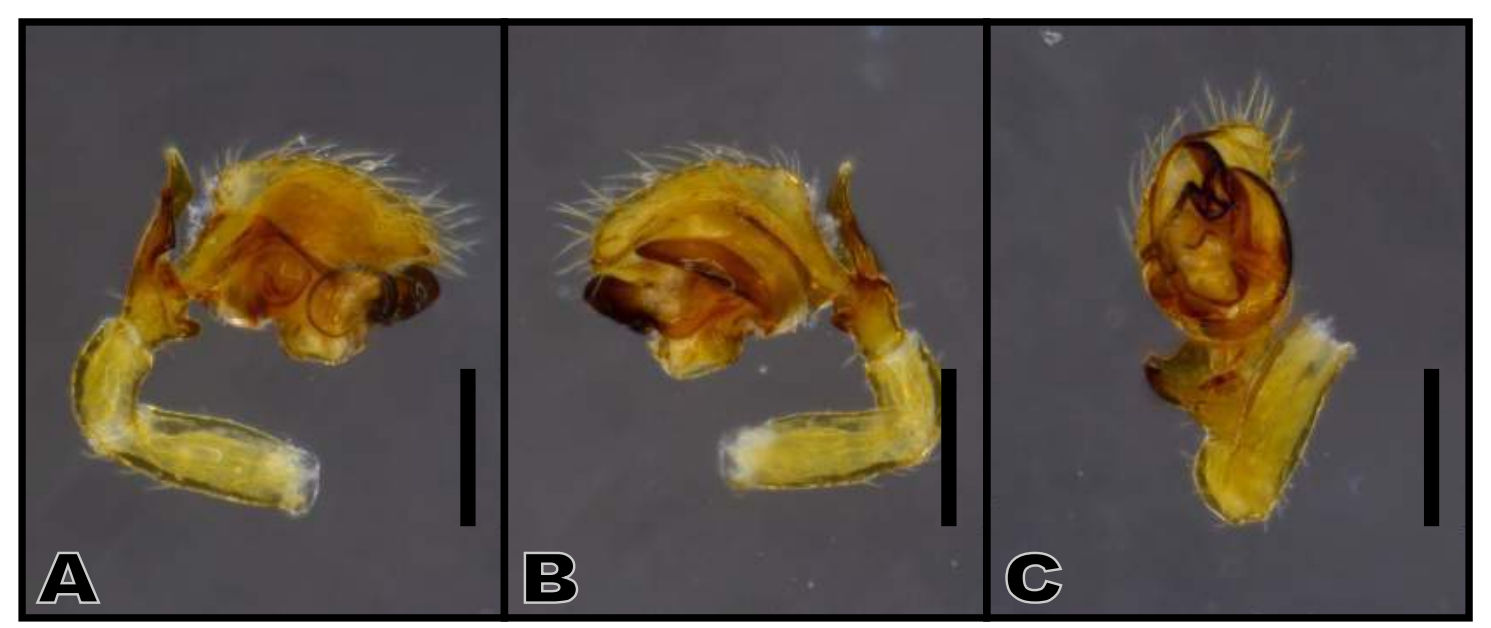

Figura 62. Hypselistoides lobatus, A-C, palpo do macho. A, retrolateral; B, prolateral; C, ventral. Escala 0,2mm. 


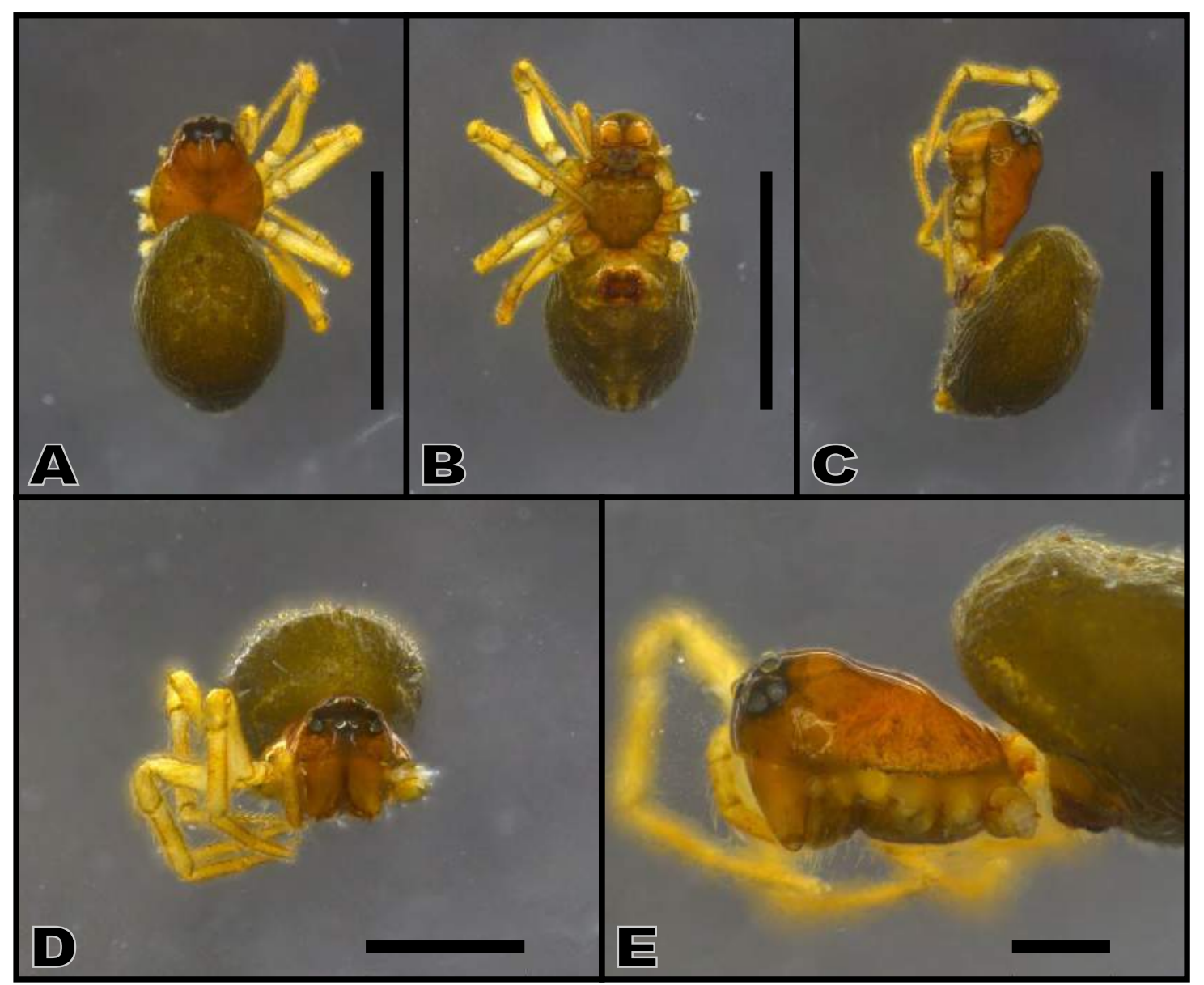

Figura 63. Hypselistoides lobatus, A-E, corpo da fêmea. A, dorsal; B, ventral; C, lateral; D, frontal; E, detalhe da região cefálica. Escala A-C, 1,0mm; D, 0,5mm; E, $0,2 \mathrm{~mm}$.

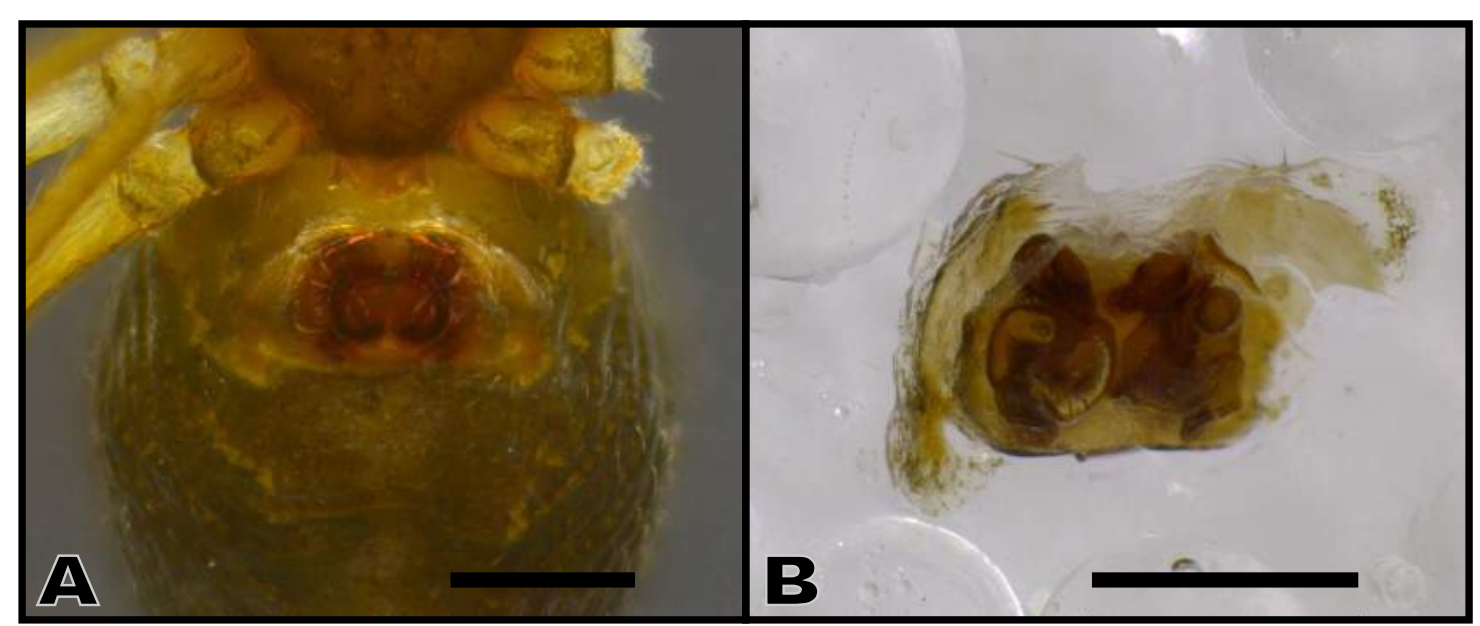

Figura 64. Hypselistoides lobatus, A-B, epígino da fêmea. A, ventral; B, dorsal. Escala $0,2 \mathrm{~mm}$ 


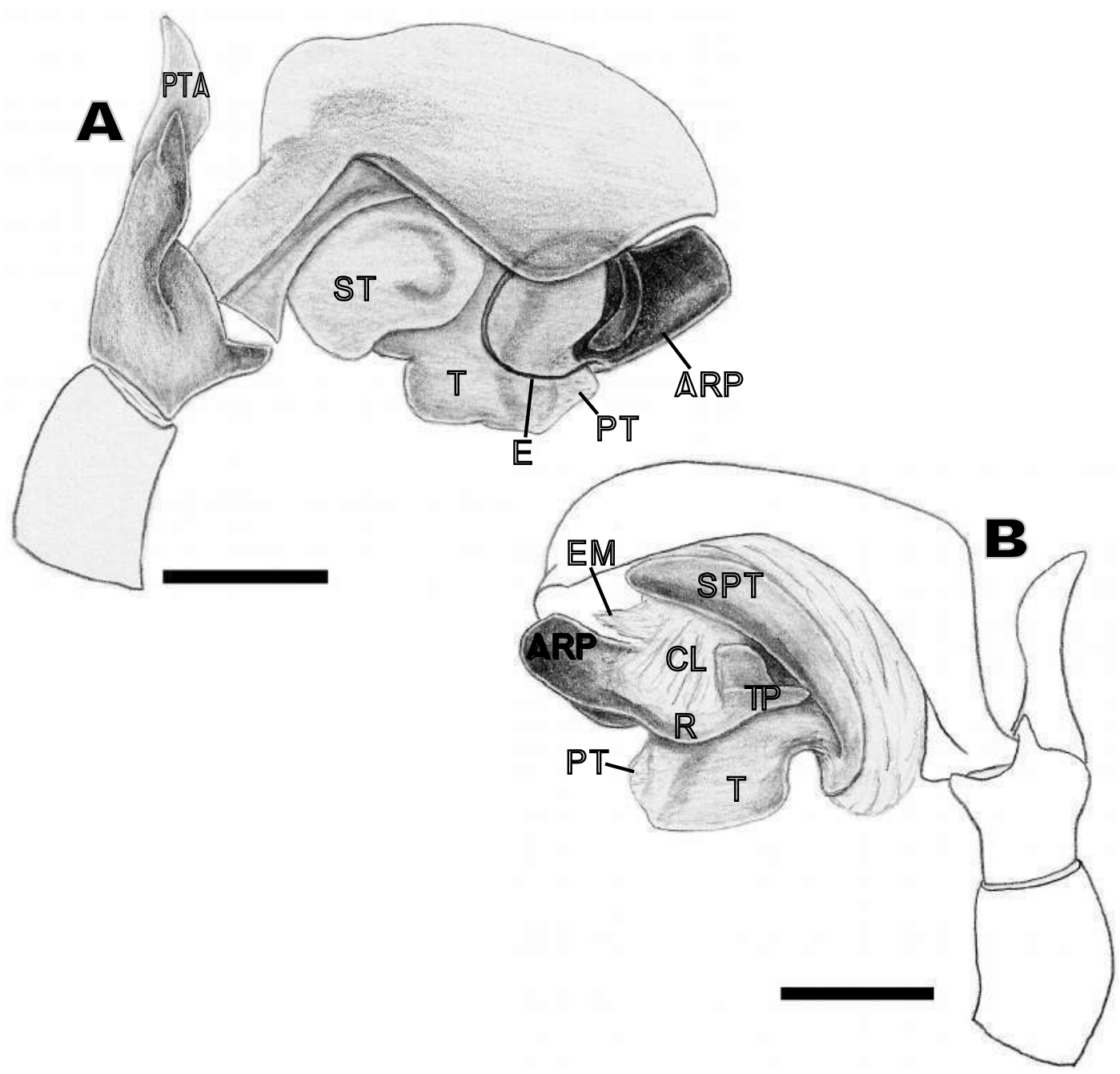

Figura 65. Hypselistoides lobatus, A-B, palpo do macho. A, retrolateral; B, prolateral. Escala 0,1mm. ARP, processo anterior do radix; CL, column; E, êmbolo; EM, membrana embólica; PT, protégulo; PTA, apófise prolateral da tíbia; R, radix; SPT, supratégulo; ST, subtégulo; T, tégulo; TP, cauda do radix. 


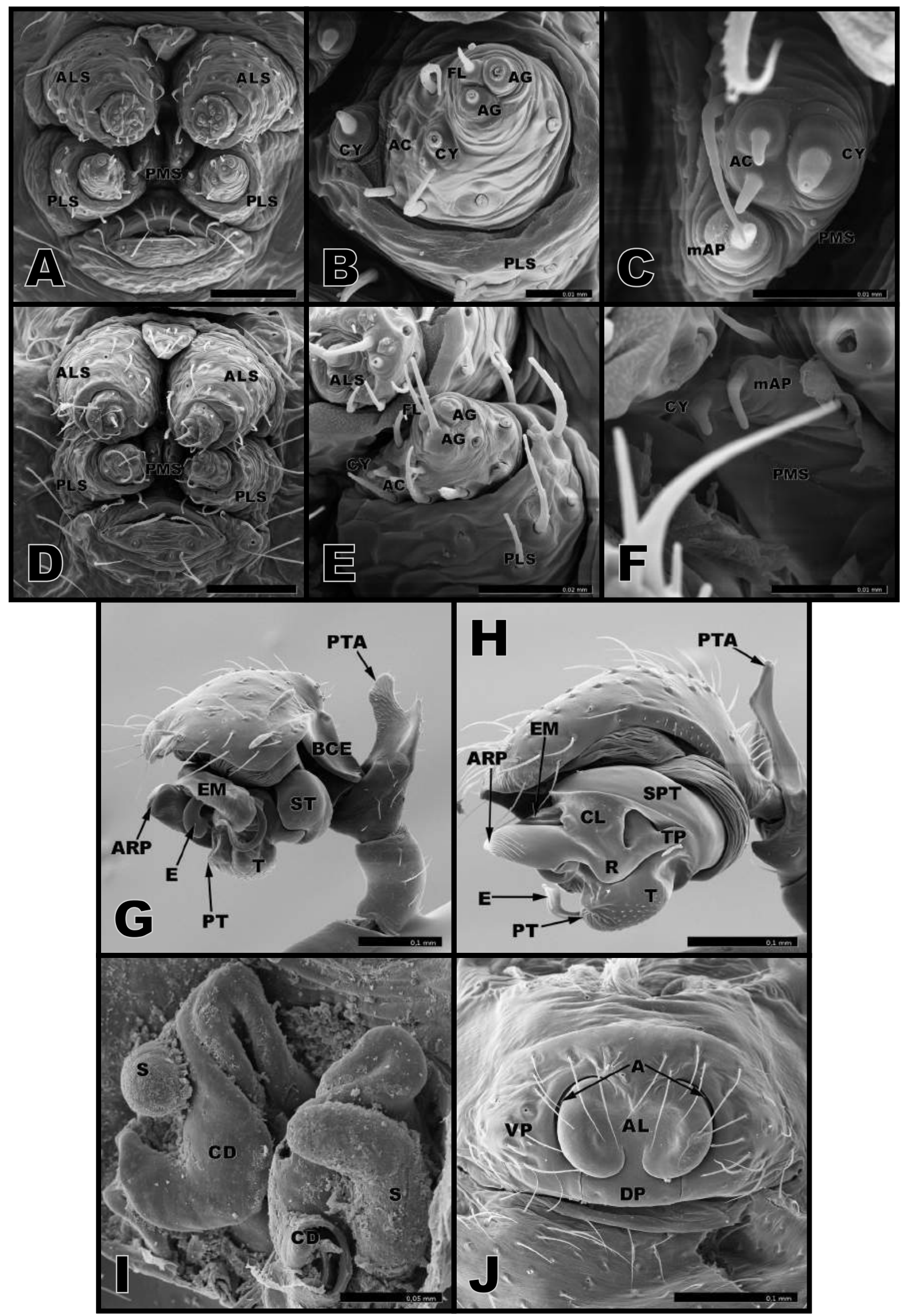

Figura 66. Hypselistoides lobatus. A-C, fiandeiras da fêmea; D-F, fiandeiras do macho; G-H, palpo do macho; I-J, epígino da fêmea. A e D, vista geral. B e E, detalhe do PLS. Ce F, detalhe do PMS. G, vista retrolateral. H, vista prolateral. I, vista dorsal. J vista ventral. 


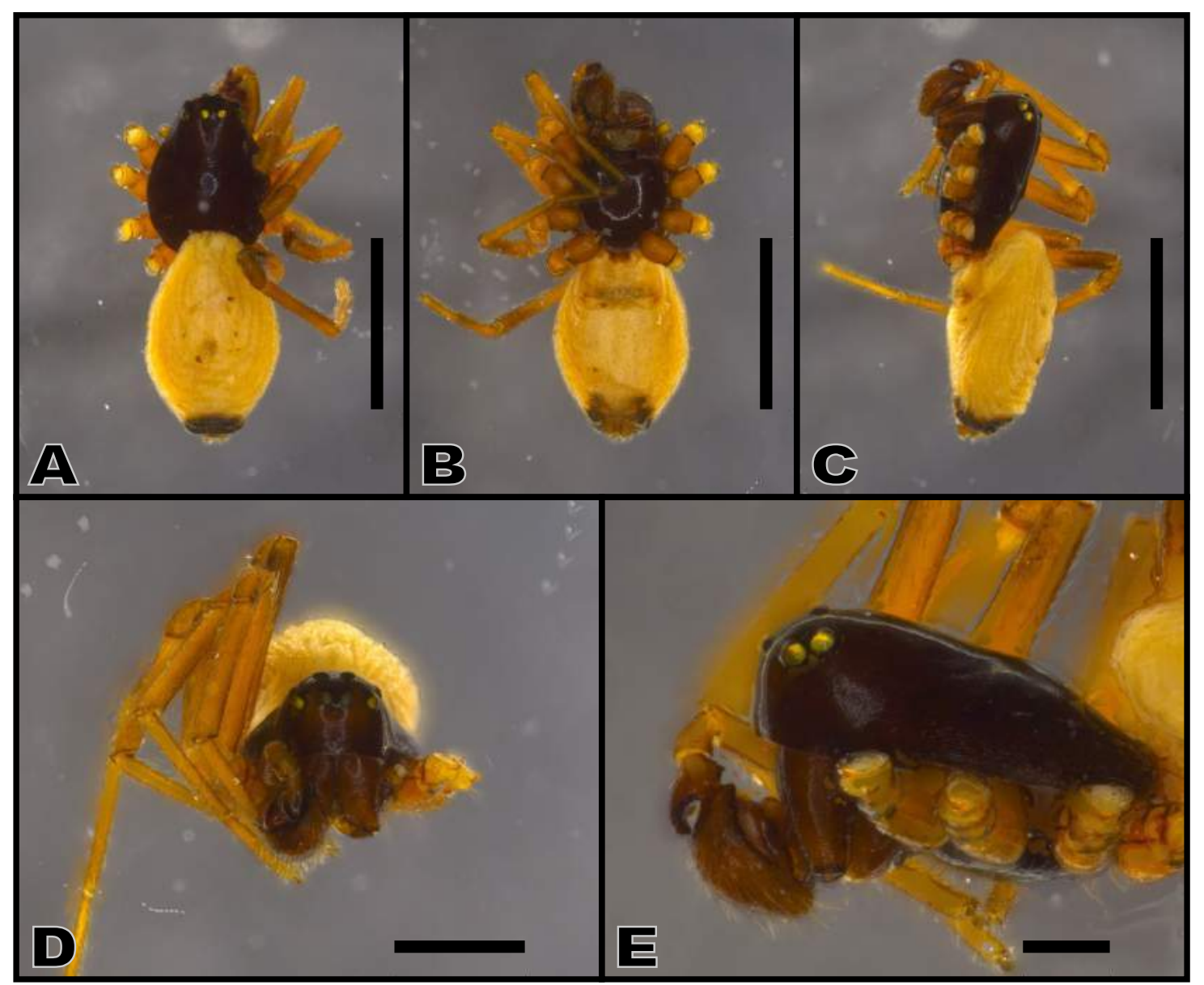

Figura 67. Hypselistoides modestus, A-E, corpo do macho. A, dorsal; B, ventral; C, lateral; D, frontal; E, detalhe da região cefálica. Escala A-C, 1,0mm; D, 0,5mm; E, $0,2 \mathrm{~mm}$.

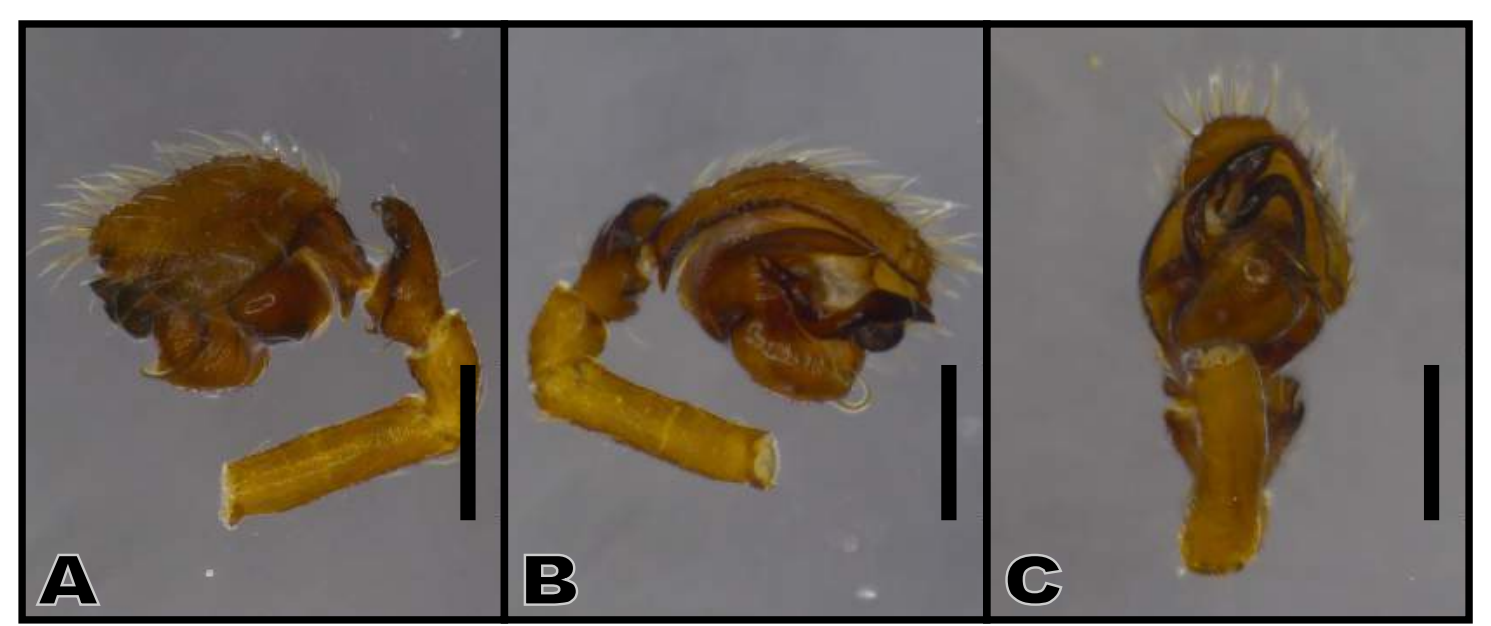

Figura 68. Hypselistoides modestus, A-C, palpo do macho. A, retrolateral; B, prolateral; C, ventral. Escala 0,2mm. 


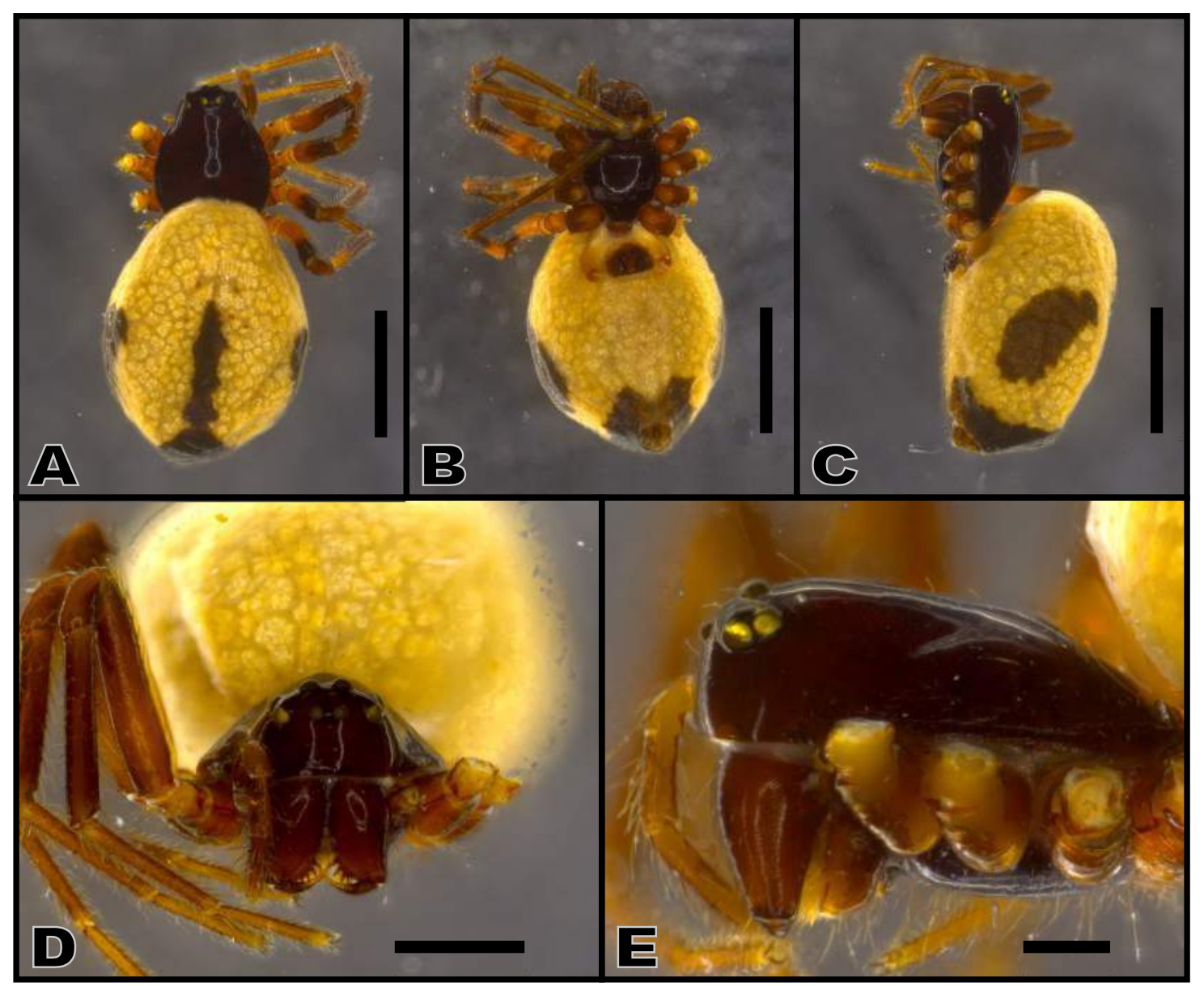

Figura 69. Hypselistoides modestus, A-E, corpo da fêmea. A, dorsal; B, ventral; C, lateral; D, frontal; E, detalhe da região cefálica. Escala A-C, 1,0mm; D, 0,5mm; E, $0,2 \mathrm{~mm}$.

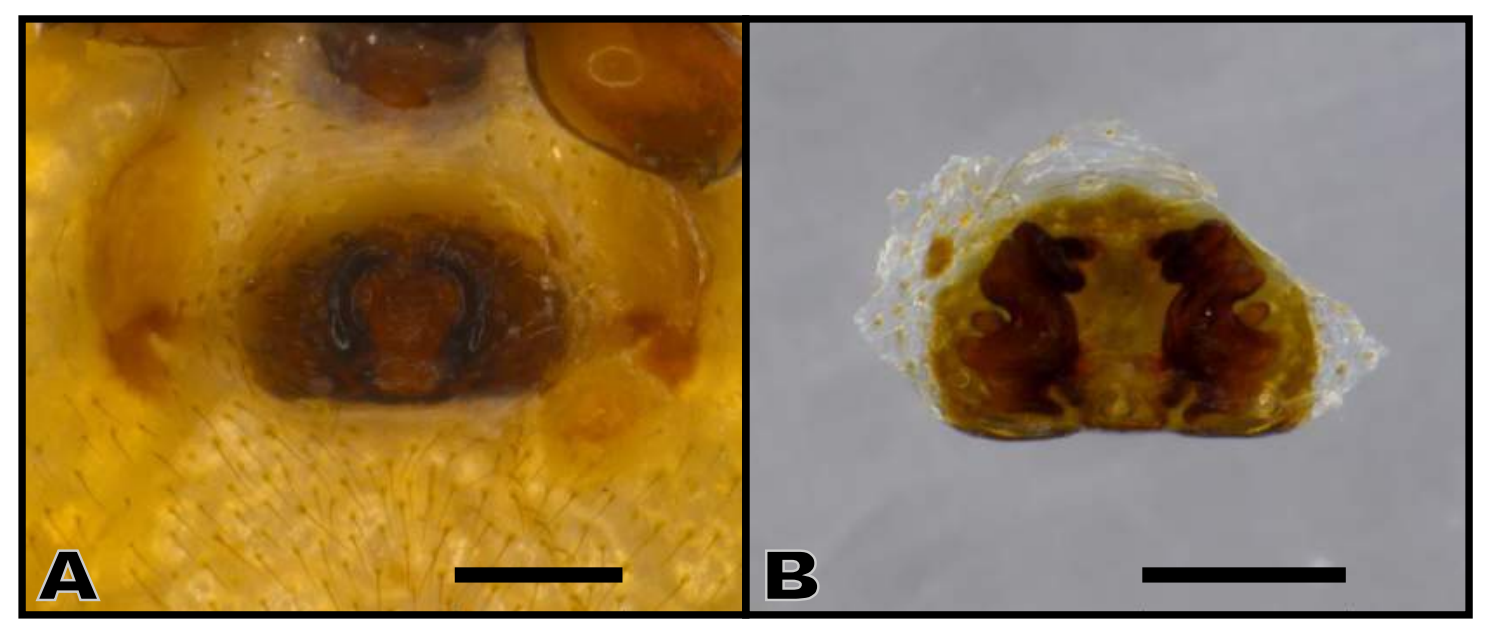

Figura 70. Hypselistoides modestus, A-B, epígino da fêmea. A, ventral; B, dorsal. Escala 0,2mm. 


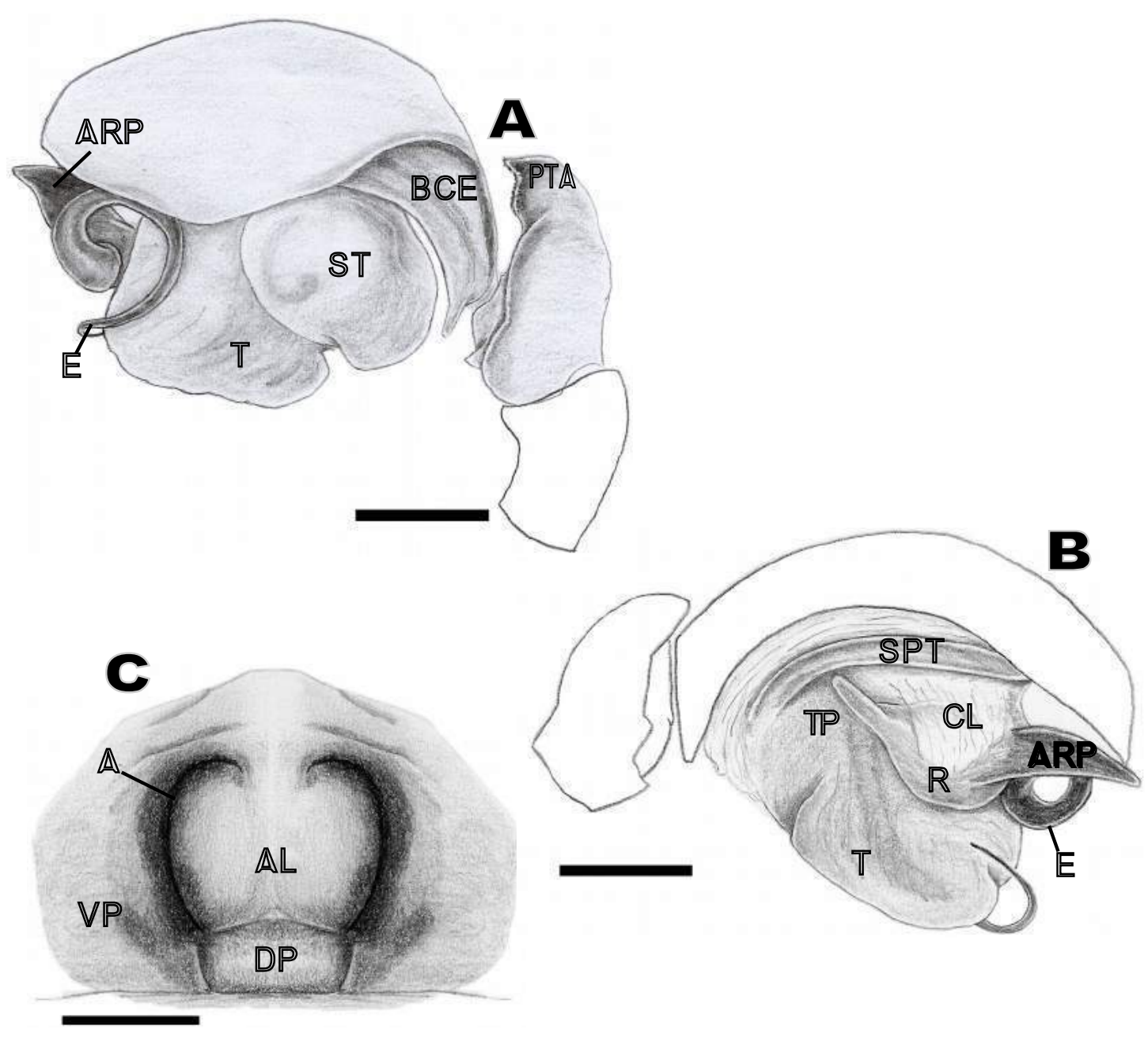

Figura 71. Hypselistoides modestus, A-B, palpo do macho; C, epígino da fêmea. A, retrolateral; B, prolateral; C, ventral. Escala 0,1mm. A, átrio; AL, lóbulo anterior da placa dorsal do epígino; BCE, base escavada do címbio; CL, column; DP, placa dorsal do epígino; E, êmbolo; PT, protégulo; PTA, apófise prolateral da tíbia; R, radix; RTA, apófise retrolateral da tíbia; SPT, supratégulo; ST, subtégulo; T, tégulo; TP, cauda do radix; VP, placa ventral do epígino. 


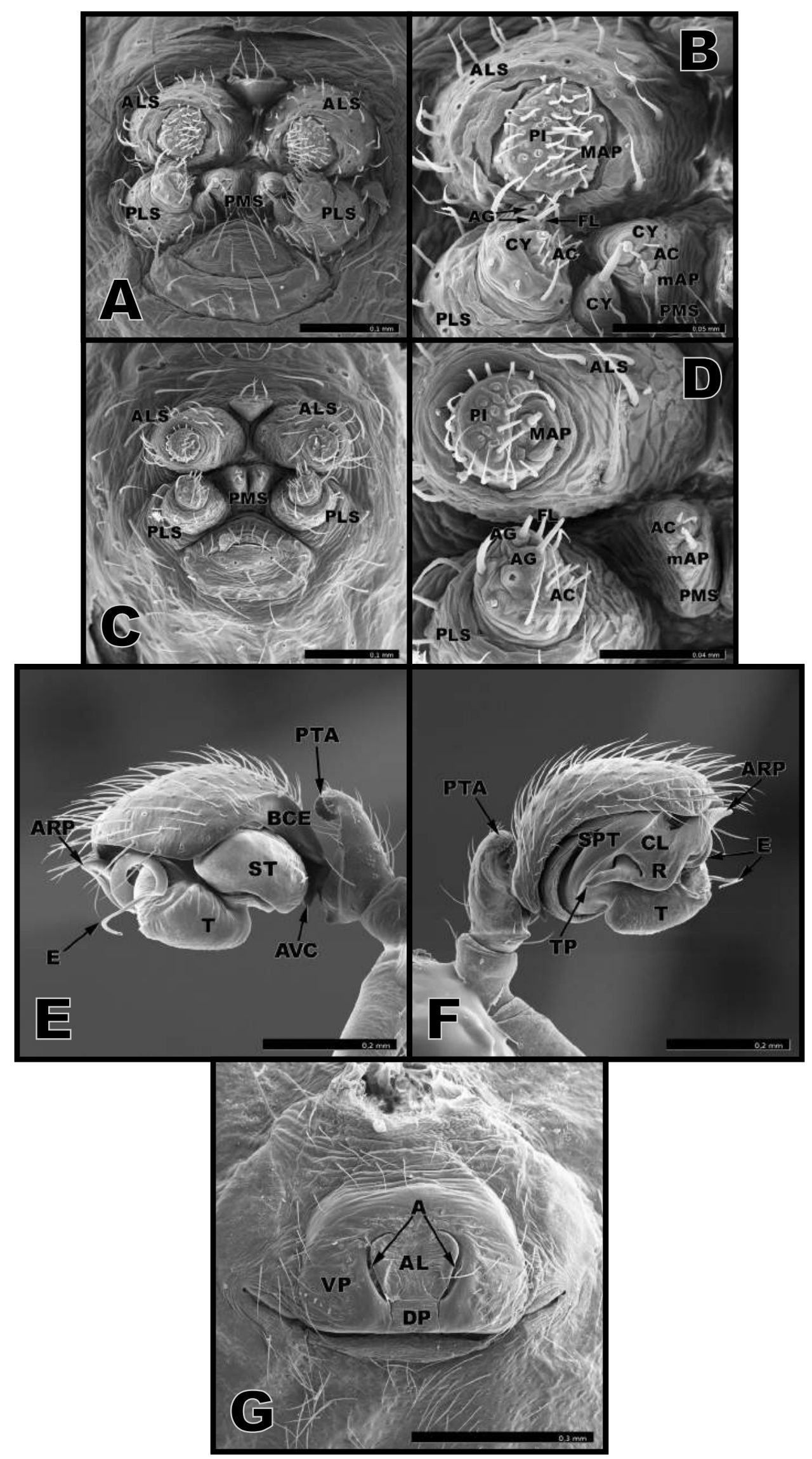

Figura 72. Hypselistoides modestus. A-B, fiandeiras da fêmea; $\mathrm{C}-\mathrm{D}$, fiandeiras do macho; E-F, palpo do macho; G, epígino da fêmea. A e C, vista geral. B e D, detalhe das fiandeiras. E, vista retrolateral. F, vista prolateral. G, vista ventral. 


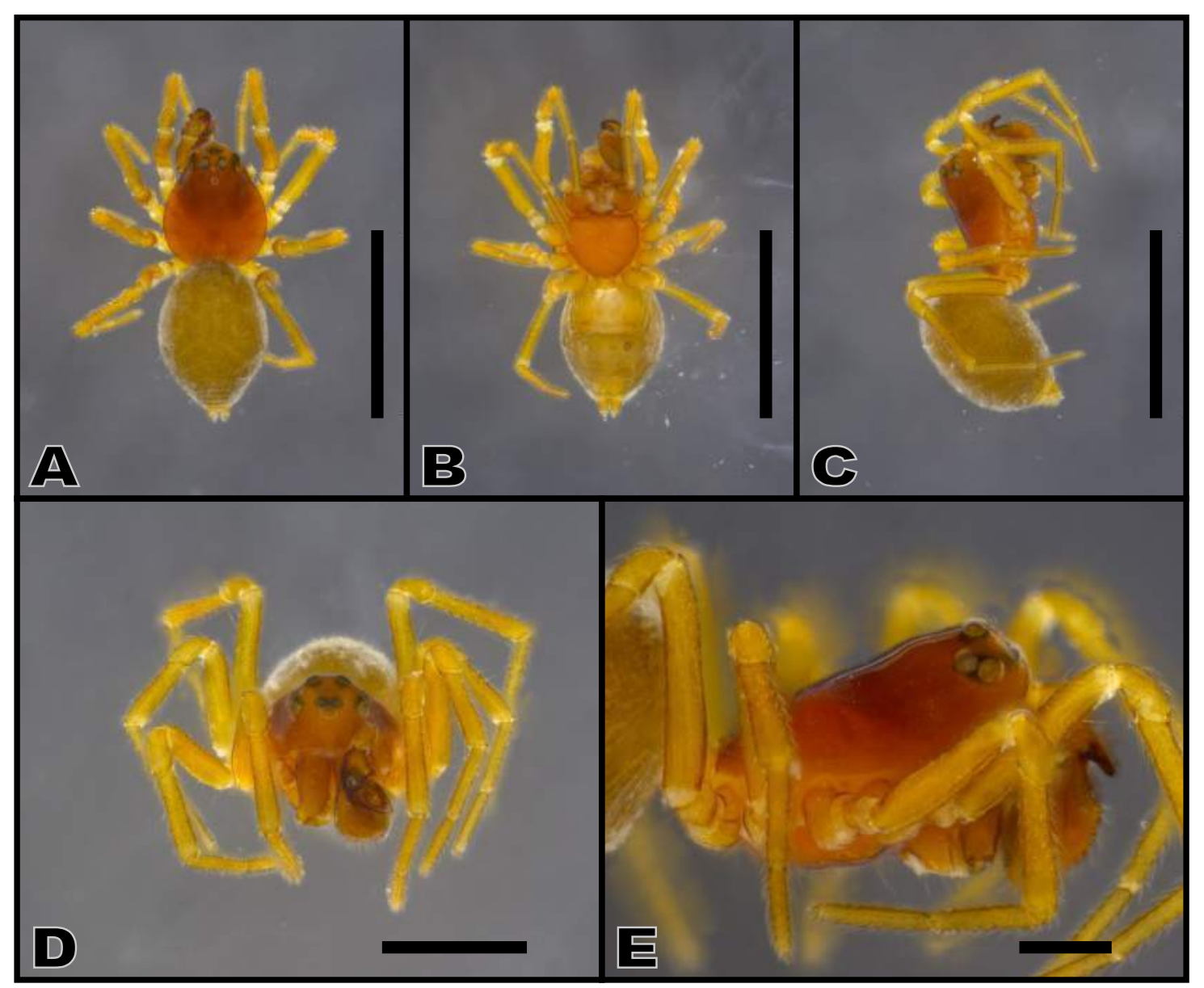

Figura 73. Hypselistoides modicus, A-E, corpo do macho. A, dorsal; B, ventral; C, lateral; D, frontal; E, detalhe da região cefálica. Escala A-C, 1,0mm; D, 0,5mm; E, $0,2 \mathrm{~mm}$.

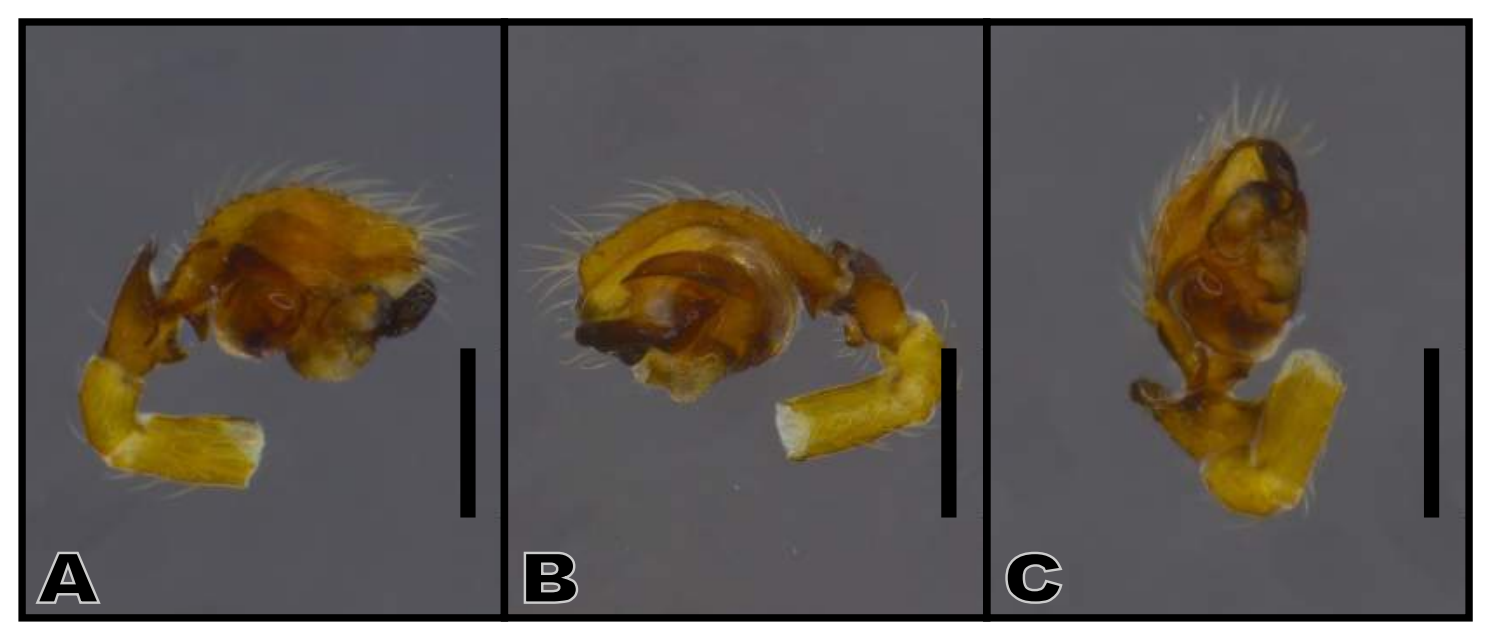

Figura 74. Hypselistoides modicus, A-C, palpo do macho. A, retrolateral; B, prolateral; C, ventral. Escala 0,2mm. 


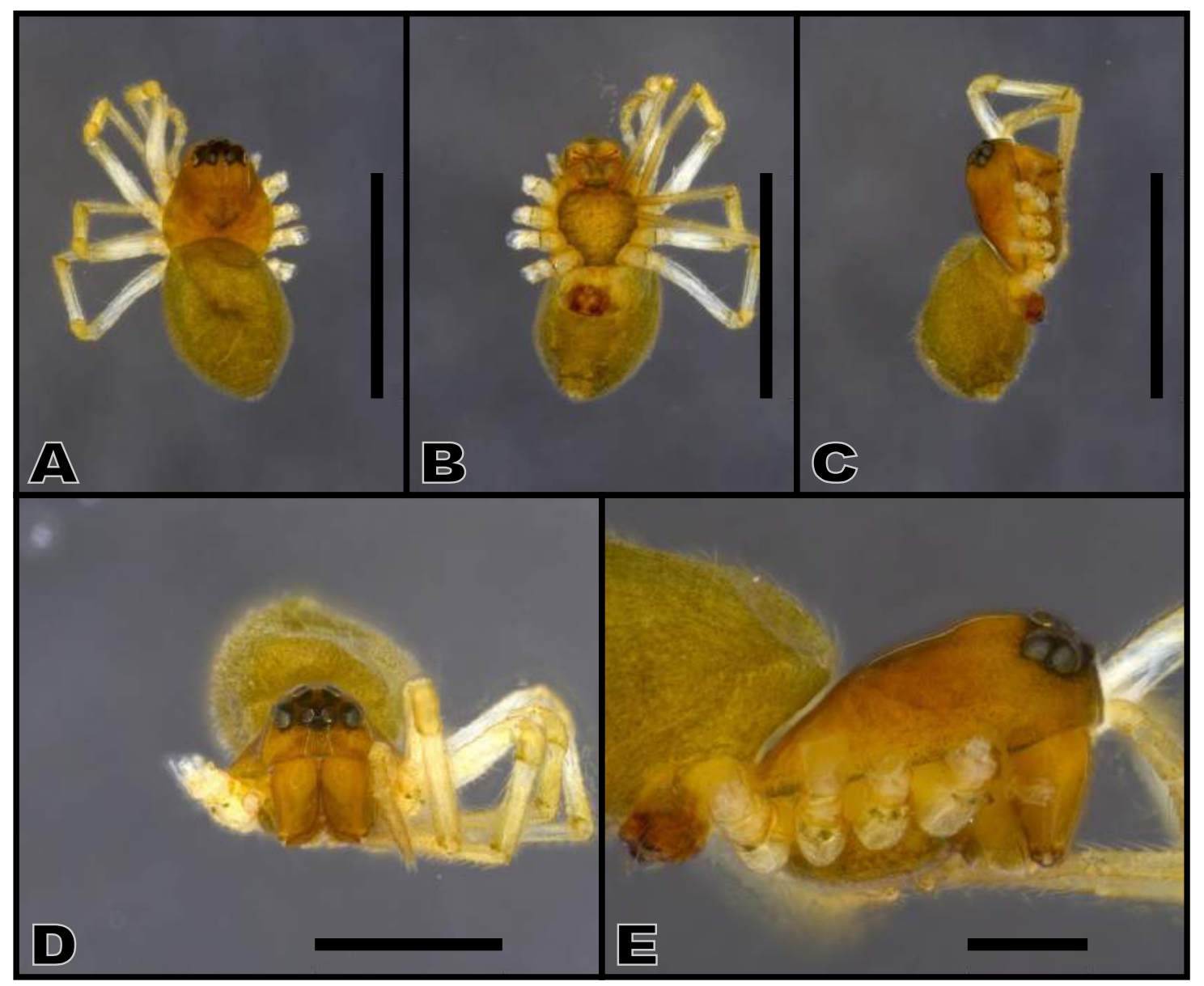

Figura 75. Hypselistoides modicus, A-E, corpo da fêmea. A, dorsal; B, ventral; C, lateral; D, frontal; E, detalhe da região cefálica. Escala A-C, 1,0mm; D, 0,5mm; E, $0,2 \mathrm{~mm}$.

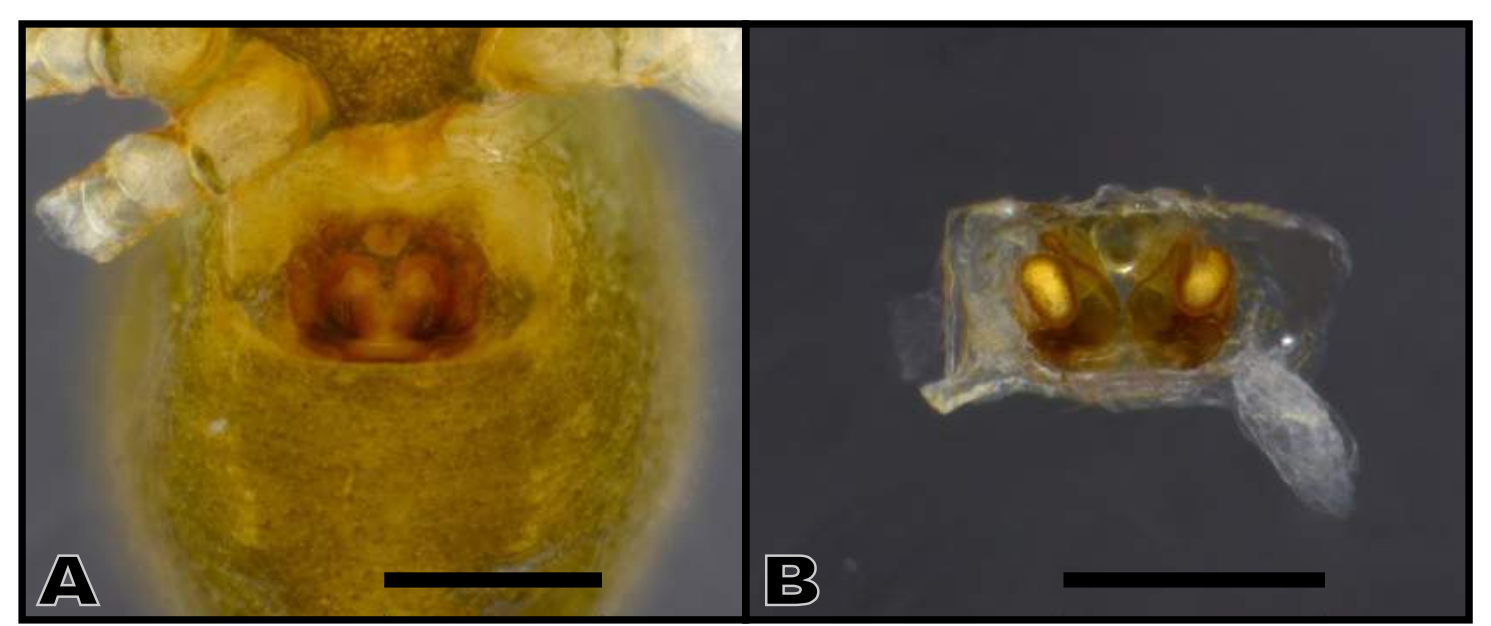

Figura 76. Hypselistoides modicus, A-B, epígino da fêmea. A, ventral; B, dorsal. Escala $0,2 \mathrm{~mm}$. 

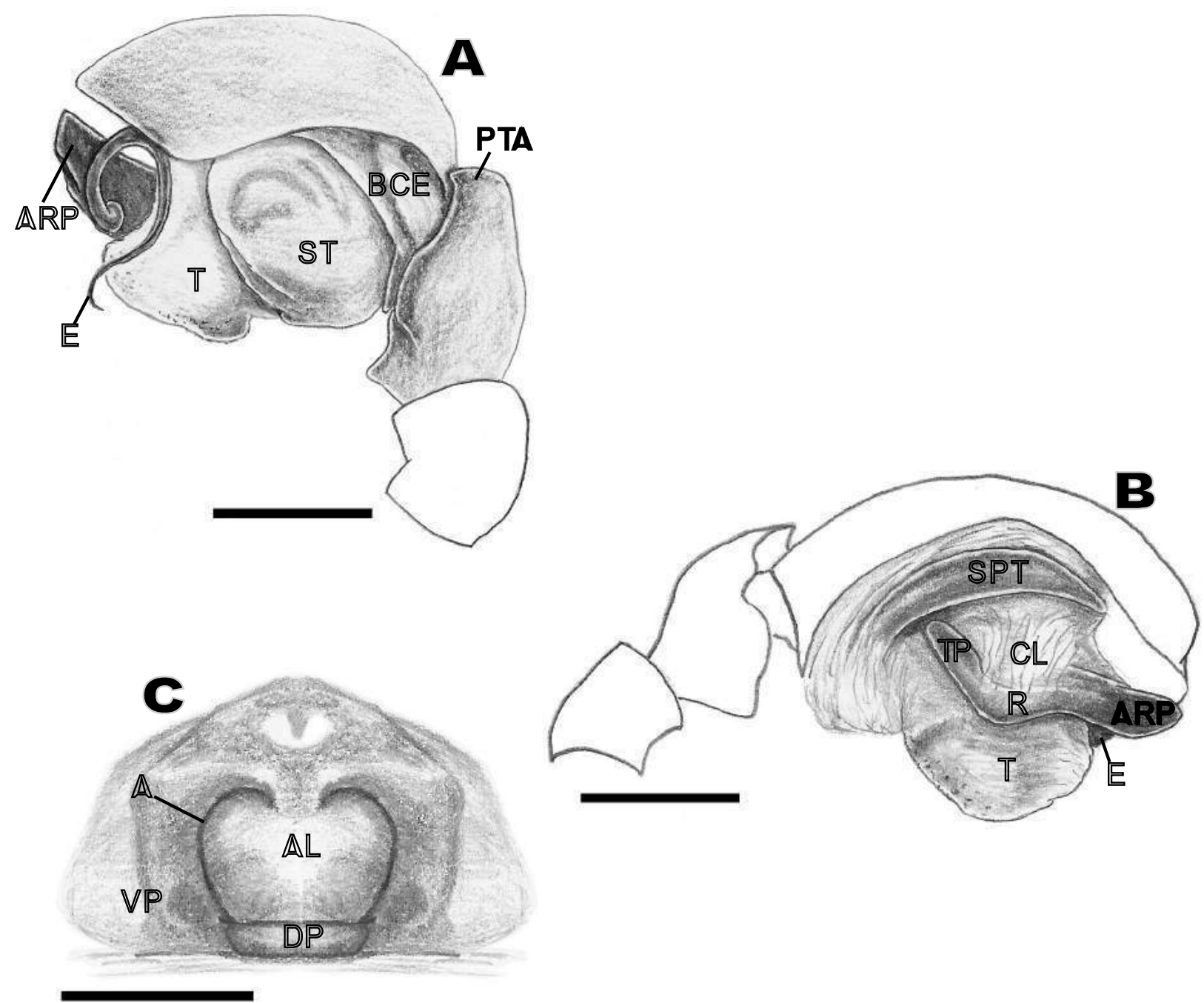

Figura 77. Hypselistoides modicus, A-B, palpo do macho; C, epígino da fêmea. A, retrolateral; B, prolateral; C, ventral. Escala 0,1mm. A, átrio; AL, lóbulo anterior da placa dorsal do epígino; BCE, base escavada do címbio; CL, column; DP, placa dorsal do epígino; E, êmbolo; PT, protégulo; PTA, apófise prolateral da tíbia; R, radix; RTA, apófise retrolateral da tíbia; SPT, supratégulo; ST, subtégulo; T, tégulo; TP, cauda do radix; VP, placa ventral do epígino. 


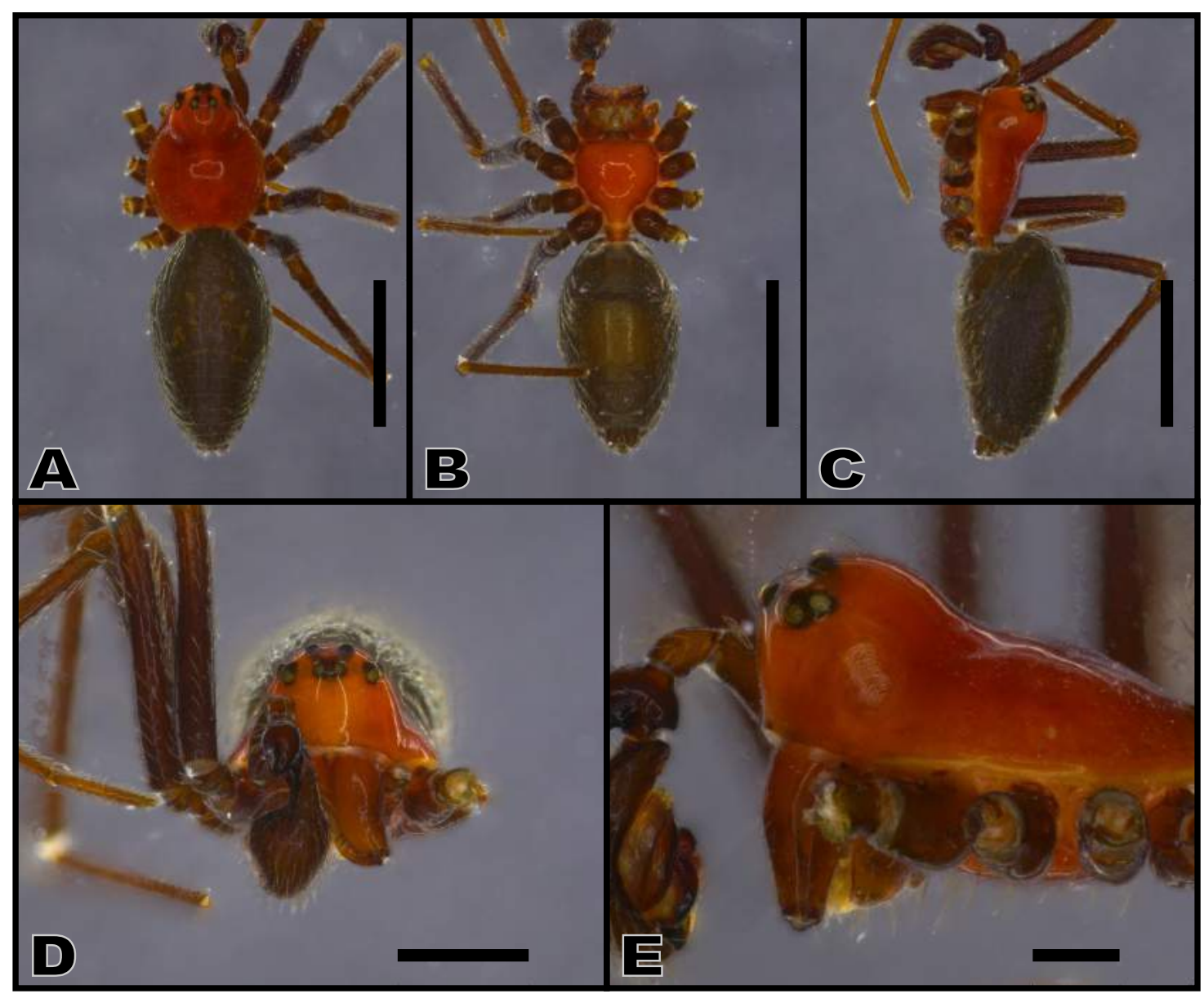

Figura 78. Hypselistoides nigripes, A-E, corpo do macho. A, dorsal; B, ventral; C, lateral; D, frontal; E, detalhe da região cefálica. Escala A-C, 1,0mm; D, 0,5mm; E, $0,2 \mathrm{~mm}$.

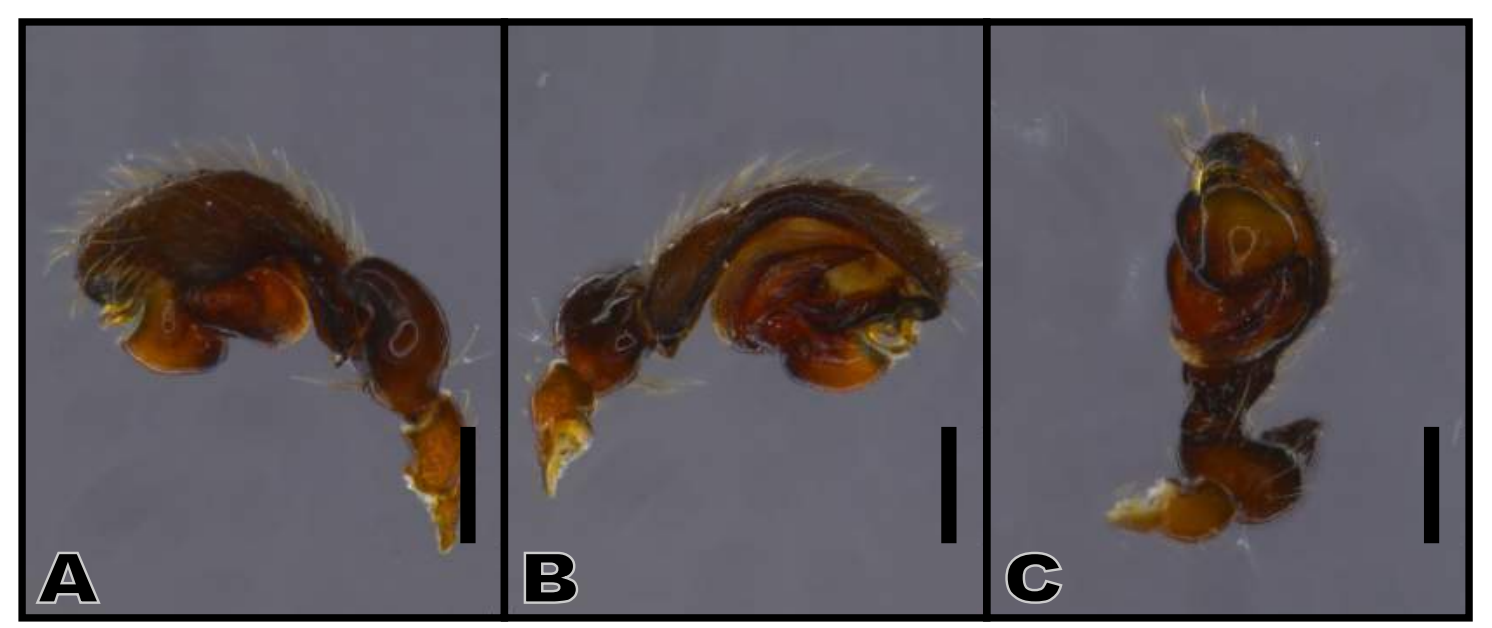

Figura 79. Hypselistoides nigripes, A-C, palpo do macho. A, retrolateral; B, prolateral; C, ventral. Escala 0,2mm. 


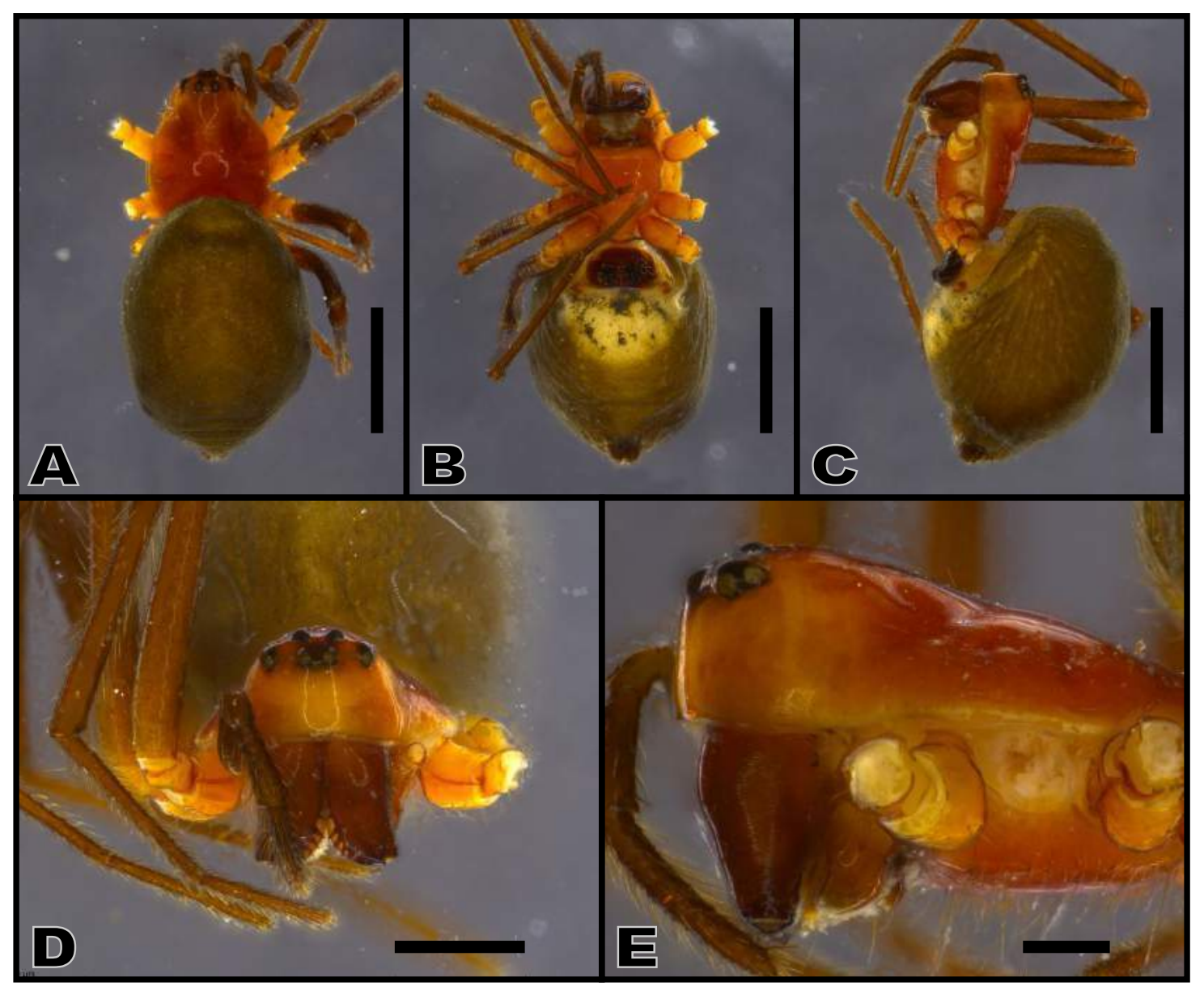

Figura 80. Hypselistoides nigripes, A-E, corpo da fêmea. A, dorsal; B, ventral; C, lateral; D, frontal; E, detalhe da região cefálica. Escala A-C, 1,0mm; D, 0,5mm; E, $0,2 \mathrm{~mm}$.

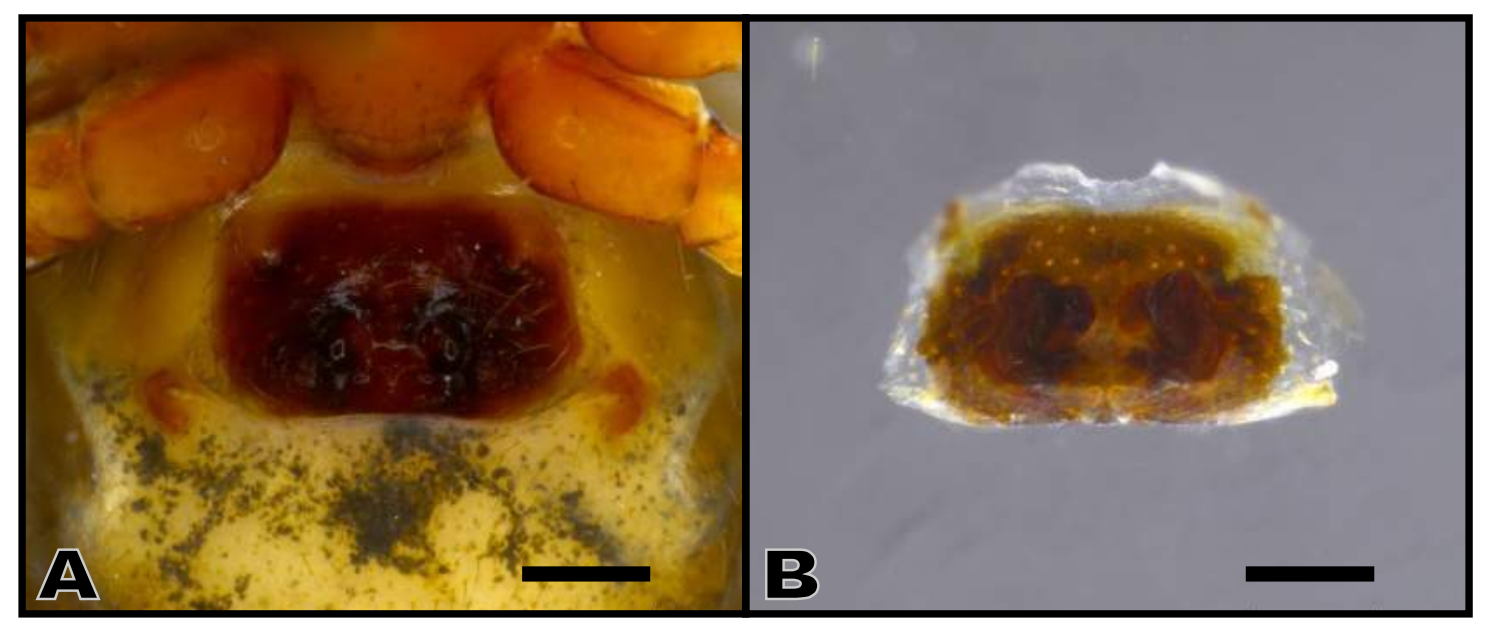

Figura 81. Hypselistoides nigripes, A-B, epígino da fêmea. A, ventral; B, dorsal. Escala $0,2 \mathrm{~mm}$. 


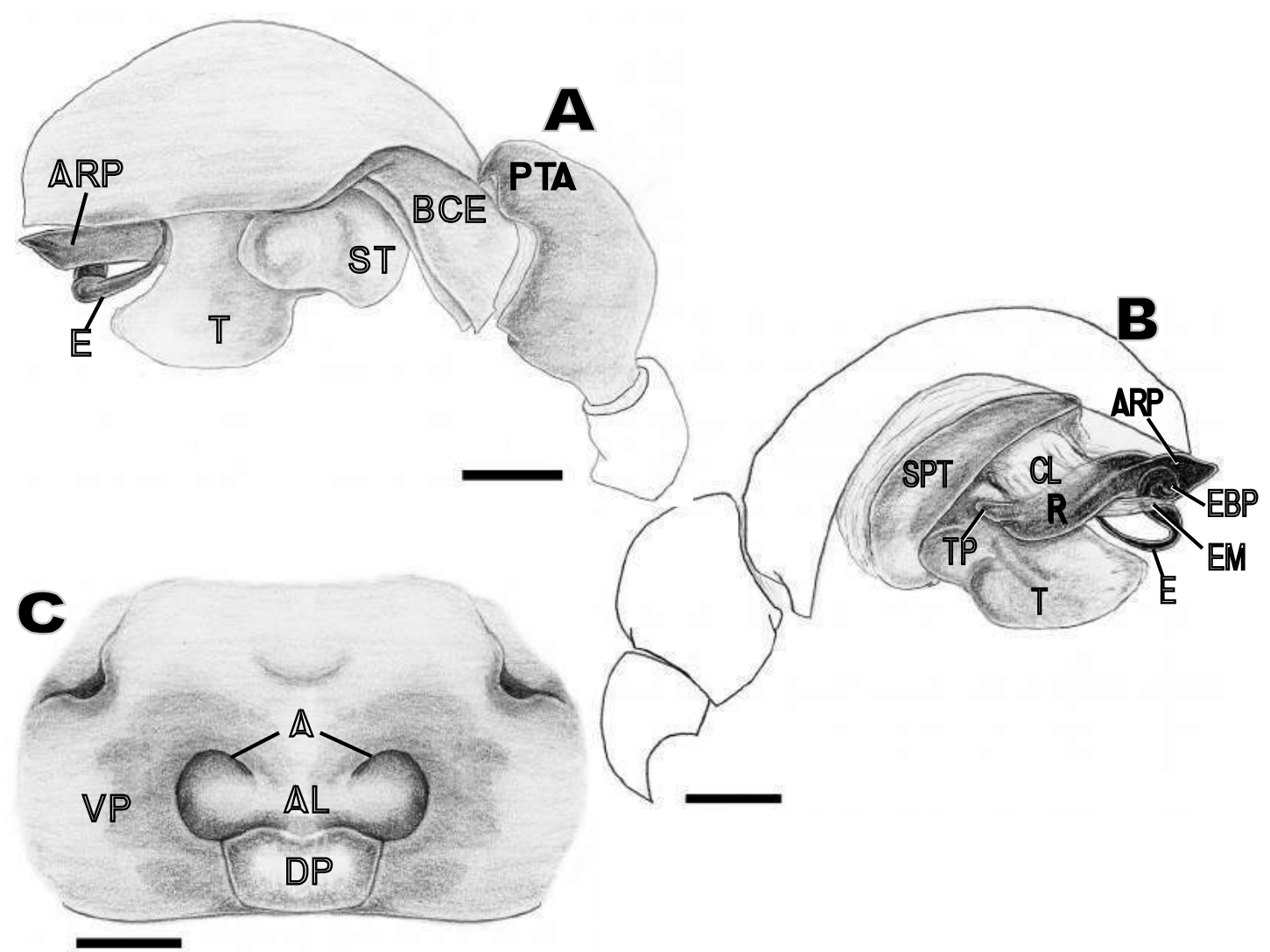

Figura 82. Hypselistoides nigripes, A-B, palpo do macho; C, epígino da fêmea. A, retrolateral; B, prolateral; C, ventral. Escala 0,1mm. A, átrio; AL, lóbulo anterior da placa dorsal do epígino; BCE, base escavada do címbio; CL, column; DP, placa dorsal do epígino; E, êmbolo; EBP, processo basal do êmbolo; EM, membrana embólica; PT, protégulo; PTA, apófise prolateral da tíbia; R, radix; RTA, apófise retrolateral da tíbia; SPT, supratégulo; ST, subtégulo; T, tégulo; TP, cauda do radix; VP, placa ventral do epígino. 


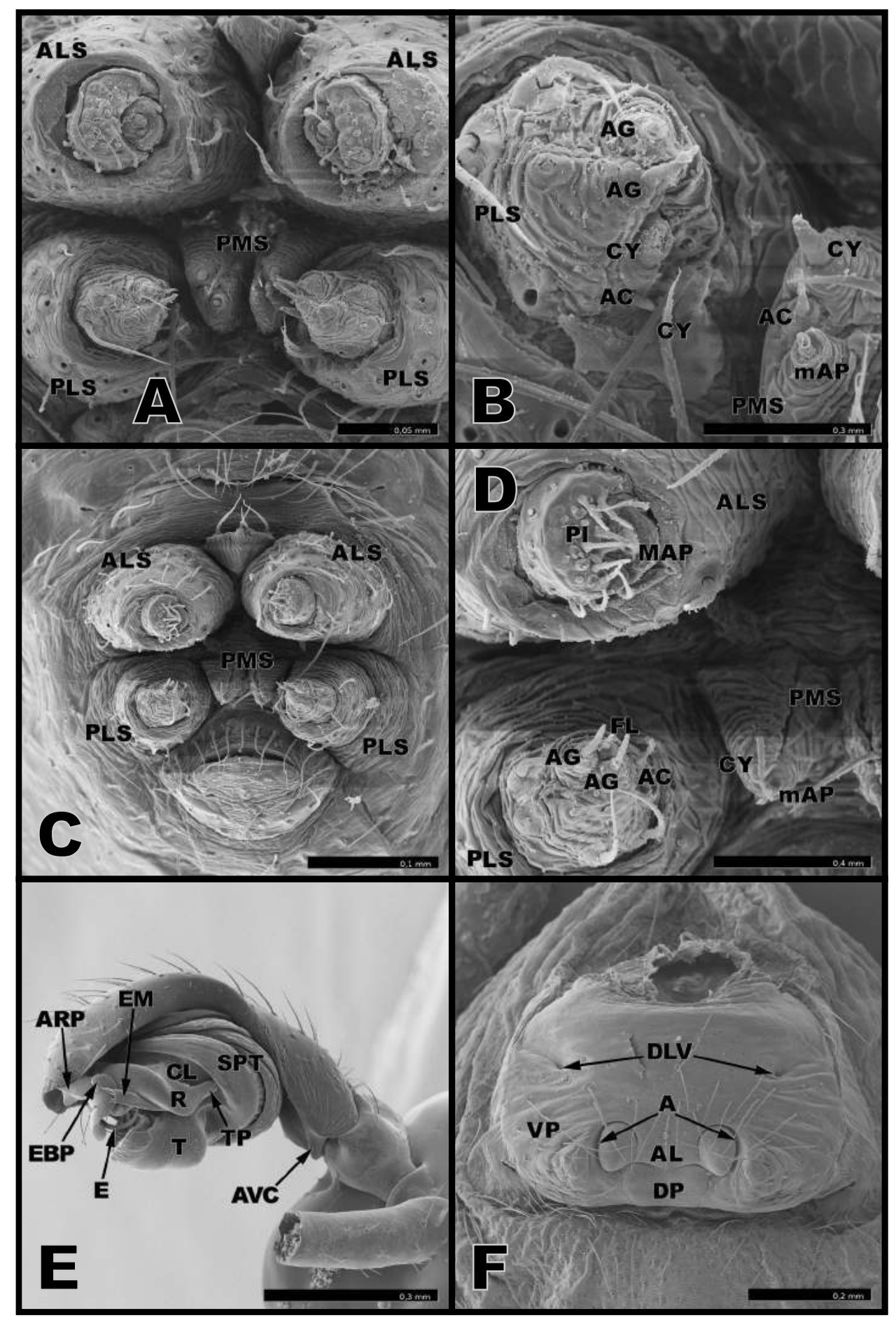

Figura 83. Hypselistoides nigripes. A-B, fiandeiras da fêmea; $\mathrm{C}-\mathrm{D}$, fiandeiras do macho; E, palpo do macho; F, epígino da fêmea. A e C, vista geral. B, detalhe do ALS e PMS. D, detalhe da fiandeira. E, vista prolateral. F, vista ventral. 


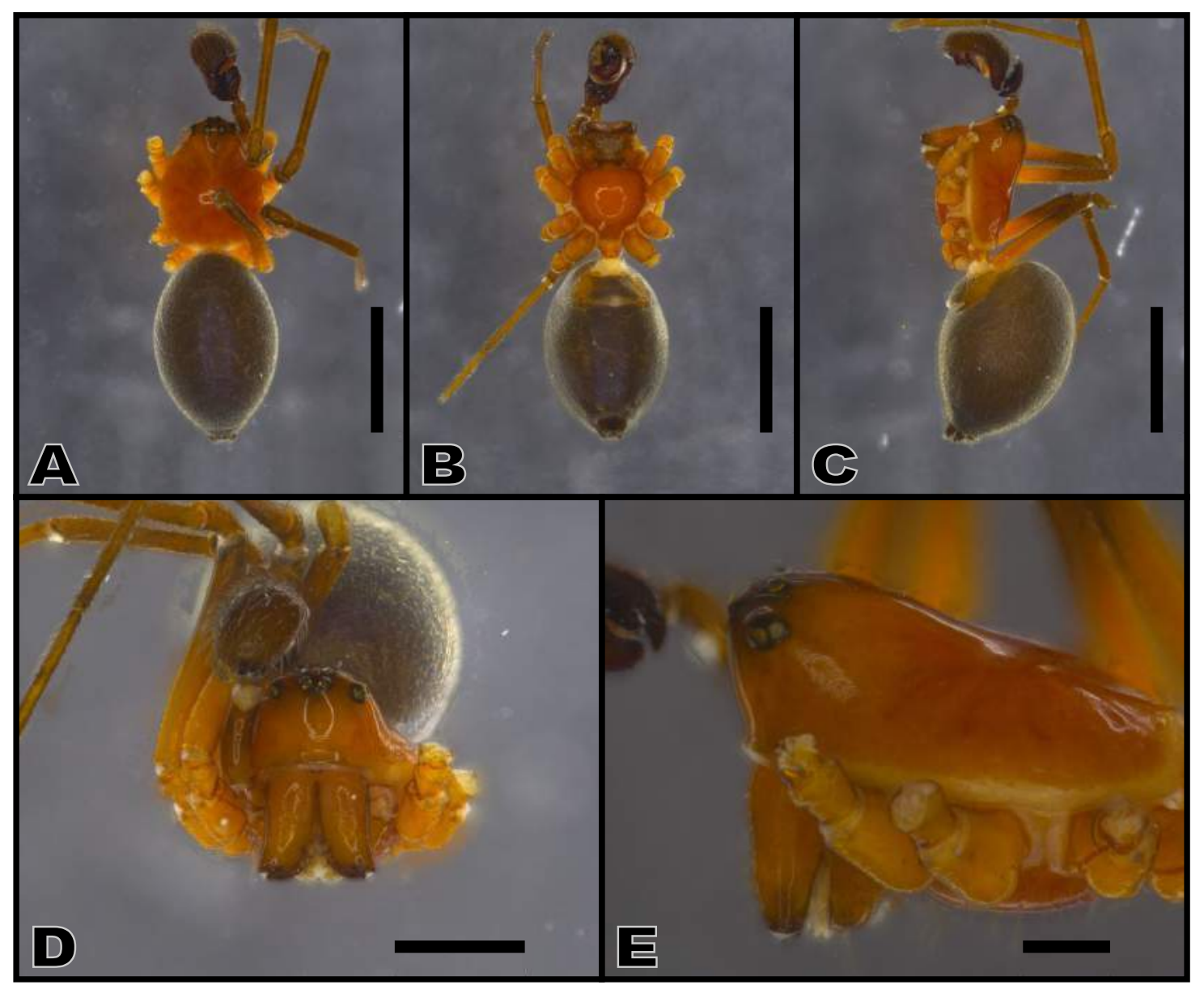

Figura 84. Hypselistoides niwinus, A-E, corpo do macho. A, dorsal; B, ventral; C, lateral; D, frontal; E, detalhe da região cefálica. Escala A-C, 1,0mm; D, 0,5mm; E, $0,2 \mathrm{~mm}$.

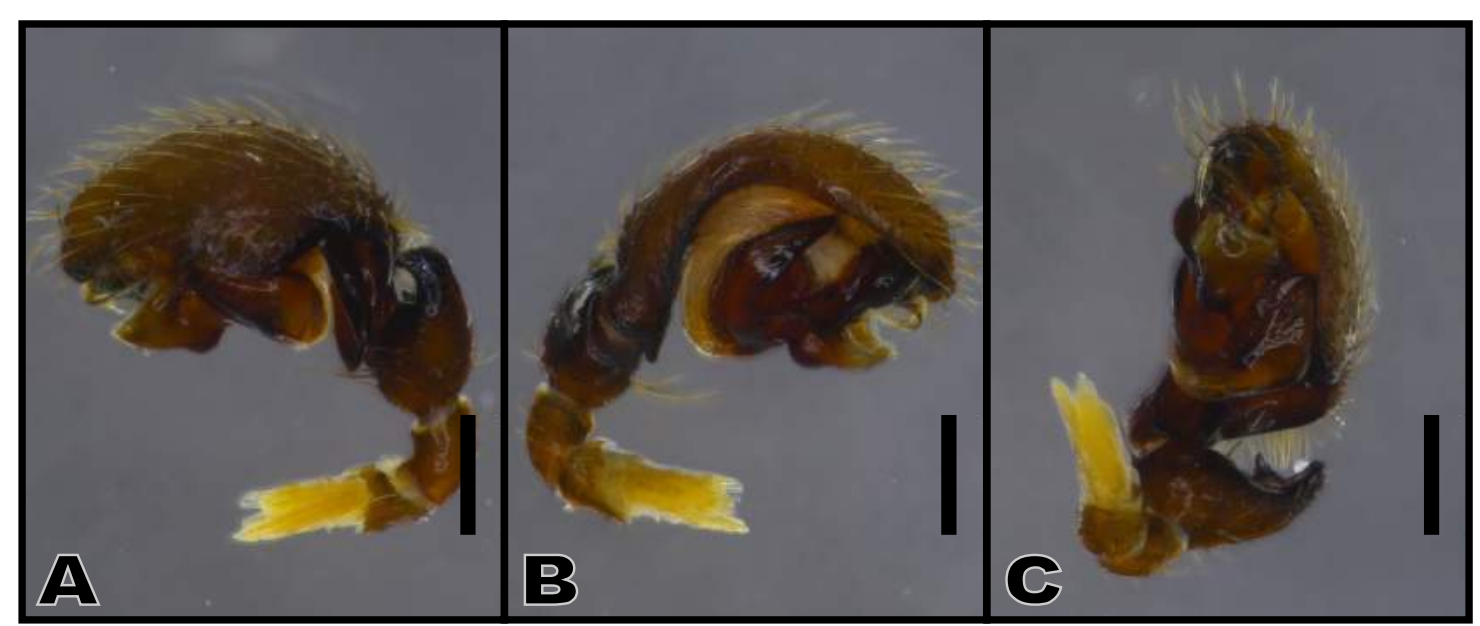

Figura 85. Hypselistoides niwinus, A-C, palpo do macho. A, retrolateral; B, prolateral; C, ventral. Escala 0,2mm. 


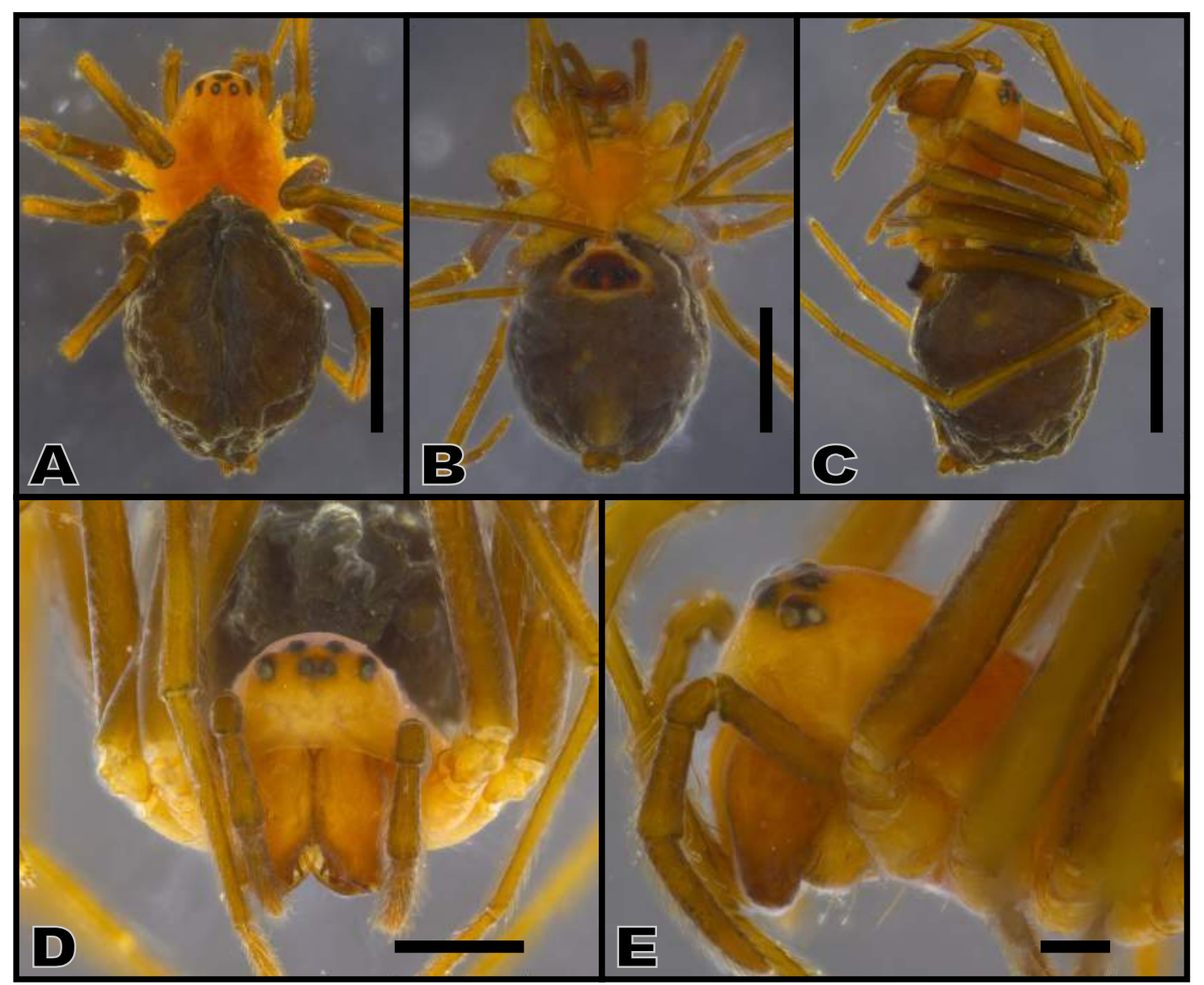

Figura 86. Hypselistoides niwinus, A-E, corpo da fêmea. A, dorsal; B, ventral; C, lateral; D, frontal; E, detalhe da região cefálica. Escala A-C, 1,0mm; D, 0,5mm; E, $0,2 \mathrm{~mm}$.

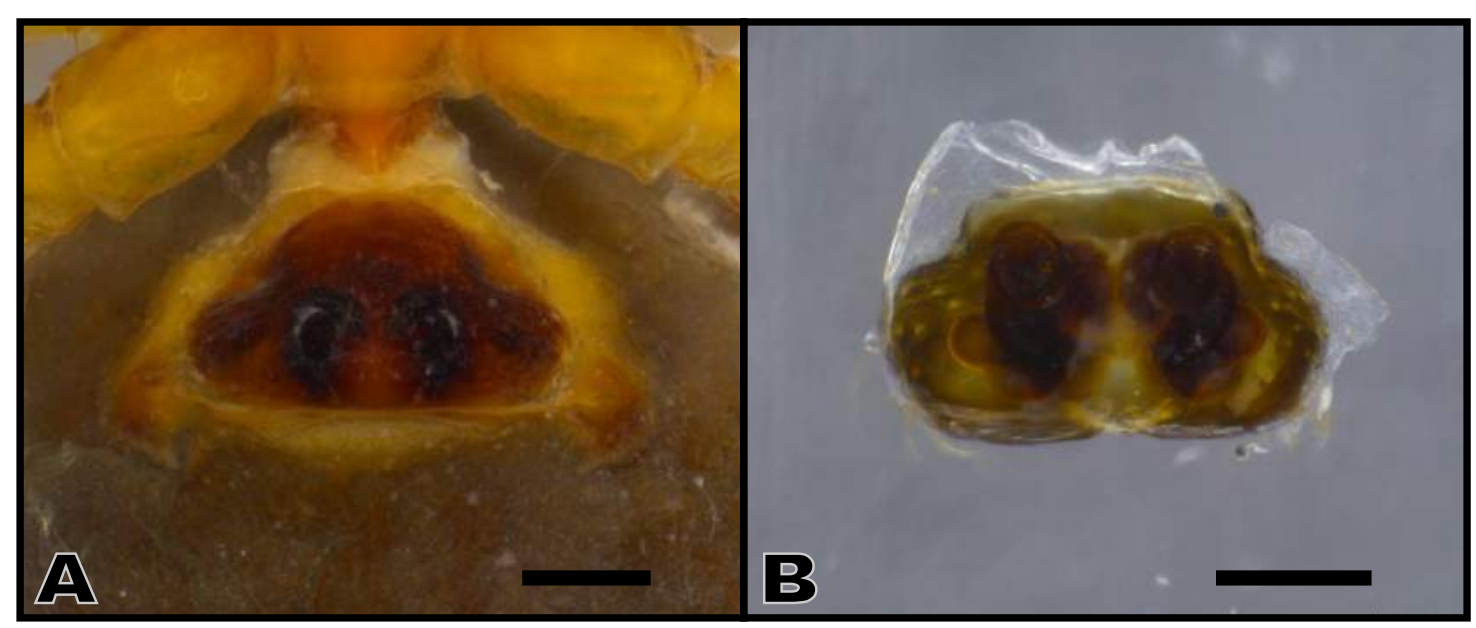

Figura 87. Hypselistoides niwinus, A-B, epígino da fêmea. A, ventral; B, dorsal. Escala $0,2 \mathrm{~mm}$. 


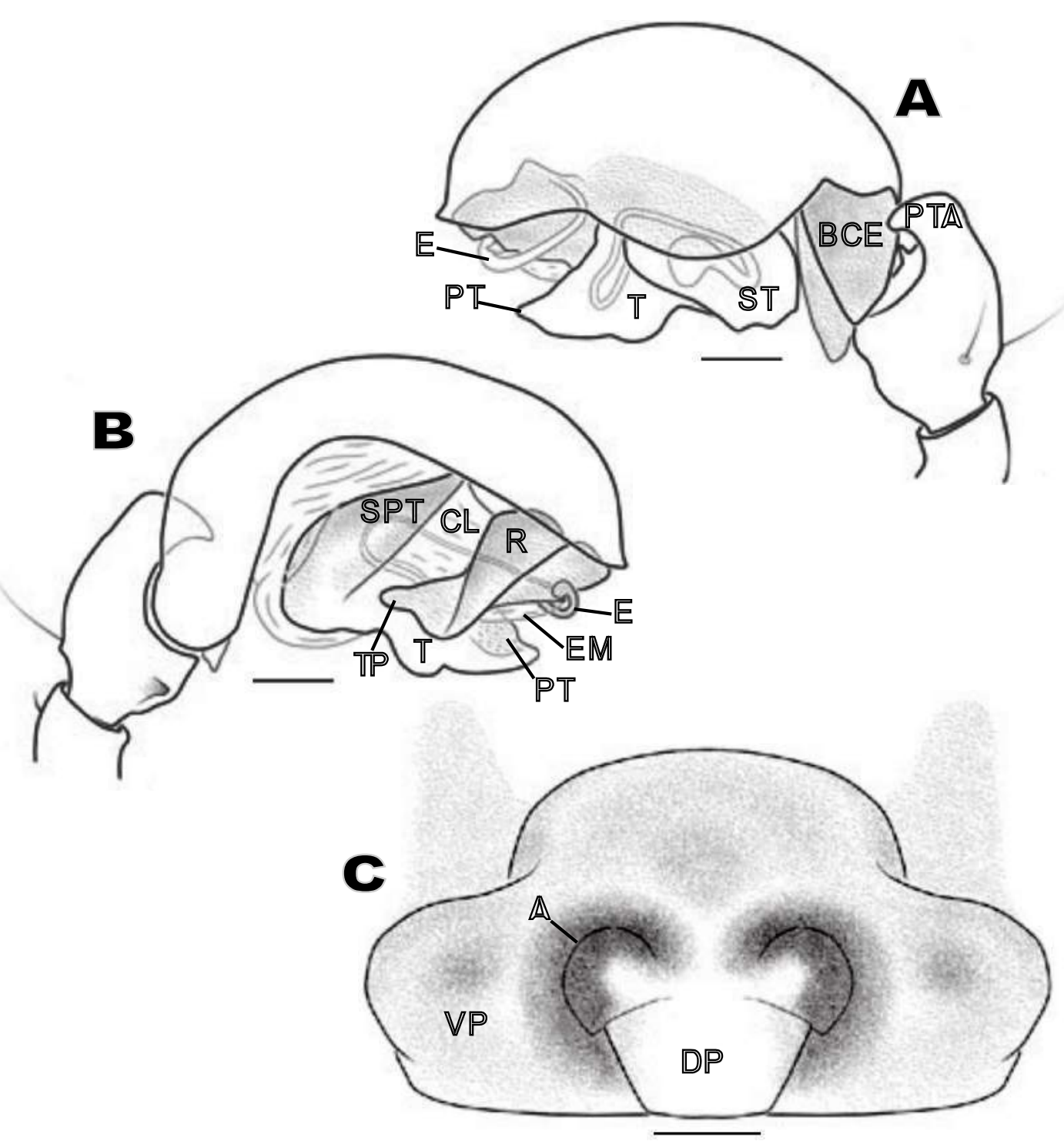

Figura 88. Hypselistoides niwinus, A-B, palpo do macho; C, epígino da fêmea. A, retrolateral; B, prolateral; C, ventral. Escala 0,1mm. A, átrio; BCE, excavação basal do címbio; CL, column; DP, placa dorsal do epígino; E, êmbolo; EM, membrana embólica; PT, protégulo; PTA, apófise prolateral da tíbia; Rradix; SPT, supratégulo; ST, subtégulo; T, tégulo; TP, cauda do radix; VP, placa ventral do epígino. Ilustração de Miller, 2007. 


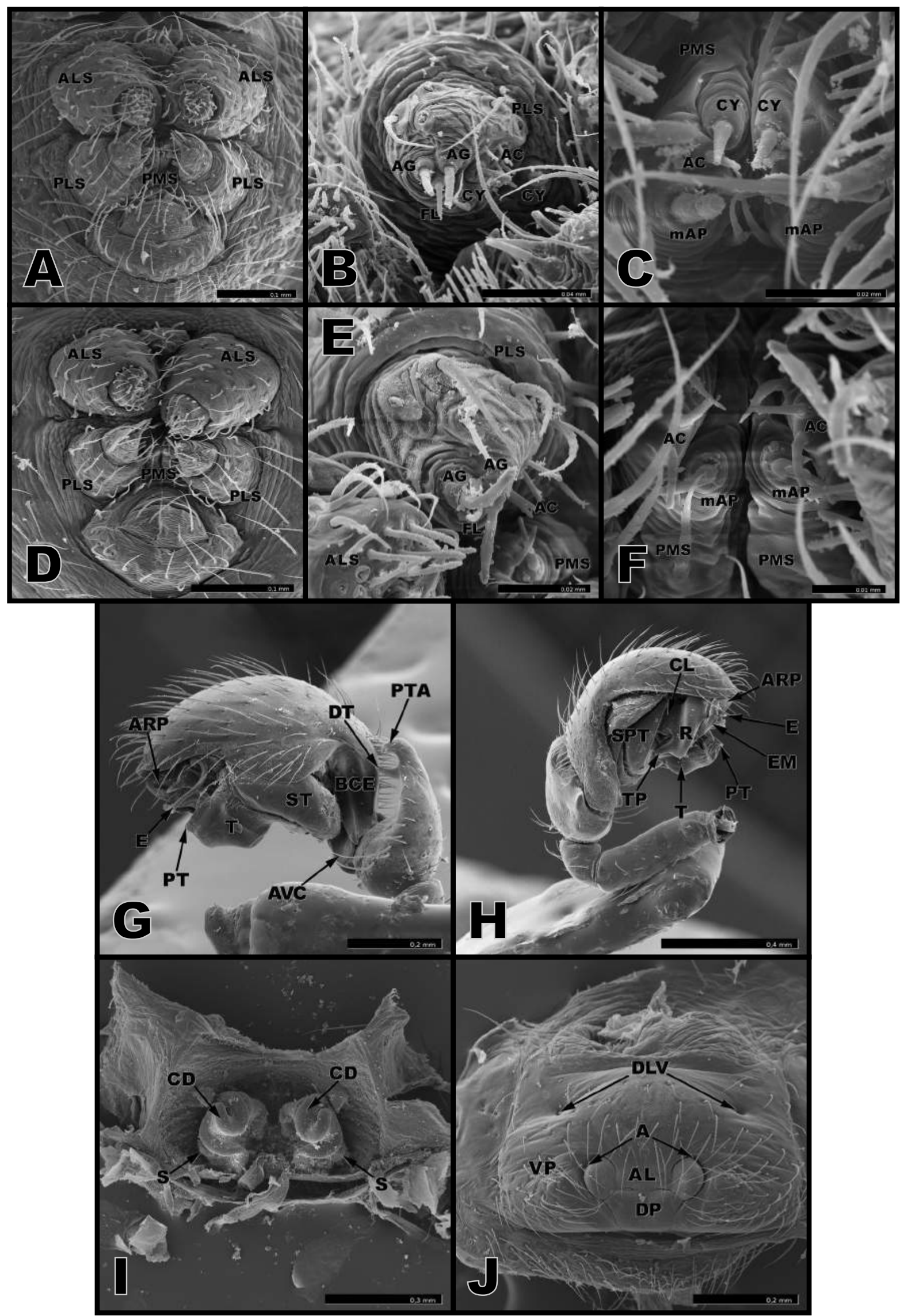

Figura 89. Hypselistoides niwinus. A-C, fiandeiras da fêmea; D-F, fiandeiras do macho; G-H, palpo do macho; I-J, epígino da fêmea. A e D, vista geral. B e E, detalhe do PLS. $\mathrm{C}$ e F, detalhe do PMS. G, vista retrolateral. H, vista prolateral. I, vista dorsal. J vista ventral. 


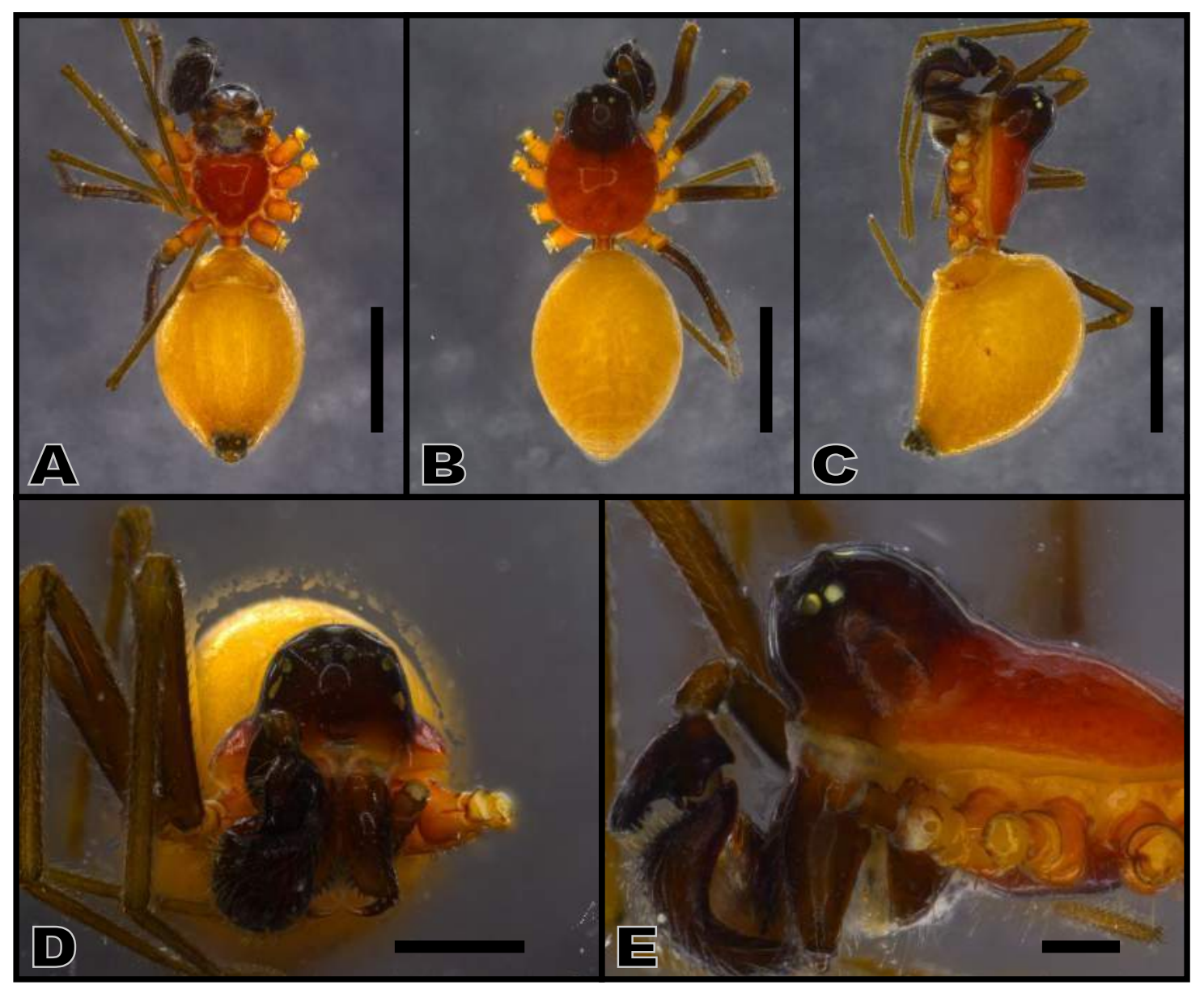

Figura 90. Hypselistoides rubicundus, A-E, corpo do macho. A, dorsal; B, ventral; C, lateral; D, frontal; E, detalhe da região cefálica. Escala A-C, 1,0mm; D, 0,5mm; E, $0,2 \mathrm{~mm}$.

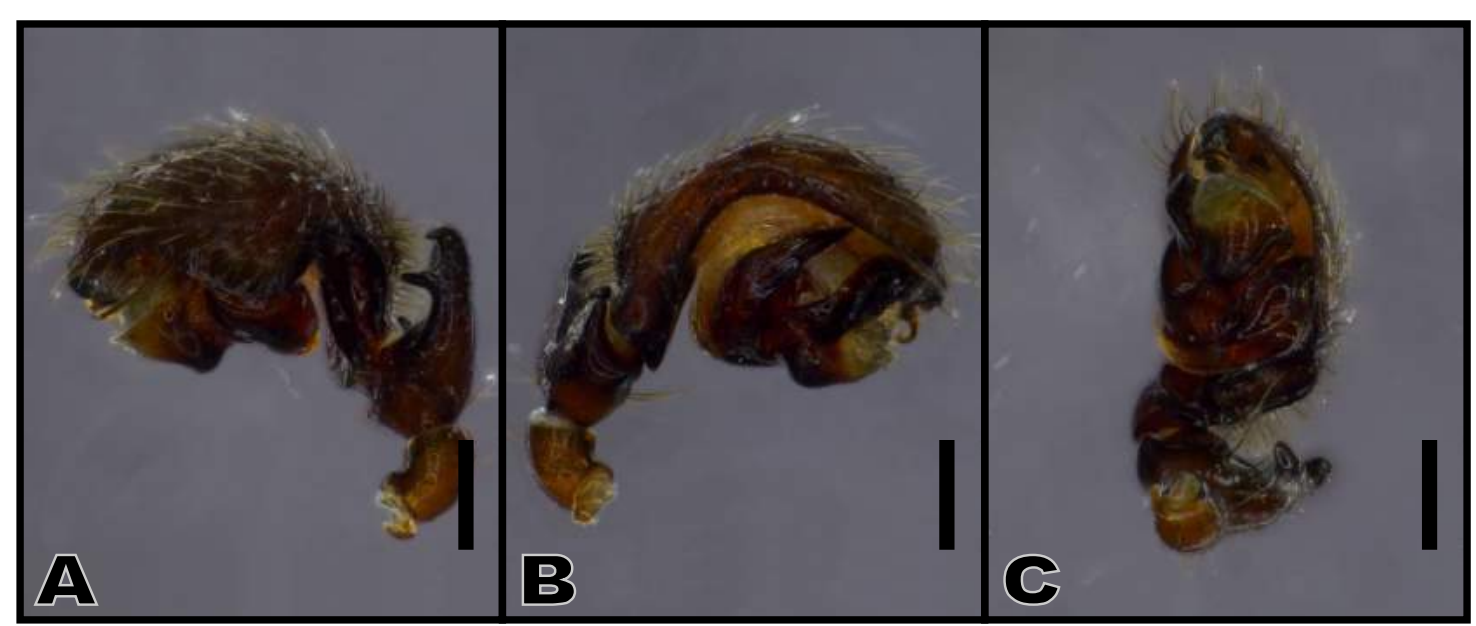

Figura 91. Hypselistoides rubicundus, A-C, palpo do macho. A, retrolateral; B, prolateral; C, ventral. Escala 0,2mm. 


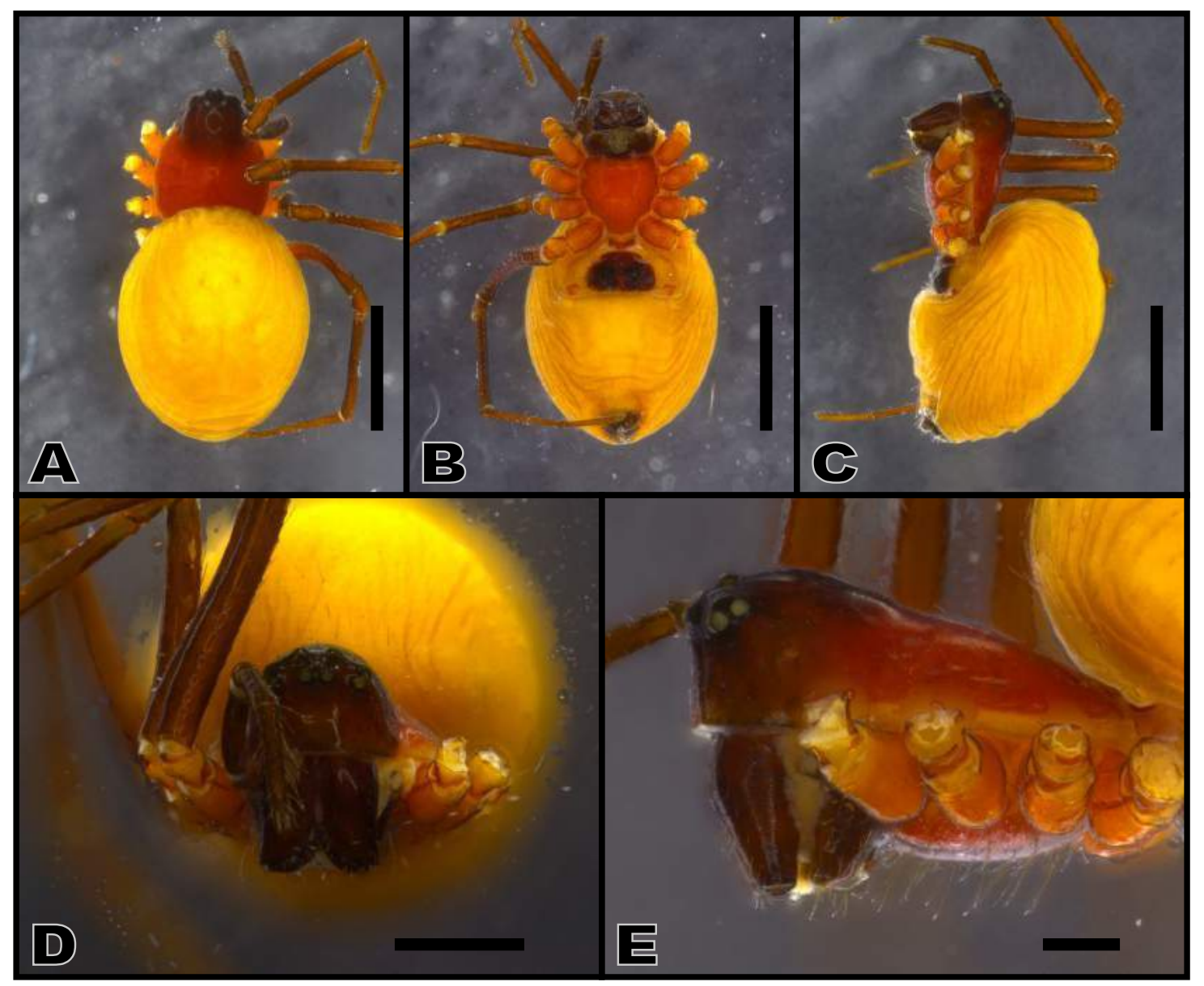

Figura 92. Hypselistoides rubicundus, A-E, corpo da fêmea. A, dorsal; B, ventral; C, lateral; D, frontal; E, detalhe da região cefálica. Escala A-C, 1,0mm; D, 0,5mm; E, $0,2 \mathrm{~mm}$.

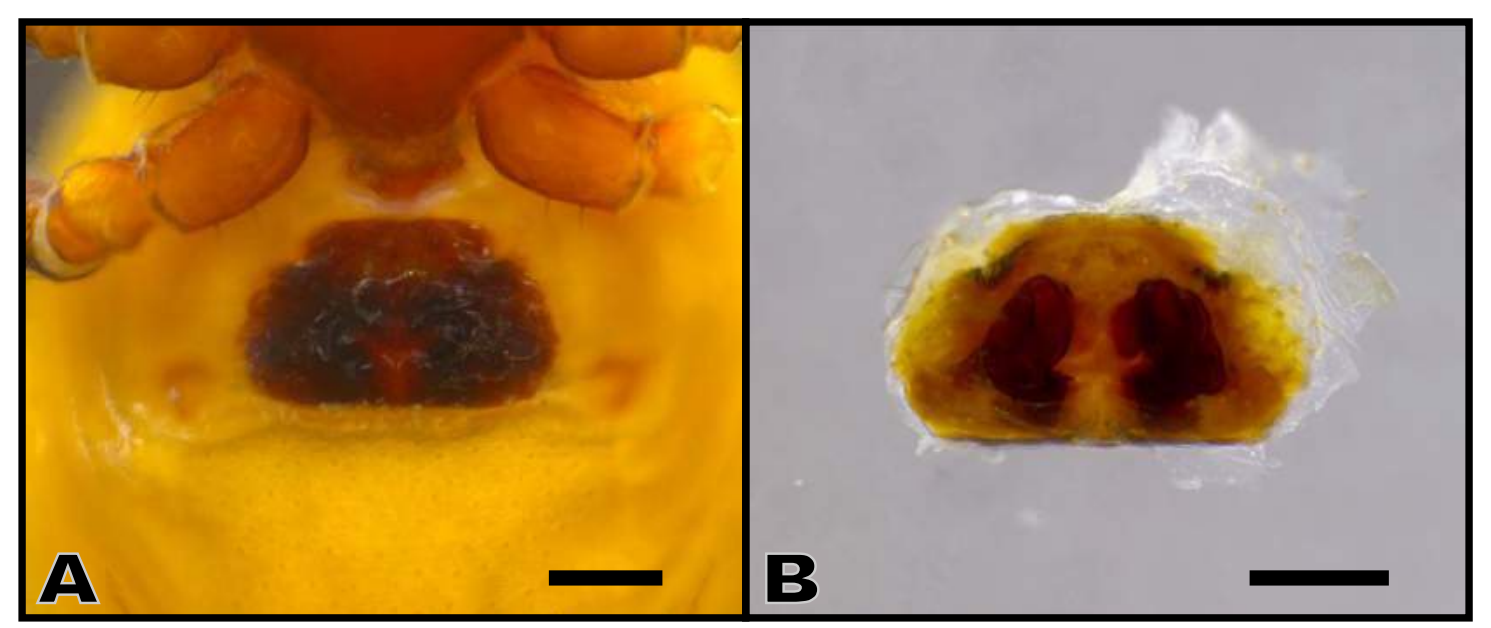

Figura 93. Hypselistoides rubicundus, A-B, epígino da fêmea. A, ventral; B, dorsal. Escala 0,2mm. 


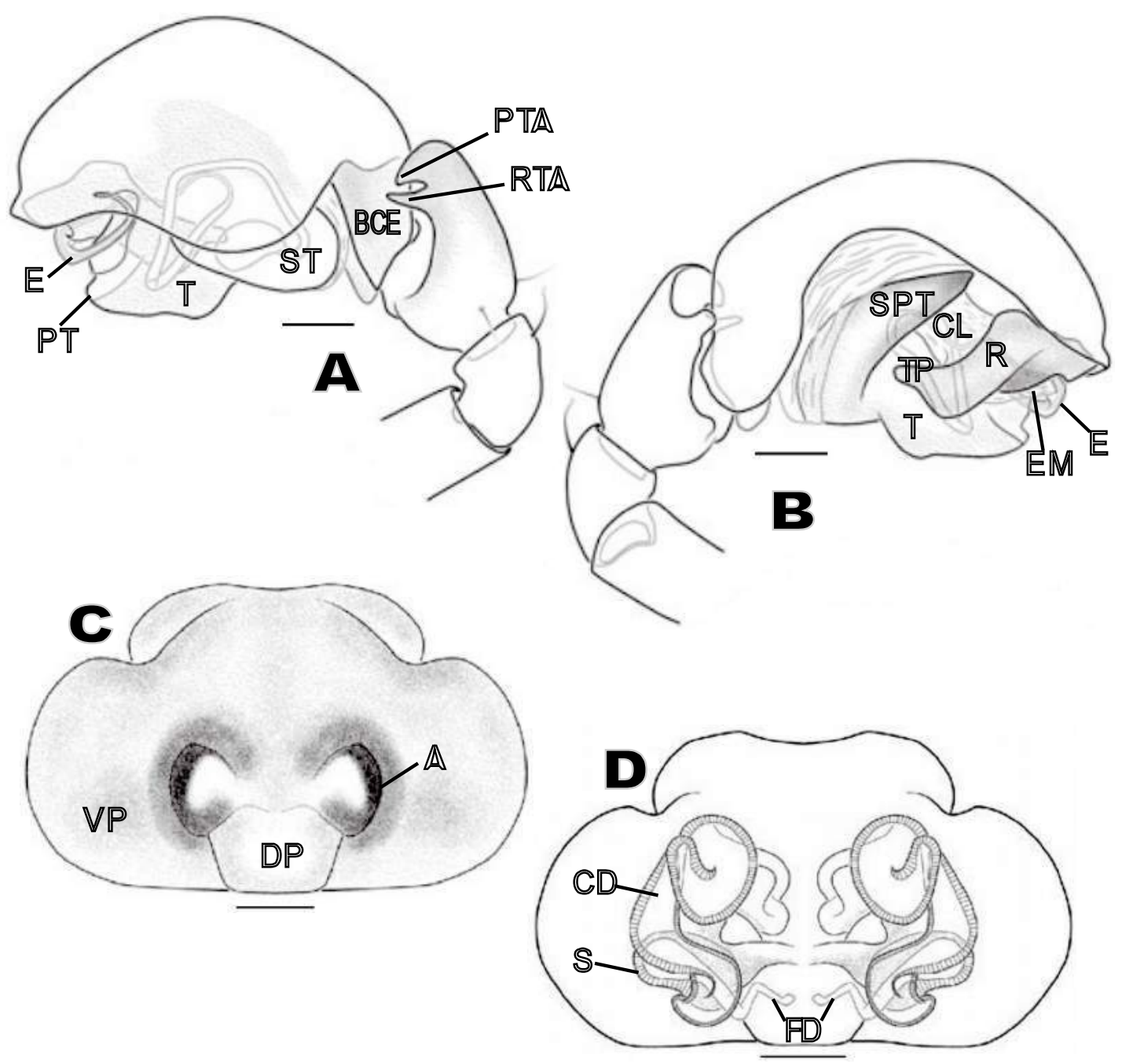

Figura 94. Hypselistoides rubicundus, A-B, palpo do macho; C, epígino da fêmea. A, retrolateral; B, prolateral; C, ventral; D, dorsal. Escala 0,1mm. A, átrio; BCE, excavação basal do címbio; CD, duto de copulação; CL, column; DP, placa dorsal do epígino; E, êmbolo; EM, membrana embólica; FD, duto de fertilização; PT, protégulo; PTA, apófise prolateral da tíbia; R, radix; RTA, apófise retrolateral da tíbia; S, espermateca; SPT, supratégulo; ST, subtégulo; T, tégulo; TP, cauda do radix; VP, placa ventral do epígino. Ilustração de Miller, 2007. 


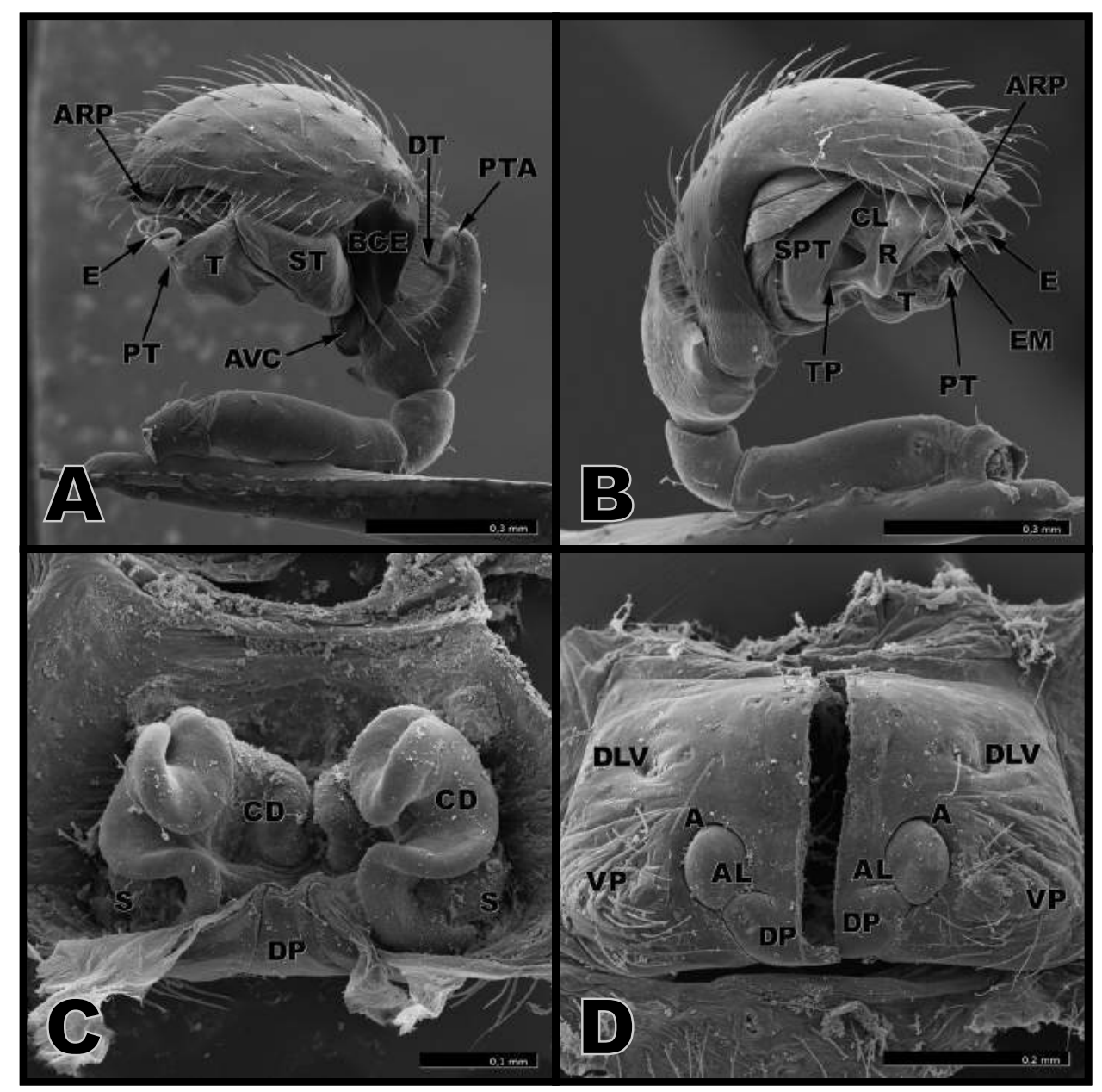

Figura 95. Hypselistoides rubicundus. A-B, palpo do macho; $\mathrm{C}-\mathrm{D}$, epígino da fêmea. A, vista retrolateral. $\mathrm{B}$, vista prolateral. $\mathrm{C}$, vista dorsal. $\mathrm{D}$, vista ventral. 


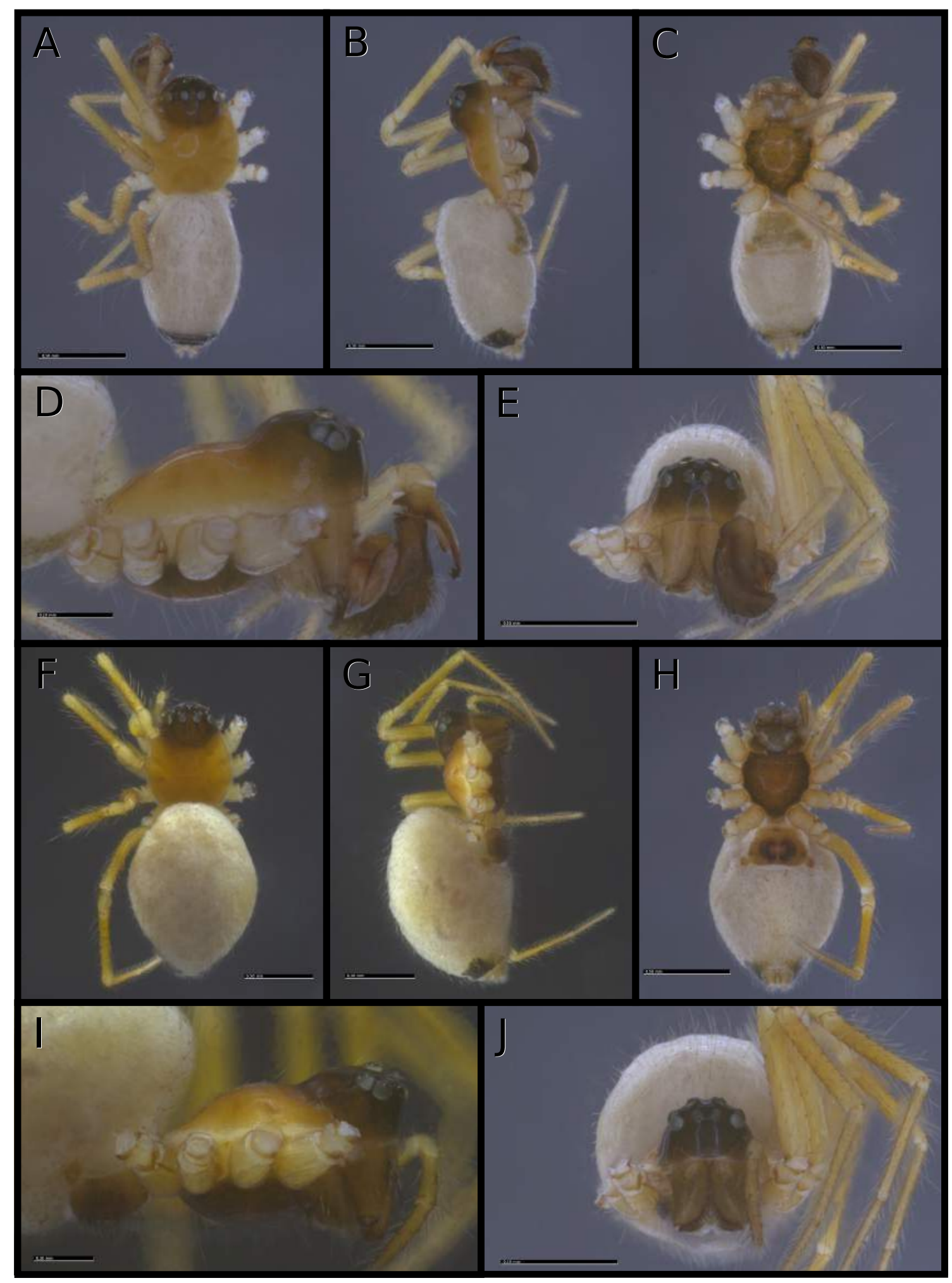

Figura 96. Hypselistoides sp.nov.01, A-E, corpo do macho, F-J, corpo da fêmea. A, F, dorsal; B, G, lateral; C, H, ventral; D, I, detalhe da região cefálica; E, J, frontal. Escala A-C, F-H 1,0mm; D, I, 0,2mm; E, J, 0,5mm. 


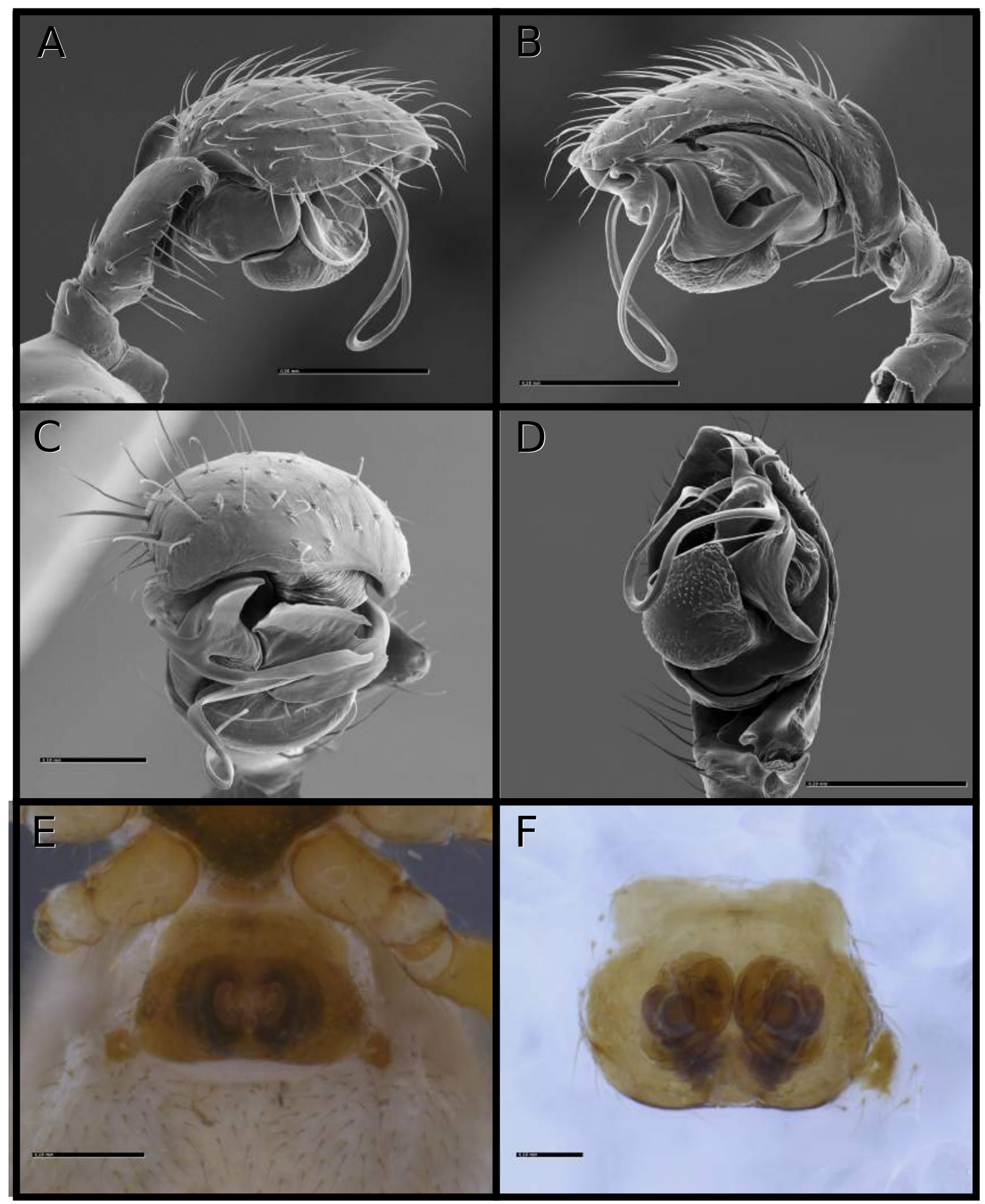

Figura 97. Hypselistoides sp.nov.01, A-D, palpo do macho, E-F, epígino da fêmea. A, retrolateral; B, prolateral; C, frontal; D, ventral, E, ventral; F, dorsal. Escala A-B, E, 0,2mm, C-D, F, 0,1mm. 

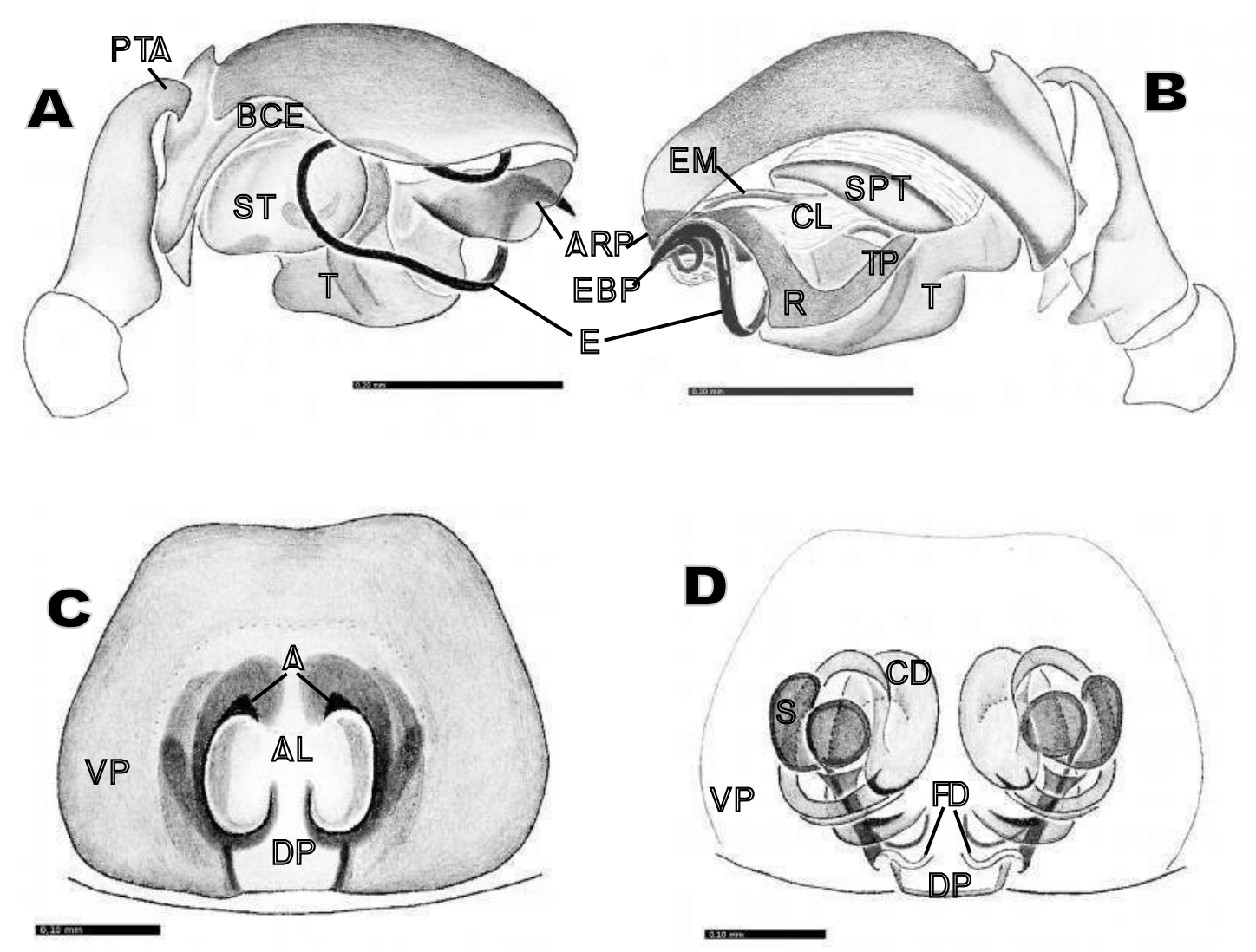

Figura 98. Hypselistoides sp.nov.01, A-B, palpo do macho; C-D, epígino da fêmea. A, retrolateral; B, prolateral; C, ventral; D, dorsal. Escala 0,2mm. A, átrio; AL, lóbulo anterior da placa dorsal do epígino; ARP, processo anterior do radix; BCE, excavação basal do címbio; EBP, processo basal do êmbolo; CD, duto de copulação; CL, column; DP, placa dorsal do epígino; E, êmbolo; EM, membrana embólica; FD, duto de fertilização; PTA, apófise prolateral da tíbia; R, radix; S, espermateca; SPT, supratégulo; ST, subtégulo; T, tégulo; TP, cauda do radix; VP, placa ventral do epígino. Ilustração de Rodrigues, in prep. 


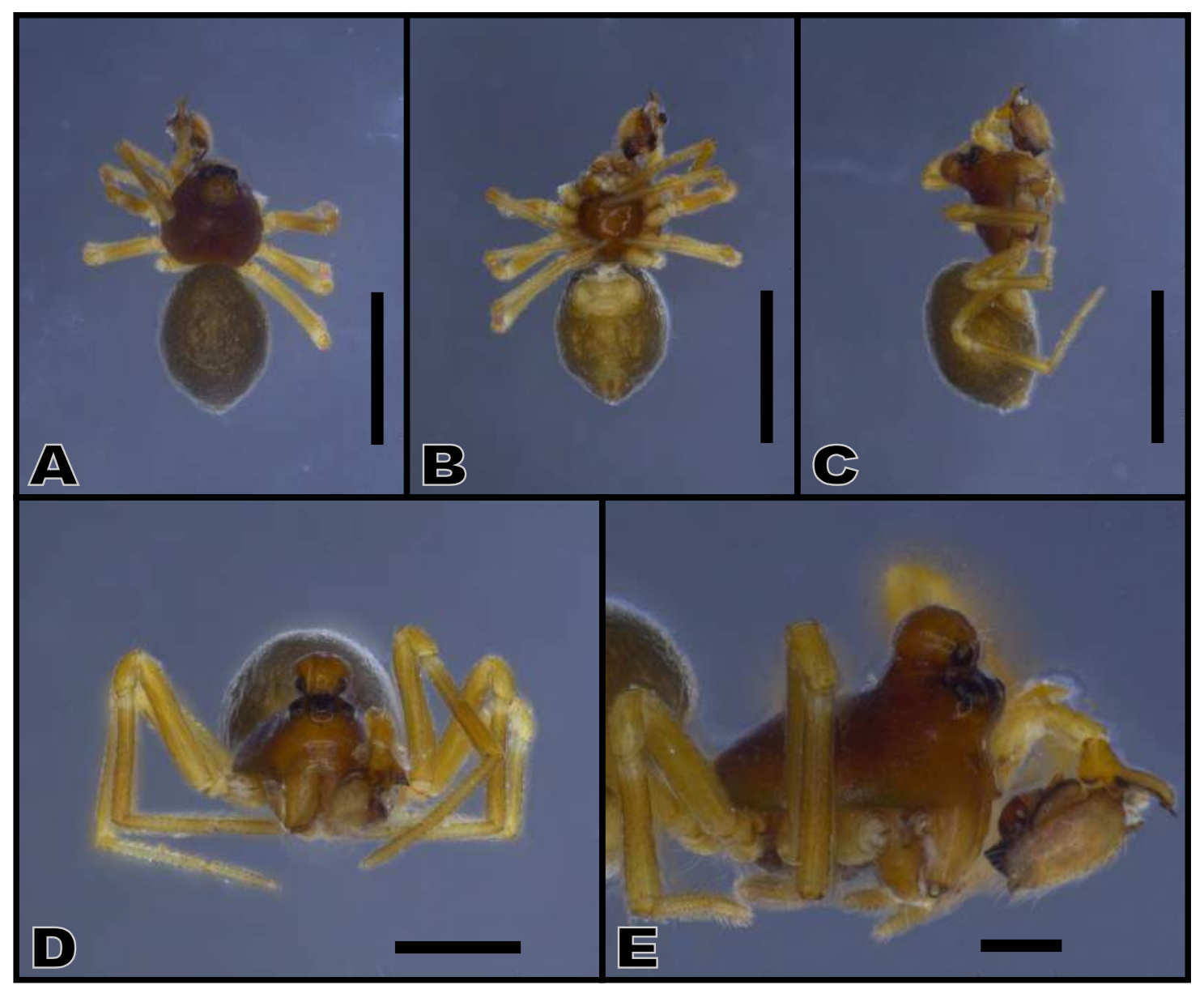

Figura 99. Clitolyna alticeps, A-E, corpo do macho. A, dorsal; B, ventral; C, lateral; D, frontal; E, detalhe da região cefálica. Escala A-C, 1,0mm; D, 0,5mm; E, 0,2mm.

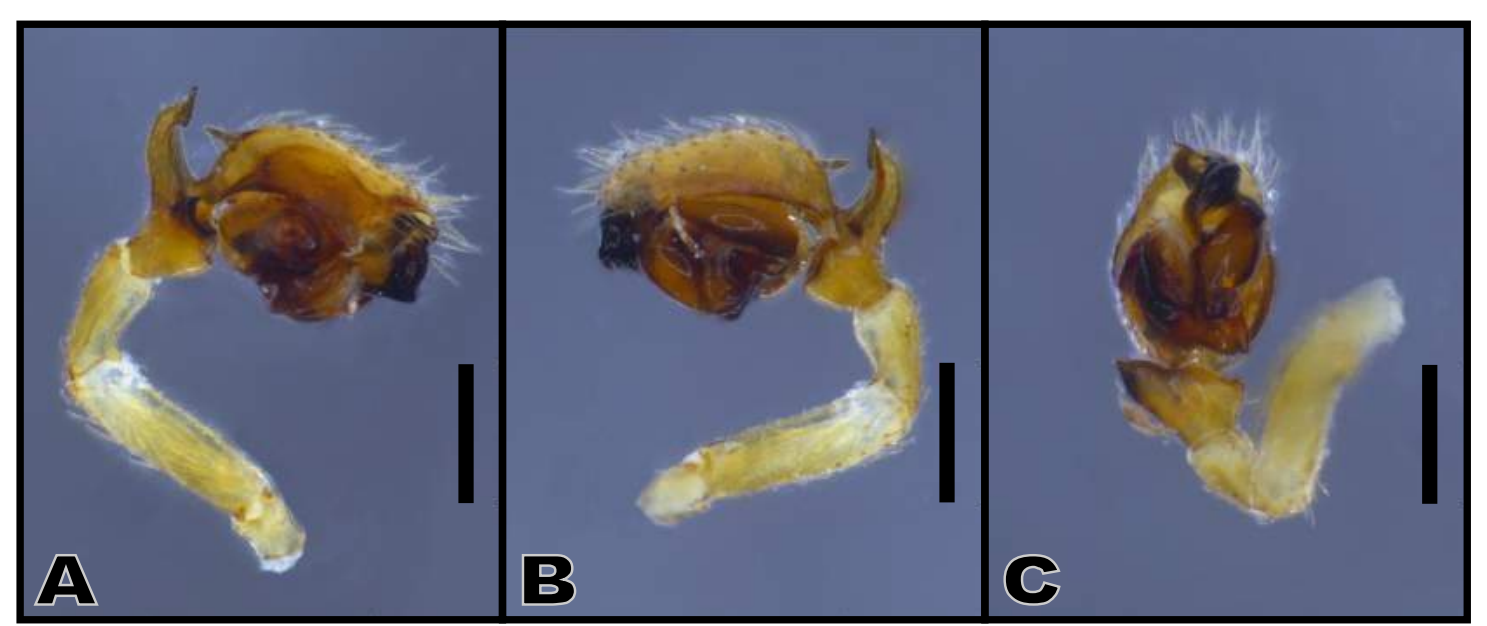

Figura 100. Clitolyna alticeps, A-C, palpo do macho. A, retrolateral; B, prolateral; C, ventral. Escala 0,2mm. 


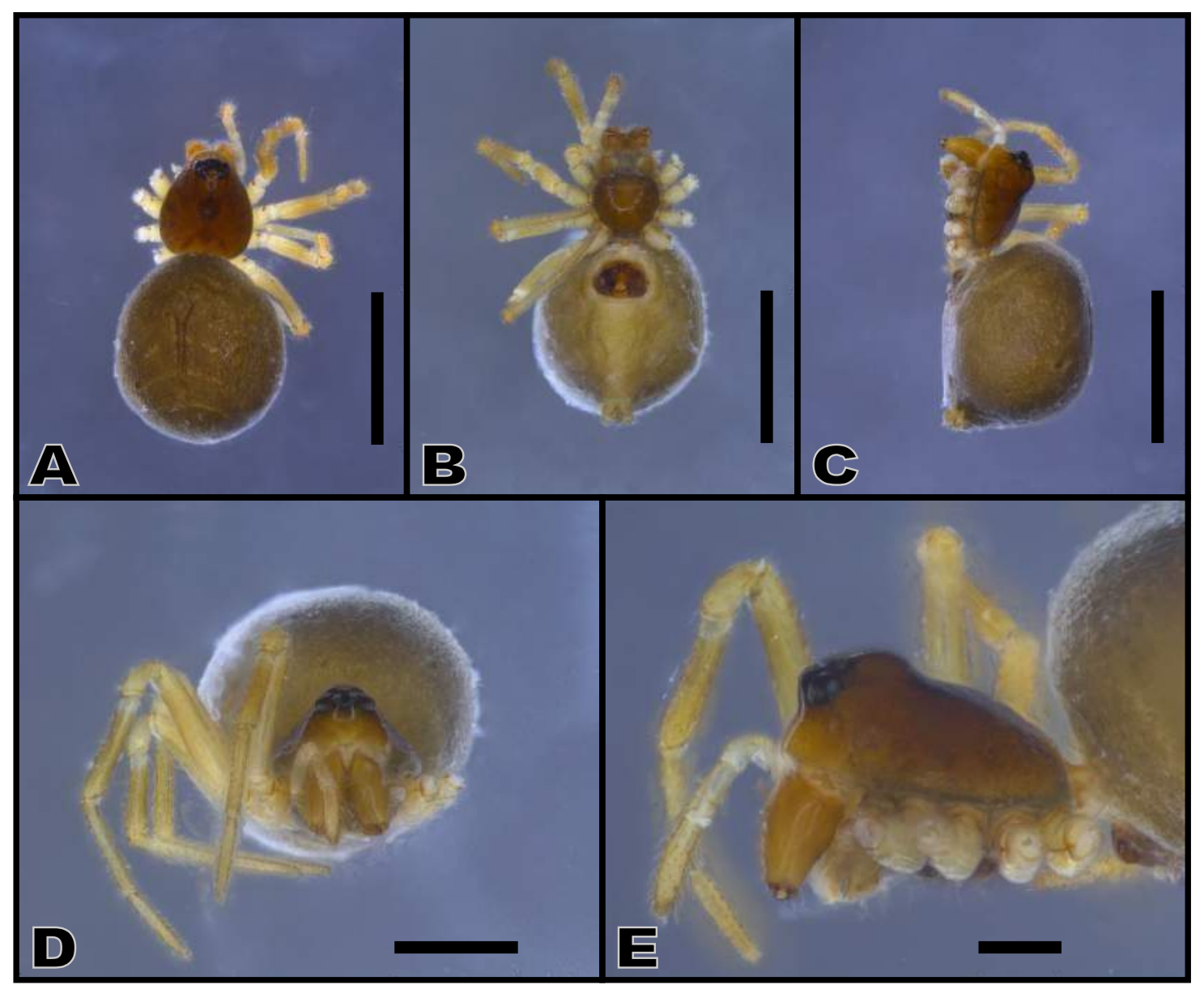

Figura 101. Clitolyna alticeps, A-E, corpo da fêmea. A, dorsal; B, ventral; C, lateral; D, frontal; E, detalhe da região cefálica. Escala A-C, 1,0mm; D, 0,5mm; E, 0,2mm.

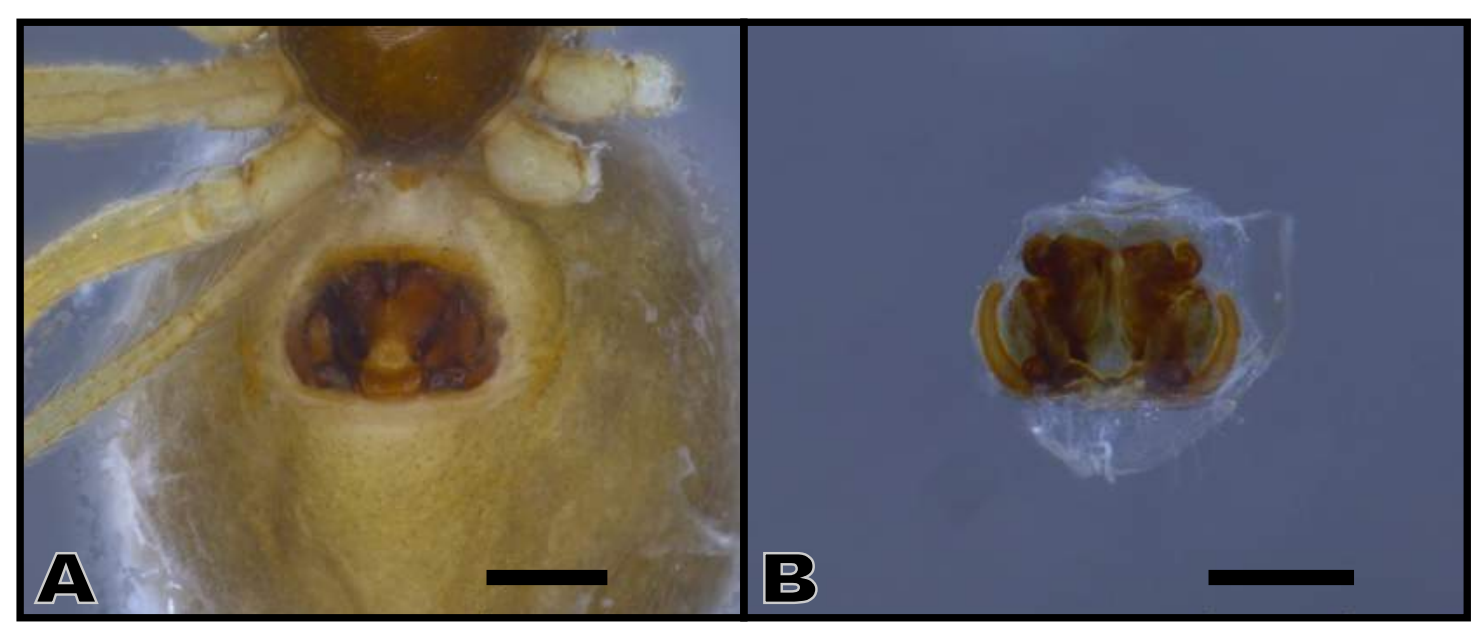

Figura 102. Clitolyna alticeps, A-B, epígino da fêmea. A, ventral; B, dorsal. Escala $0,2 \mathrm{~mm}$. 


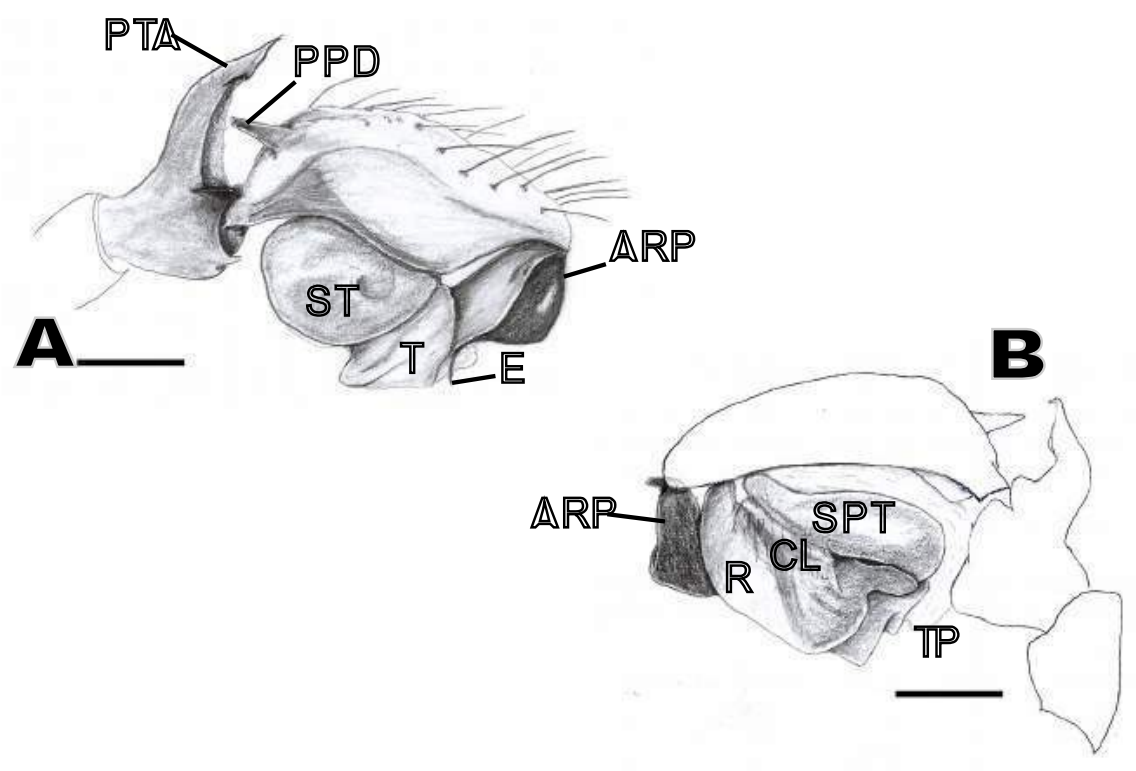

Figura 103. Clitolyna aticeps, A-B, palpo do macho. A, retrolateral; B, prolateral. Escala 0,1mm. ARP, processo anterior do radix; CL, column; E, êmbolo; PPD, Processo posterior dorsal do címbio; PTA, apófise prolateral da tibia; R, radix; SPT, supratégulo; ST, subtégulo; T, tégulo; TP, cauda do radix; 


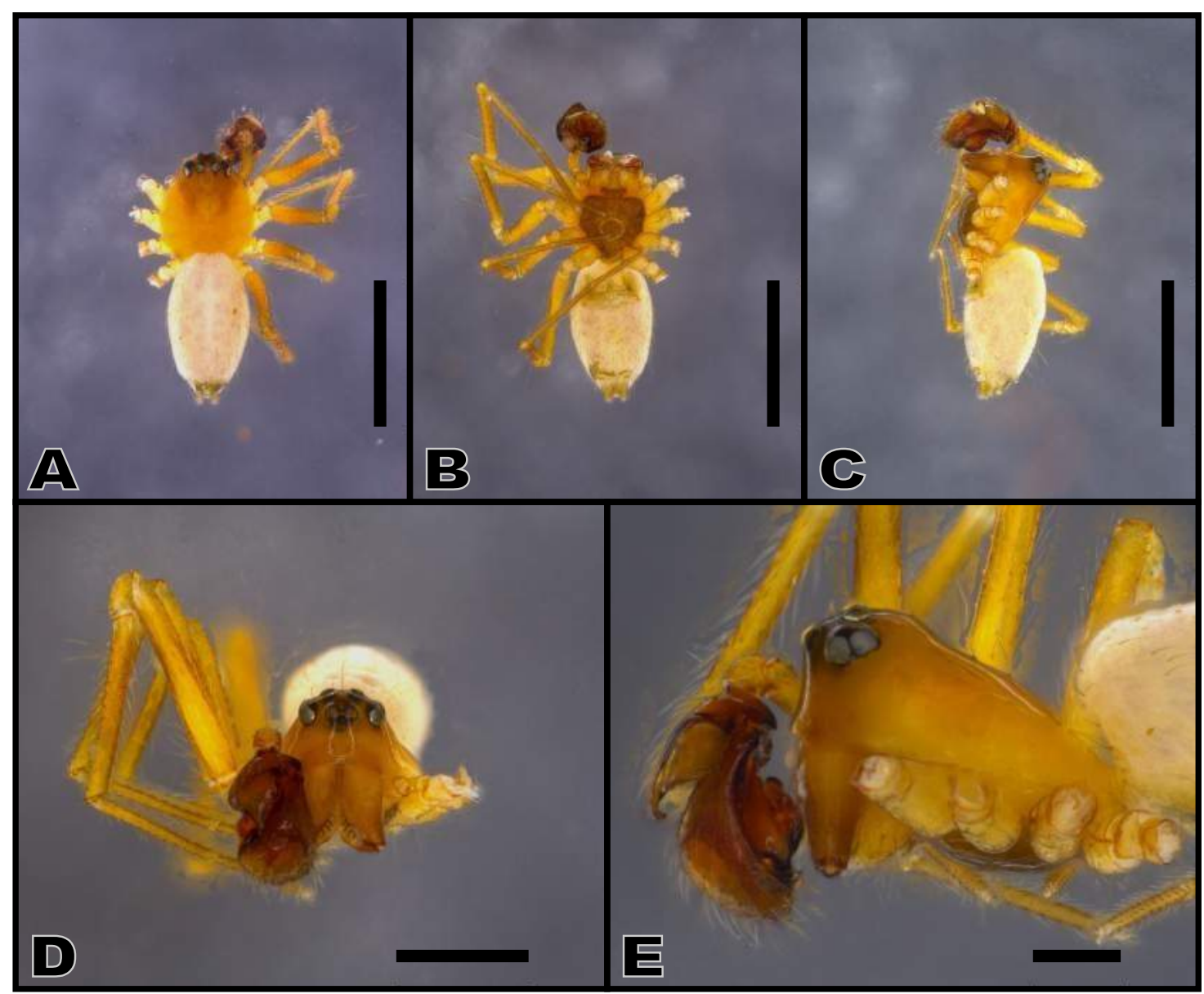

Figura 104. Clitolyna castanea, A-E, corpo do macho. A, dorsal; B, ventral; C, lateral;

D, frontal; E, detalhe da região cefálica. Escala A-C, 1,0mm; D, 0,5mm; E, 0,2mm.

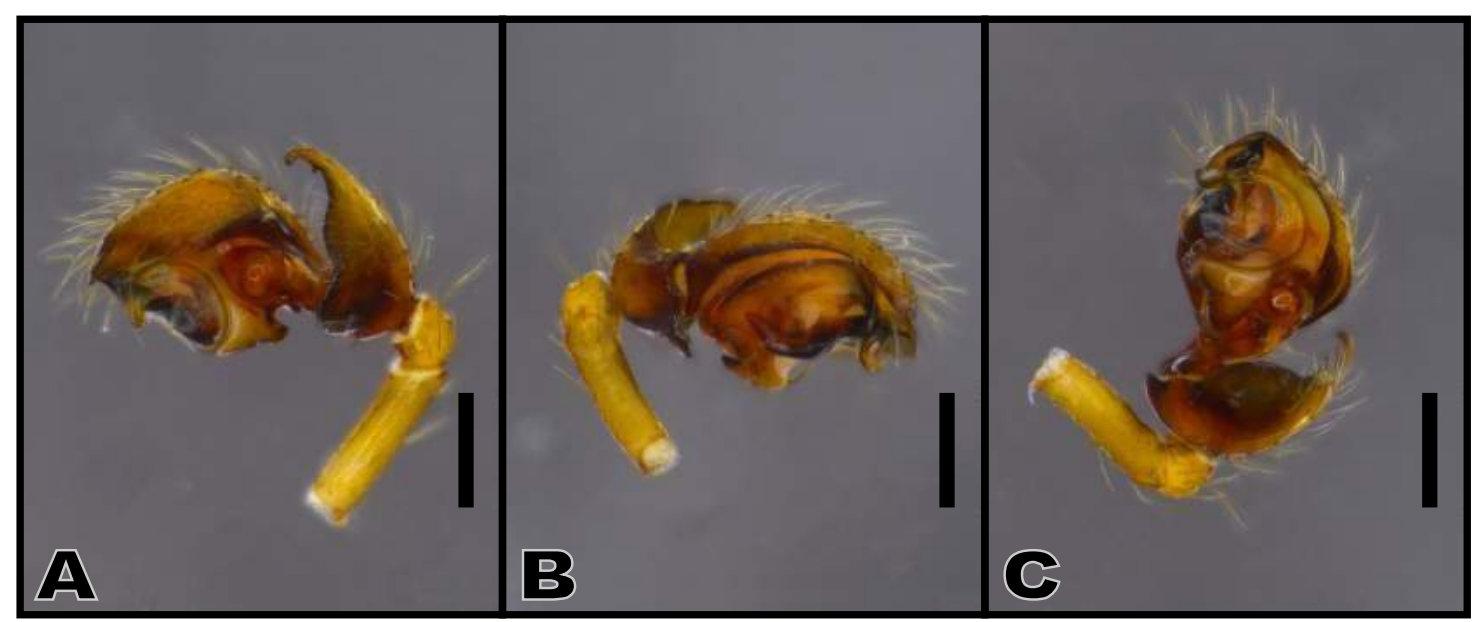

Figura 105. Clitolyna castanea, A-C, palpo do macho. A, retrolateral; B, prolateral; C, ventral. Escala 0,2mm. 


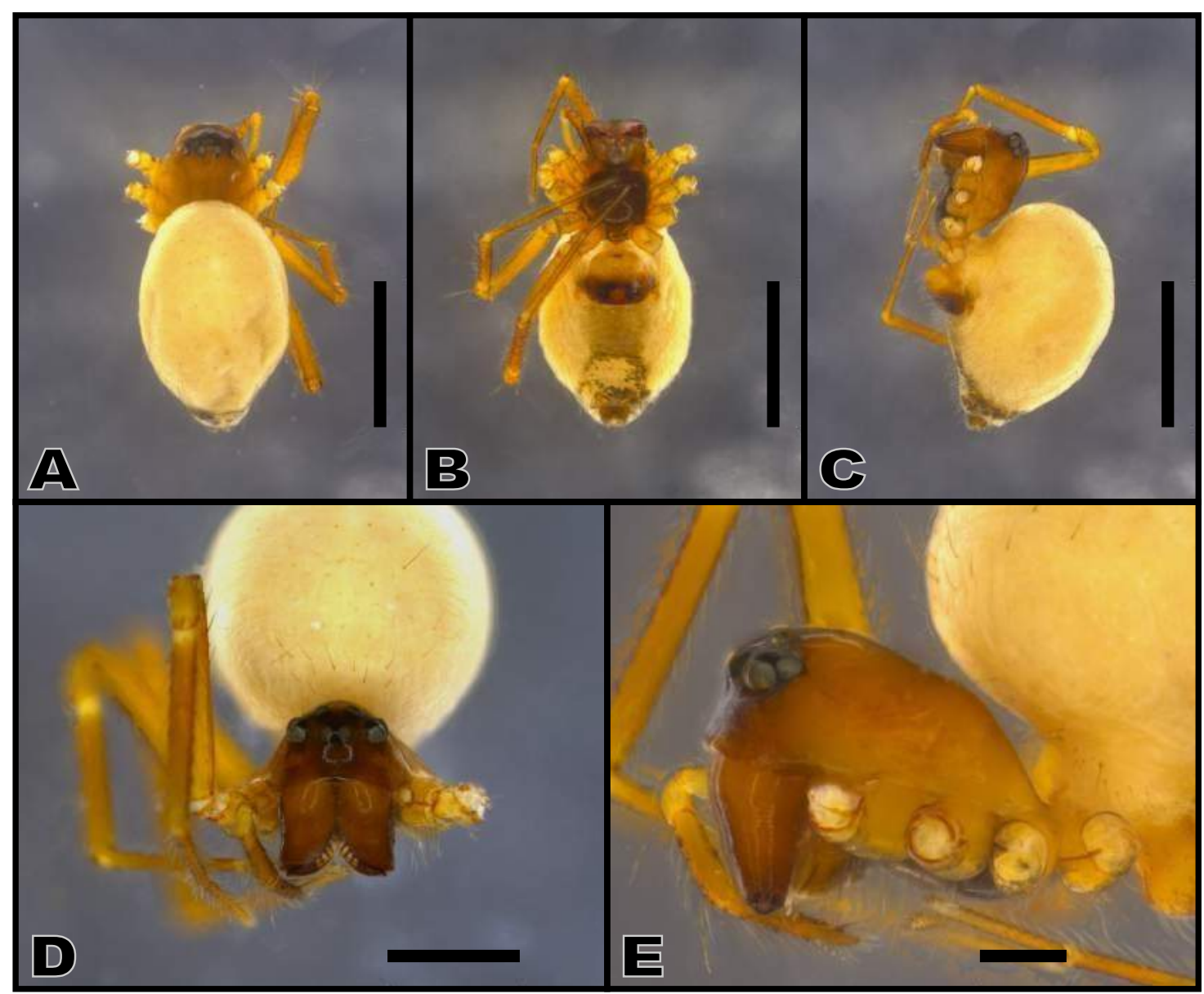

Figura 106. Clitolyna castanea, A-E, corpo da fêmea. A, dorsal; B, ventral; C, lateral;

D, frontal; E, detalhe da região cefálica. Escala A-C, 1,0mm; D, 0,5mm; E, 0,2mm.

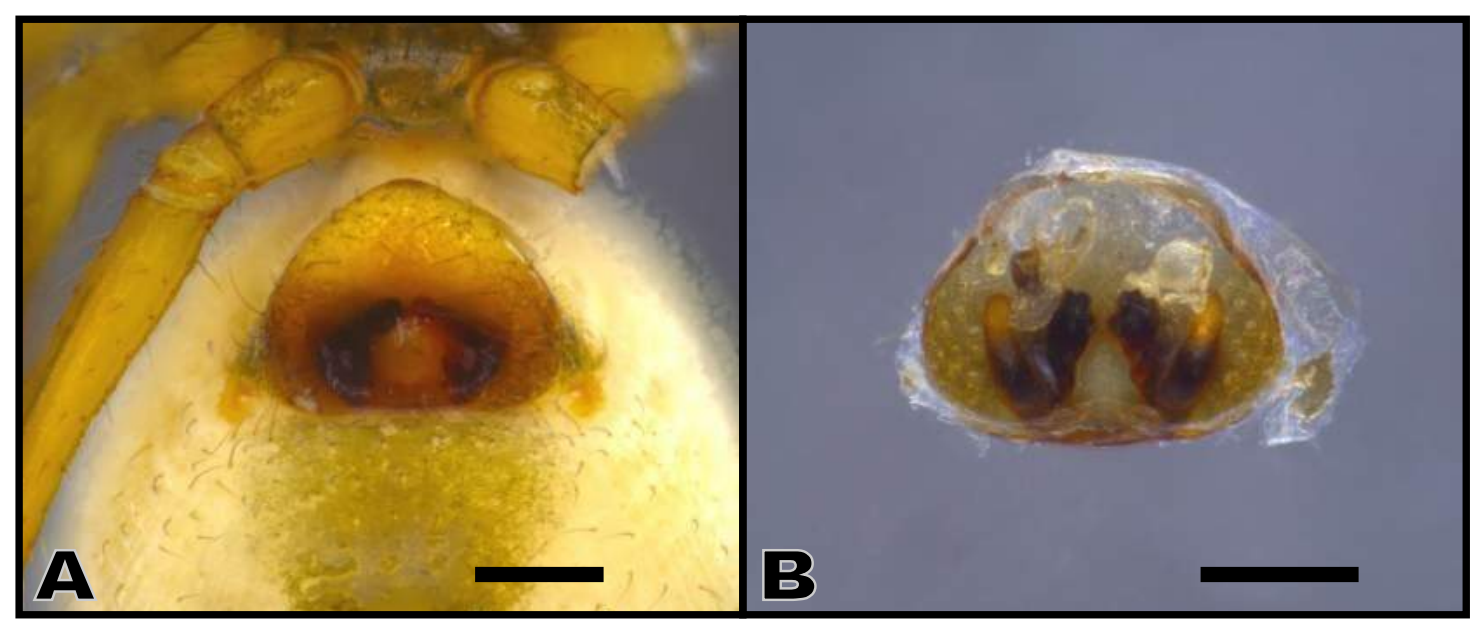

Figura 107. Clitolyna castanea, A-B, epígino da fêmea. A, ventral; B, dorsal. Escala $0,2 \mathrm{~mm}$. 


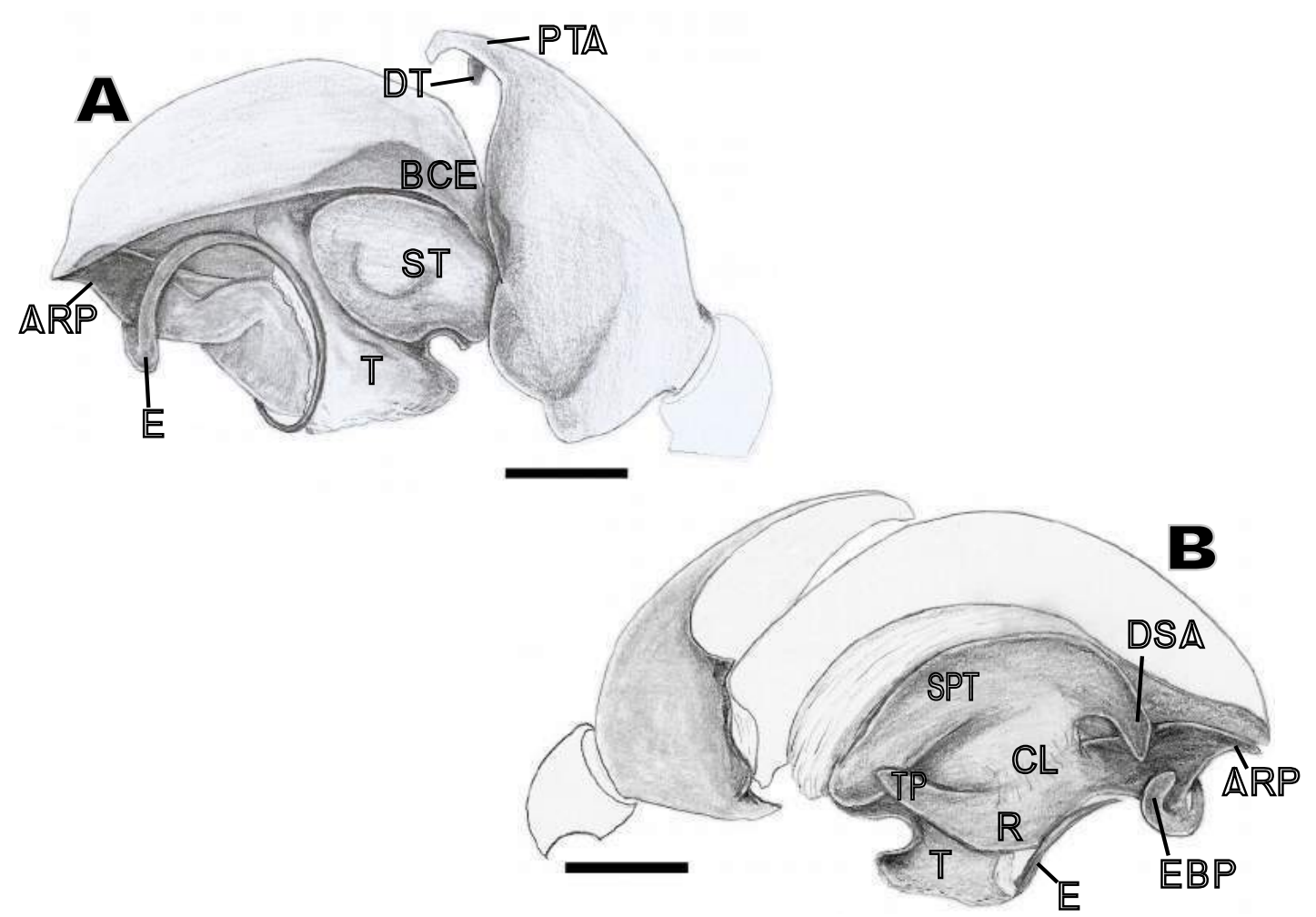

Figura 108. Clitolyna castanea, A-B, palpo do macho. A, retrolateral; B, prolateral. Escala 0,1mm. ARP, processo anterior do radix; BCE, excavação basal do címbio; CL, column; DSA, apófise distal suprategular; DT, dente distal da apófise prolateral da tíbia; E, êmbolo; EBP, processo basal do êmbolo; PTA, apófise prolateral da tíbia; R, radix; SPT, supratégulo; ST, subtégulo; T, tégulo; TP, cauda do radix. 


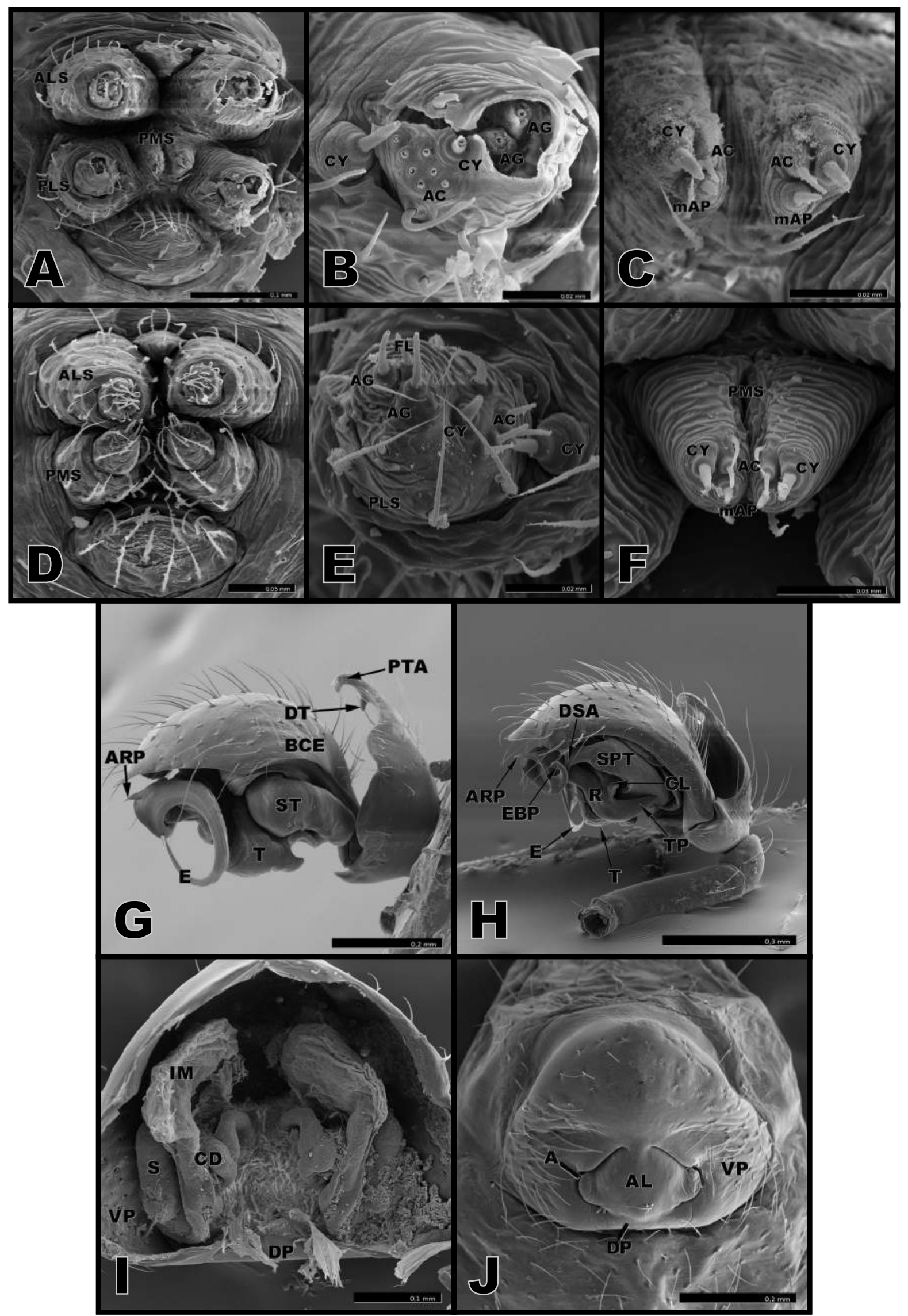

Figura 109. Clitolyna castanea. A-C, fiandeiras da fêmea; D-F, fiandeiras do macho; G-H, palpo do macho; I-J, epígino da fêmea. A e D, vista geral. B e E, detalhe do PLS. $\mathrm{C}$ e $\mathrm{F}$, detalhe do PMS. G, vista retrolateral. H, vista prolateral. I, vista dorsal. J vista ventral. 


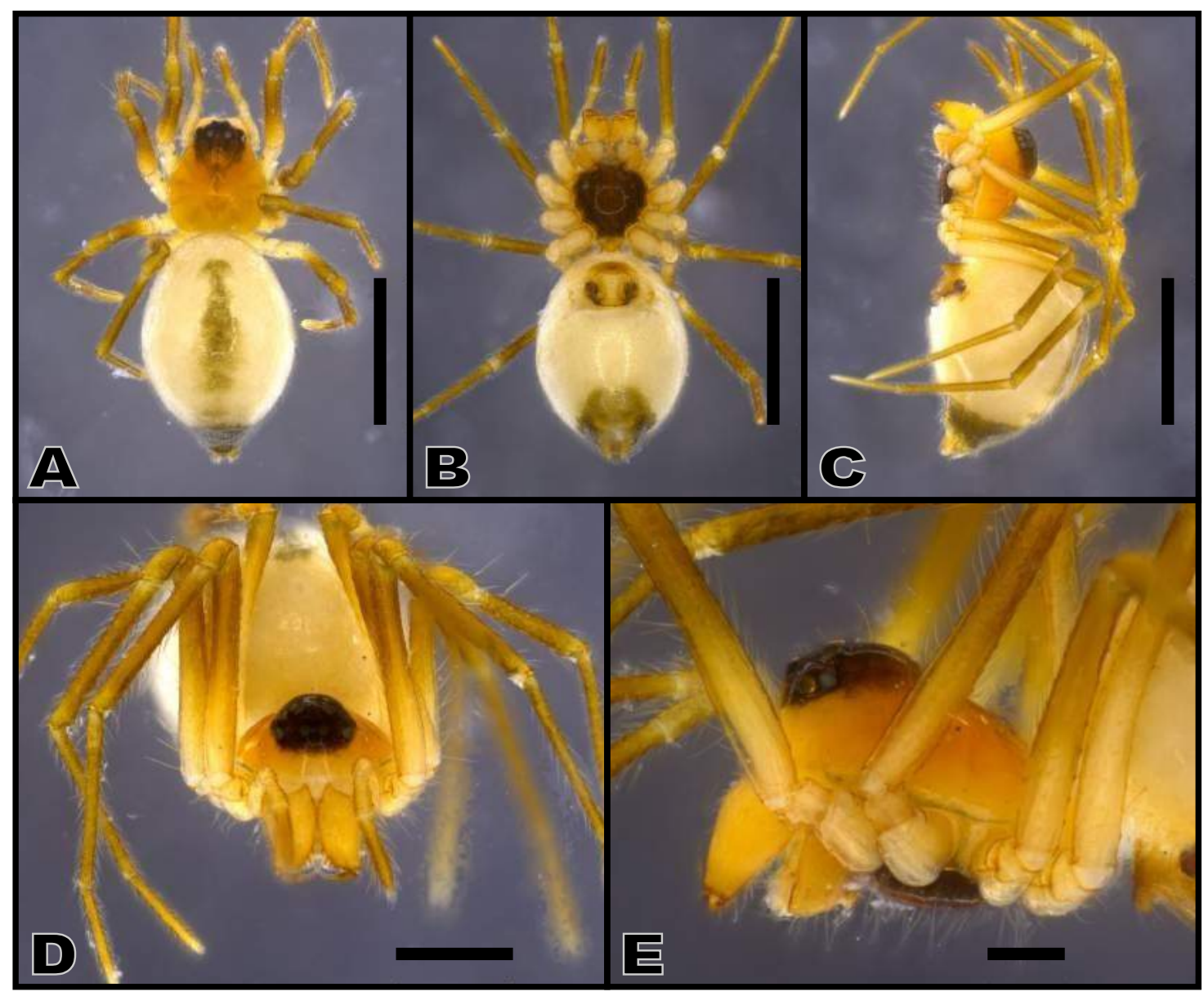

Figura 110. Clitolyna crassa, A-E, corpo da fêmea. A, dorsal; B, ventral; C, lateral; D, frontal; E, detalhe da região cefálica. Escala A-C, 1,0mm; D, 0,5mm; E, 0,2mm.

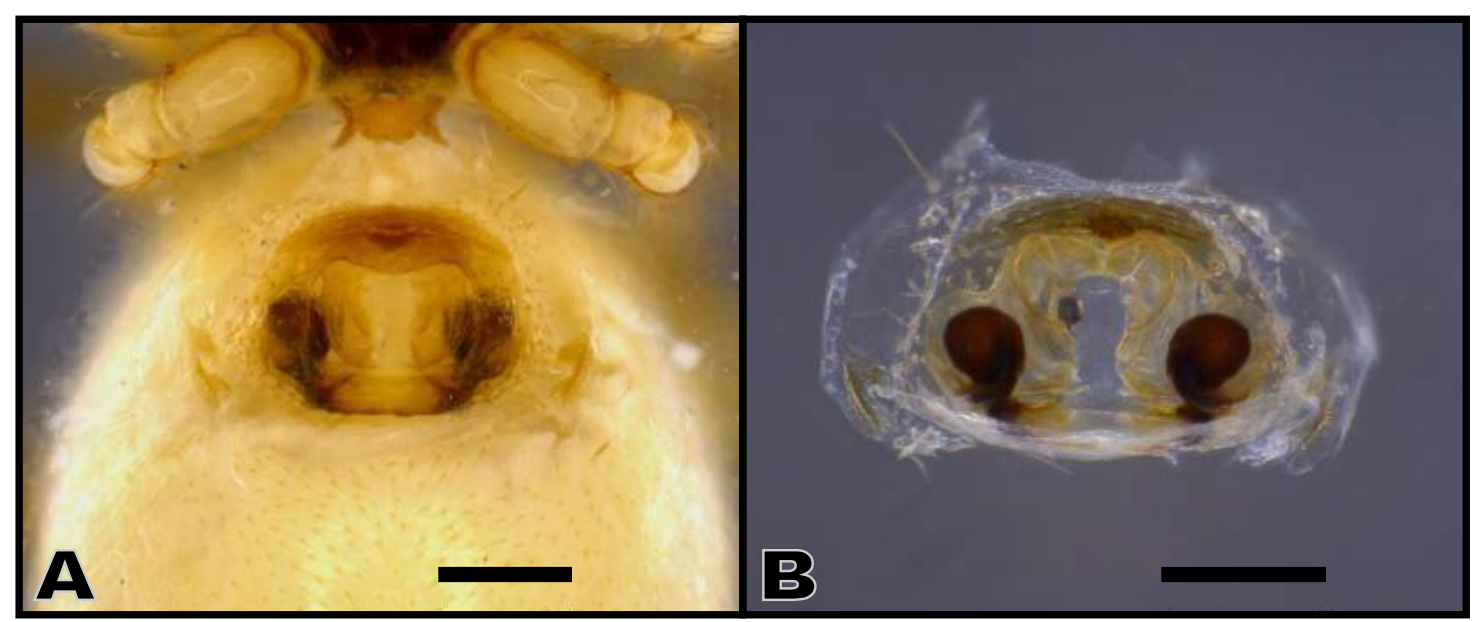

Figura 111. Clitolyna crassa, A-B, epígino da fêmea. A, ventral; B, dorsal. Escala $0,2 \mathrm{~mm}$ 

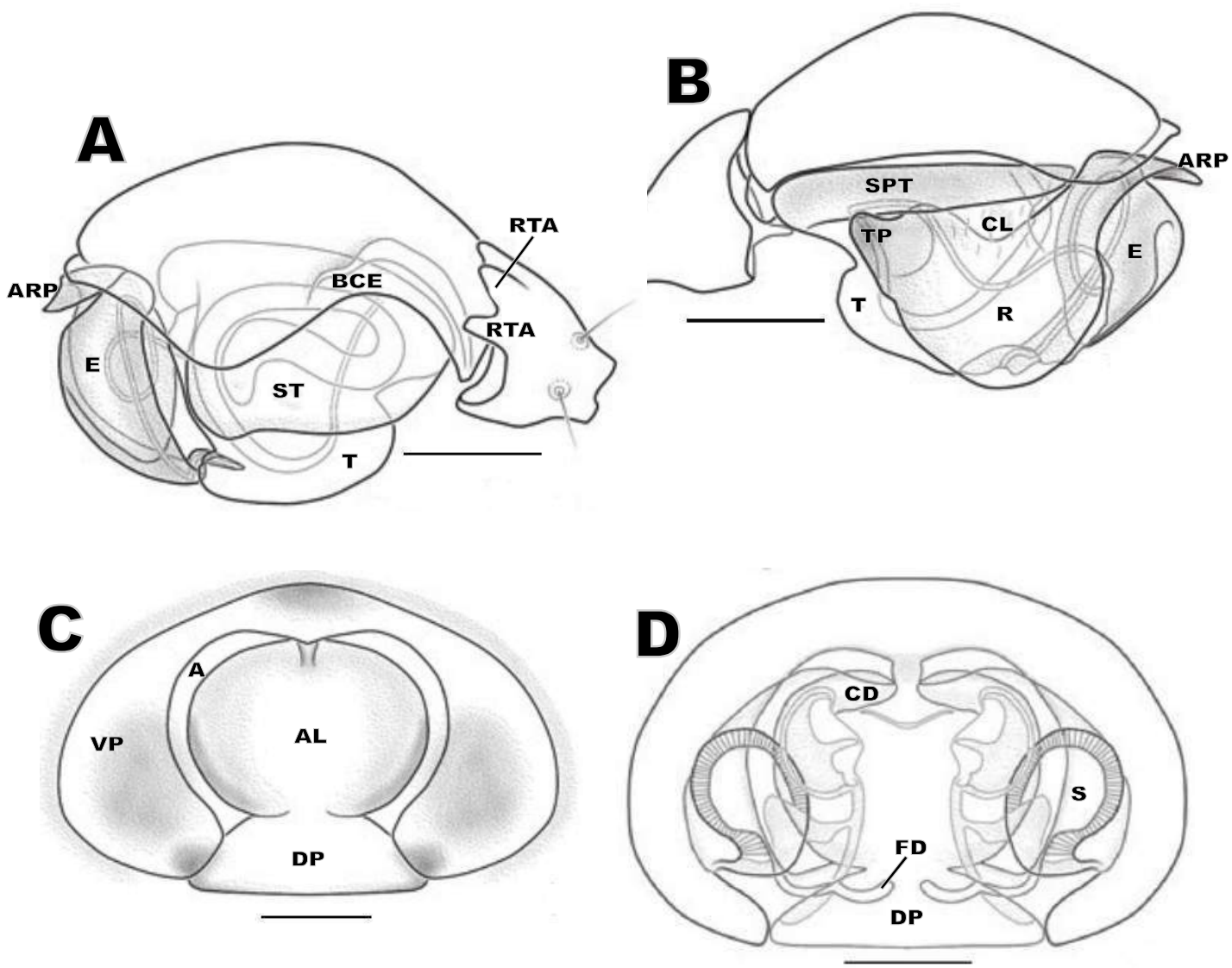

Figura 112. Clitolyna crassa, A-B, palpo do macho; C-D, epígino da fêmea. A, retrolateral; B, prolateral; C, ventral; D, dorsal. Escala 0,1mm. A, átrio; AL, lóbulo anterior da placa dorsal do epígino; ARP, processo anterior do radix; BCE, cavidade basal do címbio; CD, duto de copulação; CL, column; DP, placa dorsal do epígino; E, êmbolo; FD, duto de fertilização; PTA, apófise prolateral da tíbia; R, radix; RTA, apófise retrolateral da tíbia; S, espermateca; SPT, supratégulo; ST, subtégulo; T, tégulo; TP, cauda do radix; VP, placa ventral do epígino. 


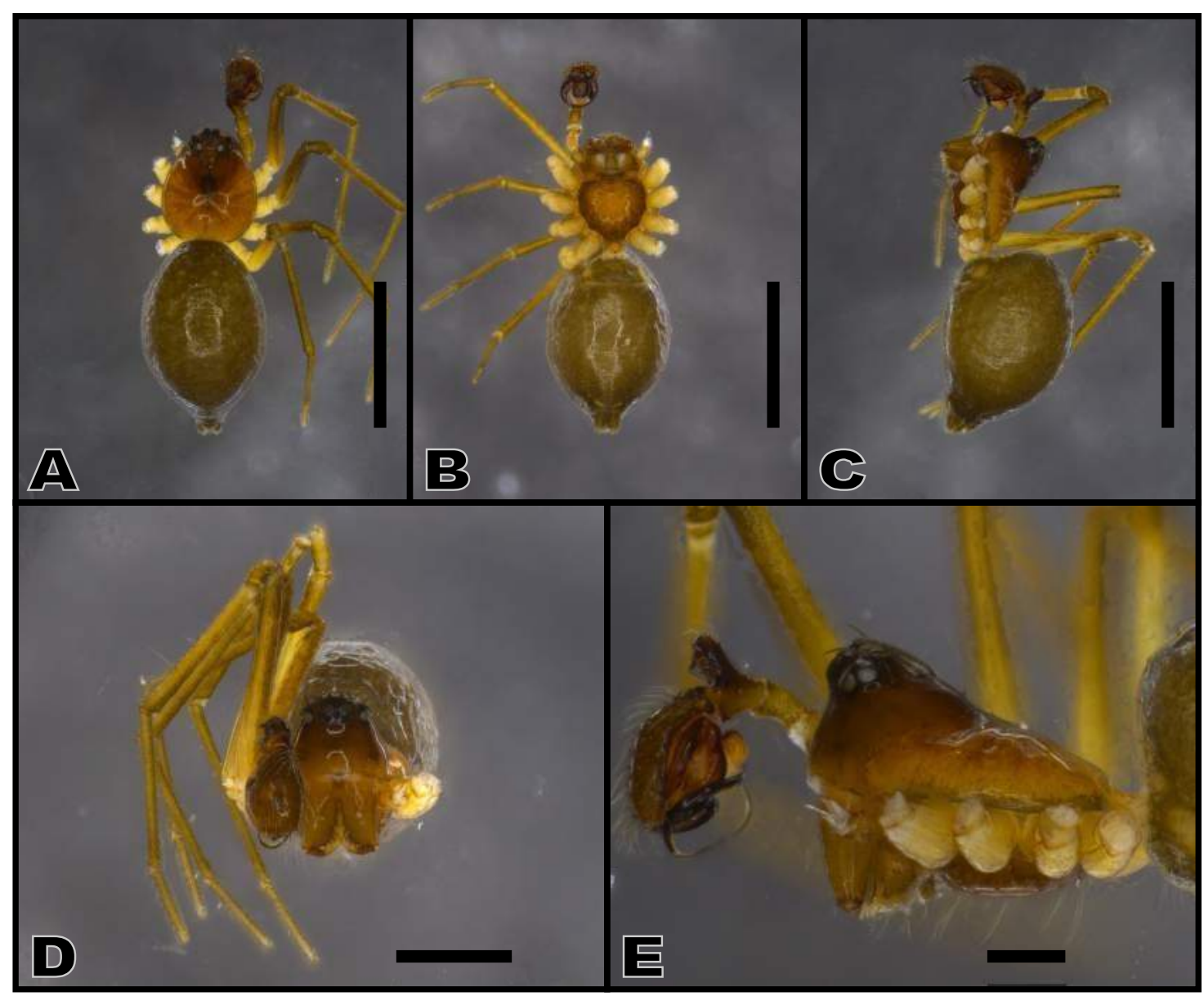

Figura 113. Clitolyna fastibilis, A-E, corpo do macho. A, dorsal; B, ventral; C, lateral; D, frontal; E, detalhe da região cefálica. Escala A-C, 1,0mm; D, 0,5mm; E, 0,2mm.

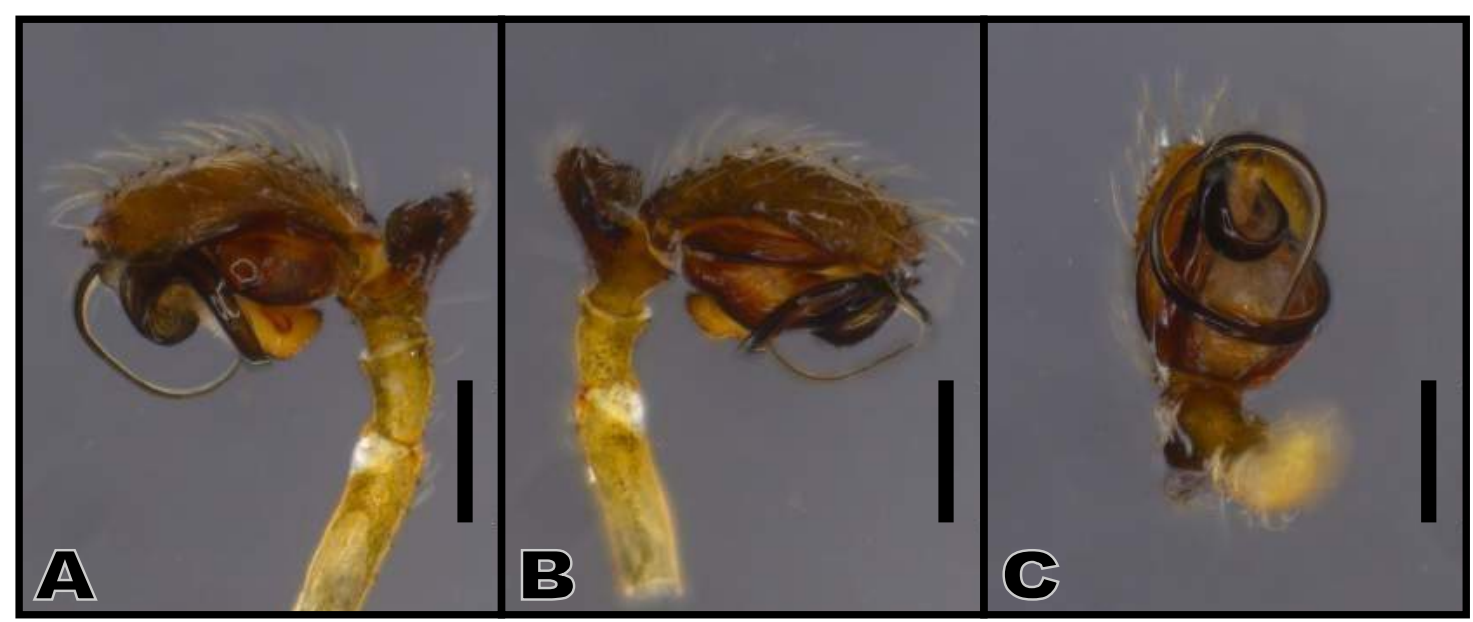

Figura 114. Clitolyna fastibilis, A-C, palpo do macho. A, retrolateral; B, prolateral; C, ventral. Escala 0,2mm. 


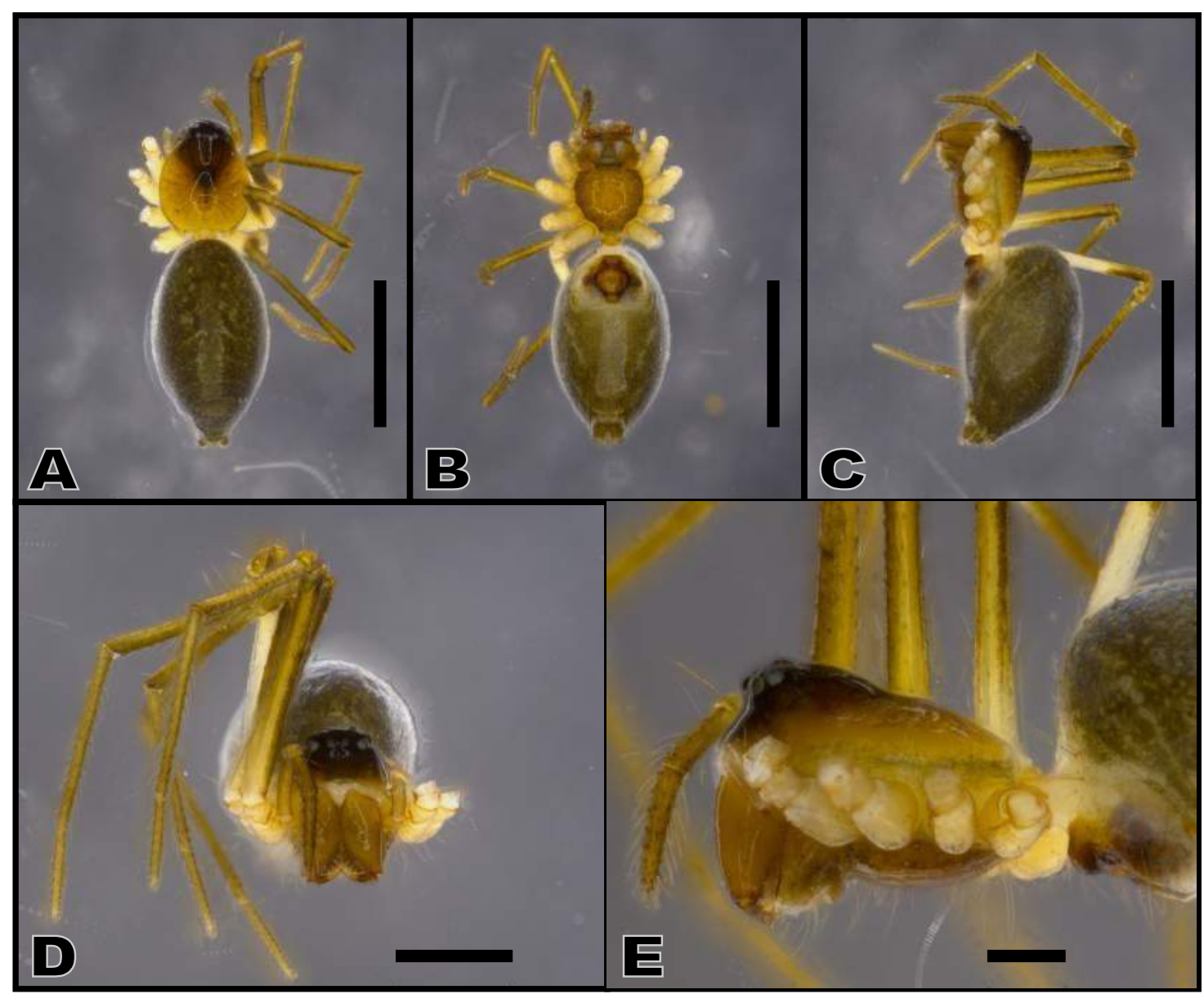

Figura 115. Clitolyna fastibilis, A-E, corpo da fêmea. A, dorsal; B, ventral; C, lateral;

D, frontal; E, detalhe da região cefálica. Escala A-C, 1,0mm; D, 0,5mm; E, 0,2mm.

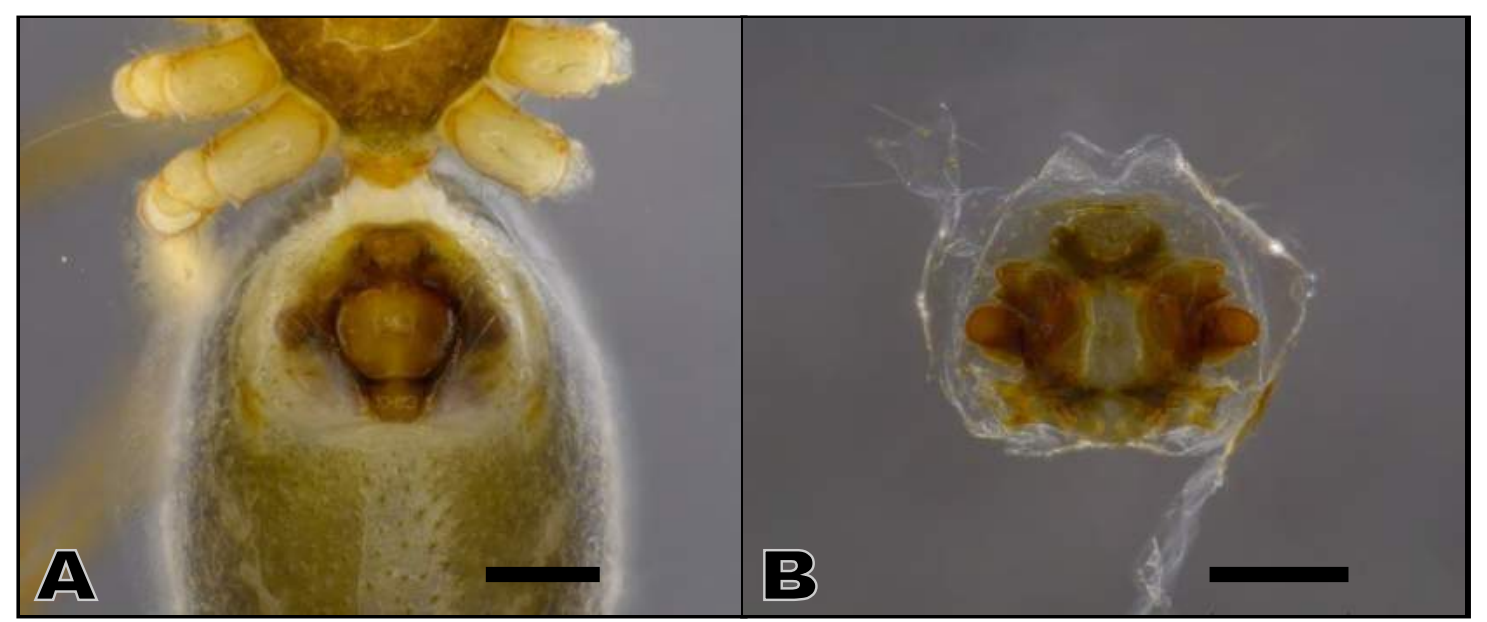

Figura 116. Clitolyna fastibilis, A-B, epígino da fêmea. A, ventral; B, dorsal. Escala $0,2 \mathrm{~mm}$. 


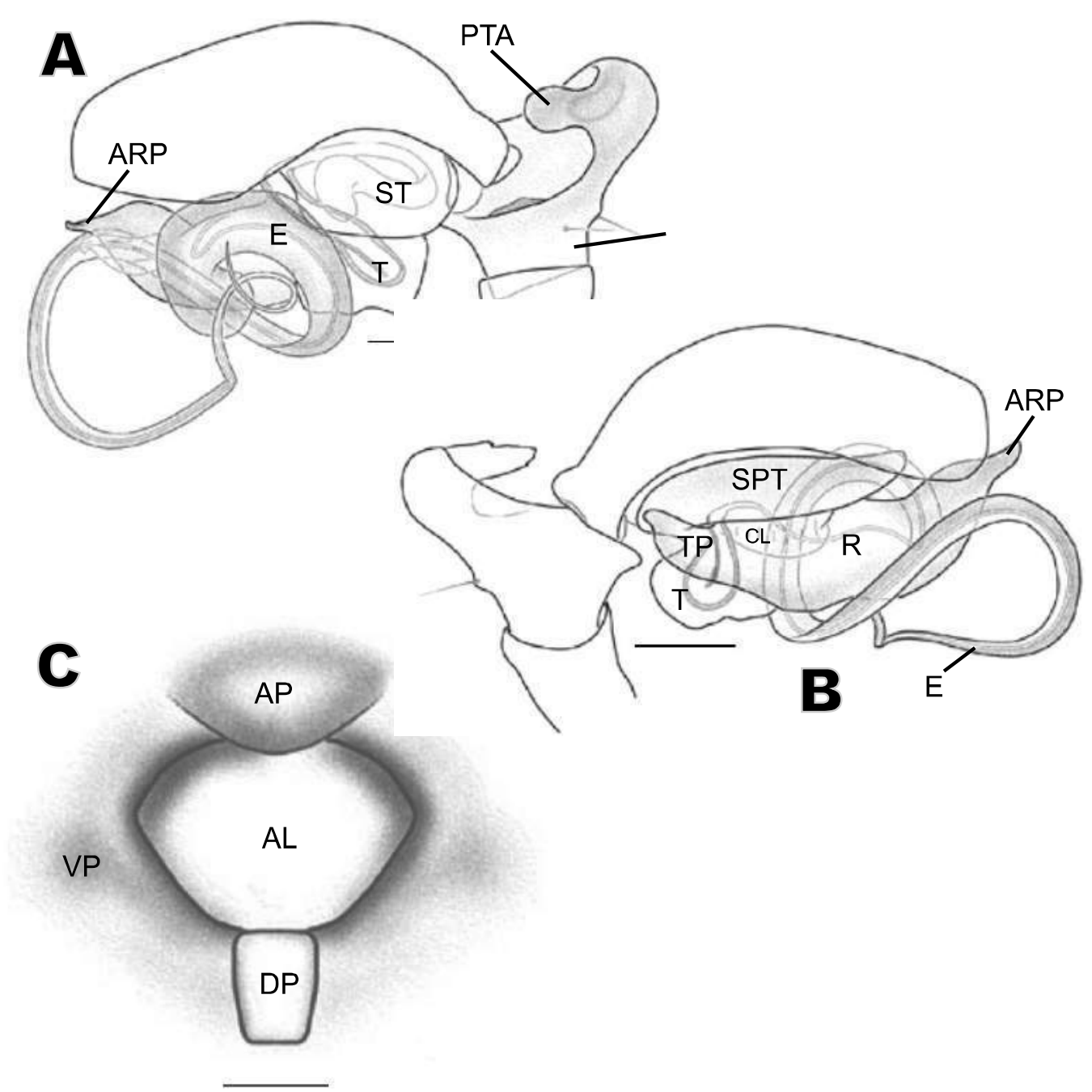

Figura 117. Clitolyna fastibilis, A-B, palpo do macho; C, epígino da fêmea. A, retrolateral; B, prolateral; C, ventral. Escala 0,1mm. A, átrio; AL, lóbulo anterior da placa dorsal do epígino; ARP, processo anterior do radix; CL, column; DP, placa dorsal do epígino; E, êmbolo; PTA, apófise prolateral da tíbia; R, radix; SPT, supratégulo; ST, subtégulo; T, tégulo; TP, cauda do radix; VP, placa ventral do epígino. Ilustração de Miller, 2007. 


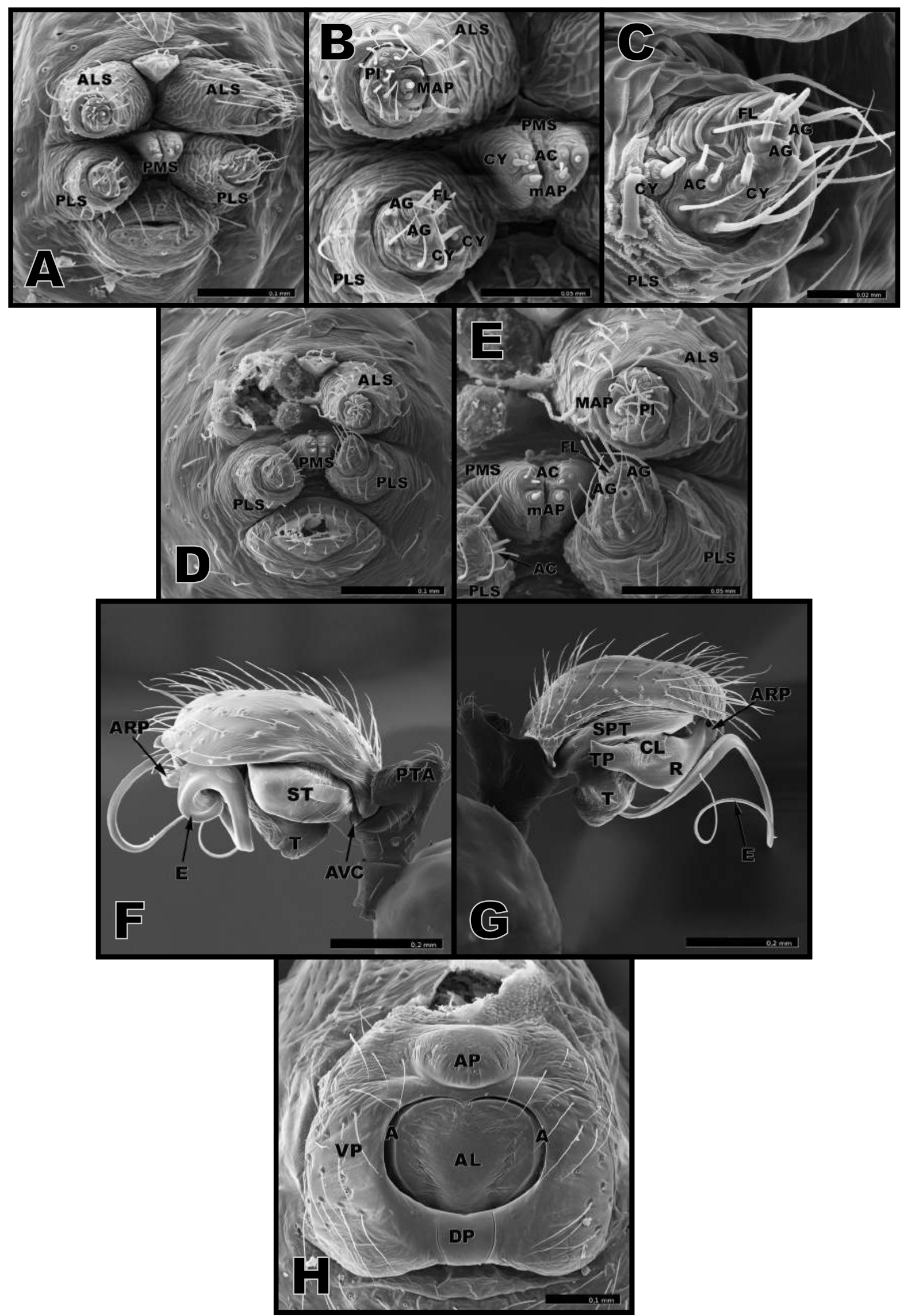

Figura 118. Clitolyna fastibilis. A-C, fiandeiras da fêmea; D-E, fiandeiras do macho; F-G, palpo do macho; H, epígino da fêmea. A e D, vista geral. B, detalhes do ALS e PMS. C, detalhe do PLS. E, detalhe da fiandeira. F, vista retrolateral. G, vista prolateral. $\mathrm{H}$, vista ventral. 


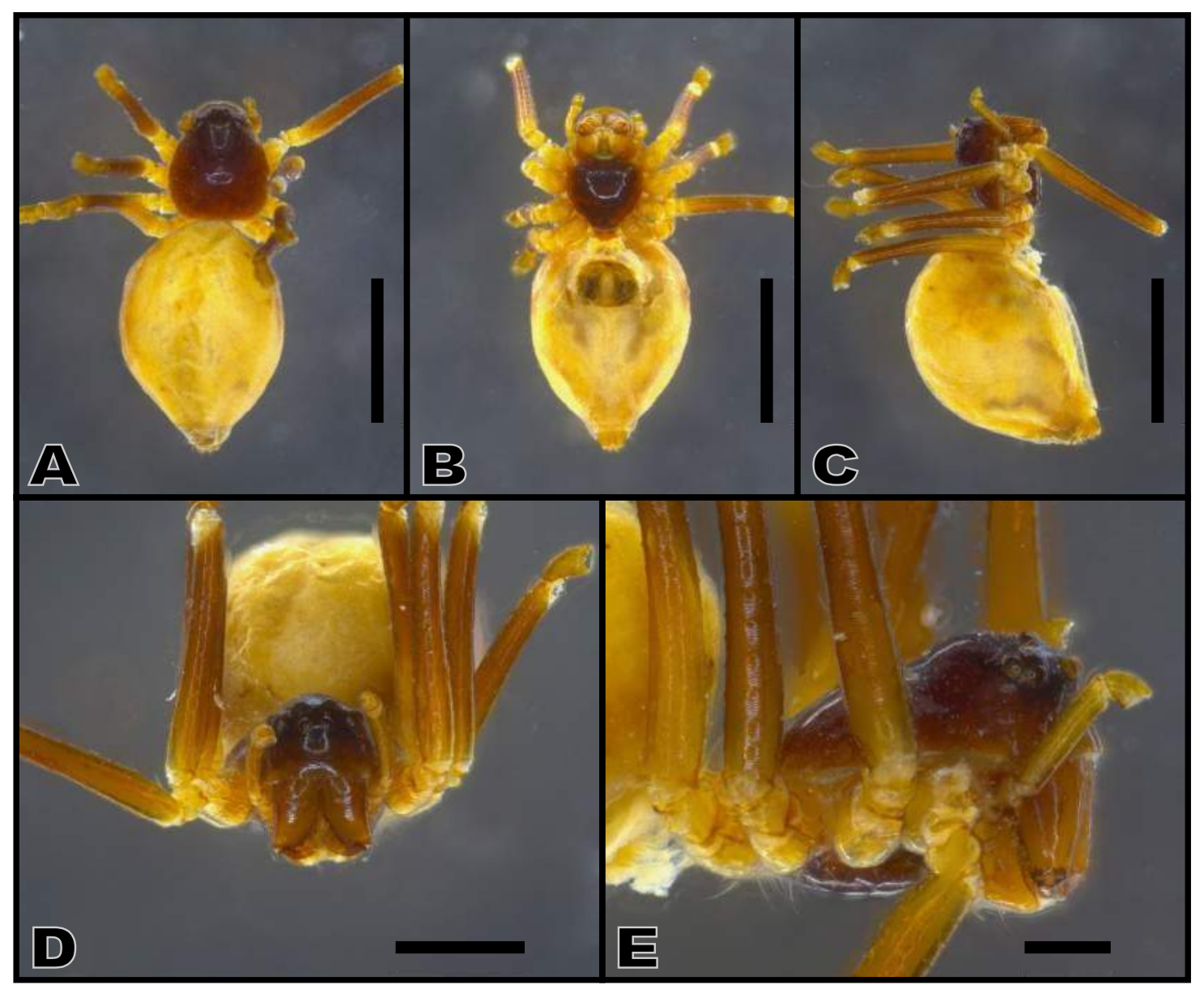

Figura 119. Clitolyna formosa, A-E, corpo da fêmea. A, dorsal; B, ventral; C, lateral; D, frontal; E, detalhe da região cefálica. Escala A-C, 1,0mm; D, 0,5mm; E, 0,2mm.

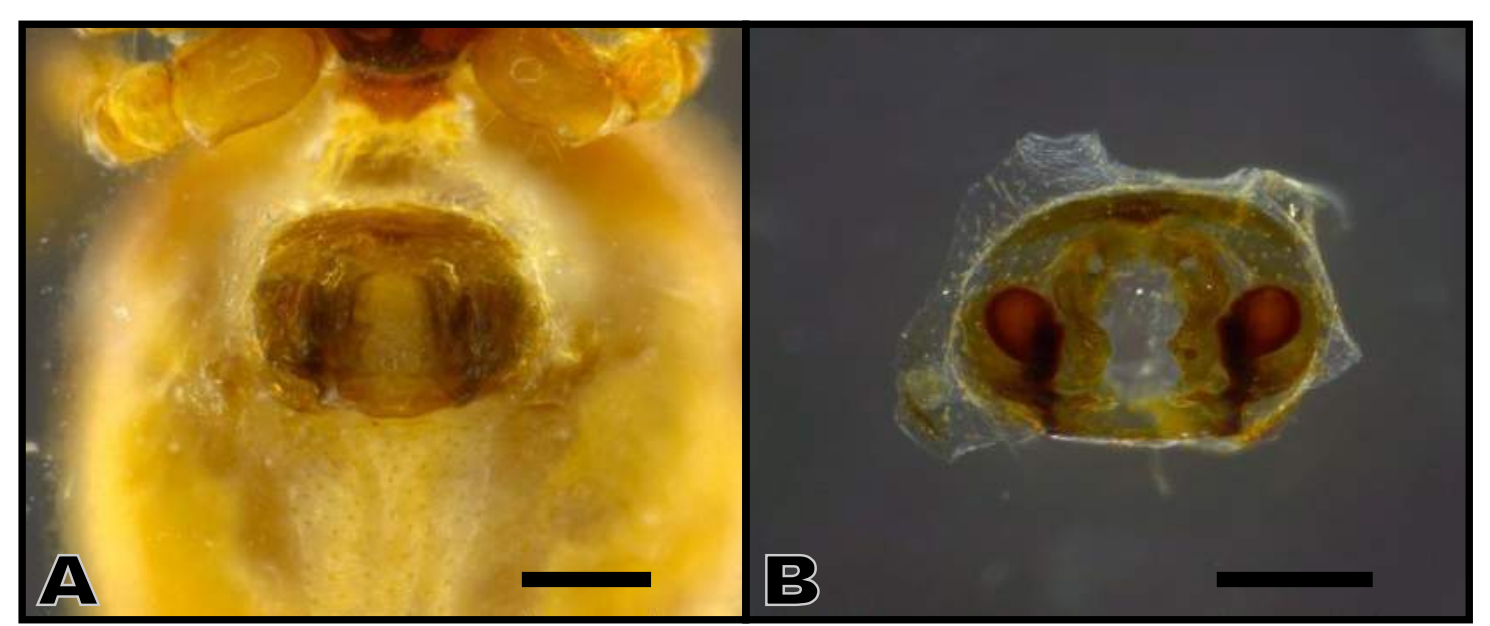

Figura 120. Clitolyna formosa, A-B, epígino da fêmea. A, ventral; B, dorsal. Escala $0,2 \mathrm{~mm}$. 


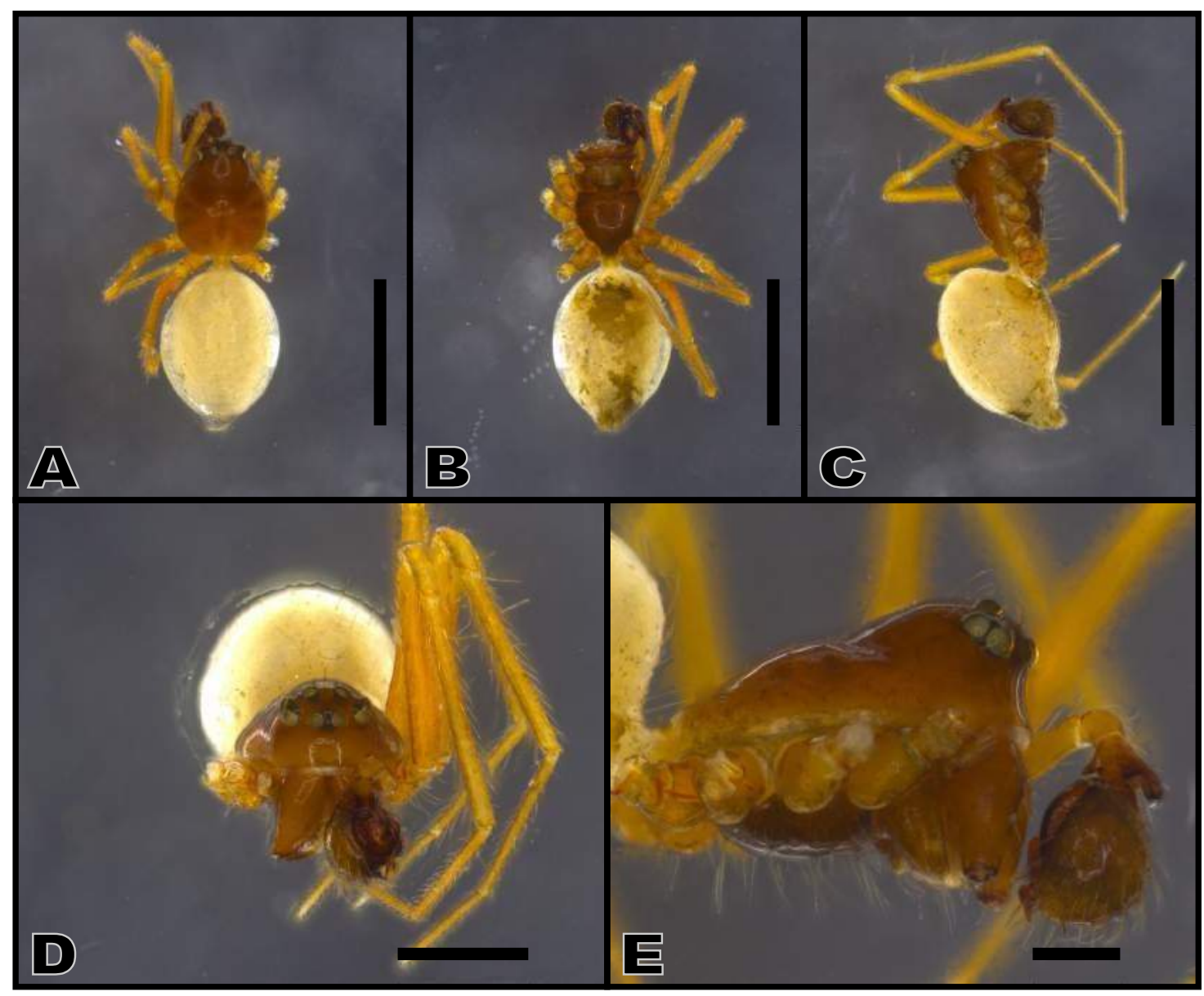

Figura 121. Clitolyna gravis, A-E, corpo do macho. A, dorsal; B, ventral; C, lateral; D, frontal; E, detalhe da região cefálica. Escala A-C, 1,0mm; D, 0,5mm; E, 0,2mm.

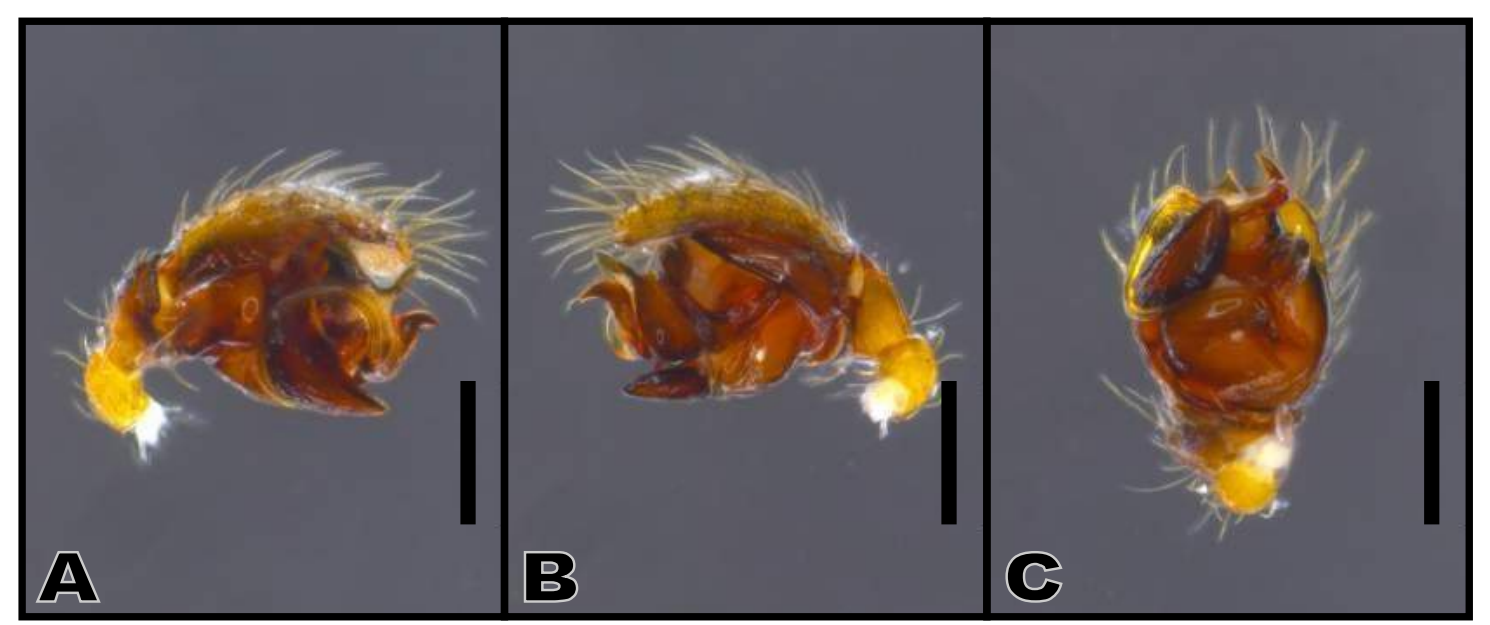

Figura 122. Clitolyna gravis, A-C, palpo do macho. A, retrolateral; B, prolateral; C, ventral. Escala 0,2mm. 


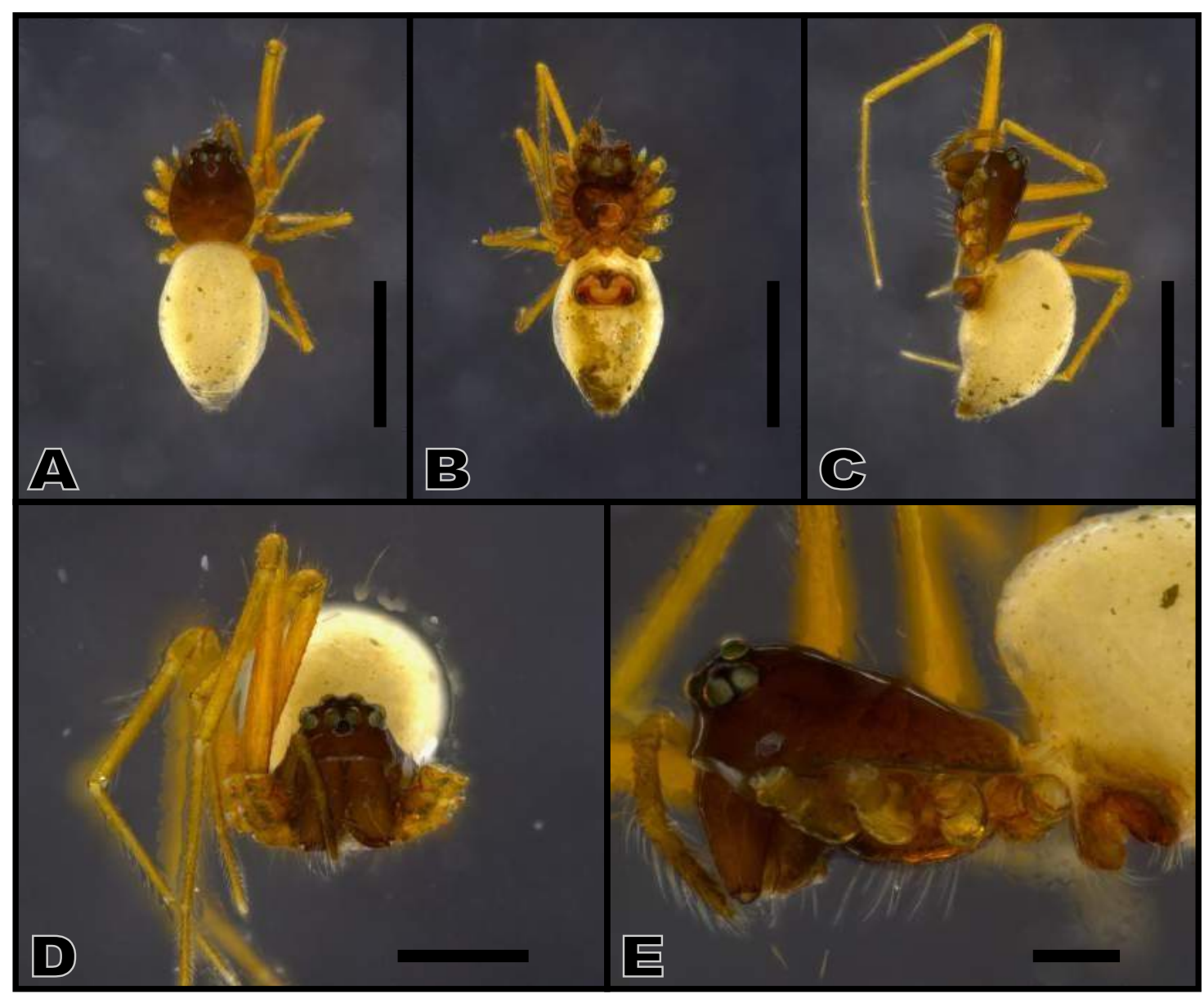

Figura 123. Clitolyna gravis, A-E, corpo da fêmea. A, dorsal; B, ventral; C, lateral; D, frontal; E, detalhe da região cefálica. Escala A-C, 1,0mm; D, 0,5mm; E, 0,2mm.

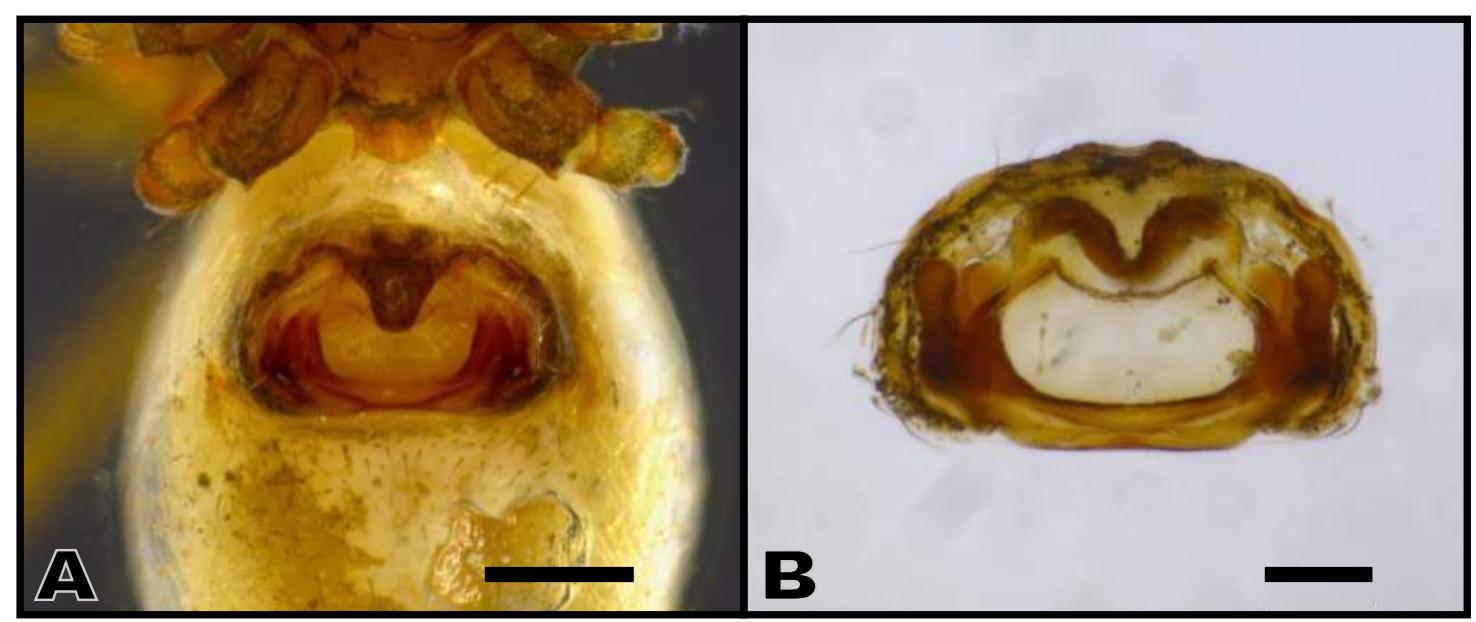

Figura 124. Clitolyna gravis, A-B, epígino da fêmea. A, ventral; B, dorsal. Escala $0,2 \mathrm{~mm}$. 


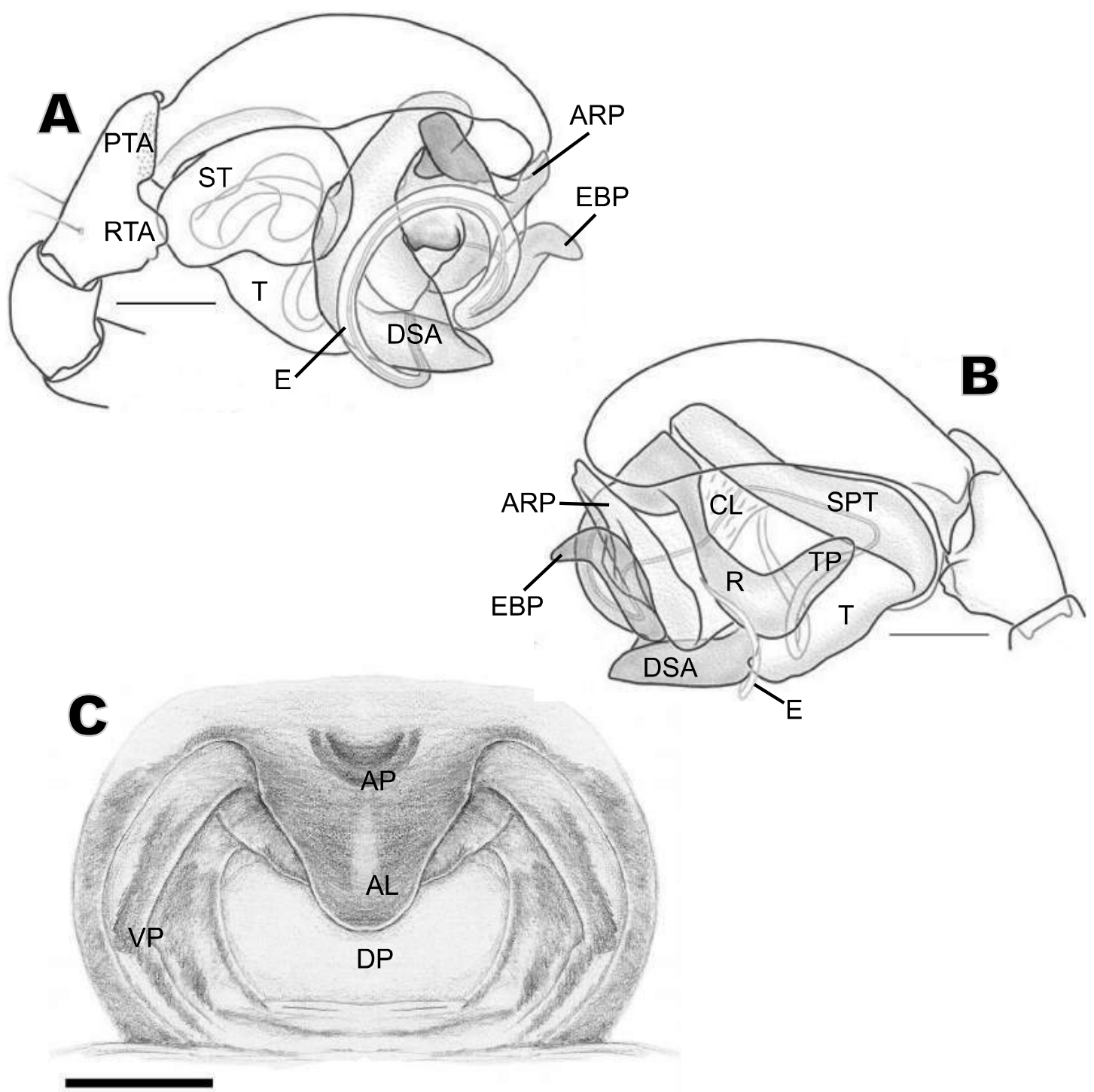

Figura 125. Clitolyna gravis, A-B, palpo do macho; C, epígino da fêmea. A, retrolateral; B, prolateral; C, ventral. Escala 0,1mm. AL, lóbulo anterior da placa dorsal do epígino; AP, processo anterior da placa ventral do epígino; ARP, processo anterior do radix; CL, column; DP, placa dorsal do epígino; DSA, apófise distal suprategular; E, êmbolo; EBP, processo basal do êmbolo; PTA, apófise prolateral da tíbia; R, radix; SPT, supratégulo; RTA, apófise retrolateral da tíbia; ST, subtégulo; T, tégulo; TP, cauda do radix; VP, placa ventral do epígino. A, B, Ilustração de Miller, 2007. 


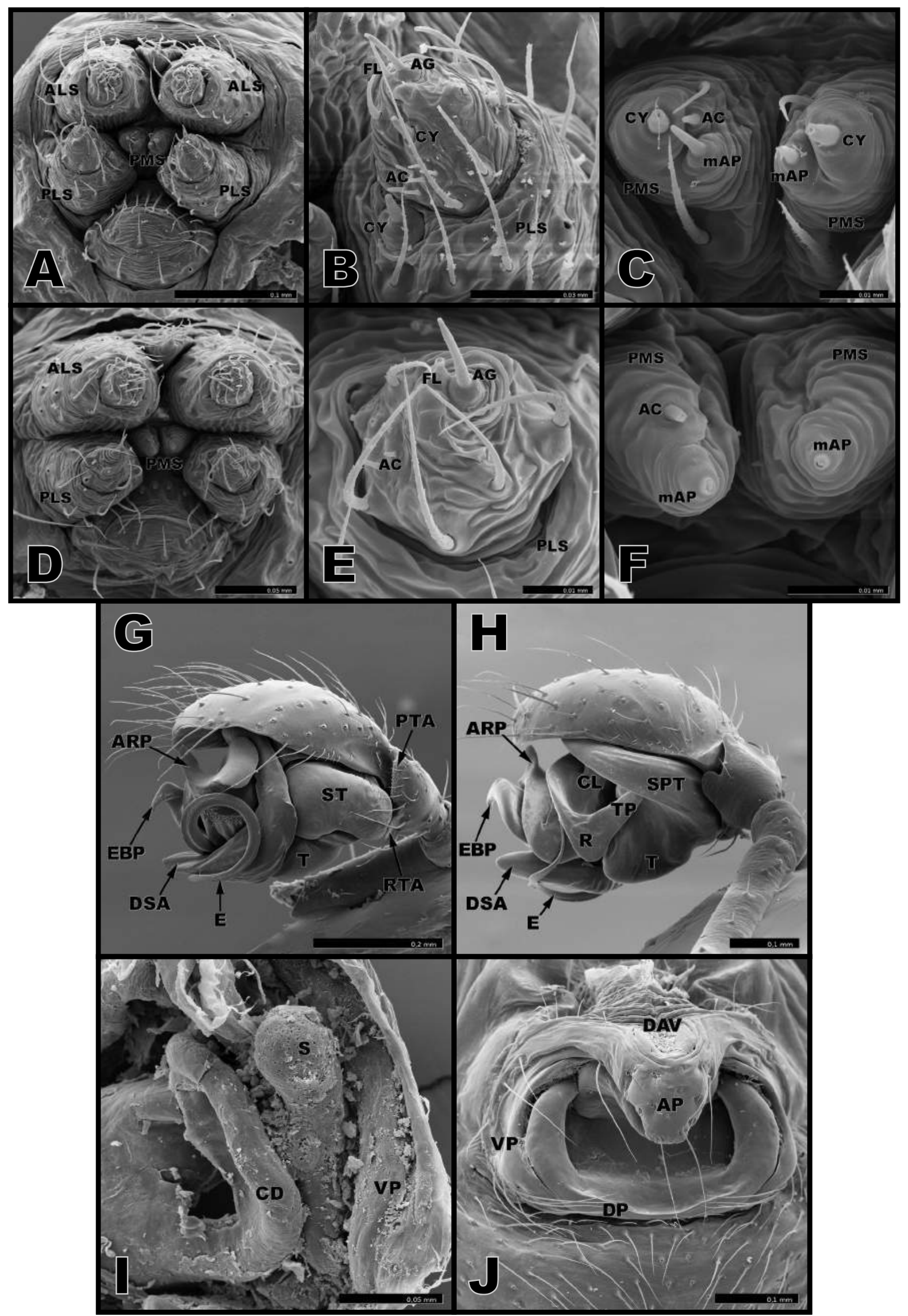

Figura 126. Clitolyna gravis. A-C, fiandeiras da fêmea; D-F, fiandeiras do macho; G$\mathrm{H}$, palpo do macho; I-J, epígino da fêmea. A e D, vista geral. B e E, detalhe do PLS. C e F, detalhe do PMS. G, vista retrolateral. H, vista prolateral. I, vista dorsal. J vista ventral. 


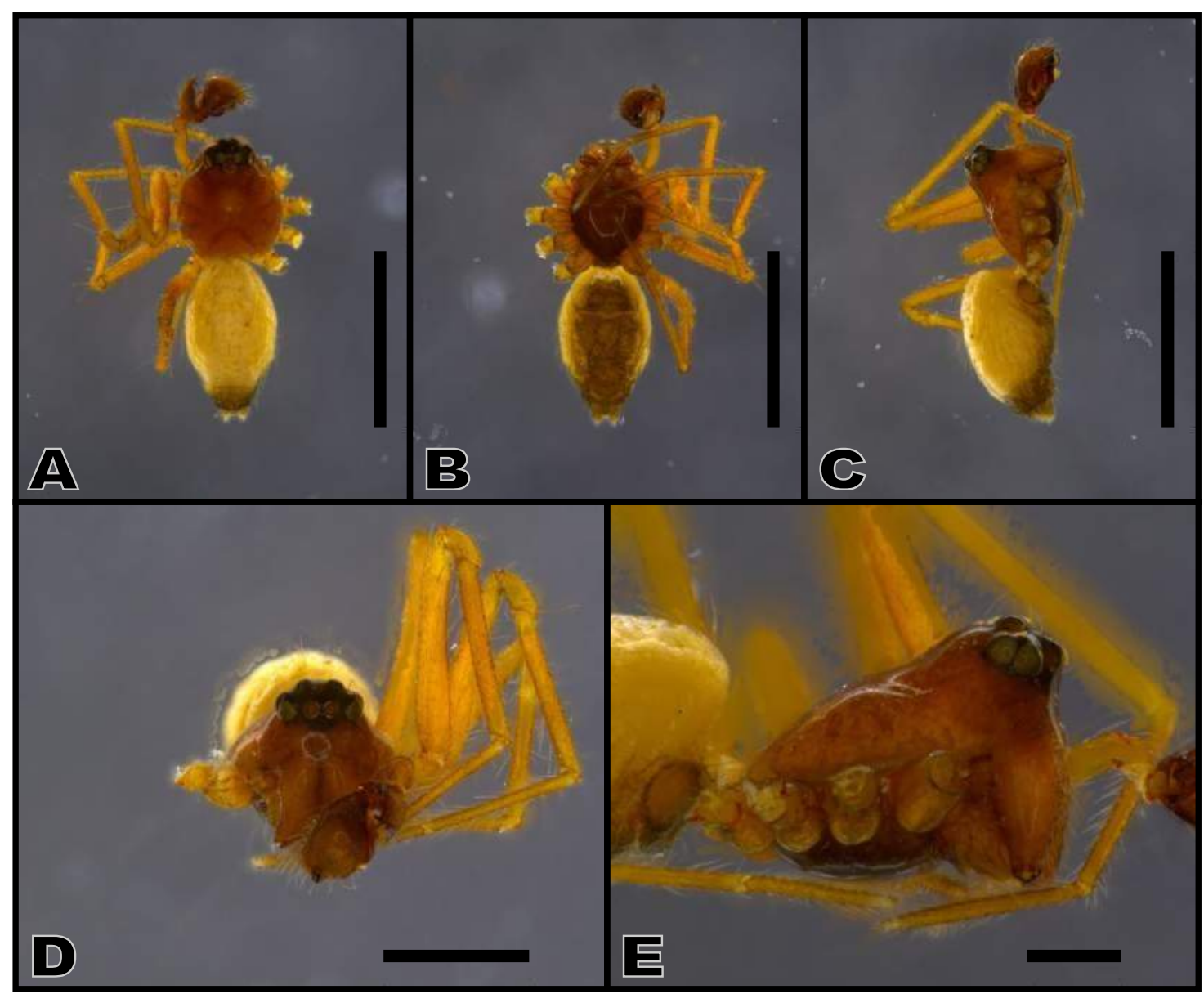

Figura 127. Clitolyna novaeteutoniae, A-E, corpo do macho. A, dorsal; B, ventral; C, lateral; D, frontal; E, detalhe da região cefálica. Escala A-C, 1,0mm; D, 0,5mm; E, $0,2 \mathrm{~mm}$.

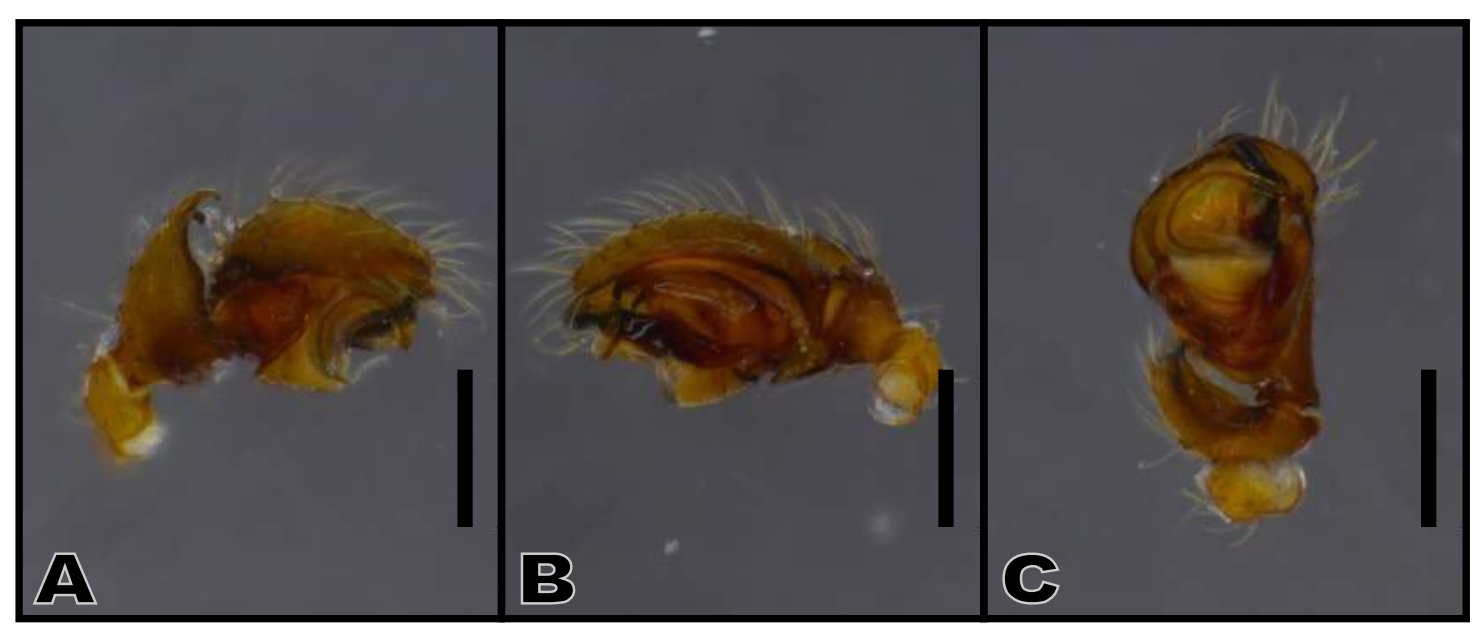

Figura 128. Clitolyna novaeteutoniae, A-C, palpo do macho. A, retrolateral; B, prolateral; C, ventral. Escala 0,2mm. 


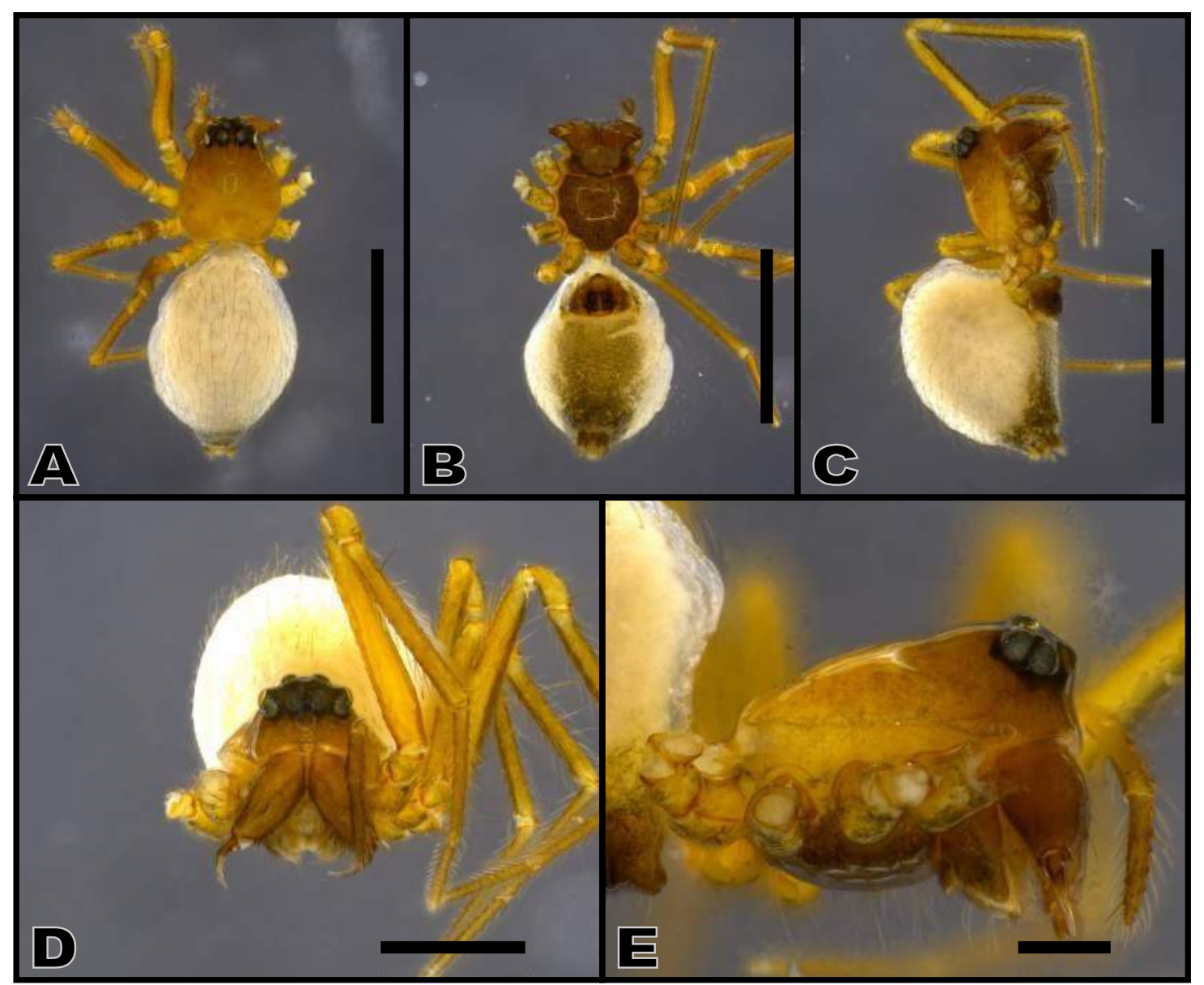

Figura 129. Clitolyna novaeteutoniae, A-E, corpo da fêmea. A, dorsal; B, ventral; C, lateral; D, frontal; E, detalhe da região cefálica. Escala A-C, 1,0mm; D, 0,5mm; E, $0,2 \mathrm{~mm}$.

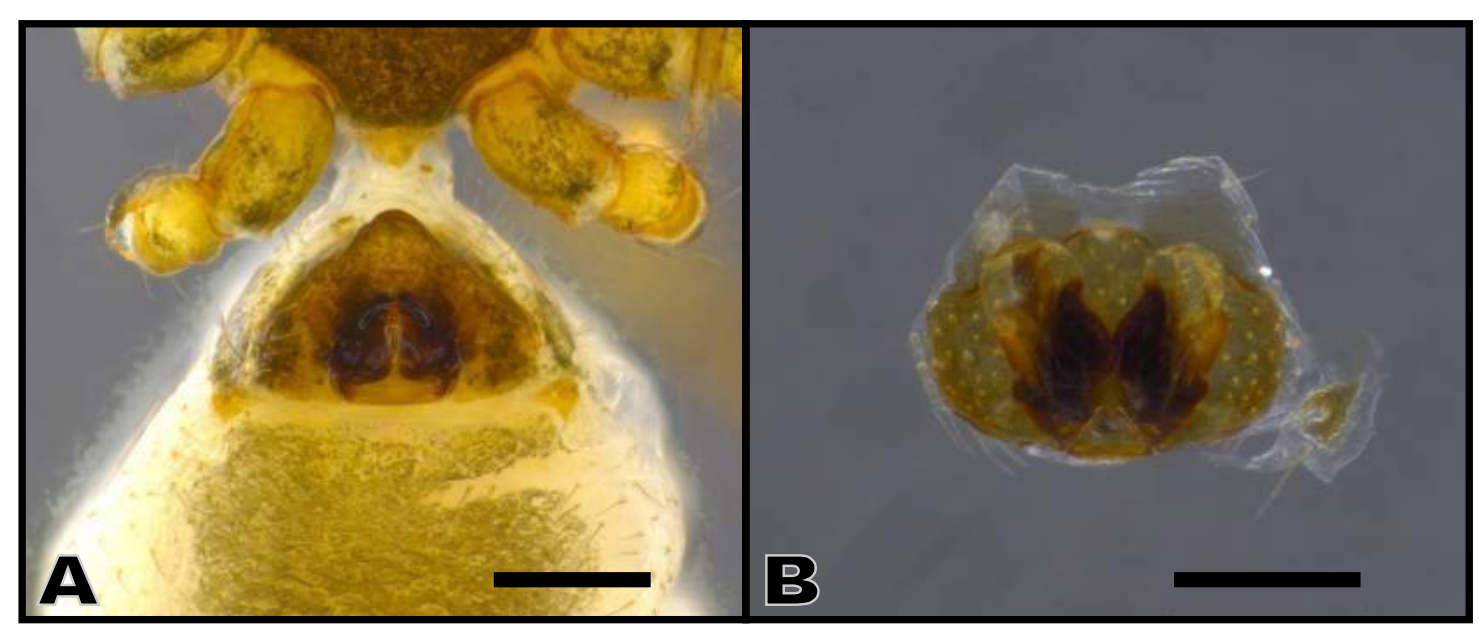

Figura 130. Clitolyna novaeteutoniae, A-B, epígino da fêmea. A, ventral; B, dorsal. Escala 0,2mm. 


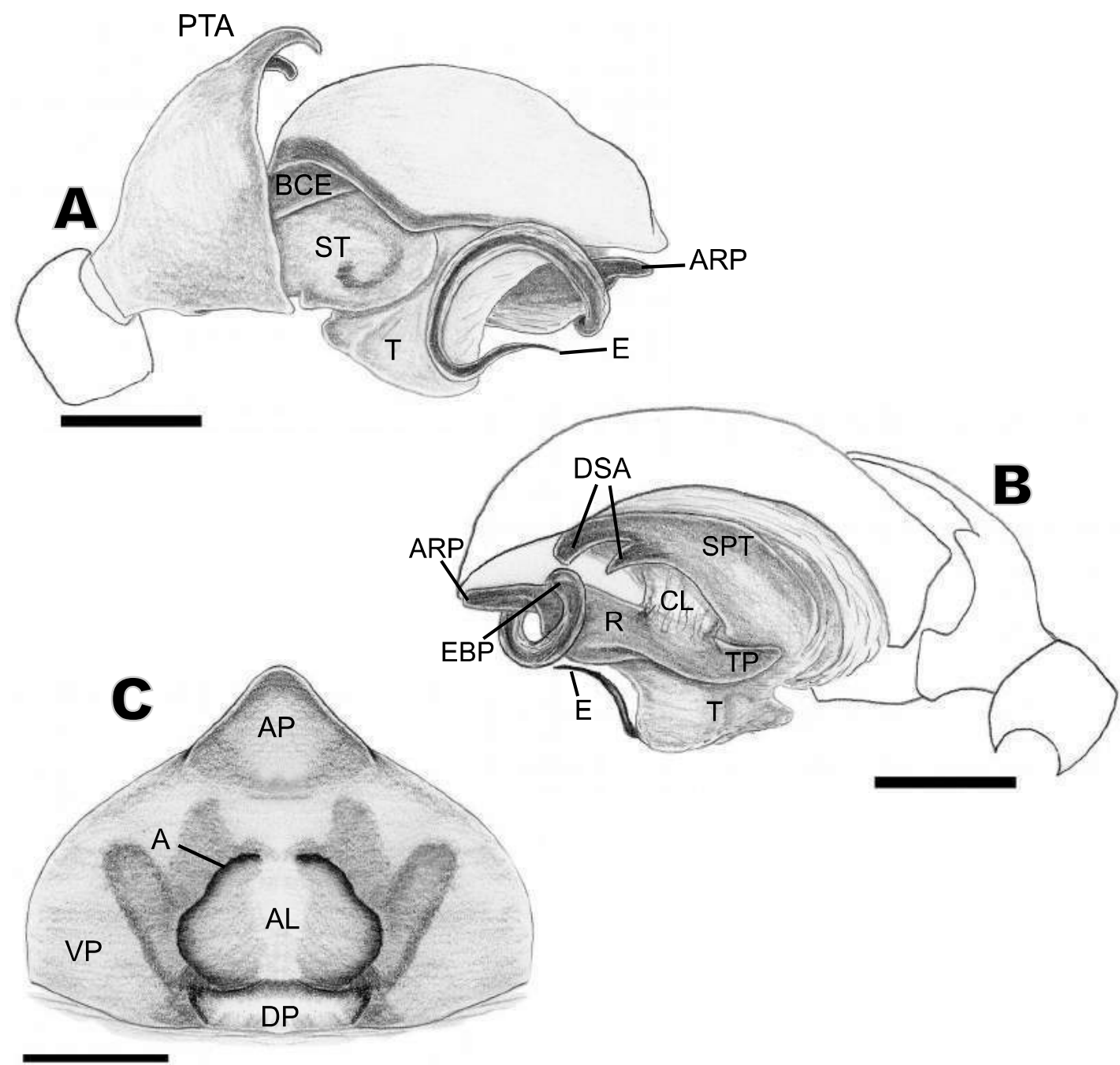

Figura 131. Clitolyna novaeteutoniae, A-B, palpo do macho; C, epígino da fêmea. A, retrolateral; B, prolateral; C, ventral. Escala 0,1mm. A, átrio; AL, lóbulo anterior da placa dorsal do epígino; AP, processo anterior da placa ventral do epígino; BCE, base escavada do címbio; CL, column; DP, placa dorsal do epígino; DSA, apófise distal suprategular; E, êmbolo; EBP, processo basal do êmbolo; PT, protégulo; PTA, apófise prolateral da tíbia; R, radix; RTA, apófise retrolateral da tíbia; SPT, supratégulo; ST, subtégulo; T, tégulo; TP, cauda do radix; VP, placa ventral do epígino. 


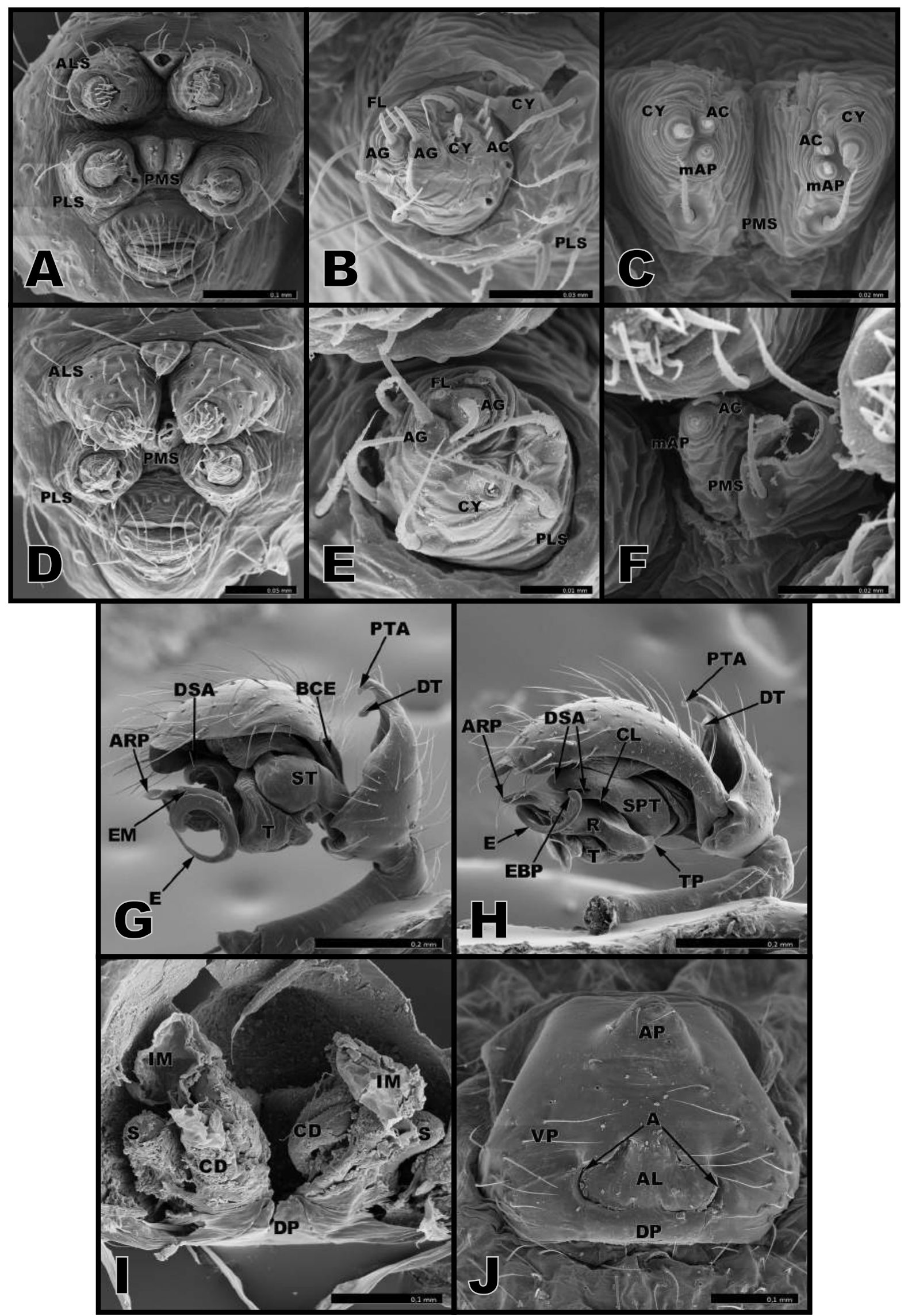

Figura 132. Clitolyna novaeteutoniae. A-C, fiandeiras da fêmea; D-F, fiandeiras do mach $_{\mathrm{O}}$; G-H, palpo do macho; I-J, epígino da fêmea. A e D, vista geral. B e E, detalhe do PLS. C e F, detalhe do PMS. G, vista retrolateral. H, vista prolateral. I, vista dorsal. J vista ventral. 


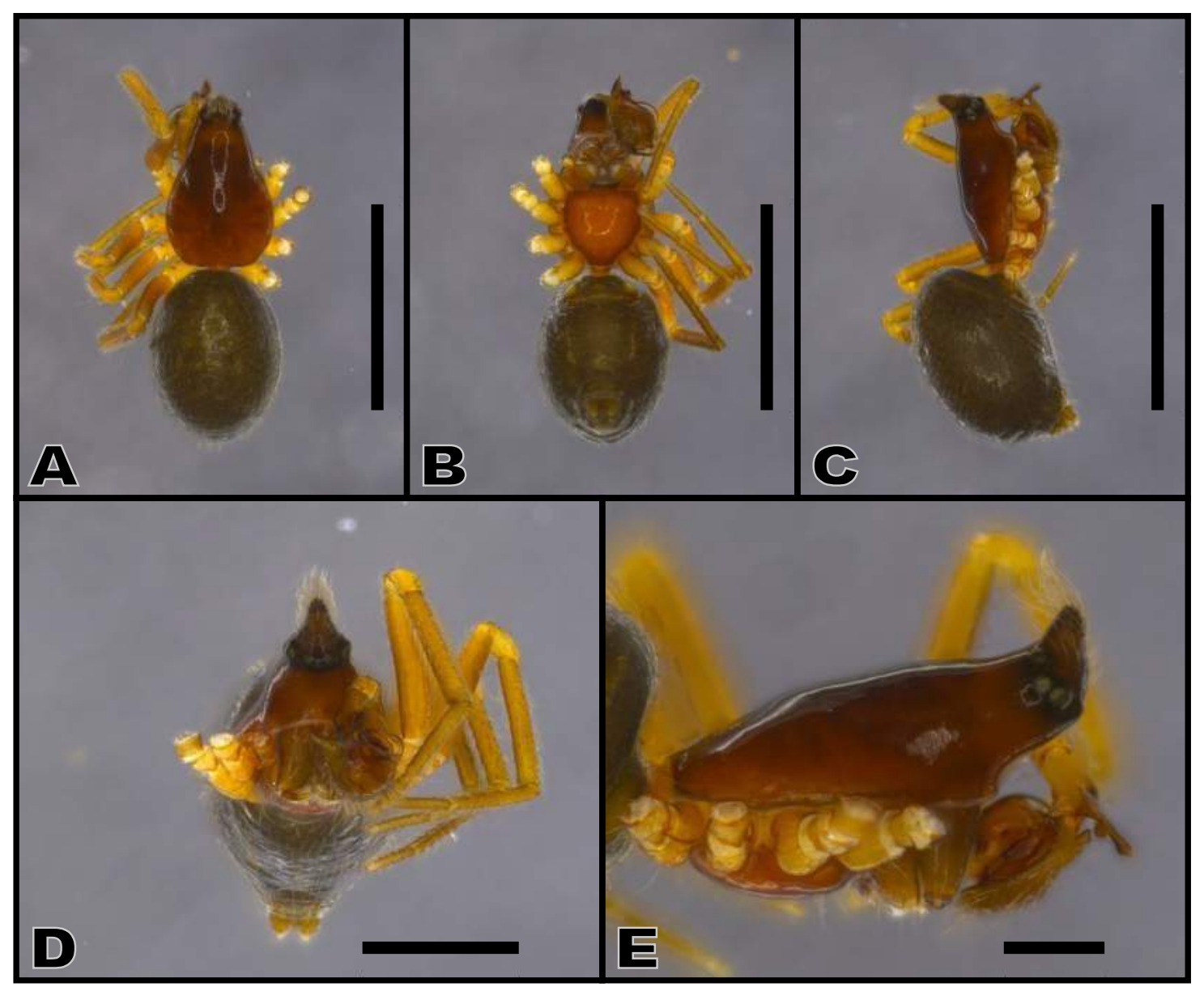

Figura 133. Clitolyna personata, A-E, corpo do macho. A, dorsal; B, ventral; C, lateral; D, frontal; E, detalhe da região cefálica. Escala A-C,1,0mm; D, 0,5mm; E, 0,2mm.

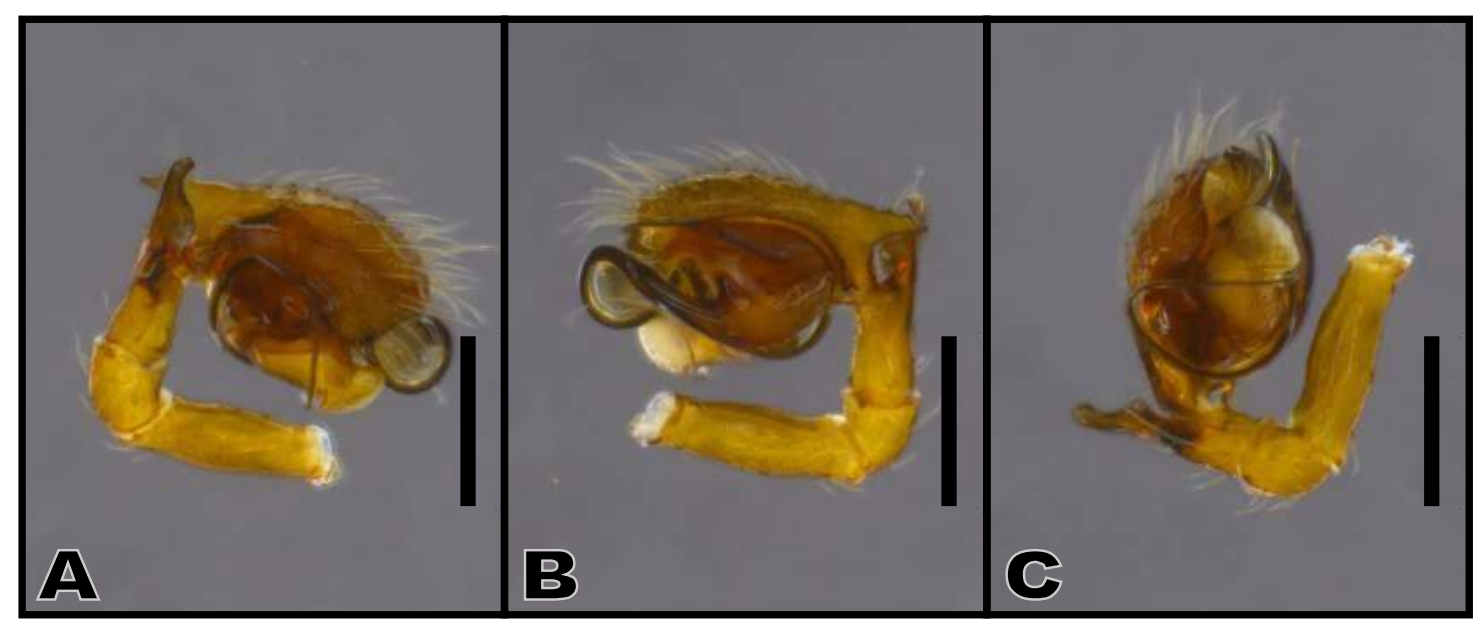

Figura 134. Clitolyna personata, A-C, palpo do macho. A, retrolateral; B, prolateral; C, ventral. Escala 0,2mm. 


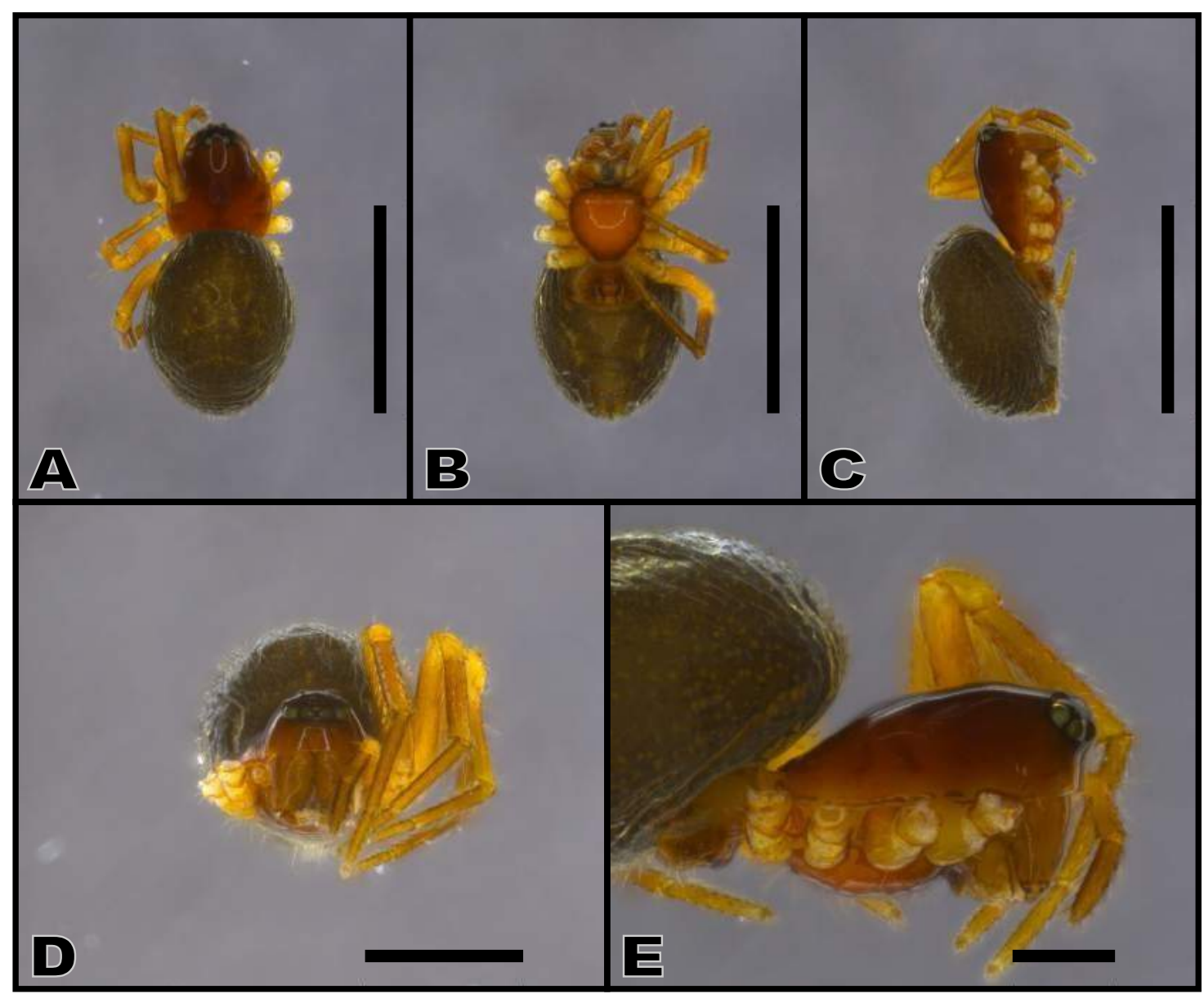

Figura 135. Clitolyna personata, A-E, corpo da fêmea. A, dorsal; B, ventral; C, lateral;

D, frontal; E, detalhe da região cefálica. Escala A-C, 1,0mm; D, 0,5mm; E, 0,2mm.

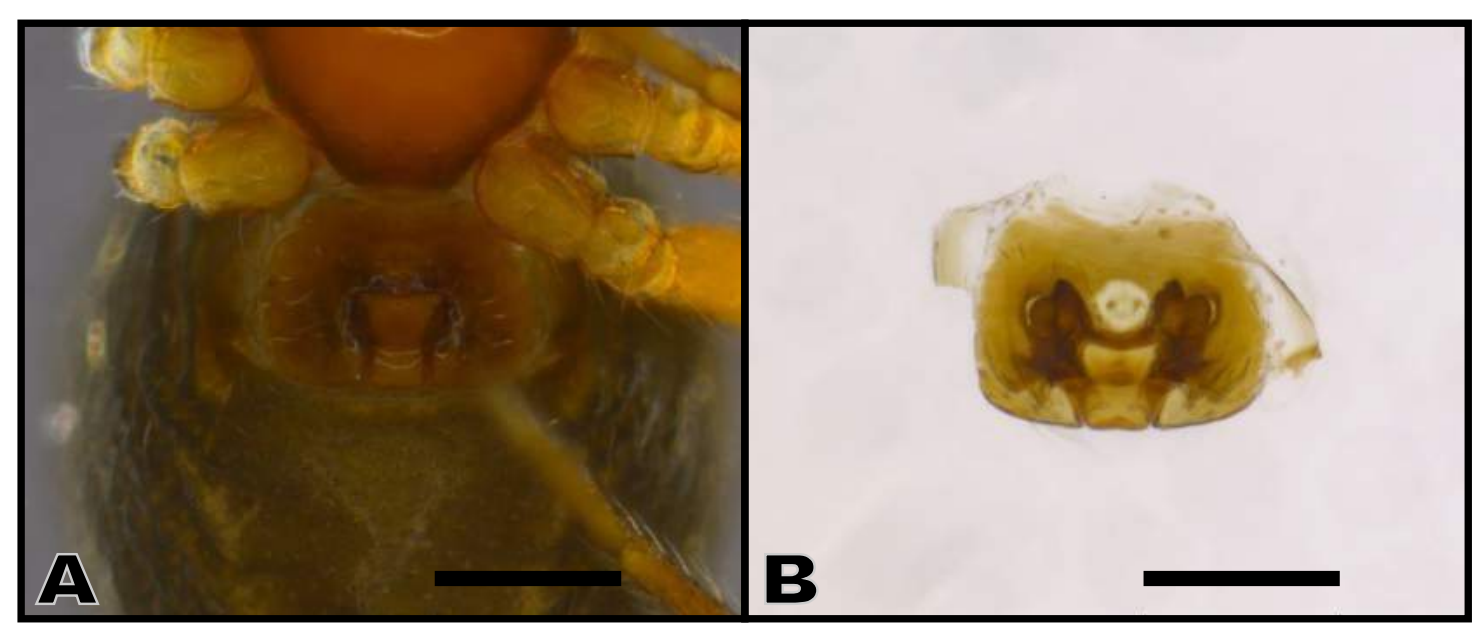

Figura 136. Clitolyna personata, A-B, epígino da fêmea. A, ventral; B, dorsal. Escala $0,2 \mathrm{~mm}$. 

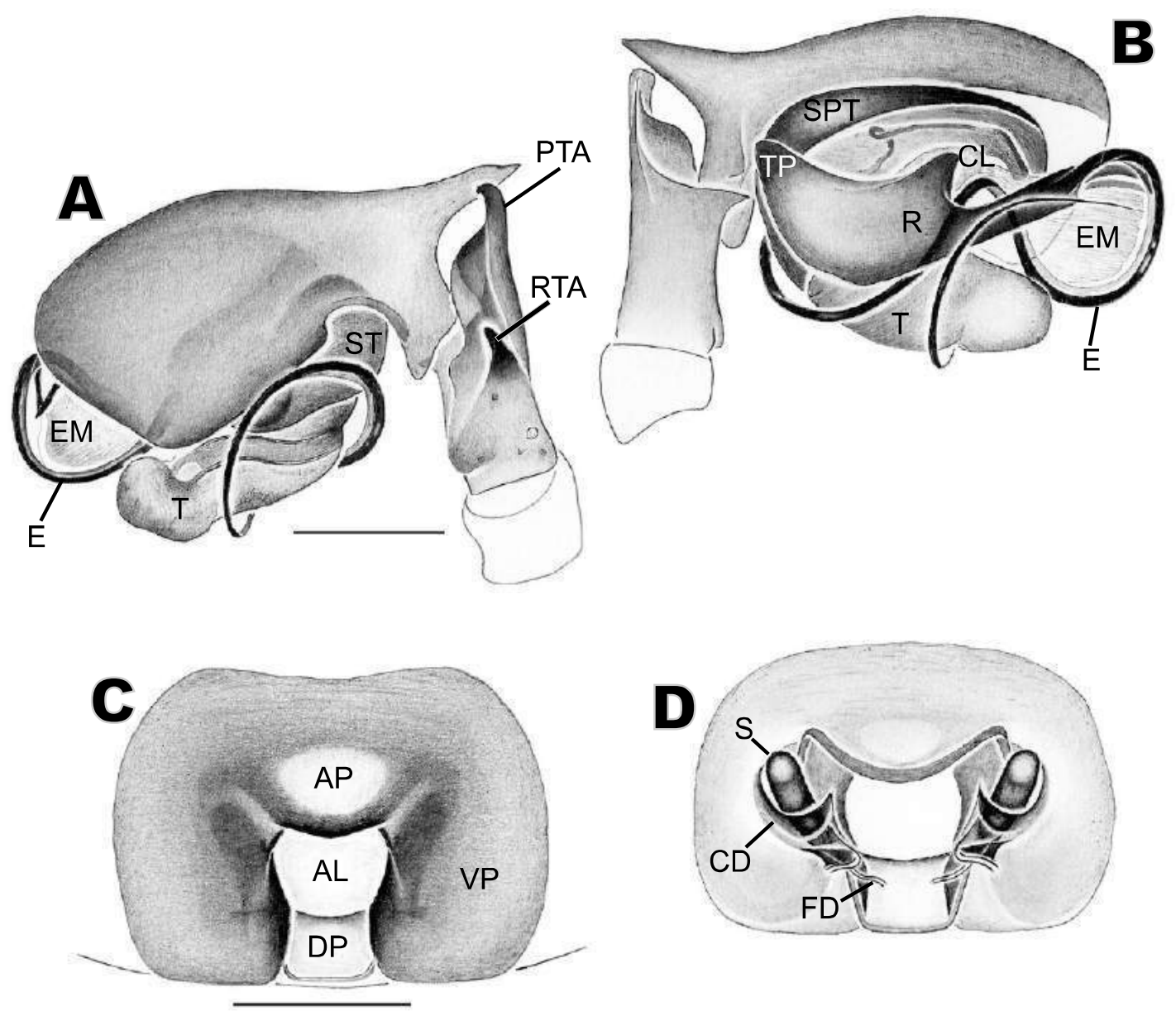

Figura 137. Clitolyna personata, A-B, palpo do macho; C, epígino da fêmea. A, retrolateral; B, prolateral; C, ventral; D, dorsal. Escala 0,1mm. A, átrio; AL, lóbulo anterior da placa dorsal do epígino; AP, processo anterior da placa ventral do epígino; CD, duto de copulação; CL, column; DP, placa dorsal do epígino; E, êmbolo; EM, membrana embólica; FD, duto de fertilização; PTA, apófise prolateral da tíbia; R, radix; RTA, apófise retrolateral da tíbia; S, espermateca; SPT, supratégulo; ST, subtégulo; T, tégulo; TP, cauda do radix; VP, placa ventral do epígino. Ilustração de Rodrigues et al. 2012. 


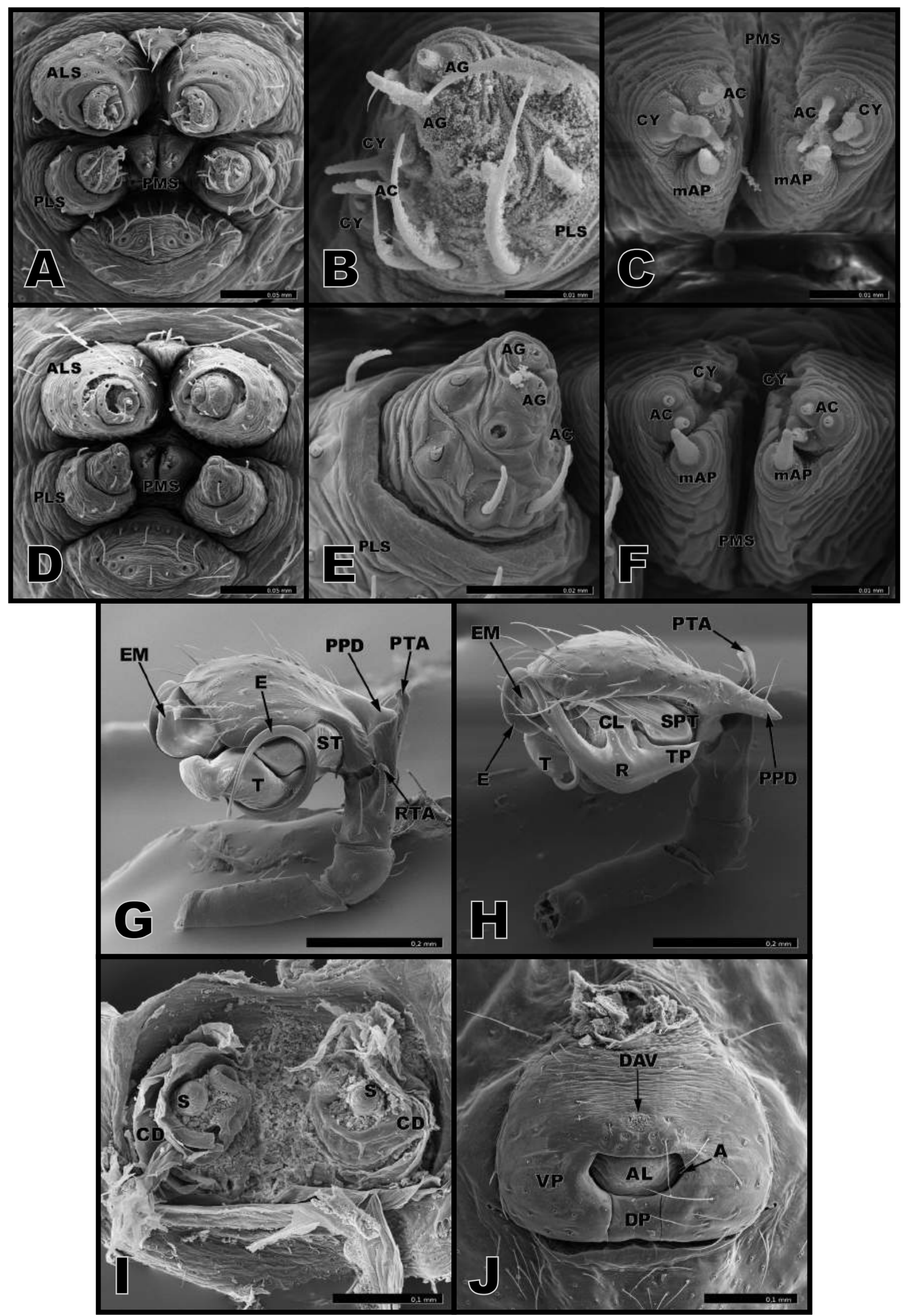

Figura 138. Clitolyna personata. A-C, fiandeiras da fêmea; D-F, fiandeiras do macho; G-H, palpo do macho; I-J, epígino da fêmea. A e D, vista geral. B e E, detalhe do PLS. $\mathrm{C}$ e F, detalhe do PMS. G, vista retrolateral. H, vista prolateral. I, vista dorsal. J vista ventral. 


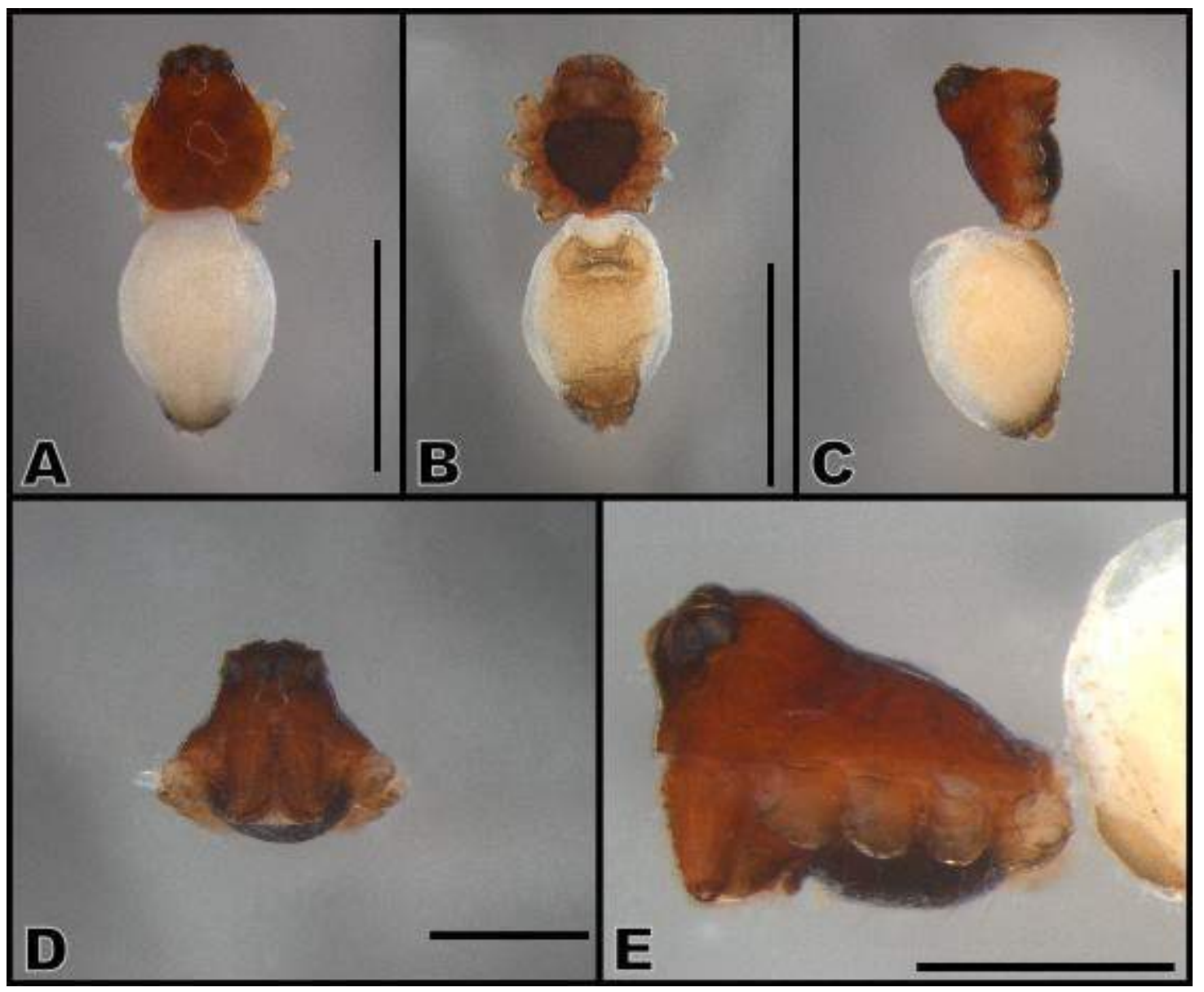

Figura 139. Clitolyna prativaga, A-E, corpo do macho. A, dorsal; B, ventral; C, lateral; D, frontal; E, detalhe da região cefálica. Escala A-C,1,0mm; D, 0,5mm; E, 0,2mm.

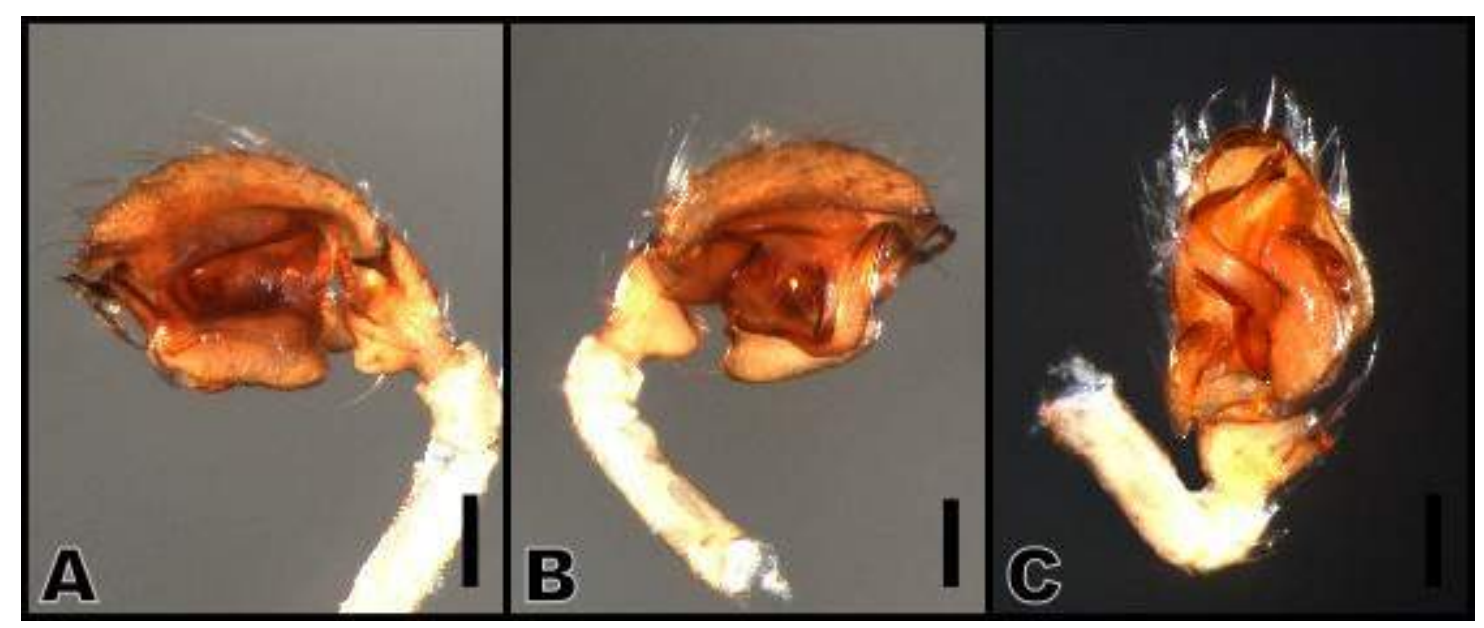

Figura 140. Clitolyna prativaga, A-C, palpo do macho. A, retrolateral; B, prolateral; C, ventral. Escala 0,2mm. 


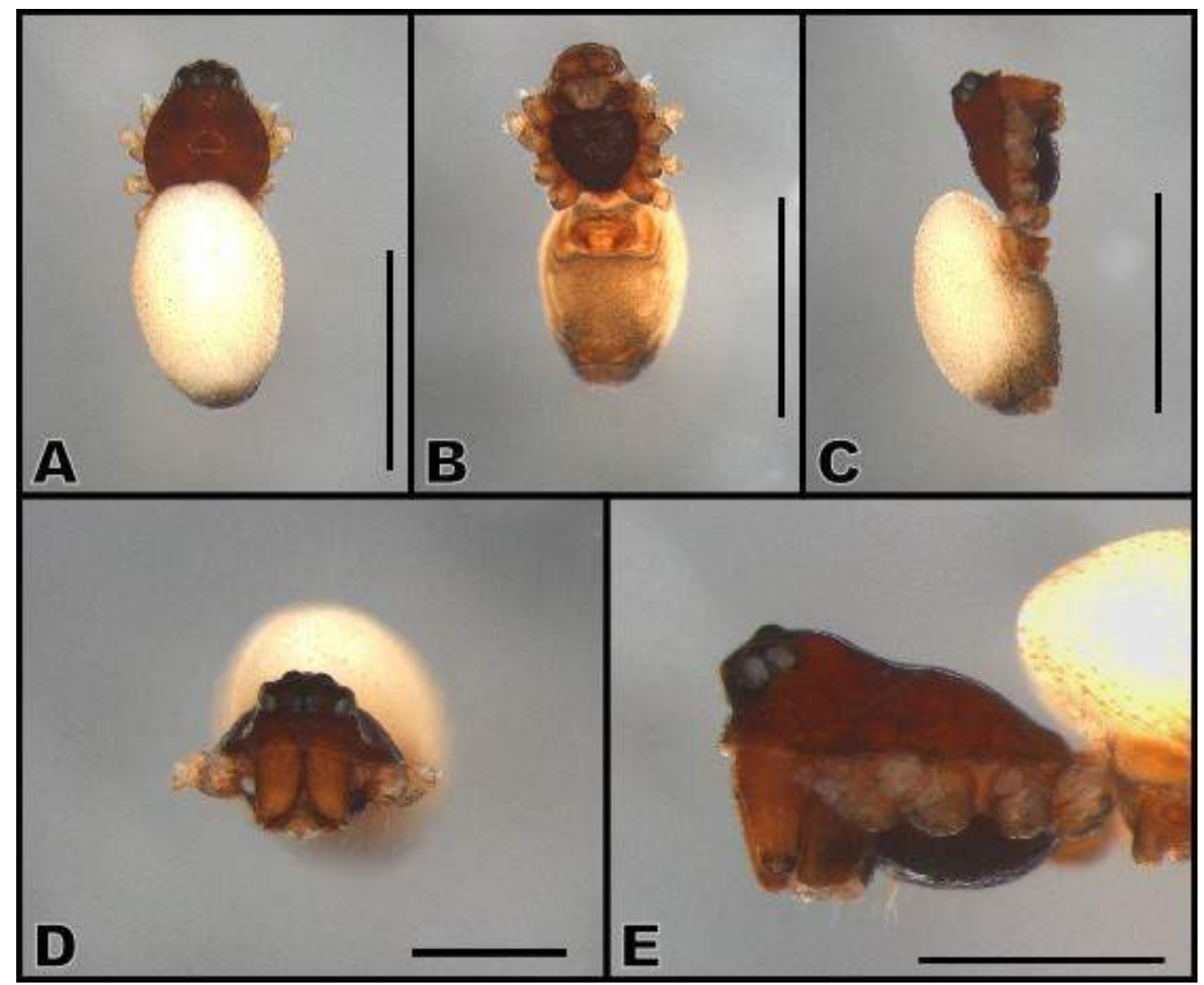

Figura 141. Clitolyna prativaga, A-E, corpo da fêmea. A, dorsal; B, ventral; C, lateral;

D, frontal; E, detalhe da região cefálica. Escala A-C,1,0mm; D, 0,5mm; E, 0,2mm.

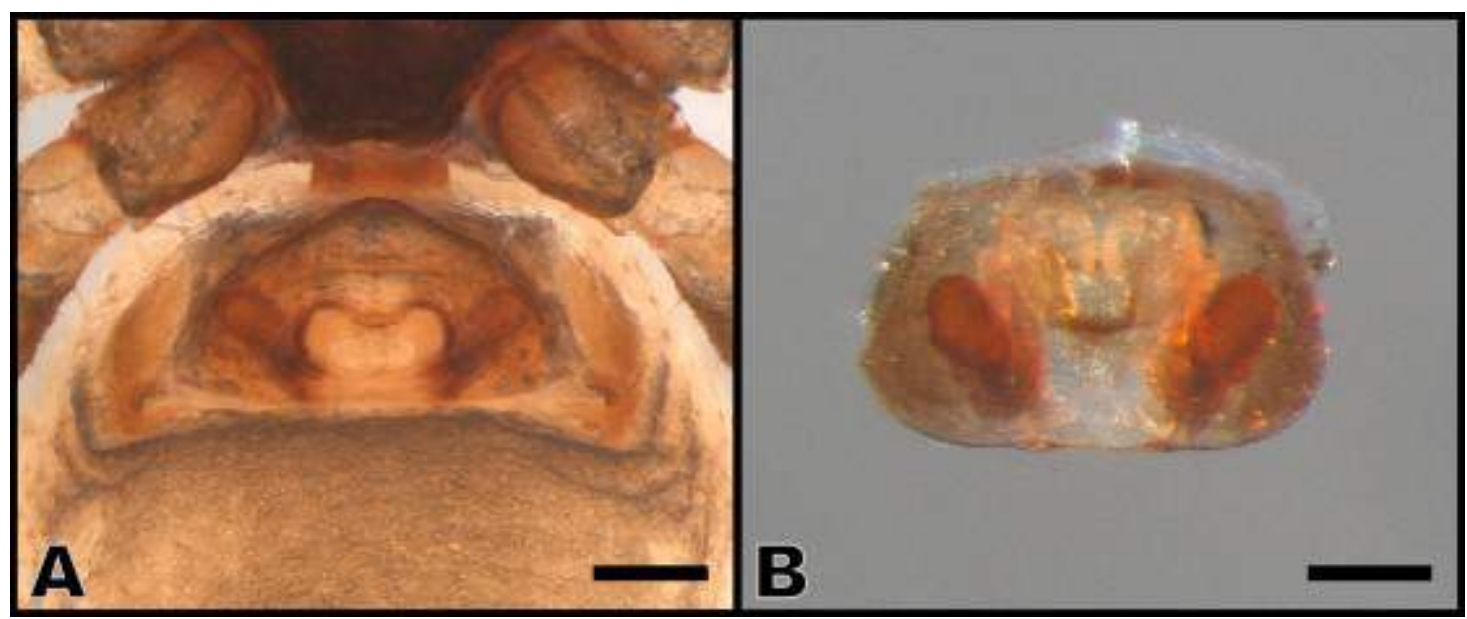

Figura 142. Clitolyna prativaga, A-B, epígino da fêmea. A, ventral; B, dorsal. Escala $0,1 \mathrm{~mm}$. 

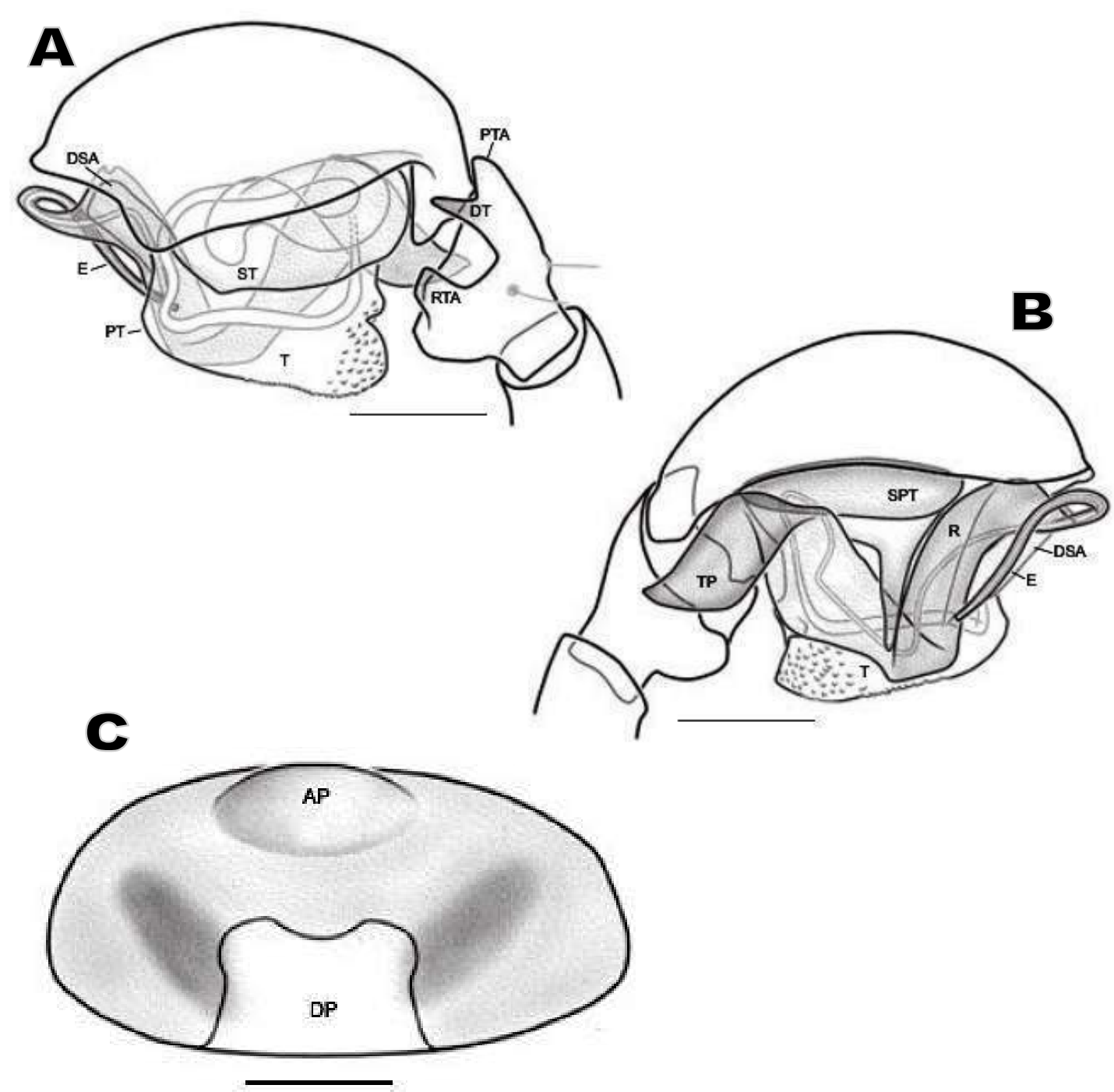

Figura 143. Clitolyna prativaga, A-B, palpo do macho; C, epígino da fêmea. A, retrolateral; B, prolateral; C, ventral; D, dorsal. Escala 0,1mm. AP, processo anterior da placa ventral do epígino; DP, placa dorsal do epígino; DSA, apófise distal suprategular; DT, dente distal da apófise prolateral da tíbia; E, êmbolo; PTA, apófise prolateral da tibia; PT, protégulo; R, radix; RTA, apófise retrolateral da tíbia; SPT, supratégulo; ST, subtégulo; TP, cauda do radix; T, tégulo. Ilustração de Miller, 2007. 


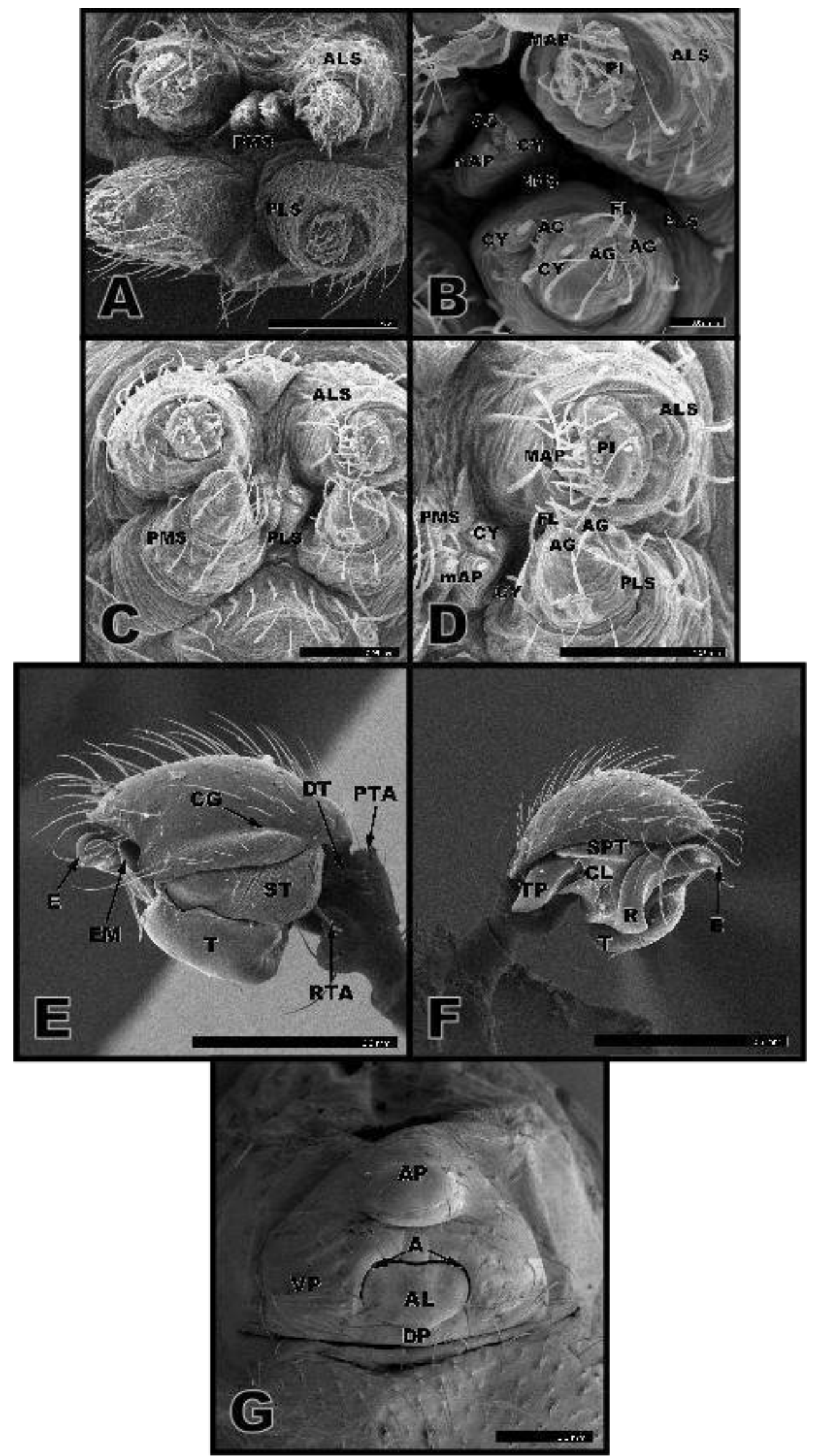

Figura 144. Clitolyna prativaga, A-B, fiandeiras da fêmea; C-D, fiandeiras do macho; E-F, palpo do macho; G, epígino da fêmea. A, C, vista geral. B, D, detalhe da fiandeira. $\mathrm{E}$, vista retrolateral. F, prolateral. G, vista ventral. 


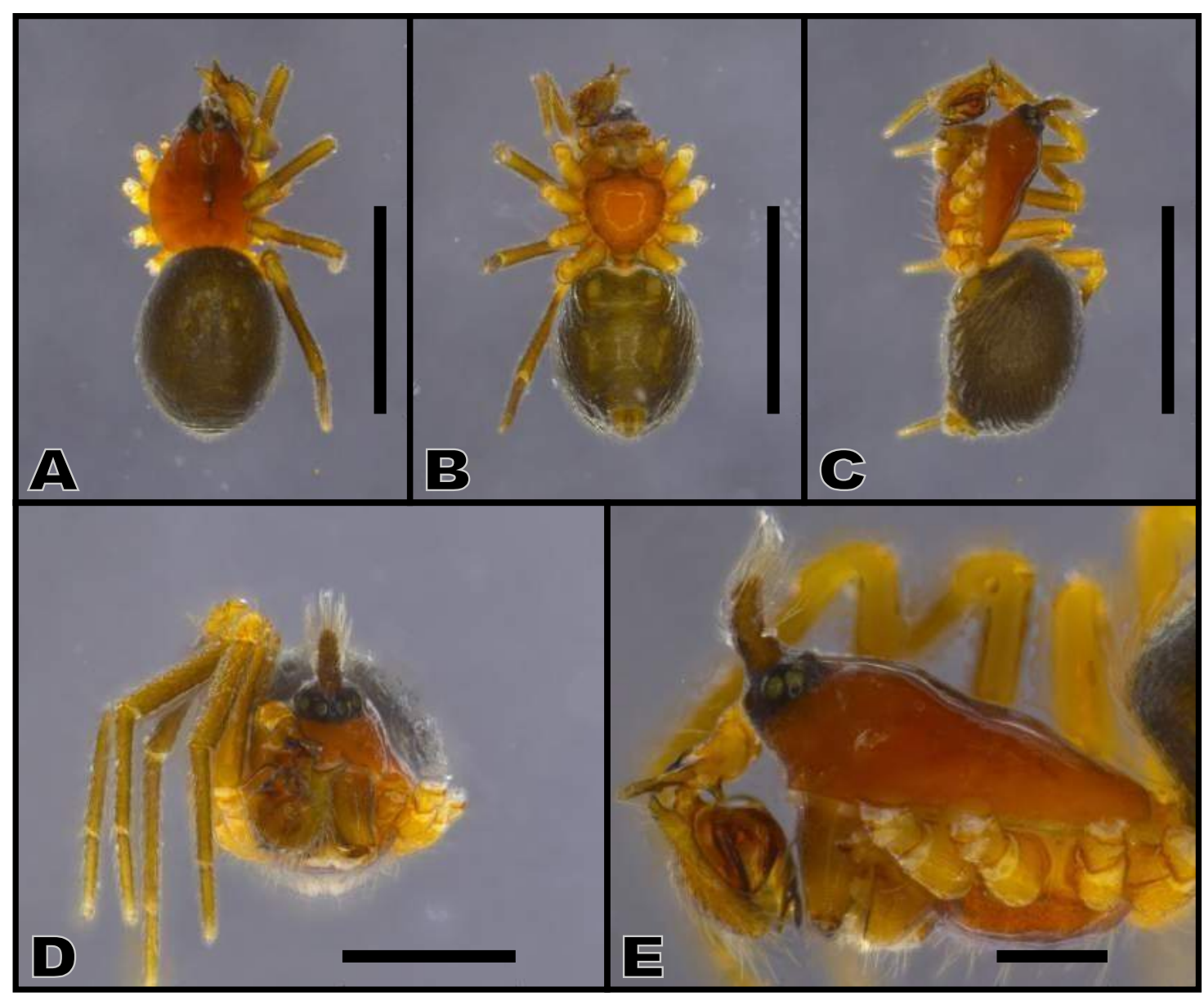

Figura 145. Clitolyna rostrata, A-E, corpo do macho. A, dorsal; B, ventral; C, lateral;

D, frontal; E, detalhe da região cefálica. Escala A-C,1,0mm; D, 0,5mm; E, 0,2mm.

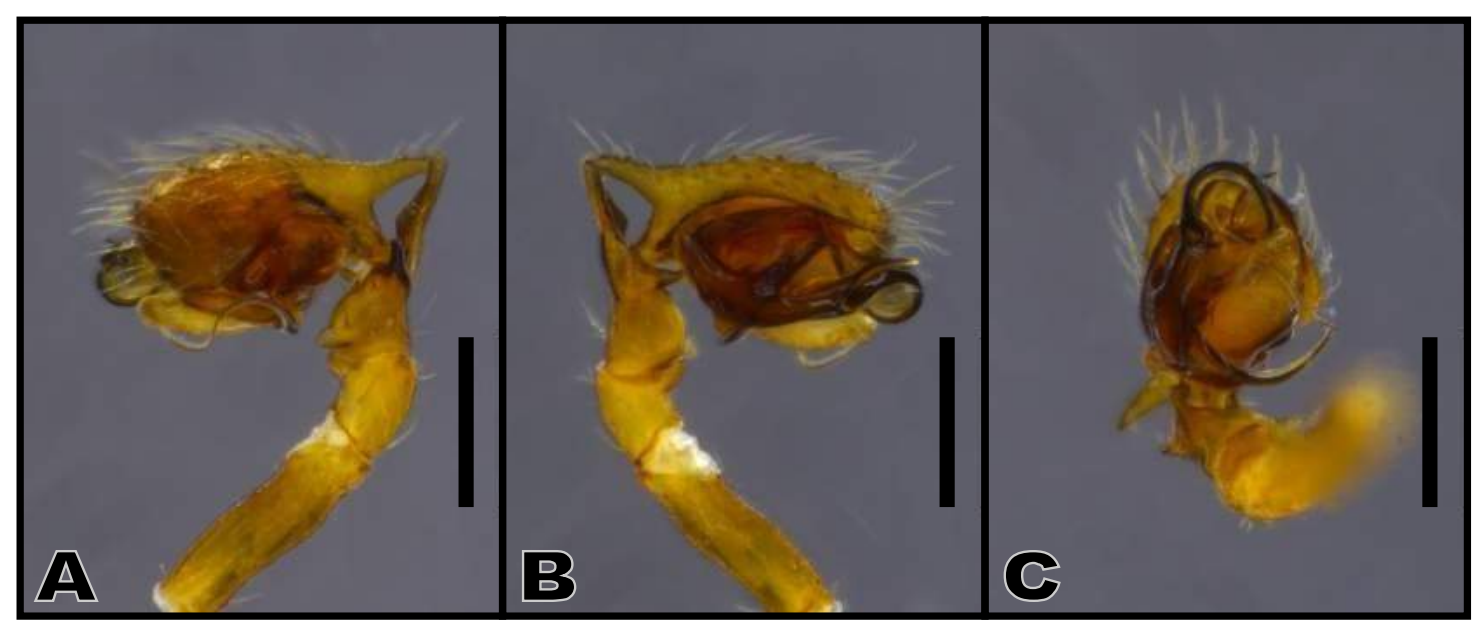

Figura 146. Clitolyna rostrata, A-C, palpo do macho. A, retrolateral; B, prolateral; C, ventral. Escala 0,2mm. 


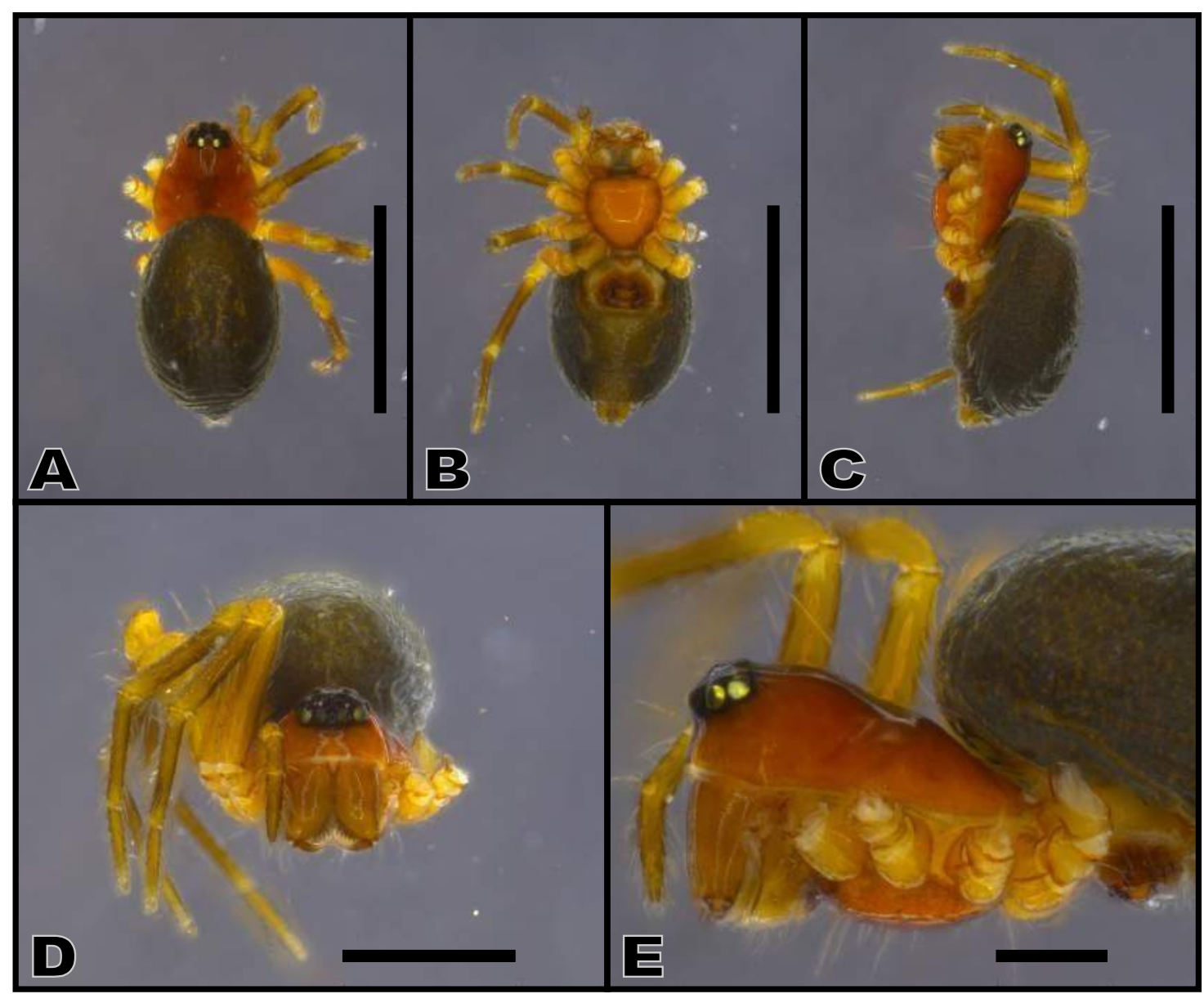

Figura 147. Clitolyna rostrata, A-E, corpo da fêmea. A, dorsal; B, ventral; C, lateral; D, frontal; E, detalhe da região cefálica. Escala A-C,1,0mm; D, 0,5mm; E, 0,2mm.

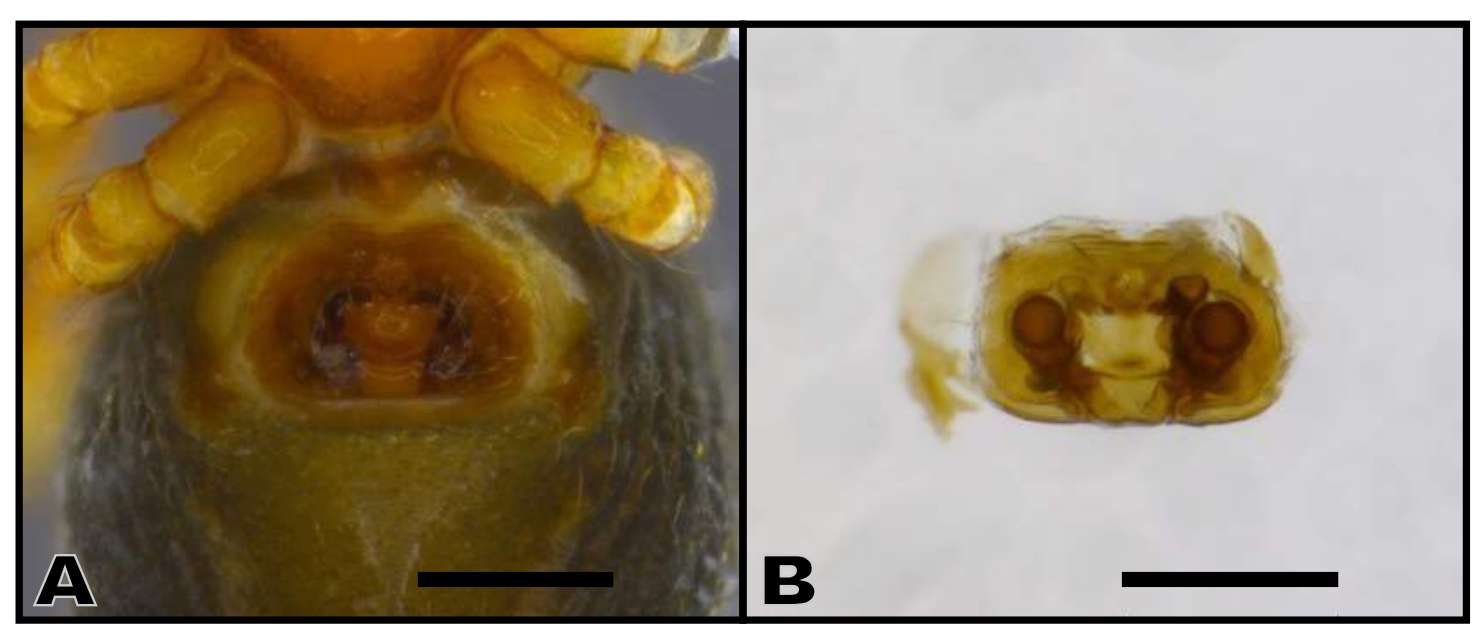

Figura 148. Clitolyna rostrata, A-B, epígino da fêmea. A, ventral; B, dorsal. Escala $0,2 \mathrm{~mm}$. 


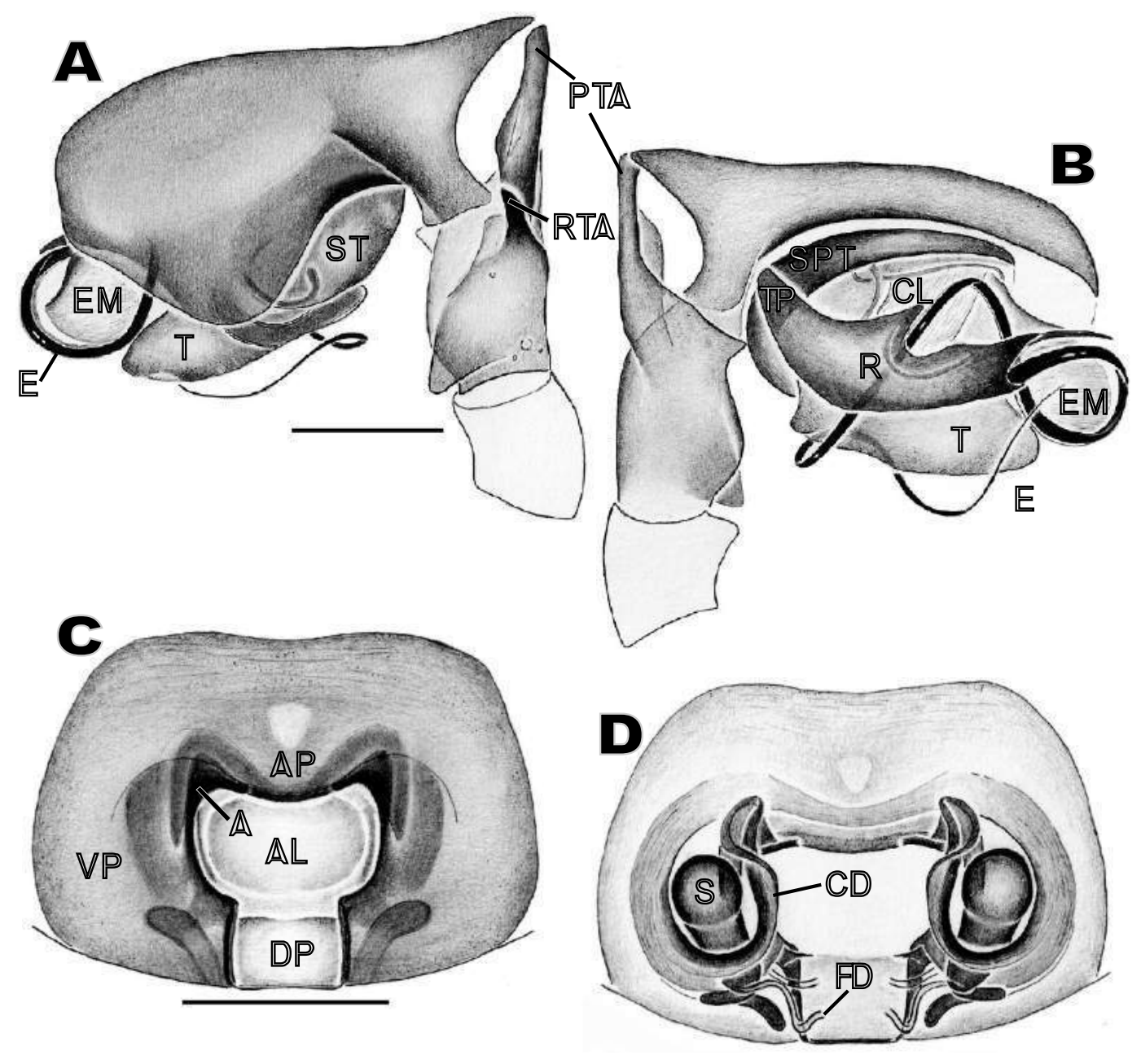

Figura 149. Clitolyna rostrata, A-B, palpo do macho; C, epígino da fêmea. A, retrolateral; B, prolateral; C, ventral; D, dorsal. Escala 0,1mm. A, átrio; AL, lóbulo anterior da placa dorsal do epígino; AP, processo anterior da placa ventral do epígino; CD, duto de copulação; CL, column; DP, placa dorsal do epígino; E, êmbolo; EM, membrana embólica; FD, duto de fertilização; PTA, apófise prolateral da tíbia; R, radix; RTA, apófise retrolateral da tíbia; S, espermateca; SPT, supratégulo; ST, subtégulo; T, tégulo; TP, cauda do radix; VP, placa ventral do epígino. Ilustração de Rodrigues et al. 2012. 


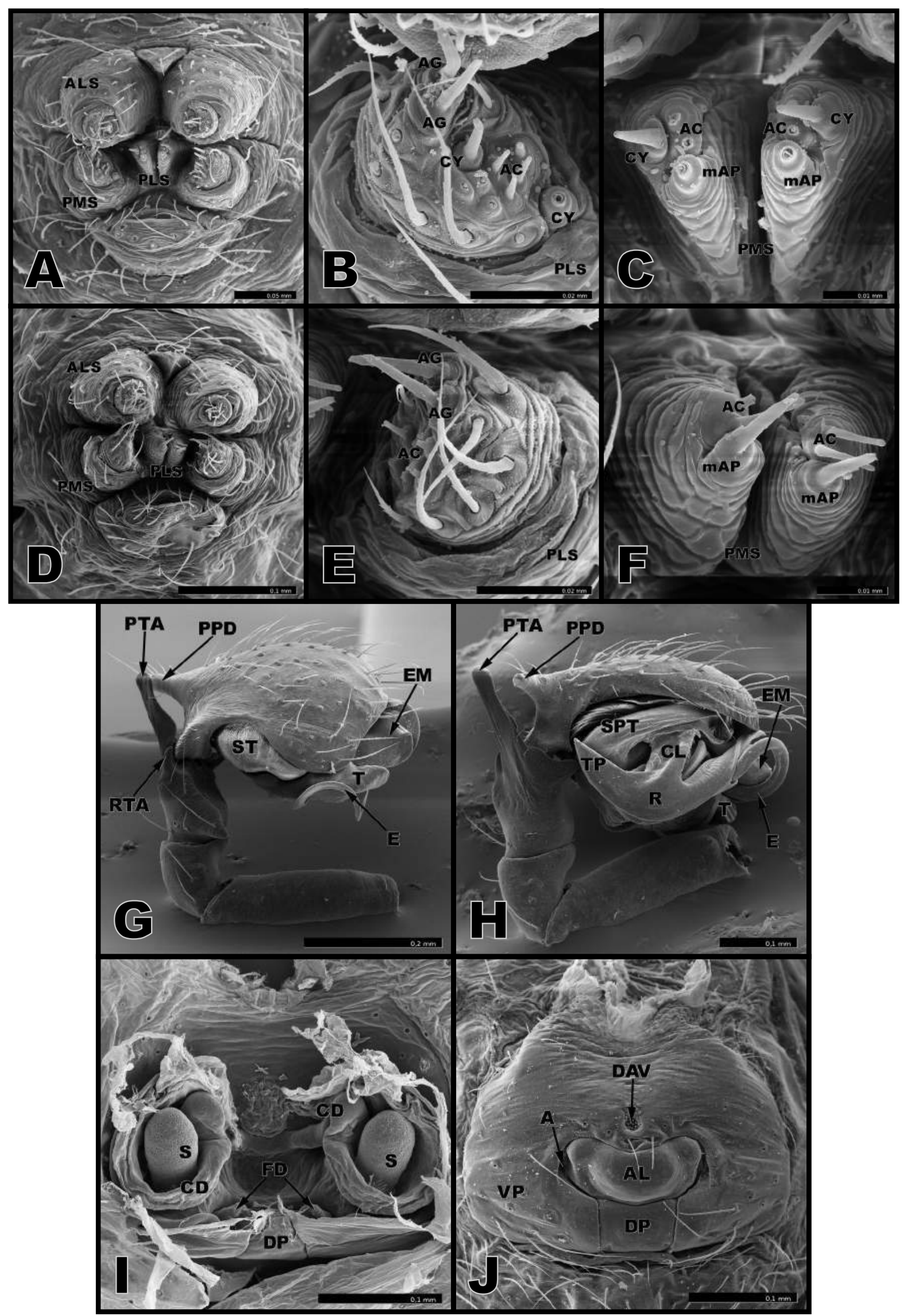

Figura 150. Clitolyna rostrata. A-C, fiandeiras da fêmea; D-F, fiandeiras do macho; G$\mathrm{H}$, palpo do macho; I-J, epígino da fêmea. A e D, vista geral. B e E, detalhe do PLS. C e F, detalhe do PMS. G, vista retrolateral. H, vista prolateral. I, vista dorsal. J vista ventral. 


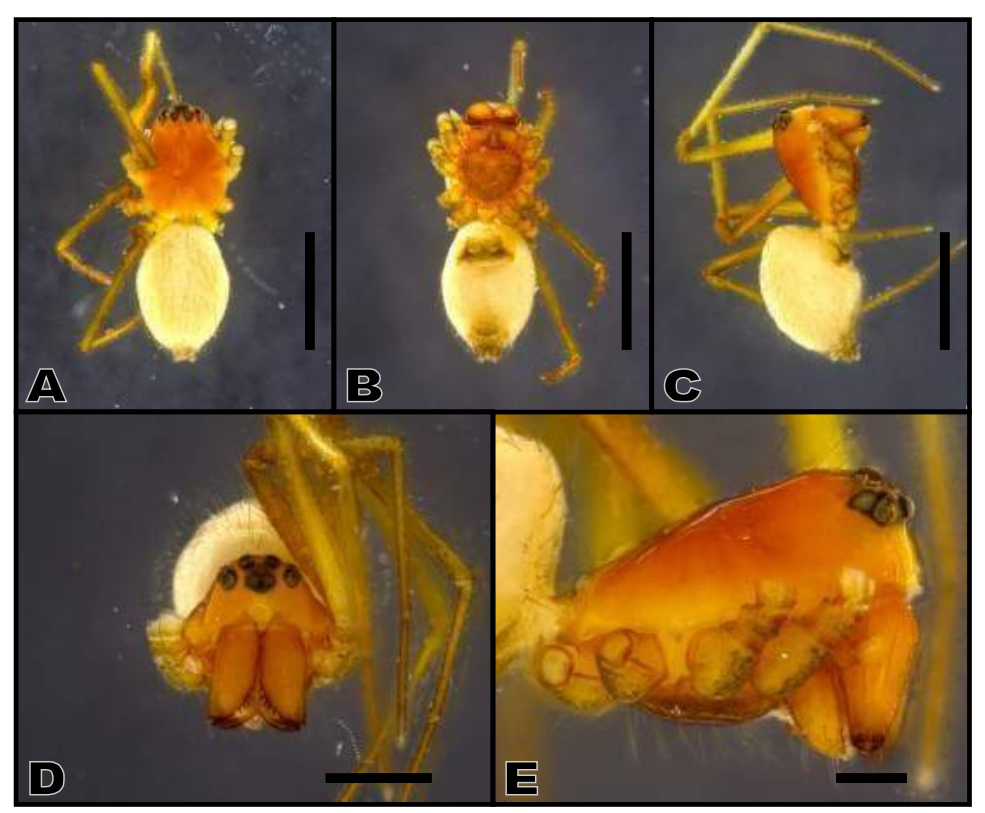

Figura 151. Clitolyna spadicaria, A-E, corpo do macho. A, dorsal; B, ventral; C, lateral; D, frontal; E, detalhe da região cefálica. Escala A-C,1,0mm; D, 0,5mm; E, $0,2 \mathrm{~mm}$.

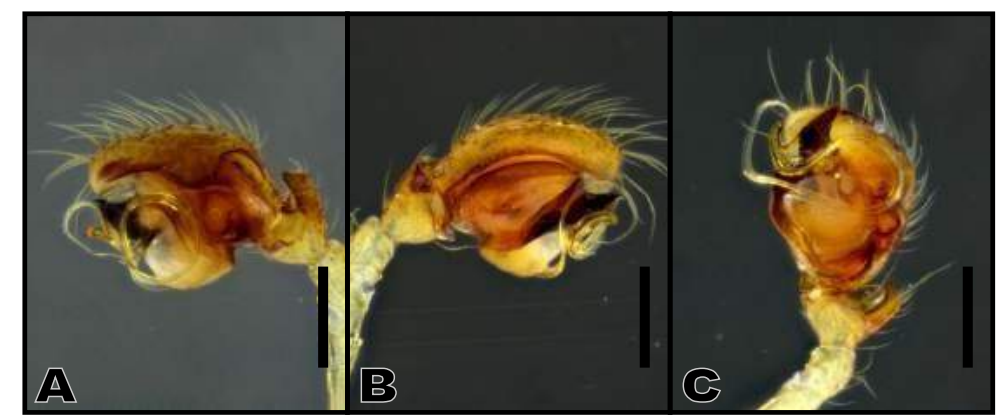

Figura 152. Clitolyna spadicaria, A-C, palpo do macho. A, retrolateral; B, prolateral; C, ventral. Escala 0,2mm.

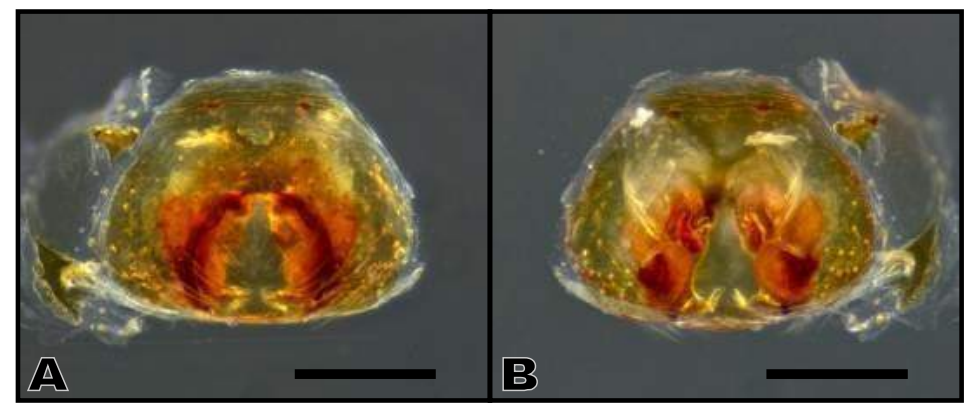

Figura 153. Clitolyna spadicaria, A-B, epígino da fêmea. A, ventral; B, dorsal. Escala $0,2 \mathrm{~mm}$. 


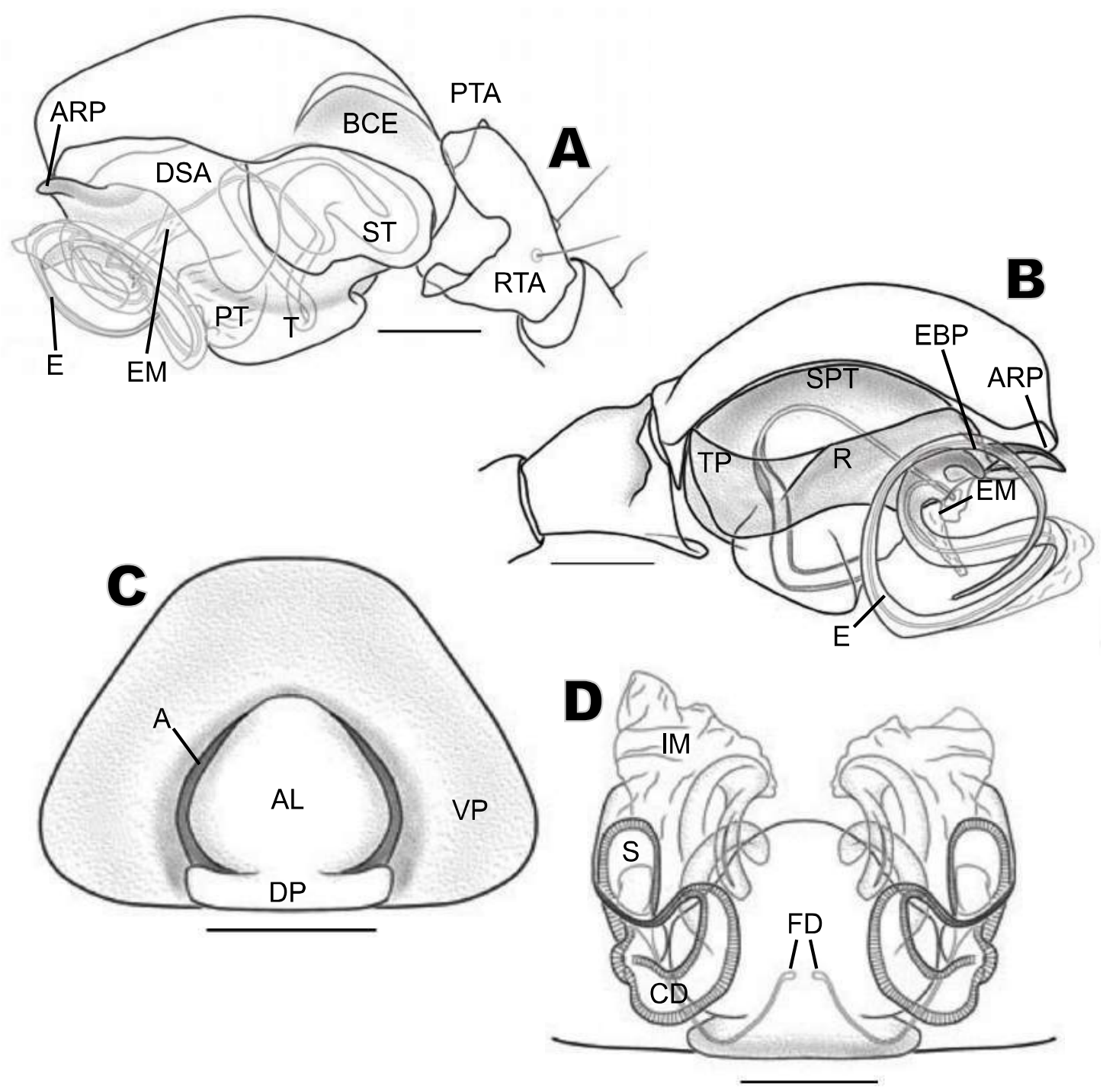

Figura 154. Clitolyna spadicaria, A-B, palpo do macho; C, epígino da fêmea. A, retrolateral; B, prolateral; C, ventral; D, dorsal. Escala 0,1mm. A, átrio; AL, lóbulo anterior da placa dorsal do epígino; ARP, processo anterior do radix; BCE, excavação basal do címbio; CD, duto de copulação; DP, placa dorsal do epígino; DSA, apófise distal suprategular; E, êmbolo; EBP, processo basal do êmbolo; EM, membrana embólica; FD, duto de fertilização; IM, membrana interna do epígino; PT, protégulo; PTA, apófise prolateral da tíbia; Rradix; RTA, apófise retrolateral da tíbia; S, espermateca; SPT, supratégulo; ST, subtégulo; T, tégulo; TP, cauda do radix; VP, placa ventral do epígino. Ilustração de Miller, 2007. 


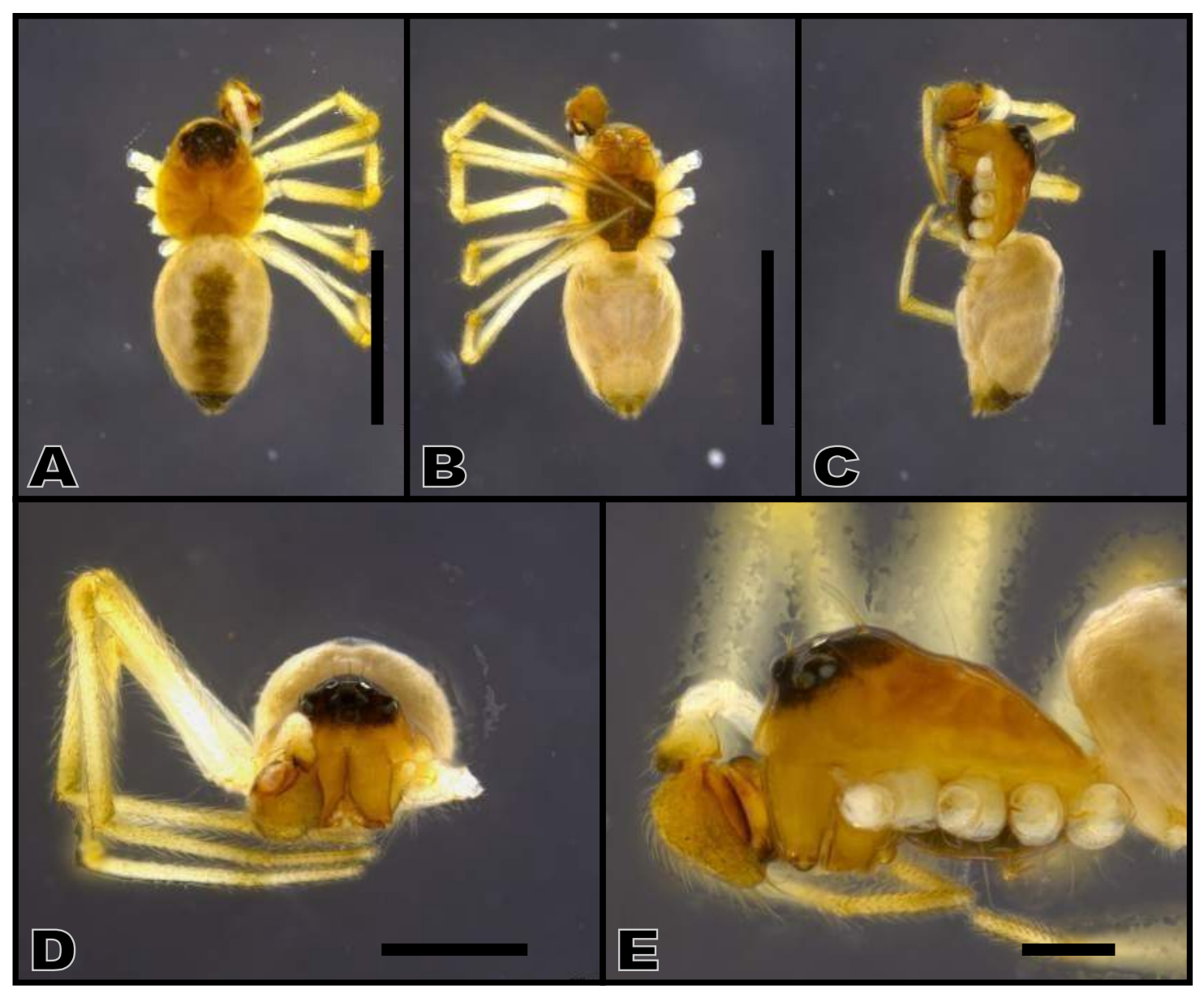

Figura 155. Clitolyna tumidosa, A-E, corpo do macho. A, dorsal; B, ventral; C, lateral; D, frontal; E, detalhe da região cefálica. Escala A-C,1,0mm; D, 0,5mm; E, 0,2mm.

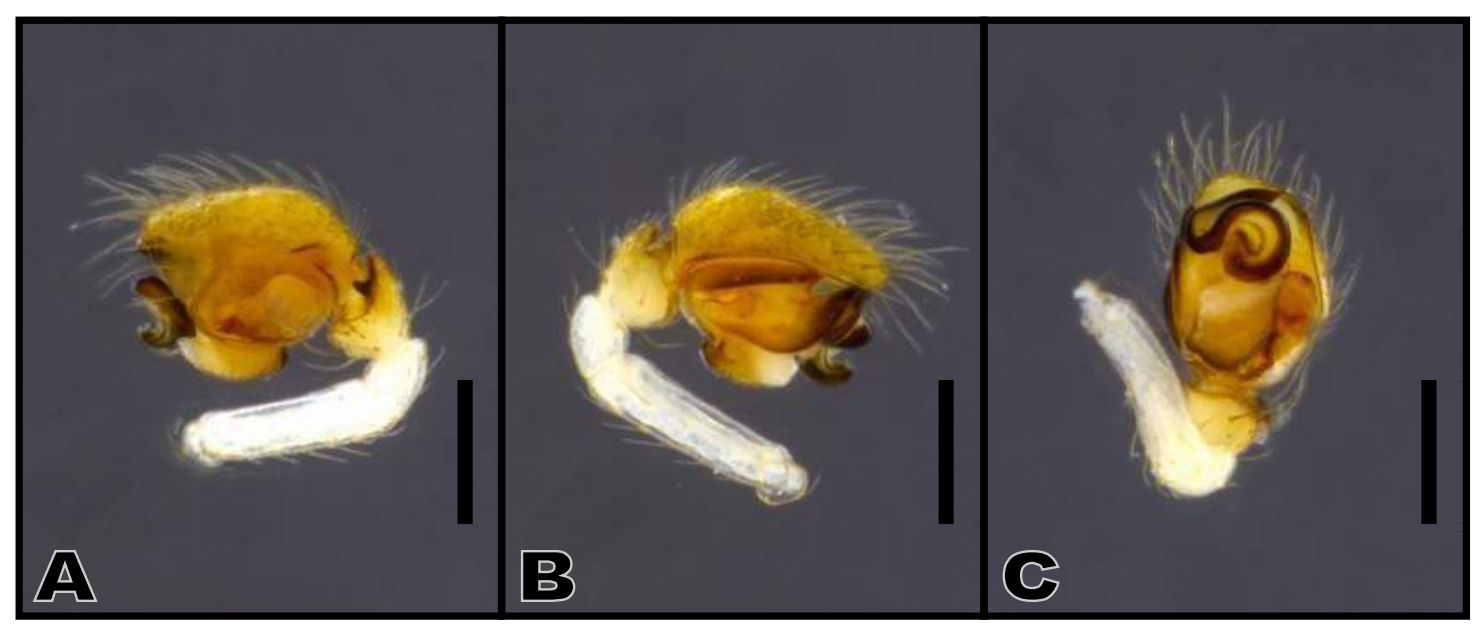

Figura 156. Clitolyna tumidosa, A-C, palpo do macho. A, retrolateral; B, prolateral; C, ventral. Escala 0,2mm. 


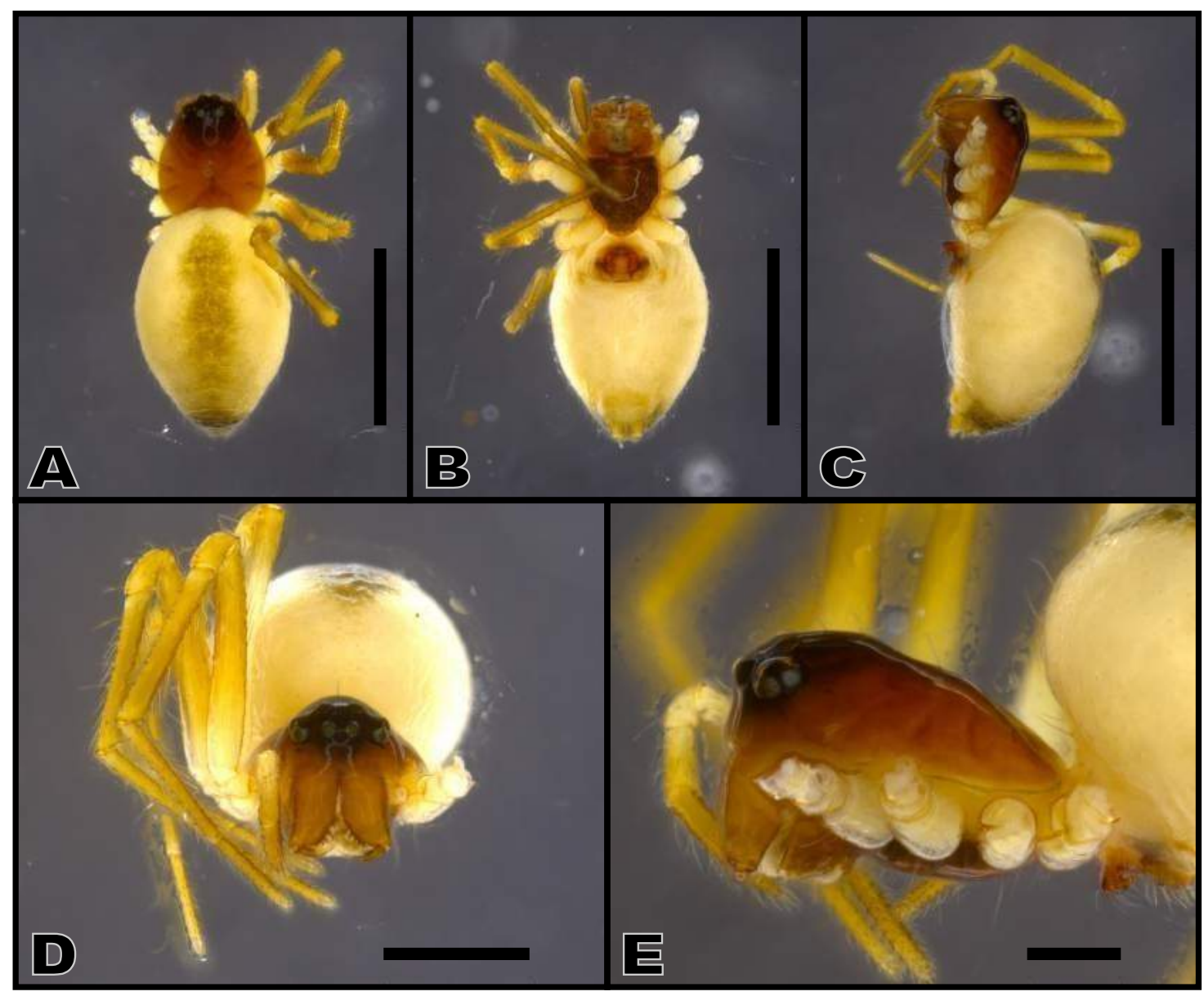

Figura 157. Clitolyna tumidosa, A-E, corpo da fêmea. A, dorsal; B, ventral; C, lateral;

D, frontal; E, detalhe da região cefálica. Escala A-C,1,0mm; D, 0,5mm; E, 0,2mm.

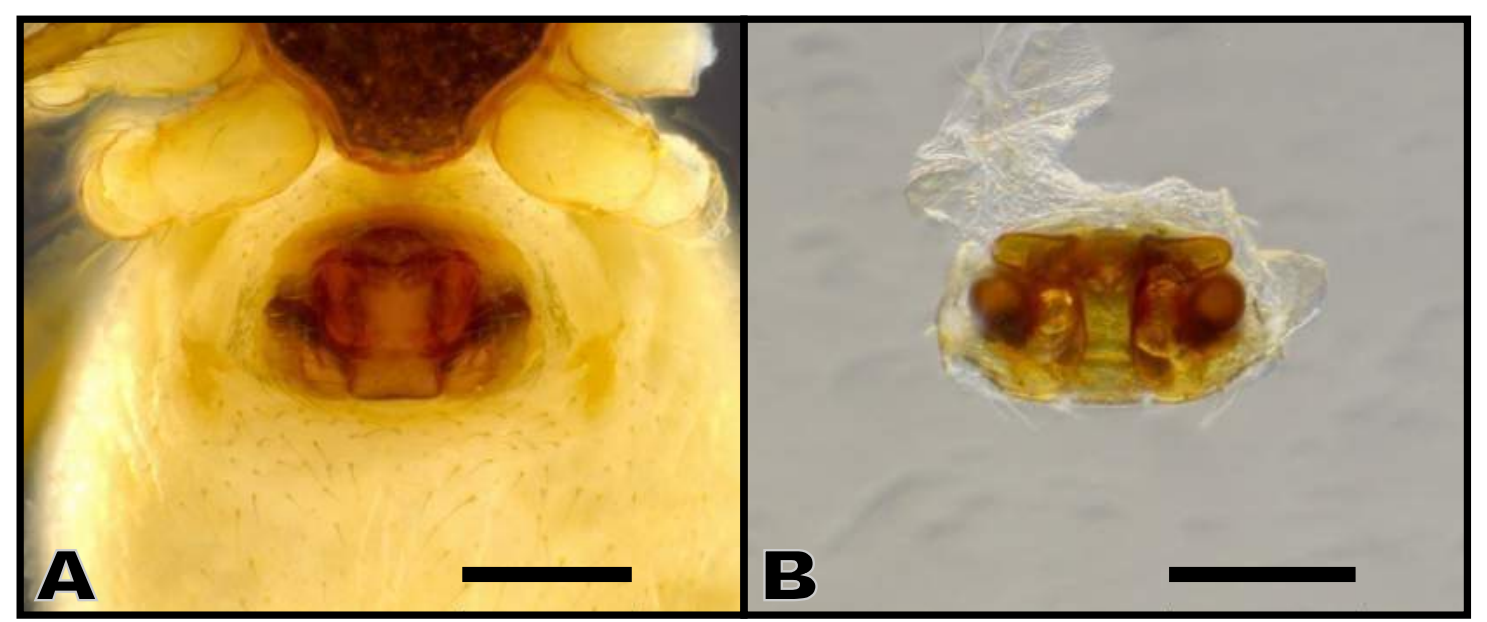

Figura 158. Clitolyna tumidosa, A-B, epígino da fêmea. A, ventral; B, dorsal. Escala $0,2 \mathrm{~mm}$. 


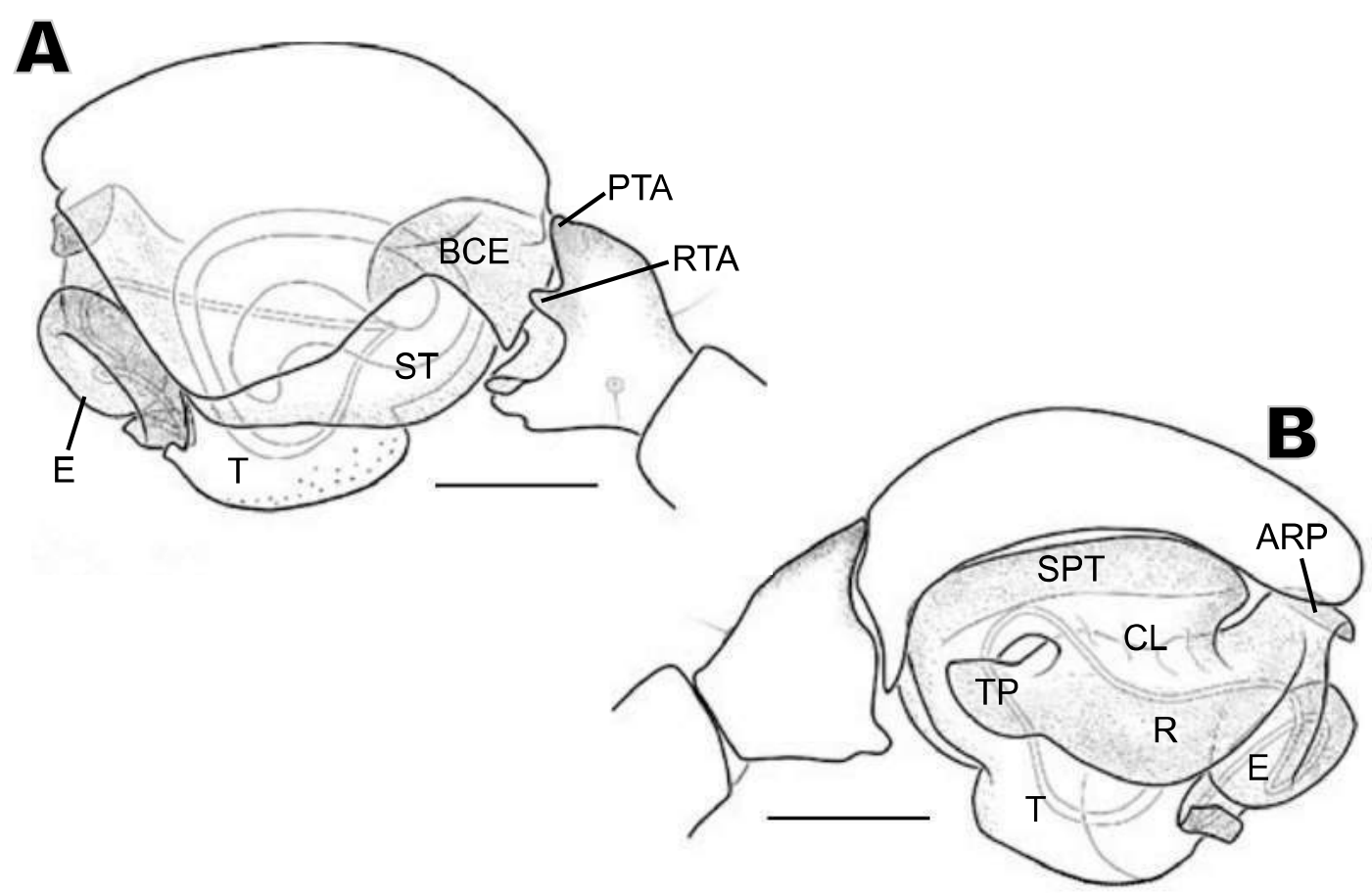

Figura 159. Clitolyna tumidosa, A-B, palpo do macho; C, epígino da fêmea. A, retrolateral; B, prolateral; C, ventral; D, dorsal. Escala 0,1mm. ARP, processo anterior do radix; BCE, excavação basal do címbio; CL, column; E, êmbolo; PTA, apófise prolateral da tíbia; R, radix; RTA, apófise retrolateral da tíbia; SPT, supratégulo; ST, subtégulo; T, tégulo; TP, cauda do radix. Ilustração de Miller, 2007. 


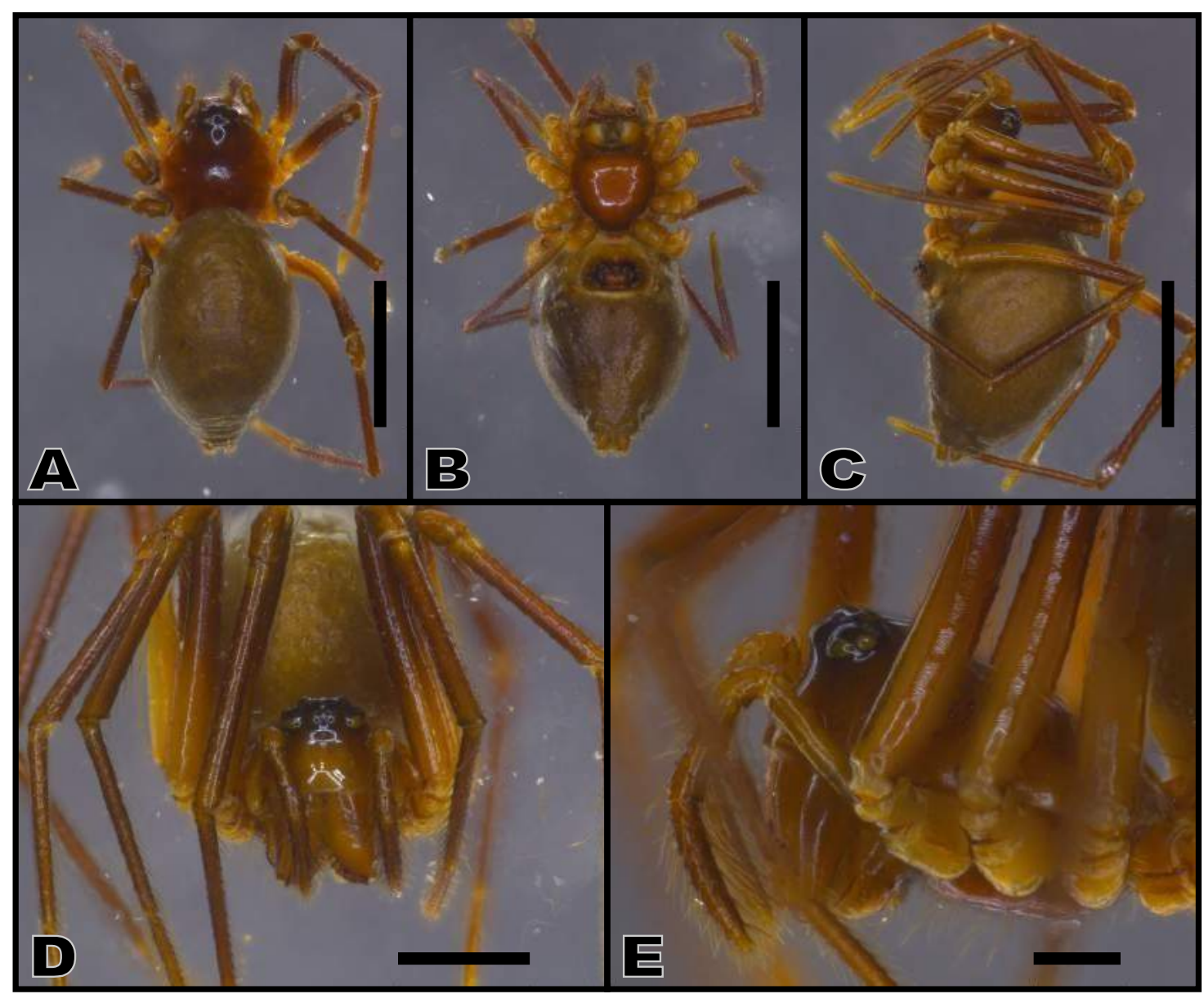

Figura 160. Clitolyna varia, A-E, corpo da fêmea. A, dorsal; B, ventral; C, lateral; D, frontal; E, detalhe da região cefálica. Escala A-C,1,0mm; D, 0,5mm; E, 0,2mm.

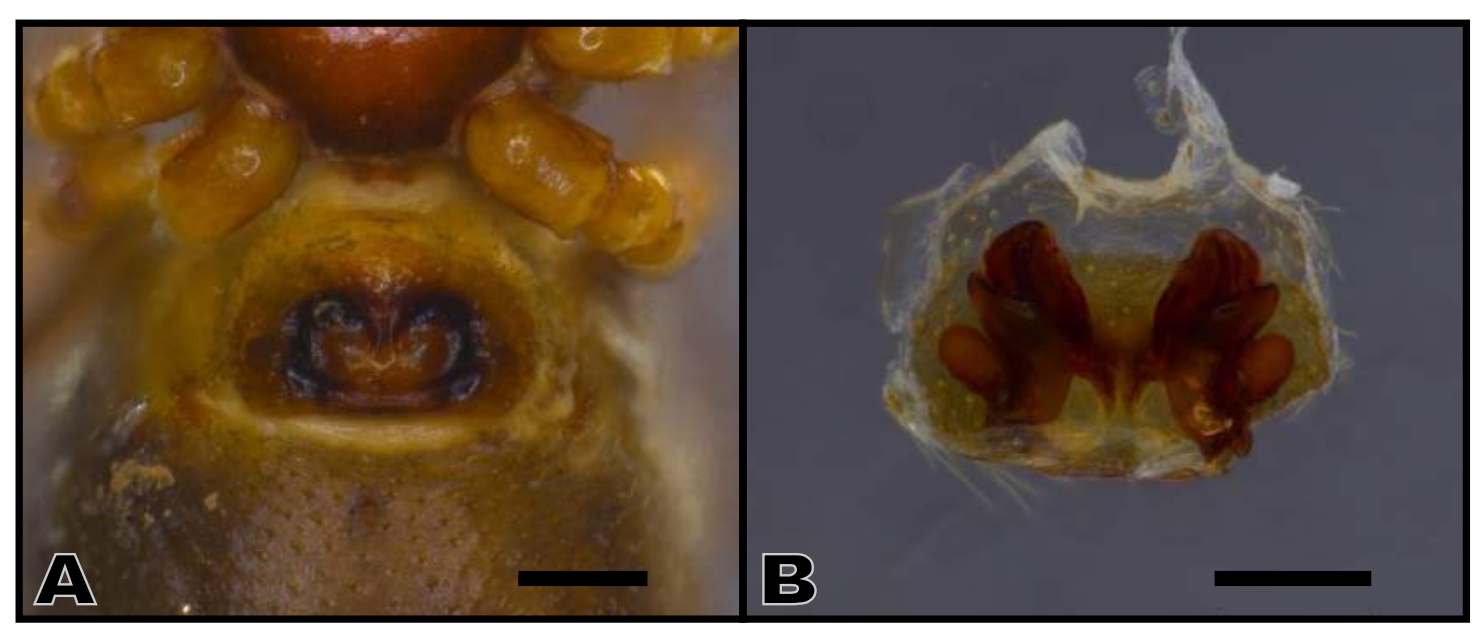

Figura 161. Clitolyna varia, A-B, epígino da fêmea. A, ventral; B, dorsal. Escala $0,2 \mathrm{~mm}$. 


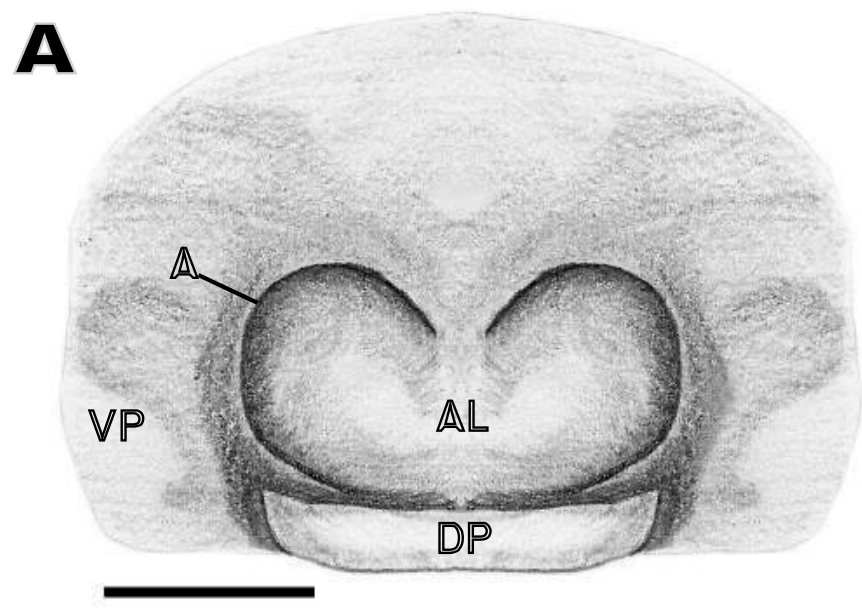

Figura 162. Clitolyna varia, A, epígino da fêmea, ventral. Escala 0,1mm. A, átrio; AL, lóbulo anterior da placa dorsal do epígino; DP, placa dorsal do epígino; VP, placa ventral do epígino. 


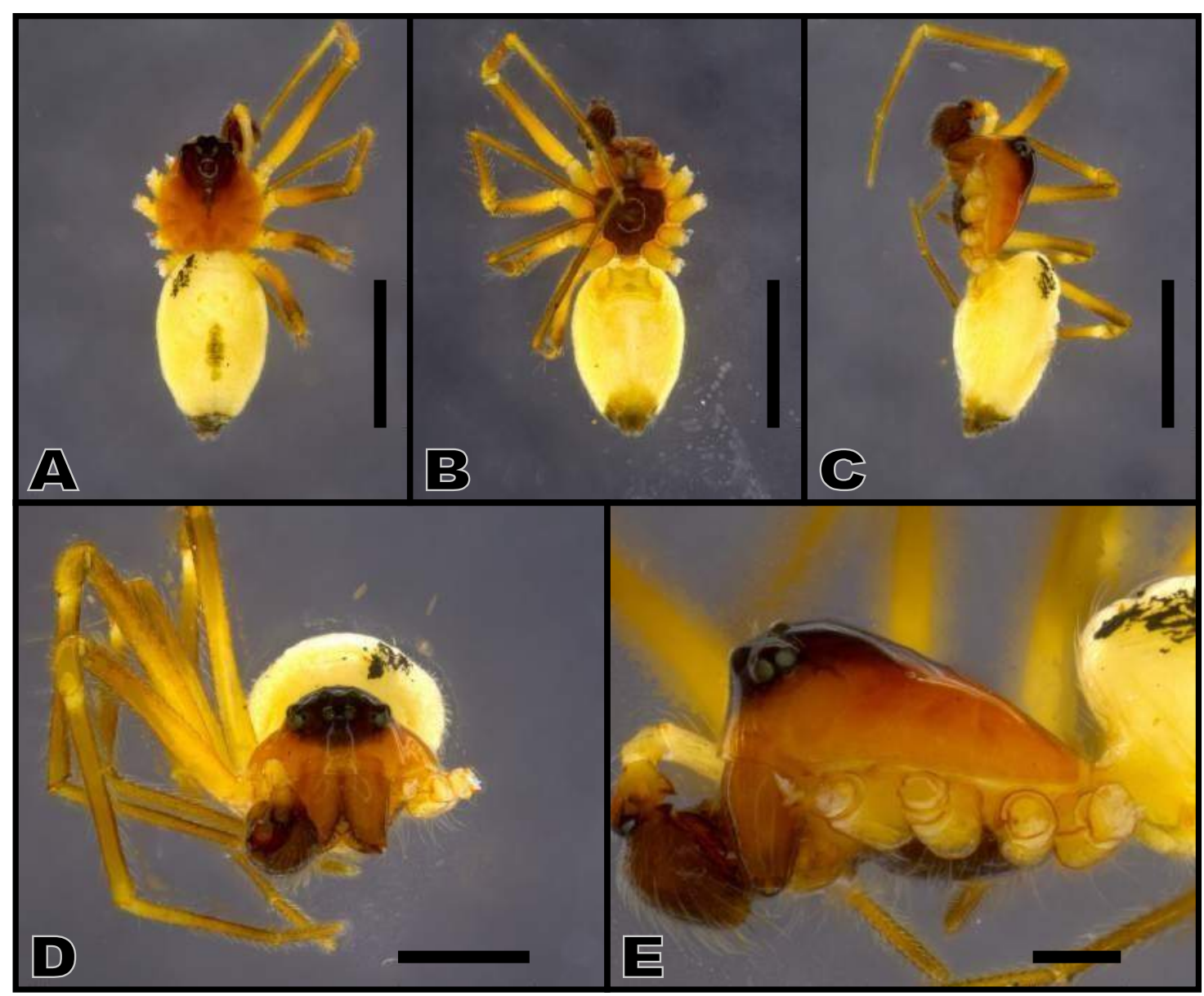

Figura 163. Clitolyna venialis, A-E, corpo do macho. A, dorsal; B, ventral; C, lateral;

D, frontal; E, detalhe da região cefálica. Escala A-C,1,0mm; D, 0,5mm; E, 0,2mm.

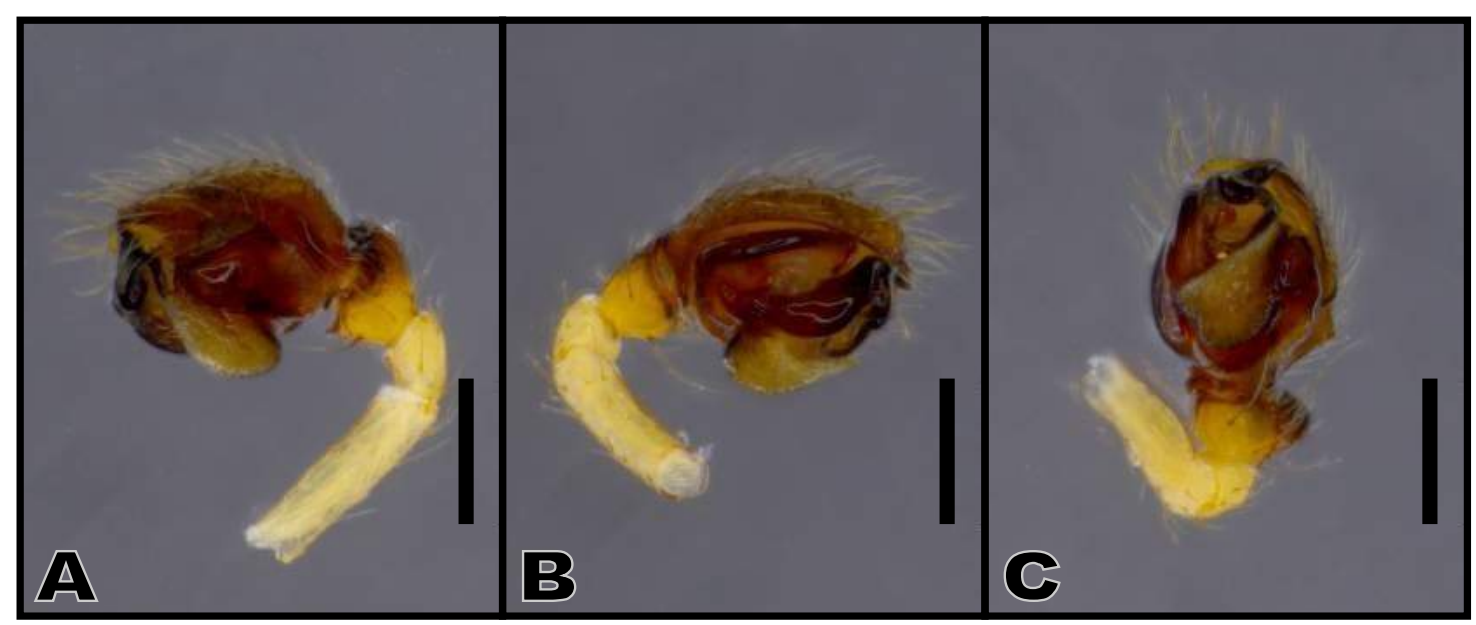

Figura 164. Clitolyna venialis, A-C, palpo do macho. A, retrolateral; B, prolateral; C, ventral. Escala 0,2mm. 


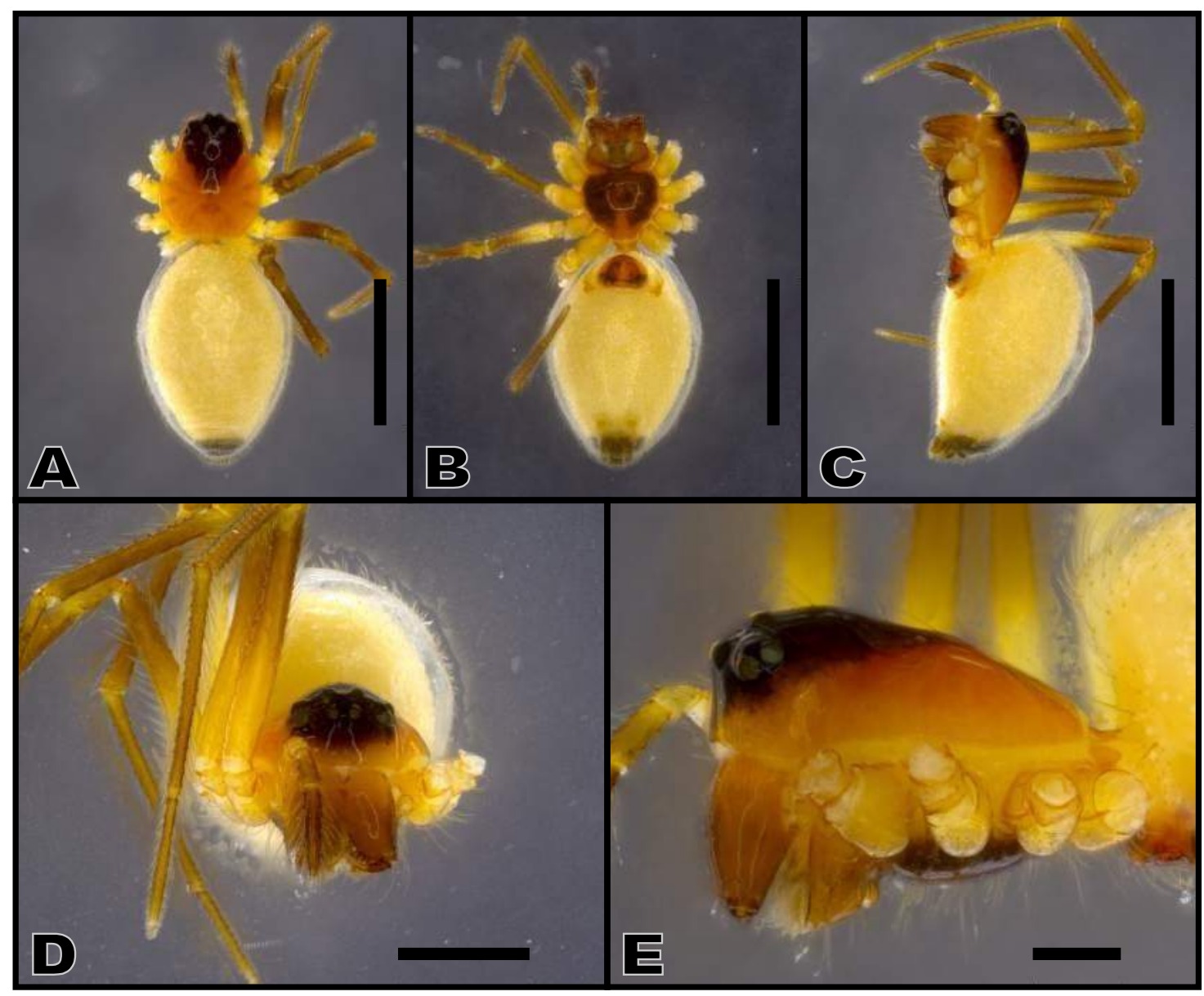

Figura 165. Clitolyna venialis, A-E, corpo da fêmea. A, dorsal; B, ventral; C, lateral; D, frontal; E, detalhe da região cefálica. Escala A-C,1,0mm; D, 0,5mm; E, 0,2mm.

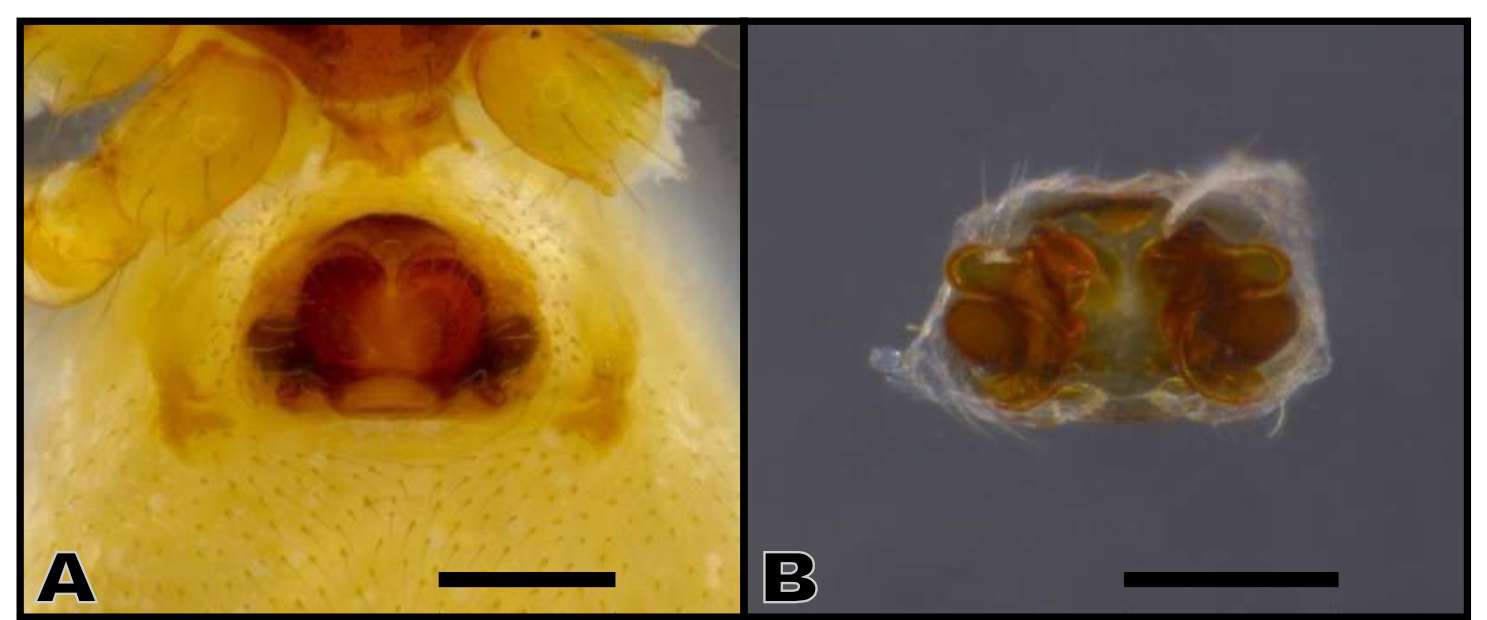

Figura 166. Clitolyna venialis, A-B, epígino da fêmea. A, ventral; B, dorsal. Escala $0,2 \mathrm{~mm}$. 


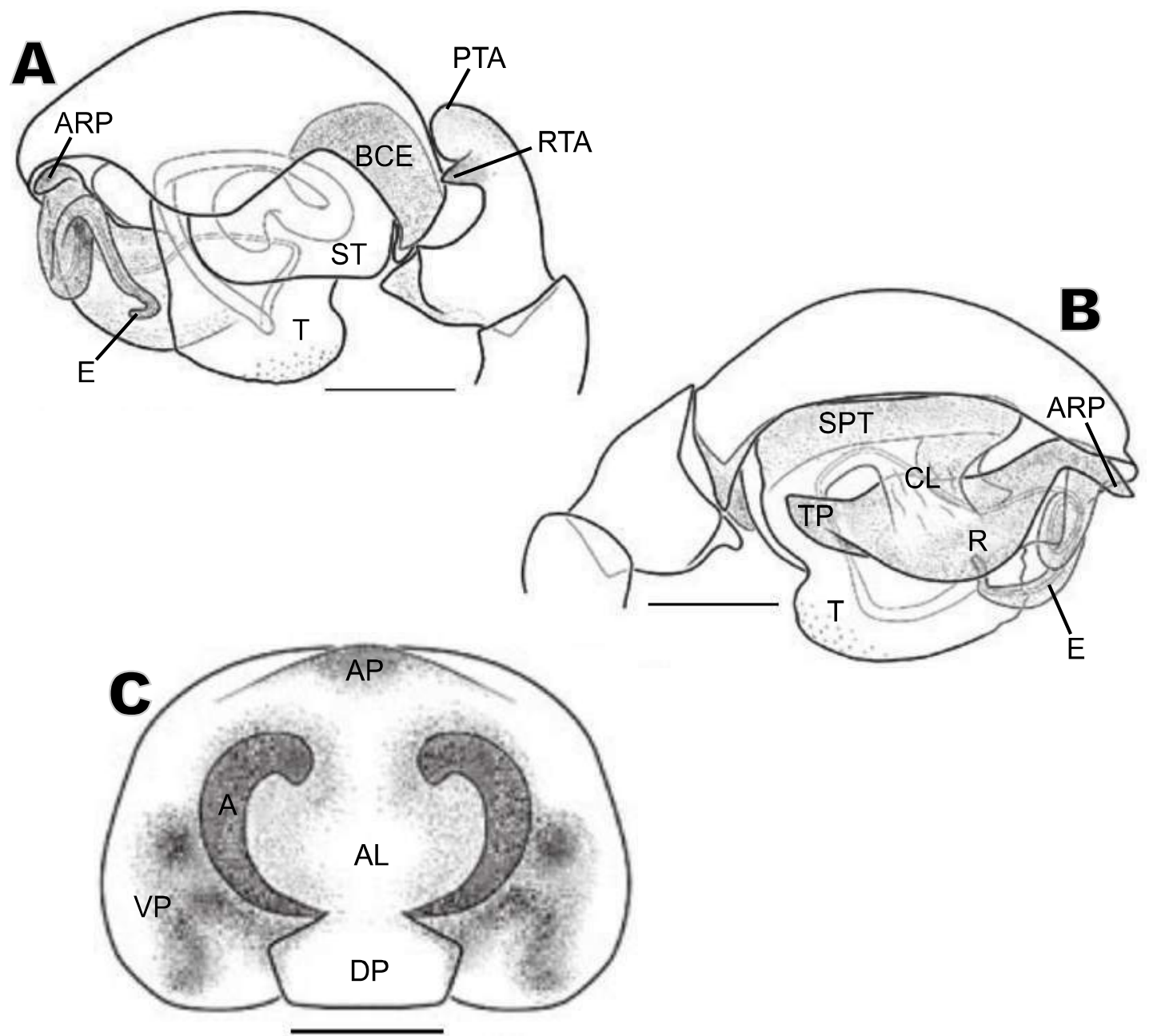

Figura 167. Clitolyna venialis, A-B, palpo do macho; C, epígino da fêmea. A, retrolateral; B, prolateral; C, ventral; D, dorsal. Escala 0,1mm. A, átrio; AL, lóbulo anterior da placa dorsal do epígino; AP, processo anterior da placa ventral do epígino; ARP, processo anterior do radix; BCE, excavação basal do címbio; CL, column; DP, placa dorsal do epígino; E, êmbolo; PTA, apófise prolateral da tíbia; R, radix; RTA, apófise retrolateral da tíbia; SPT, supratégulo; ST, subtégulo; T, tégulo; TP, cauda do radix; VP, placa ventral do epígino. Ilustração de Miller, 2007. 


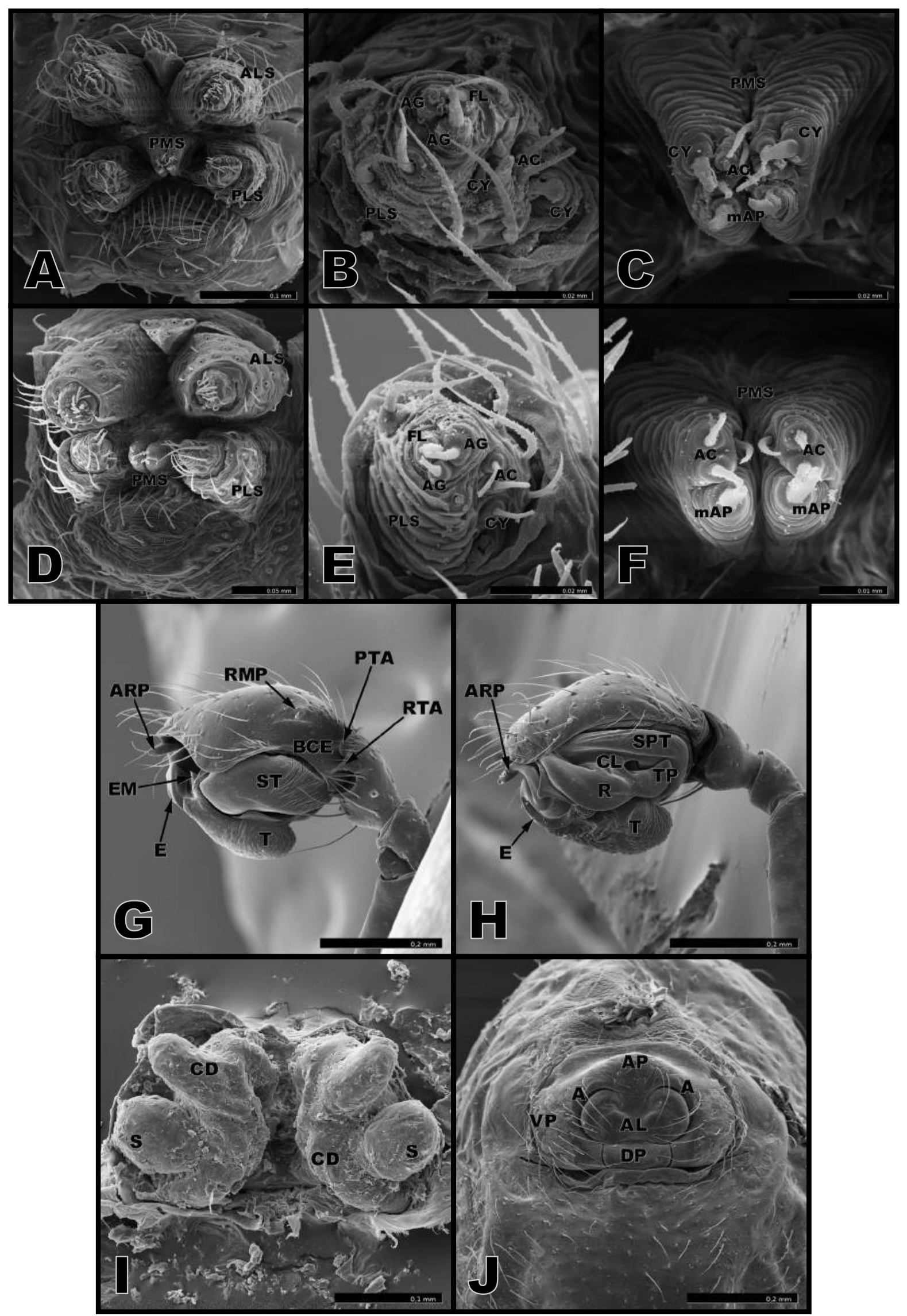

Figura 168. Clitolyna venialis. A-C, fiandeiras da fêmea; D-F, fiandeiras do macho; G$\mathrm{H}$, palpo do macho; I-J, epígino da fêmea. A e D, vista geral. B e E, detalhe do PLS. C e F, detalhe do PMS. G, vista retrolateral. H, vista prolateral. I, vista dorsal. J vista ventral. 


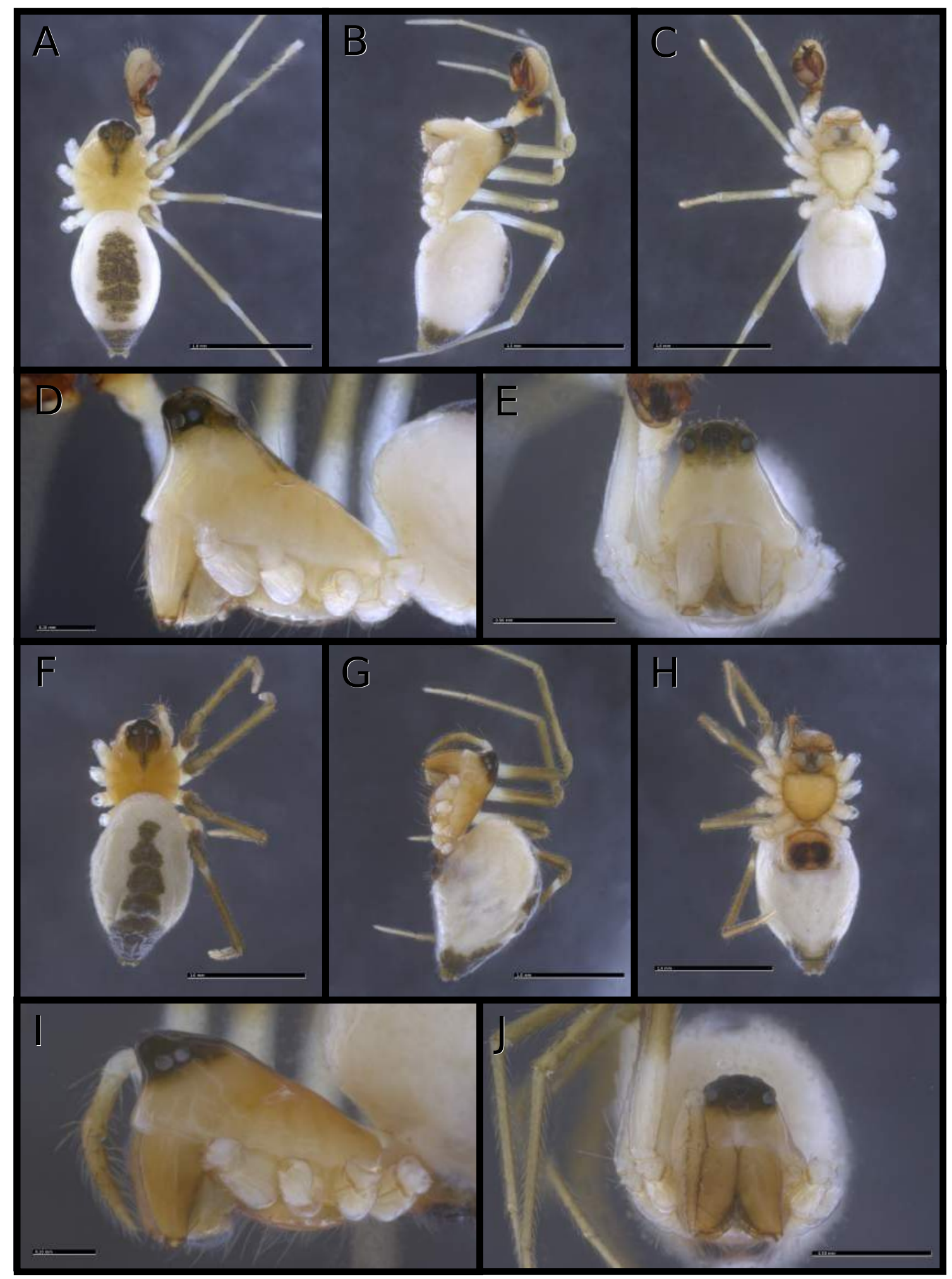

Figura 169. Clitolyna sp.nov.01, A-E, corpo do macho, F-J, corpo da fêmea. A, F, dorsal; B, G, lateral; C, H, ventral; D, I, detalhe da região cefálica; E, J, frontal. Escala A-C, F-H1,0mm; D, I, 0,2mm; E, J, 0,5mm. 


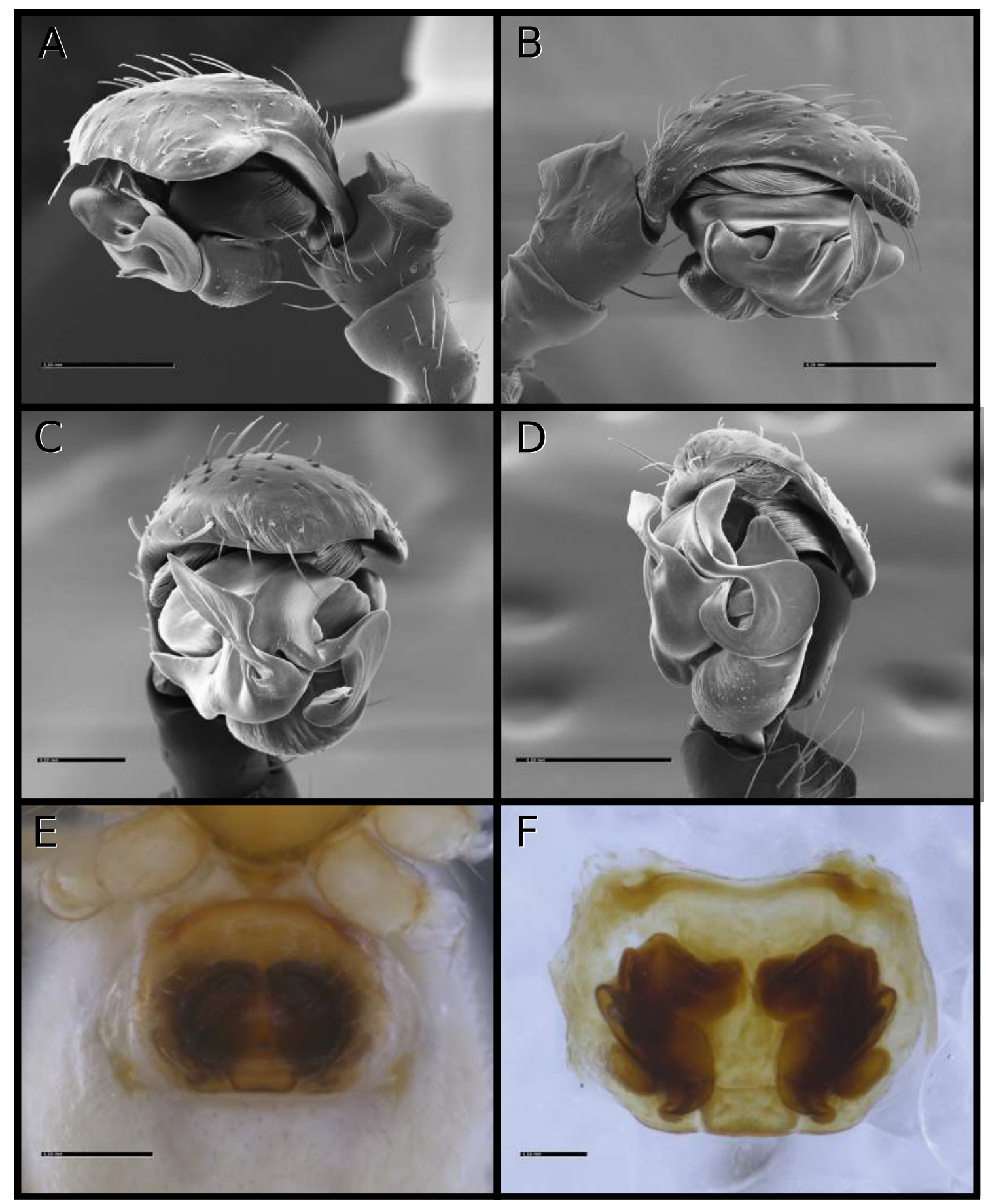

Figura 170. Clitolyna sp.nov.01, A-D, palpo do macho, E-F, epígino da fêmea. A, retrolateral; B, prolateral; C, frontal; D, ventral, E, ventral; F, dorsal. Escala A-B, E, 0,2mm, C-D, F, 0,1mm. 

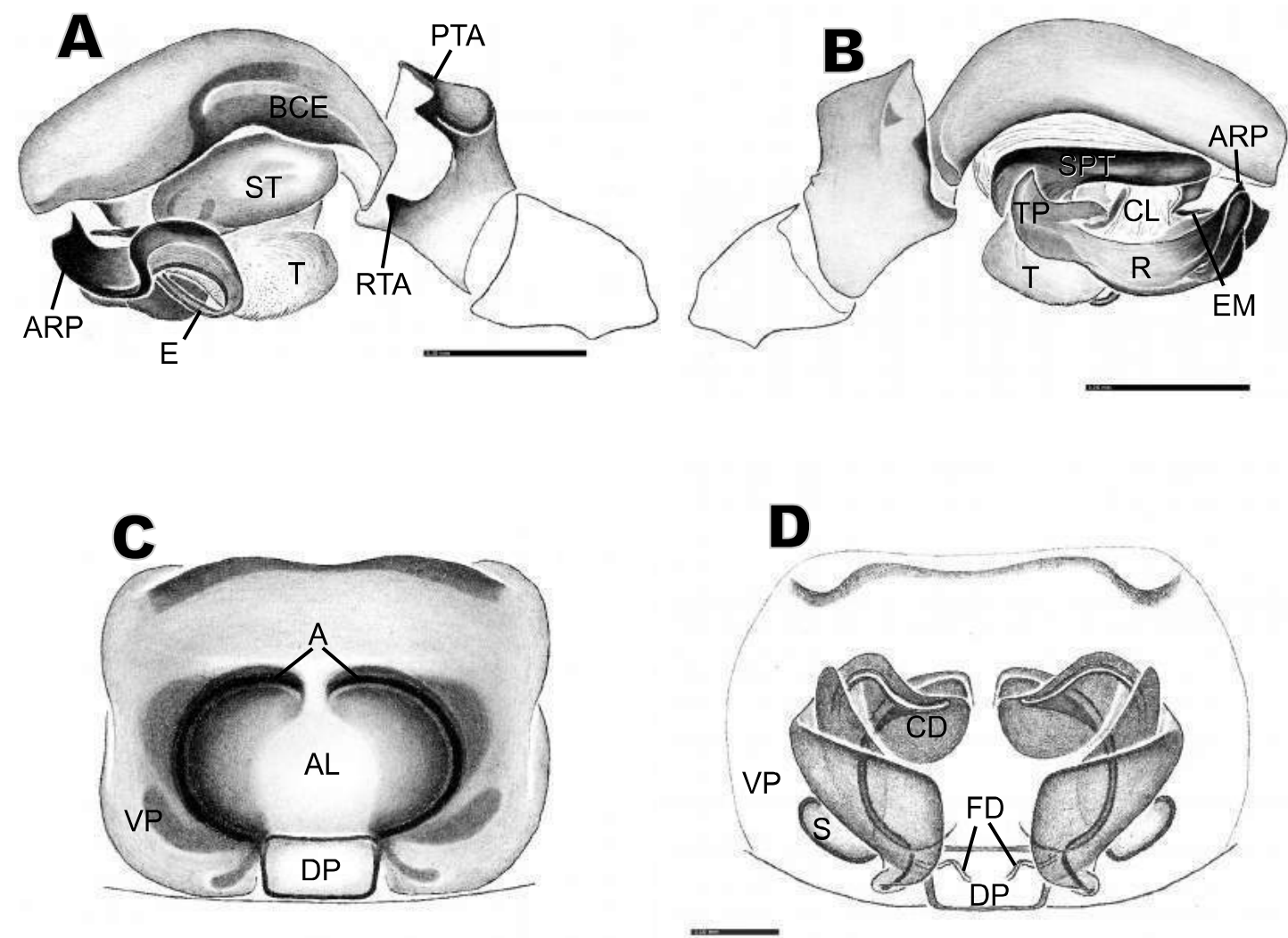

Figura 171. Clitolyna sp.nov.01, A-B, palpo do macho; C-D, epígino da fêmea. A, retrolateral; B, prolateral; C, ventral; D, dorsal. Escala 0,2mm. A, átrio; AL, lóbulo anterior da placa dorsal do epígino; ARP, processo anterior do radix; BCE, excavação basal do címbio; CD, duto de copulação; CL, column; DP, placa dorsal do epígino; E, êmbolo; EM, membrana embólica; FD, duto de fertilização; PTA, apófise prolateral da tíbia; R, radix; RTA, apófise retrolateral da tíbia; S, espermateca; SPT, supratégulo; ST, subtégulo; T, tégulo; TP, cauda do radix; VP, placa ventral do epígino. Ilustração de Rodrigues, in prep. 


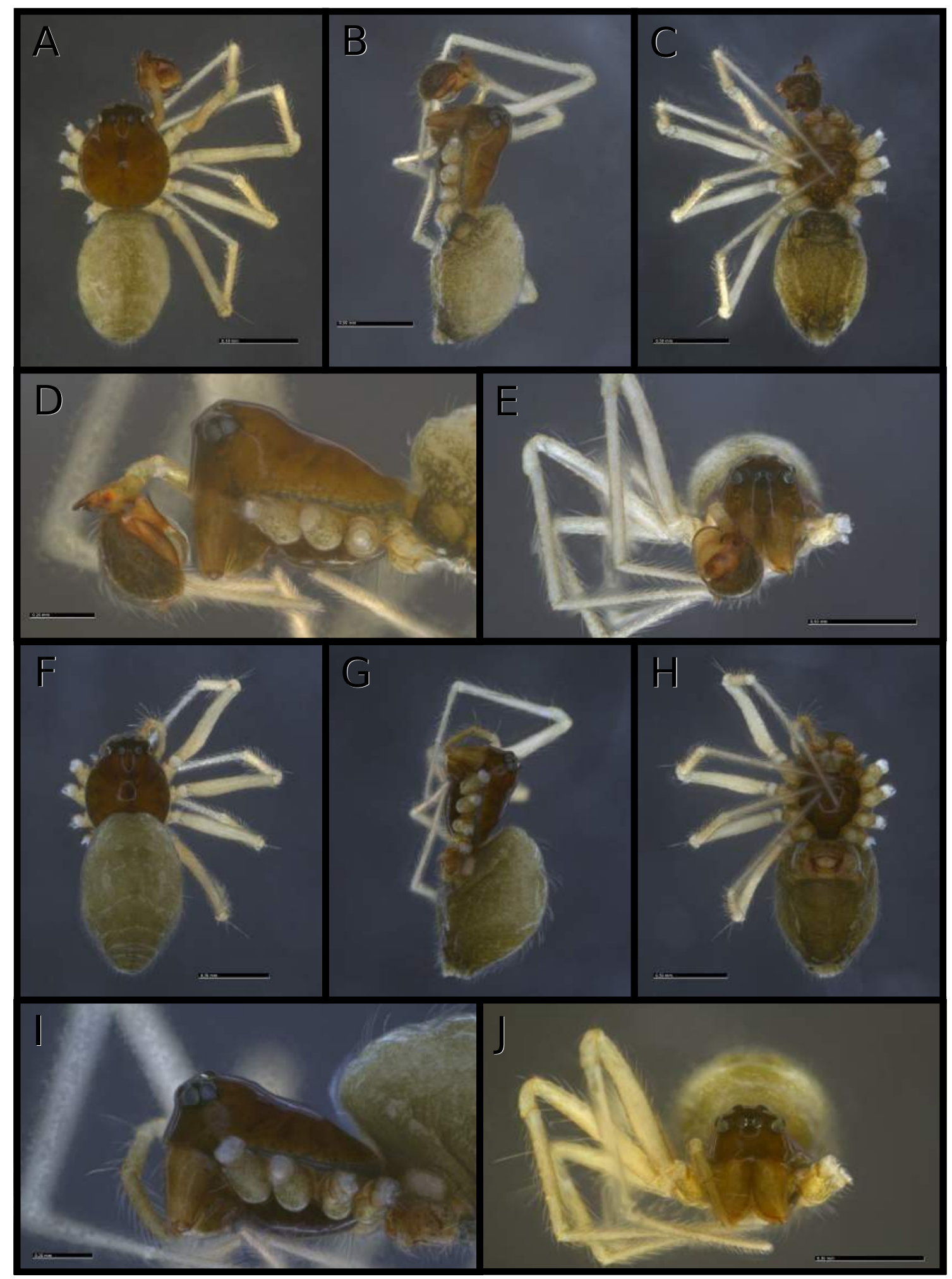

Figura 172. Clitolyna sp.nov.02, A-E, corpo do macho, F-J, corpo da fêmea. A, F, dorsal; B, G, lateral; C, H, ventral; D, I, detalhe da região cefálica; E, J, frontal. Escala A-C, F-H1,0mm; D, I, 0,2mm; E, J, 0,5mm. 


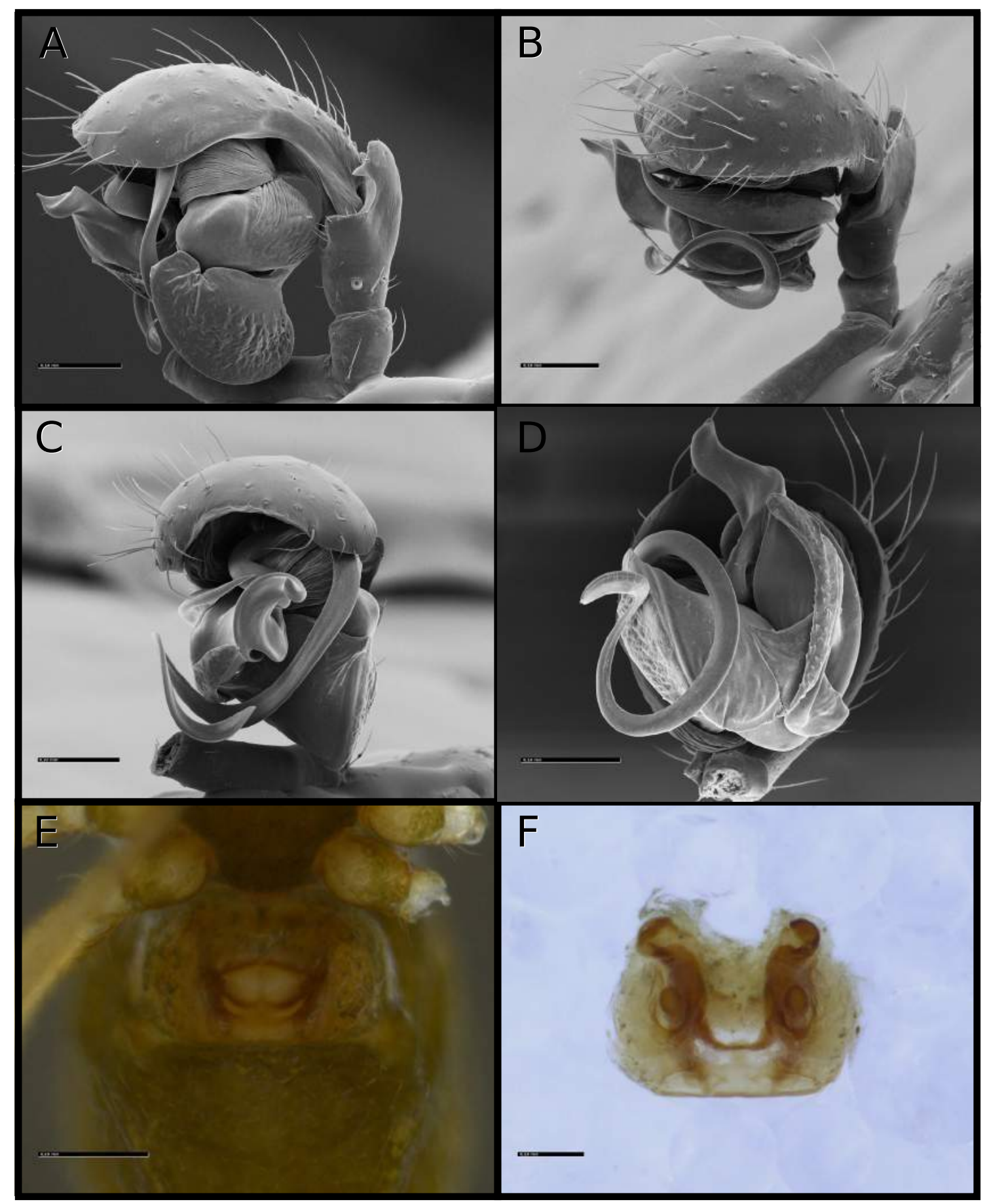

Figura 173. Clitolyna sp.nov.02, A-D, palpo do macho, E-F, epígino da fêmea. A, retrolateral; B, prolateral; C, frontal; D, ventral, E, ventral; F, dorsal. Escala A-B, E, 0,2mm, C-D, F, 0,1mm. 


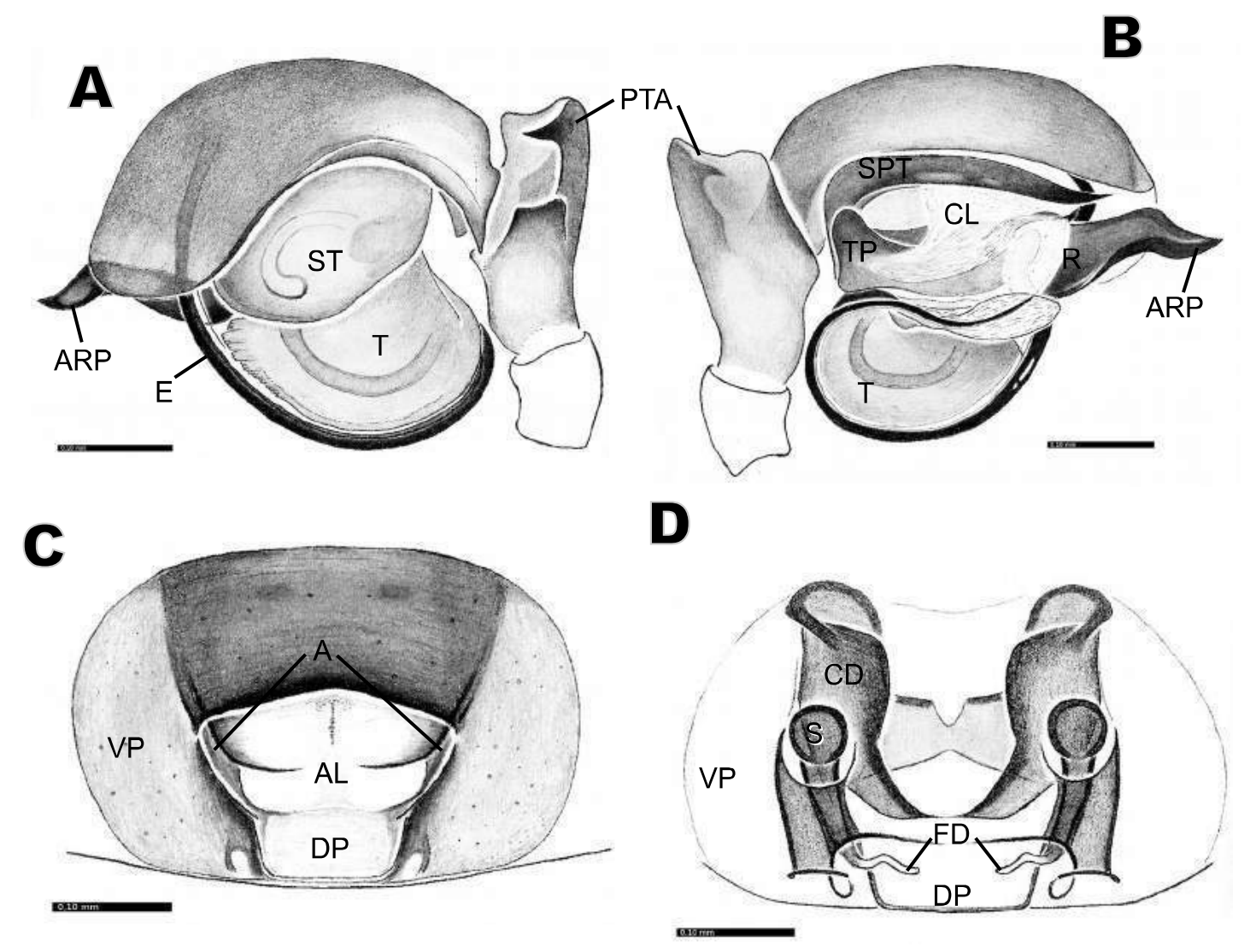

Figura 174. Clitolyna sp.nov.02, A-B, palpo do macho; C-D, epígino da fêmea. A, retrolateral; B, prolateral; C, ventral; D, dorsal. Escala 0,1mm. A, átrio; AL, lóbulo anterior da placa dorsal do epígino; ARP, processo anterior do radix; $\mathrm{CD}$, duto de copulação; CL, column; DP, placa dorsal do epígino; E, êmbolo; FD, duto de fertilização; PTA, apófise prolateral da tíbia; R, radix; S, espermateca; SPT, supratégulo; ST, subtégulo; T, tégulo; TP, cauda do radix; VP, placa ventral do epígino. Ilustração de Rodrigues, in prep. 


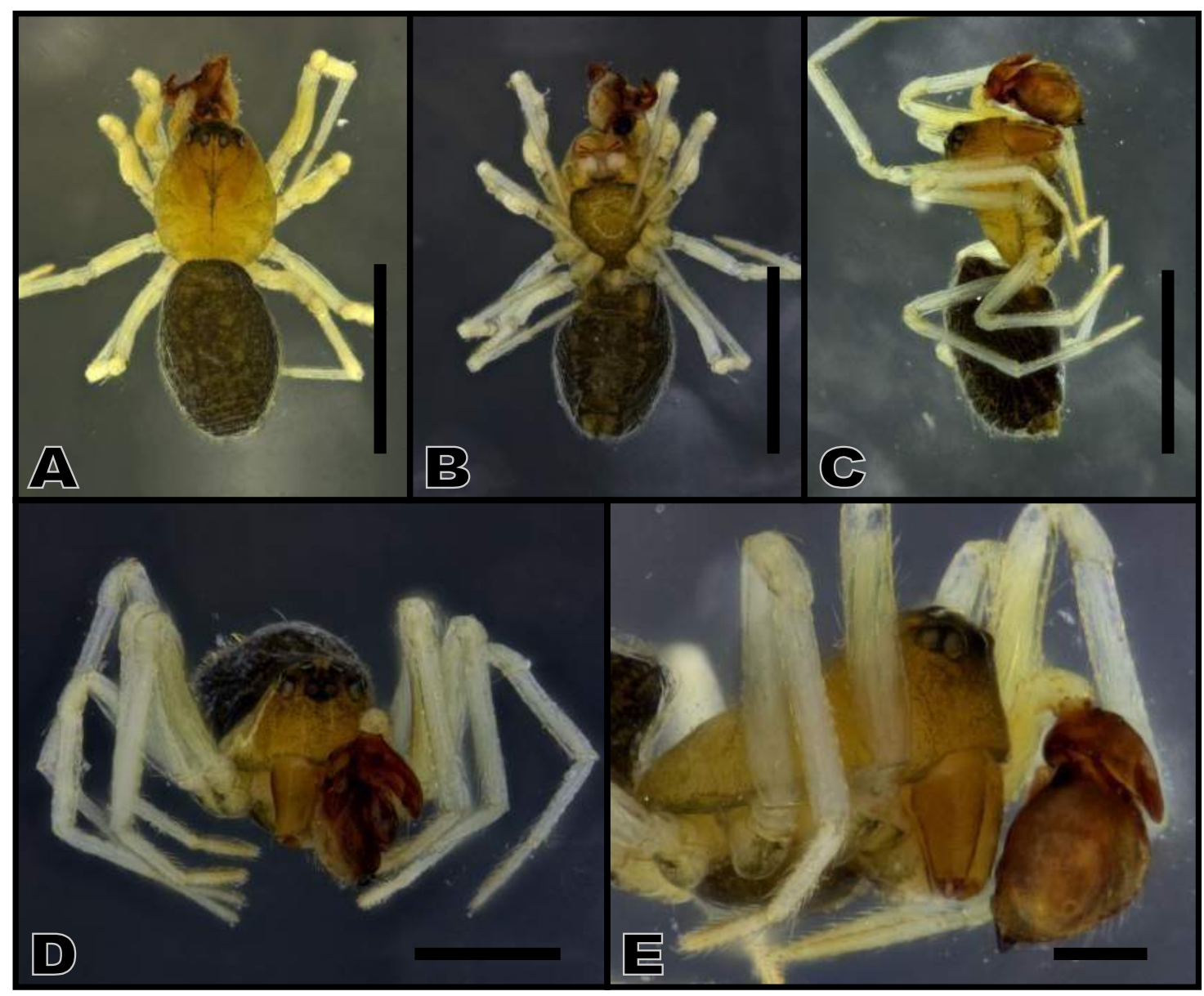

Figura 175. Gen.nov. magnipalpis, A-E, corpo do macho. A, dorsal; B, ventral; C, lateral; D, frontal; E, detalhe da região cefálica. Escala A-C,1,0mm; D, 0,5mm; E, $0,2 \mathrm{~mm}$.

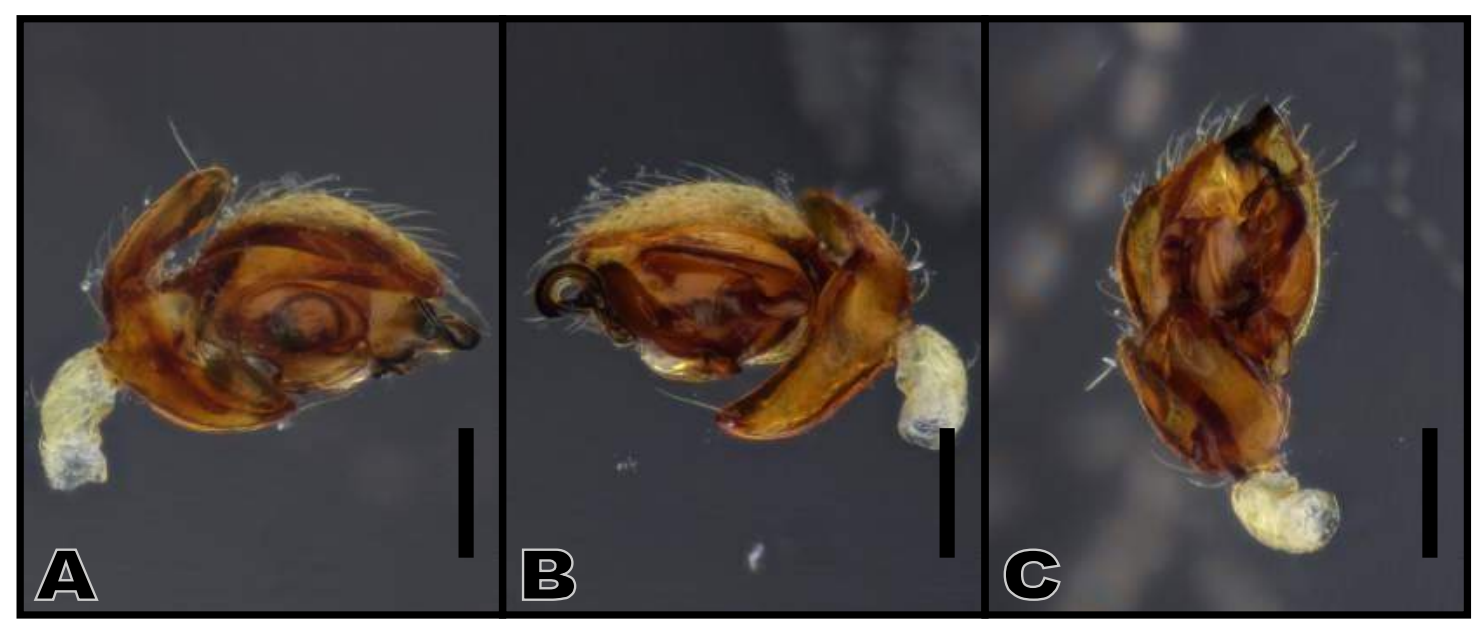

Figura 176. Gen.nov. magnipalpis, A-C, palpo do macho. A, retrolateral; B, prolateral; C, ventral. Escala $0,2 \mathrm{~mm}$. 


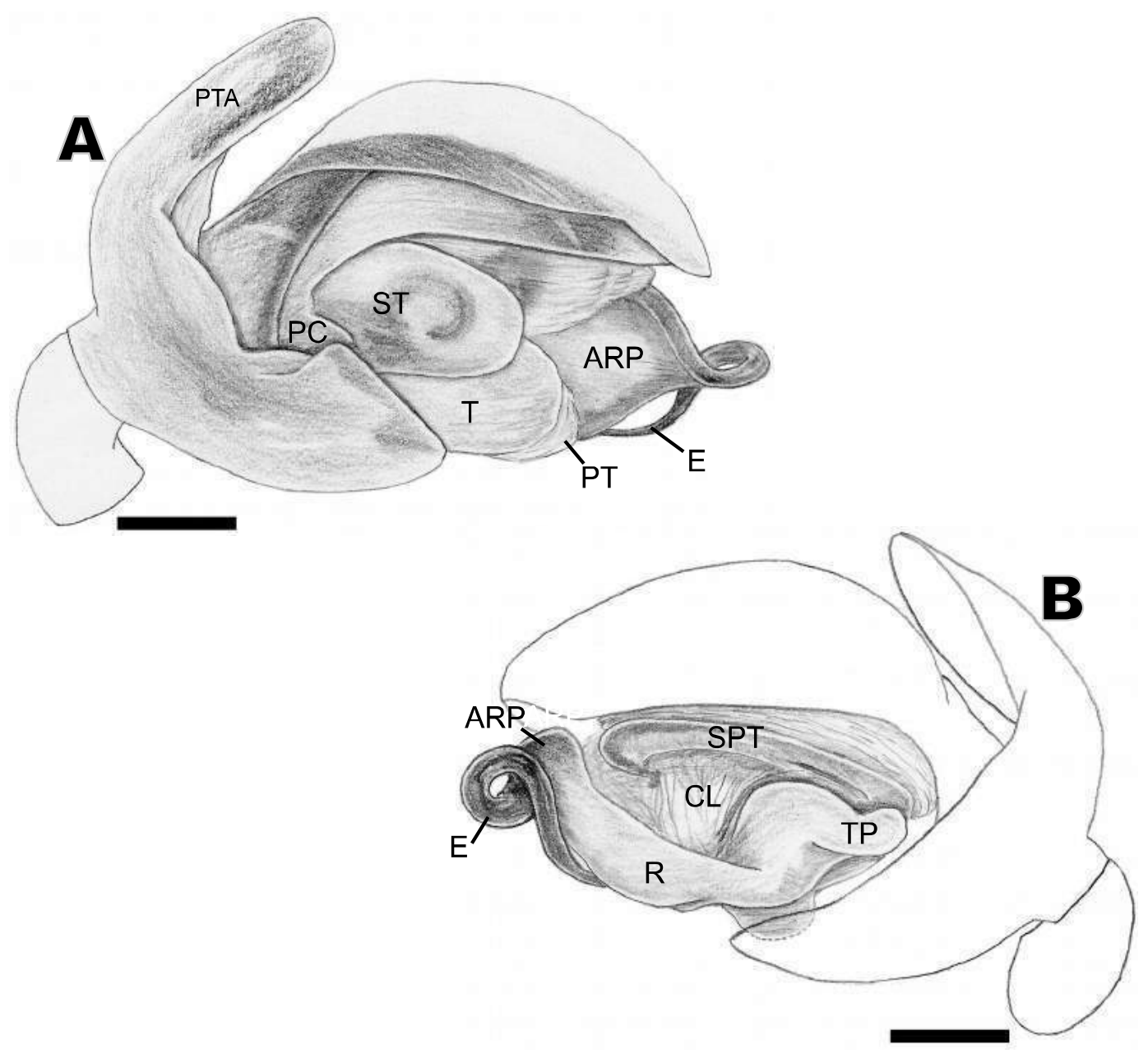

Figura 177. Gen.nov. magnipalpis, A-B, palpo do macho. A, retrolateral; B, prolateral. Escala 0,1mm. ARP, processo anterior do radix; CL, column; E, êmbolo; PC, paracímbio; PT, protégulo; PTA, apófise prolateral da tíbia; R, radix; SPT, supratégulo; ST, subtégulo; T, tégulo; TP, cauda do radix. 


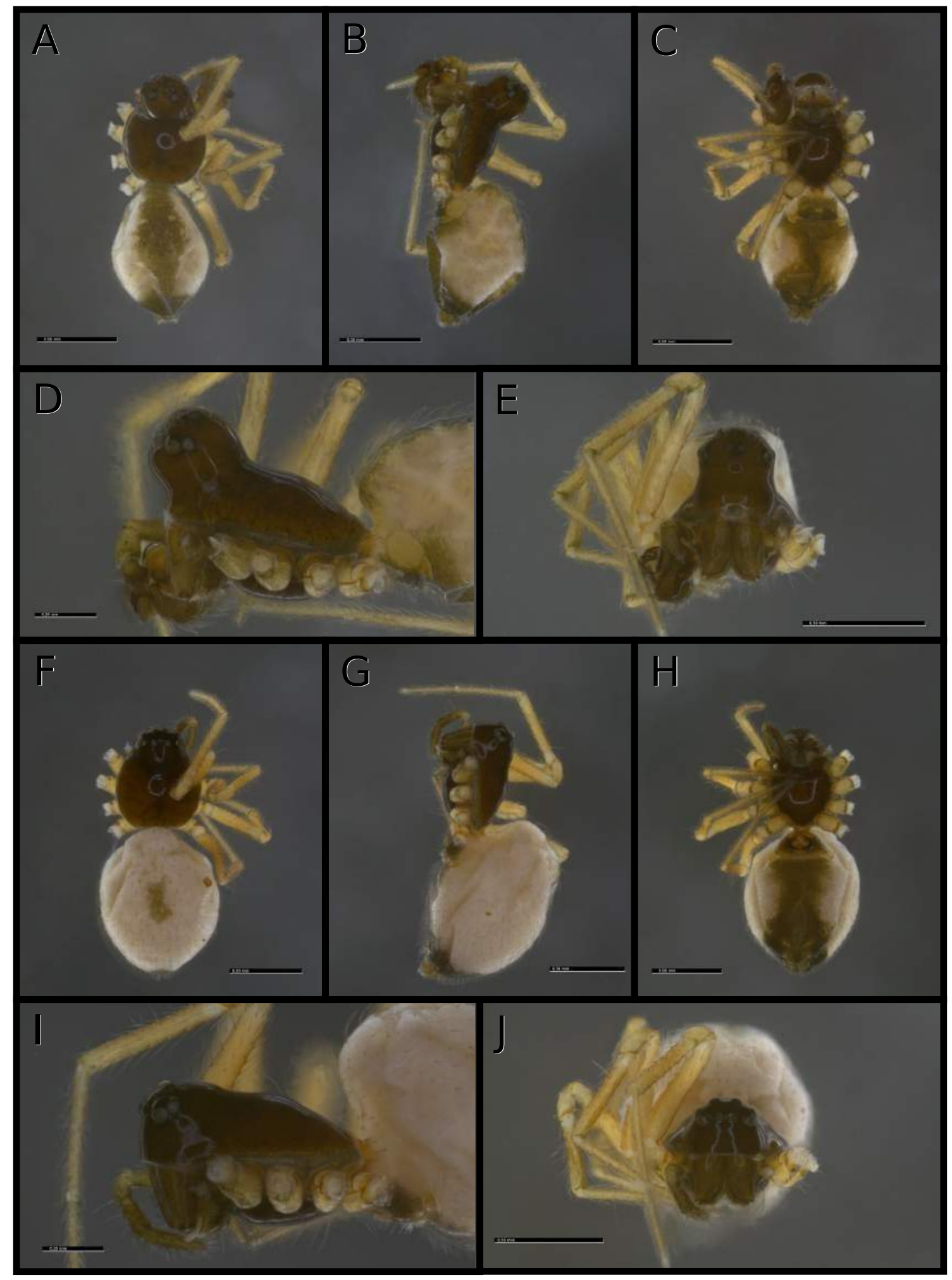

Figura 178. Gen.nov. sp.nov.01, A-E, corpo do macho, F-J, corpo da fêmea. A, F, dorsal; B, G, lateral; C, H, ventral; D, I, detalhe da região cefálica; E, J, frontal. Escala A-C, F-H 1,0mm; D, I, 0,2mm; E, J, 0,5mm. 


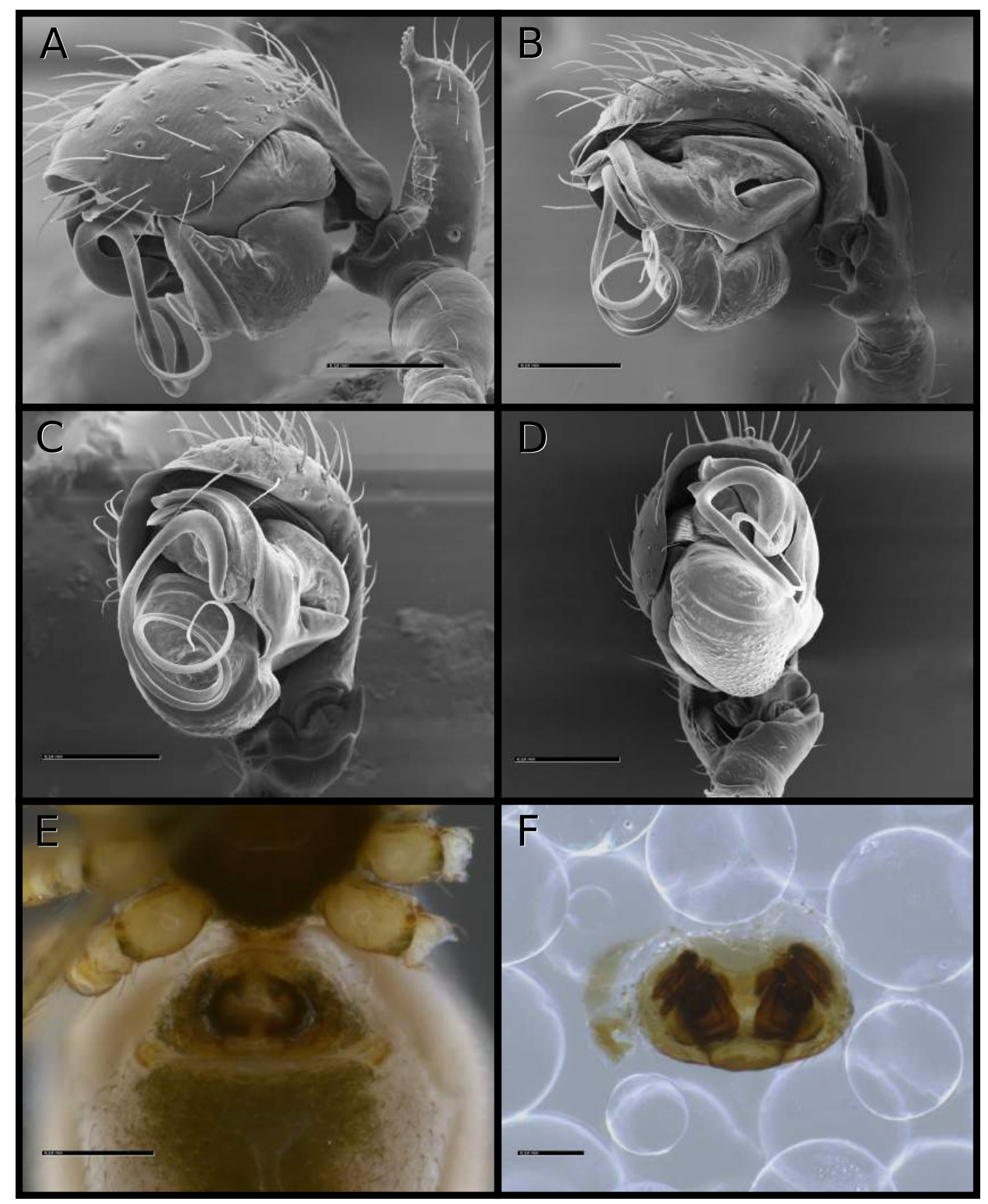

Figura 179. Gen.nov. sp.nov.01, A-D, palpo do macho, E-F, epígino da fêmea. A, retrolateral; B, prolateral; C, frontal; D, ventral, E, ventral; F, dorsal. Escala A-B, E, 0,2mm, C-D, F, 0,1mm. 

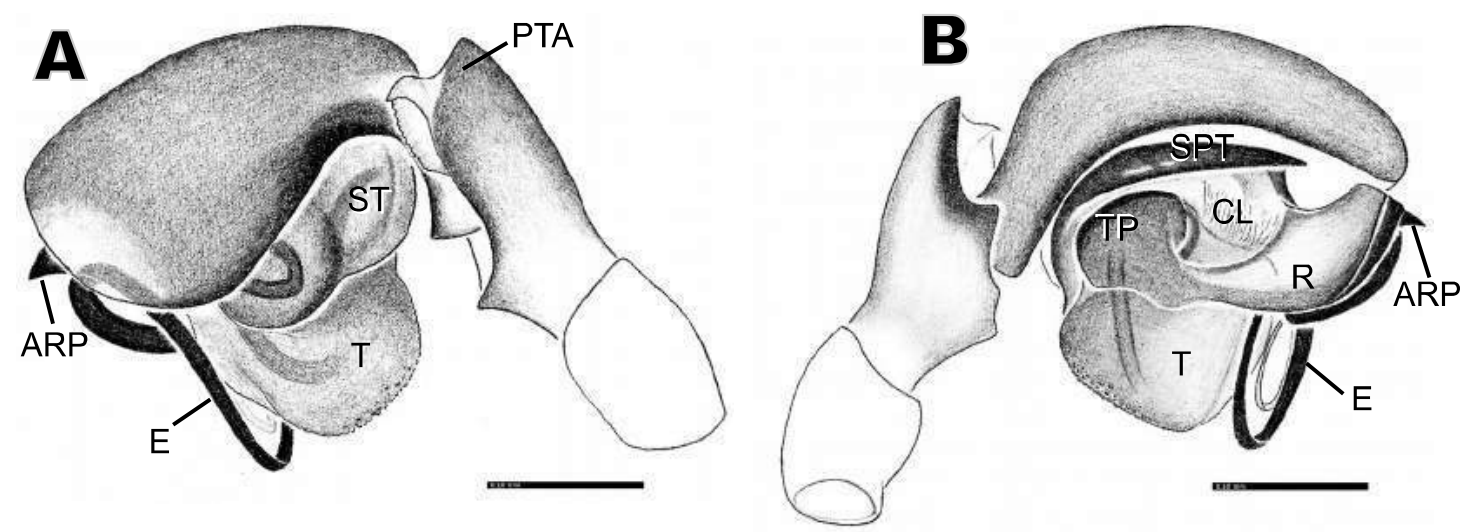

Figura 180. Gen.nov. sp.nov.01, A-B, palpo do macho; C-D, epígino da fêmea. A, retrolateral; B, prolateral; C, ventral; D, dorsal. Escala 0,2mm. ARP, processo anterior do radix; CL, column; E, êmbolo; PTA, apófise prolateral da tíbia; R, radix; SPT, supratégulo; ST, subtégulo; T, tégulo; TP, cauda do radix. Ilustração de Rodrigues, in prep. 


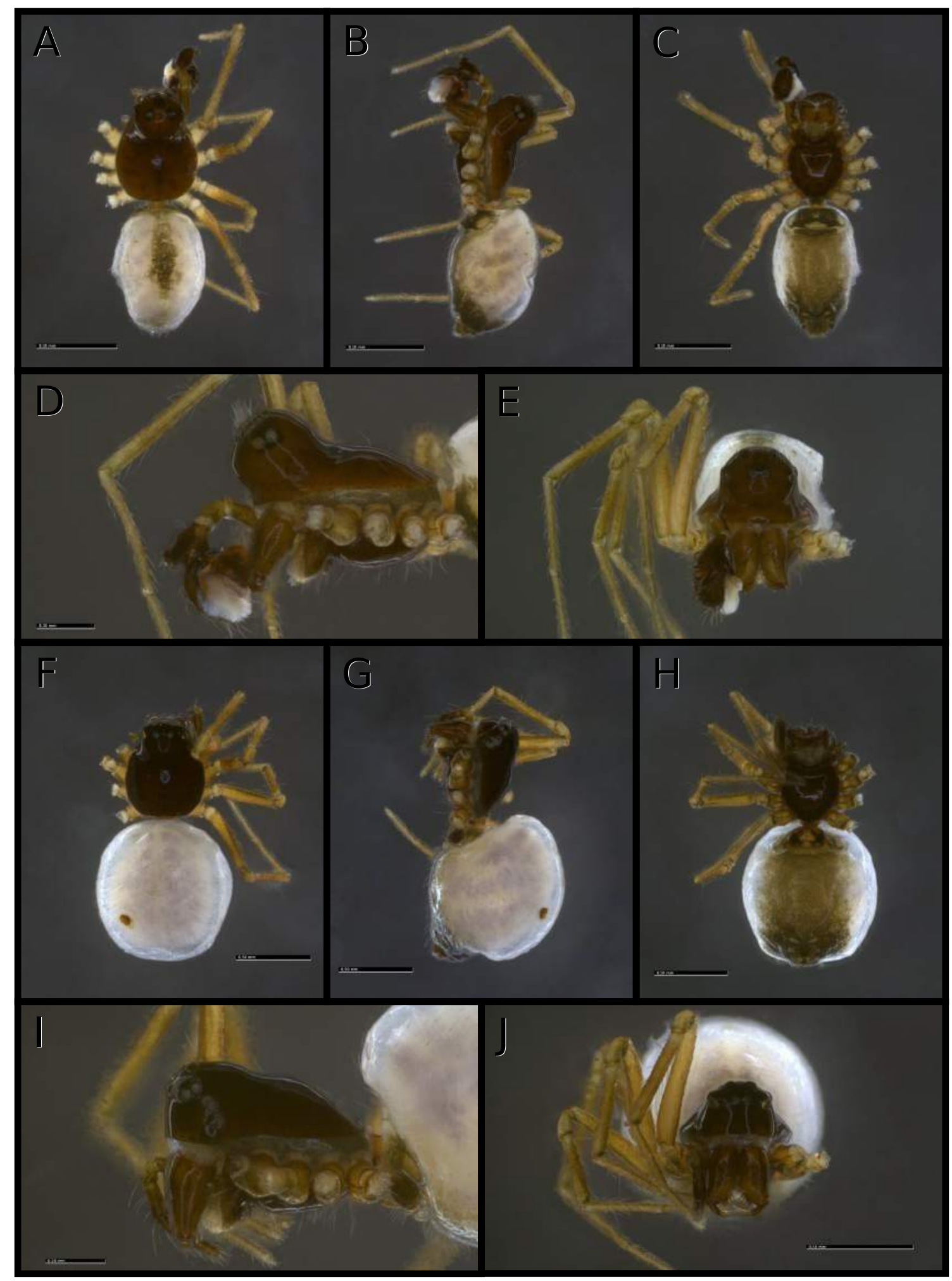

Figura 181. Gen.nov. sp.nov.02, A-E, corpo do macho, F-J, corpo da fêmea. A, F, dorsal; B, G, lateral; C, H, ventral; D, I, detalhe da região cefálica; E, J, frontal. Escala A-C, F-H 1,0mm; D, I, 0,2mm; E, J, 0,5mm. 


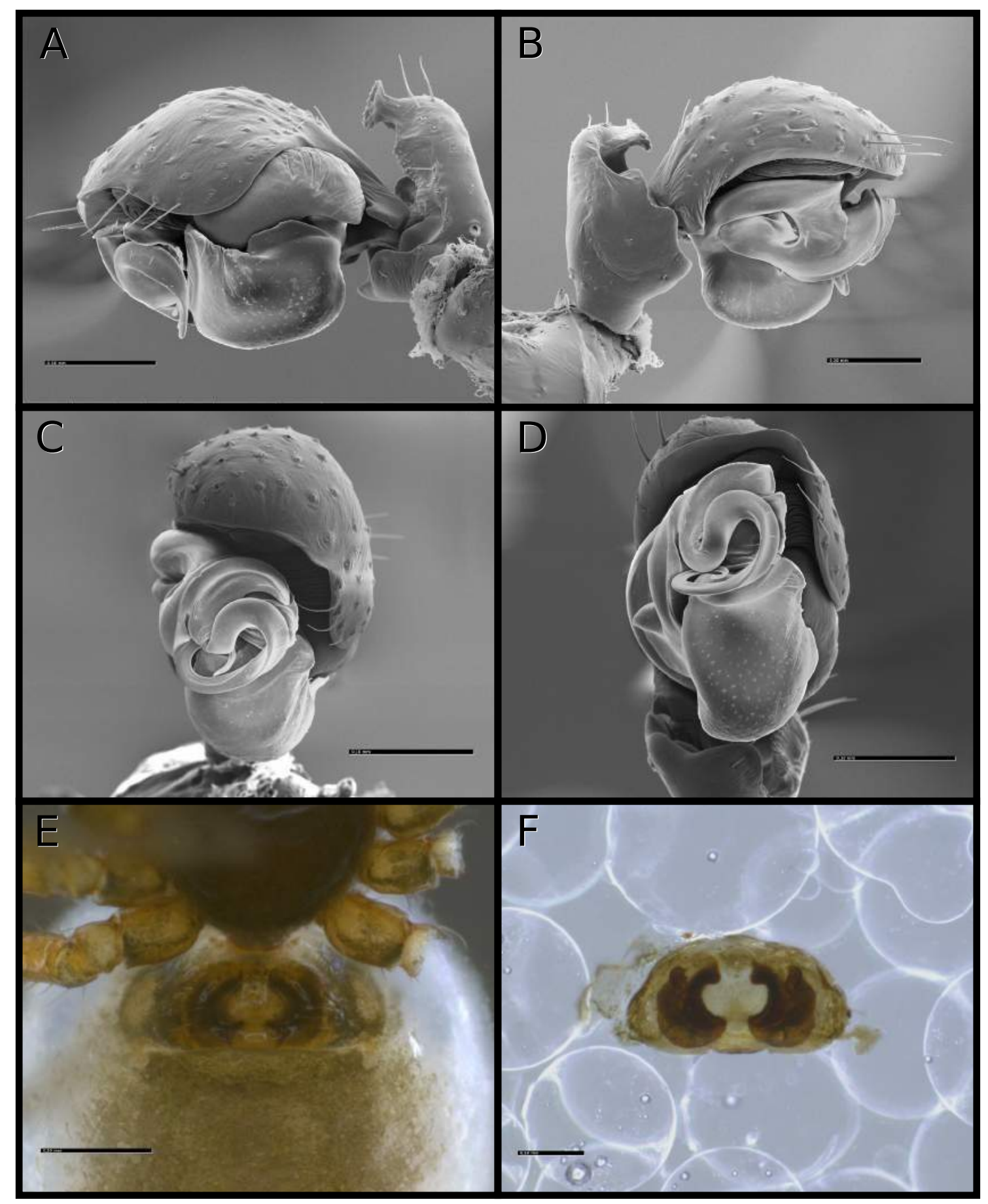

Figura 182. Gen.nov. sp.nov.02, A-D, palpo do macho, E-F, epígino da fêmea. A, retrolateral; B, prolateral; C, frontal; D, ventral, E, ventral; F, dorsal. Escala A-B, E, 0,2mm, C-D, F, 0,1mm. 

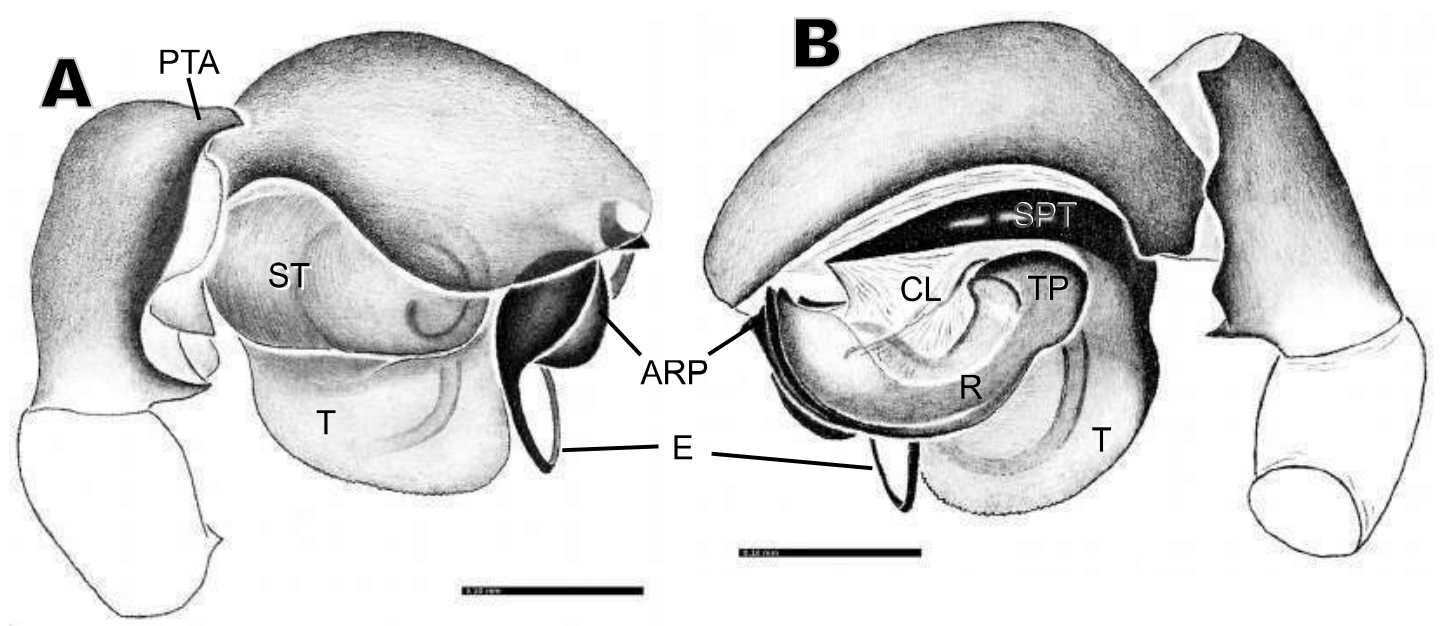

Figura 183. Gen.nov. sp.nov.02, A-B, palpo do macho; C-D, epígino da fêmea. A, retrolateral; B, prolateral; C, ventral; D, dorsal. Escala 0,2mm. ARP, processo anterior do radix; CL, column; E, êmbolo; PTA, apófise prolateral da tíbia; R, radix; SPT, supratégulo; ST, subtégulo; T, tégulo; TP, cauda do radix. Ilustração de Rodrigues, in prep. 


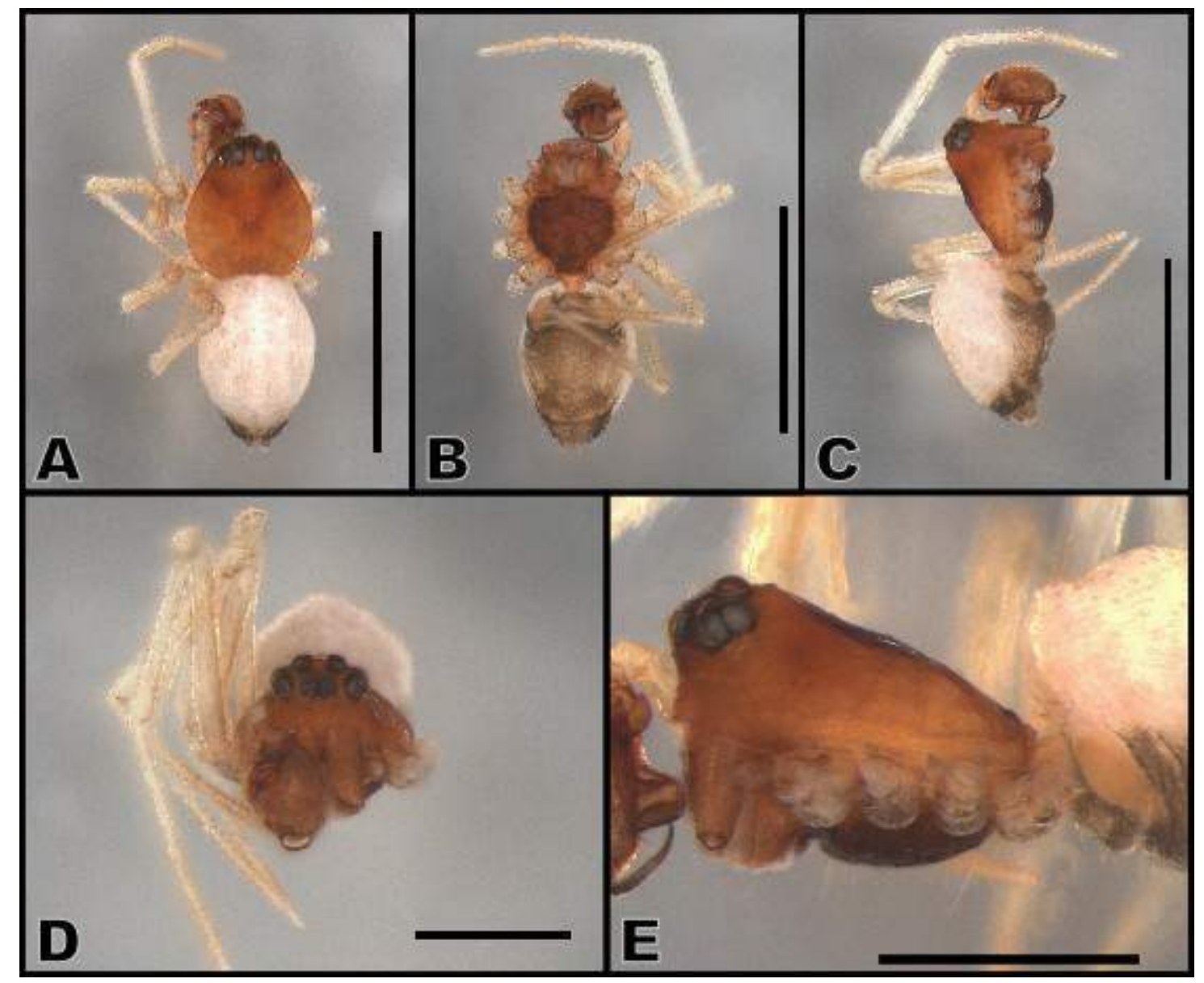

Figura 184. Clitolyna chumota, A-E, corpo do macho. A, dorsal; B, ventral; C, lateral; D, frontal; E, detalhe da região cefálica. Escala A-C,1,0mm; D, 0,5mm; E, 0,2mm.

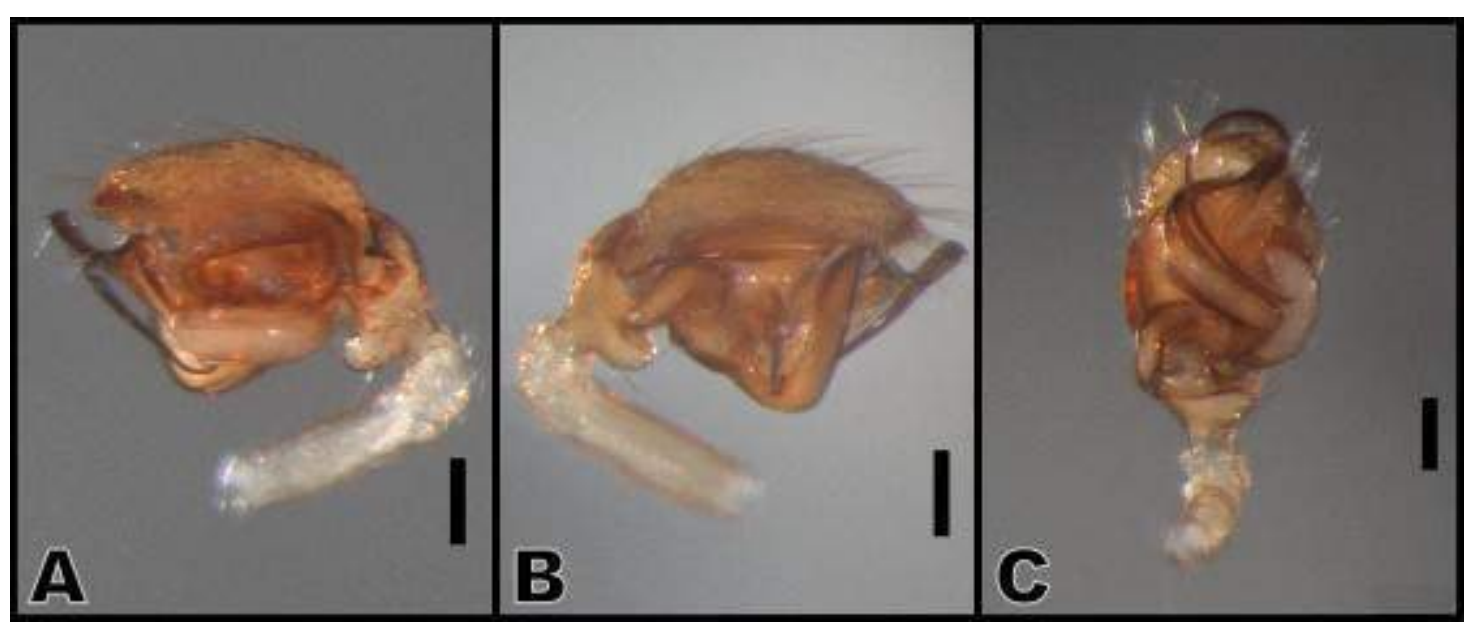

Figura 185. Clitolyna chumota, A-C, palpo do macho. A, retrolateral; B, prolateral; C, ventral. Escala 0,2mm. 


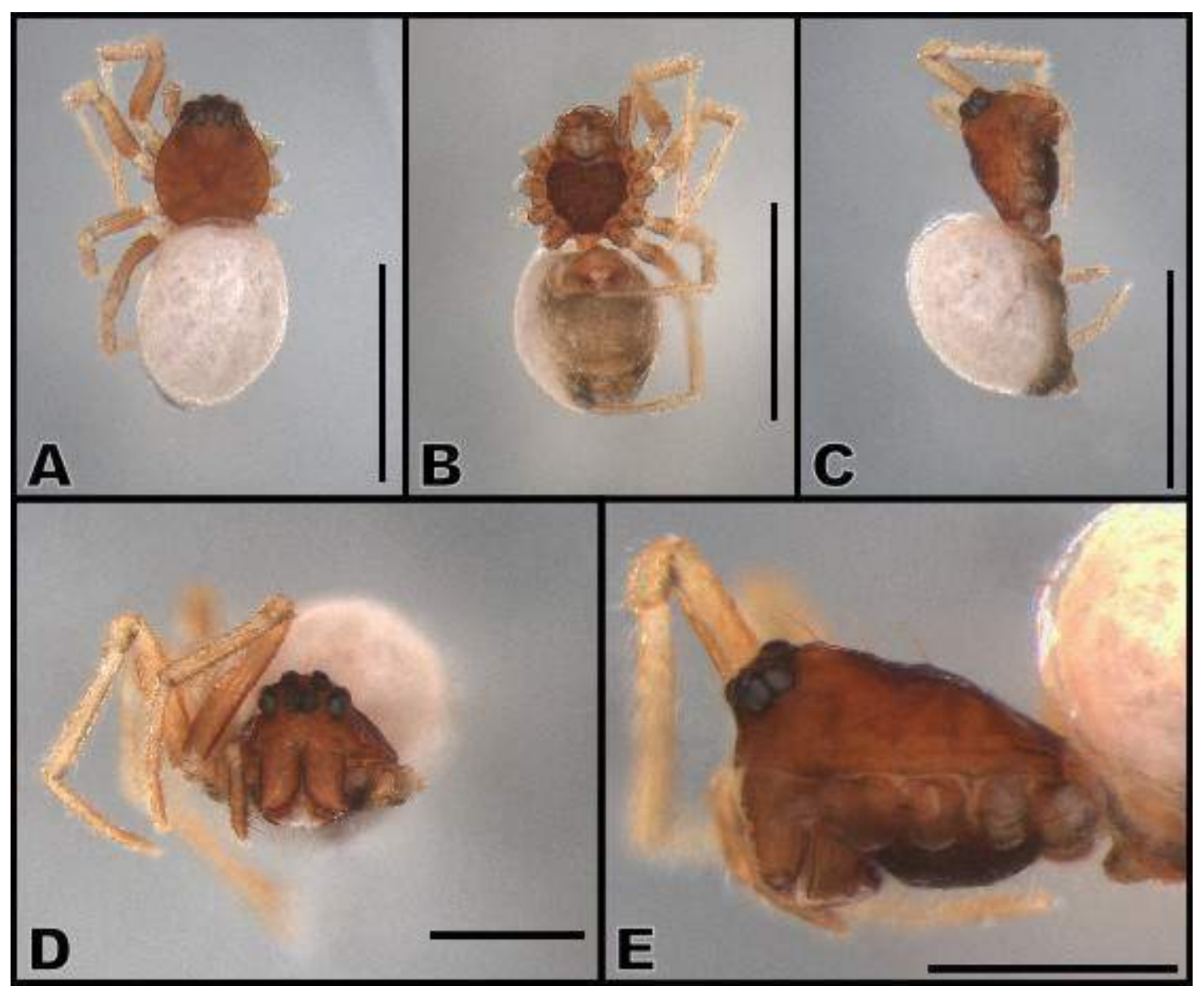

Figura 186. Clitolyna chumota, A-E, corpo do fêmea. A, dorsal; B, ventral; C, lateral;

D, frontal; E, detalhe da região cefálica. Escala A-C,1,0mm; D, 0,5mm; E, 0,2mm.

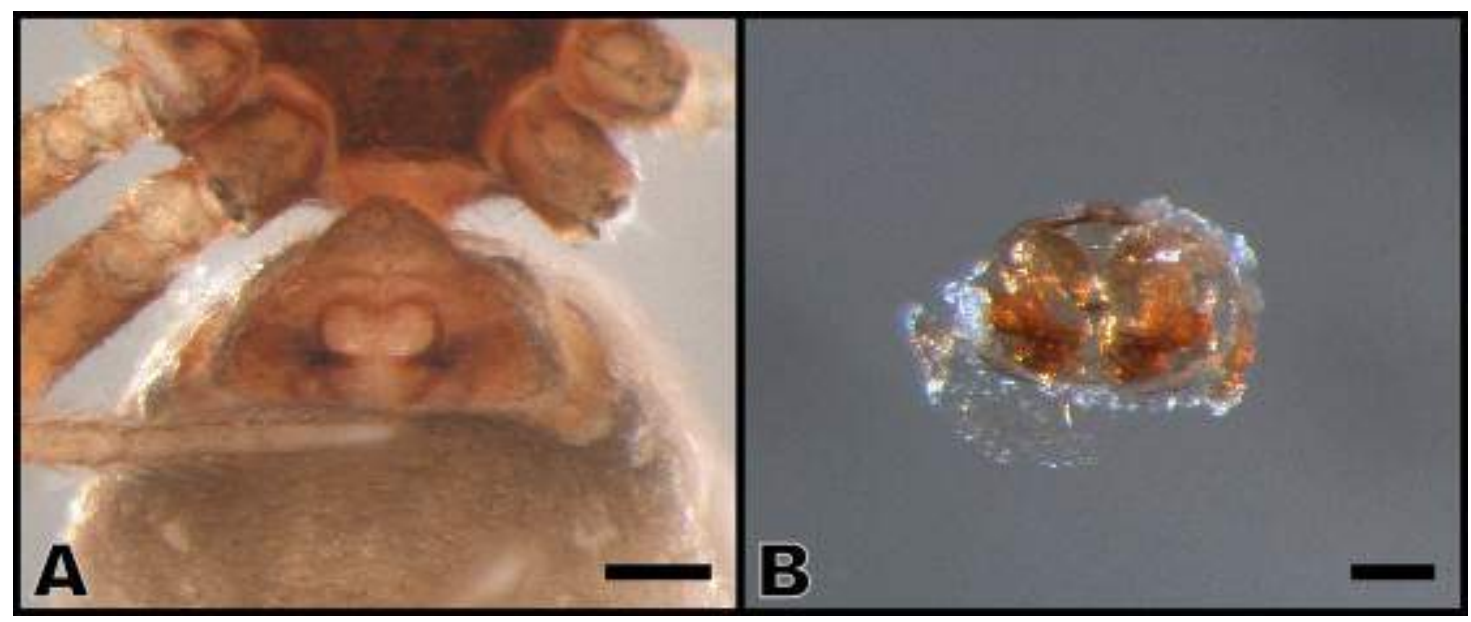

Figura 187. Clitolyna chumota, epígino da fêmea. A, ventral; B, dorsal. Escala $0,2 \mathrm{~mm}$. 


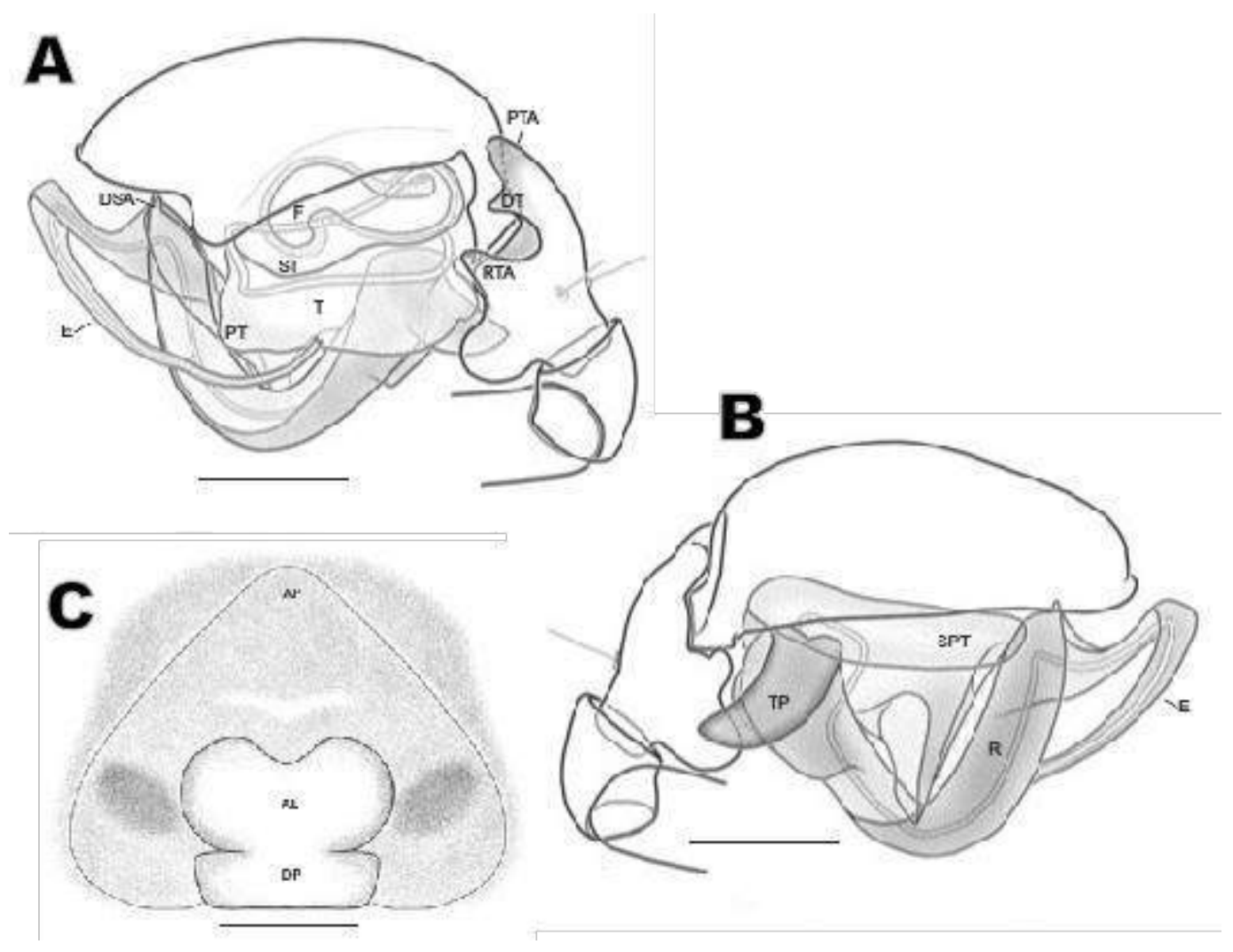

Figura 188. Clitolyna chumota, A-B, palpo do macho; C, epígino da fêmea. A, retrolateral; B, prolateral; C, ventral; D, dorsal. Escala 0,1mm. AP, processo anterior da placa ventral do epígino; DP, placa dorsal do epígino; DSA, apófise distal suprategular; DT, dente distal da apófise prolateral da tíbia; E, êmbolo; PTA, apófise prolateral da tibia; PT, protégulo; R, radix; RTA, apófise retrolateral da tíbia; SPT, supratégulo; ST, subtégulo; TP, cauda do radix; T, tégulo. Ilustração de Miller, 2007. 


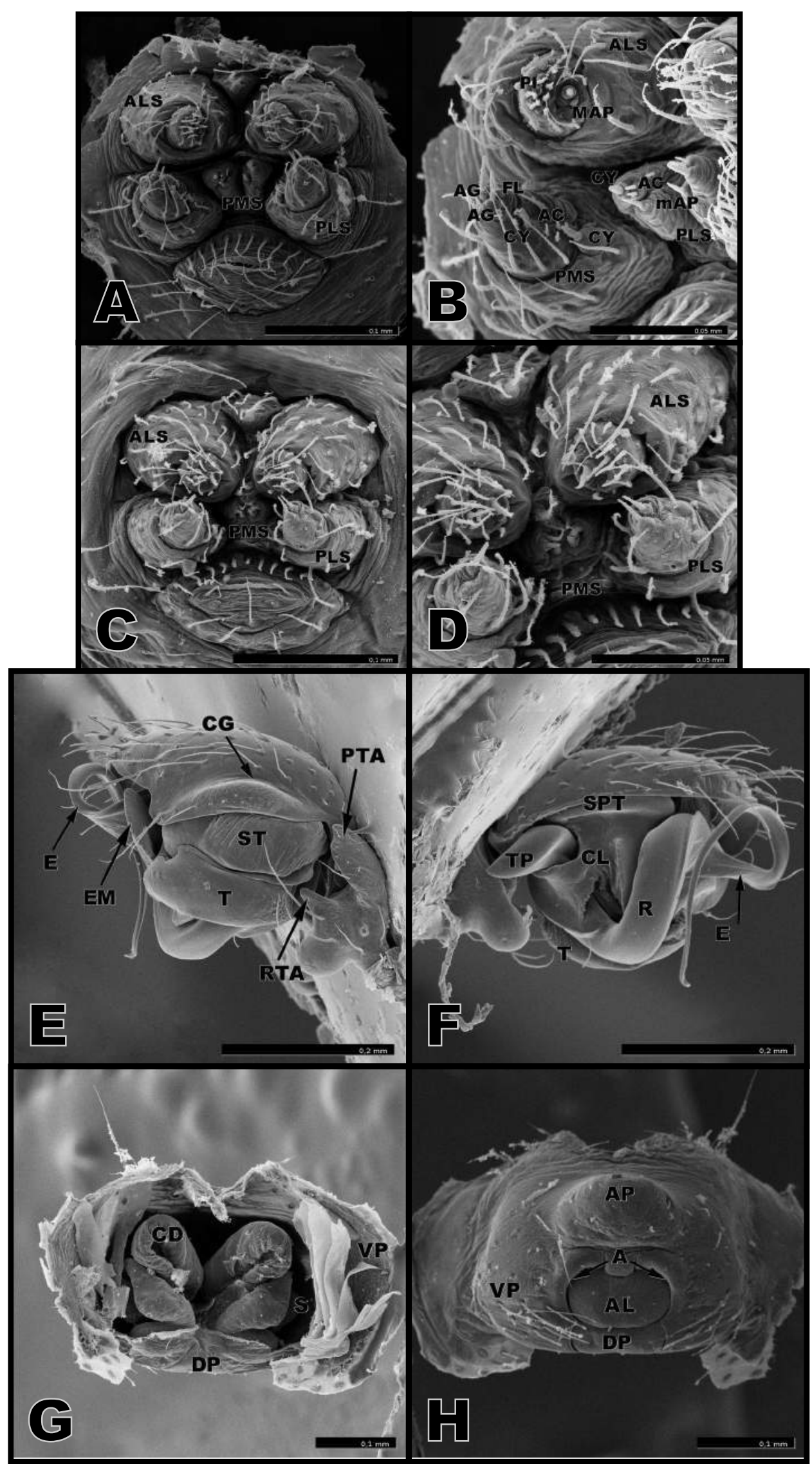

Figura 189. Clitolyna chumota, A-B, fiandeiras da fêmea; C-D, fiandeiras do macho; EF, palpo do macho; G-H, epígino da fêmea. A, C, vista geral. B, D, detalhe da fiandeira. $\mathrm{E}$, vista retrolateral. $\mathrm{F}$, vista prolateral. $\mathrm{G}$, vista dorsal. $\mathrm{H}$, vista ventral. 


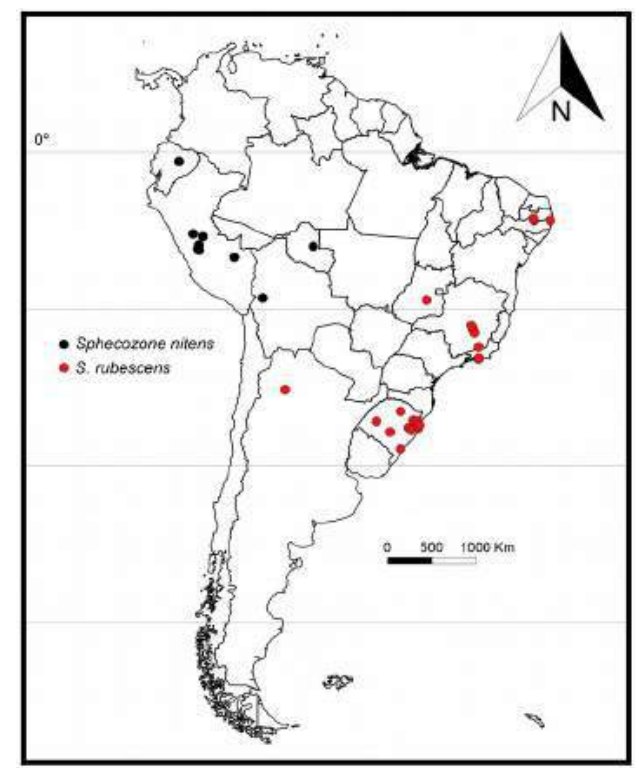

Mapa 1. Distribuição de Sphecozone nitens e S. rubescens.
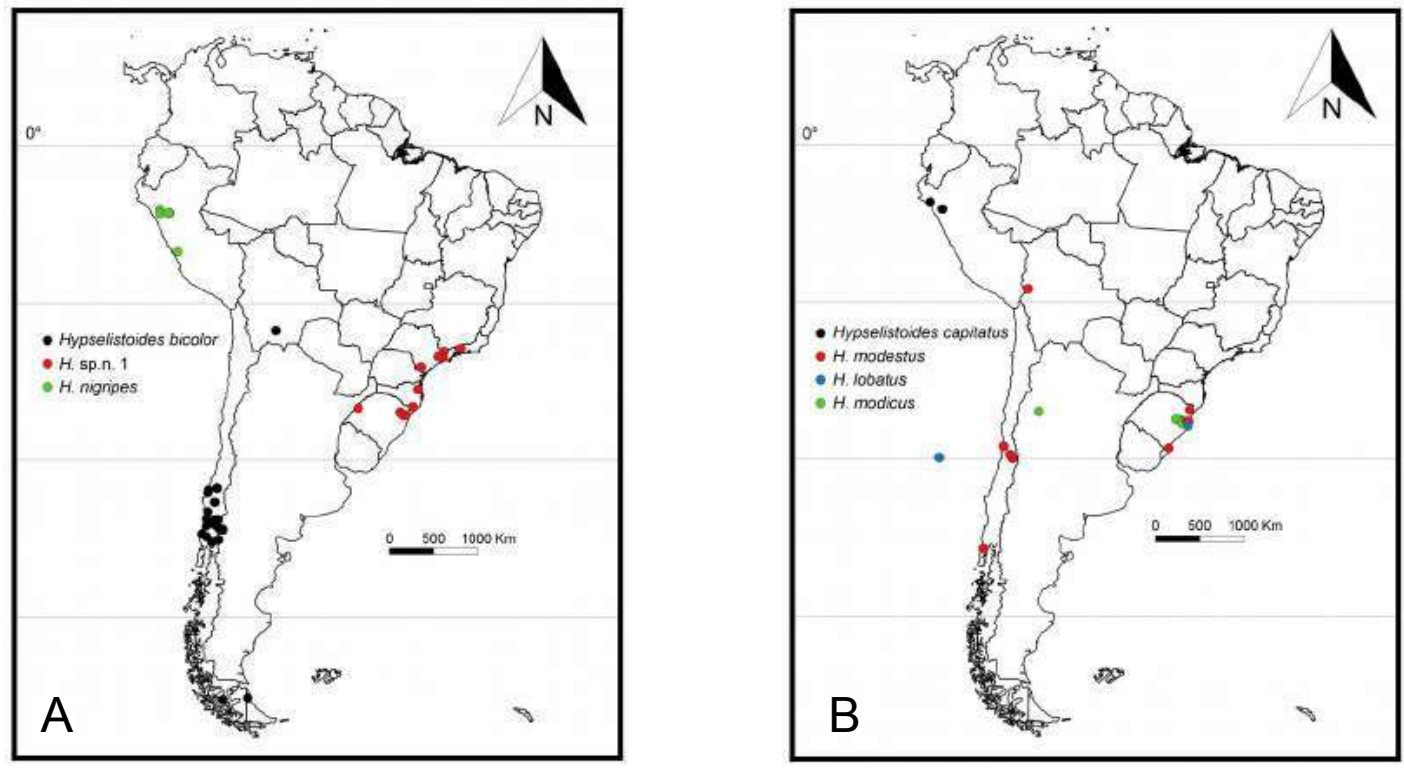

Mapa 2. A, Distribuição de Hypselistoides bicolor, Hypselistoides sp.nov.01 e $H$. nigripes; B, Distribuição de $H$. capitatus, $H$. modestus, $H$. lobatus e $H$. modicus. 


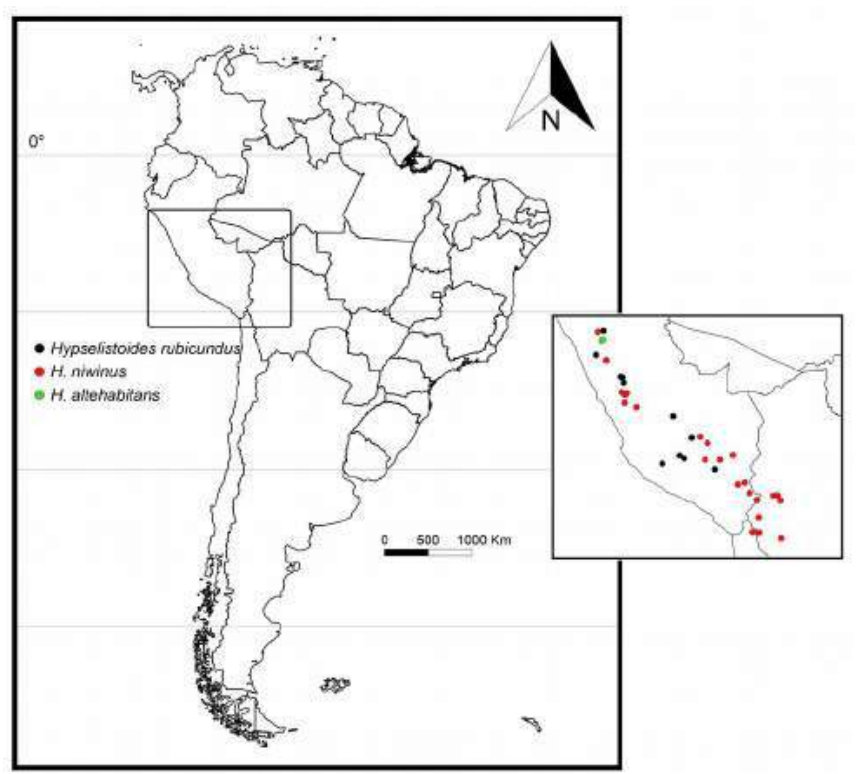

Mapa 3. Distribuição de Hypselistoides rubicundus, H. niwinus e H. altehabitans.

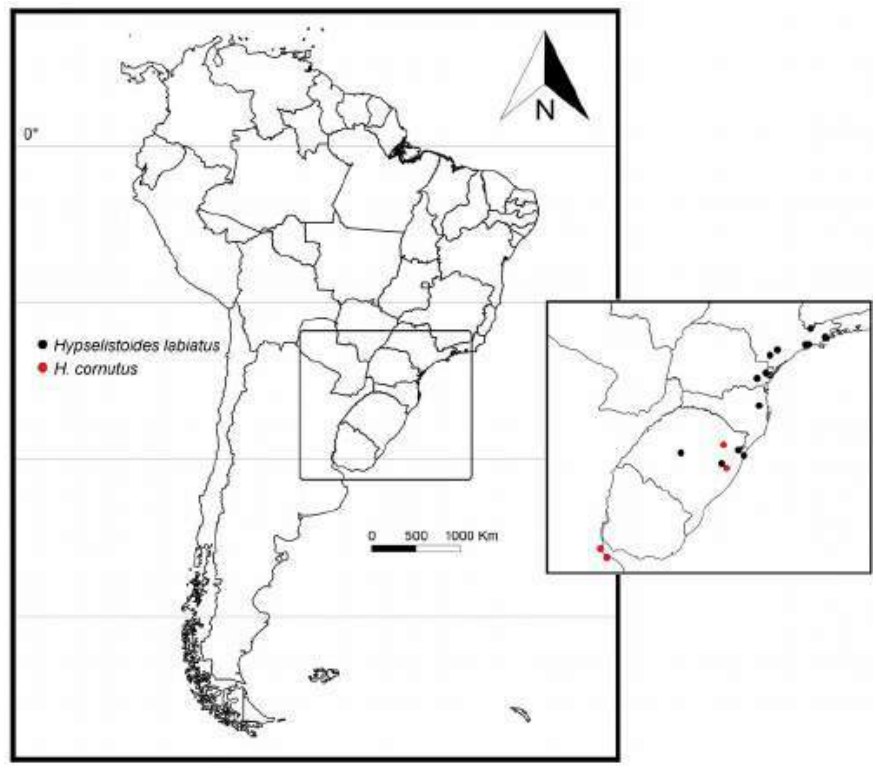

Mapa 4. Distribuição de Hypselistoides labiatus e H. cornutus. 


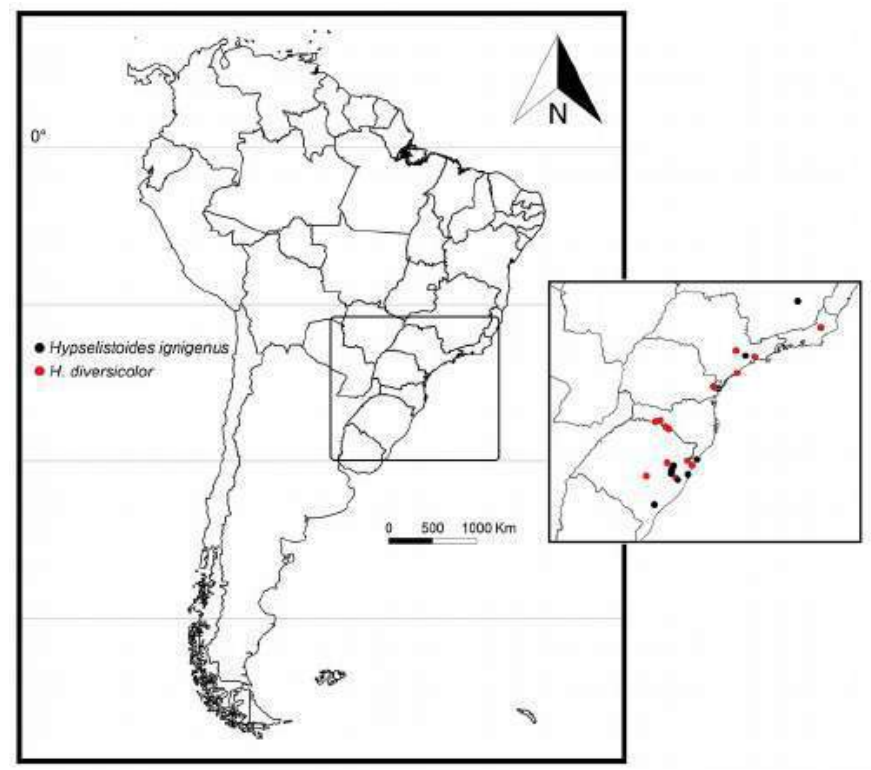

Mapa 5. Distribuição de Hypselistoides ignigenus e H. diversicolor.

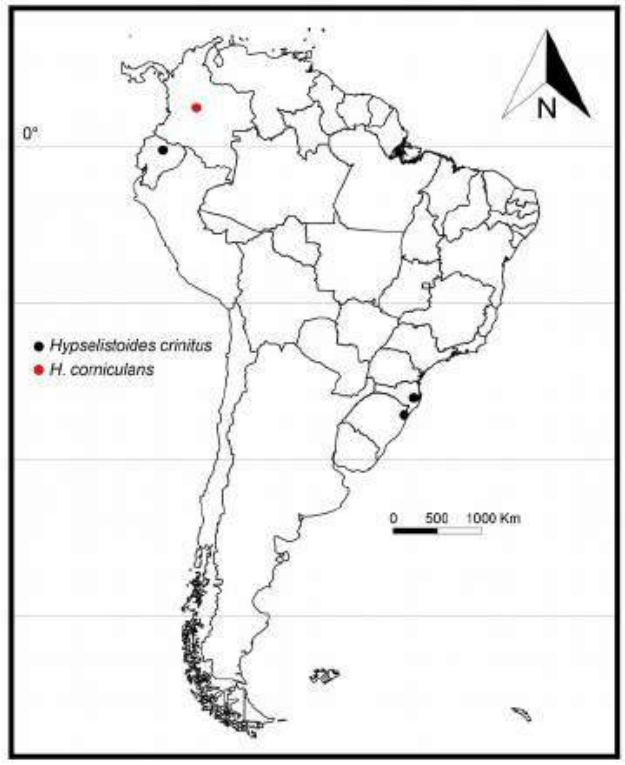

Mapa 6. Distribuição de Hypselistoides crinitus e H. corniculans. 

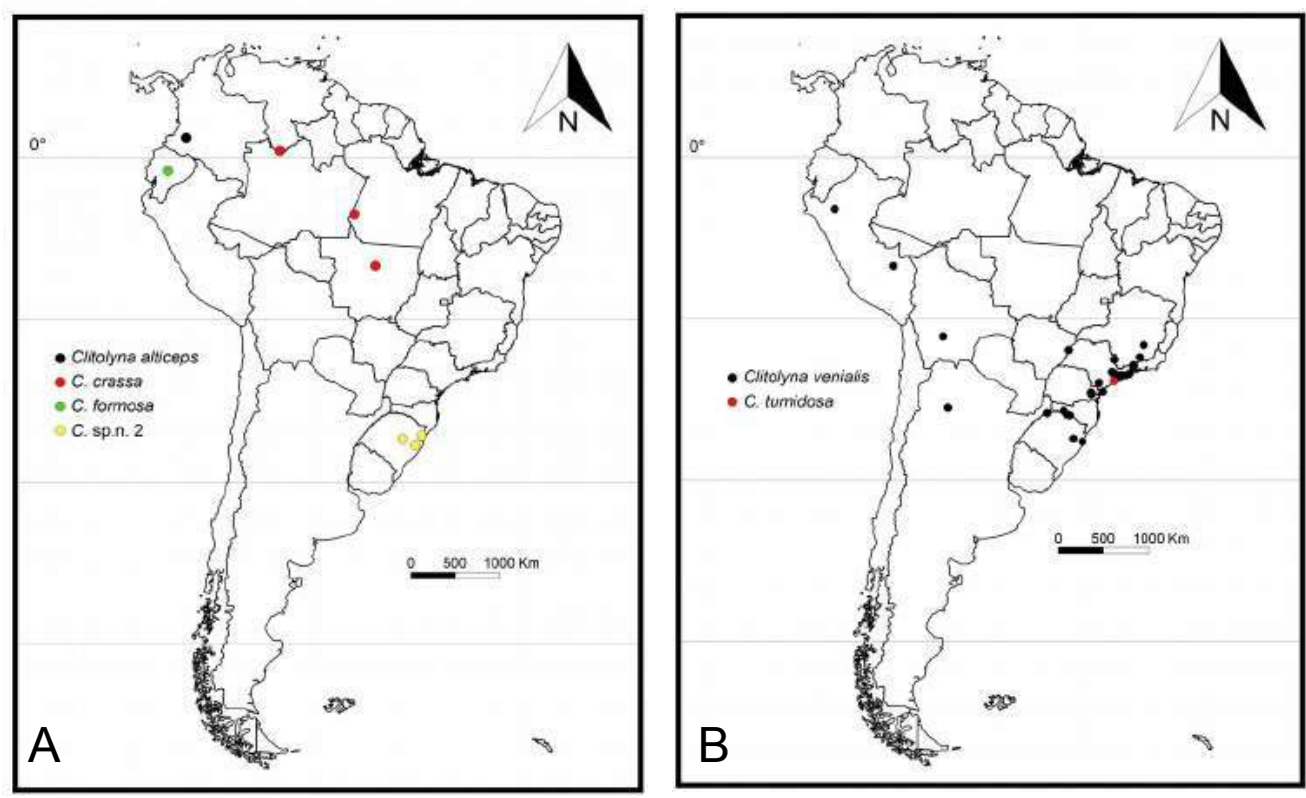

Mapa 7. A, Distribuição de Clitolyna alticeps, C. crassa, C. formosa e Clitolyna sp.nov.02; B, Distribuição de C. venialis e C. tumidosa.

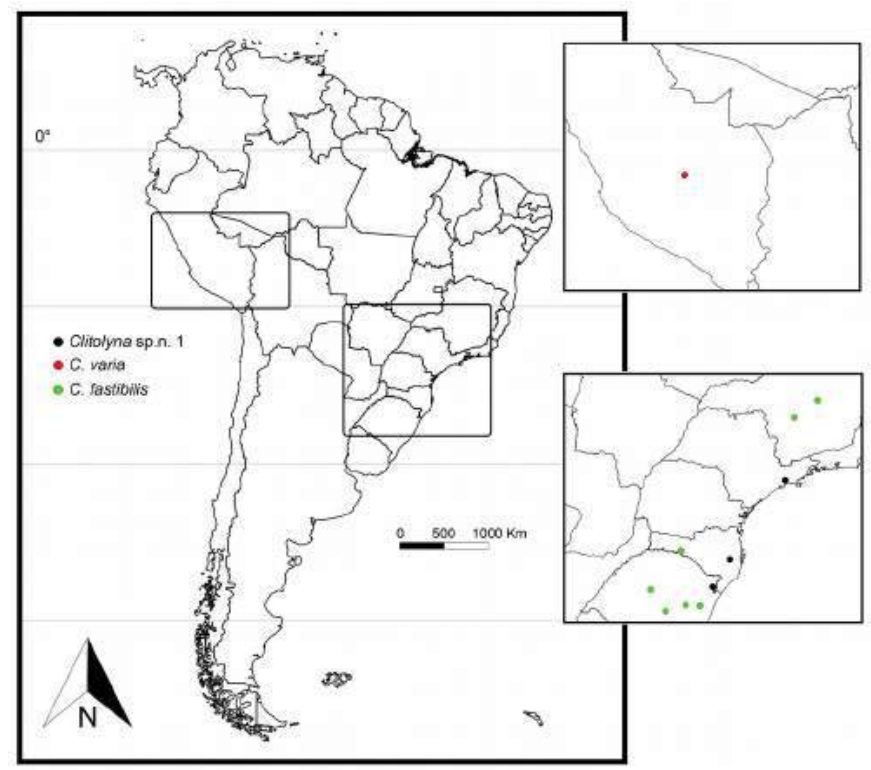

Mapa 8. Distribuição de Clitolyna sp.nov.01, C. varia e C. fastibilis. 


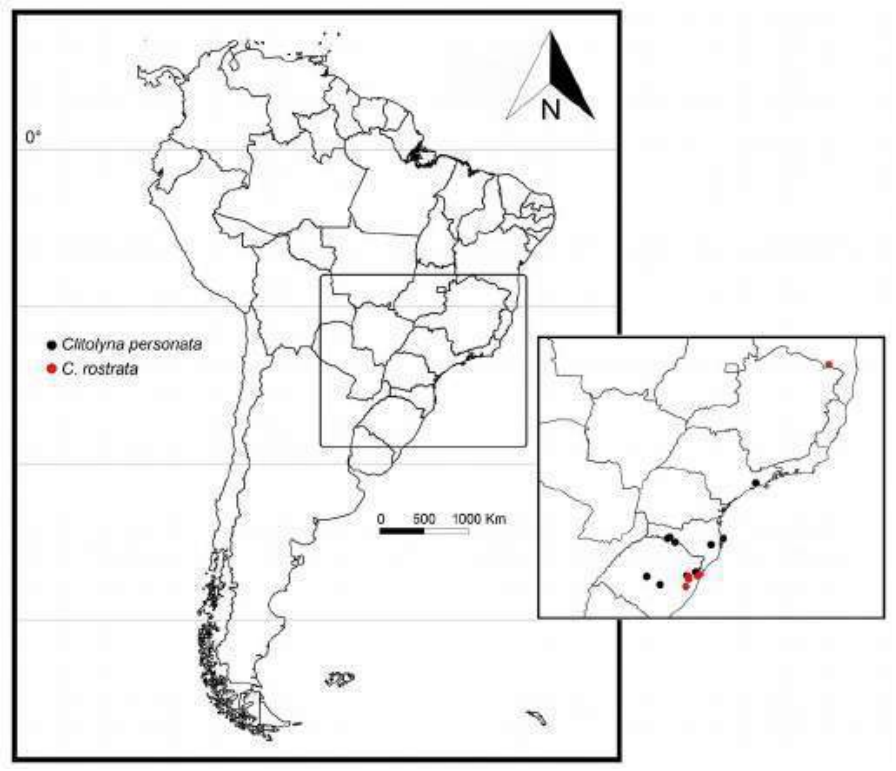

Mapa 9. Distribuição de Clitolyna personata e C. rostrata.

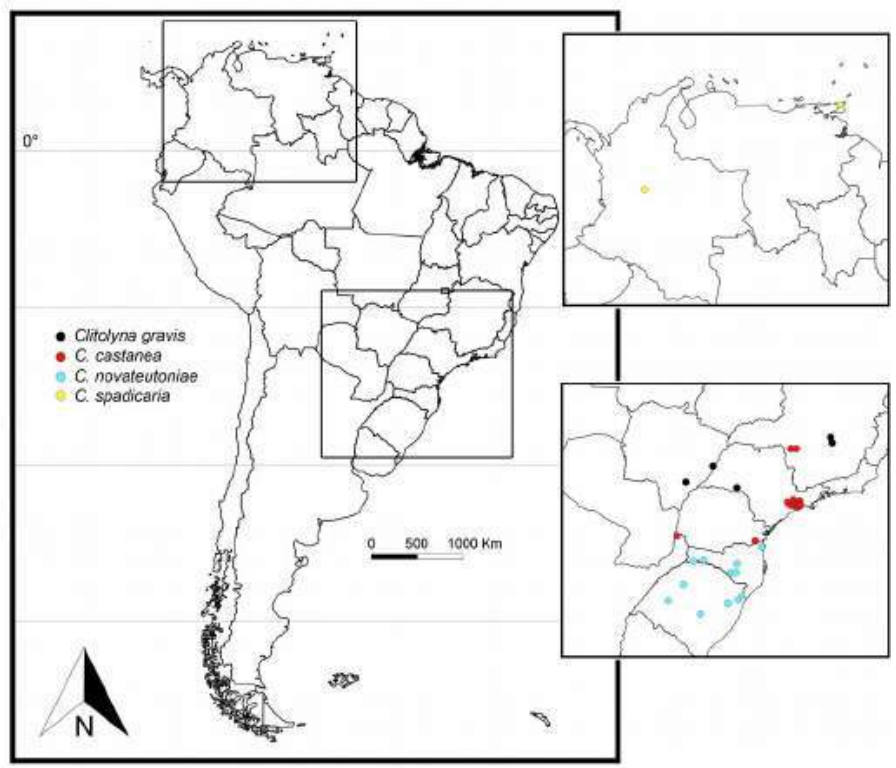

Mapa 10. Distribuição de Clitolyna gravis, C. castanea, C. novaeteutoniae e C. spadicaria. 

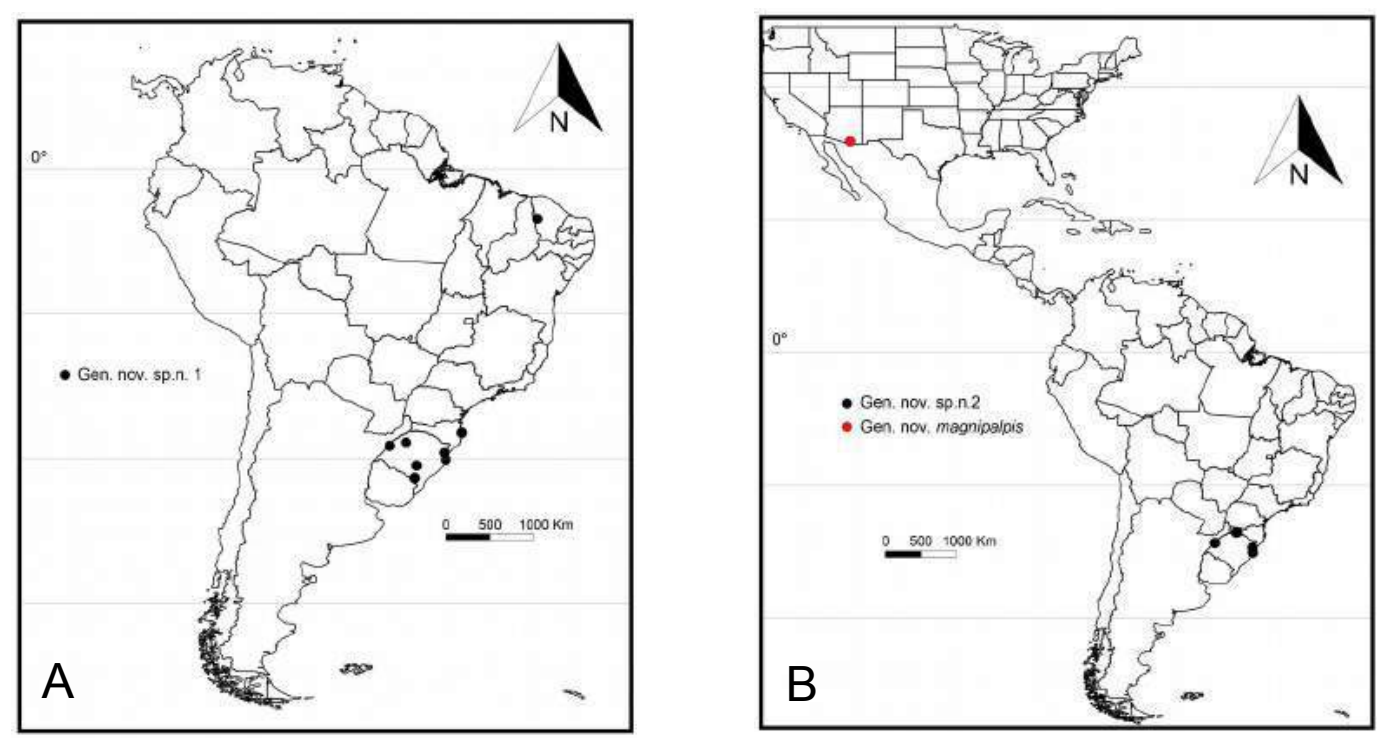

Mapa 11. A, Distribuição do Gen.nov. sp.nov.01; B, Distribuição do Gen.nov. sp.nov.02 e Gen.nov. magnipalpis. 
Tabela 1. Lista das espécies válidas do gênero Sphecozone (grupo-interno). * Espécie-tipo.

\begin{tabular}{|c|c|c|c|}
\hline Espécies & Sexo & Localidade & Museu disponível \\
\hline S. altehabitans (Keyserling, 1886) & 우 & Peru & MUSM; PAINZ \\
\hline S. alticeps Millidge, 1991 & $\sigma^{\pi} \mathrm{e}+$ & Colombia & AMNH \\
\hline S. araeonciformis (Simon, 1895) & $o^{x} \mathrm{e}+$ & Argentina & MNHN \\
\hline S. bicolor (Nicolet, 1849) & $\sigma^{x} \mathrm{e}+9$ & Chile, Argentina & AMNH; MNHN; NHRM \\
\hline S. capitata Millidge, 1991 & $\sigma^{x}$ e + & Peru & MUSM \\
\hline S. castanea (Millidge, 1991) & $\sigma^{x} \mathrm{e}+$ & Brazil & AMNH; MCZ \\
\hline S. corniculans Millidge, 1991 & $\sigma^{x}$ & Colombia & MCZ \\
\hline S. cornuta Millidge, 1991 & $o^{*}$ & Argentina & AMNH \\
\hline S. crassa (Millidge, 1991) & $\sigma^{x}$ e + & Colombia, Brazil & AMNH \\
\hline S. crinita Millidge, 1991 & $\sigma^{x}$ e + & Ecuador & AMNH \\
\hline S. diversicolor (Keyserling, 1886) & $o^{x}$ e +9 & Brazil, Argentina & AMNH; BMNH \\
\hline S. fastibilis (Keyserling, 1886) & $o^{x}$ e + & Brazil, Argentina & $\mathrm{BMNH}$ \\
\hline S. formosa (Millidge, 1991) & क & Ecuador & AMNH \\
\hline S. gravis (Millidge, 1991) & $0^{x}$ & Bolivia & AMNH \\
\hline S. ignigena (Keyserling, 1886) & $o^{x} \mathrm{e}+$ & Brazil, Argentina & AMNH; BMNH \\
\hline S. labiata (Keyserling, 1886) & $o^{x} \mathrm{e}+9$ & Brazil & $\mathrm{BMNH}$ \\
\hline S. lobata Millidge, 1991 & $0^{x}$ & Juan Fernandez Is. & AMNH \\
\hline S. longipes (Strand, 1908) & \% & Peru & MNHU \\
\hline S. magnipalpis Millidge, 1993 & $0^{x}$ & USA & AMNH \\
\hline S. melanocephala (Millidge, 1991) & ㅇ & Brazil & AMNH \\
\hline S. modesta (Nicolet, 1849) & \multicolumn{2}{|c|}{$o^{x}$ e + Bolivia, Brazil, Chile, Argentina } & MNHN \\
\hline S. modica Millidge, 1991 & $\sigma^{x}$ e + & Argentina & AMNH \\
\hline S. nigripes Millidge, 1991 & $o^{x}$ e + & Peru & AMNH; MUSM \\
\hline S. nitens Millidge, 1991 & $o^{x}$ e + & Ecuador, Peru & AMNH; MUSM; PAINZ \\
\hline S. niwina (Chamberlin, 1916) & $o^{x} \mathrm{e}+$ & Peru, Bolivia, Chile & AMNH; MCZ \\
\hline S. novaeteutoniae (Baert, 1987) & $\sigma^{x} \mathrm{e}+$ & Brazil & RBINS \\
\hline S. personata (Simon, 1894) & $\sigma^{x}$ e + & Brazil & MNHN \\
\hline S. rostrata Millidge, 1991 & $\sigma^{x}$ e + & Brazil & AMNH \\
\hline S. rubescens O. P.-Cambridge, 1870 * & $\sigma^{x}$ e + & Brazil, Paraguay, Argentina & AMNH; BMNH \\
\hline S. rubicunda (Keyserling, 1886) & $\sigma^{x} \mathrm{e}+9$ & Peru & MUSM; PAINZ \\
\hline S. spadicaria (Simon, 1894) & $\sigma^{x}$ e + & Colombia, Trinidad, Venezuela & MNHN \\
\hline S. tumidosa (Keyserling, 1886) & $o^{x}$ & Brazil, Argentina & $\mathrm{BMNH}$ \\
\hline S. varia Millidge, 1991 & \% & Peru & AMNH \\
\hline S. venialis (Keyserling, 1886) & $\sigma^{x} \mathrm{e}+$ & Brazil, Argentina & AMNH; BMNH \\
\hline
\end{tabular}


Tabela 2. Espécies de Erigoninae utilizadas como grupo externo. * Espécie-tipo.

\begin{tabular}{|c|c|c|}
\hline Gênero & Espécies & Localidade \\
\hline Ceratinopsis Emerton, 1882 & C. interpres (O. P.-Cambridge, 1874)* & Estados Unidos \\
\hline Dolabritor Millidge, 1991 & D. spineus Millidge, 1991* & Colômbia \\
\hline Grammonota Emerton, 1882 & G. pictilis (O. P.-Cambridge, 1875)* & Estados Unidos, Canada \\
\hline Gonatoraphis Millidge, 1991 & G. lysistrata Miller, 2007 & Colômbia \\
\hline Intecymbium Miller, 2007 & I. antarcticum (Simon, 1895)* & Chile, Argentina \\
\hline Moyosi Miller, 2007 & M. prativaga (Keyserling, 1886)* & Brasil, Argentina \\
\hline Psilocymbium Millidge, 1991 & P. acanthodes Miller, 2007 & Argentina \\
\hline Tutaibo Chamberlin, 1916 & T. phoeniceus (O. P.-Cambridge, 1894) & México, Guatemala \\
\hline
\end{tabular}




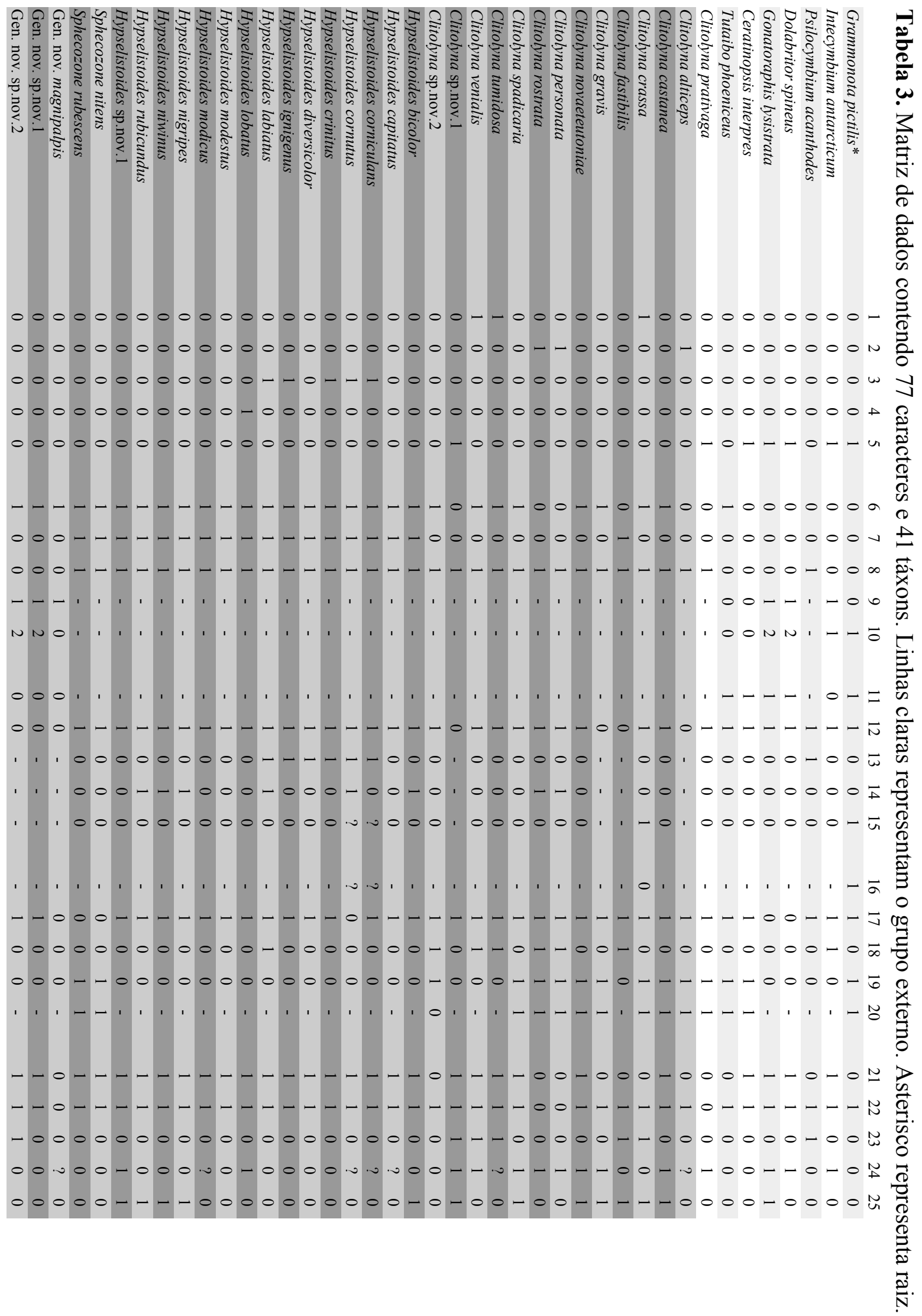



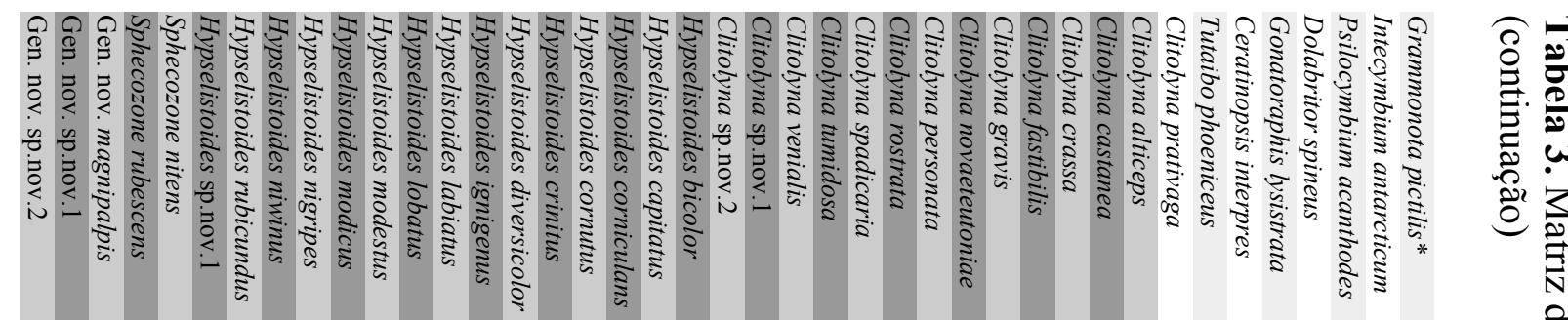

$00-00-000-0-0000000000000-10000000000-000 \mu$

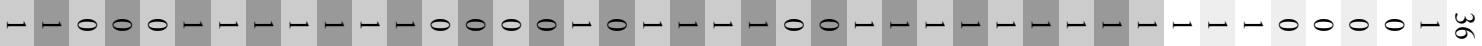

- - v- - - - - - - - - - - - - v- - - - - - - - - - - - - - - - - - - - - $000 \mathrm{j}$

$00.0000000000-00 . v 000-0000000-00000100.1, w_{\infty}$

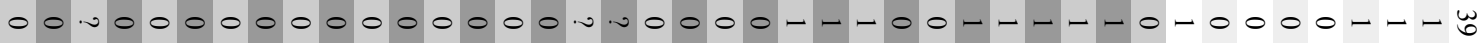

$00.00000000000000 .00000000-10-000000000000 \frac{1}{0}$

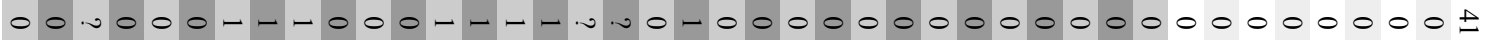

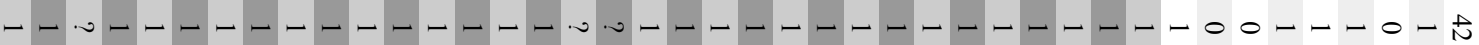

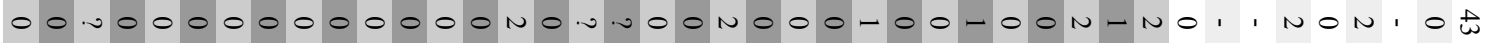
- - ט- - - - - - - - - - - v.v--- - - - - - - - - - - - - - - - - - - $00.00000000000000 . v 000000-1--100-0000-0000 \mathrm{H}$

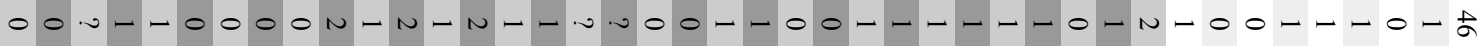

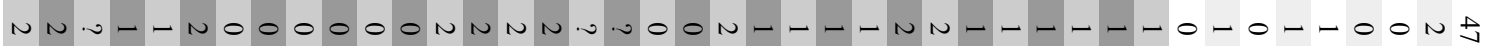

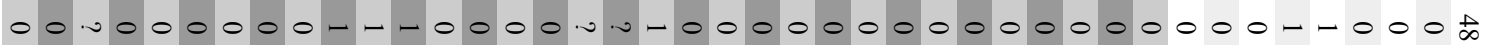
- - - - - - - - - 


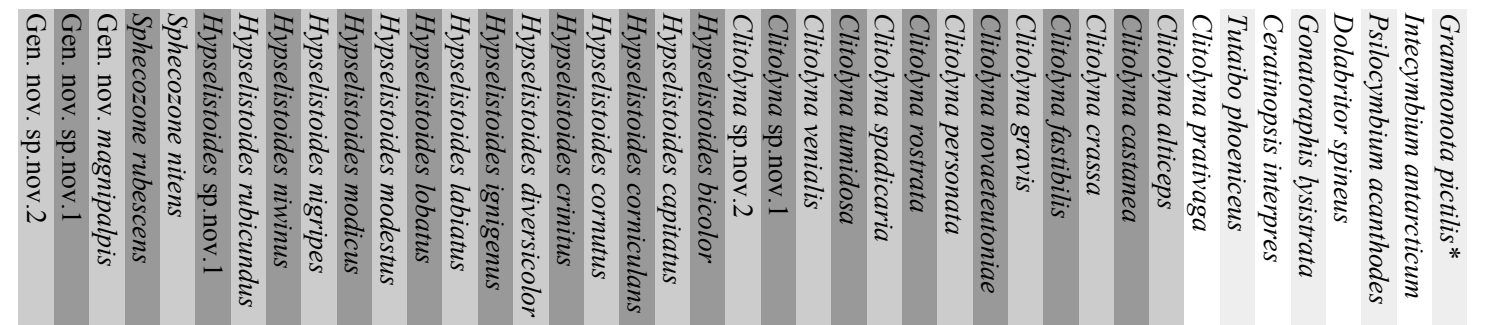

$00000000000000000000000000000000-0000-000 \underline{n}$ $0000000000000000000000000000000000000000-\mu$ $0000000000000000000000000-100000000000000 \mu$ $0000000000000000000000000000000000000-000 \frac{1}{1}$

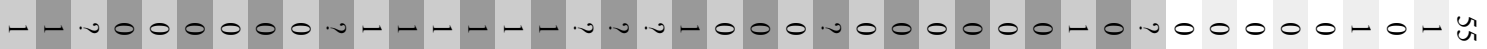

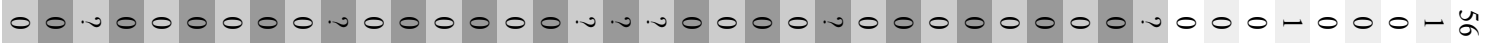

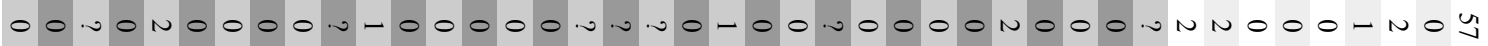
N N. ט $\omega \omega \omega \omega \omega .0$.

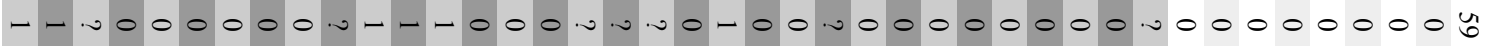

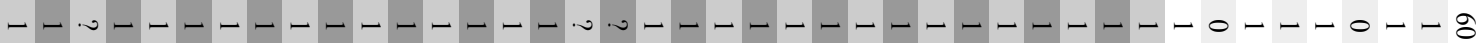

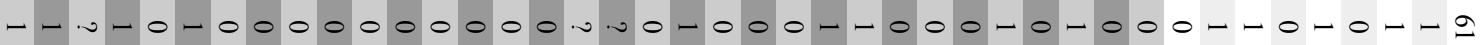
- - .

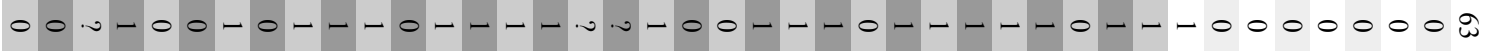

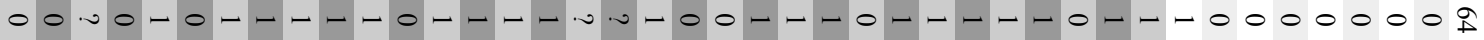
nN.

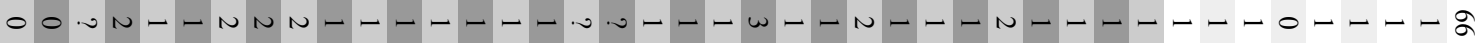

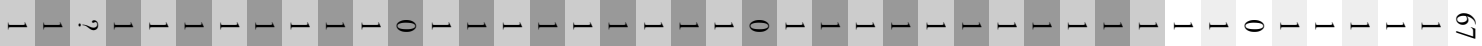

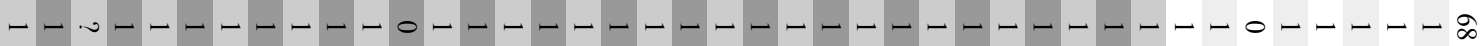

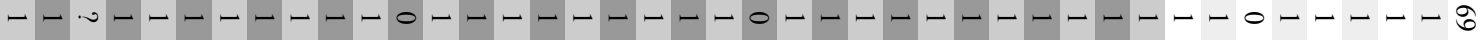
- - . - - - - - - - o- - - - - - - - - - - - - - - - - - - - - - - - - $000-100000000000000-0-0000000-00-0000-00-11$ N. nN.

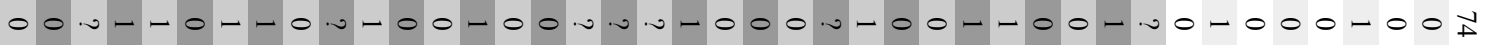

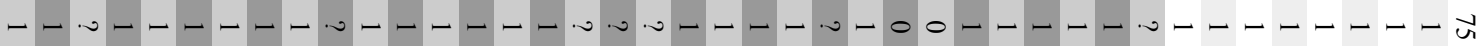

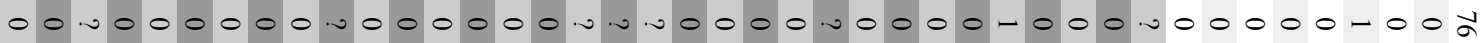

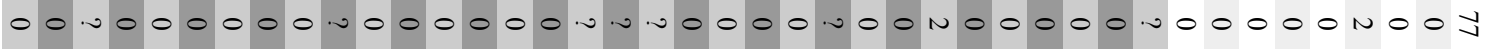

